\title{
The influence of white-tailed deer on plant communities in West Virginia and stakeholder attitudes toward deer management with respect to plant conservation
}

\author{
Kelley Lynne Flaherty \\ West Virginia University
}

Follow this and additional works at: https://researchrepository.wvu.edu/etd

\section{Recommended Citation}

Flaherty, Kelley Lynne, "The influence of white-tailed deer on plant communities in West Virginia and stakeholder attitudes toward deer management with respect to plant conservation" (2014). Graduate Theses, Dissertations, and Problem Reports. 382.

https://researchrepository.wvu.edu/etd/382

This Dissertation is protected by copyright and/or related rights. It has been brought to you by the The Research Repository @ WVU with permission from the rights-holder(s). You are free to use this Dissertation in any way that is permitted by the copyright and related rights legislation that applies to your use. For other uses you must obtain permission from the rights-holder(s) directly, unless additional rights are indicated by a Creative Commons license in the record and/ or on the work itself. This Dissertation has been accepted for inclusion in WVU Graduate Theses, Dissertations, and Problem Reports collection by an authorized administrator of The Research Repository @ WVU.

For more information, please contact researchrepository@mail.wvu.edu. 


\section{THE INFLUENCE OF WHITE-TAILED DEER ON PLANT COMMUNITIES IN WEST VIRGINIA AND STAKEHOLDER ATTITUDES TOWARD DEER MANAGEMENT WITH RESPECT TO PLANT CONSERVATION}

Kelley Lynne Flaherty

Dissertation submitted to the Davis College of Agriculture, Natural Resources, and Design at West Virginia University in partial fulfillment of the requirements for the degree of

Doctor of Philosophy In Forest Resources Science

James T. Anderson, Ph.D., Major Advisor John W. Edwards, Ph.D. James S. Rentch, Ph.D. James Crum, Ph.D. Robert Whyte, Ph.D.

Division of Forestry and Natural Resource

\section{Morgantown, West Virginia 2014}

Keywords: Community, Dispersal, Exclosure, Metapopulation, Odocoileus virginianus, Polemonium vanbruntiae, Wetland, White-tailed Deer Copyright 2014 Kelley Flaherty 


\section{Abstract \\ The influence of white-tailed deer on plant communities in West Virginia and stakeholder attitudes toward deer management with respect to plant conservation}

\section{Kelley L. Flaherty}

White-tailed deer (Odocoileus virginianus) may impact plant species by reducing individual survival or reduce reproductive potential by feeding on flowering parts or seeds. Herbivory may benefit plant populations by increasing dispersal of seeds. The combination of these factors may influence the composition of native plant communities. Plants adapted to browsing herbivores of the deciduous forests of the eastern United States may be depleted under heavy browsing pressure. The recovery of deer populations from near extirpation was seen as a wildlife management success story. However, the maintenance of abnormally high deer density levels over many years may have taken a toll on plant communities. Some biologists now question whether or not white-tailed deer could be considered overabundant in some parts of their range. An overabundant population of white-tailed deer may affect ecosystem function by changing the abundance and distribution of preferred browse plants. Much of the research concerning the effects of deer on plant communities has focused on their role as browsers and the potential for overbrowsing of upland plant species. Fewer studies of deer diet have been directed solely toward rare or endangered herbaceous or woody plants. Populations of rare species often have a metapopulation distribution. That is, they exist in a series of local populations, due either to natural distribution or to the effects of human disturbance that are linked by dispersal. Many rare or declining species exist in non-equilibrium metapopulations in which the rate of colonization is not sufficient to counter rates of local extinction. Dispersal of plants is tied directly to reproduction and some plant species may rely on herbivores as seed dispersers to aid seed dispersal into new patches. The purpose of this study is to evaluate the influences of whitetailed deer browse on plant populations in West Virginia. The study was organized into three general sections: 1) the influence of white-tailed deer browse and seed dispersal on rare plant species and communities in Canaan Valley, West Virginia, 2) the impact of white-tailed deer density on forest understory recruitment in upland forests throughout West Virginia, and 3) public attitudes toward rare plant conservation and white-tailed deer management.

I located eight populations of the rare, wetland herb Polemonium vanbruntiae Britt. in May 2005 and an additional two populations in 2006. I monitored these populations from the first week of May through September from 2005 through 2007. I established 10 semi-permanent sampling quadrats within each population and identified individual ramets that were; seedlings, non-flowering vegetative ramets, and flowering ramets. I monitored flowering stems within the population every three weeks from early June until late September to determine the number of seeds produced per stem as well as the number of stems lost to white-tailed deer herbivory. I analyzed 13 a priori models, created using morphometric characteristics, using linear regression along with information theoretic methods to rank these characteristics as predictors of seed production. I used the best performing model to estimate the percentage of seeds lost due to white-tailed deer florivory. Lastly, I compared the percentages of stems browsed and the percentages of seeds browsed in Canaan Valley NWR to those in Canaan Valley State Park with a two-factor analysis of variance. I used stagestructured matrix modeling to predict the population growth rate and estimate extinction rates for each population monitored. I compared the rates of population increase $(\lambda)$ with and without whitetailed deer florivory using a paired $t$-test. Extinction probabilities were calculated with and without 
the effects of deer florivory for each population. I monitored 789 flowering ramets over three years. Seed loss due to consumption of flowering stems ranged between 0 and $99 \%$ within individual populations and stem loss ranged between 0 and $97 \%$. I found a significant difference in percent stems browsed between the Canaan Valley State Park populations $(\bar{x}=57 \pm 19 \%)$ and the Canaan Valley NWR populations $(\bar{x}=40 \pm 18 \%)$. There was a significant difference in percent predicted seed loss between the Canaan Valley State Park $(\bar{x}=64 \pm 6 \%)$ populations and the Canaan Valley NWR populations $(\bar{x}=36 \pm 5 \%$ ). The estimated population growth rate ranged from 1.09 to 1.24 ( $\bar{x}=1.17 \pm 0.11)$ without deer florivory and was 0.99 to $1.20(\bar{x}=1.08 \pm 0.13)$ with deer florivory. In only one population, $\lambda$ was reduced to less than 1 , indicating a population decline.

At the wetland community level, I sampled Solidago spp.-Rubus hispidus dominated wet meadow communities and regenerating Populus spp. dominated communities in Canaan Valley, WV. Within each community, I randomly established three types of treatment plots (early, late, and continuously protected) and located a paired control plot $4 \mathrm{~m}$ from each treatment plot. Treatment plots were $1 \mathrm{~m}^{2}$ and surrounded by fenced $2 \mathrm{~m} \times 2 \mathrm{~m}$ exclosures. I recorded all plant species within each plot along with Daubenmire cover-class ratings for all species. I used Blocked Multiple Response Permutation Procedures (MRBP) in PC-Ord to compare vegetation communities in treatment with control plots and compared species richness within plots after two years protection from browse using a repeated-measure, two-way analysis of variance. I also examined the changes in woody, forb and graminoid metacommunites as well as the differences between wetland indicator status categories. I recorded 75 species in plots in Solidago spp.-Rubus hispidus communities and 99 species within plots in Populus spp. regeneration communities. There were no significant differences in species richness found between fenced and control plots in either community. In Solidago spp.-Rubus hispidus communities I found that community composition differed significantly between treatment and control plots in the early plots when data were gathered in the spring and in the late plots when data were gathered in the fall. When plots were protected year-round, a significant change in community composition was only apparent on data gathered in the spring. In Solidago spp.-Rubus hispidus communities, woody species cover class increased more in the continuously protected plots than in both the early and late plots when data were gathered in the fall. There were significant changes detected in the forb species cover classes between control and fenced plots when measured in the fall. I measured an increase in cover class of forbs in plots that were fenced early in the year and a decrease in forb cover class of associated control plots. In Populus spp. communities, differences between control and treatment plots in community composition were only apparent in data gathered in the spring for plots protected in the late plots and year-round. In Populus spp. communities, forb communities measured in the fall differed between fenced and control plots. Though the forb cover class increased for both fenced and control plots under all fencing regimes, the change in forb communities was greater for fenced plots protected early, late and continuously than in the paired control plots. I also found a difference in the change in woody species cover class between control and fenced plots when measured in the spring but not in the fall. There was no significant difference in the changes between wetland indicator status categories for either community.

I also analyzed a dataset collected from twenty sites that were selected from upland forests throughout West Virginia by West Virginia Division of Natural Resources (WVDNR) biologists. Vegetation-monitoring sites were constructed between 1984 and 1990 using two strands of $1.22 \mathrm{~m}$ tall woven wire fencing to create a $100 \mathrm{~m}^{2}$ treatment plot. Within each treatment plot and paired control plot, nine $1 \mathrm{~m}$ by $1 \mathrm{~m}$ subplots were nested within nine $2 \mathrm{~m}$ by $2 \mathrm{~m}$ subplots. Plots were monitored by WVDNR personnel in 3-year intervals between June and September by counting and identifying all stems in the ground cover and understory vegetation within subplots. I pooled data based on the number of years following plot establishment and used a 2-way repeated measures 
analysis of variance to compare the number of stems, species richness, and the Shannon diversity values between control plots and treatment plots over time. I used blocked Multiple Response Permutation Procedures (MRBP) to determine if differences existed between fenced and control plots at 3-year intervals after fence construction. Finally, I calculated an index representing the difference between control plots and treatment plots for each species using those species with the greatest differences in a seedling-sapling ratio index and used linear regression to evaluate the relation between the seedling-sapling ratio for control plots and the total deer density at the site from 1993 2007 as measured by West Virginia Division of Natural Resources harvest data. I recorded 197 species present in the ground cover; and 79 species present in the understory over the study period. After 21 years, I found no significant difference between treatment groups in predicting stem abundance, species richness or Shannon diversity values in the ground cover however, treatment had an effect on the stem abundance and Shannon diversity values at the understory level. Understory species richness also differed between control and treatment plots in years 6, 9, 15, 18, and 21. At the ground cover level, I found no significant difference in community composition occurred 21 years after plot initiation, but significant differences occured in understory community composition between treatment plots and control plots $6,15,18$, and 21 years after plot establishment. I found no relation between the seedling-sapling ratio and deer density.

I collected fresh white-tailed deer fecal pellet groups bi-monthly from May to December 2005 and 2006 in wetland habitats along $300 \mathrm{~m}$ randomly placed transects through both herbaceous, shrub and forested wetlands within the Canaan Valley NWR and Canaan Valley State Park. Following a three month period of cold stratification the seeds were spread on top of a layer of potting mix within $10 \mathrm{~cm}$ diameter planting pots and kept moist. I determined the wetland indicator status of all plants germinated from pellet piles. I also classified each species as graminoid, forb or woody species. I used a chi-square test to compare the proportion of species germinated and frequency of occurrence each year that were either upland (UPL) or facultative upland (FACU) with those that were either facultative wetland (FACW) or obligate wetland (OBL) species. I repeated these tests for the proportion and frequency of germination of plants that were graminoid, forbs or woody. I collected 55 pellet piles in 2005 and 160 pellet piles in 2006. Of those collected in 2005, $45 \%$ of the pellet piles planted germinated at least one species resulting in a total of 14 species. Of those collected in 2006, 38\% of the pellet piles germinated at least one species resulting in a total of 32 species. There was no significant difference between the proportion of species germinated in either 2005 or 2006 that have a FACW or OBL wetland indicator status and those that had a FACU status. In 2005, the proportion of individual stems that were FACU not significantly different than those that were FACW and OBL stems combined. However, the proportion of individual stems that were FACU (59\%) was significantly more than the combined proportion of FACW (7\%) and OBL (9\%) stems counted. In 2005 and 2006, the proportion of germinated species that were graminoids, forbs and woody species did not significantly differ. The frequency and proportion of stems germinated of both graminoids and forbs were significantly higher than for woody species in 2005. In 2006, the frequency of pellet piles germinating graminoid species was significantly higher than the frequency of woody species, but was not higher than the frequency of forbs. The proportion of individual stems that were forbs and graminoids were significantly greater than the proportion of woody stems.

I surveyed residents of Canaan Valley as well as residents of the surrounding areas in Tucker County, WV, nonresident who owned land in Canaan Valley as well as those who only visit Canaan Valley to assess attitudes toward rare plant conservation and the status and management of white-tailed deer in Canaan Valley. I sampled residents and nonresident landowners in 2005 by mail surveys and visitors to Canaan Valley by providing survey forms to the visitors' centers at Canaan Valley NWR and Canaan Valley State Park. Opinion questions were subjected to Principal Components Analysis (PCA) to identify underlying constructs. I modeled three principal component 
scores as a function of socio-demographic factors determined from the questionnaire and their twoway interaction using a multi-factor analysis of variance (ANOVA). Additionally, I examined the principal components using a Potential for Conflict Index (PCI) that numerically described the amount of disparity between respondents in a particular group. I received a response rate of 35\% for mailed surveys and received 46 visitors' responses. The three retained principal components accounted for $60 \%$ of the variation in the data. I found that people who had experienced crop or landscape damage had significantly larger mean principal component (PC) 1 scores than those who did not corresponding with a lower tolerance of deer. Those that had experienced crop or landscape damage were more likely to describe Canaan Valley white-tailed deer populations as being overabundant. Tucker County residents had higher PC 2 scores on average than nonresident landowners indicating lower valuation of plants and plant communities. While for the most part stakeholder groups agreed that they enjoyed seeing wild plants, Tucker County residents appeared less likely to agree that deer could harm plant communities and that plants should be protected from deer. Hunters had significantly higher PC 3 scores on average than nonhunters that corresponded to a greater support for management actions for white-tailed deer.

My study suggests that white-tailed deer may consume almost $100 \%$ of the sexually reproductive ramets within some $P$. vanbruntiae populations in a given year. As $P$. vanbruntiae can reproduce clonally, high levels of seed loss such as those exhibited here may not immediately affect population persistence. However, a reduction in dispersal may reduce genetic diversity and the formation of new populations. At the community level, elevated deer densities present in the postlogging era impact the herbaceous community by selectively browsing forb species, especially in the spring. On a state-wide scale, the density of white-tailed deer impacting the control plots at many of these sites has been at or exceeded the capacity of the upland forest to regenerate the current community. At some sites, few, overstory species are currently reaching the understory growth level thus the future of the forest cover at these sites is uncertain. However, the potential still exists to regenerate the current forest community at many sites. However, if browse pressure persists as the seed sources decline, the potential for recovery of the current ecosystem will likewise decline. A difference in proportion of stems from upland species that germinated from fecal samples in 2006 suggests that upland plants may be more adapted to dispersal by white-tailed deer, though this difference in frequency might be attributed to the success of a few FACU plants. As dispersers, white-tailed deer could play a role in maintaining or enhancing metapopulations of wetland plants patchily distributed in an upland matrix; however, deer may also confound wetland restoration by dispersing seeds of some exotic, invasive species. Dispersal of graminoid species by deer may help to maintain or expand herbaceous openings at both wetland and upland sites by dispersing the seeds of graminoid species as well as reducing the capacity for woody species regeneration. Although many of the views of residents and nonresidents were similar, Tucker County residents were less likely to favor rare plant conservation. Many of the visitors and nonresidents come to Canaan Valley specifically because of its unique characteristics and appear to place more value on these unique plants. Recognition of differences in attitudes between stakeholder groups could be helpful in designing educational programs for users of natural areas. In this case, education and emphasis on the importance of rare plant diversity in Canaan Valley may bring more local support for their conservation. 


\section{ACKNOWLEDGMENTS}

I thank Dr. James Anderson for his continued support and seemingly never-ending patience throughout my time at WVU. The opportunities and guidance he has provided over the years have been invaluable at the beginning of my teaching career. I also thank the committee members; Dr. James Crum, Dr. John Edwards, Dr. James Rentch, and Dr. Robert Whyte for their support, advice, and motivation. I thank the following people for their assistance in the field during the duration of my data collection; LeAnne Bonner, Jason Love, Joe Osbourne, Ryan Ward, Walter Veselka, Jacob Harrell, Graham Nesselrod, and Rob Sylvester. I thank Dr. Philip Turk for assistance with statistical analysis. I also thank the Canaan Valley Institute, Regional Research Institute, and West Virginia University Davis College of Agriculture, Natural Resources and Design (McIntire -Stennis) for providing the funding for this project.

I thank Dr. David Argent, Dr. Carol Bocetti, and Dr. Brian Paulson for their continued support in completing this project. I also thank my family, especially parents whose love and guidance throughout the years have given me the confidence to tackle this project. I thank my father for helping to cultivate an interest in natural resources that led me down this path.

I dedicate this manuscript to the memory of Mr. William Grafton. His infectious good humor in the face of the rain and black flies made field work in Canaan Valley much more enjoyable. Mr. Grafton has motivated me to develop both as a naturalist and a teacher and I can only hope to inspire my students in the future as he has. 


\section{TABLE OF CONTENTS}

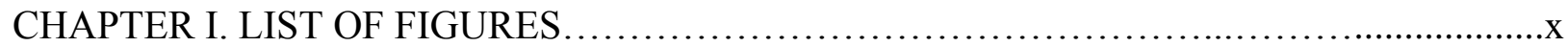

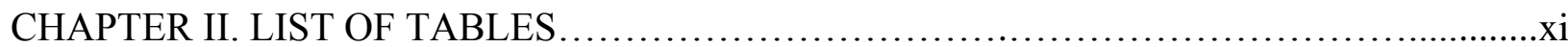

CHAPTER II. LIST OF FIGURES .....................................................

CHAPTER III. LIST OF TABLES ..................................................

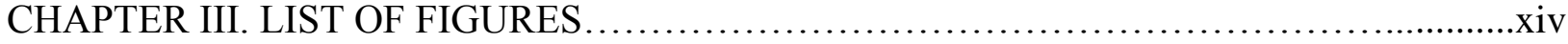

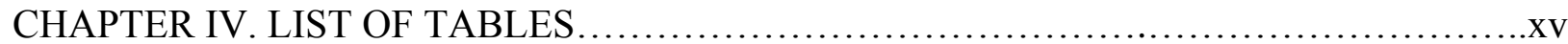

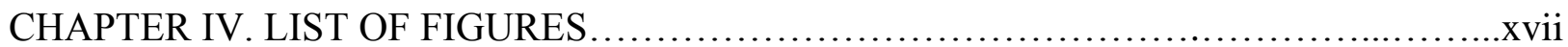

CHAPTER V. LIST OF TABLES ..................................................

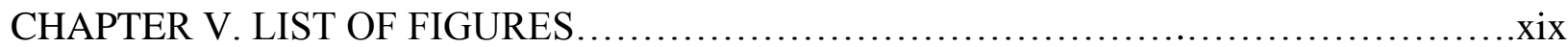

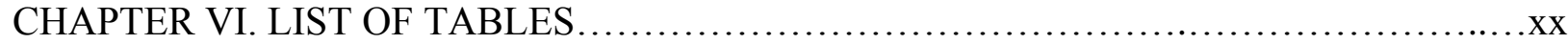

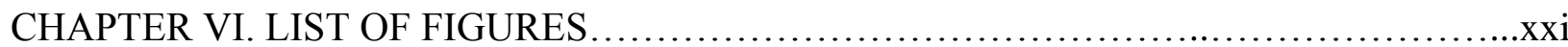

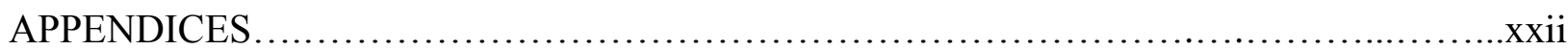

CHAPTER I............................................................................

WHITE-TAILED DEER HERBIVORY AND RARE PLANTS: INTRODUCTION AND

LITERATURE REVIEW

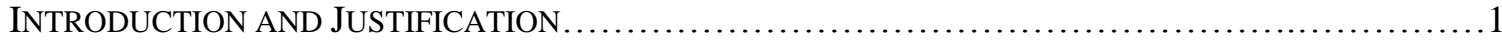

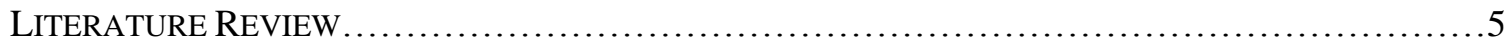

The Role of Metapopulation Theory in Conservation Biology .........................5

Overpopulation and Vegetation Communities...................................... 8

Alternate Stable States.........................................................11

The Role of White-tailed Deer in Seed Dispersal.....................................12

Polemonium vanbruntiae ........................................................... 13

Public Attitudes Toward White-tailed Deer Management.............................. 14

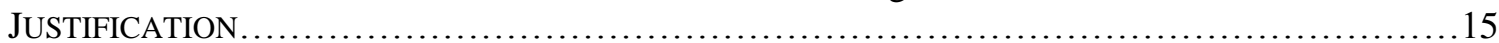

OBJECTIVES ...

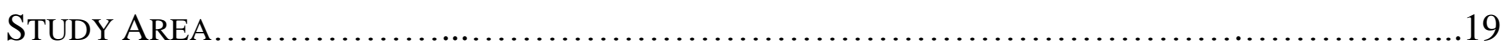

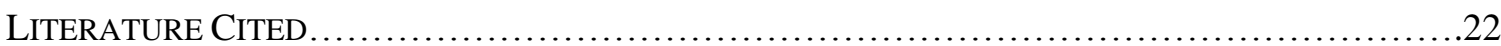

CHAPTER II..................................................................... 40

WHITE-TAILED DEER FLORIVORY INFLUENCES THE POPULATION DEMOGRAPHY OF

POLEMONIUM VANBRUNTIAE IN CANAAN VALLEY, WEST VIRGINIA, USA

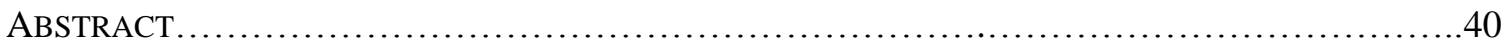

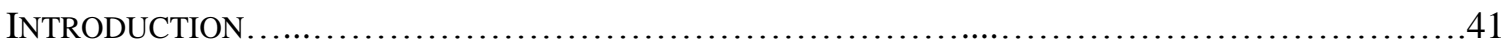

The Role of White-tailed Deer in Seed Dispersal..................................44

Polemonium vanbruntiae ...................................................... 44

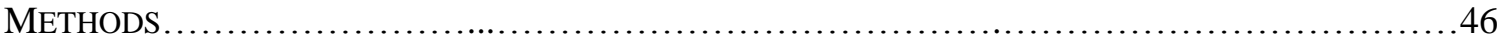

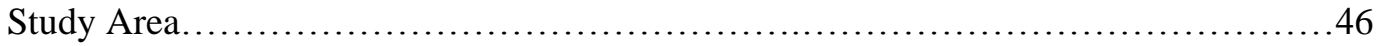

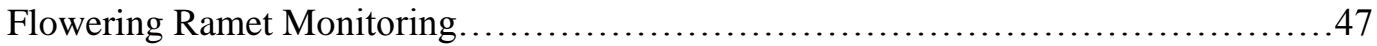

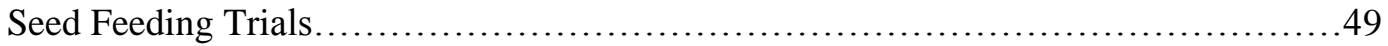

Statistical Analysis........................................................... 49

Population Modelling ........................................................... 51

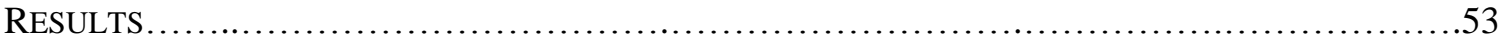

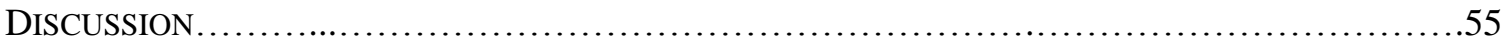

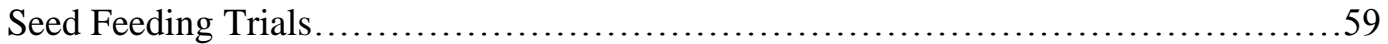

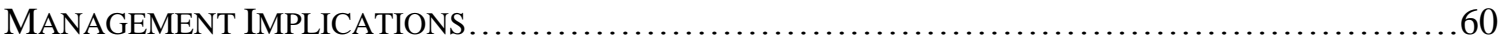




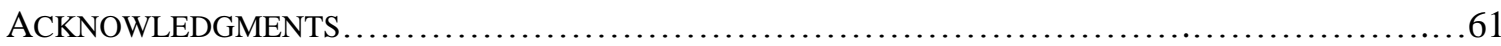

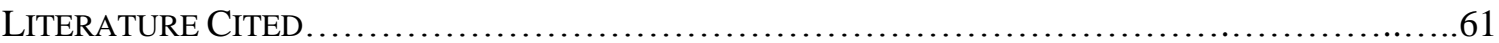

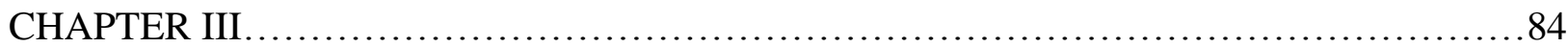

THE INFLUENCE OF WHITE-TAILED DEER HERBIVORY ON HERBACEOUS

WETLAND PLANT COMMUNITIES IN CANAAN VALLEY, WEST VIRGINIA (USA)

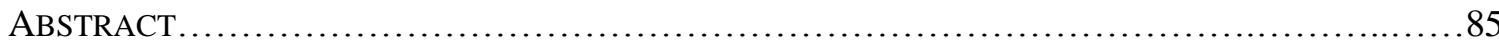

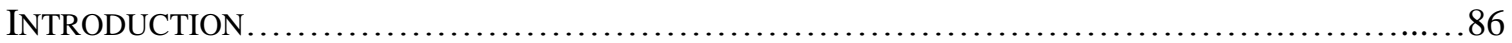

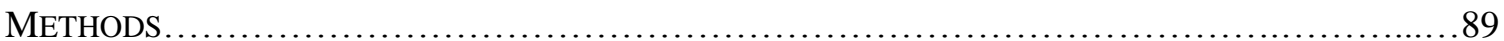

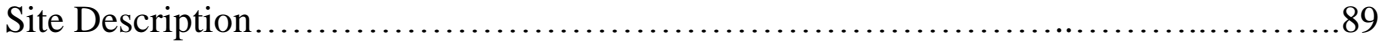

Plant Community Analysis.................................................... 90

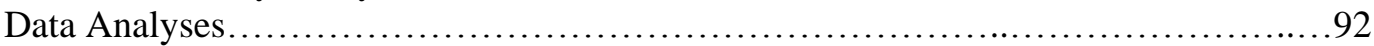

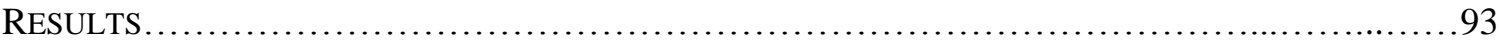

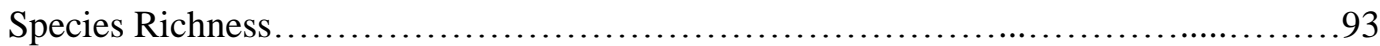

Solidago spp.- Rubus hispidus. Community Analysis..................................... 94

Populus spp. Community Analysis............................................... 96

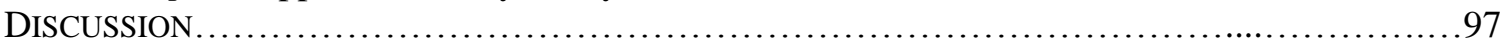

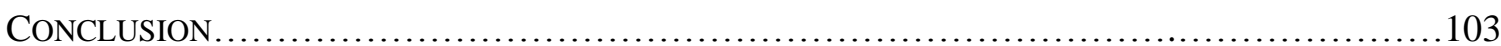

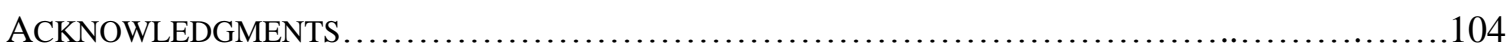

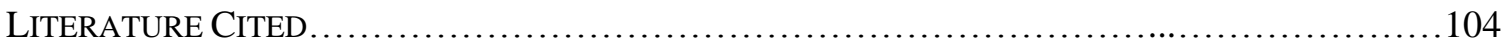

CHAPTER IV .................................................................. 124

THE INFLUENCE OF WHITE-TAILED DEER ON THE STRUCTURE AND COMPOSITION OF EASTERN DECIDUOUS FOREST UNDERSTORY

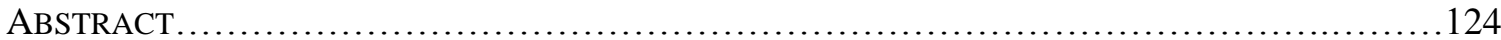

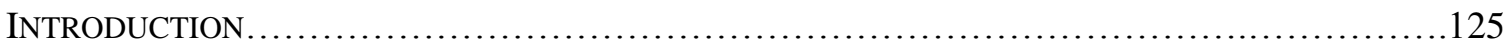

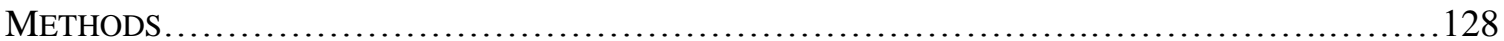

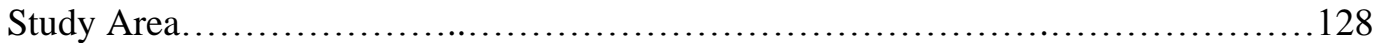

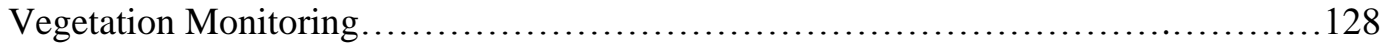

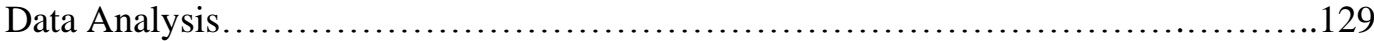

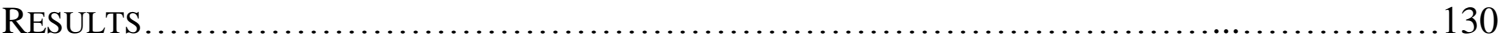

Ground Cover Level...................................................... 130

Understory Level......................................................... 131

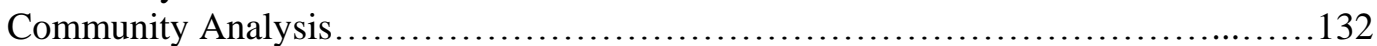

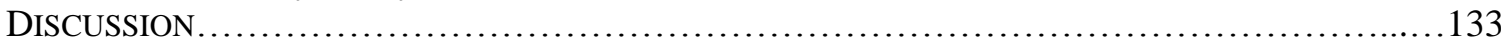

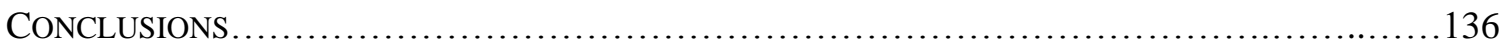

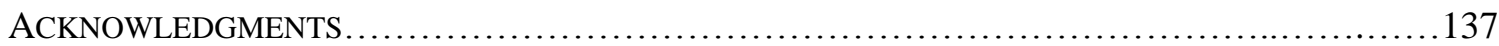

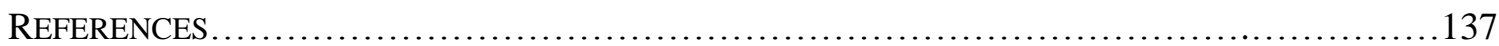

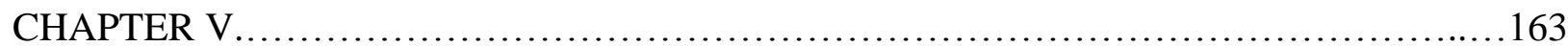

WETLAND SEED DISPERSAL BY WHITE-TAILED DEER IN CANAAN VALLEY, WV

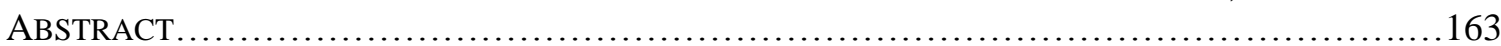

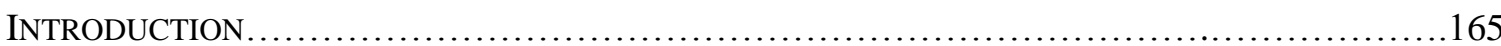

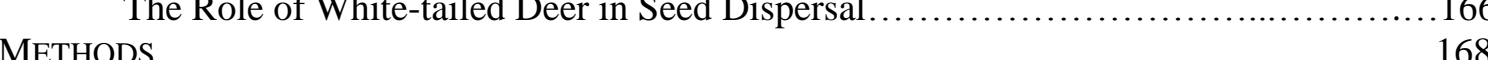

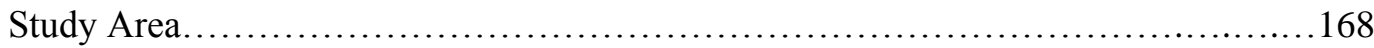

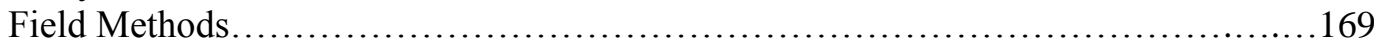

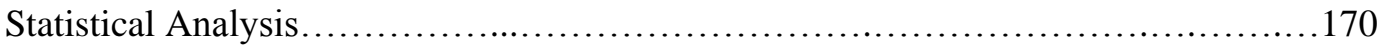

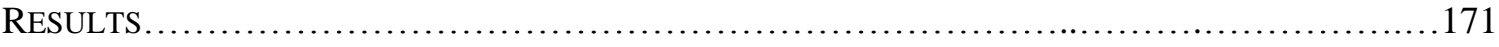

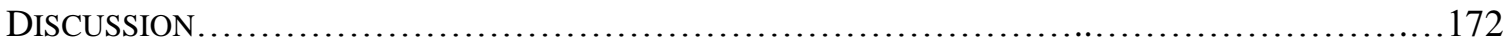




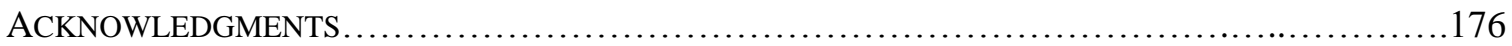

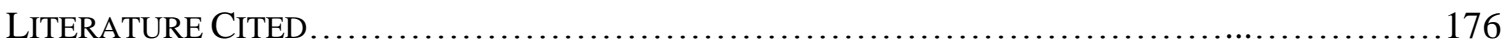

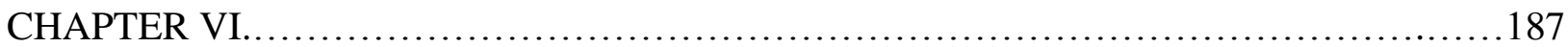

COMPARING STAKEHOLDER ATTITUDES TOWARD WHITE-TAILED DEER

MANAGEMENT IN CANAAN VALLEY, WEST VIRGINIA

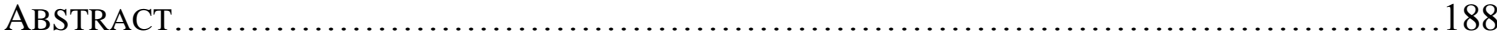

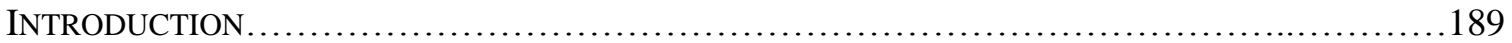

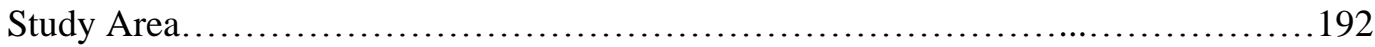

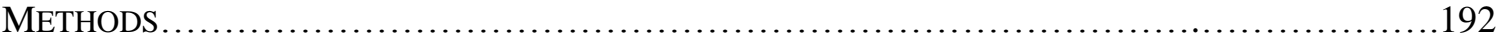

Selecting Stakeholder Groups.............................................. 192

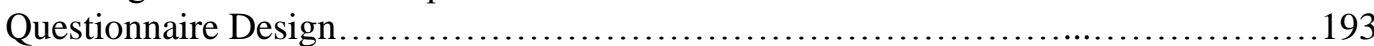

Statistical Analysis.......................................................... 193

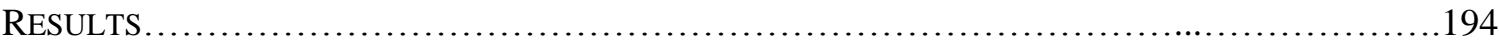

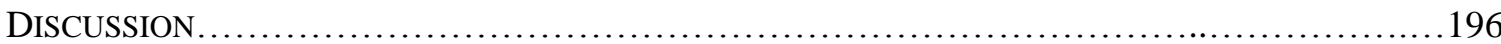

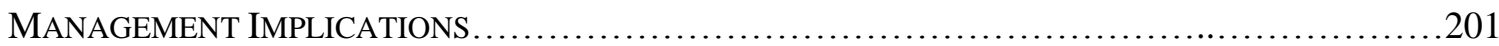

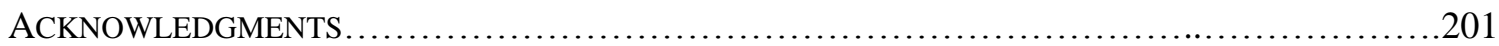

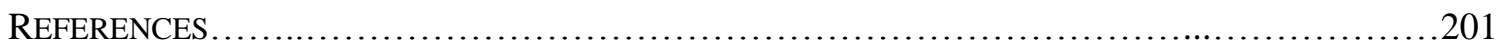

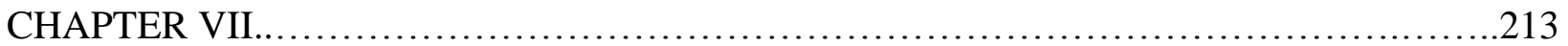

MANAGEMENT IMPLICATIONS FOR WHITE-TAILED DEER HERBIVORY: COMMUNITY

INFLUENCE AND STAKEHOLDER RESPONSE

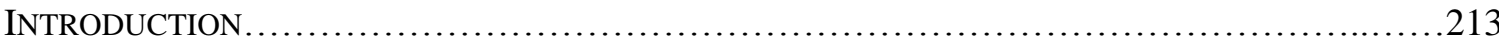

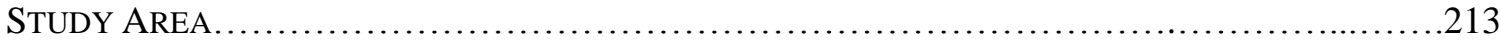

The Influence of White-tailed Deer Florivory on Polemonium vanbruntiae.............214

The Influence of White-tailed Deer Herbivory on Wetland

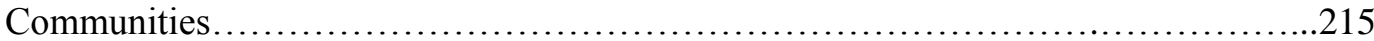

The Influence of White-tailed Deer Herbivory on Upland

Communities....................................................................216

White-tailed Deer Seed Dispersal through Endozoochory ...........................218

Stakeholder Views of White-tailed Deer Management and Plant

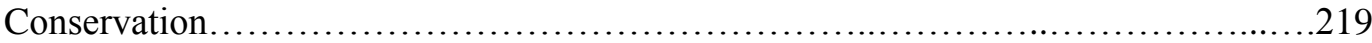

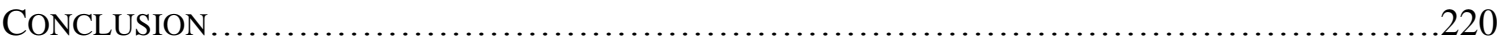

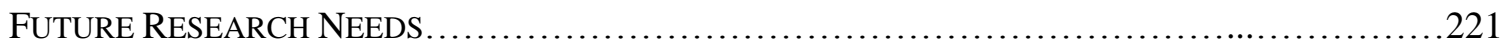

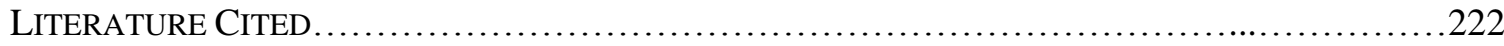




\section{CHAPTER I. LIST OF FIGURES}

Figure 1. Flowering stem of bog Jacob's-ladder (Polemonium vanbruntiae) in Canaan Valley, West Virginia, USA. Photo by Stephen M. Young.

Accessed U.S. Forest Service Website

Figure 2. Bog Jacob's-ladder (Polemonium vanbruntiae) populations are often associated with alder communities and beaver ponds in Canaan Valley, West Virginia, USA

Figure 3. Study areas located throughout West Virginia, USA. Red stars indicate West Virginia Division of Natural Resource white-tailed deer exclosure study sites located throughout the state. Canaan Valley located in Tucker County, WV is shown in black.

Figure 4. Land Cover Types in the Canaan Valley, West Virginia. Study sites were concentrated in the wetland forest, wetland shrub, and wetland herbaceous and moss cover types. 


\section{CHAPTER II. LIST OF TABLES}

Table 1. Akaike's Information Criterion values for 13 models predicting the seed production of Polemonium vanbruntiae 2005 and 2006

Table 2. Transition matrix model (A) for Polemonium vanbruntiae. Each matrix element $\left(\mathrm{a}_{\mathrm{ij}}\right)$ represents the probability that each individual in stage $\mathrm{i}$ will be derived from an individual at stage $\mathrm{j}$ in one time interval...

Table 3. Mean matrix of transition probabilities for 10 Polemonium vanbruntiae populations without white-tailed florivory in Canaan Valley, West Virginia, 2005 - 2007.

Table 4. Percent of Polemonium vanbruntiae flowering stems browsed in years 2005-2007. Populations 1-5 are located in Canaan Valley State Park. Populations 6-10 are located in Canaan Valley National Wildlife Refuge.

Table 5. Sensitivity analysis of the mean transition matrix model for Polemonium vanbruntiae populations without white-tailed florivory in Canaan Valley, West Virginia, 2005 - 2007

Table 6. Elasticity analysis of the mean transition matrix model for Polemonium vanbruntiae populations without white-tailed florivory in Canaan Valley, West Virginia, 2005 - 2007 


\section{CHAPTER II. LIST OF FIGURES}

Figure 1. A single flowering ramet of Polemonium vanbruntiae. Arrows depict the location of measurements for model formation. Image Source Britton and Brown. 1913. Accessed: USDA Plants Database......................................74

Figure 2. The flowering stem and seed head of Polemonium vanbruntiae dries in late fall... .75

Figure 3. Locations of Polemonium vanbruntiae populations in Canaan Valley, West Virginia from $2005-2007$. 76

Figure 4. Direction of transition probabilities from the transition matrix for Polemonium vanbruntiae where class 1 represents seeds, class 2 represents seedlings, class 3 represents vegetative ramets, class 4 represents flowering ramets, and class 5 represents dormant individuals

Figure 5. Scatter plot of the estimated seed production for seeds produced in 2007 based on the best fitting model compared to the seeds that were actually produced

Figure 6 . The potential mean seed production of browsed plants and actual production of unbrowsed plants in monitored populations of Polemonium vanbruntiae in Canaan Valley, WV in 2007

Figure 7. The estimated percent of Polemonium vanbruntiae seeds consumed by white-tailed deer in 10 population in Canaan Valley, West Virginia in $2005-2007$

Figure 8. The estimated percent of Polemonium vanbruntiae stems consumed by white-tailed deer in 10 population in Canaan Valley, West Virginia in $2005-2007$

Figure 9. Comparison of the percentage of Polemonium vanbruntiae stems browsed to the estimated percent of seeds consumed by white-tailed deer in Canaan Valley, West Virginia in 2005 - 2007

Figure 10. Predicted population increase rates $(\lambda)$ for all Polemonium vanbruntiae populations with and without white- tailed deer florivory. Standard error bars represent the $95 \%$ error estimates of $\lambda$ calculated in the Popbio package of Program R. 


\section{CHAPTER III. LIST OF TABLES}

Table 1.Blocked Multiple Response Permutation Procedure (MRBP) tests of plant community composition differences between fenced and unfenced plots in Canaan Valley, WV from 2005 - 2007 grouped by period of protection and time of data collection. The T-statistic describes the difference between selected groups. The p-value describes the likelihood of reaching the observed T-statistic. The A-statistic describes within group homogeneity compared to what is expected by chance. Bold text indicates significant differences $(\mathrm{P}<0.05)$.

Table 2. Species displaying the largest changes within fenced plots in Solidago spp.-Rubus hispidus. communities in Canaan Valley, WV. Mean values represent the difference in percent cover based on the midpoint of cover class categories between 2005 and 2007. A positive value indicates higher percent coverage in 2007. Negative values indicate lower percent coverage in 2007 than 2005. Blank values indicate no change recorded for that monitoring period. Wetland Indicator Status was recorded from the 2014 Army Corps of Engineers National Wetland Plant List.

Table 3. Species displaying the largest changes within fenced plots in Populus spp. communities. A positive value indicates higher percent coverage in 2007 than 2005. Negative values indicate lower percent coverage in 2007 that 2005. Data represented were collected in the spring in plots protected late in the year and year-round. Blank values indicate no change recorded for that monitoring period...

Table 4. Number of species within each wetland plant indicator status category showing a change (increase or decrease) in average cover class catergory after two years (2005 -2007) of fencing treatment in Populus spp. and Solidago spp. -Rubus hispidus. dominated communities in Canaan Valley, WV. Early and late plots were protected for a portion of the year while continuous plots were protected year-round. 


\section{CHAPTER III. LIST OF FIGURES}

Fig. 1. Map of Canaan Valley, WV with locations of Populus spp. exclosures (red) and Solidago spp.-Rubus hispidus exclosures (blue) that were in place

Fig. 2. Plot location within each study site indicating the sizes of exclosures and relative spacing of control plots. Spacing between exclosures is not to scale. Exclosures were constructed in 2005 and removed in 2007

Fig. 3. Average species richness in control and fenced plots within Solidago spp.-Rubus hispidus communities in Canaan Valley, WV from 2005-2007

Fig. 4. Average species richness in control and fenced plots within Populus spp. regeneration communities in Canaan Valley, WV from 2005-2007.

Fig. 5. Average change in cover for forbs, graminoids and woody species that are protected early, late, and continuously in Solidago spp.-Rubus hispidus communities in Canaan Valley, WV when data were collected in the spring of 2005 through 2007.

Fig. 6. Average change in cover for forbs, graminoids, and woody species that are protected early, late, and continuously in Solidago spp.-Rubus hispidus communities in Canaan Valley, WV when data were collected in the fall 2005 through 2007 .

Fig. 7. Average change in cover for forbs, graminoids, and woody species that are protected early, late, and continuously in Populus spp. regeneration communities in Canaan Valley, WV when data were collected in the spring of 2005 through 2007

Fig. 8. Average change in cover for forbs, graminoids, and woody species that are protected early, late, and continuously in Populus spp. regeneration communities in Canaan Valley, WV when data were collected in the fall of 2005 through 2007. 


\section{CHAPTER IV. LIST OF TABLES}

Table 1. West Virginia Division of Natural Resources monitoring sites and monitoring dates from 1984 through 2007

Table 2. Multiple Response Blocked Permutation values calculated every three years after plot initiation on West Virginia Division of Natural Resources deer-browse exclosure sites, $1984-2007$. The T-statistic describes the difference between selected groups. The p-value describes the likelihood of reaching the observed T-statistic. The A-statistic describes within group homogeneity compared to what is expected by chance.

Table 3. Multiple Response Blocked Permutation values calculated every three years after plot initiation on West Virginia Division of Natural Resources deer-browse exclosure sites located in Oak-Hickory (Quercus spp. - Carya spp.) dominated stands, 1984-2007. The T-statistic describes the difference between selected groups. The p-value describes the likelihood of reaching the observed T-statistic. The A-statistic describes within group homogeneity compared to what is expected by chance

Table 4. Multiple Response Blocked Permutation values calculated every three years after plot initiation on West Virginia Division of Natural Resources deer-browse exclosure sites located in the Northern Ridge and Valley Ecoregion, 1984 - 2007. The T-statistic describes the difference between selected groups. The p-value describes the likelihood of reaching the observed T-statistic. The A-statistic describes within group homogeneity compared to what is expected by chance

Table 5. Multiple Response Blocked Permutation values calculated every three years after plot initiation on a subset of West Virginia Division of Natural Resources deer-browse exclosure sites selected through hierarchical clustering, 1984 - 2007. The T-statistic describes the difference between selected groups. The P-value describes the likelihood of reaching the observed T-statistic. The A-statistic describes within group homogeneity compared to what is expected by chance.

Table 6. Calculated values for species showing the greatest difference in ground cover abundance in years 12, 15 and 21 on West Virginia Division of Natural Resources deer-browse exclosure sites. Positive values indicate higher abundance on treatment plots. Negative values indicate higher abundance on control plots. 
Table 7. Calculated values for species showing the greatest difference in understory stem abundance in years 6, 9, 12, 15 and 21 on West Virginia Division of Natural Resources deer-browse exclosure sites. Positive values indicate higher abundance on treatment plots. Negative values indicate higher abundance on control plots......................................... 150

Table 8. Deer harvest per square kilometer at West Virginia Division of Natural Resources management areas corresponding to monitoring sites, $1993-2007 \ldots \ldots \ldots \ldots \ldots \ldots . . .152$ 


\section{CHAPTER IV. LIST OF FIGURES}

Figure 1. Locations of West Virginia Division of Natural Resources deer-browse exclosure sites, $1984-2007$.

Figure 2. Design of control and treatment plots. Ten meter squares indicate the location of fence and boundary of control plots. Two meter squares indicate the plots measuring understory cover. One meter square indicate the plots measuring groundcover

Figure 3. The average stem abundance at ground cover level in West Virginia Division of Natural Resources control and exclosure plots....

Figure 4. The average species richness at ground cover level in West

Virginia Division of Natural Resources control and exclosure plots.

Figure 5. The average stem abundance at understory level in West

Virginia Division of Natural Resources control and exclosure plots

Figure 6. The average species richness at understory level in West Virginia Division of Natural Resources control and exclosure plots

Figure 7. The average species richness at understory level in West Virginia Division of Natural Resources control and exclosure plots, $1984-2007$

Figure 8. Average Shannon diversity index at the understory level in West Virginia Division of Natural Resources control and exclosure plots, $1984-2007$

Figure. 9. Hierarchical cluster analysis of West Virginia Division of Natural Resources groundcover exclosure plots, $1984-2007$.

Figure 10. The relation between seedling/sapling ratio of preferred browse species and total harvest at West Virginia Division of Natural Resource exclosure sites, $1993-2005$. 162 


\section{CHAPTER V. LIST OF TABLES}

Table 1. Species germinated from 55 white-tailed deer pellet piles collected in 2005 from 3 locations in Canaan Valley, West Virginia......................................... 181

Table 2. Species germinated from 160 white-tailed deer pellet piles collected in 2006 from 9 locations in Canaan Valley, WV ................................................ 182 


\section{CHAPTER V. LIST OF FIGURES}

Figure 1. Pellet pile survey locations from 2005-2006 in Canaan Valley, West Virginia. Inset picture shows the location of Canaan Valley in West Virginia.

Figure 2. The frequency (number of pellet piles germinating each species) and abundance (number of individual seedlings of each species) of germinated seedlings from pellet groups collected in 2005-2006 in Canaan Valley, WV displayed as the proportion from each wetland status group. These groups include facultative wetland (FACW; plants with $67-99 \%$ frequency of occurrence in wetlands), obligate wetland (OBL; plants with $>99 \%$ frequency of occurrence in wetlands), facultative upland (FACU; plants with $67-99 \%$ frequency of occurrence in non-wetlands), and upland (UPL; plants with $>99 \%$ frequency of occurrence in non-wetlands

Figure 3. The frequency (number of pellet piles germinating each species) and abundance (number of individual seedlings of each species) of germinated seedlings displayed as the proportion from each growth form. 


\section{CHAPTER VI. LIST OF TABLES}

Table 1. Mean likert scores for 4 stakeholder groups regarding white-tailed deer in Canaan Valley, West Virginia, 2005. A score of negative 2.0 corresponds to strongly disagree and a score of 2.0 corresponds to strongly agree. Scaling was reversed for question 10 to facilitate interpretation. For questions 8, 18, 19, and 20, a score of -1 corresponds to no and a score of 1 corresponds to yes. For question 7 , a score of 0 indicates respondent has never been involved in a collision, a score of 1 indicates respondent has been involved in a collision more that 5 years ago, a score of 2 indicates respondent has been involved in a collision $>1$ but $<5$ years ago, a score of 3 indicates respondent has been involved in a collision within the past year.

Table 2. Principal components and constructs derived from survey dataset groups regarding white-tailed deer in Canaan Valley, West Virginia, 2005.

Table 3. Mean and Potential for Conflict Index (PCI) values for four questions contributing to Principal Component 2 by resident group. Mean values of -2 correspond to strongly disagree and 2 corresponds to strongly agree.

Higher PCI values indicate higher potential for conflict among group members 207 


\section{CHAPTER VI. LIST OF FIGURES}

Figure 1. Scatter plot matrix for all three Principal Component Scores for respondents that had (Yes) and had not (No) experienced damage to crops

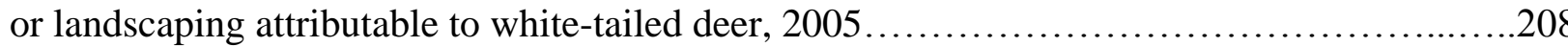

Figure 2. Potential for Conflict Indices (PCI) for the six questions contributing to Principal Component One by respondents that had and had not experienced damage to crops or landscaping. Circles are centered on the mean response for each group where -2.0 corresponds to strongly disagree and 2.0 corresponds to strongly agree. Larger circles indicate higher potential for conflict within group members. PCI values are given next to the corresponding point

Figure 3. Scatter plot matrix for all three Principal Component Scores for respondents that were Canaan Valley residents $(\mathrm{CV})$, nonresident landowners (NR), Tucker County residents (TC), and visitors to Canaan Valley (V), 2005

Figure 4. Scatter plot matrix for all three Principal Component Scores for respondents that had (Yes) and had not (No) participated in hunting of any species within the past year, 2005

Figure 5. Potential for Conflict Indices (PCI) for the four questions contributing to Principal Component Three by hunters and nonhunters. Circles are centered on the mean response for each group where -2.0 corresponds to strongly disagree and 2.0 corresponds to strongly agree. Larger circles indicate higher potential for conflict among group members. PCI values are given next to the corresponding point 


\section{LIST OF APPENDICES}

Appendix 1. Deer density estimates from spotlight sampling conducted in Canaan Valley, WV in 2005 - 2006. Estimates were calculated using the distance sampling program Distance version 6.2 release 1. Strip width refers to the effective strip width of the detection function for each sampling event.

Appendix 2. R Code for the calculation of population growth rates and confidence intervals with the popbio package

Appendix 3. R Code for the calculation of probability of reaching quasi-extinction thresholds with the popbio package

Appendix 4. Mean percent cover of species sampled in Solidago spp.-Rubus hispidus. communities in Canaan Valley, WV from 2005 - 2007. Blank values indicate the species was not recorded in the treatment group

Appendix 5. Mean percent cover of species sampled in Populus spp. communities in Canaan Valley, WV from 2005 - 2007. Blank values indicate the species was not recorded in the treatment group.

Appendix 6. Mean stem density for species observed in the ground cover in West Virginia Division of Natural Resource deer exclosure plots and corresponding control plots, $1984-2007$

Appendix 7. Mean stem densities for species observed in the understory of West Virginia Division of Natural Resource deer exclosure plots and corresponding control plots, $1984-2007$.

Appendix 8. Survey Instrument administered by mail to stakeholder groups in Canaan Valley and Tucker County, WV. Survey instrument was provided to visitors at Canaan Valley State Park and National Wildlife Refuge. 


\title{
CHAPTER I
}

\section{WHITE-TAILED DEER HERBIVORY AND RARE PLANTS: INTRODUCTION AND LITERATURE REVIEW}

\author{
Kelley L. Flaherty \\ West Virginia University \\ Division of Forestry and Natural Resources \\ Wildlife and Fisheries Resources Program \\ Morgantown, WV 26506 \\ Email:klf20@hotmail.com
}

\section{INTRODUCTION AND JUSTIFICATION}

As the wildlife management discipline moves away from a focus on game production and toward a more holistic ecological approach, the role of white-tailed deer (Odocoileus virginianus Zimm.) as a keystone herbivore comes more into question (Waller and Alverson 1997). Along with many other native herbivores, white-tailed deer were nearly extirpated due to over-hunting in the $19^{\text {th }}$ and early $20^{\text {th }}$ century. Recognizing the potential loss of this game species, stocking efforts and strict game laws, including prohibiting the killing of does, were implemented in many states to control unrestricted hunting. Numbers of deer remained low throughout the early $1900 \mathrm{~s}$ (McCabe and McCabe 1984). Eastern hardwood and coniferous forests were intensively logged at the same time which created an abundance of early successional growth benefiting existing deer populations by providing ideal food sources and cover. At the same time, a lack of natural predators due to hunting and trapping reduced mortality. The recovery of deer populations from near extirpation was seen as a wildlife management success story (Waller and Alverson 1997).

In 2006, big game hunters spent more than $\$ 11.8$ billion (2006 data; US Department of the Interior 2006) on hunting licenses as well as related travel and equipment. Higher deer densities were a boon for rural communities that depended on natural resource tourism (i.e., hunting, fishing, and wildlife viewing) as a major annual source of income. Likewise, hunters as 
well as other recreational tourists enjoyed the benefits of higher deer densities. Deer feed preferentially on some exotic species (Sheldon and Causey 1974) and therefore high herbivore densities may reduce the abundance or prevent the invasion of some invasive plant species (Maron and Vila 2001). For these reasons, there are many advocates for the maintenance of high deer densities (Diefenbach et al. 1997). However, the maintenance of abnormally high deer density levels over many years may have taken a toll on the habitat on which the population depends (Tilghman 1989, deCalesta and Stout 1997). Some biologists now question whether or not white-tailed deer could be considered overabundant in some parts of their range (McShea and Rappole 1997b, Stromayer and Warren 1997). Overabundance of a wildlife population has been defined as fitting into one of four categories: when an animal threatens human life and livelihood, when animals depress the densities of favored species (e.g. crops or timber), when animals are too numerous for their own good, and when their numbers cause ecosystem dysfunction (Caughley 1981).

Many plant species are distributed in metapopulations, defined as a set of local populations characterized by local extinctions in which dispersal and colonization play an important role in the maintenance of the metapopulation as a whole (Hanski 1991). This patchy distribution may be a natural characteristic of the species or brought on by human induced environmental changes and fragmentation and is particularly evident by the numerous rare or declining plant species (Craighead and Vyse 1996).

The rates of local extinctions and colonizations are central to metapopulation theory and the resulting models (Hanski 1991). Large herbivores may impact plant metapopulation dynamics through several routes. At the microhabitat level, feeding on plant parts may alter the growth rate and ultimately the survival of individuals (Anderson and Loucks 1979, Whitney 
1984, Alverson and Waller 1997, Stromayer and Warren 1997). Feeding on flowering parts of accessible herbaceous species reduces or eliminates the chances of fertilization for the individual and potential for fertilization of other individuals in the population (Loeffler and Wegner 2000). Large herbivores also may be considered seed dispersers or seed predators of certain species (Cambell and Gibson 2001, Vellend et al. 2003, Furedi and McGraw 2004, Myers et al. 2004). Many plant species have evolved to use fruit to attract herbivores to consume and disperse seeds (Drezner et al. 2001). Plant species with smaller seeds may use the plant's foliage to attract herbivores that consume and disperse smaller seeds along with plant parts or carry seeds externally (Janzen 1984). In this aspect, herbivores can benefit plant populations by distributing seeds, along with fertilization in the form of fecal matter, into new areas and thus increasing the colonization rate. However, as not all seed types have evolved to pass through the digestive tract of all herbivorous species, seeds may fall prey to herbivores that consume and digest them (Furedi and McGraw 2004). In this aspect, seed predators inadvertently work to reduce the potential for colonization within a metapopulation.

On a community scale, the combination of these factors may influence the composition of plant communities that in turn affect other organisms dependent on these communities (deCalesta 1994, Flowerdew and Elwood 2001). While some ecosystems such as prairies and savannahs are dependent on large population of migrating grazers, plants adapted to browsing herbivores of the deciduous forests of the eastern United States may be depleted under heavy browsing pressure (Waller and Alverson 1997). The selection of preferred plant species for consumption by an overabundant population of herbivores may result in the loss of that component of the plant community as well as a loss of plant community diversity. 
These factors may be even more important in rare plant communities. In the 200 years between 1780 and 1980, it is estimated that the amount of land occupied by wetlands across the contiguous United States has declined by 53\% due, in part to drainage for agricultural use and land development (Dahl 1990). Many of the plants found in wetland habitats are considered obligate (OBL), meaning they are adapted to saturated or flooded soils and are found in wetland conditions $>99 \%$ of the time (Tiner 2000). Additionally, facultative (FAC) and facultative wetland (FACW) plants occur in wetlands $34-66$ and $66-99 \%$ of the time (Tiner 2000). Many obligate wetland and facultative wetland plant species have become extinct, threatened, or rare or have decreased ranges due to loss of suitable wetland habitat (Tiner 2000). As a whole, West Virginia has the lowest percentage of land area in wetlands of any state, in part, because of the topography (Tiner 2000), thus making existing wetland habitat extremely valuable. Moreover, the state, boasts some of the few high elevation wetlands in the east.

Recently, there has been an increased interest in restoring wetlands across the United States to prevent the loss of wetland-dependent species and restore more economically tangible wetland functions such as flood control and water purification (Tiner 2000). Likewise, there has been an increasing interest in native plant conservation including those characteristic of wetlands. While there has been extensive research on the relations of white-tailed deer to upland plant communities (Alverson and Waller 1997, deCalesta and Stout 1997, Stromayer and Warren 1997, Rooney and Waller 2003), few have examined wetland plants. Two studies focused on the influence of white-tailed deer herbivory in a coastal marsh (Geddes and Mopper 2006, Tobler et al. 2006) and a mangrove wetland (Barrett et al. 2006). Few published studies have examined the relation of deer to freshwater wetland plant species (Loeffler and Wegner 2000, Gregg 2004, Kery and Gregg 2004). 


\section{LITERATURE REVIEW}

The Role of Metapopulation Theory in Conservation Biology

Metapopulation theory describes a population of species or communities that exists as a set of smaller populations that are connected by dispersal or colonization (Hastings 1991, Alexander et al. 2012). The rates of local population extinction and colonization are central to metapopulation dynamics models such as that given by Levins (1969) which describes the metapopulation in terms of local populations;

$$
\mathrm{dp} / \mathrm{dt}=\mathrm{mp}(1-\mathrm{p})-\mathrm{ep}
$$

in which $\mathrm{p}(\mathrm{t})$ is the proportion of available patches that are occupied at time $\mathrm{t}$, $\mathrm{e}$ is the rate of local extinction and $\mathrm{m}$ is the rate of colonization rate of empty patches (Hanski 1991). The concept of metapopulation dynamics is similar to the theory of island biogeography (Alexander et al. 2012, May et al. 2013); however, in island biogeography theory the source of colonists is a mainland population with little chance of extinction. In a metapopulation, the source of colonists is the existing set of local populations each with a finite lifetime and a given chance of going extinct (Hanski and Gilpin 1991, May et al. 2013).

Populations of rare species often have a metapopulation distribution. That is, they exist in a series of local populations due either to natural distribution or to the effects of human disturbance (Hansson 1991). Hanski (1991) described three types of rare species with respect to metapopulation distribution; species with a large local abundance $(\mathrm{N})$ and a small proportion of occupied patches (p) are known as urban species, species with a large $\mathrm{p}$ but small $\mathrm{N}$ are termed rural species, and species with both small $\mathrm{N}$ and $\mathrm{p}$ are satellite species. If, the rates of colonization and local extinction are in balance the metapopulation as a whole will not go extinct. However, many rare or declining species exist in nonequilibrium metapopulations in 
which the rate of colonization is nonexistent or is not sufficient to counter rates of local extinction (Harrison 1991, Noël et al. 2013). Anthropogenic influences on species such as habitat fragmentation or changes in the environment may not only decrease the rate of colonization but may increase the rate of local population extinction thus driving the entire metapopulation toward extinction (Heinken and Weber 2013, Noël et al. 2013).

The fields of conservation and restoration biology are particularly interested in the effects of human influences on metapopulation of rare species (Primack and Miao 1992). Human induced environmental and habitat changes have contributed to the rarity and current decline of many species. The rates of local population extinction may not be important for species that are colonizing new patches, but these rates may be more critical for rare species (Harrison 1991, Marini et al. 2012). If all local populations of a patchily distributed metapopulation become extinct at the same time then the entire metapopulation and thus species becomes extinct (Hanski 1991). Understanding what contributes to the decline of local populations contributes to efforts in conserving and restoring local populations which, in turn, contributes to the conservation of the species as a whole. Some species naturally occur in a patchy distribution; however, some species that occur in naturally continuous populations have been converted to a metapopulation because a change in some environmental factor fragmented some aspect of the species' habitat (Craighead and Vyse 1996, May et al. 2013). An overabundant population of white-tailed deer may, as a human induced factor of a changing environment, have the ability to change the abundance and distribution of preferred browse plants (deCalesta and Stout 1997, Martin et al. 2011, Tanentzap et al. 2011).

Plant populations differ from animals in that they are sessile and individuals cannot actively disperse from patch to patch (Husband and Barrett 1996). Instead, dispersal is tied 
directly to reproduction and is often more random in nature than dispersal of animal populations (Hansson 1991; Marini et al. 2012). Plants use a variety of vectors as both pollen and seed transports (Drezner et al. 2001). Some plants do not disperse seeds or use a ballistic dispersal mechanism to distribute seeds within their immediate surroundings (Loeffler and Wegner 2000, Drezner et al. 2001). While this may guarantee that seeds fall into a patch that would favor growth and may increase the local population, there is little or no colonization to external patches. Many plants rely on wind or water to disperse pollen and seeds that may allow them to colonize patches at great distances, but in patchy environments, wind dispersal does not ensure pollen or seeds reach patches with favorable growing conditions (Drezner et al. 2001). Plants that rely on herbivores as seed dispersers may ensure seedling establishment in other suitable patches by using fruit or foliage as an attractant to occupied patches (Janzen 1984). The evolution of fruit is believed to have occurred as a means to attract herbivores and frugivores to consume both fruit and seed to be deposited after digestion, ideally in nutrient rich fecal material (Willson and Whelan 1990). Additionally, Janzen (1984) hypothesized that in many plants that do not bear fruit the vegetation acts as an attractant to herbivores who then consume seeds with vegetative matter. However, the colonization of unoccupied patches may still be random as plants cannot attract the herbivores to suitable patches that they do not occupy. Conversely, some herbivores may consume seeds that are not adapted to pass through the digestive tract thus reducing the potential for both increasing the local population or colonization of new patches (Furedi and McGraw 2004, Alexander et al. 2012). Potential for long distance dispersal differs with the species and capacity for movement of the disperser (Willson 1993, Jaroszewicz and Piroznikow 2011). Finally, in a situation where flowering plants are consumed before the production of seeds, overall plant reproduction is decreased by the loss of seed production. 
Drezner et al. (2001) discussed the method of seed dispersal of riparian plants and argued that obligate wetland plants are more often dispersed by water or wind while upland plants are more often dispersed by animals. This study, however, looked at few obligate wetland plants (n =3) and many upland plants. Additionally, the traditional method of determining dispersal mechanism is to classify a plant based on seed characteristics. However, many seeds do not have characteristic signs for a particular dispersal method, some species may have more than one dispersal method (Drezner et al. 2001, Panter and Dolman 2012), and though a seed may be physically adapted for one type of dispersal, it is not known whether or not, that seed could still germinate if consumed by an herbivore.

\section{$\underline{\text { Overpopulation and Vegetation Communities }}$}

Behind studies on deer foods and habits, the effect of white-tailed deer on their habitat is one of the most studied and controversial topics in the fields of wildlife management, forestry, and ecology (Warren 1997). Many studies have been driven by economical factors such as loss of crops or regeneration of preferred timber species. This, in fact, is a major concern of the forestry profession. As early as 1947, Aldo Leopold, known as the father of wildlife management, recognized the impact that overabundant populations of white-tailed deer may have on vegetation (Leopold et al. 1947). In compilation of information from across the United States, Leopold et al. (1947) showed that deer "irruptions" were occurring and having a detrimental effect on local vegetation as well as the deer populations themselves. In Pennsylvania, Hough (1965) found that high densities of deer changed the occurrence of certain plant species in permanent forested plots. Through a 20-year photographic record, he observed a loss of preferred species first, followed by a reduction in less desirable plant species. Speciesspecific studies found deer had detrimental effects on hemlock (Tsuga canadensis)(Anderson 
and Loucks 1979, Whitney 1984, Alverson and Waller 1997, Stromayer and Warren 1997), white cedar (Thuja occidentalis), yellow birch (Betula lutea)(Stromayer and Warren 1997), and various oak species (Quercus spp.)(Healy 1997, Rooney and Waller 2003, Griscom et al. 2011, Long et al. 2012). A simulated browse study in individual young red (Pinus resinosa) and white pine (Pinus strobus) trees showed that repeated severe browsing has a detrimental effect on height of trees and survival (Marshall et al. 1955). Similarly, Saunders and Puettmann (1999) found that heavy artificial browsing reduced both height and diameter growth of white pine seedlings.

Exclosure studies examining community level changes suggest that high levels of deer browse tend to decrease stem density and species richness (Goetsch et al. 2011, Levine et al. 2012, McGarvey et al. 2013) affecting the community composition at the sapling stage that may translate into the overstory when chronic high densities persist (Nuttle et al. 2011, Tanentzap et al. 2011, Holm et al. 2013). Similar results were found concerning species composition and stem density on fixed deer density plots within enclosures (Tilghman 1989, deCalesta and Stout 1997, DiTommaso et al. 2014). Natural refugia from deer browse can provide clues as to the effects of deer densities on forest communities. Community composition differs within the same location on the forest floor and on top of boulders (Carson et al. 2005, Comisky et al. 2005). Root wads from trees that had blown down may also act as refugia for a variety of species (Krueger and Peterson 2006, Chollet et al. 2013).

While much of the research on the effects of white-tailed deer on vegetative communities has thus far been concentrated on economically important forest species, deer also have been shown to have negative impacts on herbaceous communities (Royo et al. 2010, Urbanek et al. 2012, Bugalho et al. 2013). Augustine and Frelich (1998) found that trillium species (Trillium 
spp.), which are locally rare in some areas of their range, can be used as an index of deer browsing intensity. Glade spurge (Euphorbia purpurea), a globally rare plant is affected by consumption of leaves as well as limited in reproduction by browsing of flowering parts by white-tailed deer (Loeffler and Wegner 2000). Deer may reduce or extirpate local populations of American ginseng (Panax quinquefolius) in West Virginia (McGraw and Furedi 2005), Turk's cap lily in Virginia (Lilium supurbum; Fletcher et al. 2001) and sundial lupine (Lupinus perennis; Frye 2012). Additionally, deer herbivory has been cited as a detriment to tallgrass prarie forbs (Anderson et al. 2001), riparian willow species (Brookshire et al. 2002), cultivated native wildlower species (DeGroote et al. 2011), and additional riparian (Opperman and Merenlender 2000) and savanna (Urbanek et al. 2012) plant community restoration efforts. Peek and Stahl (1997) described an instance in which a large population of deer extirpated 150 vascular plant species from a city park in Ohio.

More recently, ecologists have suggested the indirect detrimental effects of too many deer. A change in vegetation can affect animal communities which use the same habitat. A change in understory species composition or a reduction in the density of the understory may affect nesting songbirds (deCalesta 1994, McShea et al. 1995, McShea and Rappole 1997a, Martin et al. 2011, Chollet and Martin 2013). Deer herbivory may either negatively affect small mammal populations through loss of ground cover species or positively affect populations by indirectly increasing fern cover (Flowerdew and Elwood 2001, Byman 2011, Bush et al. 2012). Deer also may influence invertebrate species by selectively browsing host plant species (Frye 2012) or reducing the abundance of flowers available to pollinators.

Despite the extensive amount of literature on white-tailed deer browse and the variety of species studied, there are comparatively few studies that focus on freshwater wetland species in 
particular (Loeffler and Wegner 2000, Kery and Gregg 2004). Barrett et al. (2006) examined the influence of deer herbivory on mangrove wetland communities, Cogger et al. (2014) examined deer herbivory in bottomland hardwoods, and Urbanek et al. (2012) included two wetland sites in a study involving the influence of deer on restored communities. Given the historic decline, wetlands may harbor a disproportiate number of threatened and endangered plant species. It is important to consider the role of white-tailed deer herbivory in determining the distribution and abundance of these species as well as the structure of wetland communites.

\section{$\underline{\text { Alternate Stable States }}$}

White-tailed deer have the potential to exert a long-term influence on forest communities through alternative means. Selective browsing resulting in a lack of a vegetative understory can promote the growth of unpalatable ground cover species such as hay-scented fern (Dennstaedtia punctilobula) (de la Cretaz and Kelty 2002, Tanentzap et al. 2011, Nuttle et al. 2014). Heavy growth of unpalatable ground cover plants can prevent the growth of tree species by reducing the amount of sunlight available on the forest floor (de la Cretaz and Kelty 2002, Royo and Carson 2006) and may exert a bottom-up control on vegetation persisting even after herbivore reductions (Royo et al. 2010, Nuttle at al. 2011). While a reduction in understory richness and diversity may negatively affect small mammal density (Bush et al. 2012, Byman et al. 2013), ground cover growth can also provide shelter for small mammals that consume seeds from overstory tree species thus preventing reproduction of the existing overstory community (Royo and Carson 2006). Thus, white-tailed deer may have the ability to influence the creation of alternate stable states in an ecosystem (Augustine et al. 1998) that is a community that exists in a different state than would be predicted by ecological succession and remains stable without a disturbance event 
(Stromayer and Warren 1997) particularly when combined with a loss of canopy species through disturbance (Holm et al. 2013, Nuttle et al. 2013).

The Role of White-tailed Deer in Seed Dispersal

Much of the research concerning the effects of deer on plant communities have focused on their role as browsers and the potential for overbrowsing of plants (Stromayer and Warren 1997, Royo et al. 2010, Kribel et al. 2011, Tanentzap et al. 2011, Nuttle et al. 2013). However, several studies have looked at the role of white-tailed deer as both seed predators and seed dispersers (Cambell and Gibson 2001, Vellend et al. 2003, Myers et al. 2004, Levine et al. 2012). Due to their large homerange size (Janzen 1984) and the potential to retain material in the digestive tract for three or more days (Mautz and Petrides 1971), white-tailed deer have the potential to carry seeds great distances. Vellend et al. (2003) suggested that this would result in $95 \%$ of germinable seeds being deposited more than $100 \mathrm{~m}$ from the parent plant and $30 \%$ deposited more than one kilometer from the parent plant. This may have a considerable effect on metapopulation initiation, growth, and gene flow of irregularly distributed and rare plant species (Myers et al. 2004). Additionally, the ability of a plant to disperse long distances can affect the genetic structure of a metapopulation by increasing homogeneity between subpopulations (Hedrick 1996, Alexander et al. 2012).

Myers et al. (2004) found that 72 species of forest and old field plants germinated from fecal pellet samples with a mean of 38 germinations per pellet group. The germinated seeds ranged from forbs to tree species and while some were seeds distributed through fruiting mechanisms, most were not. However, Cambell and Gibson (2001) found only two species germinated from 22 pellet group samples. Williams et al. (2008) found that deer dispersed 40 different exotic species and suggested that, in addition to reducing reproduction of native plants, 
dispersal of exotics could help to reduce native plant populations. While deer may play an important part in the dispersal of seed for many plants, they also may play a role in the spread of exotic species (Cambell and Gibson 2001, Vellend 2002, Robertson 2012, Castellano and Gorchev 2013, Kalisz et al. 2014). Additionally, for some plant species including American ginseng (Furedi and McGraw 2004), white-tailed deer are demonstrated seed predators or consumers, that is, all seeds consumed in the act of herbivory are digested or are non-viable once passed through the digestive system thus reducing the realized reproductive output of these plants.

\section{Bog Jacob's-Ladder (Polemonium vanbruntiae Britt.)}

Bog Jacob's-ladder (Figure 1) is a perennial that ranges from Quebec south to West Virginia and from Maine east to West Virginia (Bermingham and Brody 2011). It is found in habitats varying from shrub swamps and forested wetlands to moist roadsides occurring mostly at elevations above 305 m (Maine Department of Conservation 2004) and is considered a facultative wetland (FACW) plant species (USDA 2012). It is ranked as a G3/G4 (rare or uncommon/common) globally and an S2 (very rare and imperiled) in the state of West Virginia (WV DNR 2012). This plant has been propagated successfully ex situ but is rare in natural populations. Bog Jacob's-ladder may reproduce sexually or asexually (Committee on the Status of Endangered Wildlife in Canada 2002).

Current threats to bog Jacob's-ladder populations in the northern part of its range include agriculture, forestry, and wetland drainage or development (Deller 2002). In Canaan Valley, past threats have included logging, agriculture, and potential activity of all-terrain vehicles. Many of the populations in Canaan Valley are now protected by the location of state and government owned land. Current threats to these populations my include flooding caused by 
beaver (Castor canadensis) activity in the valley (Figure 2). There is anecdotal evidence of white-tailed deer browsing on this species but it is not currently considered a management concern in Canadian populations. However, the deer densities at these locations may not be as high as Canaan Valley populations (Michael 1992).

Public Attitudes Toward White-tailed deer Management

In the 1940s, Leopold et al. (1947) found that it was difficult to convince hunters and the general public, who experienced first hand the shortage of deer as a result of over-hunting, that an overabundance of deer could exist at all much less be a detriment to their habitat. Today, it is still difficult to convince hunters, who have experienced the low abundance of deer in earlier decades of the 1900s, that overabundance is a problem and, in the case of reduced deer herds, that the problem exists at all (Diefenbach et al. 1997). Since the early 1900s, a greater proportion of the nation's general public is disconnected with wildlife and its habitat. Though the urban sprawl phenomenon brought many more people out of the cities and created suburban centers out of formally rural land, the suburbanites have not embraced the hunting heritage of rural America. Instead, white-tailed deer have taken on roles which range from lawn ornament, to garden pest, to road hazard. As hunting has decreased as a pastime (Diefenbach and Shea 2011), more people have embraced animal welfare or animal rights perspectives which do not condone the use of hunting as a management tool for deer populations (Rutberg 1997).

As wildlife is considered a public resource, its management often involves input from the public sector (Green et al. 1997, McShea and Rappole 1997b, Shafer-Nolan 1997). Thus, state and local agencies charged with managing deer herds need to balance the attitudes of hunters, antihunters, and nonhunters with public safety and sound biology (Urbanek et al. 2013). 


\section{Justification}

There has been increasing interest in exploring the effects of deer in an ecological context. As early as the 1940s, wildlife biologists as well as foresters began noticing the effect of abnormally high populations of deer on the regeneration of timber species (Leopold et al. 1947). Since then, most of these efforts have been directed at forested upland habitats, specifically at the reproduction of economically important species (Healy 1997, Rooney and Waller 2003). Fewer studies of deer diet have been directed solely toward rare or endangered herbaceous or woody plants (Miller et al. 1992, Russel et al. 2001).

To date, there has been comparatively little research on the effects of white-tailed deer browsing on herbaceous wetland plants primarily because wetlands have not been a focus of white-tailed deer study in general (Russel et al. 2001). Many plant species found in the wetlands of West Virginia may be considered rare or endangered because of the relative rarity of this habitat in the state. In the high elevation wetlands of West Virginia, this situation is even more evident as many of the plants are typical of northern climates and may be locally rare in the state (Fortney 1993, WV DNR 2012). White-tailed deer densities in the Canaan Valley today are drastically different from historical estimates of deer population densities primarily as a result of human intervention in the species' environment (i.e., fragmentation, vegetation alteration and reduction of the predator community). The potential for over-browsing by white-tailed deer could be considered as another human mediated environmental change (Primack and Miao 1992, Stromayer and Warren 1997). It is important to understand how these changes may affect metapopulation extinction and colonization rates of rare plants to inform conservation decisions for these species (Primack and Miao 1992, Alexander et al. 2012).

Canaan Valley provides an ideal area to research these effects because of the protected 
status of much of the land, the economic draw of the wetlands, the high density of white-tailed deer in areas restricted to hunting, and the rarity of many of the plant species in the valley. Michael (1992) suggested that a difference in white-tailed deer abundance existed between several existing balsam fir stands within Canaan Valley. Deer abundance in Canaan Valley may be different from West Virginia Division of Natural Resource estimates for the entire county because of differences in vegetation, human development, and hunting restriction on both the National Wildlife Refuge (permit) and Canaan Valley State Park (prohibited). It is important to determine the relative abundance of deer in Canaan Valley as a whole and whether or not abundance differs by area to determine the relation to vegetation characteristics and make future management recommendations regarding deer numbers.

\section{Objectives}

White-tailed deer have had demonstrated browsing effects on numerous plant species. While research on browse effects on wetland plants is limited, there is evidence that white-tailed deer affect many other herbaceous species through herbivory. Deer have been implicated in the decline of many rare species. However, many other plants benefit from the consumption and dispersal of seeds by deer. The purpose of this study is to evaluate the influences of white-tailed deer herbivory, florivory, and seed consumption on plant populations in West Virginia. The study is organized into three general sections: 1) the influence of white-tailed deer browsing and seed dispersal on rare plant species and communities in Canaan Valley, West Virginia, 2) the influence of white-tailed deer density on forest understory recruitment in upland forests throughout West Virginia, and 3) public attitudes toward rare plant conservation and white-tailed deer management. 
The specific objectives of the first portion of the study are to:

1. Quantify the rates of browsing on Polemonium vanbruntiae in Canaan Valley, WV;

2. Estimate demographics of local populations within metapopulations with respect to local population extinction rates and evaluate the rates of growth or decline for local population with respect to the effects of white-tailed deer browsing;

3. Estimate the seed loss of these species due to white-tailed deer herbivory;

4. Conduct feeding trials of seeds from wetland plant species of interest on captive deer to determine the percentage of seeds that pass though the digestive tract and that are germinable after digestion;

5. Collect natural fecal pellet piles from in and around Canaan Valley wetlands to determine the species of germinable seeds they contain as well as what percentage come from wetland plants; and

6. Evaluate the effects of white-tailed deer browsing on community composition in aspen (Populus tremuloides) regeneration cuts and Solidago spp.-Rubus hispidus dominated wet meadow communites.

I anticipate that rates of browsing on $P$. vanbruntiae populations will increase with increasing relative deer densities. I predict that, due to the conspicuous nature of $P$. vanbruntiae flowers within their environment, white-tailed deer may selectively browse the largest flowers disproportionately affecting seed production and dispersal potential. I predict that white-tailed deer will take advantage of regenerating aspen as winter browse. I hypothesize that many wetland plants, in particular, those considered rare, are not adapted to long distance seed dispersal by herbivores associated with upland habitats such as the white-tailed deer and are thus consumed rather than carried by deer. 
In reference to these predictions, the following null hypotheses will be tested:

1. Rates of browse for $P$. vanbruntiae populations will not vary with respect to density of white-tailed deer;

2. Estimated seed production will not differ between browsed and unbrowsed ramets within a population;

3. A greater proportion of germinable seeds collected from natural fecal pellet piles will be from upland plant species as opposed to obligate wetland plant species; and

4. There will be no difference between control (unfenced) and exclosure plots in Populus tremuloides regeneration cuts and Solidago spp.-Rubus hispidus dominated wet meadow communites.

The specific objectives of the second portion of the study are to:

1. Determine which species of ground cover $(<50 \mathrm{~cm})$ and understory $(>50 \mathrm{~cm}$ but $<$ $2.54 \mathrm{~cm} \mathrm{DBH})$ are most susceptible to deer browsing at different densities; and

2. Evaluate a relationship between deer density and the recruitment of species into the understory of upland forests in West Virginia.

I anticipate that highly palatable browse species would show a difference in abundance between control plots and fenced plots even at low deer densities thus there will be a difference in the understory of unfenced plots as a result of white-tailed deer browse. At high deer densities, only species that are not preferred by white-tailed deer will appear in the understory community. At all densities, abundance of species in the ground cover layer may not be affected by white-tailed deer browse (Sweetapple and Nugent 2004). I predict that, as deer density increases, the number of palatable species that are present in the understory will decline due to increased browsing pressure. 
In reference to these predictions, the following null hypotheses will be tested:

1. There will be no difference in abundance of species between the control and fenced plots;

2. There will be no difference in the magnitude of difference between control and fenced plots between species at different deer densities, and

3. There is no relation between the species richness of preferred species in the understory and deer density.

The specific objective of the third portion of the study is to:

1. Compare the attitudes of residents and nonresidents of Canaan Valley and Tucker County, WV toward rare plant conservation and white-tailed deer management. Many of the visitors to Canaan Valley may have a different demographic makeup in terms of age, education, and recreational goals than residents. I anticipate that nonresidents would be more likely to favor the conservation of rare plants but less likely to advocate lethal means for control of white-tailed deer numbers.

In reference to this prediction, the following null hypothesis will be tested;

1. There will be no difference between attitudes of residents and nonresidents of Canaan Valley with respect to rare plant conservation and white-tailed deer management.

Study Area

$\underline{\text { Canaan Valley }}$

The Canaan Valley, located in Tucker County, West Virginia (Figure 3), is the highest elevation valley east of the Rocky Mountains (Fortney 1975). As such, the climate and accordingly, the vegetation, of the valley is more similar to northern boreal forests than to the deciduous forests of surrounding West Virginia. Once home to large stands of red spruce (Picea 
rubens), intense logging followed by fires drastically changed the soils and vegetation of the valley to their present condition (Fortney 1975). The valley floor averages $975 \mathrm{~m}$ above sea level. This coupled with surrounding mountains which rise 150-240 $\mathrm{m}$ above the valley create a relatively cool, moist climate and a short growing season. The average annual precipitation is $141 \mathrm{~cm}$ (National Climate Data Center 2014). In addition, high-elevation valleys in the Appalachian region often function as frost pockets that trap and hold cooler air (Byers et al. 2007). The average growing season is approximately 90 days (Griscom et al. 2011). These characteristics set Canaan Valley apart from lower elevation wetland and upland areas in the surrounding counties.

The Canaan Valley, West Virginia encompasses about $176 \mathrm{~km}^{2}$ (17,600 ha) of land. Approximately $20 \%$ of the land area is made up of various wetland community types and another $23 \%$ is northern hardwood forest (Figure 4). Of all the high-elevation wetlands in West Virginia, Canaan Valley is home to the largest contiguous wetland areas (3,000 ha, Byers et al. 2007). Fortney (1975) described 27 distinct wetland community types ranging from quaking aspen (Populus tremuloides) stands to sphagnum (Sphagnum spp.) and polytrichum (Polytrichum spp.) bogs. Agriculture, rural development, and recreational land make up another portion of the valley (Michael 1992). The Canaan Valley is home to Canaan Valley State Park and the Canaan Valley National Wildlife Refuge as well as land owned by the West Virginia Division of Natural Resources. Deer hunting is allowed by permit within the National Wildlife Refuge lands and is conducted on private holdings throughout Canaan Valley. However, hunting has been prohibited in sections of the southern end of the Valley (i.e., Canaan Valley Resort State Park) since 1971 (Michael 2002). Sampling was conducted on a combination of these public access properties in the valley. 
The impact of white-tailed deer on plant populations has previously been studied on balsam fir (Abes balsamea) and showy lady's slipper (Cypripedium reginae)(Gregg 2004, Kery and Gregg 2004) in the Canaan Valley. Study of balsam fir communities in Canaan Valley, WV indicated that higher deer densities reduced balsam fir reproduction (Michael 1992; Cherefko et al. 2009). The status of balsam fir as a preferred browse species is unclear. Michael (1992) considered balsam fir to be a preferred browse species. However, Stromayer and Warren (1997) suggested the opposite. This discrepancy may be due to geographic variation in abundance and additional browse species availability. Leopold et al. (1947) noted that, in Wisconsin, evidence of heavy browse on balsam fir was a precursor to fawn starvation in winter suggesting that it was one of the last plants to be browsed heavily by an overabundant population. Cherefko et al. (2009) found that deer browse in Canaan Valley had an impact on young balsam fir trees. Though significant negative impacts of white-tailed deer browse on balsam fir have not been extensively reported elsewhere, Canaan Valley may have the highest densities $\left(32 \mathrm{deer} / \mathrm{km}^{2}\right)$ of deer within balsam fir range (Michael 1992).

\section{$\underline{\text { West Virginia Deer Exclosure Sites }}$}

Upland forest sites were randomly selected by the West Virginia Division of Natural Resources for the location of fenced deer exclosures. Nineteen sites were located in 14 counties throughout the state (Figure 3). Most sites were located in oak-hickory stands, however, several were located in mixed or northern hardwood stands. Sites were grouped into areas of low deer density (buck kill of $<2$ per square mile or $<5.18$ per square $\mathrm{km}$ ), moderate deer density $(2-5$ bucks killed per square mile or 5.19-12.95 per square $\mathrm{km}$ ) and high deer density (> 5 bucks killed per square mile or > 12.96 per square $\mathrm{km}$ ) according to annual harvest data. 


\section{LITERATURE CITED}

Alexander, H.M., B.L. Foster, F. Ballantyne, C.D. Collins, J. Antonovics, and R.D. Holt. 2012. Metapopulations and metacommunities: combining spatial and temporal perspectives in plant ecology. Journal of Ecology 100:88-103.

Alverson W.S. and D.M. Waller. 1997. Deer populations and the widespread failure of hemlock regeneration in northern forests. Pages 280-297 in McShea, W.J., H.B. Underwood, and J.H. Rappole, eds. 1997. The science of overabundance: deer ecology and population management. Smithsonian Institution Press. Washington D.C., USA.

Anderson, R.C., E.A. Corbett, M.R. Anderson, G.A. Corbett, and T.M. Kelley. 2001. High white-tailed deer density has negative impact on tallgrass prairie forbs. Journal of the Torrey Botanical Society 128:381-392.

Anderson, R.C. and O.L. Loucks. 1979. White-tailed deer influence on structure and composition of Tsuga canadensis forests. Journal of Applied Ecology 16:855-861.

Augustine D.J., L.E. Frelich, and P.A. Jordan. 1998. Evidence for two alternate stable states in an ungulate grazing system. Ecological Applications 8:1260-1269.

Augustine, D.J. and L.E. Frelich. 1998. Effects of white-tailed deer on populations of an understory forb in fragmented deciduous forests. Conservation Biology 12:995-1004.

Barrett, M.A., P. Stiling, and R.R. Lopez. 2006. Long-term changes in plant communites influenced by key deer herbivory. Natural Areas Journal 26:235-243.

Bermingham, L.H. and A.K. Brody. 2011. Pollen source affects female reproductive success and early offspring traits in the rare endemic plant Polemonium vanbruntiae (Polemoniaceae). Plant Species Biology 26:244-253.

Brookshire, E.N.J., J.B. Kauffman, D. Lytjen, and N. Otting. 2002. Cumulative effects of wild 
ungulate and livestock herbivory on riparian willows. Oecologica 132:559-566.

Bugalho, M.N., I. Ibáñez, and J.S. Clark. 2013. The effects of deer herbivory and forest type on tree recruitment vary with plant growth stage. Forest Ecology and Management 308:90-100.

Bush, E.R., C.D. Buesching, E.M. Slade, and D.W. Macdonald. 2012. Woodland recovery after suppression of deer: cascade effects for small mammals, wood mice (Apodemus sylvaticus) and bank voles (Myodes glareolus). PLoS ONE 7(2): e31404.

Byers, E.A., J.P. Vanderhorst, and B.P. Streets. 2007. Classification and conservation assessment of high elevation wetland communities in the Allegheny mountains of West Virginia. West Virginia Natural Heritage Program, WVDNR, Elkins, WV.

Byman, D. 2011. The effects of deer exclosures on voles and shrews in two forest habitats. Northeastern Naturalist 18:509-520.

Byman, D., S.D. Harding, and F.W. Spear. 2013. Demographic effects of white-tailed deer (Odocoileus virginianus) exclosures on white-footed mice (Peromyscus leucopus). American Midland Naturalist 170:171-183.

Cambell, J.E. and D.E. Gibson. 2001. The effect of seeds of exotic species transported by via horse dung along trail corridors. Plant Ecology 157:23-35.

Carson, W.P., J. Banta, A. Royo, and C. Kirschbaum. 2005. Plant communities growing on boulders in the Allegheny National Forest: evidence for boulders as refugia from deer and as a bioassay of overbrowsing. Natural Areas Journal 25:10-18.

Castellano, S.M. and D.L. Gorchov. 2013. White-tailed deer (Odocoileus virginianus) disperse seeds of the invasive shrub, Amur honeysuckle (Lonicera maackii). Natural Areas Journal 33:78-80. 
Caughley, G. 1981. Overpopulation. Pages 7-19 in P.A. Jewell, S. Holt, and D. Hart Eds. Problems in management of locally abundant wild mammals. Academic Press, New York. USA.

Cherefko, C., C. Fridley, J. Medsger, M. Woody, and J.T. Anderson. 2009. Impacts of whitetailed deer and balsam wooly adelgid on balsam fir in Canaan Valley. in Canaan Valley and its Environs: A Landscape Heritage Celebration. Canaan Valley Institute, Davis, WV.

Chollet, S. and J.L. Martin. 2013. Declining woodland birds in North America: should we blame Bambi? Diversity and Distributions 19:481-483.

Chollet. S, C. Baltzinger, L. Ostermann, F. Saint-André, and J.L. Martin. 2013. Importance for forest plant communities of refuges protecting from deer browsing. Forest Ecology and Management 289:470-477.

Comisky, L., A.A. Royo, and W.P. Carson. 2005. Deer browsing creates rock refugia gardens on large boulders in the Allegheny National Forest, Pennsylvania. American Midland Naturalist 154:201-206.

Committee on the Staus of Endangered Wildlife in Canada. 2002. COSEWIC Assessment and update status report on the Van Brunt's Jacob's-ladder (Polemonium vanbruntiae) in Canada. Ottawa, ON, Canada.

Cogger, B.J., N.R. De Jager, M. Thomsen, and C. Reinhardt-Adams. 2014. Winter browse selection by white-tailed deer and implications for bottomland forest restoration in the upper Mississippi River valley, USA. Natural Areas Journal 34:144-153.

Craighead, F.L. and E.R. Vyse. 1996. Brown/Grizzly bear metapopulations. Pages 325-352 in 
McCullough, D. R., ed. 1996. Metapopulations and Wildlife Conservation. Island Press. Washington D.C., USA.

Dahl, T.E. 1990. Wetlands Losses in the United States 1780 's to 1980 's. U.S. Department of the Interior, Fish and Wildlife Service, Washington, D.C. 13 pp. Available online: http://www.fws.gov/wetlands/Documents/Wetlands-Losses-in-the-United-States-1780sto-1980s.pdf.

deCalesta, D.S. 1994. Effect of white-tailed deer on songbirds within managed forests in Pennsylvania. Journal of Wildlife Management 58:711-718.

deCalesta, D.S. and S.L. Stout.1997. Relative deer density and sustainability: a conceptual framework for integrating deer management with ecosystem management. Wildlife Society Bulletin 25:252-258.

DeGroote, L.W., H.K. Ober, J.H. Aldrich, J.G. Norcini, and G.W. Knox. 2011. Susceptibility of cultivated native wildflowers to deer damage. Southeastern Naturalist 10:761-771.

de la Cretaz, A.L. and M.J. Kelty. 2002. Development of tree regeneration in fern-dominated forest understories after reduction of deer browsing. Restoration Ecology 10:416-426.

Deller, M. 2002. Polemonium van-bruntiae Britton (Appalachian Jacob's ladder) New England Plant Conservation Program Conservation and Research Plan for U. S. Forest Service Region 9. New England Wild Flower Society, Framingham, Massachusetts, USA.

Diefenbach, D.R. and S.M. Shea. 2011. Managing white-tailed deer: eastern North America. Pages 481-497 in Hewitt, D.G., ed. 2011. Biology and management of white-tailed deer. CRC Press. New York, NY., USA.

Diefenbach, D.R., W.L. Palmer, and W.K. Shope. 1997. Attitudes of Pennsylvania sportsman 
towards managing white-tailed deer to protect the ecological integrity of forests. Wildlife Society Bulletin 25:244-251.

DiTommaso A, S.H. Morris, J.D. Parker, C.L. Cone, and A.A. Agrawal. 2014. Deer browsing delays succession by altering aboveground vegetation and belowground seed banks. PLoS ONE 93: e91155. doi:10.1371/journal.pone.0091155.

Drezner, T.D., P.L. Fall, and J.C. Stromberg. 2001. Plant distribution and dispersal mechanisms at Hassayampa River Preserve, Arizona, U.S.A. Global Ecology and Biogeography 10:205-217.

Fletcher, J.D., L.A. Shipley, W.J. McShea, and D.L. Shumway. 2001. Wildlife herbivory and rare plants: the effects off white-tailed deer, rodents, and insects on growth and survival of Turk's cap lily. Biological Conservation 101:229-238.

Flowerdew, J.R. and S.A. Elwood. 2001. Impacts of woodland deer on small mammal ecology. Forestry 74:277-287.

Frye, J.A. 2012. The effect of deer browse on sundial lupine: implications for frosted elfins Northeastern Naturalist 19:421-430.

Fortney, R.H. 1975. The Vegetation on Canaan Valley, West Virginia: a taxonomic and ecological study. Dissertation; West Virginia University, Morgantown, West Virginia, USA.

Fortney, R.H. 1993. Canaan Valley - An area of special interest within the upland forest region. Pages 46-65 in Stephenson, S. L., ed. 1993. Upland Forests of West Virginia. McClain Printing Co., Parsons, West Virginia, USA.

Furedi, M.A. and J.A. McGraw. 2004. White-tailed deer: dispersers or predators of American ginseng seed? American Midland Naturalist 152:268-276. 
Geddes, N.A. and S. Mopper. 2006. Effects of environmental salinity on vertebrate florivory and wetland communiies. Natural Areas Journal 26:31-37.

Goetsch, C., J. Wigg, A.A. Royo, T. Ristau, and W.P. Carson. 2011. Chronic over browsing and biodiversity collapse in a forest understory in Pennsylvania: results from a 60 year-old deer exclusion plot. Journal of the Torrey Botanical Society 138:220-224.

Green, D., G.R. Askins, and P.D. West. 1997. Public opinion: obstacle or aid to sound deer management. Wildlife Society Bulletin 25:367-370.

Gregg, K.B. 2004. Recovery of showy lady's slippers (Cypripedium reginae Walter) from moderate and severe herbivory by white-tailed deer (Odocoileus virginianus Zimmerman). Natural Areas Journal 24:232-241.

Griscom, B., H. Griscom, and S. Deacon. 2011. Species-specific barriers to tree regeneration in high elevation habitats of West Virginia. Restoration Ecology 19:660-670.

Hanski, I. 1991. Single-species metapopulation dynamics: concepts, models and observations. Biological Journal of the Linnean Society 42:17-38.

Hanski, I. and M. Gilpin. 1991. Metapopulation dynamics: brief history and conceptual domain. Biological Journal of the Linnean Society 42:3-16.

Hansson, L. 1991. Dispersal and connectivity in metapopulations. Biological Journal of the Linnean Society 42:89-103.

Harrison, S. 1991. Local extinction in a metapopulation context: an empirical evaluation. Biological Journal of the Linnean Society 42:73-88.

Hastings, A. 1991. Structures models of metapopulation dynamics. Biological Journal of the Linnean Society 42:57-71.

Healy, W.M. 1997. Influence of deer on the structure and composition of oak forests in central 
Massachusetts. Pages 249-266 in McShea, W.J., H.B. Underwood, and J.H. Rappole, eds. 1997. The science of overabundance: deer ecology and population management. Smithsonian Institution Press. Washington D.C., USA.

Hedrick, P.W. 1996. Genetics of metapopulations: aspects of a comprehensive perspective. Pages 29-52 in McCullough, D.R., ed. 1996. Metapopulations and Wildlife Conservation. Island Press. Washington D.C., USA.

Heinken, T., and E.Weber. 2013. Consequences of habitat fragmentation for plant species: do we know enough? Perspectives in Plant Ecology, Evolution, and Systematics 15:205-216.

Holm, J.A., J.R. Thompson, W.J. McShea, and N.A. Bourg. 2013. Interactive effects of chronic deer browsing and canopy gap disturbance on forest successional dynamics. Ecosphere $4: 1-23$.

Hough, A.F. 1965. A twenty year record of understory vegetational change in a virgin Pennsylvania forest. Ecology 46:370-373.

Husband, B.C. and S.C.H. Barrett. 1996. A metapopulation perspective in plant population biology. Journal of Ecology 84:461-469.

Janzen, D.H. 1984. Dispersal of small seeds by big herbivores: foliage is the fruit. American Naturalist 123:338-353.

Jaroszewicz, B. and E. Pirożnikow. 2011. Dung longevity influences the fate of endozoochorically dispersed seeds in forest ecosystems. Botany 89:779-785.

Kalisz, S., R.B. Spigler, and C.C. Horvitz. 2014. In a long-term experimental demography study, excluding ungulates reversed invader's explosive population growth rate and restored natives. Proceeding of the National Academy of Sciences of the United States of 
America 111:doi: 10.1073/pnas.1310121111.

Kery, M and K.B. Gregg. 2004. Demographic analysis of dormancy and survival in the terrestrial orchid Cypripedum reginae. Journal of Ecology 92:686-695.

Kribel, J.R., K.B. Kolman, and S. Ware. 2011. Rapid change in sapling and seedling layers in an otherwise stable hardwood forest: an effect of deer browsing. Castanea 76:140-148.

Krueger, L.M. and C. J. Peterson. 2006. Effects of white-tailed deer on Tsuga canadensis regeneration: evidence of microsites as refugia from browsing. American Midland Naturalist 156:353-362.

Leopold, A., I.K. Sowls, and D.L. Spencer. 1947. A survey of overpopulated deer herds in the U.S. Journal of Wildlife Management 11:162-177.

Levine, C.R., R.J. Winchcombe, C.D. Canham, L.M. Christenson, and M.L. Ronsheim. 2012. Deer impacts on seed banks and saplings in eastern New York. Northeastern Naturalist 19:49-66.

Levins, R. 1969. Some demographic and genetic consequences of environmental heterogeneity for biological control. Bulletin of the Entomological Society of America 15:237-240.

Loeffler, C.C. and B.C. Wegner. 2000. Demographics and deer browsing in three Pennsylvania populations of the globally rare glade spurge, Euphorbia purpurea, fern. Castanea 65: $273-290$.

Long, R.P., P.H. Brose, and S.B. Horsley. 2012. Responses of northern red oak seedlings to lime and deer exclosure fencing in Pennsylvania. Canadian Journal of Forest Research 42:698-709.

Maine Department of Conservation. 2004. Polemonium vanbruntiae: rare plant fact sheet. Natural Areas Program. Augusta, ME, U.S.A. 
Marini, L., H.H. Bruun, R.K. Heikkinen, A. Helm, O. Honnay, J. Krauss, I. Kuhn, R. Lindborg, M. Partel, and R. Bommarco. 2012. Traits related to species persistence and dispersal explain changes in plant communities subjected to habitat loss. Diversity and Distributions 18:898-908.

Maron, J.L. and M. Vila. 2001. When do herbivores affect plant invasion? Evidence for the natural enemies and biotic resistance hypotheses. Oikos 95:361-373.

Marshall, W.H., T. Schantz-Hanson, and K. Winsness. 1955. Effects of simulated browsing on small red and white pine trees. Journal of Forestry 53:420-424.

Martin, T.G., P. Arcese, and N. Scheerder. 2011. Browsing down our natural heritage: deer impacts on vegetation structure and songbird populations across an island archipelago. Biological Conservation 144:459-469.

Mautz, W.M. and G.A. Petrides. 1971. Food passage rate in the white-tailed deer. Journal of Wildlife Management 35:723-731.

May, F., I. Giladi, M. Ristow, Y. Ziv, and F. Jeltsch. 2013. Metacommunity, mainland-island system or island communities? Assessing the regional dynamics of plant communities in a fragmented landscape. Ecography 36:842-853.

McCabe, R.E. and T.R. McCabe. 1984. Of slings and arrows: An historical retrospection. Pages 19-72 in Halls, L.K., ed. 1984. White-tailed Deer Ecology and Management. Stackpole Books. Harrisburg, PA, USA.

McGarvey, J.C., N.A. Bourg, J.R. Thompson, W.J. McShea, and X. Shen. 2013. Effects of twenty years of deer exclusion on woody vegetation at three life-history stages in a mid-Atlantic temperate deciduous forest. Northeastern Naturalist 20:451-468.

McGraw, J. B. and M. A. Furedi. 2005. Deer browsing and population viability of a forest 
understory plant. Science 307:920-922.

McShea, W.J., M.V. McDonald, G.E. Morton, R. Meier, and J. H. Rappole. 1995. Long term monitoring of Kentucky warbler habitat. Auk 112:375-381.

McShea W.J. and J.H. Rappole. 1997(a). Herbivores and the ecology of forest understory birds. Pages 298-309 in McShea, W.J., H.B. Underwood, and J.H. Rappole, eds. 1997. The Science of Overabundance: Deer Ecology and Population Management. Smithsonian Institution Press. Washington D.C., USA.

McShea W.J. and J.H. Rappole. 1997(b). The science and politics of managing deer within a protected area. Wildlife Society Bulletin 25:443-446.

Michael, E.D. 1992. Impact of deer browsing on regeneration of balsam fir in Canaan Valley, West Virginia. Northern Journal of Applied Forestry 9:89-90.

Michael, E.D. 2002. A valley called Canaan: 1885-2002. Mcclain Printing Co. Parsons, WV. USA.

Miller, S.G., Bratton, S.P., and J. Hadidian. 1992. Impacts of white-tailed deer on endangered and threatened vascular plants. Natural Areas Journal 12:67-74.

Myers, J.A., M.Vellend, S. Gardesca, and P.L. Marks. 2004. Seed dispersal by white-tailed deer; implications for long-distance, migration and invasion of plants in eastern North America. Oecologica 139:35-44.

National Climate Data Center. 2014. National Oceanic and Atmospheric Administration: Canaan Valley, WV. Accessed online: httpllwww.ncdc.noaa.gov.

Noël, F., N. Machon, and A. Robert. 2013. Integrating demographic and genetic effects of connections on the viability of an endangered plant in a highly fragmented habitat. Biological Conservation 158:167-174. 
Nuttle, T., T.E. Ristau, and A.A. Royo. 2014, Long-term biological legacies of herbivore density in a landscape-scale experiment: forest understorys reflect past deer density treatments for at least 20 years. Journal of Ecology 102:221-228.

Nuttle, T., A.A. Royo, M.B. Adams, and W.P. Carson. 2013. Historic disturbance regimes promote tree diversity only under low browsing regimes in eastern deciduous forest Ecological Monographs 83:3-17.

Nuttle, T., E.H. Yerger, S.H. Stoleson, and T.E. Ristau. 2011. Legacy of top-down herbivore pressure ricochets back up multiple trophic levels in forest canopies over 30 years. Ecosphere 2:1-11.

Opperman, J.J. and A.M. Merenlender. 2000. Deer herbivory as an ecological constraint to restoration of degraded riparian corridors. Restoration Ecology 8:41-47.

Panter, C.J. and P.M. Dolman. 2012. Mammalian herbivores as potential seed dispersal vectors in ancient woodland fragments. Wildlife Biology 18:292-303.

Peek, L.J. and J.F. Stahl. 1997. Deer management techniques employed by the Columbus and Franklin county park district, Ohio. Wildlife Society Bulletin 25:440-442.

Primack, R.B. and S.L. Miao. 1992. Dispersal can limit local plant distribution. Conservation Biology 6:514-519.

Robertson, D.J. 2012. Trees, deer and non-native vines: two decades of northern piedmont forest restoration. Ecological Restoration 30:59-70.

Rooney, T.P. and D.M. Waller. 2003. Direct and indirect effects of white-tailed deer in forest ecosystems. Forest Ecology and Management 181:165-176.

Royo, A.A. and W.P. Carson. 2006. On the formation of dense understory layers in forests worldwide: consequences and implications for forest dynamics, biodiversity and 
succession. Canadian Journal of Forest Research 36:345-362

Royo, A.A., S.L. Stout, D.S. deCalesta, and T.G. Pierson. 2010. Restoring forest herb communities through landscape-level deer herd reductions: Is recovery limited by legacy effects? Biological Conservation 143:2425-2434.

Russel, F.L., D.B. Zippin, and N.L. Fowler. 2001. Effects of white-tailed deer (Odocoileus virginianus) on plants, plant populations and communities: a review. American Midland Naturalist 146:1-26.

Rutberg, A.T. An animal welfare perspective. Pages 37-54 in McShea, W.J., H.B. Underwood, and J.H. Rappole, eds. 1997. The Science of Overabundance: Deer Ecology and Population Management. Smithsonian Institution Press. Washington D.C., USA

Saunders, M.R. and K.J. Puettmenn. 1999. Effects of overstory and understory competition and simulated herbivory on growth and survival of white pine seedlings. Canadian Journal of Forest Resources 29:536-545.

Shafer-Nolan, A.L. 1997. The science and politics of deer overabundance at Cuyahoga Valley National Recreation Area, Ohio. Wildlife Society Bulletin 25:457-461.

Sheldon, J.J. and K. Causey. 1974. Use of Japanese honeysuckle by white-tailed deer. Journal of Forestry 72:286-287.

Stromayer, K.A.K. and R.J. Warren. 1997. Are over abundant deer herds in the eastern United States creating alternate stable states in forest plant communities? Wildlife Society Bulletin 25:227-234.

Sweetapple, P.J. and G. Nugent. 2004. Seedling ratios: a simple method for assessing ungulate impacts on forest understories. Wildlife Society Bulletin 32:137-147.

Tanentzap, A.J., D.R. Bazely, S. Koh, M. Timciska, E.G. Haggith, T.J. Carleton, and D.A. 
Coomes. 2011. Seeing the forest for the deer: do reductions in deer-disturbance lead to forest recovery? Biological Conservation 144:376-382.

Tilghman, N.G. 1989. Impacts of white-tailed deer on forest regeneration in northwestern Pennsylvania. Journal of Wildlife Management 53:524-532.

Tiner, R.W. 2000. Wetland indicators: a guide to wetland identification, delineation and mapping. Lewis Publishers. Boca Raton, FL, USA.

Tobler, M.A., P.A. Van Zandt, K.H. Hasenstein, and S. Mopper. 2006. Growth and reproduction of a clonal plant in response to salinity and florivory Wetlands $26: 803-812$.

United States Department of the Interior Fish and Wildlife Service. 2006. National survey of fishing, hunting, and wildlife-associated recreation. United States Department of the Interior. Washington D.C., 164 pp.

Urbanek, R.E., C.K. Nielsen, M.A. Davenport, and B.D. Woodson. 2013. Determinants of public perceptions of suburban deer density. Human Dimensions of Wildlife 18:82-96.

Urbanek, R.E., C.K. Nielsen, G.A. Glowacki, and T.S. Preuss. 2012. Effects of white-tailed deer (Odocoileus virginianus Zimm.) herbivory in restored forest and savanna plant communities. American Midland Naturalist 167:240-255.

USDA. Published: 2012. PLANTS profiles. [Web site] United States Department of Agriculture, Natural Resources Conservation Service. http://www.plants.usda.gov. Accessed: 2012.

Vellend, M., 2002. A pest and an invader: white-tailed deer (Odocoileus virginianus Zimm.) as a seed dispersal agent for honeysuckle shrubs (Lonicera L.). Natural Areas Journal 22:230-234.

Vellend, M., J.A. Myers, S. Gardescu, and P.L. Marks. 2003. Dispersal of trillium seeds by 
deer: implications for long-distance migration of forest herbs. Ecology 84:1067-1072.

Waller, D.M and W.S. Alverson. 1997. The white-tailed deer: a keystone herbivore. Wildlife Society Bulletin 25:217-226.

Warren, R.J. 1997. The challenge of deer overabundance in the $21^{\text {st }}$ century. Wildlife Society Bulletin 25:213.

West Virginia Department of Natural Resources. 2012. Rare Species List. West Virginia Nongame Wildlife and Natural Heritage Program. Elkins, WV, USA.

Whitney, G.G. 1984. Fifty years of change in the arboreal vegetation of Heart's Content, an old growth hemlock-white pine - northern hardwood stand. Ecology 65:403-408.

Williams, S.C., J.S. Ward, and U. Ramakrishnan. 2008. Endozoochory by white-tailed deer (Odocoileus virginianus) across a suburban/woodland interface. Forest Ecology and Management 255:940-947.

Willson, M.F. 1993. Mammals as seed-dispersal mutualists in North America. Oikos 67:159-176.

Willson, M.F. and C.J. Whelan. 1990. The evolution of fruit color in fleshy-fruited plants. American Naturalist 136:790-809. 


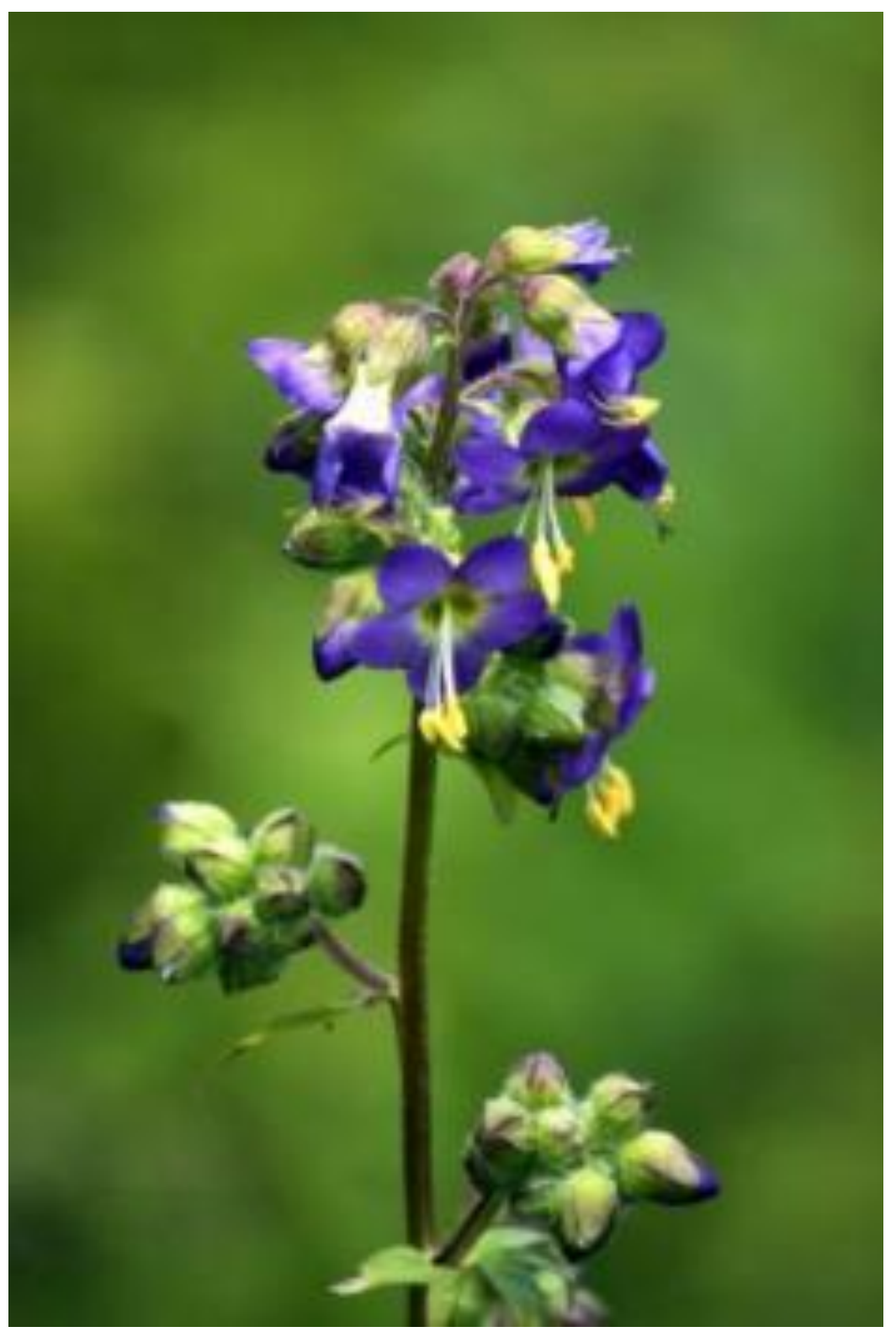

Figure 1. Flowering stem of bog Jacob's-ladder (Polemonium vanbruntiae) in Canaan Valley, West Virginia, USA. Photo by Stephen M. Young. Accessed U.S. Forest Service Website 


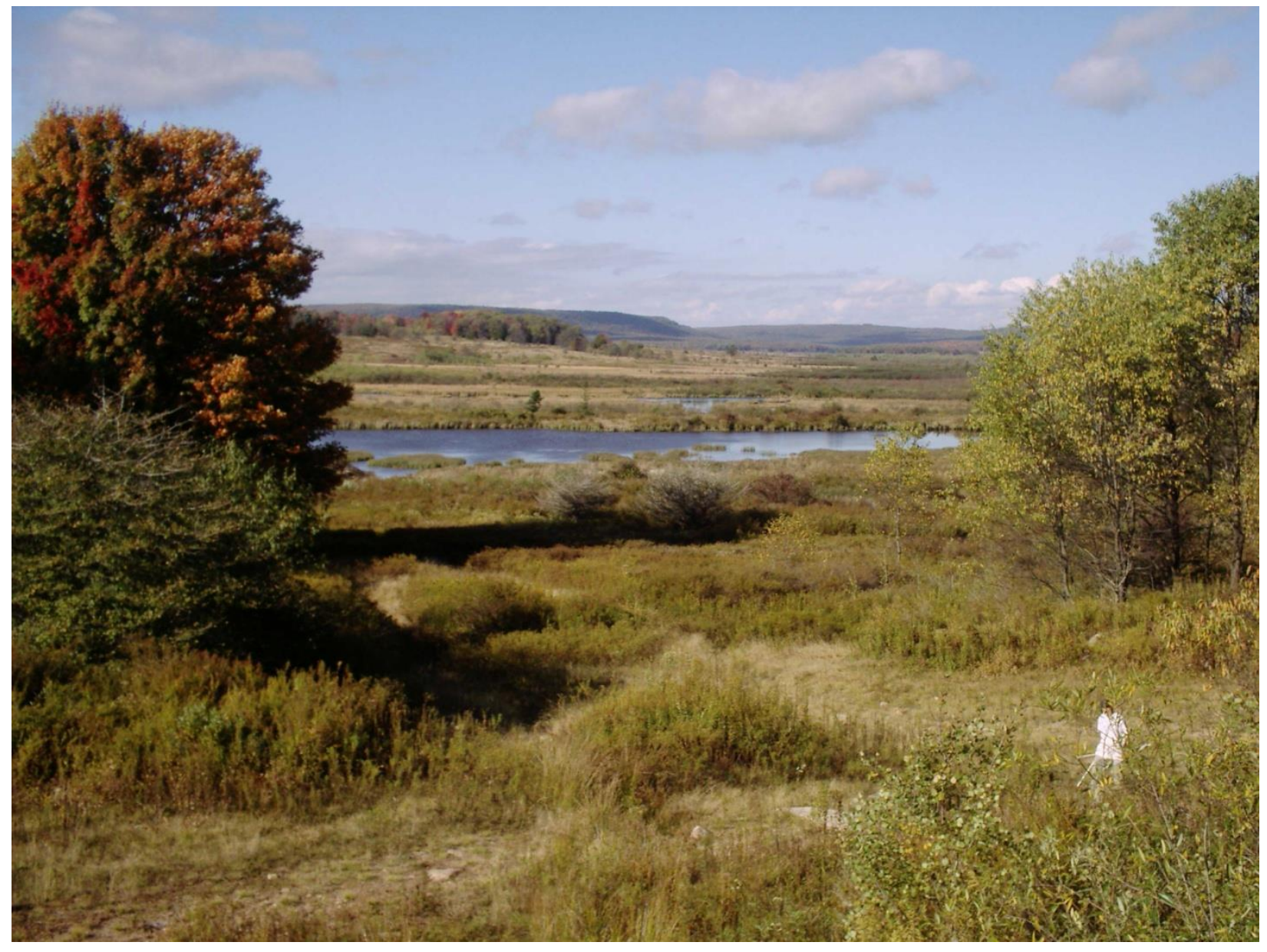

Figure 2. Bog Jacob's-ladder (Polemonium vanbruntiae) populations are often associated with alder communities and beaver ponds in Canaan Valley, West Virginia, USA. 


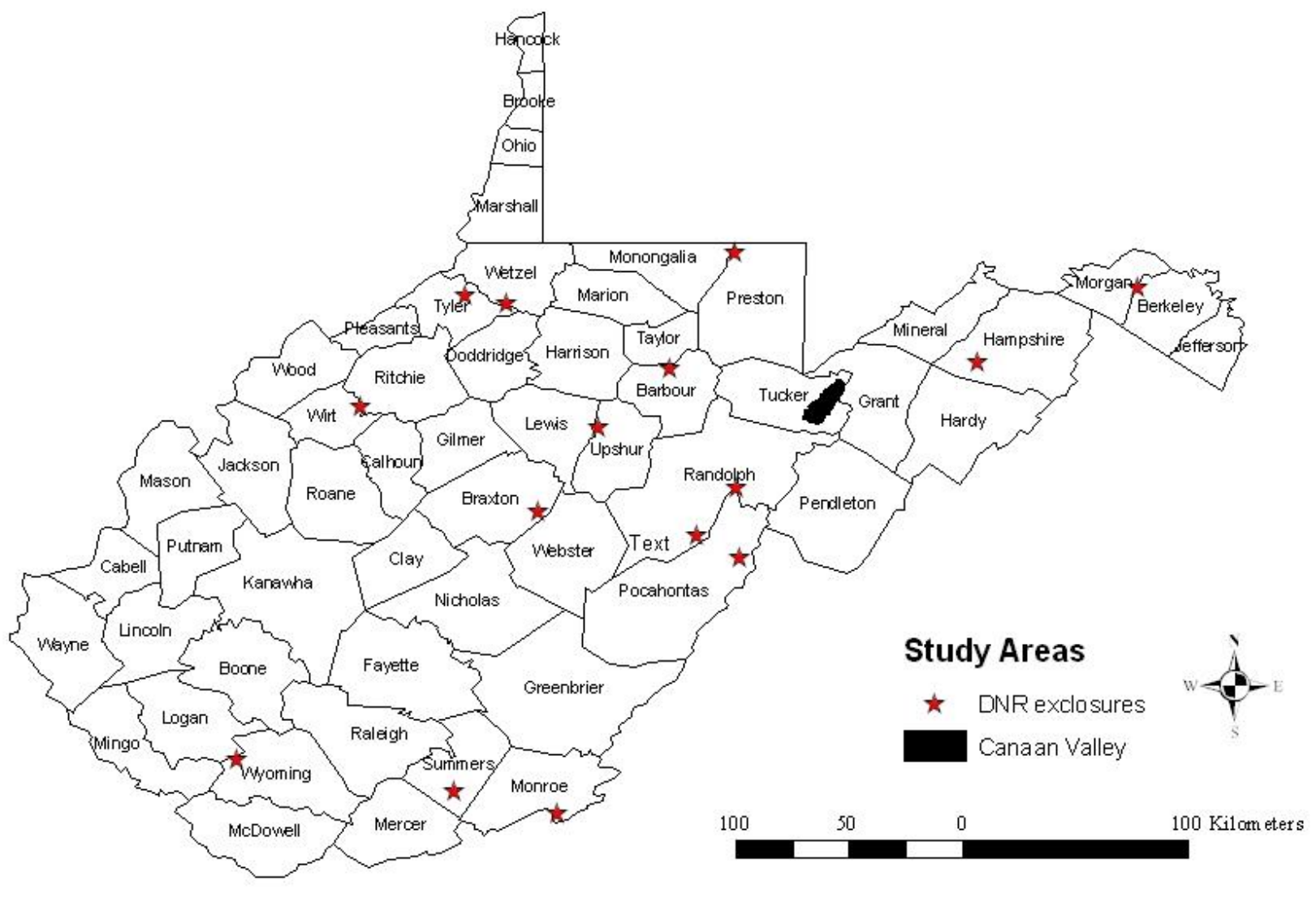

Figure 3. Study areas located throughout West Virginia, USA. Red stars indicate West Virginia Division of Natural Resource white-tailed deer exclosure study sites located throughout the state. Canaan Valley located in Tucker County, WV, is shown in black. 


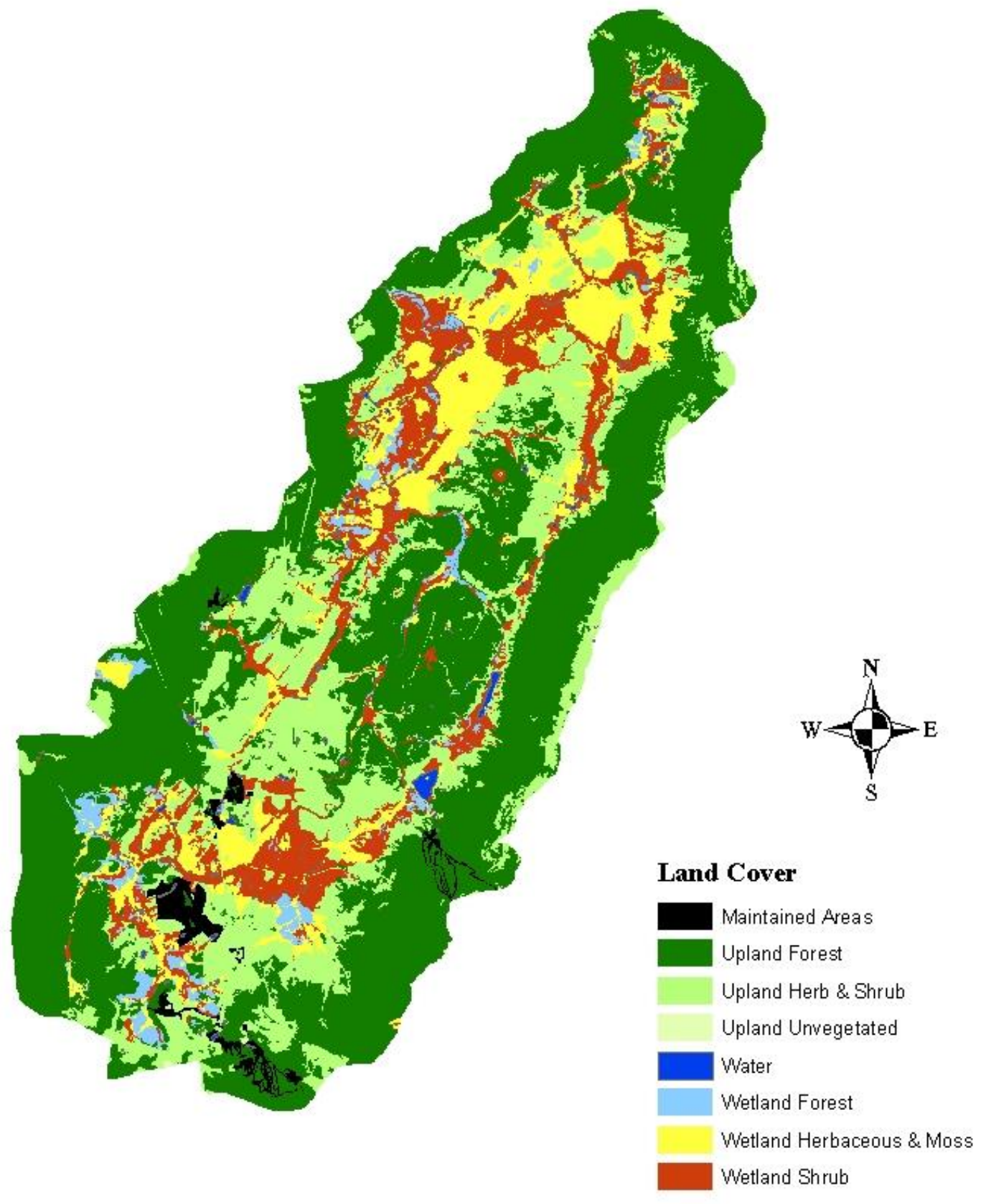

$\begin{array}{llll}2.5 & 1.25 & 0 & 2.5 \text { Kilometers }\end{array}$

Figure 4. Land cover types in Canaan Valley, West Virginia. Study sites were concentrated in the wetland forest, wetland shrub, and wetland herbaceous and moss cover types. 


\title{
CHAPTER II
}

\section{White-tailed Deer Florivory Influences the Population Demography of Polemonium}

\section{vanbruntiae in Canaan Valley, West Virginia, USA}

\author{
Kelley L. Flaherty ${ }^{12}$, William N. Grafton ${ }^{3}$, and James T. Anderson ${ }^{1}$
}

1 Division of Forestry and Natural Resources, West Virginia University, Morgantown, WV 26506, USA

2 Current address: College of Science. Technology, and Math, Alderson Broaddus University, Philippi, WV 26416, USA

3 Deceased

ABSTRACT: White-tailed deer (Odocoileus virginianus Zimm.) may influence the reproduction and dispersal of plant species through herbivory of flowering stems. Whether or not seeds are adapted for dispersal by white-tailed deer (Odocoileus virginianus Zimm.), the consumption of flowers before seed formation reduces seed production and the genetic contribution of that individual through pollen dispersal. We examined the effects of white-tailed deer herbivory on the seed production of Bog Jacob's-ladder (Polemonium vanbruntiae Britt.), a facultative wetland plant considered rare throughout its range. Seed loss to herbivory was modelled using the basal stem width and number of flowers as predictors. We monitored life-stage transitions in ten local populations in Canaan Valley, West Virginia from 2005-2007 and modelled the population growth rate and estimated extinction rates for each population accounting for the loss of seeds due to white-tailed deer florivory. Seed loss due to consumption of flowering stems ranged between 0 and $96 \%$ within individual populations $(\bar{x}=52 \pm 4.5 \%)$. A significant 
difference in seed production occurred between browsed $(\bar{x}=0.6 \pm 0.18)$ and unbrowsed $(\bar{x}=24$ \pm 1.43 ) plants. Predicted seed loss was significantly higher in the Canaan Valley State Park $(\bar{x}$ $=57 \pm 19 \%)$ than in the Canaan Valley National Wildlife Refuge $(\bar{x}=40 \pm 18 \%)$ populations. The observed levels of white-tailed deer florivory have the potential to significantly reduce population growth rates $(\mathrm{p}<0.0001)$; however, we found consumption of flowers alone by white-tailed deer is not enough to cause a decline in $P$. vanbruntiae populations. A high rate of seed production coupled with the perennial and clonal nature of this species make it less susceptible to declines due to seed loss. Although white-tailed deer florivory may not increase local population extinction rates, loss of seed production may result in a loss of the potential for colonization of new patches.

\section{INTRODUCTION}

By virtue of their rarity and dependence on specialized habitats, many threatened and endangered species exhibit a metapopulation distribution (Hansson, 1991; Alexander et al., 2012). The balance between the rates of colonization and local population extinction is critical to the maintenance of a metapopulation. In many rare or declining species, the rate of colonization (local population establishment) is not sufficient to counter the rate of local population extinction (Harrison, 1991). Thus, it is necessary to understand the factors that contribute to the decline of local populations as well as to understand the role of dispersal and colonization to conserve the metapopulation as a whole.

In terms of metapopulation survival, plant populations differ from animals in that individuals cannot disperse. Instead, dispersal is tied directly to reproduction and is often more random in nature than the dispersal of animal populations (Hansson, 1991; Alexander et al., 2012). Plant species have evolved to use a variety of seed dispersal mechanisms (Drezner et al., 
2001). Each method has implications for metapopulation persistence in fragmented habitat. Seed dispersal by herbivores may be an adaptation to ensure both long-distance dispersal and colonization of suitable patches by using fruit or foliage as an attractant to occupied patches (Janzen, 1984; Alexander et al., 2012). In this way, white-tailed deer (Odocoileus virginianus) could increase metapopulation persistence through increased dispersal and colonization. Conversely, when seeds that are not adapted for endozoochory are consumed, reproduction within the local population is reduced along with the potential for dispersal and colonization of new patches.

Although browsing on plant parts can alter the growth rate and ultimately the survival of individual plants (Alverson and Waller, 1997; Stromayer and Warren, 1997; Byman, 2011; Griscom et al., 2011; Masse and Cote, 2012), feeding on flowering parts of accessible herbaceous species reduces or eliminates the chances of fertilization for the individual and potential for fertilization of other individuals in the population (Loeffler and Wegner, 2000; Alexander et al., 2012; Frye, 2012). Conversely, by distributing seeds, along with fertilization in the form of fecal matter, into new areas and thus increasing the colonization rate, herbivores may benefit plant populations for which they are seed dispersers. However, loss of seeds to herbivores that consume and digest them can reduce the potential for both increasing the local population and colonization of new patches within a metapopulation (McGraw and Furedi, 2005; Levine et al., 2012).

\section{The Role of White-tailed Deer in Seed Dispersal}

The influence of white-tailed deer browsing on the survival of plant species has been well studied. However, the vast majority of available literature has focused on the effects of browsing on the survival of upland plant species and in particular commercially important timber 
and agricultural species (Russel et al., 2001). Less well studied is the impact of white-tailed deer herbivory on herbaceous species and plant reproduction (Urbanek et al., 2012). Few studies have been conducted on the impact of white-tailed deer on wetland herbaceous plant species (Loeffler and Wegner, 2000; Kery and Gregg, 2004) primarily because wetlands have not been a focus of white-tailed deer studies in general (Russel et al., 2001). As many of the studies of white-tailed deer browse have previously been driven by economic factors, few have been directed solely toward rare or endangered herbaceous or woody plants (Miller et al., 1992). To date, there has been little research on the effects of white-tailed deer browsing on herbaceous wetland plants (Geddes and Mopper, 2006; Tobler et al., 2006) and even less focus on freshwater wetland plant species (Loeffler and Wegner, 2000; Bermingham, 2010).

Recently, however, the role of white-tailed deer as both seed predators and seed dispersers has been more closely examined (Campbell and Gibson, 2001; Vellend et al., 2003; Furedi and McGraw, 2004; Myers et al., 2004). White-tailed deer have a relatively large homerange (Janzen, 1984) and the potential to retain material in the digestive tract for three or more days (Mautz and Petrides, 1971). Thus, they have the potential to carry seeds distances of up to $10 \mathrm{~km}$ (Gill and Beardall, 2001). Vellend et al. (2003) suggested that this would result in 95\% of germinable seeds being deposited more than $100 \mathrm{~m}$ from the parent plant and 30\% deposited more than $1 \mathrm{~km}$ from the parent plant. Dispersal by herbivores could greatly expand the potential dispersal distance of plants and could have a considerable effect on metapopulation initiation, growth, and gene flow of irregularly distributed and rare plant species (Myers et al., 2004). However, long distance dispersal by herbivores may move some wetland seeds into upland conditions where they may be less likely to germinate. Increased dispersal distance may also benefit exotic, invasive plant species that could be detrimental to native plant populations 
(Maron and Vila, 2001; Vellend, 2002; Williams and Ward, 2006). Although deer may play an important part in the dispersal of seed for many plants, for some plant species including American ginseng (Panax quinquefolius L.; Furedi and McGraw, 2004), white-tailed deer are demonstrated seed predators or consumers, that is, all seeds consumed in the act of herbivory are digested or are non-viable once passed through the digestive system thus reducing the realized reproductive output of these plants.

Whether or not seeds are adapted for dispersal by white-tailed deer, the consumption of flowers before seed formation reduces seed production and the genetic contribution of that individual through pollen dispersal. White-tailed deer florivory has the potential to reduce population viability of rare plant species through reduced seed production as well as the survival of browsed individuals (Loeffler and Wegner, 2000; Tobler et al., 2006; Frye, 2012). The extent of this effect may vary based on the contributions of reproductive individuals to the population.

\section{Polemonium vanbruntiae}

Polemonium vanbruntiae is a perennial wetland plant that ranges from Quebec south to West Virginia and from Maine west to West Virginia (Britton and Brown, 1913; Sabourin, 2002). It is found in areas varying from shrub swamps and forested wetlands to moist roadsides occurring mostly at elevations above $305 \mathrm{~m}$ (Hill et al., 2008; Bermingham and Brody, 2011). It is ranked as G3 (rare or uncommon) globally (Bermingham, 2010) and S2 in the state of West Virginia (WV DNR, 2012). This plant has been propagated successfully ex situ but is rare in natural populations. Polemonium vanbruntiae may reproduce sexually or asexually (Sabourin, 2002).

Polemonium vanbruntiae ramets can be detected above the soil beginning in late April to early May. Flowering ramets can be distinguished from vegetative ramets by alternate, pinnately 
compound leaves along a main stalk (Figure 1). Vegetative ramets generally originate as single, pinnately compound leaves from a common origin. Buds are produced in early June with ramets producing flowers from late June to mid-July. Seed production can be measured by mid-August. In mid-September, the seed head and portions of the stem begin to dry and the fruit opens (Figure 2). The dispersal mode of Polemonium vanbruntiae seed is thought to be primarily passive. However, seed heads may also be moved by spring flooding or wind dispersal of seed heads over the winter snow crust (Sabourin, 2002; Hill et al., 2008). Winter seed dispersal can allow seed to travel hundreds of meters. Deer herbivory of flowering stems could have the potential to reduce winter dispersal in populations.

Current threats to $P$. vanbruntiae populations in the northern part of its range include agriculture, forestry, and wetland drainage or development (Deller, 2002). In Canaan Valley, West Virginia past threats have included logging, agriculture, and potential activity of all-terrain vehicles. Many, but not all of the populations in Canaan Valley are now protected by the location of state and government owned land. Current threats to these populations may include flooding caused by beaver (Castor canadensis) activity in the valley (Anderson and Bonner, 2014). There is evidence of white-tailed deer browsing on this species but it is not currently considered a management concern in northern populations (Bermingham, 2010). However, the deer densities at these locations may not be as high as Canaan Valley populations (Sabourin, 2002; 2.8-3.8 deer/ha, Cherefko et al., 2009).

Throughout much of the range of Polemonium vanbruntiae Britt., white-tailed deer densities are considered to be higher than during pre-colonial times and high deer densities have been blamed for the decline of many flowering species (deCalesta and Stout, 1997; Royo et al., 2010). Previous studies have detected correlations between deer density and some wildflower 
species (Augustine and Frelich, 1998; Loeffler and Wegner, 2000; Royo et al., 2010; Urbanek et al., 2012). It is unclear how the maintenance of high deer densities affects conservation efforts for this species. There is anecdotal evidence of heavy white-tailed deer browsing on this species in West Virginia (Elizabeth Byers, West Virginia Division of Natural Resources, Personal Communication). However, it is not known whether the annual loss of reproduction translates into long-term declines in population viability in a perennial, clonal species.

The objective of this study was to determine if browsing by white-tailed deer has the potential to affect the viability of localized populations of Polemonium vanbruntiae by reducing seed production. We test the null hypothesis that natural rates of deer florivory have no effect on the rate of population growth $(\lambda)$ within local Polemonium vanbruntiae populations.

\section{Methods}

\section{Study Area}

Canaan Valley, located in Tucker County, West Virginia, is the largest highelevation valley east of the Rocky Mountains (Fortney, 1975). The valley floor averages $943 \mathrm{~m}$ above sea level. The mountains that surround Canaan Valley rise $150-240 \mathrm{~m}$ above the valley and help to create a relatively cool, moist climate and a short growing season. Canaan Valley functions as a frost pocket that traps and holds cooler air (Byers et al., 2007). The average annual precipitation is $141 \mathrm{~cm}$ (National Climate Data Center, 2014). The average freeze period is approximately 90 days (Griscom et al., 2011). These characteristics make the climate and accordingly, the vegetation, of Canaan Valley more similar to boreal forests of the northeastern United States and Canada than to the deciduous forests of surrounding West Virginia and make Canaan Valley a unique wetland habitat in West Virginia (Fortney, 1993).

Canaan Valley, West Virginia encompasses about $176 \mathrm{~km}^{2}$ (17,600 ha) of land. 
Approximately $20 \%$ of this land area is made up of various wetland community types. Canaan Valley is home to the largest contiguous high-elevation wetland area in West Virginia (3,000 ha, Byers et al., 2007). Canaan Valley is home to Canaan Valley Resort State Park and the Canaan Valley National Wildlife Refuge as well as the Little Canaan Wildlife Management Area (WMA). Deer hunting is allowed within the National Wildlife Refuge lands (by permit), at Little Canaan WMA, and is conducted on private holdings throughout Canaan Valley. However, hunting has been prohibited in sections of the southern end of the Valley (i.e., Canaan Valley Resort State Park) since 1971 (Michael, 2002). Sampling was conducted in Canaan Valley Resort State Park, Canaan Valley Wildlife Refuge, and Little Canaan WMA.

The impact of white-tailed deer on plant populations in Canaan Valley has previously been studied on balsam fir (Abies balsamea, Michael, 1992), showy lady's slipper (Cypripedium reginae, Gregg, 2004; Kery and Gregg, 2004), and red spruce (Picea rubens)(Griscom et al., 2011). Higher deer densities reduced balsam fir reproduction (Michael, 1992) and young balsam fir trees (Cherefko et al., 2009).

\section{Flowering Ramet Monitoring}

We located eight populations of $P$. vanbruntiae in May 2005 and an additional two populations in 2006 (Figure 3). Populations were located by historical data and active searching. We monitored these populations from the first week of May through September from 2005 through 2007. The perimeter of all populations was delineated using a Trimble hand-held Geographic Positioning System (GPS) unit. In small populations (< 50 flowering individuals), all flowering ramets were marked at the base of the stem with a uniquely numbered aluminum tag for future identification. Tags were concealed in the vegetation at the base of the plant. Where possible a small piece of colored tape was attached to overhanging vegetation $0.5 \mathrm{~m}$ 
above the stem to permit future identification of individual plants. Alternately, a colored flag was placed $1 \mathrm{~m}$ from the marked stem. In larger populations (> 50 flowering individuals), >25 flowering ramets were randomly selected by marking every $10^{\text {th }}$ individual along a transect through the length of the population. Transects were used to prevent excessive trampling of unmonitored ramets.

We visited each plant every three weeks to monitor flower production and browse pressure. We recorded the height $(\mathrm{cm})$ of each flowering stem, the width $(\mathrm{mm})$ of the stem at its base, and the number of leaflets present on the main flowering stem of the plant (Figure 1). Additionally, we recorded the number of flowers present during the monitoring event that fell during the second week of June in all years. We determined the number of seeds that were produced on unbrowsed stems during subsequent visits produced by feeling each bud to determine if a seed capsule had formed. The number of browsed stems was recorded for each three week period.

We established 10 semi-permanent sampling quadrats within each population. Within each sampling quadrat, we identified individual ramets that were; seedlings ( $\leq 3$ leaves), nonflowering vegetative ramets, and flowering ramets. We counted the number of ramets in each stage within a sample plot. We averaged the number within each category over all plots within the population and multiplied the average by the area of the population calculated in ArcGIS to determine the total number in each category for the population each year. Population structure was observed once per year between 15 June and 30 June during 2005-2007. We monitored flowering stems within the population every three weeks from early June until late September to determine the number of seeds produced per stem as well as the number of stems lost to whitetailed deer herbivory. 


\section{Seed Feeding Trials}

We conducted feeding trials of seeds to captive white-tailed deer to evaluate whether deer could act as dispersers or predators of seeds. Due to the global rarity of the species, we used commercially available seeds of Polemonium reptans, the only other species of the Polemonium genus found naturally in West Virginia. We used 10 captive deer that were housed at the West Virginia Wildlife Center located in French Creek, WV.

Feeding trials were initiated on 25 July 2008 and continued for a period of three weeks. We mixed approximately 1300 Polemonium seeds per day with the normal feed of corn and grain. One day after the initiation of the feeding trials, we began collecting fecal pellets from the deer enclosure. Pellets were collected every other day for a period of 21 days. After collection fecal pellets were washed through a $500 \mu \mathrm{m}$ sieve. All residual material collected was examined for the presence of Polemonium seeds.

\section{Statistical Analysis}

We measured four external morphometric characteristics (number of leaflets per stem [stem], height [height], basal width of the stem [width], the number of flowers present [flowers]) of flowering ramets found in ten populations throughout Canaan Valley, West Virginia during the 2005-2007 growing seasons. We created 13 a priori models using these variables as predictors of seed production (Table 1). We used linear regression along with information theoretic methods (Burnham and Anderson, 1998) to rank these variables as predictors of seed production. We selected the height of a flowering stem as an indicator because height has been used as a predictor of moist soil plant seed production (Anderson, 2006) and may be an indicator of deer browsing intensity (Anderson, 1994). We also selected the basal stem width as a potential indicator of flowering stem height that would remain constant even if flowering stems 
were browsed (Loeffler and Wegner, 2000). We examined all variables for multicollinearity using the variance inflation factors (vif $\leq 5)$ and condition number $(\kappa<30)$. From these variables, all possible models were fit using linear regression on data from unbrowsed stems. We did not examine interactions between the variables. We ranked the models using Akaike's information criterion corrected for small sample size (Burnham and Anderson, 1998).

We calculated the number of seeds produced on unbrowsed stems in each population. We used the morphometric characteristics found in the model with the best predictive power to estimate the number of seeds that would have been produced from browsed stems. We used these numbers to estimate the percentage of seeds lost due to herbivory as a percentage of all seeds that would have been produced from browsed plants. To estimate the predictive power of the model over time, we used linear regression to determine the relation between the number of seeds our 2005-2006 model predicted would have been produced from unbrowsed stems in 2007 to the number that were actually produced.

We compared the number of seeds produced on unbrowsed stems to the number of seeds actually produced by browsed stems as well as the number of seeds we estimated the browsed stems would potentially produce using analysis of variance on rank transformed values to determine if there was a selection pressure toward larger and potentially more productive ramets. We also compared the values of the predictive characteristics used in the model between browsed and unbrowsed stems. We arcsine square root transformed the percentages of stems browsed and the percentages of seed loss due to deer herbivory and compared these values using Pearson Product Moment Correlation. We also fit a regression equation through the origin and tested whether the slope of this line was equal to one. A significant difference from one would suggest that the seed model either over or under-estimated potential seed production. 
Lastly, we compared the percentages of stems browsed and the percentages of seeds browsed in sites on the Canaan Valley National Wildlife Refuge to sites in Canaan Valley State Park by arcsine square root transforming percentage values and comparing refuge and state park sites across years with a two-factor analysis of variance. All analysis was done in Program R (R Development Core Team., 2008).

We used an $\alpha$ level of 0.1 for all analyses to reduce type II error because Polemonium vanbruntiae is considered very rare or imperiled in West Virginia (National Research Council Committee on Scientific Issues in the Endangered Species Act, 1995).

\section{Population modeling}

We determined the status of individually marked stems during the spring following their initial marking. Those stems that did not germinate the following spring but were present the year after were considered to be dormant during the previous year. As we could not determine if a plant was dormant until two years following, the transition rate from dormancy to vegetative ramets was considered for plants from the 2005 growing season and was pooled over all populations. Fecundity rates of flowering ramets were determined by counting the number of seed capsules produced on unbrowsed stems during seed production. Each seed capsule present on a ramet represented the number of possible seeds. We multiplied seed capsule production by an average of 10 seeds per capsule (Hill et al., 2008). We used a seed germination value of $23.75 \%$ from Polemonium vanbruntiae seed germination trials in Vermont (Hill et al., 2008) as the rate for all of our populations.

We used stage-structured matrix modeling to predict the population growth rate and estimate extinction rates for each population monitored. We created a stage-structured transition matrix (Table 2) to represent these three visible stages as well as seeds and a dormant stage 
(Figure 4). Each populated cell in a transition matrix represented the probability of transition from stage $a_{i}$ to stage $a_{j}$. Stage transition probabilities were estimated by monitoring individual ramets within semi-permanent study plots.

We used the Popbio (Stubben and Milligan, 2007) package for Program R to calculate the rate of population increase $(\lambda)$ and the $95 \%$ confidence intervals for this statistic for each of the populations monitored in Canaan Valley based on our stage-transition matrix (Appendix 2). The Popbio package was created to run MATLAB code for matrix analysis (Morris and Doak, 2002). We calculated these statistics twice, with and without deer florivory, for each population. We constructed matrices without the effects of deer florivory by using the average number of seeds per flowering ramet as the measure of fecundity (stage transition $a_{14}$, Table 3 ). Next, we compared these to matrices that included the effects of deer florivory. We reduced the fecundity by dividing the seed production in each population by the total number of flowering ramets (browsed and unbrowsed) monitored in each population. We compared the rates of population increase $(\lambda)$ with and without white-tailed deer florivory using a paired $t$-test.

We calculated the sensitivity and elasticity of the mean matrix of all populations without florivory using the Poptools extension to Microsoft Excel (Hood, 2008). The sensitivity of a transition matrix represents the absolute change in $\lambda$ given a small change in each stage transition probability. As fecundity rates are typically higher than survival rates that are restricted from 0 to 1 , the elasticity of a matrix is the relative contribution of each stage transition to changes in $\lambda$.

We calculated a cumulative distribution function from the transition matrices using the stoch.quasi.ext function within the Popbio program (Appendix 3) and used the cumulative proportion of extinction after 50 years as the probability of extinction for each population. We used the densities from the final population estimates in 2007 as the input vector for $\mathrm{N}_{\mathrm{t}}$. We 
removed the seeds, seedlings and dormant individuals from the quasi-extinction threshold because of difficulty in counting these individuals (Morris and Doak, 2002). Extinction probabilities were calculated with and without the effects of deer florivory for each population.

\section{RESULTS}

We monitored 276 flowing ramets in 2005, 263 in 2006, and 250 in 2007 (Table 4). Our best performing model included the basal stem width and number of flowers as predictors of seed production $\left(\right.$ Seeds $=-14.2577+8.06308[$ width $]+0.48648[$ flowers $], R^{2}=0.50$, Table 2 ) . We found that our model explained approximately 53\% of the variance observed in 2007 seed production across populations (Figure 5). We found no difference between the stem width and flower number on unbrowsed plants (width $\bar{x}=3.8 \pm 0.08 \mathrm{~mm}$, flower number $\bar{x}=11 \pm 3.0$ ) and those of browsed plants (stem width $\bar{x}=3.49 \pm 0.06 \mathrm{~mm}$, flower number $\bar{x}=9.0 \pm 2.0, \mathrm{P}>0.05$ ). We found a significant difference between the mean number of seeds produced by unbrowsed plants $(\bar{x}=24 \pm 1.43)$ and those actually produced on browsed plants $(\bar{x}=0.6 \pm 0.18)$ in 2007 $\left(\mathrm{F}_{1,234}=1.43, \mathrm{P}<0.001\right)$. We found a significant difference in potential mean seed production of browsed plants as predicted by the model above and actual production of unbrowsed plants $\left(\mathrm{F}_{1,234}=1.23, \mathrm{P}<0.001\right)$ in 2007 . However, there was a significant interaction between browse variable and the population ID $\left(\mathrm{F}_{1,234}=3.66, \mathrm{P}<0.001\right)$ suggesting that this difference does not exist for all populations (Figure 6). We also found a significant difference between the potential mean seed production of both browsed $(\bar{x}=15 \pm 0.56)$ and unbrowsed ramets $(\bar{x}=18 \pm 0.78$, $\left.\mathrm{F}_{1,234}=12.91, \mathrm{P}<0.001\right)$ in 2007. Seed loss due to consumption of flowering stems ranged between 0 and $96 \%$ within individual populations $(\bar{x}=52 \pm 4.5 \%$, Figure 7$)$.

Overall stem loss ranged between 26 and $97 \%$ ( $\bar{x}=50 \pm 3.5 \%$, Figure 8 ). We found a significant difference in percent stems browsed between the Canaan Valley State Park 
populations $(\bar{x}=57 \pm 19 \%)$ and the Canaan Valley NWR populations $\left(\bar{x}=40 \pm 18 \%, \mathrm{~F}_{1,16}=\right.$ 3.27, $\mathrm{P}=0.085)$, but there was no difference between years $\left(\mathrm{F}_{1,16}=0.5349, \mathrm{P}=0.59\right)$ and no significance to the interaction between these terms $\left(\mathrm{F}_{1,16}=1.04, \mathrm{P}=0.37\right)$. There was a significant difference in potential loss of seed production to deer browse as predicted by the model above between the Canaan Valley State Park $(\bar{x}=64 \pm 6 \%)$ populations and the Canaan Valley NWR populations $\left(\bar{x}=36 \pm 5 \%, \mathrm{~F}_{1,16}=11.8, \mathrm{P}<0.003\right)$, but there was no difference between years $\left(F_{1,16}=0.25 \mathrm{P}=0.621\right)$ and no significance to the interaction between these terms $\left(F_{1,16}=0.049, P=0.827\right)$. The percentages of stems browsed and seed loss within populations was highly-correlated $\left(\mathrm{r}=0.81, \mathrm{SE}=0.001, \mathrm{t}_{25}=6.92, \mathrm{P}<0.0001\right)$. We found that the slope of regression equations through the origin was significantly different than one in 2006 (slope $=0.73$ $\pm 0.011, \mathrm{t}_{8}=2.432, \mathrm{P}=0.038$ ), but not in 2005 (slope $=0.618 \pm 0.262, \mathrm{t}_{6}=1.458, \mathrm{P}=0.188$ ) or 2007 (slope $\left.=0.63 \pm 0.21, \mathrm{t}_{7}=1.75, \mathrm{P}=0.119\right)$ (Figure 9).

White-tailed deer in Canaan Valley tended to browse flowering ramets of Polemonium vanbruntiae early in the growing season, before seeds were produced and sometimes before flower emergence. We rarely found evidence of browse on vegetation that was not associated with flowering ramets. The estimated population growth rate ranged from 1.09 to 1.24 ( $\bar{x}=$ $1.17, \mathrm{SE}=0.11)$ without deer florivory. This translates to an annual rate of increase of $9 \%$ to $24 \%$ without florivory. With deer florivory, the estimated growth rate ranged from 0.99 to 1.20 $(\bar{x}=1.08, \mathrm{SE}=0.13)$. This represents an annual change in population ranging from a $1 \%$ decrease to a $20 \%$ increase across populations. In all populations, reduction of seed production through the consumption of flowers by deer reduced estimates of the population growth rate (Figure 10). The reduction of $\lambda$ was considered statistically significant $(\mathrm{p}<0.0001)$; however, in 
only one population (State Park Population A), was $\lambda$ reduced to less than 1 indicating a population decline.

Sensitivity analysis of the mean matrix (Table 3) without florivory suggested that the population growth rate was most sensitive to changes in seed germination rates and the transition from vegetative ramets to flowering ramets (Table 5). However, when we examined the elasticities for the same matrix, we found that seed production was proportionally as important as other stage transitions (Table 6).

Given the current population size, white-tailed deer florivory did not tend to increase the probability of local population extinction within the next 50 years. Only one population (AFrame 1) that currently consists of only a few flowering ramets was in danger of extinction within the next 50 years given current rates of florivory. However, the probability of extinction in this population was only $1.2 \%$ after 50 years.

All deer pellet piles collected, were evaluated for the presence of undigested Polemonium reptans seeds. No seeds were detected in any pellet pile samples.

\section{Discussion}

We found that actual mean seed production of browsed stems was significantly less than production of unbrowsed stems. In order to calculate the potential production from browsed ramets, we used a model that included both stem width and the number of flowers as predictive characteristics of seed production. Annual browse pressure, as measured by the percent of browsed stems within populations was moderate (26\%) to extremely high (97\%) in some populations. As monitored stems were marked in late May and ramets that were browsed prior to this visit may not have been visible, actual browse pressure may be even higher. Seed consumption by deer represents a potentially significant loss of sexual reproduction within the 
population and may lead to a loss of genetic diversity and colonization potential. Furedi and McGraw (2004) found that more than 50\% of fruit-bearing ginseng plants were browsed completely by deer in most populations and in some as much as $100 \%$ of fruit-bearing plants were browsed. These authors also observed that ginseng plants were often browsed prior to fruit production. This was the case for the majority of the browsed $P$. vanbruntiae in this study. Comparatively, white-tailed deer consumed only $28 \%$ of the terminal stems in populations of Turk's cap lily (Lilium superbum, Fletcher et al., 2001). Protected clusters of sundial lupine (Lupinus perennis) had a greater number of inflorescences and seed pods than those exposed to deer browsing (Frye, 2012). Selection of flowers may be a result of nutritional differences between flowers and leaves or from the seasonally conspicuous nature of the flowers.

The similarity in predictive characteristics of browsed and unbrowsed ramets suggests that white-tailed deer randomly select $P$. vanbruntiae flowers rather than select larger, more productive ramets. However, we found that the slope of a line examining the relation between percent of stems browsed and the percent of seeds browsed was significantly different from one in 2006. Had there been a direct relation between the numbers of stems browsed and the number of seeds browsed, we would have expected this line to approximate a 1:1 relation. Additionally, we found a significant difference between the average numbers of seeds produced from unbrowsed plants and the number we estimated would have been produced from browsed stems for some populations. These two comparisons point to the fact that differences between expected and actual production may have arisen from model error rather than from browse selection.

The impacts of deer browse on flowering stems may be more severe in small population 
than larger ones (Loeffler and Wegner, 2000, Diamond and Boyd, 2004; Bermingham and Brody, 2011). In our study, however, we found that high browse rates were more a factor of location of the population. We found both percent stems browsed and percent predicted seed loss were higher in the state park than the wildlife refuge populations. Hunting was prohibited within the state park boundaries, but is permitted within the national wildlife refuge. The monitored populations in the state park are localized around high-traffic areas of the park whereas the populations on the national wildlife refuge are distributed throughout the length of the valley including the more remote portions of the northern end of Canaan Valley. Deer are often seen around the main road through the wetland portions of the state park and surrounding the resort hotel. They have been a tourist attraction to the park and might be attracted to vehicles and visitors that provide food (though feeding is prohibited in the park and refuge) and more accustomed to human presence. Localization of deer around specific populations (i.e. Abes Run B, State Park Parking lot, State Park A and State Park B, Figure 3) may lead to increased time within $P$. vanbruntiae populations and increased browsing rates. Additionally, the close proximity of these populations might increase the probability of a few deer encountering multiple populations whereas some populations on the wildlife refuge (i.e. A-Frame A and B) consisted of only a few flowering stems and no known populations within close proximity.

We found that rates of seed loss in Polemonium vanbruntiae due to deer florivory was generally not sufficient to cause population declines where populations were in relatively large numbers. Populations with fewer flowering stems (A-frame A, State Park Populations A and B) may be at risk for declines due to deer browse given a $\lambda<1$ or confidence intervals on $\lambda<1$. However, population projections show that even with deer florivory, these populations were not at risk of extinction within the next 50 years. 
Our estimation of seed production as a measure of the fecundity of flowering ramets includes individuals that may be dispersing outside the localized population. As Polemonium vanbruntiae is potentially dispersed outside the local population by wind and water, the rate of emigration depends on annual variation in winter snowfall and flooding and is likely highly variable. Previous work has suggested that seed heads may travel up to $200 \mathrm{~m}$ from the parent plant over frozen snow (Sabourin, 2002). However, it is unclear how often such long distance travel takes place. Additionally, populations may be linked by dispersal through waterways. Dispersing individuals may be critical for metapopulation persistence, they should be considered as emigrants from a population rather than a factor in local population viability analysis. Measurement of the potential for seed loss through other means as well as the potential for dispersal is needed to examine mechanisms for connectivity between existing populations and the formation of additional populations.

We selected a quasi-extinction threshold of eight individuals (not including seeds, seedlings or dormant individuals) hopefully allowing for at least two flowering ramets and additional vegetative ramets. While the presence of one individual ramet can lead to the production of clones as well as to the production of seeds through selfing (Hill et al., 2008; Bermingham and Brody, 2011), it is not known what the long-term effects of inbreeding may be on a local population.

We found that the transition state that contribute to stasis such as the transition from vegetative to flowering ramets and maintenance of vegetative ramets contributed most to local population persistence (Table 5). This may be typical for perennial species (Furedi, 2004). Thus, maintenance of vegetative ramets may increase the chance of local population persistence. Besides the contribution to population persistence and growth, a population may persist as 
vegetative ramets and may be less likely to attract white-tailed deer through flowering.

Herbivory may also result in increased vegetative growth of browsed ramets.

Our analysis indicates that deer herbivory of flowering ramets may not, by itself, cause a decline in local populations. However, deer florivory seemed to have a larger effect on $\lambda$ in smaller populations. It is not known whether historic browse has reduced these populations to their current level or if other factors limit their size. Many of the smaller population existed as clumped ramets associated with alder (Alnus spp.) root clumps, whereas larger populations were more uniform. This variation is also found in other parts of the range (Hill et al., 2008).

Clumped populations may be a result of periodic flooding and hydrology may be an abiotic limiting factor.

While loss of seed production may not increase population extinction rates, seed loss reduces the availability of seeds for both sexual reproduction and emigration. The persistence of the metapopulation as a whole relies on both local population persistence and the colonization of new patches. A reduction in seed production may make less seeds available for dispersal to unoccupied patches. Nonetheless, deer appear to have little impact on the long-term persistence of Polemonium vanbruntiae populations in West Virginia.

\section{White-tailed Deer Seed Feeding Trial}

We recognize that white-tailed deer have the potential to disperse seeds of browsed plants when consumed, increasing the effective potential for dispersal in many plants. However, our seed feeding trials of Polemonium reptans seeds to captive white-tailed deer indicate that whitetailed deer, when they consume Polemonium seeds, are seed predators rather than dispersers and would not contribute to movement of seeds between or contribute to the establishment of new localized populations of $P$. vanbruntiae in Canaan Valley. Thus consumption of flowering 
ramets can reduce the potential for local population growth, reduce the chance of establishing new populations, and reduce gene flow between populations. While we did not conduct trials with $P$. vanbruntiae seeds, we believe that our results would apply to the dispersal of that species.

\section{MANAGEMENT IMPLICATIONS}

Our study suggests that white-tailed deer may consume almost $100 \%$ of the sexually reproductive ramets within $P$. vanbruntiae populations in a given year. In some cases, small populations in Canaan Valley produced only two flowering ramets in a year (A-Frame 2007, Table 1). A difference in browse rates exists between the Canaan Valley Resort State Park and Canaan Valley NWR populations that could be attributed to a difference in deer densities and management practices between the two public areas.

As $P$. vanbruntiae can reproduce clonally, high levels of seed loss such as those exhibited here may not have an immediate effect on population persistence. However, a loss of flower and seed production can reduce dispersal into new populations and will reduce genetic variation in a population due to a reduction in sexual reproduction. Although, many populations of $P$. vanbruntiae in Canaan Valley are large enough that browse rates recorded in this study will not threaten population viability, some historically recorded populations were not present during this study. If smaller populations are threatened by seed loss and dispersal is limited from larger populations, isolated populations are at risk of localized extirpation. A reduction in the number of localized populations threatens the metapopulation as a whole.

The alteration of deer densities in Canaan Valley to reduce browsing may not immediately benefit $P$. vanbruntiae populations and may be impractical for this sole purpose. The protection of flowering stems in smaller populations from browsing through fencing may be 
a reasonable short-term alternative. However, previous fencing efforts to protect Cypripedium reginae in Canaan Valley Resort State Park have been inadequate. To be effective, fencing should be tall enough to prevent deer browsing and must be maintained. Alternately, a method of protecting flowering stems individually until seed formation could be conceived.

\section{ACKNOWLEDGMENTS}

We thank Leah Ceperly, Elizabeth Byers, Barbara Sargent and LeAnne Bonner for assistance in locating populations of Polemonium vanbruntiae populations. We thank the staff of Canaan Valley National Wildlife Refuge and Canaan Valley State Park as well as field assistants Jacob Harrell, and Graham Nesselrod for assistance in conducting field portions of this study. We thank Rob Sylvester and the staff at the West Virginia Wildlife Center for assistance in conducting seed feeding trials. Feeding trials were conducted under Animal Care and Use Committee permit number 06-0406. Funding for this project was provided by Canaan Valley Institute, Regional Research Institute, and West Virginia University Davis College of Agriculture, Natural Resources and Design (McIntire -Stennis). This is scientific article number xxxx of the West Virginia University Agricultural and Forestry Experiment Station.

\section{LITERATURE CITED}

Alexander, H.M., B.L. Foster, F. Ballantyne, C.D. Collins, J. Antonvics, and R.D. Holt. 2012. Metapopulations and metacommunities: combining spatial and temporal perspectives in plant ecology. Journal of Ecology 100:88-103.

Alverson, W.S. and D.M. Waller. 1997. Deer populations and the widespread failure of hemlock regeneration in northern forests. in W.J. McShea, H.B. Underwood, and J.H. Rappole, eds. The science of overabundance: deer ecology and population management. Smithsonian Institution Press, Washington D.C., U.S.A. 
Anderson, J.T. 2006. Evaluating competing models for predicting seed mass of Walter's millet. Journal of Wildlife Management 34:156-158.

Anderson, R.T. 1994. Height of white-flowered trillium (Trillium grandiflorum) as an index of deer browsing intensity. Ecological Applications 4:104-109.

Anderson, J.T. and J.L. Bonner. 2014. Modeling Habitat suitability for beaver (Castor canadensis) using geographic information systems. International Proceedings of Chemical, Biological, and Environmental Engineering 61:12-23.

Augustine, D.J. and L.E. Frelich. 1998. Effects of white-tailed deer on populations of an understory forb in fragmented deciduous forests. Conservation Biology 12: 995-1004.

Bermingham, L.H. 2010. Deer herbivory and habitat type influence long-term population dynamics of a rare wetland plant. Plant Ecology 210:359-378.

Bermingham, L.H. and A.K. Brody. 2011. Pollen source affects female reproductive success and early offspring traits in the rare endemic plant Polemonium vantruntiae (Polemoniaceae). Plant Species Biology 26:244-253.

Britton, N.L. and A. Brown. 1913. Polemonium vanbruntiae Britton. in An illustrated flora of the northern United States, Canada and the British Possessions. Charles Scribner's Sons, New York, NY, U.S.A.

Burnham, K.P. and D.R. Anderson. 1998. Model selection and inference: a practical information-theoretic approach. Springer-Verlag, New York, NY, U.S.A.

Byers, E. A., J.P. Vanderhorst, and B.P. Streets. 2007. Classification and conservation assessment of high elevation wetland communities in the Allegheny Mountains of West Virginia. West Virginia Natural Heritage Program, West Virginia Division of Natural Resources. Elkins, WV, U.S.A. 
Byman, D. 2011. The effects of deer exclosures on voles and shrews in two forest habitats. Northeastern Naturalist 18:509-520.

Campbell, J.E. and D.E. Gibson. 2001. The effect of seeds of exotic species transported by via horse dung along trail corridors. Plant Ecology 157:23-35.

Cherefko, C., C. Fridley, J. Medsger, M. Woody, and J.T. Anderson. 2009. Impacts of whitetailed deer and balsam wooly adelgid on balsam fir in Canaan Valley. in Canaan Valley and its Environs: A Landscape Heritage Celebration. Canaan Valley Institute, Davis, WV, U.S.A.

deCalesta, D. and S.L. Stout. 1997. Relative deer density and sustainability: a conceptual framework for integrating deer management with ecosystem management. Wildlife Society Bulletin 25: 252-258.

Deller, M. 2002. Polemonium van-bruntiae Britton (Appalachian Jacob's ladder) New England Plant Conservation Program Conservation and Research plan for U.S. Forest Service region 9. New England Wild Flower Society, Framingham, MA, U.S.A.

Diamond, A.R. and R.S. Boyd. 2004. Distribution, habitat characteristics, and population trends of the rare southeastern endemic Rudbeckia auriculata (Perdue) Kral (Asteraceae). Castanea 69:249-264.

Drezner, T.D., P.L. Fall, and J.C. Stromberg. 2001. Plant distribution and dispersal mechanisms at Hassayampa river preserve, Arizona, USA. Global Ecology and Biogeography 10: 205-217.

Fletcher, J.D., L.A. Shipley, W.J. McShea, and D.L. Shumway. 2001. Wildlife herbivory and rare plants: the effects off white-tailed deer, rodents, and insects on growth and survival of Turk’s cap lily. Biological Conservation 101:229-238. 
Fortney, R.H. 1975. The Vegetation on Canaan Valley, West Virginia: a taxonomic and ecological study. Dissertation; West Virginia University, Morgantown, WV, U.S.A.

Fortney, R.H. 1993. Canaan Valley - An area of special interest within the upland forest region. in S. L. Stephenson (ed.) Upland Forests of West Virginia. McClain Printing Co., Parsons, WV, U.S.A.

Frye, J.A. 2012. The effect of deer browse on sundial lupine: implications for frosted elfins. Northeastern Naturalist 19:421-430.

Furedi, M.A. 2004. Effects of herbivory by white-tailed deer (Odocoileus virginianus) on the population ecology and conservation biology of American ginseng (Panax cinquefolius). Ph.D. Dissertation. West Virginia University. Morgantown, West Virginia, USA.

Furedi, M.A. and J.A. McGraw. 2004. White-tailed deer: dispersers or predators of American ginseng seed? American Midland Naturalist 152:268-276.

Geddes, N.A. and S. Mopper. 2006. Effects of environmental salinity on vertebrate florivory and wetland communities. Natural Areas Journal 26:31-37.

Gill, R.M.A. and V. Beardall. 2001. The impact of deer on woodlands: the effect of browsing and seed dispersal on vegetation structure and composition. Forestry 74:209-218.

Gregg, K.B. 2004. Recovery of showy lady's slippers (Cypripedium reginae Walter) from moderate and severe herbivory by white-tailed deer (Odocoileus virginianus Zimmerman). Natural Areas Journal 24:232-241.

Griscom, B., H. Griscom, and S. Deacon. 2011. Species-specific barriers to tree regeneration in high-elevation habitats of West Virginia. Restoration Ecology 19:660-670.

Hansson, L. 1991. Dispersal and connectivity in metapopulations. Biological Journal of the Linnean Society 42:89-103. 
Harrison, S. 1991. Local extinction in a metapopulation context: an empirical evaluation. Biological Journal of the Linnean Society 42:73-88.

Hill, L.M., A.K. Brody, and C. L. Tedesco. 2008. Mating strategies and pollen limitation in a globally threatened perennial Polemonium vanbruntiae. Acta Oecologica 33:314-323.

Hood, G.M. 2008. Poptools version 3.0.6. http://www.cse.csiro.au/poptools.

Janzen, D.H. 1984. Dispersal of small seeds by big herbivores: foliage is the fruit. American Naturalist 123:338-353.

Kery, M. and K.B. Gregg. 2004. Demographic analysis of dormancy and survival in the terrestrial orchid Cypripedum reginae. Journal of Ecology 92:686-695.

Levine, C.R., R.J. Winchcombe, C.D. Canham, L. M. Christenson, and M.L. Ronsheim. 2012. Deer impacts on seed banks and saplings in eastern New York. Northeastern Naturalist 19:49-66.

Loeffler, C.C. and B.C. Wegner. 2000. Demographics and deer browsing in three Pennsylvania populations of the globally rare Glade Spurge, Euphorbia purpurea, fern. Castanea 65: $273-290$.

Maron, J.L. and M. Vila. 2001. When do herbivores affect plant invasion? Evidence for the natural enemies and biotic resistance hypotheses. Oikos 95:361-373.

Masse, A. and S.D. Cote. 2012. Linking alternative food sources to winter habitat selection of herbivores in overbrowsed landscapes. Journal of Wildlife Management 76:544-556.

Mautz, W.M. and G.A. Petrides. 1971. Food passage rate in the white-tailed deer. Journal of Wildlife Management 35:723-731.

McGraw, J.B. and M.A. Furedi. 2005. Deer browsing and population viability of a forest understory plant. Science 307:920-922. 
Michael, E.D. 1992. Impact of deer browsing on regeneration of balsam fir in Canaan Valley, West Virginia. Northern Journal of Applied Forestry 9:89-90.

Michael, E.D. 2002. A valley called Canaan: 1885-2002. McClain Printing Co. Parsons, WV, U.S.A.

Miller, S.G., Bratton, S.P., and J. Hadidian. 1992. Impacts of white-tailed deer on endangered and threatened vascular plants. Natural Areas Journal 12:67-74.

Morris, W.F. and D.F. Doak. 2002. Quantitative conservation biology: theory and practice of population viability analysis. Sinauer, Sunderland, Massachusetts, USA.

Myers, J.A., M. Vellend, S. Gardesca, and P.L. Marks. 2004. Seed dispersal by white-tailed deer: implications for long-distance, migration and invasion of plants in eastern North America. Oecologica 139:35-44.

National Climate Data Center. 2014. National Oceanic and Atmospheric Administration: Canaan Valley, WV. Accessed online: http\|www.ncdc.noaa.gov.

National Research Council (U.S.). Committee on scientific issues in the Endangered Species Act 1995. Science and the endangered species act. National Academies Press, Washington, D.C., U.S.A.

R Development Core Team. 2008. R: A Language and Environment for Statistical Computing. R Foundation for Statistical Computing. Vienna, Austria.

Royo, A.A., S.L. Stout, D.S. deCalestaa, T.G. Pierson. 2010. Restoring forest herb communities through landscape-level deer herd reductions: Is recovery limited by legacy effects? Biological Conservation 143:2425-2434.

Russel, F.L., D.B. Zippin, and N.L. Fowler. 2001. Effects of white-tailed deer (Odocoileus virginianus) on plants, plant populations and communities: a review. American Midland 
Naturalist 146:1-26.

Sabourin, A. 2002. COSEWIC assessment and update status report on the van Brunt's Jacob's ladder Polemonium vanbruntiae. Committee on the Status of Endangered Wildlife in Canada. Ottawa, ON.

Stromayer, K.A.K., and R.J. Warren. 1997. Are over abundant deer herds in the eastern United States creating alternate stable states in forest plant communities. Wildlife Society Bulletin 25:227-234.

Stubben, C.J. and B G. Milligan. 2007. Estimating and analyzing demographic models using the Popbio package in R. Journal of Statistical Software 22:11.

Tobler, M.A., P. A. Van Zandt, K.H. Hasenstein, and S. Mopper. 2006. Growth and reproduction of a clonal plant in response to salinity and florivory. Wetlands 26:803-812.

Urbanek, R.E., C.K. Nielsen, G.A. Glowacki, and T.S. Preuss. 2012. Effects of white-tailed deer (Odocoileus virginianus Zimm.) herbivory in restored forest and savanna plant communities. American Midland Naturalist 167:240-255.

Vellend, M., 2002. A pest and an invader: white-tailed deer (Odocoileus virginianus Zimm.) as a seed dispersal agent for honeysuckle shrubs (Lonicera L.). Natural Areas Journal 22:230-234.

Vellend, M., J.A. Myers, S. Gardescu, and P.L. Marks. 2003. Dispersal of Trillium seeds by deer: implications for long-distance migration of forest herbs. Ecology 84:1067-1072.

West Virginia Division of Natural Resources. 2012. Rare Species List. West Virginia Nongame Wildlife and Natural Heritage Program.

Williams, S.C. and J.S. Ward. 2006. Exotic seed dispersal by white-tailed deer in southern Conneticut. Natural Areas Journal 26:383-390. 
Table 1. Akaike's Information Criterion values for 13 models predicting the seed production of Polemonium vanbruntiae 2005 and 2006.

\begin{tabular}{|c|c|c|c|c|c|c|}
\hline Model & Terms & AIC & $\mathbf{K}^{\mathbf{a}}$ & $\Delta_{\mathbf{i}}^{\mathbf{b}}$ & $\mathbf{w}_{i}{ }^{c}$ & $\mathbf{R}^{2}$ \\
\hline 1 & Stems ${ }^{\mathrm{d}}$ & 1535.58 & 2 & 116.37 & 0.00 & 0.07 \\
\hline 2 & Width $^{\mathrm{e}}$ & 1442.91 & 2 & 23.70 & 0.00 & 0.42 \\
\hline 3 & Population $^{\mathrm{f}}$ & 1627.76 & 11 & 208.55 & 0.00 & 0.13 \\
\hline 4 & Flowers $^{\mathrm{g}}$ & 1484.92 & 2 & 65.71 & 0.00 & 0.28 \\
\hline 5 & Height $^{\mathrm{h}}$ & 1505.29 & 2 & 86.08 & 0.00 & 0.20 \\
\hline 6 & Year & 1547.22 & 3 & 128.01 & 0.00 & 0.02 \\
\hline 7 & Year + Population & 1658.06 & 13 & 238.85 & 0.00 & 0.15 \\
\hline 8 & Stems + Width + Height + Flowers + Population + Year & 1655.14 & 17 & 235.93 & 0.00 & 0.53 \\
\hline 9 & Stems + Width + Height + Flowers & 1432.03 & 5 & 12.82 & 0.00 & 0.51 \\
\hline 10 & Width + Height & 1444.51 & 3 & 25.30 & 0.00 & 0.43 \\
\hline 11 & Height + Flowers & 1466.54 & 3 & 47.33 & 0.00 & 0.36 \\
\hline 12 & Width + Flowers & 1419.21 & 3 & 0.00 & 0.94 & 0.50 \\
\hline 13 & Width + Height + Flowers & 1425.03 & 4 & 5.82 & 0.05 & 0.51 \\
\hline
\end{tabular}

a. $\mathrm{K}$ is the number of estimable parameters in the model

b. $\Delta_{\mathrm{i}}$ is $\mid \mathrm{AIC}_{\text {clowest }}-\mathrm{AIC}$ cij $\mid$ for the ith model in comparison

c. $\mathrm{w}_{\mathrm{i}}$ is the Akaike weight of the model

d. Stems refers to the number of leaflets associated with the main stem

e. Width is the width of the stem at its base

f. Population refers to individual populations of Polemonium vanbruntiae

g. Flowers refers to the number of flowers present during one sampling period

h. Height is the height of the flowering stem 
Table 2. Transition matrix model (A) for Polemonium vanbruntiae. Each matrix element $\left(\mathrm{a}_{\mathrm{ij}}\right)$ represents the probability that each individual in stage $\mathrm{i}$ will be derived from an individual at stage $\mathrm{j}$ in one time interval.

\begin{tabular}{cccccc}
\hline \hline & & & Vegetative & Flowering & \\
& Seeds & Seedlings & Ramets & Ramets & Dormancy \\
\hline Seeds & 0 & 0 & 0 & $\mathrm{a}_{14}$ & 0 \\
Seedlings & $\mathrm{a}_{21}$ & 0 & 0 & 0 & 0 \\
Vegetative Ramets & 0 & $\mathrm{a}_{32}$ & $\mathrm{a}_{33}$ & 0 & $\mathrm{a}_{53}$ \\
Flowering Ramets & 0 & 0 & $\mathrm{a}_{43}$ & $\mathrm{a}_{44}$ & 0 \\
Dormancy & 0 & 0 & 0 & $\mathrm{a}_{54}$ & 0 \\
\hline
\end{tabular}


Table 3. Mean matrix of transition probabilities for 10 Polemonium vanbruntiae populations without white-tailed florivory in Canaan Valley, West Virginia, 20052007.

\begin{tabular}{cccccc}
\hline \hline & & & Vegetative & Flowering & \\
& Seeds & Seedlings & Ramets & Ramets & Dormancy \\
\hline Seeds & 0 & 0 & 0 & 134 & 0 \\
Seedlings & 0.2375 & 0 & 0 & 0 & 0 \\
Vegetative Ramets & 0 & 0.058 & 0.64 & 0.86 & 0.05 \\
Flowering Ramets & 0 & 0 & 0.3251 & 0.015 & 0 \\
Dormancy & 0 & 0 & 0.01 & 0.02 & 0 \\
\hline
\end{tabular}




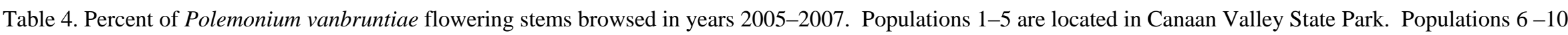
are located in Canaan Valley National Wildlife Refuge.

\begin{tabular}{|c|c|c|c|c|c|c|c|c|c|c|}
\hline & \multirow[b]{2}{*}{ Population ID } & \multicolumn{3}{|c|}{2005} & \multicolumn{3}{|c|}{2006} & \multicolumn{3}{|c|}{2007} \\
\hline & & \# Monitored & \# Browsed & $\%$ Browsed & \# Monitored & \# Browsed & $\%$ Browsed & $\begin{array}{c}\# \\
\text { Monitored } \\
\end{array}$ & \# Browsed & $\begin{array}{c}\% \\
\text { Browsed }\end{array}$ \\
\hline 1 & State Park Pop A & $13_{\mathrm{a}}$ & 9 & 69 & $19_{\mathrm{a}}$ & 13 & 68 & $29 \mathrm{a}$ & 28 & 97 \\
\hline 2 & State Park Pop B & $13_{\mathrm{a}}$ & 4 & 31 & $20 \mathrm{a}$ & 12 & 60 & $31_{\mathrm{a}}$ & 15 & 48 \\
\hline 3 & State Park Parking Lot & $50_{\mathrm{b}}$ & 32 & 64 & $39_{b}$ & 27 & 69 & $45_{b}$ & 19 & 42 \\
\hline 4 & Abes Run A & $50_{\mathrm{b}}$ & 13 & 26 & $50_{\mathrm{b}}$ & 21 & 42 & $50_{\mathrm{b}}$ & 22 & 44 \\
\hline 5 & Abes Run B & - & - & - & $14_{\mathrm{a}}$ & 9 & 64 & $35_{\mathrm{b}}$ & 25 & 71 \\
\hline 6 & A- Frame A & $14_{\mathrm{a}}$ & 7 & 50 & $5 \mathrm{a}$ & 3 & 60 & $2_{\mathrm{a}}$ & 1 & 50 \\
\hline 7 & A-Frame B & - & - & - & $4 a$ & 0 & 0 & $18_{\mathrm{b}}$ & 14 & 78 \\
\hline 8 & Cortland Pop A & $35_{\mathrm{b}}$ & 11 & 31 & $36 b$ & 12 & 33 & $40_{\mathrm{b}}$ & 11 & 28 \\
\hline 9 & Cortland Pop B & $26_{b}$ & 11 & 42 & $25_{\mathrm{b}}$ & 11 & 44 & - & - & - \\
\hline \multirow[t]{2}{*}{10} & Camp 70 & $75_{b}$ & 26 & 35 & $51_{\mathrm{b}}$ & 18 & 35 & $50_{\mathrm{b}}$ & 17 & 34 \\
\hline & Total & 276 & 113 & $\bar{x}=43.5$ & 263 & 126 & $\bar{x}=47.5$ & 250 & 130 & $\bar{x}=54.6$ \\
\hline
\end{tabular}

a represents populations with all flowering individuals monitored.

$\mathrm{b}$ represents populations where random samples of flowering individuals were monitored. 
Table 5. Sensitivity analysis of the mean transition matrix model for Polemonium vanbruntiae populations without white-tailed florivory in Canaan Valley, West Virginia, 2005-2007.

\begin{tabular}{cccccc}
\hline \hline & & & Vegetative & Flowering & \\
& Seeds & Seedlings & Ramets & Ramets & Dormancy \\
\hline Seeds & 0 & 0 & 0 & 0.002 & 0 \\
Seedlings & 1.545 & 0 & 0 & 0 & 0 \\
Vegetative Ramets & 0 & 0.633 & 0.362 & 0.058 & 0.003 \\
Flowering Ramets & 0 & 0 & 1.449 & 0.232 & 0 \\
Dormancy & 0 & 0 & 0.01 & 0.002 & 0 \\
\hline
\end{tabular}


Table 6. Elasticity analysis of the mean transition matrix model for Polemonium vanbruntiae populations without white-tailed florivory in Canaan Valley, West Virginia, 2005-2007.

\begin{tabular}{cccccc}
\hline \hline & & & Vegetative & Flowering & \\
& Seeds & Seedlings & Ramets & Ramets & Dormancy \\
\hline Seeds & 0 & 0 & 0 & 0.203 & 0 \\
Seedlings & 0.203 & 0 & 0 & 0 & 0 \\
Vegetative Ramets & 0 & 0.203 & 0.132 & 0.028 & 0 \\
Flowering Ramets & 0 & 0 & 0.23 & 0.002 & 0 \\
Dormancy & 0 & 0 & 0 & 0 & 0 \\
\hline
\end{tabular}




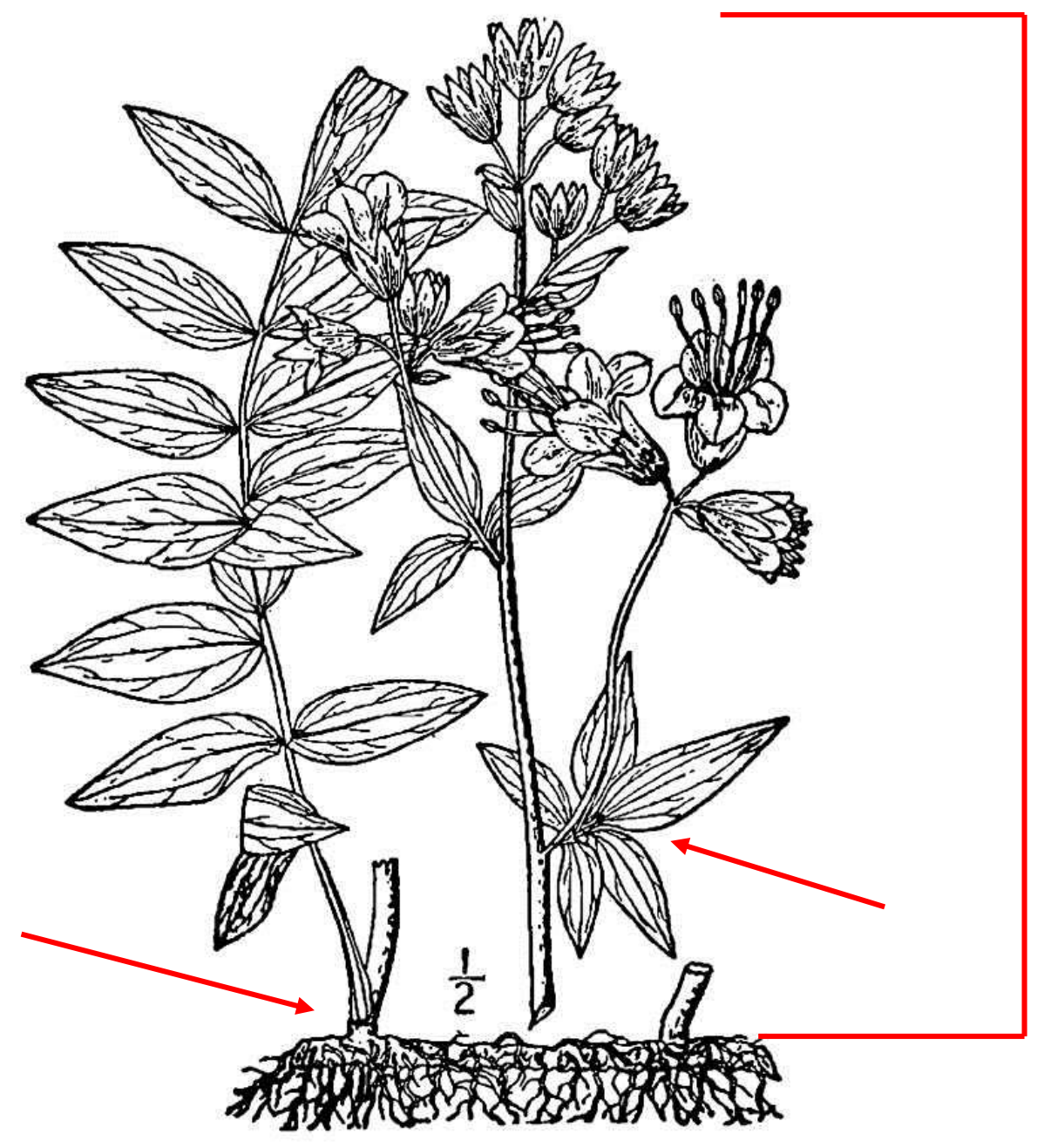

Figure 1. A single flowering ramet of Polemonium vanbruntiae. Arrows depict the location of measurements for model formation. Image Source Britton and Brown. 1913. Accessed: USDA Plants Database. 


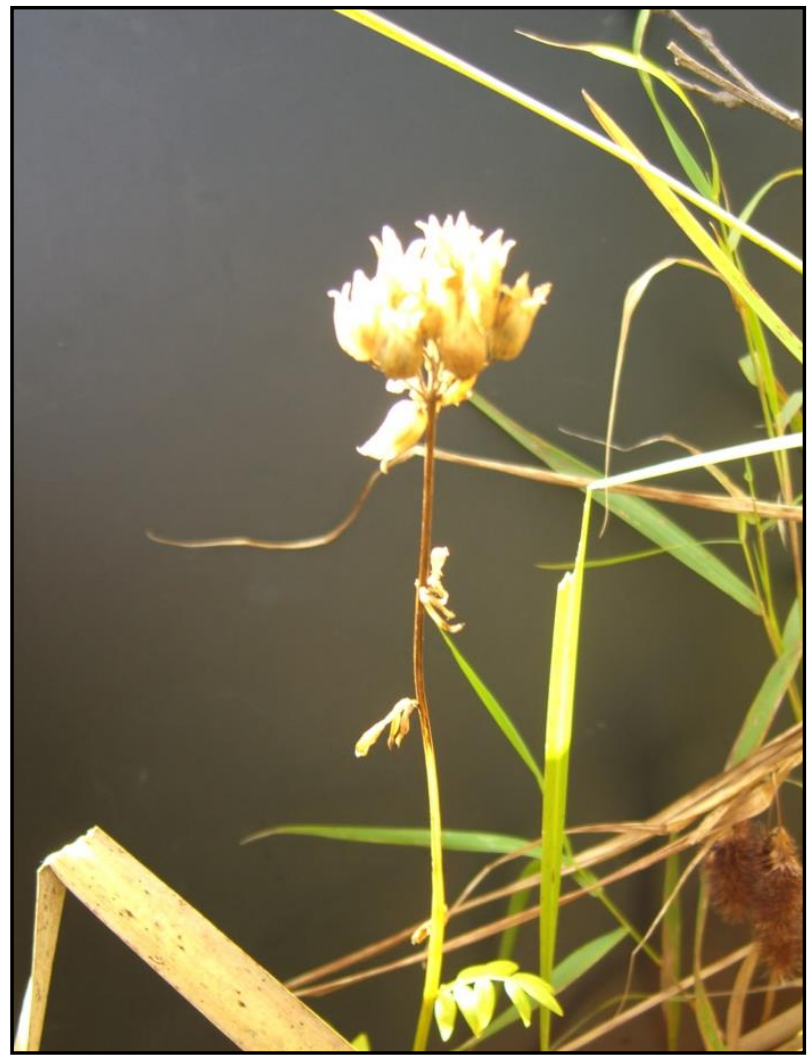

Figure 2. The flowering stem and seed head of Polemonium vanbruntiae dries in late fall. 


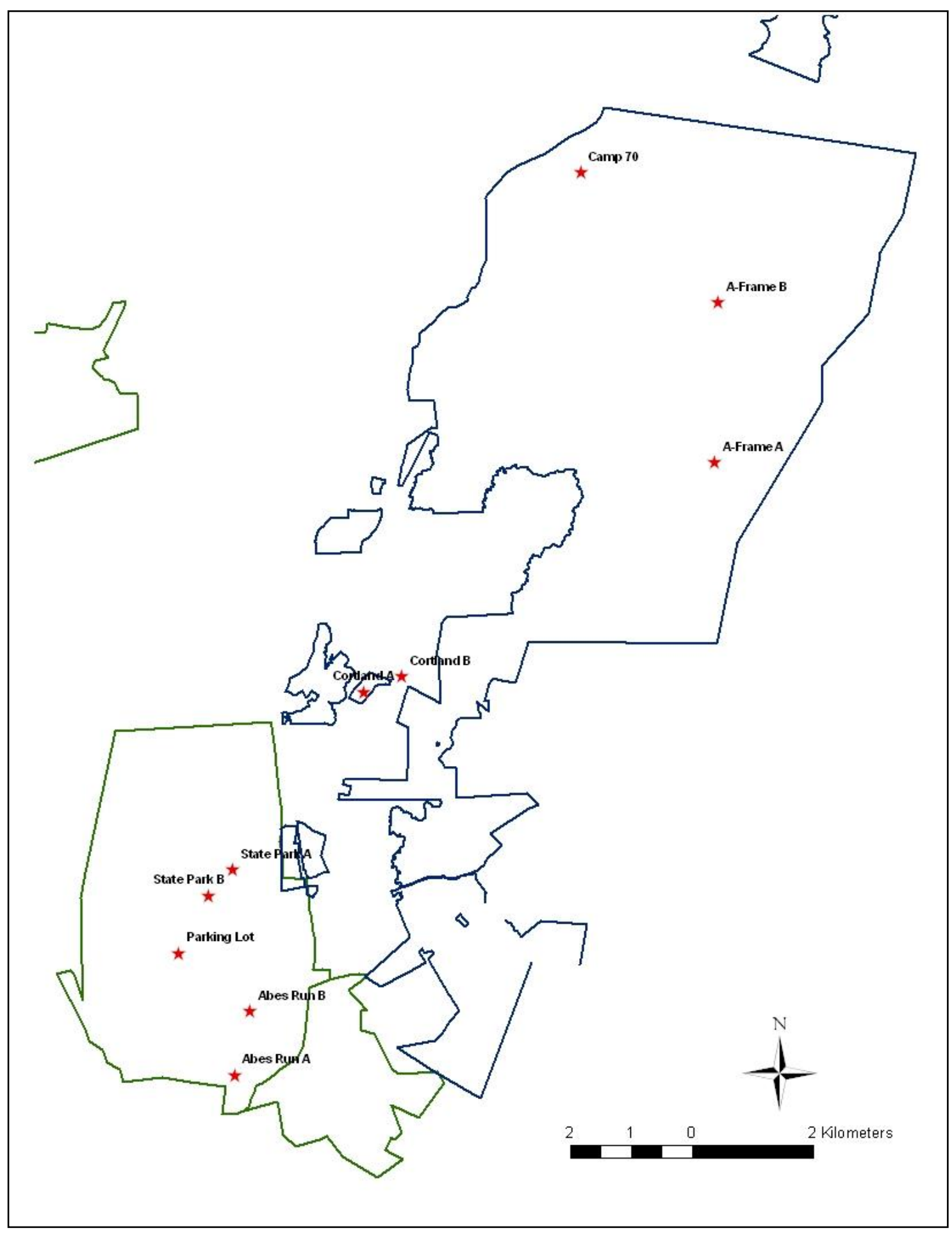

Figure 3. Locations of Polemonium vanbruntiae populations in Canaan Valley, West Virginia monitored from $2005-2007$. 


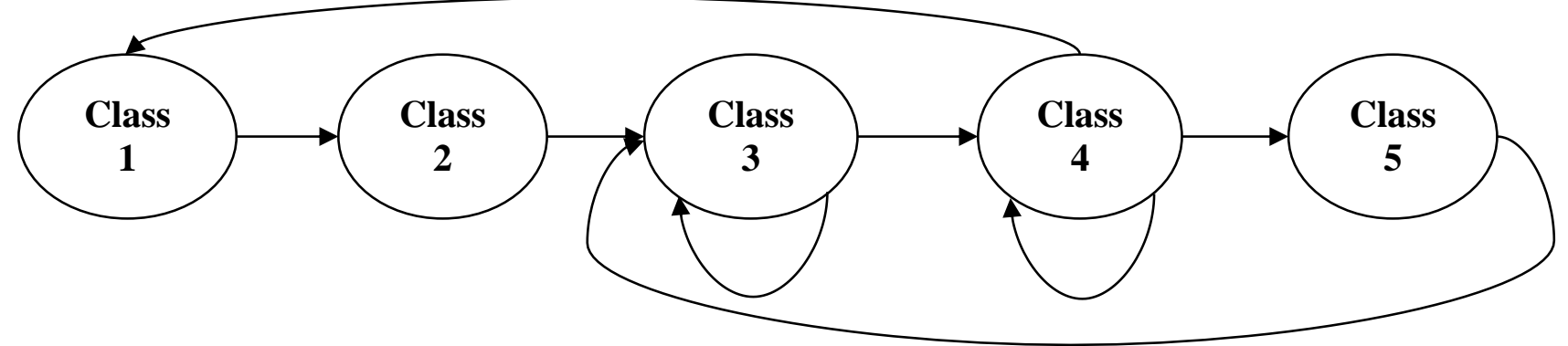

Figure 4. Direction of transition probabilities from the transition matrix for Polemonium vanbruntiae where class 1 represents seeds, class 2 represents seedlings, class 3 represents vegetative ramets, class 4 represents flowering ramets, and class 5 represents dormant individuals. 


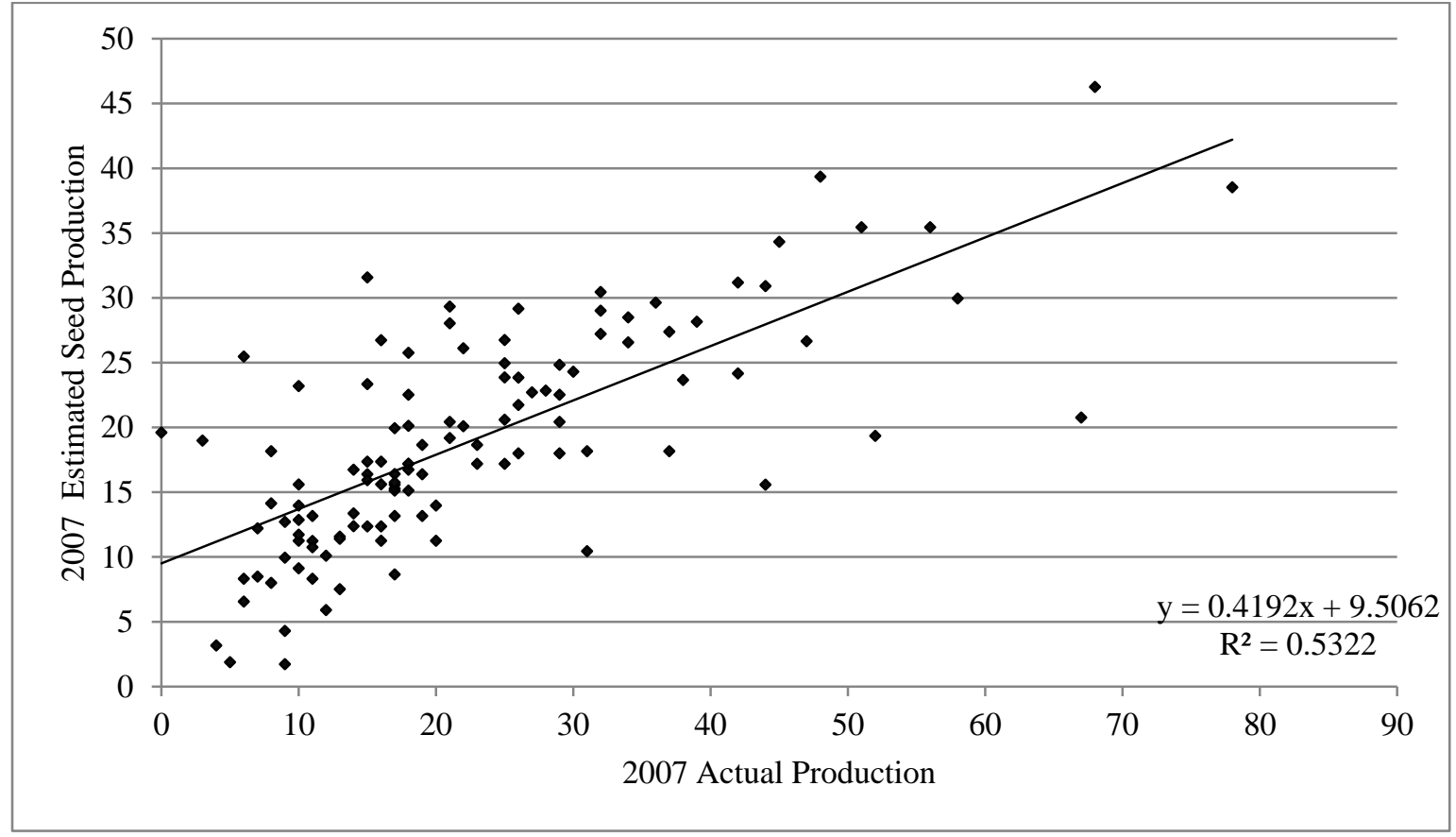

Figure 5. Scatter plot of the estimated seed production for unbrowsed plants in 2007 based on the best fitting model from 2005 and 2006 data compared to the seeds that were actually produced. 


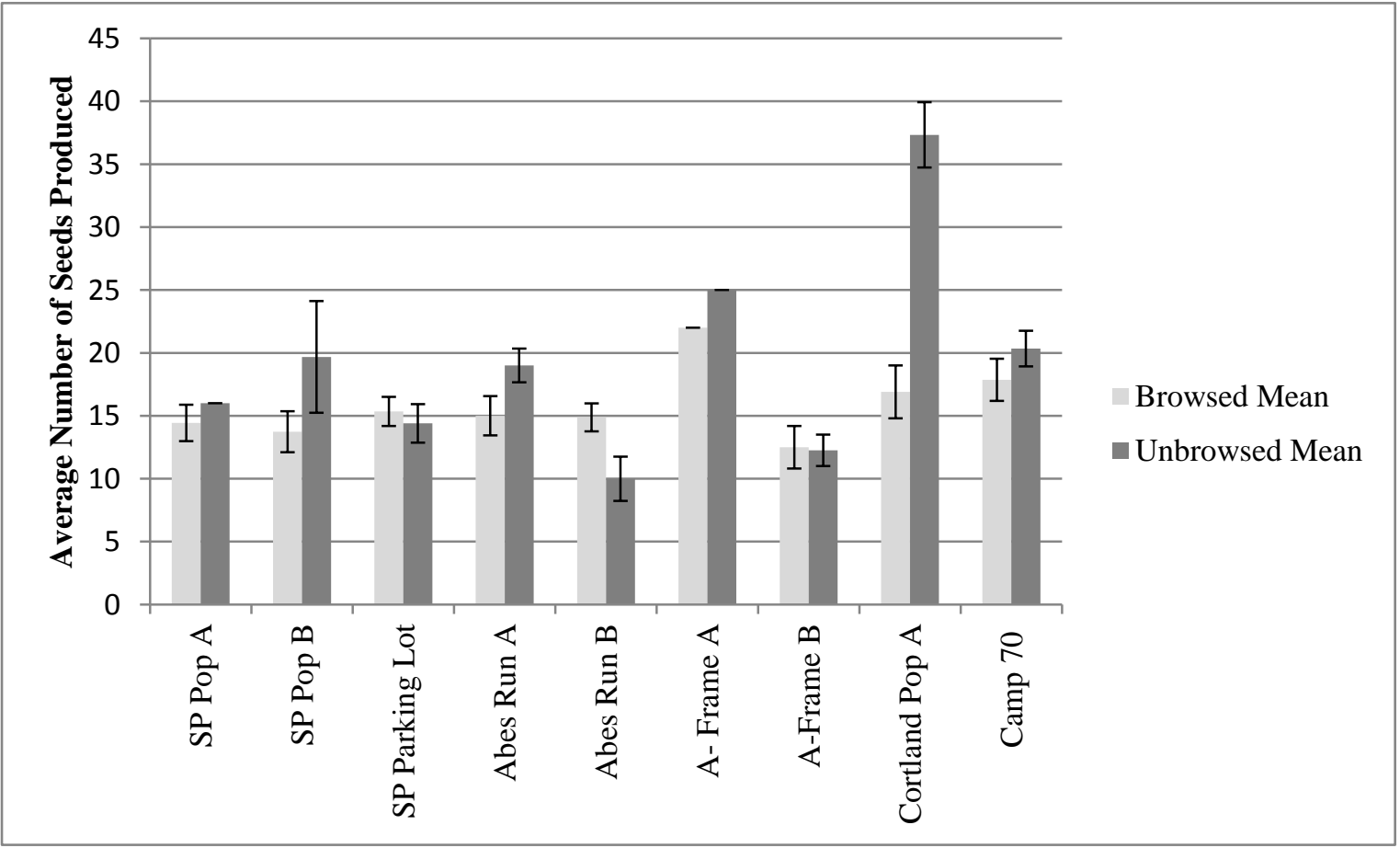

Figure 6. The potential mean seed production of browsed plants and actual production of unbrowsed plants in monitored populations of Polemonium vanbruntiae in Canaan Valley, WV in 2007 


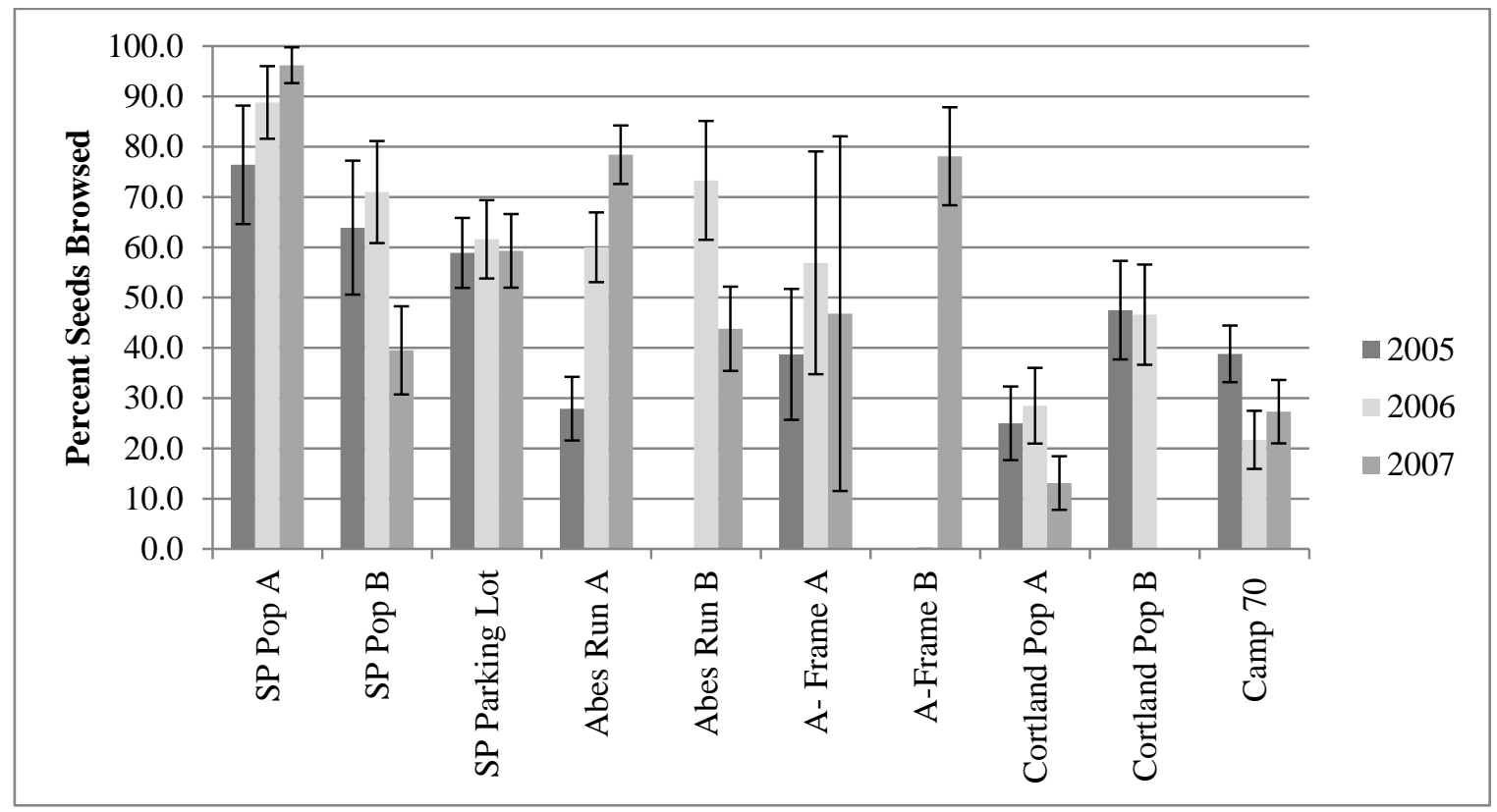

Figure 7. The estimated percent of Polemonium vanbruntiae seeds consumed by whitetailed deer in 10 populations in Canaan Valley, West Virginia in 2005-2007. 


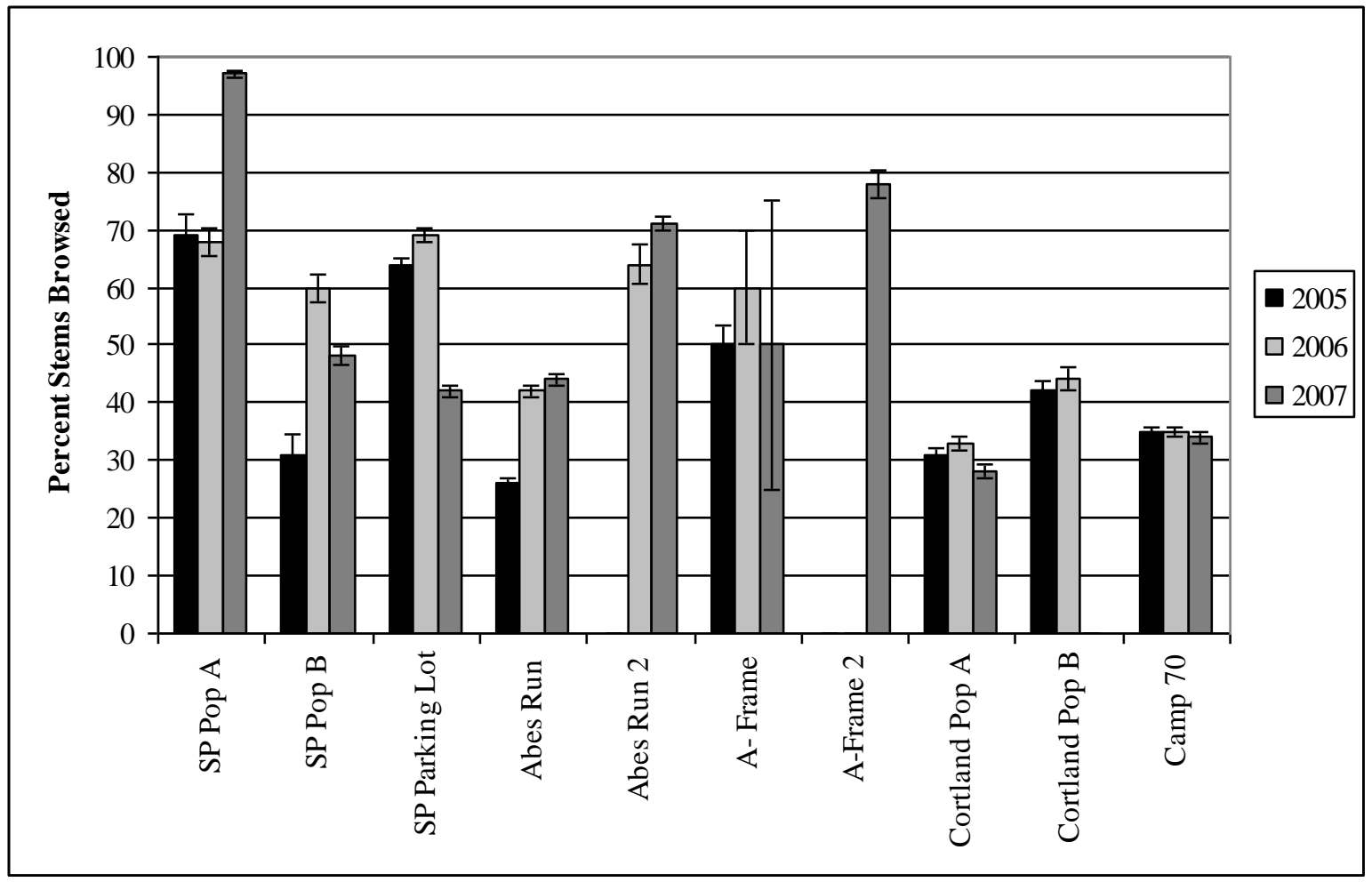

Figure 8 . The estimated percent of Polemonium vanbruntiae stems consumed by white-tailed deer in 10 population in Canaan Valley, West Virginia in 2005-2007. 


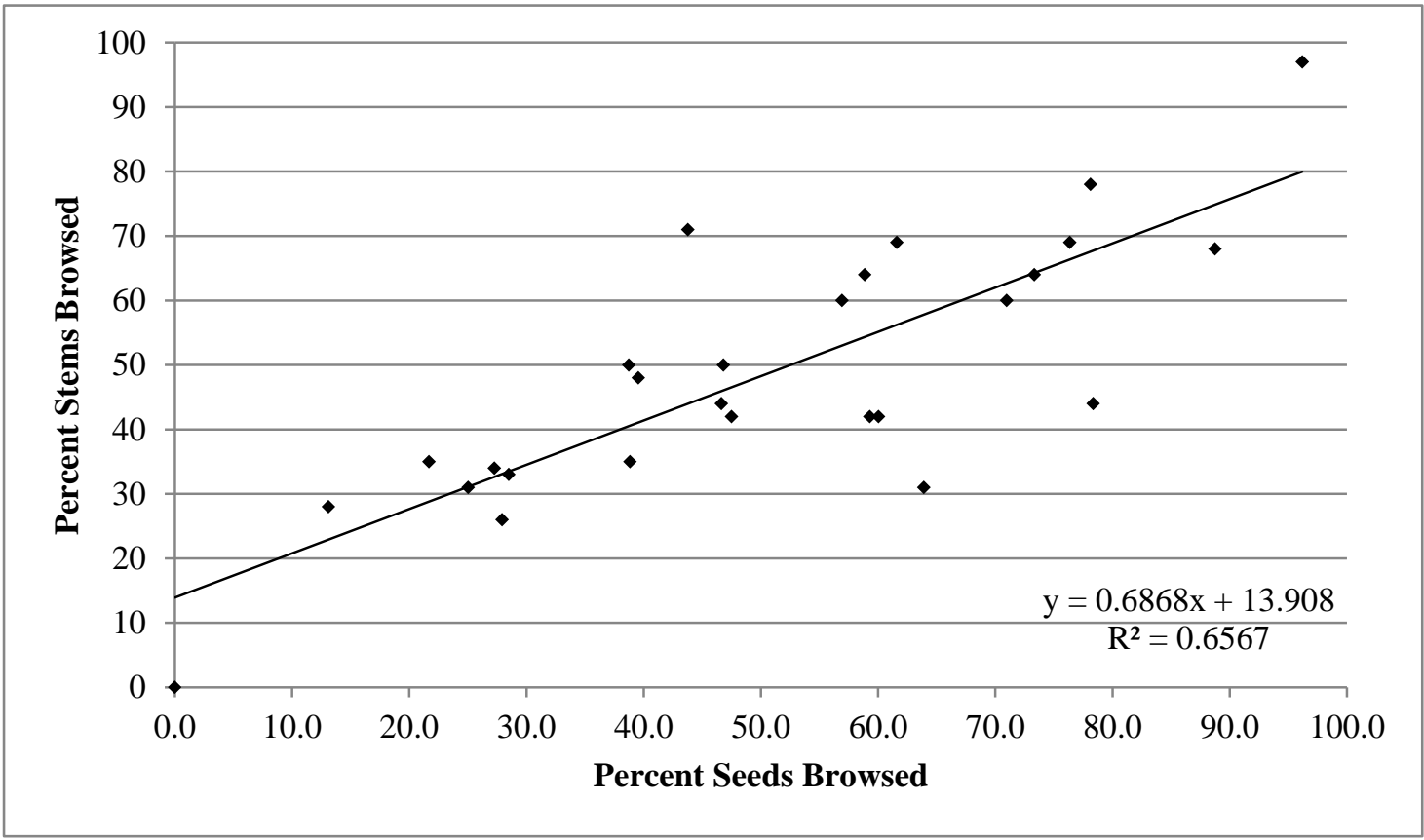

Figure 9. Comparison of the percentage of Polemonium vanbruntiae stems browsed to the estimated percent of seeds consumed by white-tailed deer in Canaan Valley, West Virginia in 2005-2007. 


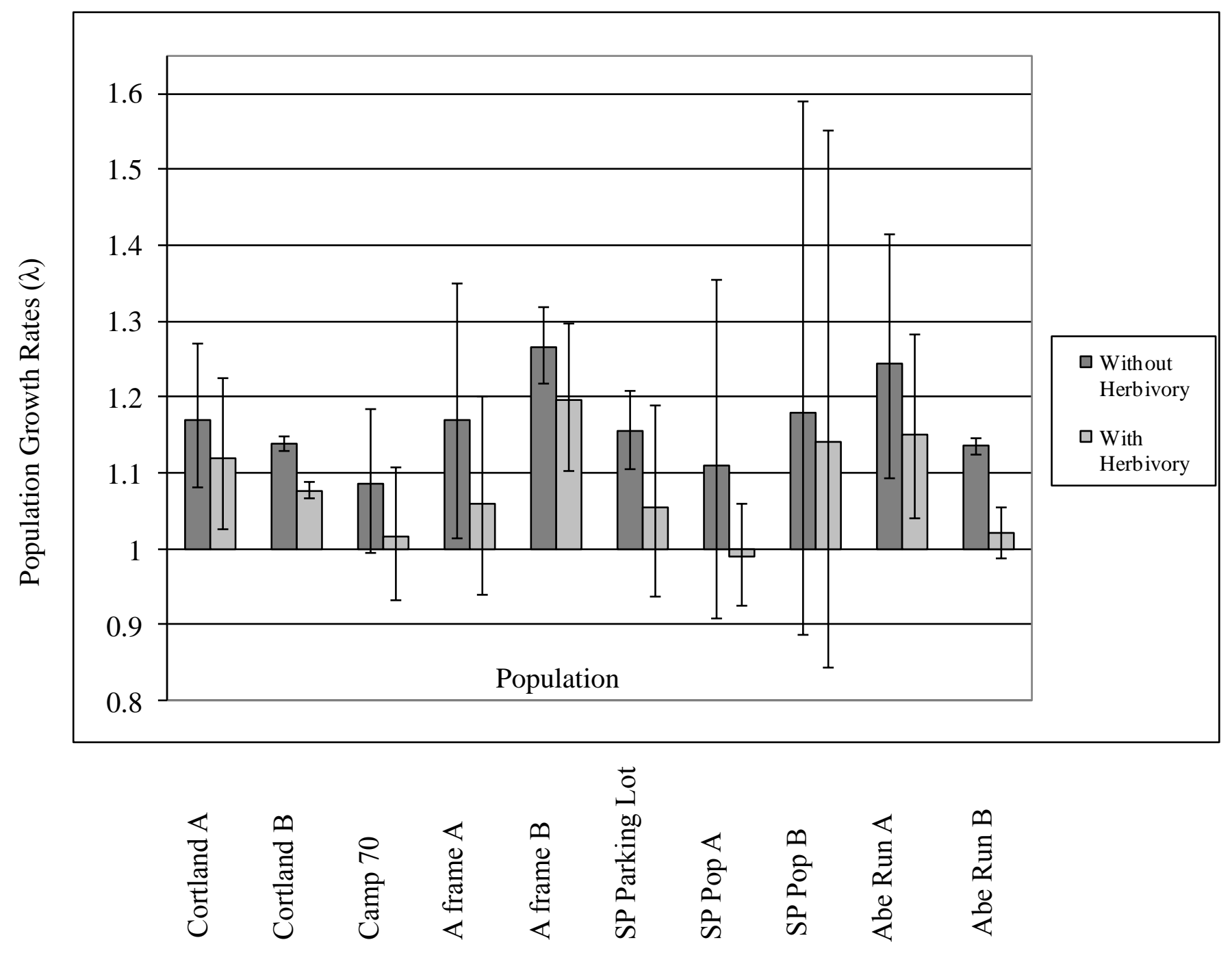

Figure 10. Predicted population increase rates $(\lambda)$ for all Polemonium vanbruntiae populations with and without white-tailed deer florivory. Standard error bars represent the 95\% error estimates of $\lambda$ calculated in the Popbio package of Program R. 


\section{CHAPTER III}

\section{The influence of white-tailed deer herbivory on herbaceous wetland plant communities in Canaan Valley, West Virginia (USA)}

Kelley L. Flaherty ${ }^{1,2}$

James S. Rentch ${ }^{1}$

James T. Anderson ${ }^{1}$

1 Division of Forestry and Natural Resources, West Virginia University, Morgantown, WV 26506, USA

2 Current address: College of Science. Technology, and Math, Alderson Broaddus University, Philippi, WV 26416, USA

\section{Corresponding author:}

Kelley Flaherty

flaherty@calu.edu

p: 724938 5979; f: 7249381514 
Abstract White-tailed deer (Odocoileus virginianus Zimm.) may have the potential to alter plant community composition and successional trajectory by browsing differentially on forb, graminoid, and woody species metacommunities. The objective of this study was to determine if the elimination of deer browsing resulted in a change in wetland plant community composition and structure. We established 66 deer exclosure plots in two wetland vegetation communities in Canaan Valley, West Virginia, USA. Plots were $1 \mathrm{~m}^{2}$ and surrounded by $2 \mathrm{~m}$ x $2 \mathrm{~m}$ exclosures including a $0.5 \mathrm{~m}$ buffer between the plot and the fence. Plots were established in April 2005 and monitoring was conducted in late-June and late October from $2005-2007$. We evaluated the differences in community composition between control and treatment plots using Blocked Multiple Response Permutation Procedures (MRBP) in program PC-Ord. We also examined the changes in woody, forb and graminoid metacommunites as well as the differences between wetland indicator status categories. We found composition differed between control and treatment plots in Solidago spp.-Rubus hispidus communities in late-protected plots when data were gathered in the fall and early-protected plots when data were gathered in the spring. We found that forb cover increased in treatment plots in Solidago spp.-Rubus hispidus communities. Composition differed in Populus spp. communities in late-protected and continuously-protected plots. There was no significant increase in cover by any one wetland indicator status category after two years of protection. Timing of browse plays a significant role in the effect that whitetailed deer have on wetland plant communities. Increased forb cover in treatment plots suggests that historical deer densities have depressed forb species through selective browsing. Whereas exclosure studies typically represent a scenario without deer, our results suggest that reducing browsing pressure can increase forb and woody species cover where previously depleted.

Keywords herbaceous $\cdot$ herbivory $\cdot$ wetland $\cdot$ white-tailed deer 


\section{Introduction}

The effect of white-tailed deer (Odocoileus virginianus) on their habitat is one of the most studied and controversial topics in the fields of wildlife management, forestry, and ecology. However, the focus of these studies have been on upland species as opposed to wetland species. In the past, economic factors such as loss of crops or regeneration of preferred timber species have provided the impetus for many studies. Species-specific studies found deer had detrimental effects on hemlock (Tsuga canadensis)(Anderson and Loucks 1979; Whitney 1984; Alverson and Waller 1997; Stromayer and Warren 1997), white cedar (Thuja occidentalis)(White 2012), yellow birch (Betula lutea)(Stromayer and Warren 1997), balsam fir (Abies balsamea)(Tremblay et al. 2007), and various oak species (Quercus spp.)(Healy 1997).

More recently there has been an increased interested in the effect of high densities of white-tailed deer on individual threatened and endangered understory species (Miller at al. 1992; Gregg 2004). Glade spurge (Euphorbia purpurea), a globally rare plant is affected by consumption of leaves as well as limited in reproduction by browsing of flowering parts by white-tailed deer (Loeffler and Wegner 2000). Deer may reduce or extirpate local populations of American ginseng (Panax quinquefolius) in West Virginia (McGraw and Furedi 2005) and Turk's cap lily (Lilium supurbum) in Virginia (Fletcher et al. 2001).

There has also been an increased focus on species richness and diversity of understory and herbaceous plant communities. Myriad studies cite white-tailed deer herbivory as an important contributing factor to the decline in species richness of forest understory forb species (Leege et al. 2010; Pellerin et al. 2010; DeGroote et al. 2011; Duguay and Farfaras 2011; Randall and Walters 2011) and the decline in sapling recruitment of preferred woody browse (Augustine and McNaughton 1998; Levine et al. 2012). Deer herbivory has been cited as a 
detriment to tallgrass prarie forbs (Anderson et al. 2001) and riparian willow species (Brookshire et al. 2002). Peek and Stahl (1997) cited an instance in which a large population of deer extirpated 150 vascular plant species from one city park in Ohio. While the majority of studies on this topic cite negative impacts to woody and forb species (Goetsch et al. 2011), several recognize an increase in graminoid species (Merrill et al. 2003; Rooney 2009; Thiemann et al. 2009; Randall and Walters 2011), less palatable woody species (Koda and Fujita 2011), and exotic species (Knight et al. 2009; Duguay and Farfaras 2011; Lefcort and Pettoello 2012) that often accompany the decline in preferred browse species.

The ability of white-tailed deer to affect plant communities may have long-term implications for trajectory of plant community restoration after disturbance (Opperman and Merenlender 2000; Rooney 2009; Holmes and Webster 2011; Tanzentap et al. 2012). Many of the ecosystems in the eastern United States have been disturbed either through timber harvest or conversion to agricultural land. The ability of a forest community to undergo a predictable secondary successional path following disturbance such as timber harvest or historical cultivation depends primarily on the ability of forest species to reach the canopy (Tanzentap et al. 2011; White 2012). Browsing by white-tailed deer prevents this by reducing the recruitment of those species into the sapling layer directly through browse (Pellerin et al. 2010) and indirectly by increasing the prevalence of less palatable graminoid and fern species that shade woody species seedlings (Augustine and McNaughton 1998; Jensen et al. 2011; Randall and Walters 2011). Numerous studies have demonstrated a loss of preferred browse species and an increase in non-preferred browse species in the sapling layer (Holmes et al. 2008). The loss of preferred browse species has included mast producing species that provide important seasonal food sources for white-tailed deer throughout much of their range (Clements et al. 2011). Thus 
altering the existing sapling community composition has repercussions far into the future. Some have even suggested that the loss of species today could lead to an alternate stable state or a community that exists in a different state than would be predicted by ecological succession and remains stable without a disturbance event (Stromayer and Warren 1997; Beschta and Ripple 2009).

Seasonal variation in browse pressure may affect the way that different types of plants respond to herbivory (Stewart et al. 2008; DeGroote et al. 2011; Jensen et al. 2011). As the primary winter food source, populations of woody plant species may be significantly reduced through winter browse pressure. Browsing during the early spring appropriates nutrients and energy seedlings and saplings would have allocated to leaf, shoot, or root production (Stewart et al. 2008; Clements et al. 2011). Repeated browsing can prevent individuals from growing out of the range of white-tailed deer browse. Deer browse on forbs is generally associated with the new growth of early spring; however, deer may also browse on senescent forms during winter months when plant tissues may be higher in crude protein and lower in tannins than woody browse species available at the same time (Windels and Jordan 2008). Browsing in spring may prevent forbs from producing flowers which reduces reproductive output.

The effect of timing on browsing of metacommunities (i.e., forbs, woody species, and graminoids) in the same environment has seldom been studied. Additionally, most studies that have measured the impact of deer browse on plant communities have focused on forest and grassland communities. Fewer studies have included wetland ecosystems (Cipollini and Cipollini 2011). We examined the effects of a high-density (2.8-3.8 deer/ha, Cherefko et al. 2009) white-tailed deer population on plant community metrics in a high-elevation wetland ecosystem by comparing communities in both unfenced (control) and fenced (treatment) plots. 
We focused on the effect of timing on browse susceptibility of forb, woody, and graminoid species, by varying the exposure of treatment plots to browse throughout the year.

Our objectives were to determine if a reduction in deer browsing affected the plant species richness, plant community composition, prevalence of wetland species, and cover of forb, graminoid, and woody species in Solidago spp.-Rubus hispidus wet meadow communities and Populus spp. regeneration communities. We tested the null hypotheses that there will be no overall change in plant species richness, plant community composition, and cover of forb, graminoid, and woody species in plots protected continuously over the two years of the study period when compared to paired control plots that are not continuously protected from deer browse. We also tested the null hypotheses that there would be no difference in the average change in cover between different wetland plant indicator classes after two years of protection from deer browse.

\section{Methods}

\section{Site Description}

Canaan Valley is a high-elevation wetland complex, located in Tucker County, West Virginia, USA. The valley floor averages $975 \mathrm{~m}$ above sea level. This coupled with surrounding mountains which rise $150-240 \mathrm{~m}$ above the valley create a relatively cool, moist climate and a short growing season. As such, the climate and accordingly, the vegetation, of the valley are more similar to northern boreal forests than to the deciduous forests of surrounding West Virginia. Once home to large stands of red spruce (Picea rubens), intense logging followed by fires drastically changed the soils and vegetation of the valley to their present condition (Fortney 1975). The average annual precipitation is $137 \mathrm{~cm}$ and annual snowfall is $305 \mathrm{~cm}$ (Stephenson 1993). The average growing season is approximately 90 days (Beverage 1967). These 
characteristics set this area apart from drier and warmer, low-elevation wetland and upland areas in the surrounding counties.

Canaan Valley encompasses about $176 \mathrm{~km}^{2}$ (17,600 ha) of land. Approximately $20 \%$ of the land area is made up of various wetland community types and another $23 \%$ is northern hardwood forest (Fig. 1). Fortney (1975) described 27 distinct wetland community types ranging from quaking aspen (Populus tremuloides) groves to sphagnum (Sphagnum spp.) and polytrichum (Polytrichum spp.) bogs.

Canaan Valley is home to Canaan Valley State Park and the Canaan Valley National Wildlife Refuge (NWR) as well as land managed by the West Virginia Division of Natural Resources for hunting. Deer hunting is allowed by permit within the National Wildlife Refuge lands and is conducted on private holdings throughout Canaan Valley. However, hunting has been prohibited in sections of the southern end of the Valley (i.e., Canaan Valley Resort State Park) for at least 20 years (Michael 1992).

Plant Community Analysis

We selected two types of wetland plant communities from those present in Canaan Valley. Solidago spp.-Rubus hispidus dominated communities and regenerating Populus spp. dominated communities were selected from the wet meadow communities found in Canaan Valley identified by Canaan Valley NWR staff. We chose Solidago spp.-Rubus hispidus dominated communities because these wet-meadow communities are rare within the state and may have an increased likelihood of rare species within these communities (e.g. Euphorbia purpurea and Luzula bulbosa, Fortney 1975). These communites were dominated by $S$. uliginosa and S. rugosa as well as R. hispidus. Additionally, the initiation of our monitoring coincided with Populus spp. regeneration cuts conducted on the Canaan Valley National Wildlife 
Refuge. These communities were dominated by $P$. tremuloides. We chose to monitor the effect of herbivory on those communities during regeneration. Within the valley, we randomly selected 10 Solidago spp.-Rubus hispidus communities previously identified by refuge staff (Fig. 1). Within each community we randomly established three treatment plots and located a paired control plot $4 \mathrm{~m}$ from each treatment plot (Fig. 2). One of the treatment plots was enclosed yearround for three years from 2005-2007 (continuous plots). Another plot was enclosed from late April through mid-July of each year (early plots). The third treatment plot was enclosed from mid-July through mid-October of each year (late plots).

We also selected four recently-cut Populus spp. communities (Fig. 1). In each of these, we randomly located three blocks of three pairs of control and treatment plots as described above. At each site, three of the treatment plots were enclosed year-round for three years (continuous plots). Three plots were enclosed from late April through mid-October (early plots). The final three treatment plots were enclosed from mid-October through late April (late plots). Treatment plots were $1 \mathrm{~m}^{2}$ and surrounded by fenced $2 \mathrm{~m} \times 2 \mathrm{~m}$ exclosures such that a $0.5 \mathrm{~m}$ buffer occurred between the plot and fence. We constructed deer exclosures from $12 \mathrm{ga}$. woven wire fencing. Plots were established in April 2005 and monitored in late-June and late October from 2005 - 2007. We recorded all plant species within the plot and recorded a Daubenmire cover-class rating for all species such that; species with $<5 \%$ plot coverage received a score of 1 , species with $>5 \%-25 \%$ plot coverage received a score of 2 , species with $>25 \%-50 \%$ plot coverage received a score of 3 , species with $>50 \%-75 \%$ plot coverage received a score of 4 , species with $>75 \%-95 \%$ plot coverage received a score of 5 , species with $>95 \%$ plot coverage received a score of 6 (Daubenmire 1959). We used cover class scores 
to improve normality and homogeneity of variances between a priori groups. Use of cover class scores also reduces bias against species with low abundance (McCune et al. 2002).

Data Analyses

We were interested in comparing the change in plant community composition after eliminating deer browsing pressure both seasonally and year-round. Therefore, we created species-by-site matrices for each of our sampled communities. We adjusted our response variable to reflect a change in species composition from the original community. For example, if the species cover was initially recorded as a 4 and was later recorded as a 3 over two years of monitoring, the response matrix would reflect this as a -1 indicating a decline in the frequency of that species within the plot. We compared the change in frequency between control (unfenced) and treatment (fenced) plots for our three groups; early, late, and year-round. We analyzed the results for the Solidago spp.-Rubus hispidus and Populus spp. communities separately.

We used Blocked Multiple Response Permutation Procedure (MRBP) in PC-Ord (McCune and Mefford 1999) to compare vegetation communities in treatment vs. control plots. Multiple Response Permutation Procedure (MRPP) is a non-parametric technique for analyzing multivariate data and requires the a priori selection of test groups. Blocking the MRPP allows for the analysis of randomized block designs or paired plot data (McCune et al. 2002). Communities were analyzed using the Euclidean distance measure. This procedure describes the homogeneity within a group using the A-statistic. An observed A statistic of one indicates identical communities within plots in a group. The separation between the control and treatment groups is described with a T-statistic. The resulting P-value describes the likelihood for finding the observed separation between random groups given the data. All species cover data are presented as raw cover class data unless otherwise specified. 
We also compared species richness within plots after two years protection from browse. A Shapiro-Wilk normality test indicated that data were not normal in either Solidago spp.-Rubus hispidus or Populus spp.regeneration communities $(\mathrm{p}<0.05)$. Thus a repeated-measures, two-way analysis of variance was performed on rank-transformed species richness data to compare richness between fenced and control plots and between early, late, and continuously protected plots. We identified the wetland indicator class for each species that exhibited a change in average cover class rating between 2005 and 2007. These groups include facultative wetland (FACW; plants with 67 - 99\% frequency of occurrence in wetlands), obligate wetland (OBL; plants with > 99\% frequency of occurrence in wetlands), Facultative (FAC; plants with equal chance of occurring in wetland or uplands), facultative upland (FACU; plants with $67-99 \%$ frequency of occurrence in non-wetlands), and upland (UPL; plants with > 99\% frequency of occurrence in non-wetlands; Lichvar et al. 2014). We compared the mean change in species cover from 2005 and 2007 in fenced plots between wetland plant indicator classes using a Kruskal-Wallis rank sum test.

\section{Results}

Species Richness

We recorded 75 species in plots in Solidago spp.-Rubus hispidus communities (Appendix 4) and 99 species within plots in Populus spp. regeneration communities (Appendix 5). Solidago spp.-Rubus hispidus community species richness within square-meter plots ranged from $6.4 \pm$

0.37 species $/ \mathrm{m}^{2}$ in control plots associated with late-protected plots when measured in the spring to $7.5 \pm 0.50 \mathrm{species} / \mathrm{m}^{2}$ recorded in control plots associated with early-protected plots when measured in the fall (Fig. 3). There were no significant differences found between fenced and control plots in Solidago spp.-Rubus hispidus communities for any treatment measured in both 
spring and fall (p>0.05, Fig. 3). Populus spp. regeneration community species richness within square-meter plots ranged from $8.4 \pm 0.80$ species $/ \mathrm{m}^{2}$ in control plots associated with continuously protected plots to $10.6 \pm 0.56$ species $/ \mathrm{m}^{2}$ recorded in fenced plots protected continuously (Fig. 4). There were no significant differences found between fenced and control plots in Populus spp. regeneration communities for any treatment measured in both spring and fall ( $\mathrm{p}>0.05, \quad$ Fig. 4$)$.

Solidago spp.-Rubus hispidus Community Analysis

We found significant differences in the change in community composition for some, but not all of our treatment regimes. In Solidago spp.-Rubus hispidus communities we found that community composition differed significantly between treatment and control plots for those protected in the early plots when data were gathered in the spring $(\mathrm{T}=-3.474, \mathrm{p}<0.01)$ and in the late plots when data were gathered in the fall $(\mathrm{T}=-5.547, \mathrm{p}<0.01)($ Table 1$)$. When plots were protected year-round, a significant change in community composition was only apparent on data gathered in the spring $(\mathrm{T}=-2.386, \mathrm{p}<0.05)($ Table 1$)$.

For treatment regimes in Solidago spp.-Rubus hispidus communities that showed a significant difference in community composition between treatment and control plots, we determined which species exhibited the greatest average change in fenced plots. The grasses; Agrostis gigantea Roth, Danthonia compressa Aust., and Festuca trachyphylla (Hack.) declined in fenced plots from 2005 under more than one treatment regime or monitoring period (Table 2). The forbs; Doellingeria umbellata (P. Mill.) Nees var. umbellata, Rubus hispidus L., Solidago rugosa Mill., and Solidago uliginosa Nutt. increased in fenced plots from 2005 under more than one treatment regime or monitoring period (Table 2). 
In Solidago spp.-Rubus hispidus communities, there was a significant difference in the change in woody species cover class between fencing periods when data were gathered in the spring $\left(\mathrm{F}_{2,52}=4.62, \mathrm{p}<0.05\right.$; Fig. 5$)$. There was an increase in woody species cover class $(\bar{x}=$ $0.029 \pm 0.020)$ for plots protected early in the year and a decrease for plots protected later $(\bar{x}=-$ $0.064 \pm 0.020$ ). There was no change in cover class for continuously protected plots or a difference between control and fenced plots for woody species. A significant difference in cover class also was detected for woody species between early, late, and continuously protected plots when data were gathered in the fall $\left(F_{2,52}=3.33, p<0.044\right.$; Fig. 6). Woody species cover class increased more in the continuously protected plots $(\bar{x}=0.021 \pm 0.01)$ in both the early $(\bar{x}=$ $0.007 \pm 0.022)$ and late $(\bar{x}=0.007 \pm 0.013)$ plots. There was no significant difference in cover class between control and fenced plots when measured in the fall $\left(F_{1,52}=0.31, p>0.50\right.$; Fig. 6). There were no significant interactions between fencing period and treatment in either season for woody species.

There were significant changes detected in the forb species cover classes between control and fenced plots when measured in the fall $\left(F_{1,52}=4.12, p<0.048\right.$; Fig. 6). We measured an increase in cover class of forbs in plots that were fenced early in the year $(\bar{x}=0.022 \pm 0.031)$ and a decrease in forb cover class of associated control plots $(\bar{x}=-0.00013 \pm 0.025)$. We measured a decrease in forb cover class in both fenced plots protected late in the year $(\bar{x}=-$ $0.0037 \pm 0.017)$ and the associated control plots $(\bar{x}=-0.0022 \pm 0.035)$. There was an increase in forb cover class in both fenced plots protected continuously $(\bar{x}=-0.0074 \pm 0.019)$ and the associated control plots $(\bar{x}=-0.00086 \pm 0.018)$. There were no significant interactions between fencing period and treatment for forb species. No differences in graminoid species cover class were detected for fencing period or treatment in either season. There were no significant 
interactions ( $>0.05)$ between the the fencing period and the fencing treatment in Solidago spp.Rubus hispidus communities. There were no significant difference in mean change based on wetland indicator class for data collected from plots protected late in the year when data were collected in the fall $\left(\chi^{2}{ }_{5}=5.73, \mathrm{p}=0.3332\right)$, from plots protected early in the year when data were gathered in the spring $\left(\chi^{2}{ }_{5}=8.98, \mathrm{p}=0.1098\right)$, and from continuously protected plots when data were gathered in the spring $\left(\chi^{2}{ }_{5}=2.51, \mathrm{p}=0.7753\right.$, Table 4$)$.

Populus spp. Community Analysis

In Populus spp. communities, differences between control and treatment plots in community composition were only apparent in data gathered in the spring for the late plots $(\mathrm{T}=$ 2.101, $\mathrm{p}<0.05)$ and year-round plots $(\mathrm{T}=-2.077, \mathrm{p}<0.05)($ Table 1). Carex debilis Michx. and Pteridium aquilinum (L.) Kuhn. declined in fenced plots from 2005 under more than one treatment regime or monitoring period (Table 3). Danthonia compressa Aust. and Rubus hispidus L. increased in fenced plots from 2005 under more than one treatment regime or monitoring period (Table 3).

In Populus spp. communities, there was a significant difference between fencing periods in the change in forb species cover class $\left(F_{2,64}=4.12, p<0.048 ;\right.$ Fig. 7$)$ when data were gathered in the spring. Forb species cover class increased in both fenced plots $(\bar{x}=0.044 \pm 0.026)$ protected early in the year and their associated control plots $(\bar{x}=0.035 \pm 0.004)$. Forb species cover class decreased in both fenced plots $(\bar{x}=-0.042 \pm 0.017)$ protected late in the year and their associated control plots $(\bar{x}=-0.01 \pm 0.029)$. Forb communities measured in the fall differed between fenced and control plots $\left(\mathrm{F}_{1,64}=15.69, \mathrm{p}<0.001 ;\right.$ Fig. 8$)$. Though the forb cover class increased for both fenced and control plots under all fencing regimes, the change in forb communities was greater for fenced plots protected early $(\bar{x}=0.076 \pm 0.018)$, late $(\bar{x}=0.046 \pm$ 
$0.015)$, and continuously $(\bar{x}=0.076 \pm 0.016)$ than in the control plots paired with early $(\bar{x}=$ $0.026 \pm 0.015)$, late $(\bar{x}=0.03 \pm 0.015)$, and continuous $(\bar{x}=0.046 \pm 0.030)$ treatments. In Populus spp. communities, we also found a difference in the change in woody species cover class between control and fenced plots when measured in the spring $\left(F_{1,64}=13.23, p<0.001\right.$; Figure 8$)$ but not in the fall $\left(\mathrm{F}_{1,64}=0.36, \mathrm{p}>0.50\right)$. Woody species cover class decreased in both fenced plots that were protected early $(\bar{x}=-0.021 \pm 0.014)$ and late $(\bar{x}=-0.031 \pm 0.016)$. However, woody species increased in control plots associated with fenced plots protected early $(\bar{x}=0.024 \pm 0.014)$. Woody species cover class increased in both fenced plots that are protected continuously $(\bar{x}=0.020 \pm 0.031)$ and the associated control $(\bar{x}=0.025 \pm 0.005)$ plots. There were no significant interactions $(p>0.05)$ between the the fencing period and the fencing treatment in Populus spp. communities. There was no significant difference in mean change based on wetland indicator class for data collected from plots protected late in the year when data was collected in the spring $\left(\chi^{2}{ }_{5}=2.01, \mathrm{p}=0.8475\right)$, and from plots protected continuously when data were gathered in the spring $\left(\chi^{2}{ }_{5}=3.55, \mathrm{p}=0.6157\right.$, Table 4$)$.

\section{Discussion}

We tested the null that overall species richness would would not change with protection from browsing. We found that this was the case for both Solidago spp.-Rubus hispidus communities and regenerating Populus spp. stands. Other studies (Stromayer and Warren 1997; Holmes et al. 2008; Jensen et al. 2011; Levine et al. 2012) have found similar results when measuring species richness and have attributed the absence of change to a balance between an increasing number of graminoid species and a decreasing number of forb and woody species. We did not expect a decrease in species richness in unfenced areas because of a history of high deer densities in the study area. Rather, we expected to see an increase in woody and forb 
species and a resulting decline in graminoid species after establishing exclosures. We did not find a significant difference in the change in graminoid species cover between fenced and control plots suggesting that we cannot attribute an overall similarity in species richness to a balance between increasing forb and woody species and declining graminoid species. However, we did observe a decline in graminoid species cover in most plots (Figs. $5-8$ ). The fact that this is not reflected in species richness may be because a single individual recorded in a plot would increase species richness but would likely not impact the percent cover of that species as was the case with many woody seedlings identified by a single individual in the plot such as the lone red maple (Acer rubrum) seedling recorded in the Solidago spp.-Rubus hispidus communities.

We found that there were changes in community composition in both Solidago spp.Rubus hispidus and regenerating Populus spp. communities but not under all treatment regimes. We also found that overall community composition was different between plots protected both continuously and in the spring when we gathered the data in the spring but only in late plots for data gathered in the fall. In Populus spp. stands, we found that there was a difference in communities in late protected plots and continuously protected plots when data were gathered in the spring. As we planned these exclosures specifically around Populus spp., we might be tempted to attribute these differences specifically to woody species. We did not see a difference in plots protected in the spring. When we focused specifically on woody species, we found that there was a decrease in woody species in these plots and, in fact, the woody species increased in the associated control plots. We did find that woody species increased in plots protected continuously. However, they also increased in the associated control plots. Randall and Walters (2011) found that, in clear-cut Populus spp. stands, high levels of deer browse would likely reduce the growth of other woody species. Loss of woody species at the seedling and sapling 
stages as a result of deer browse has the potential to affect the over-story community trajectory for years to come.

The changes in forb cover in Populus spp. communities were not straightforward and interpretations differed based on when data were collected. When collected in the spring, increases (for spring protected plots) and decreases (for late protected plots) were similar for the treatment and control plots. An increase in forb species in plots protected in the spring would support the idea that forbs are especially susceptible to white-tailed deer browse when new growth appears in the spring. However, a similar response in the control plots was not expected. Likewise, an average decline in forb species was not expected in late plots as the spring browse pressure should not have differed from pre-fencing conditions. Several authors have attributed similar results to "fenceline effects" that result from control plots located next to exclosures. These "fenceline effects" also might bias the results toward the extreme because of higher rates of deer herbivory immediately surrounding the exclosures (Russell et al. 2001, Comisky et al. 2005). The Populus spp. regeneration cuts themselves may have attracted deer from the surrounding herbaceous wetland areas (Barrett and Stiling 2006). However, it is more likely that similarity between treatment and control plots resulted from the effects of canopy removal on these communities. These changes may have masked any potential impacts resulting from elimination of browse. Likewise, the increased availability of Populus spp. to deer may have reduced browse pressure on other species.

Although we considered more than the frequency of Populus spp. when measuring the woody species in Populus spp. dominated communities, they were the most abundant woody species within these plots. The growth rate of Populus spp. saplings following harvest may have impacted our results. The fencing used for exclosures was only $99 \mathrm{~cm}$ tall. Regenerating 
Populus spp. saplings grew higher than the exclosures within their first year of growth whereas other seedlings and saplings would have been better protected by the fence. Although the saplings were not completely protected from browse, they may have been less susceptible to browse than those growing in unfenced control plots.

In Solidago spp.-Rubus hispidus communities, our data agree with the null hypothesis of no change in species richness in treatment plots when compared to control plots. When we gathered data in the fall, plots that were continuously protected increased in woody species more so than other treatment plots. We might expect to see an increase in woody species in these plots; however, we would also expect to see a difference from the associated control plots. Also, we saw a greater increase in woody species in control plots associated with other fencing treatments. These results might be explained by the low frequency of woody species initially found in this community. Low woody species frequency may be a result of historical alterations to the vegetation and soils of the area or might be a result of long-term exposure to high-deer densities (Beschta and Ripple 2009; Chaideftou et al. 2011).

Forb species composition in Solidago spp.-Rubus hispidus communities increased in spring-protected plots and continuously-protected plots. We also saw a simultaneous decrease in graminoid species in the same plots; however, this difference was not considered statistically significant. Studies have found that high-density white-tailed deer populations tend to reduce forb cover and increase the less-preferred graminoid species (Thiemann et al. 2009; Goetsch et al. 2011; Urbanek et al. 2012a; Urbanek et al. 2012b). These results suggest that the trend can be reversed with protection from deer browse. Additionally, the lack of change in late protected plots suggests that timing of browse does make a difference in forb species composition. Merrill 
et al. (2003) determined that a reduction in graminoid cover resulted from an increase in woody shrub cover.

Our results suggest that protection from deer browse does not favor either wetland or upland plants. We found that there was not a significant difference in the average change between wetland plant indicator status categories though individual species may have increased or decreased. Thus, a reduction in deer density would not likely shift community composition away from wetland species. Conversely, while high deer densities may negatively impact individual species, they do not tend to reduce overall wetland plant cover.

White-tailed deer exclosure studies used to measure the impacts of deer herbivory on plant populations have been criticized for a variety of reasons. Nonrandom location of study plots in areas of high deer density may bias the results toward greater impacts of herbivory (Russell et al. 2001). Many exclosure studies are criticized for small sample size (Russell et al. 2001) resulting from the difficulty and expense of building and maintaining large exclosures (Kirschbaum and Anacker 2005). Lastly, exclosure studies generally provide results from two extremes; no deer or high deer densities. Neither of these scenarios are a natural management goal for white-tailed deer populations (Russell et al. 2001). Studies of deer enclosures, while much more expensive and difficult to maintain, may provide insight in effects at multiple deer densities (deCalesta 1994).

Our study of deer exclusion plots in Canaan Valley attempted to remedy some of these problems through study design. We used smaller exclosures that were easier and less expensive to build and transport into wetland areas. This allowed us to increase the sample size beyond some limited exclosure studies of the past. However, the small exclosure size may not have been sufficient in Populus spp. regeneration cuts as the fence was not tall enough to completely 
protect the fast growing Populus spp. saplings (Westell 1954). Although deer were not able to affect herbaceous cover within these exclosures, impacts to Populus spp. growth may have influenced microhabitat characteristics that affect understory growth. More fenced plots also allowed us to investigate the effects of timing on herbivory. Periodic removal of exclosures helped us to address the failure of exclosure studies to simulate management regimes that include some deer herbivory.

Rooney and Waller (2003) increased exclosure sample size to survey rare forest herbaceous species. We also had a relatively large sample size compared to other exclosure studies; however, we randomly located plots within our study sites. Although this prevented bias in selecting areas of high or low deer herbivory and allowed us to examine the community composition as a whole, we were not able to examine the effect of herbivory on specific rare plant species.

Several authors have used natural refugia such as boulders or island isolation to study the impact of deer on plant communities without the effects of artificial exclosures (Balgooyen and Waller 1995; Rooney 1997; Comisky et al. 2005). This type of study was not possible in the Solidago spp.-Rubus hispidus of Canaan Valley because of the open nature of such herbaceous wet-meadow communities. Future study of the regeneration of woody plant communities such as the Populus spp. cuts examined here could benefit from a cutting plan designed to create "exclosure" that mimic natural phenomena.

An extended study period may allow for additional change in community composition and differentiation. Other studies have found higher species richness within exclosures $>4$ years after initiation (Holmes et al. 2008; Pellerin et al. 2010; Duguay and Farfaras 2011; Holmes and Webster 2011; Urbanek et al. 2012b). However, Rutherford and Schmitz (2010) found that deer 
may not impact richness and abundance of plant species, in part, because historical deer densities may have limited the number of palatable species. Anecdotal observation of control and treatment plots in 2008, suggest a difference in species cover between treatment plots and surrounding vegetation community that may not be measurable with percent cover estimates. Though stem count methods are tedious and often prohibitive in herbaceous community studies, percent cover estimates may be too subjective to detect differences in species cover and community composition over short time periods. Other methods of quantification should be examined for future studies.

\section{Conclusion}

Historically, the red spruce climax community that covered Canaan Valley likely supported lower white-tailed deer densities than are present today. The herbaceous wet-meadow communities in Canaan Valley today increase the availability of forage during the spring and summer and may increase the carrying capacity from historical densities. However, our study suggests, that the elevated deer densities present in the post-logging era impact the herbaceous community by selectively browsing forb species, especially in the spring. Suppression of woody species through selective browsing may play a role in suppressing succession to the historical spruce communites.

Our study indicates that timing of herbivory may be a factor in the impact of white-tailed deer browse on some species. However, protecting wetland communities seasonally should not be considered a time or cost effective measure to increase the frequency of wetland species. On a small scale, these exclosures were not difficult to move periodically; however, there is likely no incentive to employ seasonal exclosures in place of continuous protection (Merrill et al. 2003; Clements et al. 2011; DeGroote et al. 2011). Seasonal protection may be more effective on 
individual plants representing threatened or endangered species where yearlong protection may not be appropriate. Our study did not examine the seed bank present at each site. It is unlikely that increased frequency of certain species is a result of seed input from outside sources but rather the reduction of browse in species already present on site. Levine et al. (2012) found that deer did not alter seed banks but did alter sapling richness. Our results suggest that extended reduction of deer browse through protection of plant communities may alter the trajectory of these communities toward a community with more woody cover.

\section{Acknowledgments}

We thank Canaan Valley Institute for providing the funding for this research. We thank Leah Ceperly and Ken Sturm for help in locating plant communities in Canaan Valley. We thank the staff of Canaan Valley National Wildlife Refuge as well as field assistants LeAnne Bonner, Jason Love, Joe Osbourne, Ryan Ward, and Walter Veselka for assistance in constructing fenced exclosures and evaluating plant communities. This is scientific article number $\operatorname{xxxx}$ of the West Virginia University Agricultural and Forestry Experiment Station.

\section{Literature Cited}

Alverson WS, Waller DM (1997) Deer populations and the widespread failure of hemlock regeneration in northern forests. In: McShea, WJ, Underwood, HB, Rappole, JH. (eds). The science of overabundance: deer ecology and population management. Smithsonian Institution Press. Washington D.C., pp 280-297

Anderson RC, Corbett EA, Anderson MR, Corbett GA, Kelley TM (2001) High white-tailed deer density has negative impact on tallgrass prairie forbs. Journal of the Torrey Botanical Society 128:381-392

Anderson RC, Loucks OL (1979) White-tailed deer influence on structure and 
composition of Tsuga canadensis forests. Journal of Applied Ecology 16:855-861

Augustine DJ, McNaughton SJ (1998) Ungulate effects on the functional species composition of plant communities: herbivore selectivity and plant tolerance. Journal of Wildlife Management 62:1165-1183

Balgooyen CP, Waller DM (1995) The use of Clintonia borealis and other indicators to gauge impacts of white-tailed deer on plant communities in northern Wisconsin, USA. Natural Areas Journal 15:308-318

Barrett MA, Stiling P (2006) Key deer impacts on hardwood hammocks near urban areas. Journal of Wildlife Management 70:1574-1579

Beschta RL, Ripple WJ (2009) Large predators and trophic cascades in terrestrial ecosystems of the western United States. Biological Conservation 142:2401-2414

Beverage W (1967) Soil survey, Tucker County, West Virginia. United States Department of Agriculture. USDA Soil Conservation Service, Washington D.C. USA

Brookshire ENJ, Kauffman JB, Lytjen D, Otting N (2002) Cumulative effects of wild ungulate and livestock herbivory on riparian willows. Oecologica 132:559-566

Chaideftou E, Thanos CA, Bergmeier E, Kallimanis AS, Dimopoulos P (2011) The herb layer restoration potential of the soil seed bank in an overgrazed oak forest. Journal of Biological Research 15:47-57

Cherefko C, Fridley C, Medsger J, Woody M, Anderson JT (2009) Impacts of whitetailed deer and balsam wooly adelgid on balsam fir in Canaan Valley. In: Canaan Valley and its Environs: A Landscape Heritage Celebration. Canaan Valley Institute, Davis, WV. 
Cipollini KA, Cipollini D (2011) Habitat assessment and conservation status of endangered northeastern bulrush. Northeastern Naturalist 18:275-291

Clements DA, Lugenbill S, Jordan DA, Van Dragt R, Pelant RK (2011) Techniques to promote garry oak seedling growth and survival in areas with high levels of herbivory and competition. Northwest Science 85:172-181

Comisky L, Royo AA, Carson WP (2005) Deer browsing creates rock refugia gardens on large boulders in the Allegheny National Forest, Pennsylvania. American Midland Naturalist 154:201-206

Daubenmire R (1959) A canopy-coverage method of vegetational analysis. Northwest Science $33: 43-64$

deCalesta DS (1994) Effect of white-tailed deer on songbirds within managed forests in Pennsylvania. Journal of Wildlife Management 58:711-718

DeGroote LW, Ober HK, Aldrich JH, Norcini JG, and Knox GW (2011) Susceptibility of cultivated native wildflowers to deer damage. Southeastern Naturalist 10:671-771

Duguay JP, Farfaras C (2011) Overabundant suburban deer, invertebrates, and the spread of an invasive exotic plants. Wildlife Society Bulletin 35:243-251

Fletcher JD, Shipley LA, McShea WJ, Shumway DL (2001) Wildlife herbivory and rare plants: the effects off white-tailed deer, rodents, and insects on growth and survival of Turk's cap lily. Biological Conservation 101:229-238

Fortney RH (1975) The vegetation of Canaan Valley, West Virginia: a taxonomic and ecological study. Dissertation; West Virginia University, Morgantown, West Virginia, USA

Goetsch C, Wigg J, Royo AA, Ristau T, Carson WP (2011) Chronic overbrowsing and 
biodiversity collapse in a forest understory in Pennsylvania: results from a 60 year-old deer exclusion plot. Journal of the Torrey Botanical Society 138:220-224

Gregg KB (2004) Recovery of showy lady's slippers (Cypripedium reginae Walter) from moderate to severe herbivory by white-tailed deer (Odocoileus virginianus Zimmerman). Natural Areas Journal 24:232-241

Healy WM (1997) Influence of deer on the structure and composition of oak forests in central Massachusetts. In: McShea, WJ, Underwood, HB, Rappole, JH. (eds). The science of overabundance: deer ecology and population management. Smithsonian Institution Press. Washington D.C., pp 249-266

Holmes SA, Curran LM, Hall KR (2008) White-tailed deer (Odocoileus virginianus) alter the herbaceous species richness in the Hiawatha National Forest, Michigan, USA. American Midland Naturalist 159:83-97

Holmes SA, Webster CR (2011) Herbivore-induced expansion of generalist species as a driver of homogenization in post-disturbance plant communities. Plant Ecology 212:753-768

Jensen NR, Webster CR, Witt JC, Grant JB (2011) Ungulate winter habitat selection as a driver of herbaceous-layer heterogeneity in northern temperate forests. Ecosphere 3:1-16

Kirschbaum CD, Anacker BL (2005) The utility of Trillium and Maianthemum as phytoindicators of deer impact in northwestern Pennsylvania, USA, Forest Ecology and Management 217:54-66

Knight TA, Dunn JL, Smith LA, Davis J, Kalisz S (2009) Deer facilitate invasive plant success in a Pennsylvania forest understory. Natural Areas Journal 29:110-116 
Koda R, Fujita N (2011) Is deer herbivory directly proportional to deer population density? Comparison of deer feeding frequencies among six forests with different deer density. Forest Ecology and Management 262:432-439

Leege LM, Thompson JS, Paris DJ (2010) The responses of rare and common trilliums (Trillium reliquum, T. cuneatum, and T. maculatum) to herbivory and invasive honeysuckle removal. Castanea 75:433-443

Lefcort H, Pettoello CL (2012) White-tailed deer trails are associated with the spread of exotic forbs. Natural Areas Journal 32:159-165

Levine CR, Winchcombe RJ, Canham CD, Christenson LM, Ronsheim ML (2012) Deer impacts on seed banks and saplings in eastern New York. Northeastern Naturalist 19:49-66

Lichvar, RW, Butterwick M, Melvin NC, Kirchner WN (2014) The national wetland plant list: 2014 update of wetland plant ratings. Phytoneuron 41:1-42

Loeffler CC, Wegner BC (2000) Demographics and deer browsing in three Pennsylvania populations of the globally rare glade spurge, Euphorbia purpurea, fern. Castanea 65: $273-290$

McCune B, Mefford R (1999) PC-Ord. Multivariate analysis of ecological data, version 4. MjM Software Design, Gleneden Bearch, OR, USA

McCune B, Grace JB, Urban DL (2002) Analysis of ecological communities. MjM Software Design, Gleneden Bearch, OR, USA

McGraw JB, Furedi MA (2005) Deer browsing and population viability of a forest understory plant. Science 307:920-922

Merrill HL, Beyer Hl, Jones GP, McDaniel GW (2003) Deciduous woodland conservation under 
heavy deer browsing on Devils Tower National Monument, USA. Journal for Nature Conservation 10:221-232

Michael ED (1992) Impact of deer browsing on regeneration of balsam fir in Canaan Valley, West Virginia. Northern Journal of Applied Forestry 9:89-90

Miller SG, Bratton SP, Hadidian J (1992) Impacts of white-tailed deer on endangered and threatened vascular plants. Natural Areas Journal 12:67-74

Opperman JJ, Merenlender AM (2000) Deer herbivory as an ecological constraint to restoration of degraded riparian corridors. Restoration Ecology 8:41-47

Peek, LJ, JF Stahl (1997) Deer management techniques employed by the Columbus and Franklin county park district, Ohio. Wildlife Society Bulletin 25:440-442

Pellerin M, Said S, Richard E, Hamaan JL, Dubois-Coli C, Hum P (2010) Impact of deer on temperate forest vegetation and woody debris as protection of forest regeneration against browsing. Forest Ecology and Management 260:429-437

Randall JA, Walters MB (2011) Deer density effects on vegetation in aspen forest understories over site productivity and stand age gradients. Forest Ecology and Management 261:408-415

Rooney TP (1997) Escaping herbivory: refuge effects on the morphology and shoot demography of the clonal forest herb, Maianthemum canadense. Journal of the Torrey Botanical Society 124:280-285

Rooney TP (2009) High white-tailed deer densities benefit graminoids and contribute to biotic homogenization of forest ground-layer vegetation. Plant Ecology 202:103-111

Rooney TP, Waller DM (2003) Direct and indirect effects of white-tailed deer in forest ecosystems. Forest Ecology and Management 181:165-176 
Russell FL, Zippin DB, Fowler NL (2001) Effects of white-tailed deer (Odocoileus virginianus) on plants, plant populations and communities: a review. American Midland Naturalist 146:1-26

Rutherford AC, Schmitz OJ (2010) Regional scale assessment of deer impacts on vegetation within western Connecticut, USA. Journal of Wildlife Management 74: $1257-1263$

Stephenson SL (1993) Upland forests of West Virginia. McClain Printing Company. Parsons, West Virginia, USA

Stewart CM, Van Deelen TR, Dawson JO (2008) Autumn herbivory by white-tailed deer and nutrient loss in planted seedlings. American Midland Naturalist 160:342-349

Stromayer KAK, Warren RJ (1997) Are over abundant deer herds in the eastern United States creating alternate stable states in forest plant communities. Wildlife Society Bulletin 25:227-234

Tanentzap, AJ, Bazely DR, Koh S, Timciska M, Haggith E, Carleton TJ, Coomes DA (2011) Seeing the forest for the deer: do reductions in deer-disturbance lead to forest recovery. Biological Conservation 144:376-382

Tanzentap AJ, Kirby KJ, Goldberg E (2012) Slow responses of ecosystems to reductions in deer (Cervidae) populations and strategies for recovery. Forest Ecology and Management 264:159-166

Thiemann JA, Webster CR, Jenkins MA, Hurley PM, Rock JH, White PH (2009) Herbaceous-layer impoverishment in a post-agricultural southern Appalachian landscape. American Midland Naturalist 162:148-168

Tremblay J, Huot J, Potvin F (2007) Density-related effects of deer browsing on the 
regeneration dynamics of boreal forests. Journal of Applied Ecology 44:552-562

Urbanek RE, Nielsen C.K., Glowacki GA, Preuss TS (2012a) Effects of white-tailed deer (Odocoileus virginianus Zimm.) herbivory in restored forest and savanna plant communities. American Midland Naturalist 167:240-255

Urbanek RE, Nielsen CK, Glowacki GA, Preuss TS (2012b) White-tailed deer (Odocoileus virginianus Zimm.) herbivory in herbaceous plant communities in Illinois. Natural Areas Journal 32:6-14

Westell CE (1954) Available browse following aspen logging in lower Michigan. Journal of Wildlife Management 18:266-271

White MA (2012) Long-term effects of deer browsing: composition, structure and productivity in a northeastern Minnesota old-growth forest. Forest Ecology and Management 269:222-228

Whitney GG (1984) Fifty years of change in the arboreal vegetation of Heart's Content, an old growth hemlock-white pine - northern hardwood stand. Ecology 65:403-408

Windels SK, Jordan PA (2008) Winter use of senescent herbaceous plants by white-tailed deer in Minnesota. American Midland Naturalist 160:253-258 
Table 1. Blocked Multiple Response Permutation Procedure (MRBP) tests of plant community composition differences between fenced and unfenced plots in Canaan Valley, WV from 2005 - 2007 grouped by period of protection and time of data collection. The T-statistic (T) describes the difference between selected groups. The $\mathrm{p}$-value (p) describes the likelihood of reaching the observed T-statistic. The A-statistic (A) describes within group homogeneity compared to what is expected by chance. Bold text indicates significant differences $(\mathrm{P}<0.05)$.

\begin{tabular}{|c|c|c|c|c|c|c|c|c|c|c|}
\hline & \multirow{2}{*}{$\begin{array}{c}\text { Monitoring } \\
\text { Period }\end{array}$} & \multicolumn{3}{|c|}{ Early } & \multicolumn{3}{|c|}{ Late } & \multicolumn{3}{|c|}{ Continuous } \\
\hline & & $\mathrm{T}$ & $\mathrm{P}$ & A & $\mathrm{T}$ & $\mathrm{P}$ & A & $\mathrm{T}$ & $\mathrm{P}$ & A \\
\hline $\begin{array}{l}\text { Solidago spp.-Rubus } \\
\text { hispidus }\end{array}$ & Fall & -1.635 & 0.066 & 0.027 & -4.547 & 0.002 & 0.010 & -0.863 & 0.181 & 0.019 \\
\hline $\begin{array}{l}\text { Solidago spp.-Rubus } \\
\text { hispidus }\end{array}$ & Spring & -3.474 & 0.004 & 0.071 & -0.192 & 0.400 & 0.003 & -2.386 & 0.026 & 0.055 \\
\hline Populus spp. & Fall & -0.516 & 0.258 & 0.027 & 0.490 & 0.673 & -0.026 & -1.282 & 0.107 & 0.064 \\
\hline Populus spp. & Spring & -1.340 & 0.087 & 0.076 & -2.1013 & 0.038 & 0.116 & -2.0775 & 0.039 & 0.073 \\
\hline
\end{tabular}


Table 2. Species displaying the largest changes within fenced plots in Solidago spp. - Rubus hispidus communities in Canaan Valley, WV. Mean values represent the difference in percent cover based on the midpoint of cover class categories between 2005 and 2007 . A positive value indicates higher percent coverage in 2007. Negative values indicate lower percent coverage in 2007 than 2005. Blank values indicate no change recorded for that monitoring period. Wetland Indicator Status was recorded from the 2014 Army Corps of Engineers National Wetland Plant List.

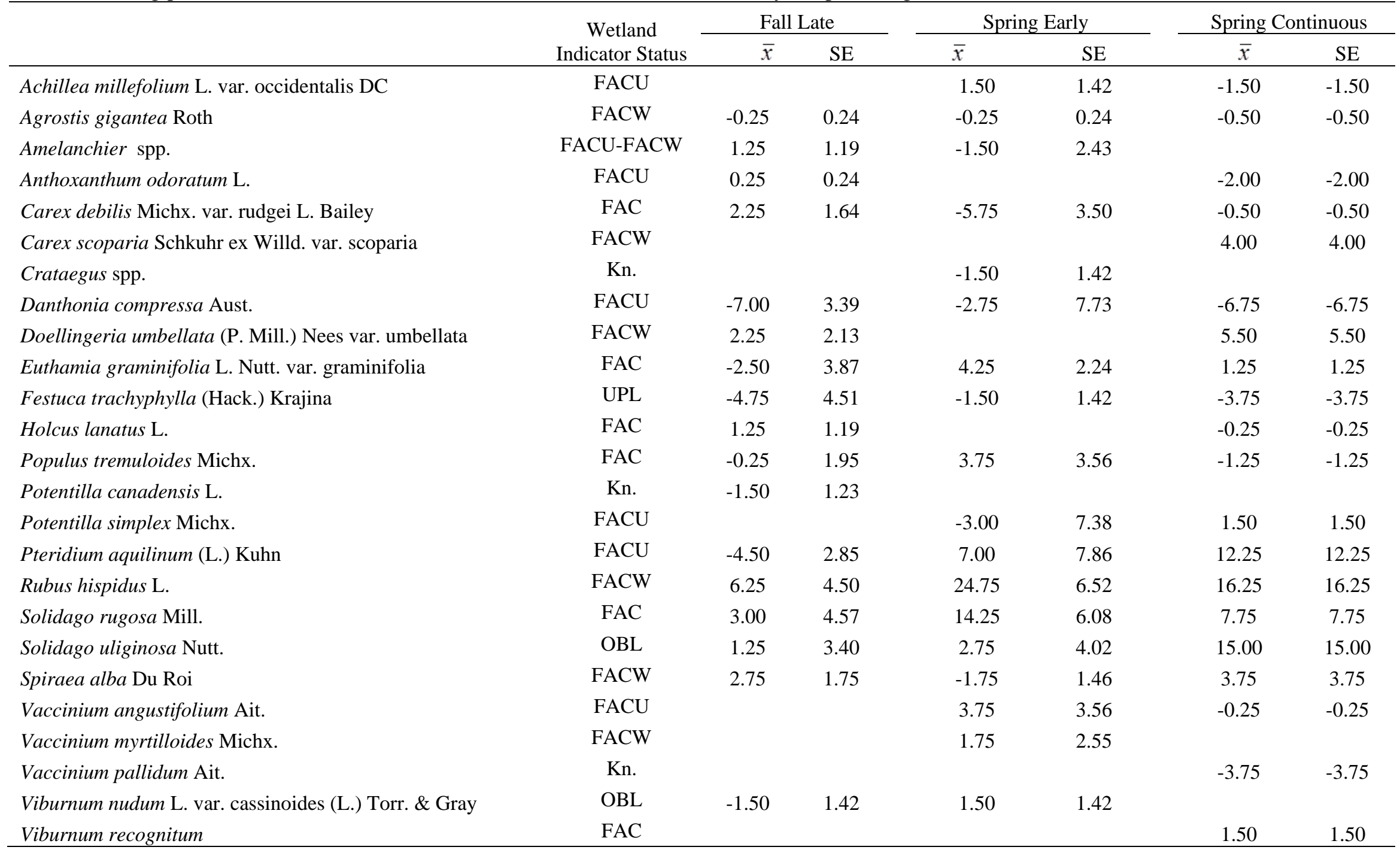


Table 3. Species displaying the largest changes within fenced plots in Populus spp. communities in Canaan Valley, WV. Mean values represent the difference in percent cover between 2005 and 2007. A positive value indicates higher percent coverage in 2005. Negative values indicate lower percent coverage in 2007 than 2005. Blank values indicate no change recorded for that monitoring period.

\begin{tabular}{|c|c|c|c|c|c|}
\hline & \multirow{2}{*}{$\begin{array}{c}\text { Wetland } \\
\text { Indicator Status }\end{array}$} & \multicolumn{2}{|c|}{$\begin{array}{c}\text { Spring } \\
\text { Continuous }\end{array}$} & \multicolumn{2}{|c|}{ Spring Late } \\
\hline & & $\bar{x}$ & SE & $\bar{x}$ & SE \\
\hline Anthoxanthum odoratum $\mathrm{L}$. & FACU & -2.83 & 1.62 & 1.17 & 2.18 \\
\hline Apocynum cannabinum $\mathrm{L}$. & FACU & 1.25 & 1.20 & & \\
\hline Doellingeria umbellata (P. Mill.) Nees & FACW & -4.42 & 4.36 & 2.63 & 1.62 \\
\hline Carex brunnescens (Pers.) Poir. & FACW & 0.83 & 0.34 & & \\
\hline Carex bushii Mack. & FACW & 0.42 & 0.27 & & \\
\hline Carex debilis Michx. var. rudgei L. Bailey & FAC & -1.71 & 1.43 & -0.25 & 0.13 \\
\hline Carex folliculata $\mathrm{L}$ & OBL & -1.04 & 1.00 & & \\
\hline Carex scoparia Schkuhr ex Willd. var. scoparia & FACW & 0.42 & 0.27 & & \\
\hline Carex virescens Muhl ex. Willd. & Kn. & -3.29 & 2.98 & & \\
\hline Crataegeus spp. & Kn. & & & 0.13 & 0.23 \\
\hline Danthonia compressa Aust. & FACU & 1.58 & 1.20 & 0.42 & 0.28 \\
\hline Dichanthelium clandestinum (L.) Gould & FAC & & & 1.42 & 1.16 \\
\hline Euthamia graminifolia L. Nutt. var. graminifolia & FAC & & & 0.13 & 0.23 \\
\hline Glyceria striata (Lam.) Hitchc. & OBL & -1.33 & 1.19 & & \\
\hline Hypericum punctatum Lam. & FAC & -2.50 & 1.61 & & \\
\hline Juncus effusus L. & FACW & 0.33 & 0.29 & & \\
\hline Poa trivialis $\mathrm{L}$. & FACW & & & 0.13 & 0.23 \\
\hline Polygonum sagittatum $\mathrm{L}$. & OBL & & & 0.13 & 0.23 \\
\hline Populus tremuloides Michx. & FAC & 20.17 & 4.03 & -3.63 & 5.27 \\
\hline Potentilla simplex Michx. & FACU & 3.75 & 1.78 & -0.92 & 1.08 \\
\hline Prunus serotina Ehrh.. & FACU & & & -0.08 & 0.08 \\
\hline Pteridium aquilinum (L.) Kuhn & FACU & -2.08 & 1.99 & -1.04 & 1.29 \\
\hline Ranunculus acris L. var. acris & FAC & & & 1.08 & 1.18 \\
\hline Rubus hispidus L. & FACW & 9.58 & 4.12 & 3.25 & 3.03 \\
\hline Solidago rugosa Mill. & FAC & 8.50 & 5.47 & -4.88 & 4.60 \\
\hline Solidago uliginosa Nutt. & OBL & -5.04 & 3.23 & 0.13 & 0.23 \\
\hline Spiraea alba Du Roi & FACW & & & 0.21 & 0.21 \\
\hline
\end{tabular}


Table 4. Number of species within each wetland plant indicator status category showing a change (increase or decrease) in average cover class catergory after two years (2005 -2007) of fencing treatment in Populus spp. and Solidago spp.-Rubus hispidus dominated communities in Canaan Valley, WV. Early and late plots were protected for a portion of the year while continuous plots were protected year-round.

\begin{tabular}{|c|c|c|c|c|c|c|c|c|c|c|}
\hline & \multicolumn{4}{|c|}{ Populus spp. } & \multicolumn{6}{|c|}{ Solidago spp. - Rubus hispidus } \\
\hline & \multicolumn{2}{|c|}{ Continuous } & \multicolumn{2}{|c|}{ Late } & \multicolumn{2}{|c|}{ Continuous } & \multicolumn{2}{|c|}{ Late } & \multicolumn{2}{|c|}{ Early } \\
\hline & Increase & Decrease & Increase & Decrease & Increase & Decrease & Increase & Decrease & Increase & Decrease \\
\hline OBL & 3 & 7 & 3 & 2 & 1 & 0 & 1 & 2 & 2 & 0 \\
\hline FACW & 7 & 6 & 3 & 0 & 3 & 3 & 3 & 1 & 6 & 0 \\
\hline FAC & 4 & 4 & 3 & 3 & 4 & 4 & 5 & 2 & 4 & 2 \\
\hline FACU & 7 & 4 & 4 & 3 & 3 & 4 & 2 & 4 & 3 & 6 \\
\hline UPL & 0 & 0 & 0 & 0 & 0 & 1 & 0 & 1 & 0 & 1 \\
\hline
\end{tabular}




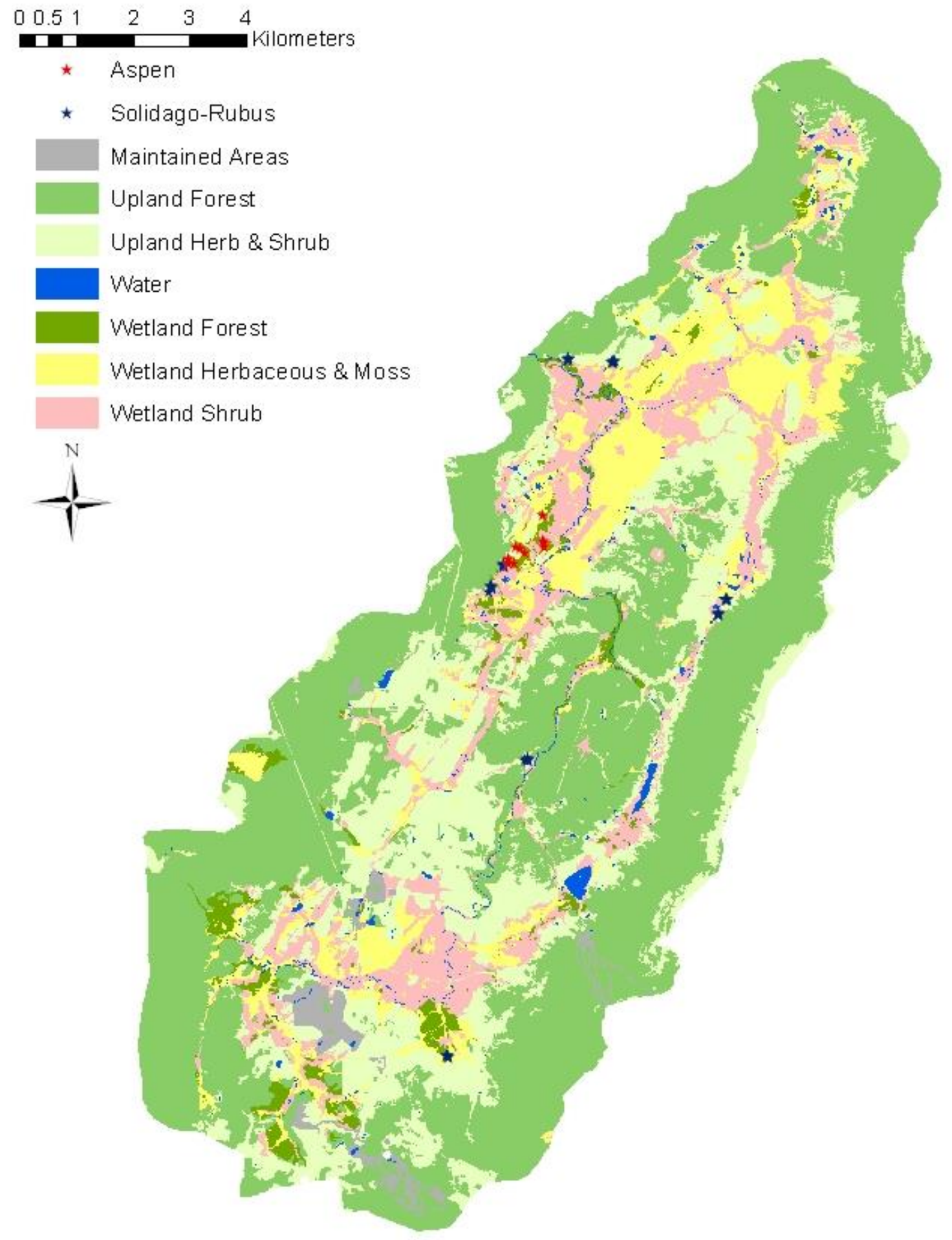

Fig. 1. Map of Canaan Valley, WV with locations of Populus spp. exclosures (red) and Solidago spp.-Rubus hispidus exclosures (blue) that were in place from 2005-2007. 

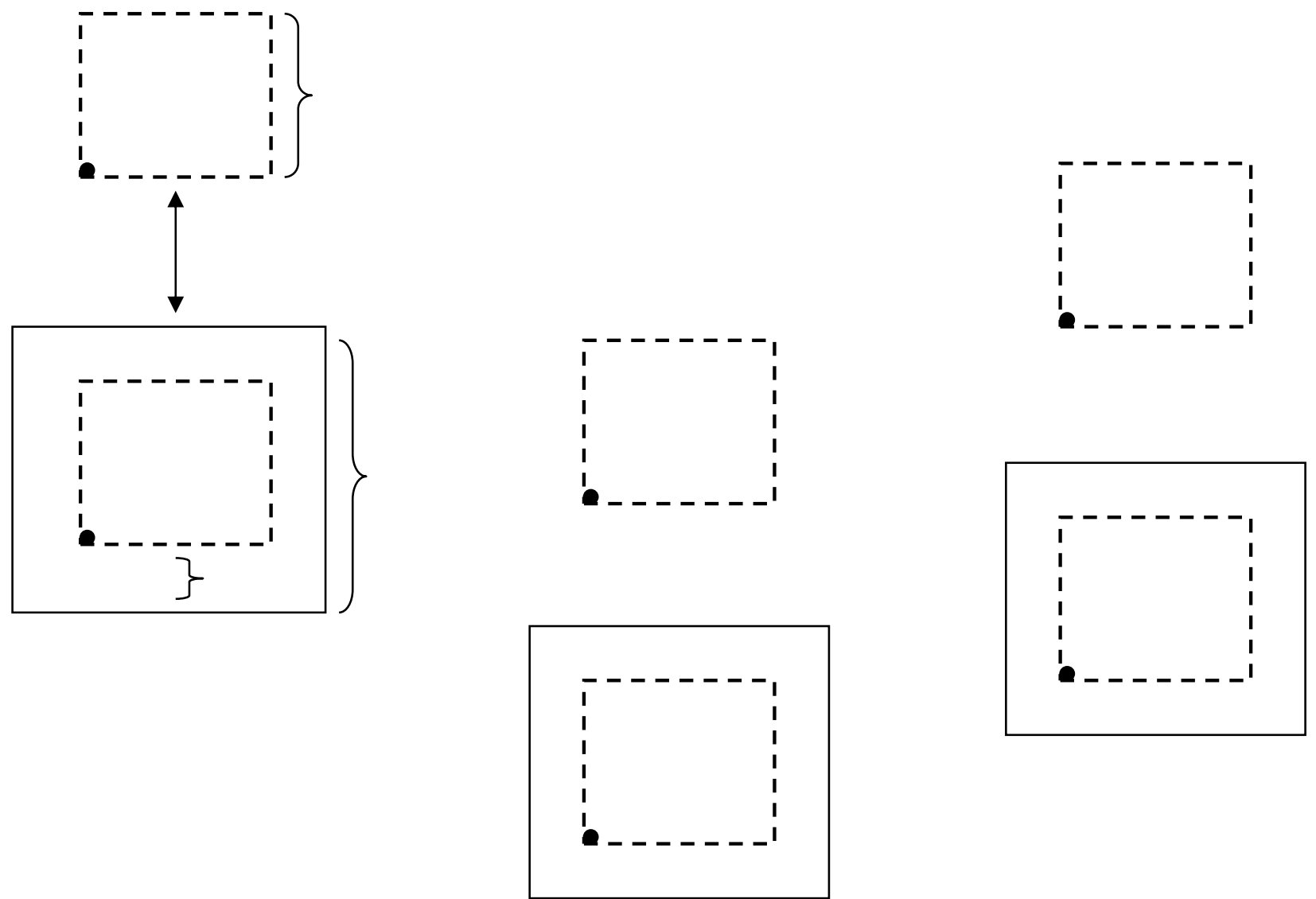

Fig. 2. Plot location within each study site indicating the sizes of exclosures and relative spacing of control plots. Spacing between exclosures is not to scale. Exclosures were constructed in 2005 and removed in 2007. 


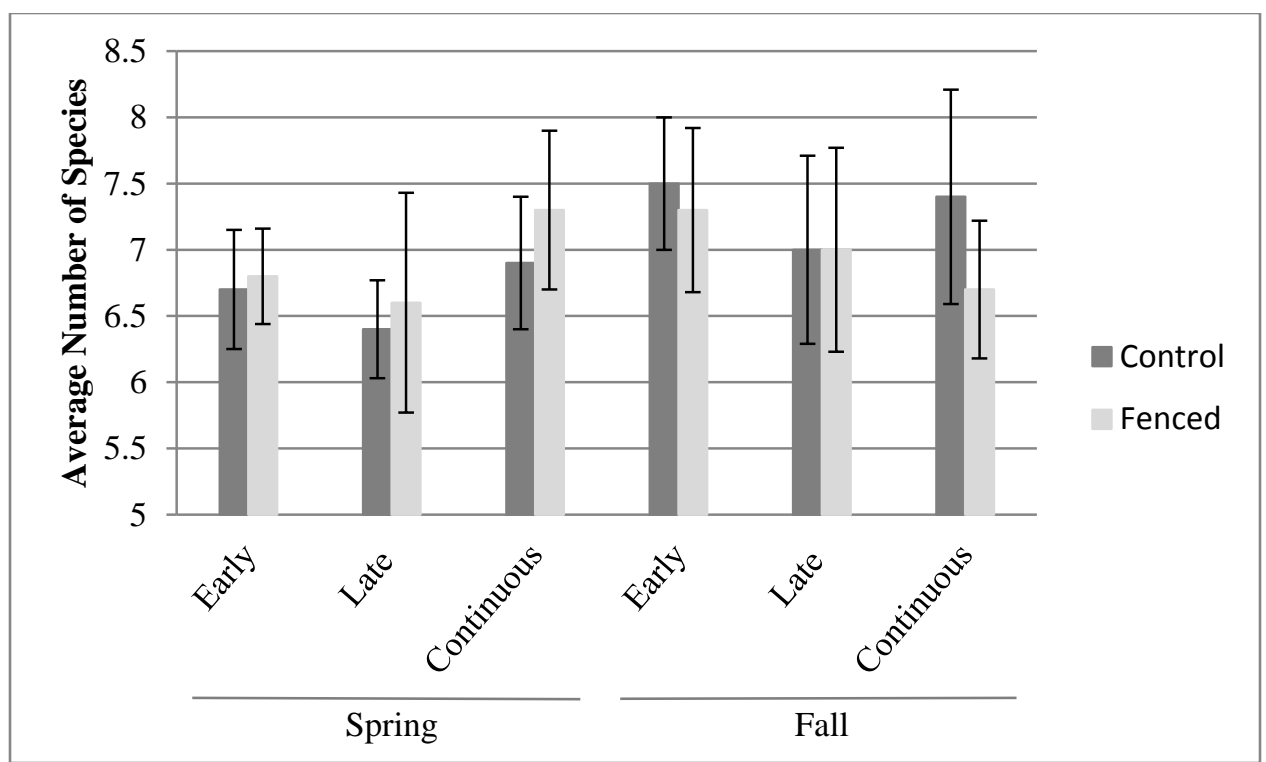

Fig. 3. Average plant species richness in control and fenced plots within Solidago spp.-Rubus hispidus communities in Canaan Valley, WV, from 2005-2007. 


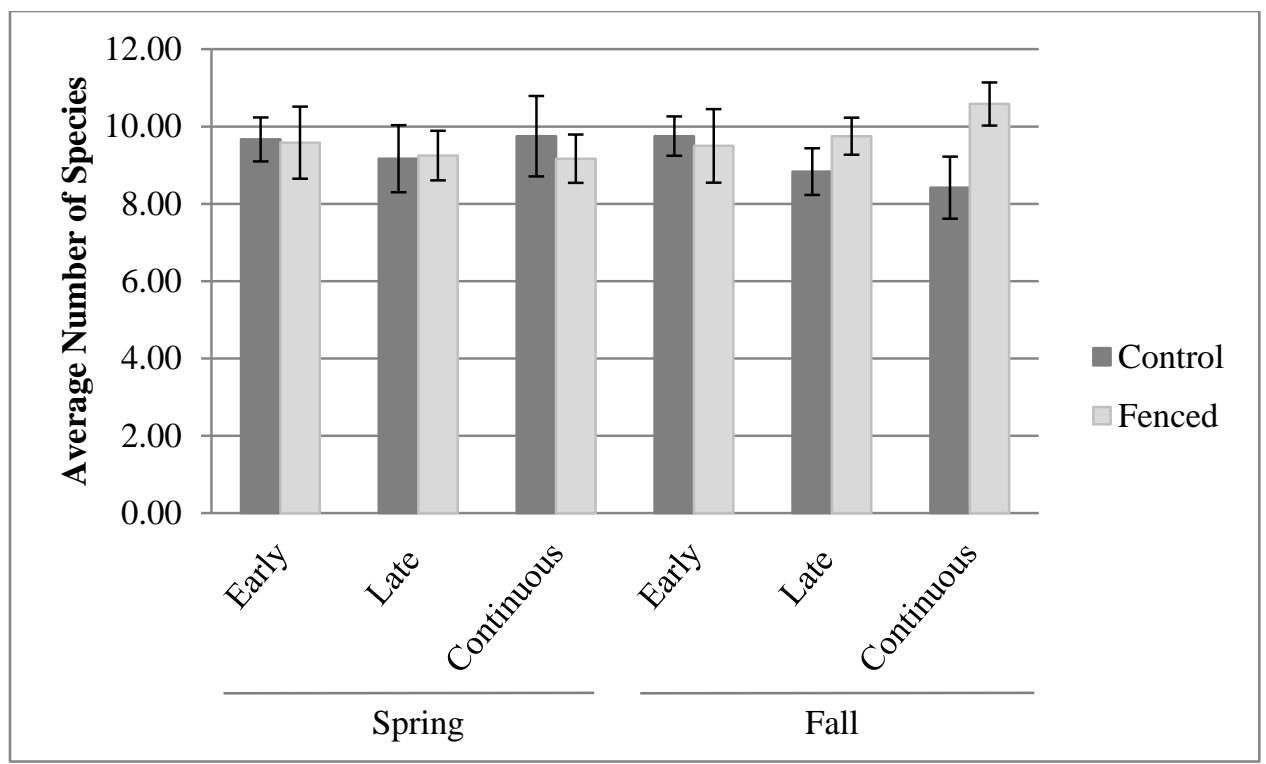

Fig. 4. Average plant species richness in control and fenced plots within Populus spp. regeneration communities in Canaan Valley, WV, from 2005-2007. 


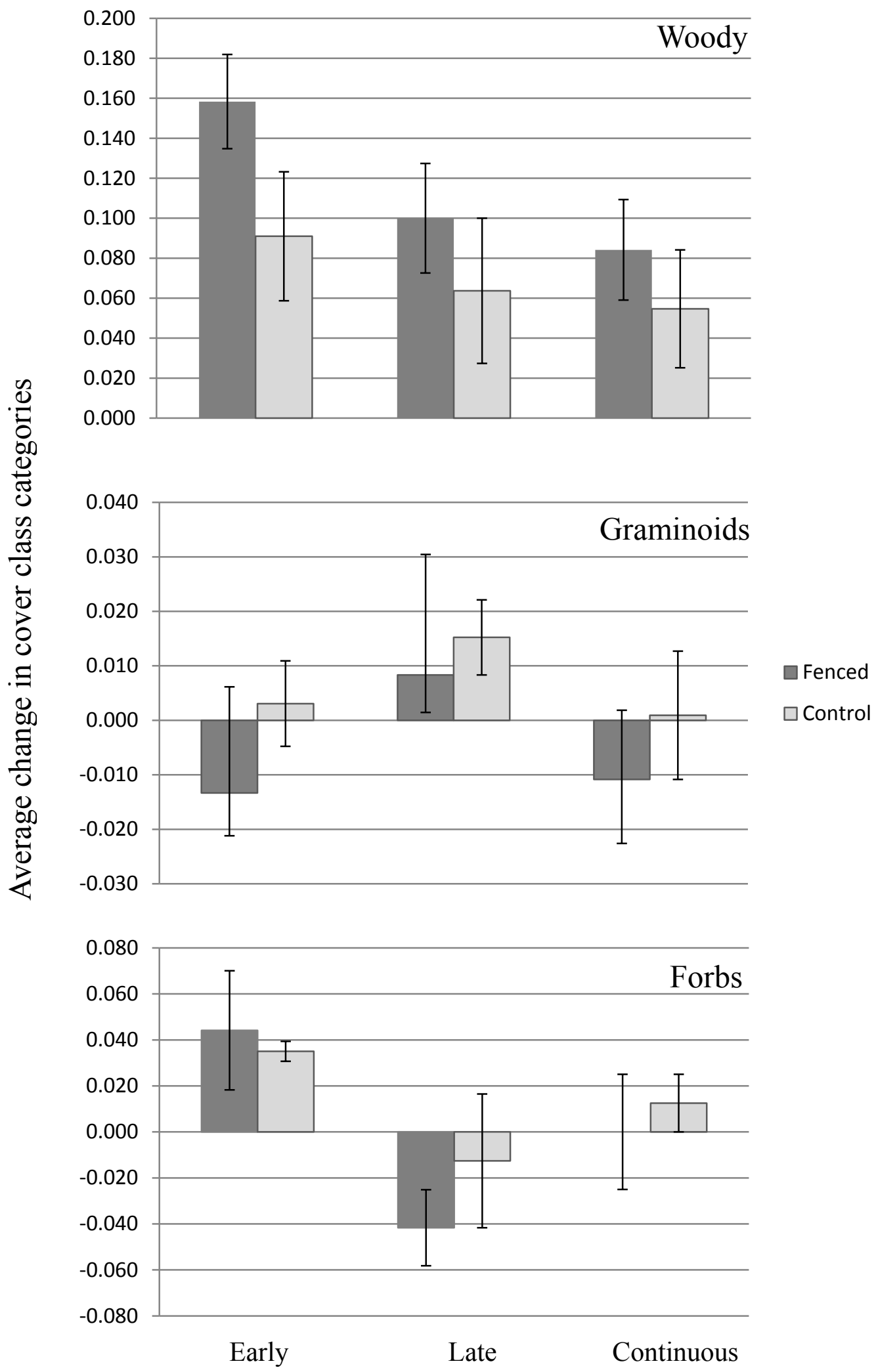

Fig. 5. Average change in cover for forbs, graminoids, and woody species that are protected early, late and continuously in Solidago spp.-Rubus hispidus communities in Canaan Valley, WV, when data were collected in the spring of 2005 through 2007. 


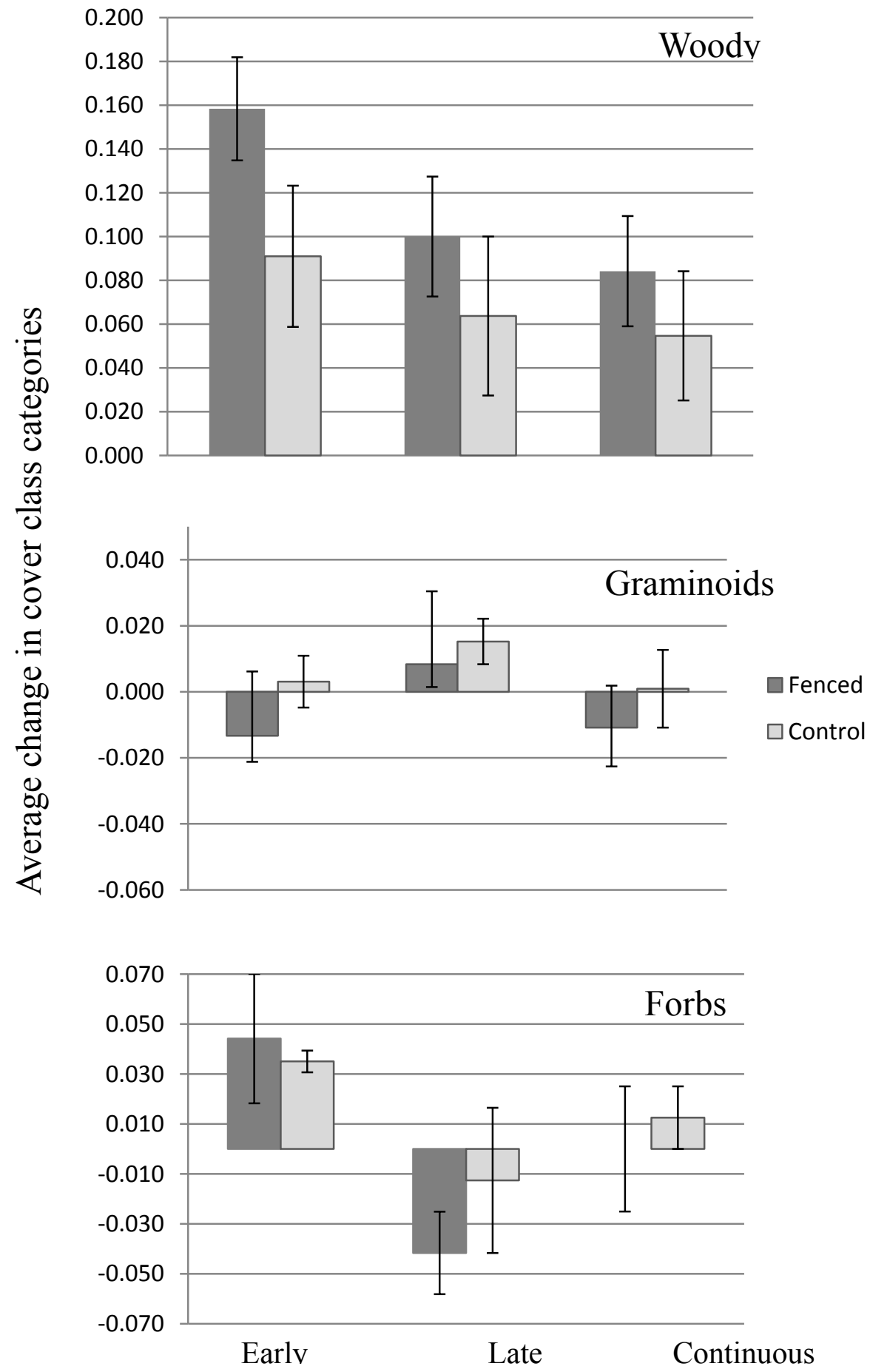

Fig. 6. Average change in cover for forbs, graminoids, and woody species that are protected early, late and continuously in Solidago spp.-Rubus hispidus communities in Canaan Valley, WV, when data were collected in the fall 2005 through 2007. 


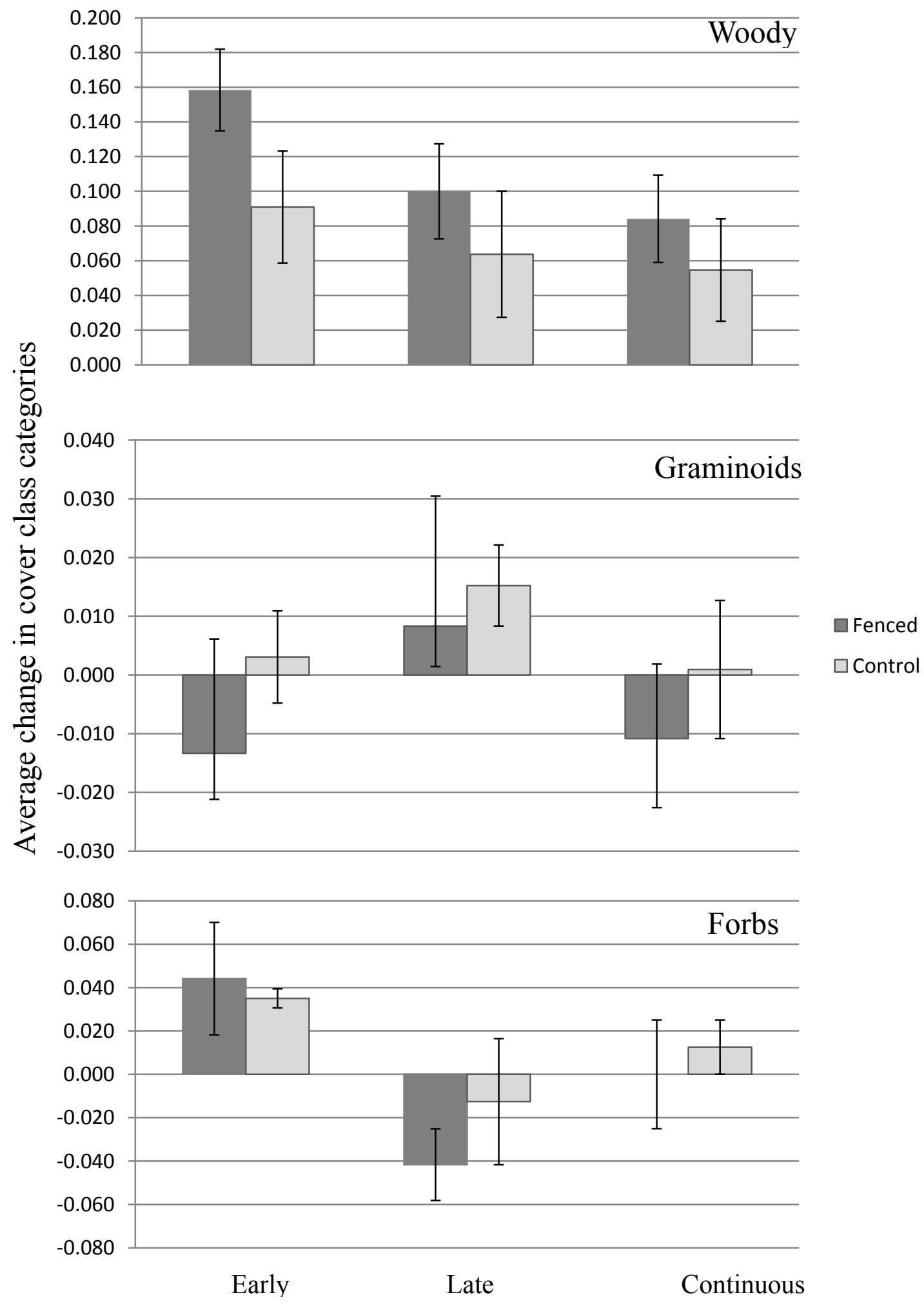

Fig. 7. Average change in cover for forbs, graminoids and woody species that are protected early, late and continuously in Populus spp. regeneration communities in Canaan Valley, WV, when data were collected in the spring of 2005 through 2007. 


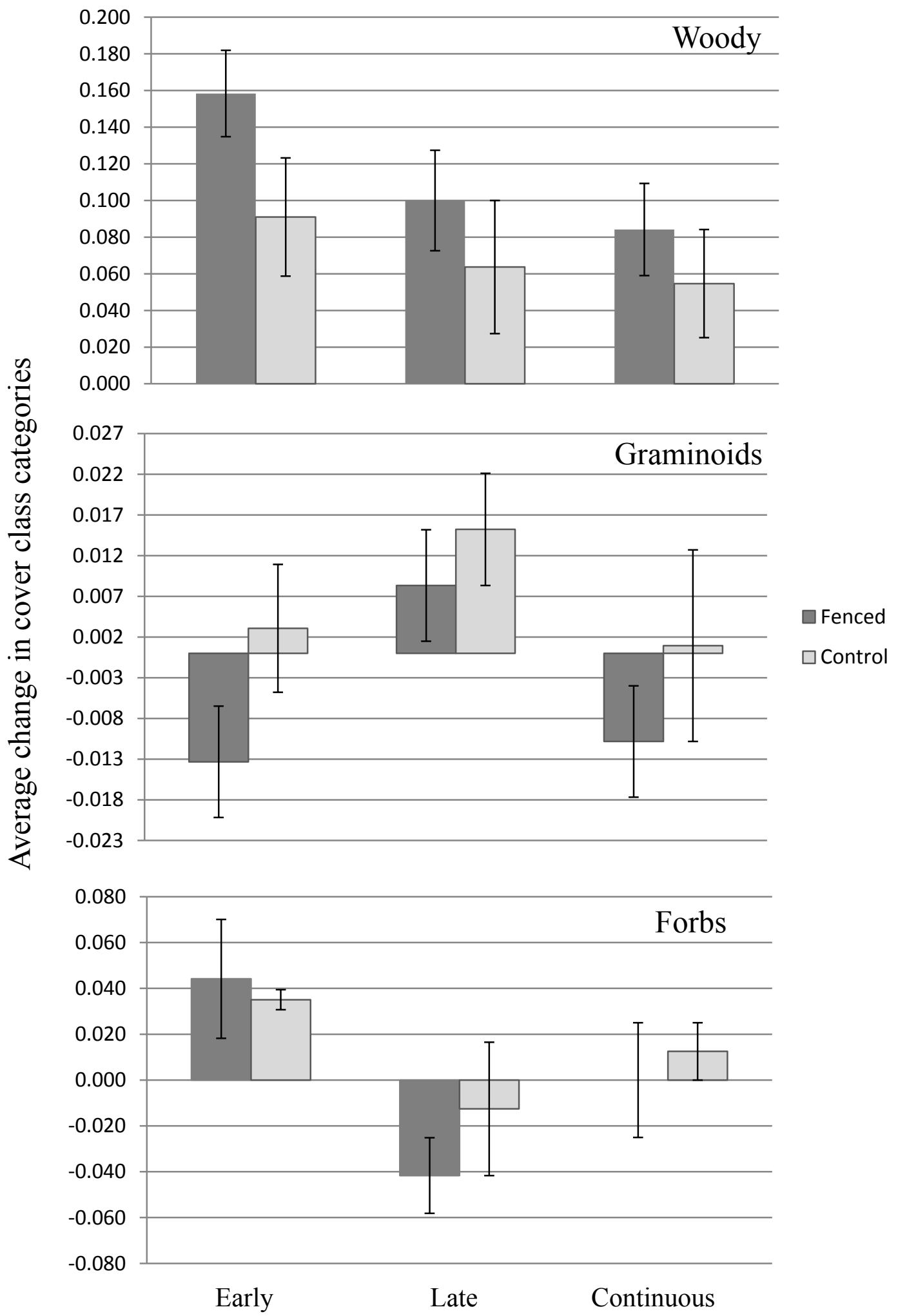

Fig. 8. Average change in cover for forbs, graminoids and woody species that are protected early, late and continuously in Populus spp. regeneration communities in Canaan Valley, WV when data were collected in the fall of 2005 through 2007. 


\title{
CHAPTER IV
}

\section{The Influence of White-tailed Deer on the Structure and Composition of Eastern Deciduous Forest Understory}

\author{
Flaherty, K.L. ${ }^{a^{*}}$, Crum, J.M. ${ }^{\mathrm{b}}$, Anderson, J.T. ${ }^{\mathrm{a}}$ \\ ${ }^{a}$ West Virginia University, Division of Forestry and Natural Resources, P.O. Box 6125, \\ Morgantown, WV 26506
}

${ }^{\mathrm{b}}$ West Virginia Division of Natural Resources, P.O. Box 67. Elkins, WV 26241

*Corresponding author. Department of Biology, 250 University Ave., California, PA 15419 Tel.: +1 724938 5979; fax: +1 724938 1514; E-mail: Flaherty@calu.edu

\begin{abstract}
Browsing by white-tailed deer (Odocoileus virginianus Zimm.) can lead to long-term changes in forest community composition by inhibiting regeneration and changing the forest habitat for understory-dependent wildlife species. We analyzed a 21 - year vegetation data set collected by the West Virginia Division of Natural Resources on randomly selected forest community sites throughout West Virginia from 1984 to 2007. Each site consisted of paired 100 $\mathrm{m}^{2}$ plots; an unfenced control plot and a treatment plot bounded by a $2.44 \mathrm{~m}$ woven wire fence. We used blocked Multiple Response Permutation Procedures to determine if differences in community composition existed between fenced and control plots at 3-year intervals after fence construction. Finally, we tested whether the frequency of saplings in control plots could predict deer abundance using a seedling/sapling ratio of "preferred species." We observed significant differences in understory community composition between treatment and control plots 6 years $(P$ $=0.024)$ after plot establishment and continued through the 21 years $(P=0.006)$ analyzed. We found no difference in ground cover community composition throughout the 21 years of data collection. Diversity values were greater in fenced than in control plots $(P<0.001)$, suggesting that changes in understory communities were not driven by the success of a single species. Species richness in the understory declined in control plots (from $5.13 \pm 2.11$ to $4.00 \pm 2.38$ ) and


increased in treatment plots (from $5.67 \pm 1.54$ to $8.92 \pm 1.60$ ) throughout the course of the study. Understory stem density also increased in treatment plots (from $5.25 \pm 1.83$ to $11.59 \pm 8.56$ stems $/ \mathrm{m}^{2}$ ) after 9 years, but similar increases were not measured in control plots. The seedlingsapling ratio of preferred species was not a significant predictor of deer density $(P<0.05)$. These results suggest that forest understories may begin to recover from chronic over-browsing within 6 years after herd elimination from a stand, provided the seed bank and seed rain from mature trees are unaffected. However, our results indicate that after 21 years, the seed bank may be affected to the degree that the ground cover community is affected. As our study sites reflect conditions throughout West Virginia, this may be the reality for many of the state's forests. Keywords: Odocoileus virginianus, deciduous forest, MRBP, community, density, West Virginia, sapling ratio, preferred species

\section{Introduction}

The recovery of white-tailed deer (Odocoileus virginianus) populations in the eastern United States from near extirpation has been considered one of the greatest natural resource conservation success stories of the $20^{\text {th }}$ century (Waller and Alverson, 1997). Historic estimates of deer densities from the time of European colonization of the Americas have ranged from $3-6$ deer $/ \mathrm{km}^{2}$. Chronic overhunting led to declines in densities to the point of localized extirpation in some areas (Warren, 2011). To prevent the loss of this species, game laws were enacted as early as 1646 (McCabe and McCabe, 1984) to reduce harvest of males and, in some cases, eliminate harvest of females (Rooney and Waller, 2003). Harvest restrictions coincided with an increase in early successional growth of eastern deciduous and coniferous forests following widespread intensive timber harvest for industry (McShea, 2012). Thus, the carrying capacity of much of the east was increased over that of the old-growth forest habitat. Finally, populations of natural predators were reduced or eliminated through hunting and trapping, reducing natural mortality of white-tailed deer populations (Cote et al., 2004; Abrams and Johnson, 2012; Potvin et al., 2003). As a result, white-tailed deer populations have reached and exceeded historical densities throughout much of their range (Abrams and Johnson, 2012; Knight et al., 2009; Rooney, 2001; Webster et al., 2005). Many biologists now question whether or not white-tailed deer could be considered overabundant in some parts of their range (Nuttle et al., 2013; Stromayer and Warren, 1997). 
Overabundance of a wildlife population has been defined as fitting into one of four categories: 1) when an animal threatens human life and livelihood, 2) when animals depress the densities of favored species, 3) when animals are too numerous for their own good, and 4) when their numbers cause ecosystem dysfunction (Caughley 1981). Extensive browsing by whitetailed deer may fit into each of these categories by reducing regeneration of desirable timber species, altering plant and animal community composition, reducing the carrying capacity of their environment by reducing palatable browse species and preventing regeneration of mast species, and potentially affecting decomposition rates by altering the forest floor microclimate.

Early research on the interaction of white-tailed deer and plant species was concentrated on economically important agricultural and timber species. Many studies have focused on just one species. White-tailed deer can have detrimental effects on the growth of eastern hemlock (Tsuga canadensis)(Alverson and Waller, 1997; Anderson and Loucks, 1979; Krueger and Peterson, 2006; Stromayer and Warren, 1997; Whitney, 1984), white cedar (Thuja occidentalis), yellow birch (Betula lutea)(Stromayer and Warren, 1997), white pine (Pinus strobus) (Marshall et al., 1955; Saunders and Puettmann, 1999), and various oak species (Quercus spp.)(Healy, 1997; Rooney and Waller, 2003). Fewer studies have examined multiple species at the community level (Russel et al., 2001). Hough (1965) recorded a loss of preferred species and decline of less preferred species through a 20-year photographic record. Similar results were found concerning species composition and stem density on fixed deer density plots within exclosures (deCalesta and Stout, 1997; Tilghman, 1989). Several studies using natural refugia rather than man-made exclosures also found differences in plant communities that were protected from white-tailed deer browsing such as higher stem abundance than exposed plots and altered community composition with fewer palatable plants present in exposed plots (Carson et al., 2005; Comisky et al., 2005; DiTommaso et al., 2014; Krueger and Peterson, 2006). At the community level, Peek and Stahl (1997) found that white-tailed deer had extirpated 150 vascular plant species from one city park in Ohio.

More recently, additional studies have indicated that intensive white-tailed deer browing may impact herbaceous forest species (Augustine and Frelich, 1998; Russel at al., 2001), endangered plant species (Loeffler and Wegner, 2000), and animal communities (Martin et al., 2011; McShea and Rappole, 1997; Miller et al., 1992). Deer herbivory has been cited as a detriment to tall grass prairie forbs (Anderson et al., 2001), riparian willow species (Brookshire 
et al., 2002), and additional riparian vegetation restoration efforts (Opperman and Merenlander, 2000). White-tailed deer can reduce and potentially extirpate local populations of American ginseng (Panax cinquefolius)(Furedi and McGraw, 2004), Turk's cap lily (Lilium superbum)(Fletcher et al., 2001), and showy lady slipper (Cypripedium reginae)(Gregg, 2004).

Historically, large populations of herbivores such as the American bison (Bison bison) were responsible for maintaining ecosystems such as tall grass prairies through seasonally heavy grazing. Species of the eastern deciduous forest that are adapted to year-long browsing by lower densities of herbivores could be depleted when browsing pressure increases (Waller and Alverson, 1997; Warren, 1997). The selection of certain plants for nutrient content or palatability can result in the loss of individual plant species and a decrease in community diversity (Dostaler et al., 2011; Moseley et al., 2011). The loss of plant community components can affect organisms that rely on those communities (deCalesta, 1994; Flowerdew and Elwood, 2001; Martin et al., 2011) and a reduction of other ecosystem services.

Through excessive browsing, white-tailed deer populations have the potential to exert long-term influence on forest communities (Heckel et al., 2010; Tremblay et al. 2006). A reduction in understory plant density may encourage the growth of ground cover species such as hay-scented fern (Dennstaedtia punctilobula)(de la Cretaz and Kelty, 2002; Powers and Nagel, 2009). Heavy growth of unpalatable ground cover plants can prevent the growth of tree species by reducing the amount of sunlight available on the forest floor and through allelopathy (de la Cretaz and Kelty, 2002; Royo and Carson, 2006). Ground cover growth also can provide shelter for small mammals which consume seeds from overstory tree species, thus preventing reproduction of the existing overstory community (Royo and Carson, 2006). Thus, white-tailed deer may have the ability to influence the creation of alternate stable states in an ecosystem (Augustine et al., 1998). An alternate stable state is a community that exists in a different state than would be predicted by ecological succession and remains stable without a disturbance event (Stromayer and Warren, 1997). A lack of recruitment of currently dominant overstory species may result in the loss of these species from the community once the seed production is reduced as mature overstory trees are lost. Likewise, future herbaceous plant communities may be changed in composition under high browse pressure once the seed bank is depleted.

This study was designed to evaluate the effects of white-tailed deer exclusion on the ground cover $(<0.5 \mathrm{~m})$ and understory $(>0.5 \mathrm{~m}$ and $<2.54 \mathrm{~cm}$ diameter at breast height $[\mathrm{DBH}])$ 
forest layers. The specific objectives of our study are to evaluate the effect of white-tailed deer browse on stem density, species diversity, and composition in the understory and ground cover forest levels using fenced areas (treatment plots) and associated unfenced control plots and to determine if the recruitment of preferred species into the understory can act as a predictor of white-tailed deer density.

\section{Methods}

\subsection{Study area}

Twenty sites were selected from public lands throughout West Virginia (Fig. 1). These lands included West Virginia Division of Natural Resources (WVDNR) wildlife management areas (WMAs) and sites on national forest land located in the state. The majority of the sites were located in oak (Quercus spp.)-hickory (Carya spp.) dominated stands that were in the pole to mixed pole-saw timber stage when the study began. Sites were established to include low, medium, and high deer density based on the buck harvest per square kilometer as reported to the WVDNR during annual hunting seasons. Low density sites had $<0.77$ bucks $/ \mathrm{km}^{2}$ harvested, medium had $0.78-1.9$ bucks $/ \mathrm{km}^{2}$ harvested, and high density areas had $>1.93$ bucks $/ \mathrm{km}^{2}$ harvested when the sites were selected between 1984 and 1990. All sites were open to public hunting according to annually established regulations. Exclosure sites were selected so that they were distributed by elevation, slope, and aspect in all regions of the state. Specific sites were selected by district biologists or area managers based on cover types typical of the area as well as accessibility by road. While most exclosures were constructed in oak-hickory stands $(n=9)$, exclosures were also established in a clearcut $(n=1)$, early successional cover $(n=2)$, in northern hardwoods (conifers and hardwoods makeup the canopy cover with conifers contributing $<25 \%, \mathrm{n}=3$ ), and in mixed hardwoods (conifers and hardwoods makeup the canopy cover with conifers contributing $>25 \%$ (Fike, 1999, $n=5$ ). Of those constructed in forested cover types, the majority were located in stands that were in pole or saw-timber stages, averaging $12.7 \mathrm{~cm}$ DBH (Allen, 1990).

2. 2 Vegetation Monitoring

Vegetation-monitoring sites were constructed throughout the state between 1984 and 1990 (Table 1). At each site, a $100 \mathrm{~m}^{2}$ ( $10 \mathrm{~m}$ by $10 \mathrm{~m}$ square) treatment plot was constructed using two strands of $1.22 \mathrm{~m}$ tall woven wire fencing for a total fence height of $2.44 \mathrm{~m}$. Control plots were established immediately adjacent to the treatment plot on a similar aspect and slope. 
Within each treatment and control plot, nine $1 \mathrm{~m}$ by $1 \mathrm{~m}$ subplots were nested within nine $2 \mathrm{~m}$ by 2 m subplots (Fig. 2).

Plots were monitored in 3-year intervals between June and September by counting all stems within subplots and identifying each to species. Stems were grouped in two vegetation categories; ground cover included herbaceous stems and woody stems that were $<0.5 \mathrm{~m}$ tall and that fell within $1 \mathrm{~m}^{2}$ subplots. Understory vegetation was defined as all stems that grew within 4 $\mathrm{m}^{2}$ subplots that were $>0.5 \mathrm{~m}$ tall and $<2.54 \mathrm{~cm} \mathrm{DBH}$.

\subsection{Data Analysis}

We pooled data based on the number of years following plot establishment. For example, we treated data collected in 1987 for plots established in 1984 and data collected in 1989 for plots established 1986 as three years post-establishment. We summarized stem counts for each control plot and treatment plot by averaging the number of stems in each subplot for each species. We calculated the species richness and Shannon diversity values for each control plot and treatment plot as a whole. We used a 2-way repeated measures analysis of variance to compare the number of stems, the number of species, and the Shannon diversity values between control plots and treatment plots over time. We considered differences to be significant at the $\alpha$ $=0.05$ level.

We used blocked Multiple Response Permutation Procedures (MRBP) in program PCOrd (McCune and Mefford 1999) to determine if differences in community composition existed between fenced and control plots at 3-year intervals after fence construction. A multipleresponse permutation procedure test is a non-parametric multivariate test of differences between a priori groups (treatment and control plots). PC-Ord calculates a T-statistic that describes the difference between selected groups; a P-value that describes the likelihood of reaching the observed T-statistic; and an A-statistic that describes within group homogeneity compared to what is expected by chance. When $\mathrm{A}=1$ the plots are completely identical and when $\mathrm{A}=0$ the communities are equal to what is expected by chance. We excluded all species that only occurred in one plot during each monitoring period. We chose to use Euclidean distance measures as other measures were not available with the blocked design in PC-Ord (McCune and Mefford 1999). We repeated this process for 2 subsets of the overall data to control for the influence of variation in initial communities. We selected those sites created in oak-hickory dominated stands and those created within the Northern Ridge and Valley ecoregion of West 
Virginia (Fig. 1). In addition, we examined the data for natural groupings using cluster analysis in PC-Ord. We used the Sorensen distance measure and flexible beta $(\beta=-0.25)$ as the linkage method to reduce chaining in group selection.

We used Indicator Species Analysis (ISA; (Dufrene and Legendre, 1997) in program PCOrd (McCune and Mefford 1999) to determine if individual species were characteristic of protected plots or open plots for each year that we found significant differences in community composition using MRBP. The ISA combines the relative abundance and relative frequency of each species used in the MRBP analysis to provide a final indicator value (IV) for each species. We used a Monte Carlo randomization analysis using 1,000 runs to determine the statistical significance of each indicator value given by a $P$-value. In addition to ISA, we estimated the influence of each species on overall community differences by calculating an index representing the difference between control plots and treatment plots during years when a significant community difference was detected using MRBP. The index was calculated by multiplying the mean difference between treatment plots and control plots by the frequency of sites on which a difference occurred. Each species was ranked so that the highest values indicated species with greater abundance inside fenced areas and the lowest (most negative) values indicated species with greater abundance outside the fenced areas.

Finally, we created an index using the seedling-sapling ratio index following Sweetapple and Nugent (2004). This ratio was calculated by the following equation:

$$
\begin{aligned}
& \text { sapling - seedling } \\
& \text { sapling + seedling }
\end{aligned}
$$

for all species. From those species found at the understory level, we selected a subset that were consistently (i.e. they only displayed positive values for the index described above) more abundant in treatment plots than control. We used linear regression to evaluate the relation between the seedling-sapling ratio for control plots and the total deer density at the site from 1993 - 2007 as measured by WVDNR harvest data. We removed all sites in which the seedlingsapling ratio was one for all time periods (e.g. Cheat Mountain, Daniel's Run, Dice Run).

\section{Results}

\subsection{Ground cover level}

We recorded 197 species present in the ground cover over the study period (Appendix 6). Immediately after plot initiation, the mean stem abundance in control plots was $31.5 \pm 8.63$ 
stems $/ \mathrm{m}^{2}$ whereas the stem abundance in treatment (fenced) plots was $35.5 \pm 12.71 \mathrm{stems} / \mathrm{m}^{2}$ (Fig. 3). After 21 years, the stem abundance in the treatment plot decreased slightly to $32.14 \pm$ $15.5 \mathrm{stems} / \mathrm{m}^{2}$ and the stem abundance in the control plots increased to $37.67 \pm 15.5 \mathrm{stems} / \mathrm{m}^{2}$. We found no significant difference based on time $\left(F_{1,19}=0.09, P=0.77\right)$ or treatment $\left(F_{1,19}=\right.$ $0.13, P=0.17)$ in predicting stem abundance. There was no significant interaction between treatment and time $\left(F_{1,19}=0.39, P=0.53\right)$. Immediately, after plot initiation, the average species richness of control plots was $15.0 \pm 2.84$; in treatment plots the average was $15.47 \pm 2.60$. After 18 years, the average species richness in control plots increased to $18.69 \pm 4.87$ and increased in treatment plots to $18.46 \pm 4.14$ (Fig. 4). The species richness decreased by year 21 to $15.5 \pm$ 5.23 in control plots and $15.5 \pm 4.60$ in treatment plots. We found no significant differences based on time $\left(F_{1,19}=0.57, P=0.44\right)$ or treatment $\left(F_{1,19}=0.21, P=0.65\right)$ in predicting species richness. There was no significant interaction between treatment and time $\left(F_{1,19}=0.039, P=\right.$ 0.84). Average Shannon diversity values for the ground cover were similar between control plots and treatment plots throughout the study. In year 21, the diversity of treatment plots was higher $(1.61 \pm 0.17)$ than control plots $(1.27 \pm 0.26)$. However, we found no significant differences based on time $\left(F_{1,19}=0.01, P=0.92\right)$ or treatment $\left(F_{1,19}=0.89, P=0.36\right)$ in predicting Shannon diversity values (Fig. 5). There was no significant interaction between treatment and time $\left(F_{1,19}=1.59, P=0.22\right)$.

\subsection{Understory level}

We recorded 79 species present in the understory over the study period (Appendix 7). Immediately after plot initiation, the mean stem abundance in control plots was $4.94 \pm 3.72$ stems $/ \mathrm{m}^{2}$, whereas the stem abundance in treatment plots was $5.25 \pm 5.10 \mathrm{stems} / \mathrm{m}^{2}$ (Fig. 6). The stem abundance in treatment plots increased to $11.59 \pm 8.56 \mathrm{stems} / \mathrm{m}^{2}$ by year 9 . After 21 years, the stem abundance in the treatment plot decreased to $5.25 \pm 1.83 \mathrm{stems} / \mathrm{m}^{2}$ and the stem abundance in the control plots was $2.45 \pm 1.23 \mathrm{stems} / \mathrm{m}^{2}$. We found that treatment $\left(F_{1,19}=12.22\right.$, $P<0.001)$ had an effect on the stem abundance, but time did not $\left(F_{1,19}=0.78, P=0.37\right.$, Fig. 6). There was no significant interaction between treatment and time $\left(F_{1,19}=0.14, P=0.71\right)$. After plot initiation, the average species richness of control plots was $5.13 \pm 2.11$ and in treatment plots, the average was $5.67 \pm 1.54$. After 21 years, the average species richness in control plots decreased to $4.00 \pm 2.38$ and increased in treatment plots to $8.92 \pm 1.60$ (Fig. 7). We found that treatment $\left(F_{1,19}=78.77, P<0.001\right)$ had a significant effect on the species richness, but time did 
$\operatorname{not}\left(F_{1,19}=1.32, P=0.37\right.$, Fig. 7$)$. There was a significant interaction between time and treatment factors $\left(F_{1,19}=9.55, P<0.01\right)$. Using Tukey's HSD for post hoc analysis, we found that species richness did not differ between control and treatment plots in year $1(P=1.00)$, and year $3(P=0.89)$; species richness was significantly different in subsequent years $(\mathrm{P}<0.05)$ with the exception of year $12(P=0.15)$. Average Shannon diversity values for the understory were higher for treatment plots than control plots throughout the study. Average diversity values were highest $(1.70 \pm 0.12)$ in treatment plots in year 18 . In the same year, the average diversity values in control plots had reached their lowest value $(0.74 \pm 0.14$, Fig. 8). We found a significant difference based on treatment $\left(F_{1,19}=40.82, P<0.001\right)$, but not time $\left(F_{1,19}=0.49, P=0.49\right)$ in predicting Shannon diversity values (Fig. 8). There was no significant interaction between treatment and time $\left(F_{1,19}=2.38, P=0.14\right)$.

\subsection{Community Analysis}

We found no difference in understory community composition during the initial observation $(T=1.10, P=0.87)$ and 3 years $(T=-1.68, P=0.057)$ following initiation for each site. Significant differences between treatment plots and control plots were observed 6 years $(T$ $=-4.34, P=0.001)$ after plot establishment and during $9(\mathrm{~T}=-4.16, \mathrm{P}=0.002), 15(T=-4.49, P$ $=0.002), 18(T=-4.63, P<0.001)$, and $21(T=-4.20, P=0.001)$ years after plot establishment. In the oak-hickory subset, we found significant differences between treatment and control plots at the understory level 6 years $(T=-1.67, P<0.05)$ and 9 years $(T=-2.66, P<0.01)$ after plot establishment, but not in subsequent years (Table 3). At the ground cover level, we found a significant difference occurred 21 years after plot initiation $(T=-0.20, P=0.03$, Table 3$)$. In the Northern Ridge and Valley ecoregion subset, we observed significant differences between treatment plots and control plots at the understory level 6 years $(T=-2.60, P=0.01)$, 15 years $(T=-2.33, P=0.02)$, and 18 years $(T=-1.98, P=0.02$, Table 4$)$ after plot establishment. At the ground cover level, we observed significant differences between treatment and control plots at the understory level 12 years $(T=-2.17, P=0.02), 15$ years $(T=-2.66, P<0.01)$, and 21 years ( $T=-2.23, P=0.03$, Table 4$)$ after plot establishment. The subset of plots analyzed using hierarchical cluster analysis included the Bluestone, Centrailia, Hughes River, Jug, R.D. Bailey, and Stoney River sites (Figure 1). At the understory level, we found a significant difference between control and treatment plots in this subset after 9 years $(\mathrm{T}=-1.96, \mathrm{P}<0.02)$ and 18 years $(\mathrm{T}=-2.19, \mathrm{P}=0.035$, Table 5). 
We found that black gum (Nyssa sylvatica) was an indicator of treatment plots 6 years after initiation $(\mathrm{P}=0.041)$. Both greenbrier (Smilax spp.) and sugar maple (Acer saccharum) were indicators of treatment plots 12 years $(\mathrm{P}=0.028$ and $\mathrm{P}=0.029$, respectively) and 15 years $(\mathrm{P}=0.033$ and $\mathrm{P}=0.030$, respectively) after intitiation. Red maple (A. rubrum) was an indicator of treatment plots 21 years after initiation $(\mathrm{P}=0.007)$. We found that Rubus spp. were the only species found to indicate treatment plots within the oak-hickory, Northern Ridge and Valley, and clustered subsets of data analyzed.

Species that consistently showed higher abundance in treatment plots were bellwort (Uvularia spp.) and Virginia creeper (Parthenocissus quinquefolia) at the ground cover level (Table 6) and Rubus spp. and greenbrier at the understory level (Table 7). Species that consistently showed higher abundance in control plots were blueberry (Vaccinium spp.) and red maple at the ground cover level (Table 6) and beech (Fagus grandifolia) and pawpaw (Asimina triloba) at the understory level (Table 7).

We examined the potential for the seedling-sapling ratio to act as a predictor of density (Table 8) at all sites combined. We found no relation between the seedling-sapling ratio and deer density $\left(R^{2}=0.02, P=0.17\right.$, Fig. 9).

\section{Discussion}

Our results indicate that white-tailed deer populations do have the potential to impact understory vegetative communities in eastern deciduous forests. We found that the community composition of forest communities relieved of white-tailed deer browse changed after 6 years at the understory level. However, at the ground cover level, no difference was observed over the 21 years of the study. Lack of seedling recruitment into the understory level is a common finding among deer exclosure or variable density studies (DiTommaso et al., 2014; Fujiki et al., 2010; Powers and Nagle, 2009; Rooney, 2009; Tanentzap et al., 2009). In a similar, 16-year study Rooney (2009) found that the species composition of exclosure plots differed significantly from control plots, but the richness and diversity of the plots did not change. This suggests that a shift toward a community based on less palatable species may be underway. He also found that his control plots grew more similar in species composition throughout the study suggesting that high densities of white-tailed deer can tend to homogenize the forest community on a regional scale. 
A common criticism of deer exclosure studies is that they exclude deer entirely from treatment plots. Rather than simulate precolonial conditions, exclosures simulate the undesirable extreme scenario of no white-tailed deer (or other large herbivores) within the community. The control plots within this study represent plots exposed to a wide range of local deer densities (Table 8) at different sites throughout the state. Though this study was initially designed to monitor plots at low, intermediate, and high deer densities, these densities did not remain static from year to year making it difficult to assign sites to apriori groups for the duration of the study. However, we believe the length of our study allows a better representation of the impact of deer populations over time, as plant communities may be influenced not only by the current deer density, but by the legacy of past higher or lower densities (Royo et al., 2010).

Indicator species analysis seeks to find species that are present in a large proportion of one treatment group and found rarely in another (McCune and Grace, 2002). Though the MRBP indicated that there was a difference between control and treatment plots, few significant indicator species were identified that increased in all plots with the relief from browse pressure. This may reflect the large range of initial forest communities in which the monitoring plots were established. In addition to indicator species analysis, we quantified which species were found more often in treatment plots and which were more abundant in control plots. The species that were more prevalent in treatment plots such as Rubus spp. and greenbrier (Smilax spp.) have been cited by others as species "preferred" by deer (Comisky et al., 2005; Dostaler et al., 2011; Healy, 1997). Likewise, species like American beech (Fagus grandifolia) and blueberry (Vaccinium spp.) are typically considered not preferred by deer (Carson et al., 2005; Kribel et al., 2011; Webster et al., 2005) and were more abundant in control plots in our study. Our results support the idea that deer impact species composition without necessarily impacting the amount of cover.

Several studies predicted that, with continued exposure to high deer densities, the increasing grass and fern cover may have secondary effects on species composition; reducing the cover of even "non-preferred" species (de la Cretaz and Kelty, 2002; Royo and Carson, 2006). We found that several taxa, including New York fern (Thelypteris noveboracensis), hay-scented fern (Dennstaedtia punctilobula), and Carex spp. declined in fenced plots over time and tended to increase in control plots over time (Appendix 6). However, the mean values for each of these varied through time. 
Alteration of the vegetative communities can have more far-reaching impacts on the ecosystem as a whole (Kishmoto et al., 2010). The treatment plots in this experiment shed light on the process of ecosystem recovery after the exclusion of a chronic disturbance in the form of high white-tailed deer densities. Although removal of deer from the plots resulted in an increase in understory level vegetation, this may not be considered true ecological restoration to a predisturbance state, because white-tailed deer existed naturally in these ecosystems though seemingly at lower densities. Though our results indicate plant species richness and abundance increase after the removal of deer, it is difficult to determine what species may have been lost prior to the initiation of the experiment and therefore, do not have the potential to return without an influx from an outside source population. Tanentzap et al. (2009) found that ecosystem recovery may not be complete 38-46 years after deer density reduction methods are implemented. This suggests that extended exposure to high-densities of white-tailed deer may exceed the capacity of certain species to recover. Thus, these extended disturbances may lead to a permanent change in community composition.

Our results indicate that there were no measurable changes in ground cover community composition after 21 years. This suggests that there are still seed sources for species from the seed bank, from the overstory species still present, or from dispersal from surrounding areas. However, the fact that there were significant differences in both stem abundance and species richness in the understory layer after a period of years suggests that, under the influence of existing deer densities, many of the tree species included in this analysis will not reach the overstory to continue to produce seeds for the ground cover layer. When the current overstory is lost, either naturally or through harvest, these species may be eliminated from the ecosystem. The true cost to the ecosystem of extended exposure of the vegetation community to high deer densities remains to be seen, because no study has continued for the extended time that it would take for many species to become reproductive and reach the overstory.

While these effects have not been empirically measured, several studies have modeled the long-term effects of data similar to what we have collected. Akashi (2009) found that when food was the only factor limiting the growth of deer populations, the forest vegetation could not remain in a stable state. However, management of the modeled deer population allowed for continued forest regeneration. As the carrying capacity and thus vegetation-herbivore balance is constantly variable, there may not be a simple threshold density at which to maintain a stable 
state (Akashi, 2009). Rather, the response of vegetation parameters to current densities must be monitored. The alteration of the vegetative community has far reaching impact throughout an ecosystem. The loss of understory diversity and density may negatively impact the understory songbird community (deCalesta, 1994, McShea et al., 1995). Changes to the vegetation community may also increase (Royo and Carson, 2006) or decrease (Flowerdew and Elwood, 2001) the density of small mammals that inhabit forest floor communities.

We did not find that the abundance of preferred browse at the understory level was a significant predictor of deer density. This may be a reflection of those species used to calculate the seedling-sapling ratios; we used all of those species found at higher abundance in treatment plots during the years that community composition was significantly different in the sapling layer. We also examined multiple subsets of these species by reducing the number of species considered and found no relation to deer density indices. Additionally, the removal of a potential outlier did not improve the fit of stem ratio as a predictor of deer density $\left(\mathrm{R}^{2}<0.01, P=0.52\right.$, Fig. 9). We believe that the deer density estimates used may not have been ideal for assessing site-specific density. The estimates used in this analysis were based on hunter harvest at the management area level. We believe large-scale estimates may not necessarily reflect what occurs at the control plot within the management area, affecting the ability to relate the presence of preferred species in the sapling layer to density. However, Bennett and Coulson (2012) tested the seedling/sapling ratio method using site-level browse counts and fecal pellet indices and also failed to relate the sapling ratio to deer browsing impacts. The aforementioned study included both native and introduced herbivores whereas Sweetapple and Nugent (2004) included only introduced herbivores. Our results suggest that more study is necessary before the seedling ratio method is used as an index of deer abundance in North America.

\section{Conclusions}

Our results indicate the density of white-tailed deer impacting the control plots and our sites has reached or exceeded the capacity of the forest to regenerate the current community. The response of vegetation to different densities was visibly apparent though not measured through this study. At some of our sites, an alternate complement of overstory tree species may replace the dominant vegetation. At some sites, few if any overstory species are currently reaching the understory growth level thus the future of the forest cover at these sites is uncertain. It is important to determine; a) the economic and intrinsic importance of the current complement 
of overstory species, b) the extent to which changes to the vegetative community will affect the local fauna, and c) the extent to which changes to the vegetative community will affect the local deer population. We believe that the seed sources still remain to produce the current complement of species. However, the impacts to the abundance of stems and species in the understory level have been chronic. We saw a significant change in this level 6 years after removal of browse pressure. Thus, the potential still exists to regenerate the current forest state. However, if browse pressure persists as the seed source declines, the potential for recovery of the current ecosystem even after removal of browse pressure is uncertain.

Though a difference in community composition occurred after 6 years at the understory level, there was no difference between control plots and treatment plots statewide at the ground cover level until year 21. Whether those seedlings were a result of the seed bank, seed rain from the existing overstory or dispersal is unclear. Continued monitoring of existing study sites could determine if the difference in ground cover composition remains after year 21 . Few studies have examined forest regeneration with respect to deer over extended time periods (Rooney and Dress, 1997; Tanentzap et al., 2009). Extended monitoring could determine the fate of the ground cover layer in treatment plots after the loss of the existing overstory and potential loss of seed rain contributing to the ground cover composition. However, monitoring at the current frequency may be unnecessary to achieve that goal.

\section{Acknowledgments}

We thank Thomas Allen and William Igo of the WVDNR for design and implementation of this study. We also thank many other WVDNR personnel for countless hours monitoring exclosures and collecting data. This is scientific article number xxxx of the West Virginia University Agricultural and Forestry Experiment Station. This research was funded by W-48-R Federal Aid in Wildlife Restoration.

\section{References}

Abrams, M.E., Johnson, S.E., 2012. Long-term impacts of deer exclosures on mixed-oak forest composition at the Valley Forge National Historical Park, Pennsylvania, USA. J. Torrey Bot. Soc. 139, 167-180.

Akashi, N., 2009. Simulation of the effects of deer browsing on forest dynamics. Ecol. Res. 24, $247-255$.

Allen, T.J., 1990. The impact of deer on forest vegetation in West Virginia: a six-year 
analysis. West Virginia Division of Natural Resources. Elkins, WV. 30 pp.

Alverson, W.S., Waller, D.M., 1997. Deer populations and the widespread failure of hemlock regeneration in northern forests, In: McShea, W.J., Underwood, H.B, Rappole, J.H. (Eds.) The science of overabundance: deer ecology and population management. Smithsonian Institution Press, Washington D.C., pp 280-297.

Anderson, R.C., Corbett, E.A., Anderson, M.R., Corbett, G.A., Kelley, T.M., 2001. High white-tailed deer density has negative impact on tallgrass prairie forbs. J. Torrey Bot. Soc. 128, 381-392.

Anderson, R.C., Loucks, O.L., 1979. White-tailed deer influence on structure and composition of Tsuga canadensis forests. J. App. Ecol. 16, 855-861.

Augustine D.J., Frelich, L.E., Jordan, P.A., 1998. Evidence for two alternate stable states in an ungulate grazing system. Ecol. App. 8, 1260-1269.

Augustine, D.J., Frelich, L.E., 1998. Effects of white-tailed deer on populations of an understory forb in fragmented deciduous forests. Conserv. Biol. 12, 995-1004.

Bennett, A., Coulson, G. 2012. The seedling ratio method for determining ungulate impacts on forest understoreys: utility in an Australian ecosystem. Ecol. Man. and Rest. 13, 198202.

Brookshire, E.N.J., Kauffman, J.B., Lytjen, D., Otting, N., 2002. Cumulative effects of wild ungulate and livestock herbivory on riparian willows. Oecologica 132, 559-566.

Carson, W.P., Banta, J., Royo, A., Kirschbaum, C., 2005. Plant communities growing on boulders in the Allegheny National Forest: evidence for boulders as refugia from deer and as a bioassay of overbrowsing. Nat. Areas J. 25, 10-18.

Caughley, G., 1981. Overpopulation. In: Jewell, P.A., Holt, S., Hart, D. (Eds.) Problems in management of locally abundant wild mammals. Academic Press, New York., pp 7-19.

Comisky, L., Royo, A.A., Carson, W.P., 2005. Deer browsing creates rock refugia gardens on large boulders in the Allegheny National Forest, Pennsylvania. Am. Mid. Nat. 154, 201-206.

Cote, S.D., Rooney, T.P., Tremblay, J., Dussault, C., Waller, D.M., 2004. Ecological impacts of deer overabundance. Ann. Rev. of Ecol., Evol. and System. 35, 113-147.

de la Cretaz, A.L., Kelty, M.J., 2002. Development of tree regeneration in fern-dominated forest understories after reduction of deer browsing. Restor. Ecol. 10, 416-426. 
deCalesta, D.S., 1994. Effect of white-tailed deer on songbirds within managed forests in Pennsylvania. J. Wild. Manage. 58, 711-718.

deCalesta, D.S., Stout, S.L., 1997. Relative deer density and sustainability: a conceptual framework for integrating deer management with ecosystem management. Wildl. Soc. Bull. 25, 252-258.

DiTommaso A., Morris S.H., Parker J.D., Cone C.L., Agrawal A.A.. 2014. Deer browsing delays succession by altering aboveground vegetation and belowground seed banks. PLoS ONE 93: e91155. doi:10.1371/journal.pone.0091155.

Dostaler, S., Ouellet, J.P., Therrien, J.F., Cote, S.D., 2011. Are feeding preferences of whitetailed deer related to plant constituents? J. Wildl. Manage. 75, 913-918.

Dufrene, M., Legendre, P., 1997. Species assemblages and indicator species: the need for a flexible asymmetrical approach. Ecol. Monogr. 67, 345-366.

Fike, J., 1999. Terrestrial and palustrine plant communities of Pennsylvania. Pennsylvania Natural Diversity Inventory. Western Pennsylvania Conservancy. Pittsburgh, PA, U.S.A. $85 \mathrm{pp}$.

Fletcher, J.D., Shipley, L.A., McShea, W.J., Shumway, D.L., 2001. Wildlife herbivory and rare plants: the effects of white-tailed deer, rodents, and insects on growth and survival of Turk's cap lily. Biol. Conserv. 101, 229-238.

Flowerdew, J.R., Elwood, S.A., 2001. Impacts of woodland deer on small mammal ecology. Forestry 74, 277-287.

Fujiki, D, Kishimoto, Y., Sakata, H., 2010. Assessing decline in physical structure of deciduous hardwood forest stands under sika deer grazing using shrub-layer vegetation cover. J. For. Res. 15, 140-144.

Furedi, M.A., McGraw, J.B., 2004. White-tailed deer: dispersers or predators of American ginseng seed? Am. Mid. Nat. 152, 268-276.

Gregg, K.B., 2004. Recovery of showy lady's slippers (Cypripedium reginae Walter) from moderate and severe herbivory by white-tailed deer (Odocoileus virginianus Zimmerman). Nat. Areas J. 24, 232-241.

Healy, W.M., 1997. Influence of deer on the structure and composition of oak forests in central 
Massachusetts. In: McShea, W. J., Underwood, H. B., Rappole, J. H. (Eds.) The science of overabundance: deer ecology and population management. Smithsonian Institution Press, Washington D.C. pp 249-266.

Heckel, C.D., Bourg, N.A., McShea, W.J., Kalisz, S., 2010. Nonconsumptive effects of a generalist ungulate herbivore drive decline of unpalatable forest herbs. Ecology 91, 319-326.

Hough, A.F., 1965. A twenty year record of understory vegetational change in a virgin Pennsylvania forest. Ecology 46, 370-373.

Kishmoto, Y., Fujiki, D., Sakata, H., 2010. Management approach using simple indices of deer density and status of understory vegetation for conserving deciduous hardwood forests on a regional scale. J. For. Res. 15, 265-273.

Knight, T.M., Dunn, J.L., Smith, L.A., Davis, J., Kalisz, S., 2009. Deer facilitate invasive plant success in a Pennsylvania forest understory. Nat. Areas J. 29, 110-116.

Kribel, J.R.G., Kolman, K.B, Ware, S., 2011. Rapid change in sapling and seedling layers in an otherwise stable hardwood forest: an effect of deer browsing. Castanea 76, 140-148.

Krueger, L.M., Peterson, C.J., 2006. Effects of white-tailed deer on Tsuga canadensis regeneration: evidence of microsites as refugia from browsing. Am. Mid. Nat. 156, 353-362.

Loeffler, C.C., Wegner, B.C., 2000. Demographics and deer browsing in three Pennsylvania populations of the globally rare glade spurge, Euphorbia purpurea, fern. Castanea 65, 273-290.

Marshall, W.H., Schantz-Hanson, T., Winsness, K., 1955. Effects of simulated browsing on small red and white pine trees. J. For. 53, 420-424.

Martin, T.G., Arcese, P., Scheerder, N., 2011. Browsing down our natural heritage: deer impact on vegetation structure and songbird populations on across an island archipelago. Biol. Conserv. 144, 459-469.

McCabe, R.E., McCabe, T.R., 1984. Of slings and arrows: An historical retrospection. in: Halls, L.K. (Ed.) White-tailed deer Ecology and Management. Stackpole Books. Harrisburg, PA, pp 19-72.

McCune, B., Grace, J.B., 2002. Analysis of Ecological Communities. MjM Software Design. Gleneden Beach, OR, U.S.A. 304 pp. 
McCune, B., Mefford, M.J., 1999. PC-ORD Multivariate Analysis of Ecological Data. Version 4.0. MjM Software. Gleneden Beach, OR, U.S.A.

McShea, W.J., 2012. Ecology and management of white-tailed deer in a changing world. Ann. N.Y. Acad. Sci. 1249, 45-56.

McShea, W.J., McDonald, M.V., Morton, G.E., Meier, R., Rappole, J. H., 1995. Long term monitoring of Kentucky warbler habitat. Auk 112, 375-381.

McShea W.J., Rappole, J.H., 1997. Herbivores and the ecology of forest understory birds. In: McShea, W. J., Underwood, H. B., Rappole, J. H. (Eds.) The science of overabundance: deer ecology and population management. Smithsonian Institution Press. Washington D.C., pp 298-309.

Miller, S.G., Bratton, S.P., Hadidian, J., 1992. Impacts of white-tailed deer on endangered and threatened vascular plants. Nat. Areas J. 12, 67-74.

Moseley, W.A., Cooper, S.M., Hewitt, D.G., Fulbright, T.E., DeYoung, C.E., 2011. Effect of supplemental feeding and density of white-tailed deer on rodents. J. Wildl. Manage. 75, 675-681.

Nuttle, T., Royo, A.A., Adams, M.B., Carson, W.P., 2013. Historic disturbance regimes promote tree diversity only under low browsing regimes in eastern deciduous forest. Ecol Monogr. 83, 3-17.

Opperman, J.J., Merenlander, A M., 2000. Deer herbivory as an ecological constraint to restoration of degraded riparian corridors. Restor. Ecol. 8, 41-47.

Peek, L.J., Stahl, J.F., 1997. Deer management techniques employed by the Columbus and Franklin County park district, Ohio. Wildl. Soc. Bull. 25, 440-442.

Potvin, F., Beaupre, P., Laprise, G., 2003. The eradication of balsam fir stands by whitetailed deer on Anticosti Island, Quebec: a 150 year process. Ecoscience 10, 487-495.

Powers, M.D., Nagel, L.M., 2009. Pennsylvania sedge cover, forest management and deer density influence tree regeneration dynamics in a northern hardwood forest. Forestry 82, 241-254.

Rooney, T.P., 2001. Deer impacts on forest ecosystems: a North American perspective. Forestry 74, 201-208.

Rooney, T.P., 2009. High white-tailed deer densities benefit graminoids and contribute to biotic homogenization of forest ground-layer vegetation. Plant Ecol. 202, 103-111. 
Rooney, T. P., Dress, W.J., 1997. Species loss over sixty-six years in the ground-layer vegetation of Heart's Content, an old-growth forest in Pennsylvania, USA. Nat. Areas J., 17, 297-305.

Rooney, T.P., Waller, D.M., 2003. Direct and indirect effects of white-tailed deer in forest ecosystems. For. Ecol. Manage. 181, 165-176.

Royo, A.A., Carson, W.P., 2006. On the formation of dense understory layers in forests worldwide: consequences and implications for forest dynamics, biodiversity and succession. Can. J. For. Res. 36, 345-1362.

Royo, A.A., Stout, S.L., deCalesta, D.S, Pierson, T.G., 2010. Restoring forest herb communities through landscape-level deer herd reductions: is recovery limited by legacy effects? Biol. Conserv. 143, 2425-2434.

Russel, F.L., Zippin, D.B., Fowler, N.L., 2001. Effects of white-tailed deer (Odocoileus virginianus) on plants, plant populations, and communities: a review. Am. Mid. Nat. 146, 1-26.

Saunders, M., Puettmann, K. J., 1999. Use of vegetational characteristics and browsing pattens to predict deer damage in eastern white pine (Pinus strobus) plantations. North. J. App. For. 16, 96-102.

Stromayer, K.A.K., Warren, R.J., 1997. Are over abundant deer herds in the eastern United States creating alternate stable states in forest plant communities. Wildl. Soc. Bull. 25, 227-234.

Sweetapple, P.J., Nugent, G., 2004. Seedling ratios: a simple method for assessing ungulate impacts on the forest understories. Wildl. Soc. Bull. 32, 137-147.

Tanentzap, A.J., Burrows, L.E., Lee, W.G., Nugent, G., Maxwell, J.M., Coomes, D.A., 2009 Landscape-level vegetation recovery from herbivory: progress after four decades of invasive red deer control. J. App. Ecol. 46, 1064-1072.

Tilghman, N.G., 1989. Impacts of white-tailed deer on forest regeneration in northwestern Pennsylvania. J. Wildl. Manage. 53, 524-532.

Tremblay, J.P., Huot, J., Potvin, F., 2006. Divergent nonlinear responses of the boreal forest field layer along an experimental gradient of deer densities. Oecologica 150, 78-88.

Waller, D.M., Alverson, W.S., 1997. The white-tailed deer: a keystone herbivore. Wildl. Soc. Bull. 25, 217-226. 
Warren, R.J., 1997. The challenge of deer overabundance in the $21^{\text {st }}$ century. Wildl. Soc. Bull. 25, 213-214.

Warren, R.J., 2011. Deer overabundance in the USA: recent advances in population control. Anim. Prod. Sci. 51, 259-266.

Webster, C.R., Jenkins, M.A., Rock, J.H., 2005. Long term response of spring flora to chronic herbivory and deer exclusion in Great Smoky Mountains National Park, USA. Biol. Conserv. 125, 297-307.

Whitney, G.G., 1984. Fifty years of change in the arboreal vegetation of Heart's Content, an old growth hemlock-white pine - northern hardwood stand. Ecology 65, 403-408. 
Table 1. West Virginia Division of Natural Resources monitoring sites and monitoring dates, $1984-2007$.

\begin{tabular}{|c|c|c|c|c|c|c|c|c|c|c|c|c|c|c|c|c|c|}
\hline Plot Location & WV Ecoregion & 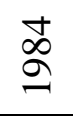 & $\begin{array}{l}0 \\
\infty \\
\stackrel{0}{ }\end{array}$ & $\stackrel{\infty}{\infty}$ & $\begin{array}{l}\text { a } \\
\text { a }\end{array}$ & ஓ̊ & ๙ু & ğ & $\stackrel{\curvearrowleft}{\Omega}$ & ๙̊ & ڤे & ఠ্ণ & ชి & ষ্ণ & ஜ̊ & ঠి & 용 \\
\hline Beaverdam & Allegheny Mountains & $\mathrm{X}$ & & $\mathrm{X}$ & & $\mathrm{X}$ & & $\mathrm{X}$ & & $\mathrm{X}$ & $\mathrm{X}$ & & $\mathrm{X}$ & & & $\mathrm{X}$ & \\
\hline Bluestone & N. Ridge and Valley & & $X$ & & $X$ & & $X$ & & $X$ & & & $X$ & & $X$ & & & $X$ \\
\hline Centrailia & Allegheny Mountains & $X$ & & $X$ & & $\mathrm{X}$ & & $\mathrm{X}$ & & $\mathrm{X}$ & $\mathrm{X}$ & & $X$ & & $X$ & & \\
\hline Cheat Mountain & Allegheny Mountains & $\mathrm{X}$ & & $\mathrm{X}$ & & $\mathrm{X}$ & & $\mathrm{X}$ & & $\mathrm{X}$ & $\mathrm{X}$ & & $\mathrm{X}$ & & & $X$ & \\
\hline Coopers Rock & Allegheny Mountains & & $X$ & & $X$ & & $X$ & & $X$ & & & $X$ & & $X$ & & & $X$ \\
\hline Daniels Run & Allegheny Mountains & & & & & $X$ & & $X$ & & $X$ & $X$ & & $X$ & & $X$ & & \\
\hline Dice Run & N. Ridge and Valley & & $X$ & & $X$ & & $\mathrm{X}$ & & $X$ & & & $X$ & & $X$ & & & $\mathrm{X}$ \\
\hline Holly River & Allegheny Mountains & $X$ & & $X$ & & $\mathrm{X}$ & & $\mathrm{X}$ & & $\mathrm{X}$ & $\mathrm{X}$ & & $X$ & & $X$ & & \\
\hline Hughes River & Southern Unglaciated & $X$ & & $X$ & & $X$ & & $\mathrm{X}$ & & $X$ & & & $\mathrm{X}$ & & $X$ & & \\
\hline Jug & Southern Unglaciated & $X$ & & $X$ & & $X$ & & $\mathrm{X}$ & & $X$ & & & $\mathrm{X}$ & & $X$ & & \\
\hline Lewis Wetzel & Southern Unglaciated & $X$ & & $X$ & & $X$ & & $X$ & & $X$ & $X$ & & $X$ & & $X$ & & \\
\hline $\begin{array}{l}\text { Little River } \\
\text { Nathaniel }\end{array}$ & N. Ridge and Valley & $X$ & & $X$ & & $X$ & & $\mathrm{X}$ & & $X$ & $X$ & & $X$ & & $X$ & & \\
\hline Mountain & N. Ridge and Valley & $X$ & & $X$ & & $X$ & & $X$ & & $X$ & & & $X$ & & $X$ & & \\
\hline Neola & N. Ridge and Valley & & $X$ & & $X$ & & $X$ & & $X$ & & & $\mathrm{X}$ & & $X$ & & & $\mathrm{X}$ \\
\hline Potts Creek & $\begin{array}{l}\text { Ridge and Valley } \\
\text { N. Cumberand }\end{array}$ & & $\mathrm{X}$ & & $X$ & & $X$ & & $X$ & & & $X$ & & $X$ & & & $X$ \\
\hline R.D. Bailey & Mountain & $X$ & & $X$ & & $X$ & & $X$ & & $X$ & & & $X$ & & $X$ & & \\
\hline Sleepy Creek & N. Ridge and Valley & $X$ & & $X$ & & $X$ & & $\mathrm{X}$ & & $X$ & & & $X$ & & $X$ & & \\
\hline Stonecoal & Southern Unglaciated & $\mathrm{X}$ & & $\mathrm{X}$ & & $\mathrm{X}$ & & $\mathrm{X}$ & & $\mathrm{X}$ & $\mathrm{X}$ & & $\mathrm{X}$ & & & $\mathrm{X}$ & \\
\hline Stoney Run & N. Ridge and Valley & $X$ & & $X$ & & $X$ & & $X$ & & $X$ & $X$ & & $X$ & & $X$ & & \\
\hline Trout Run & N. Ridge and Valley & $X$ & & $X$ & & $X$ & & $X$ & & $X$ & $X$ & & $X$ & & $X$ & & \\
\hline
\end{tabular}


Table 2. Multiple Response Blocked Permutation values calculated every three years after plot initiation on West Virginia Division of Natural Resources deerbrowse exclosure sites, $1984-2007$. The T-statistic describes the difference between selected groups. The A-statistic describes within group homogeneity compared to what is expected by chance. The P-value describes the likelihood of reaching the observed T-statistic.

\begin{tabular}{cccccccc}
\hline & \multicolumn{3}{c}{ Ground Cover } & & \multicolumn{3}{c}{ Understory } \\
\cline { 2 - 3 } \cline { 6 - 7 } Year & $\mathrm{T}$ & $\mathrm{A}$ & $\mathrm{P}$ & & $\mathrm{T}$ & $\mathrm{A}$ & $\mathrm{P}$ \\
\hline Initial & 1.498 & -0.007 & 0.945 & & 1.100 & -0.011 & 0.8700 \\
3 & -0.338 & -0.002 & 0.338 & & -1.680 & 0.021 & 0.0570 \\
6 & 0.199 & -0.001 & 0.562 & & -4.342 & 0.039 & $\mathbf{0 . 0 0 1}$ \\
9 & -0.648 & 0.005 & 0.224 & & -4.158 & 0.066 & $\mathbf{0 . 0 0 2}$ \\
12 & -0.397 & 0.002 & 0.327 & & -1.476 & 0.034 & 0.080 \\
15 & -0.500 & 0.004 & 0.287 & & -4.486 & 0.115 & $\mathbf{0 . 0 0 2}$ \\
18 & -1.151 & 0.013 & 0.128 & & -4.626 & 0.059 & $\mathbf{0 . 0 0 0}$ \\
21 & -0.766 & 0.011 & 0.214 & & -4.202 & 0.061 & $\mathbf{0 . 0 0 1}$ \\
\hline
\end{tabular}


Table 3. Multiple Response Blocked Permutation values calculated every three years after plot initiation on West Virginia Division of Natural Resources deerbrowse exclosure sites located in Oak-Hickory (Quercus spp. - Carya spp.) dominated stands, $1984-2007$. The T-statistic describes the difference between selected groups. The A-statistic describes within group homogeneity compared to what is expected by chance. The P-value describes the likelihood of reaching the observed T-statistic.

\begin{tabular}{cccccccc}
\hline & \multicolumn{3}{c}{ Ground Cover } & & \multicolumn{3}{c}{ Understory } \\
\cline { 2 - 3 } \cline { 6 - 7 } Year & $\mathrm{T}$ & $\mathrm{A}$ & $\mathrm{P}$ & & $\mathrm{T}$ & $\mathrm{A}$ & $\mathrm{P}$ \\
\hline Initial & -0.419 & 0.006 & 0.316 & & -0.148 & 0.002 & 0.406 \\
3 & -1.101 & 0.041 & 0.136 & & 1.093 & -0.040 & 0.880 \\
6 & -0.804 & 0.004 & 0.206 & & -1.667 & 0.022 & $\mathbf{0 . 0 4 8}$ \\
9 & -0.630 & 0.007 & 0.253 & & -2.662 & 0.006 & $\mathbf{0 . 0 0 8}$ \\
12 & -1.524 & 0.024 & 0.069 & & 0.159 & -0.001 & 0.572 \\
15 & -0.302 & $<0.001$ & 0.449 & & -1.057 & 0.018 & 0.146 \\
18 & 0.970 & -0.028 & 0.852 & & -1.691 & 0.011 & 0.058 \\
21 & -0.201 & 0.034 & $\mathbf{0 . 0 3 0}$ & & -1.526 & 0.019 & 0.076 \\
\hline
\end{tabular}


Table 4. Multiple Response Blocked Permutation values calculated every three years after plot initiation on West Virginia Division of Natural Resources deer-browse exclosure sites located in the Northern Ridge and Valley Ecoregion, $1984-2007$. The T-statistic describes the difference between selected groups. The A-statistic describes within group homogeneity compared to what is expected by chance. The P-value describes the likelihood of reaching the observed T-statistic.

\begin{tabular}{cccccccc}
\hline & \multicolumn{3}{c}{ Ground Cover } & & \multicolumn{3}{c}{ Understory } \\
\cline { 2 - 4 } \cline { 6 - 7 } Year & $\mathrm{T}$ & $\mathrm{A}$ & $\mathrm{P}$ & & $\mathrm{T}$ & $\mathrm{A}$ & $\mathrm{P}$ \\
\hline Initial & -1.580 & 0.019 & 0.124 & & -0.545 & $<0.001$ & 0.432 \\
3 & -0.487 & 0.002 & 0.310 & & 1.220 & -0.010 & 0.890 \\
6 & -0.950 & 0.006 & 0.171 & & -2.603 & 0.009 & $\mathbf{0 . 0 1 1}$ \\
9 & -1.220 & 0.015 & 0.111 & & -0.734 & 0.011 & 0.233 \\
12 & -2.170 & 0.010 & $\mathbf{0 . 0 2 0}$ & & -0.332 & $<0.001$ & 0.486 \\
15 & -2.017 & 0.021 & $\mathbf{0 . 0 3 1}$ & & -2.330 & 0.010 & $\mathbf{0 . 0 1 9}$ \\
18 & 0.979 & -0.019 & 0.836 & & -1.975 & 0.005 & $\mathbf{0 . 0 2 3}$ \\
21 & -2.230 & 0.053 & $\mathbf{0 . 0 2 6}$ & & 0.339 & -0.003 & 0.615 \\
\hline
\end{tabular}


Table 5. Multiple Response Blocked Permutation values calculated every three years after plot initiation on a subset of West Virginia Division of Natural Resources deerbrowse exclosure sites selected through hierarchical clustering, $1984-2007$. The Tstatistic describes the difference between selected groups. The A-statistic describes within group homogeneity compared to what is expected by chance. The P-value describes the likelihood of reaching the observed T-statistic.

\begin{tabular}{cccccccc}
\hline & \multicolumn{3}{c}{ Ground Cover } & & \multicolumn{3}{c}{ Understory } \\
\cline { 2 - 4 } \cline { 6 - 7 } Year & $\mathrm{T}$ & $\mathrm{A}$ & $\mathrm{P}$ & & $\mathrm{T}$ & $\mathrm{A}$ & $\mathrm{P}$ \\
\hline Initial & 0.902 & -0.008 & 0.816 & & 0.843 & -0.042 & 0.795 \\
3 & 1.320 & -0.034 & 0.911 & & -1.143 & 0.048 & 0.086 \\
6 & -0.984 & 0.002 & 0.452 & & -1.396 & 0.011 & 0.073 \\
9 & -1.146 & 0.026 & 0.128 & & -1.957 & 0.027 & $\mathbf{0 . 0 1 5}$ \\
12 & 0.725 & -0.007 & 0.764 & & -1.000 & 0.030 & 0.159 \\
15 & -0.563 & 0.025 & 0.282 & & -1.000 & 0.053 & 0.159 \\
18 & -0.858 & 0.024 & 0.196 & & -2.190 & 0.053 & $\mathbf{0 . 0 3 4}$ \\
21 & 1.000 & $<0.001$ & 0.841 & & -0.209 & 0.005 & 0.421 \\
\hline
\end{tabular}


Table 6. Index values for species showing the greatest difference in ground cover stem abundance in years 12, 15, and 21 on West Virginia Division of Natural Resources deer-browse exclosure sites. The index was calculated by multiplying the average difference between treatment and control plots by the number of sites at which a difference occurred. Positive values indicate higher abundance on treatment plots. Negative values indicate higher abundance on control plots. Blank cells indicate an index value of 0 for that year.

\begin{tabular}{|c|c|c|c|}
\hline \multirow[b]{2}{*}{ Species } & \multicolumn{3}{|c|}{ Year } \\
\hline & 12 & 15 & 21 \\
\hline Bedstraw (Galium spp.) & -1.67 & & \\
\hline Bellwort (Uvularia spp.) & 5.81 & 3.86 & 0.98 \\
\hline Blueberry (Vaccinium spp.) & -2.06 & -10.61 & -9.70 \\
\hline Buckberry (Gaylussacia ursina (M.A. Curtis) Torr) & & -1.15 & -3.63 \\
\hline Buttercup (Ranunculus spp.) & & -1.05 & \\
\hline Canada Mayflower (Maianthemum canadense Desf.) & & & 0.93 \\
\hline Cherry (Prunus spp.) & 11.55 & -15.89 & \\
\hline Christmas Fern (Polystichum acrostichoides (Michx.) & & & \\
\hline Schott) & & -3.12 & \\
\hline Cinquefoil (Potentilla spp.) & 1.50 & & -5.44 \\
\hline Desmodium (Desmodium spp.) & -0.89 & & -4.59 \\
\hline Dewberry (Rubus spp. L.H.Bailey) & & 1.54 & \\
\hline Geranium (Geranium spp. L.) & 1.40 & & \\
\hline Goldenrod (Solidago spp.) & & & 2.59 \\
\hline Ironwood (Ostrya virginiana (Mill.) K. Koch) & & -0.95 & \\
\hline Jack in the Pulpit (Arisaema triphyllum (L.)) & & & \\
\hline Multiflora Rose (Rosa multiflora Thunb.) & & & 1.44 \\
\hline New York Fern (Thelypteris noveboracensis (L.) Nieuwl.) & & 2.19 & -20.11 \\
\hline Panicum (Panicum spp.) & -3.39 & -6.79 & -1.76 \\
\hline Poison Ivy (Toxicodendron radicans (L.) Kuntze) & 2.49 & 1.52 & \\
\hline Red Maple (Acer rubrum L.) & -39.60 & -24.44 & -20.57 \\
\hline Red Oak (Quercus rubra L.) & -1.39 & & \\
\hline Rubus (Rubus spp.) & 9.17 & 4.06 & \\
\hline Sassafras (Sassafras albidum (Nutt.) Nees) & -1.67 & & \\
\hline Sedge (Carex spp.) & & & -1.99 \\
\hline Serviceberry (Amelanchier arborea Michx.) & & & -1.62 \\
\hline Sheep Sorrel (Rumex acetosella L.) & & -1.51 & \\
\hline Sugar Maple (Acer saccharum Marshall) & 2.78 & & 1.52 \\
\hline Teaberry (Gaultheria procumbens L.) & 3.27 & 3.83 & 14.39 \\
\hline Violet (Viola spp. L.) & -50.73 & -9.78 & 12.22 \\
\hline Virginia Creeper (Parthenocissus quinquefolia (L.) Planch.) & 4.86 & 3.17 & 2.39 \\
\hline White Oak (Quercus alba L.) & -3.56 & & \\
\hline White Snakeroot (Ageratina altissima (L.) King \& H. Rob.) & -4.58 & 2.33 & -1.31 \\
\hline Wood Fern (Dryopteris spp.) & & & 5.19 \\
\hline
\end{tabular}


Table 7. Index values for species showing the greatest difference in understory stem abundance in years $6,9,15,18$, and 21 on West Virginia Division of Natural Resources deer-browse exclosure sites. The index was calculated by multiplying the average difference between treatment and control plots by the number of sites at which a difference occurred. Positive values indicate higher abundance on treatment plots. Negative values indicate higher abundance on control plots. Blank cells indicate an index value of 0 for that year.

\begin{tabular}{|c|c|c|c|c|c|}
\hline \multirow[b]{2}{*}{ Species } & \multicolumn{5}{|c|}{ Year } \\
\hline & 6 & 9 & 15 & 18 & 21 \\
\hline Beech (Fagus grandifolia Ehrh.) & & -0.37 & -0.77 & -0.35 & -0.76 \\
\hline Black Gum (Nyssa sylvatica Marshall) & & & 0.53 & & \\
\hline Black Locust (Robinia pseudoacacia L.) & & & & & -0.02 \\
\hline Black Oak (Quercus velutina Lam.) & & & -0.06 & -0.14 & -0.17 \\
\hline Blueberry (Vaccinium spp.) & & -0.08 & & & \\
\hline Buckberry (Gaylussacia ursina Torr) & -0.01 & -0.38 & -0.40 & -0.53 & -0.05 \\
\hline Buckeye (Aesculus glabra Willd.) & -0.01 & -0.01 & & & \\
\hline Cherry (Prunus spp.) & & 1.20 & & & 0.55 \\
\hline Crabapple (Malus spp.) & -0.01 & & & & \\
\hline Dogwood (Cornus florida L.) & 1.16 & 0.77 & & & \\
\hline Euonymus (Euonymus bungeanus Maxim.) & & -0.01 & & -0.01 & \\
\hline Greenbrier (Smilax spp.) & 1.40 & 2.06 & 6.10 & 7.64 & 6.28 \\
\hline Hazelnut (Corylus americana Walter) & 0.55 & 1.86 & 1.64 & 2.04 & \\
\hline Huckleberry (Gaylussacia spp. Kunth) & -0.47 & & -0.02 & & \\
\hline Ironwood (Ostrya virginiana (Mill.) K. Koch) & 0.70 & & & 1.43 & 0.64 \\
\hline Japanese Honeysuckle (Lonicera japonica Thunb.) & 0.47 & & 0.55 & 1.66 & \\
\hline Maple Leaf Viburnum (Viburnum acerifolium L.) & -0.01 & & & & \\
\hline Mountain Laurel (Kalmia latifolia L.) & & 0.76 & & 1.09 & -0.73 \\
\hline Mountain Maple (Acer spicatum Lam.) & & -0.01 & & & \\
\hline Multiflora Rose (Rosa multiflora Thunb.) & & & & & 0.79 \\
\hline PawPaw (Asimina triloba (L.) Dunal) & -0.07 & -0.37 & -0.09 & -0.34 & -0.18 \\
\hline Red Cedar (Juniperus virginiana L.) & & & & -0.01 & \\
\hline Red Maple (Acer rubrum L.) & 1.33 & 2.40 & 2.00 & 3.34 & 3.64 \\
\hline Red Oak (Quercus rubra L.) & & & & & 0.57 \\
\hline Red Spruce (Picea rubens Sarg.) & & -0.01 & & & \\
\hline Redbud (Cercis canadensis L.) & & & -0.01 & & \\
\hline Rubus (Rubus spp.) & 12.97 & 21.54 & 4.68 & 3.31 & 2.14 \\
\hline Sassafras (Sassafras albidum (Nutt.) Nees) & 0.67 & 0.70 & 0.59 & & \\
\hline Serviceberry (Amelanchier arborea Michx.) & & 0.62 & 0.62 & 3.12 & 0.55 \\
\hline Spice Bush (Lindera benzoin (L.) Blume) & & & & & -0.13 \\
\hline Striped Maple (Acer pensylvanicum L.) & & & -0.06 & & \\
\hline Sugar Maple (Acer saccharum Marshall) & & & 3.25 & 1.55 & 1.33 \\
\hline
\end{tabular}


Table 7. Continued

\begin{tabular}{lccccc}
\hline & \multicolumn{5}{c}{ Year } \\
\cline { 2 - 6 } Species & 6 & 9 & 15 & 18 & 21 \\
\hline Sumac (Rhus spp.) & 5.12 & & & & -0.01 \\
Tatarian Honeysuckle (Lonicera tatarica L.) & & & & -0.02 \\
Virginia Pine (Pinus virginiana Mill.) & & -0.01 & -0.01 & & \\
White Oak (Quercus alba L.) & -0.02 & & -0.09 & -0.06 & -0.05 \\
White Pine (Pinus strobus L.) & -0.16 & -0.04 & -0.18 & -0.19 & -0.14 \\
\hline
\end{tabular}


Table 8. Deer harvest per square kilometer at West Virginia Division of Natural Resources management areas corresponding to monitoring sites, 1993-2007.

\begin{tabular}{|c|c|c|c|c|c|c|c|c|c|c|c|c|c|c|c|}
\hline Plot Location & 1993 & 1994 & 1995 & 1996 & 1997 & 1998 & 1999 & 2000 & 2001 & 2002 & 2003 & 2004 & 2005 & 2006 & 2007 \\
\hline 1. Beaverdam & 3.89 & 3.72 & 5.48 & 2.97 & 3.69 & 3.93 & 4.33 & 3.55 & 2.38 & 3.27 & 1.06 & 0.70 & 0.56 & 0.76 & 0.68 \\
\hline 2. Bluestone & 4.78 & 4.76 & 3.32 & 5.72 & 5.61 & 4.89 & 3.96 & 4.99 & 6.44 & 7.10 & 2.32 & 2.33 & 3.03 & 2.60 & 3.82 \\
\hline 3. Centrailia & 2.79 & 2.24 & 4.05 & 3.51 & 5.20 & 3.00 & 3.65 & 2.91 & 3.55 & 3.37 & 1.50 & 1.17 & 0.87 & 1.06 & 1.86 \\
\hline 4. Cheat Mountain & 4.41 & 3.55 & 4.83 & 2.61 & 3.45 & 2.53 & 3.55 & 3.16 & 1.46 & 1.74 & 0.73 & 0.58 & 0.50 & 0.59 & 0.46 \\
\hline 5. Coopers Rock & 4.45 & 4.59 & 6.74 & 9.19 & 7.99 & 5.21 & 4.41 & 5.54 & 4.39 & 4.74 & 4.20 & 3.21 & 3.63 & 1.17 & 1.52 \\
\hline 6. Daniels Run & 5.95 & 4.65 & 6.28 & 4.65 & 2.53 & 3.10 & 2.20 & 2.61 & 1.71 & 2.04 & 1.39 & 1.55 & 2.20 & 3.02 & 2.12 \\
\hline 7. Dice Run & 3.28 & 2.01 & 3.57 & 2.64 & 3.20 & 2.65 & 2.59 & 2.77 & 2.17 & 1.21 & 0.84 & 0.72 & 0.89 & 1.05 & 0.51 \\
\hline 8. Holly River & 2.79 & 2.24 & 4.05 & 3.51 & 5.20 & 3.00 & 3.65 & 2.91 & 3.55 & 3.37 & 1.50 & 1.17 & 0.87 & 1.06 & 1.86 \\
\hline 9. Hughes River & 6.40 & 6.37 & 7.14 & 7.21 & 10.37 & 6.22 & 4.67 & 6.79 & 7.16 & 7.04 & 3.78 & 3.90 & 3.88 & 2.57 & 1.19 \\
\hline 10. The Jug & 7.11 & 8.41 & 12.06 & 11.10 & 15.52 & 6.59 & 8.33 & 8.15 & 7.63 & 6.50 & 5.03 & 5.55 & 4.77 & 3.21 & 2.60 \\
\hline 11. Lewis Wetzel & 1.96 & 1.96 & 3.36 & 4.51 & 6.20 & 3.49 & 4.23 & 5.65 & 4.60 & 6.45 & 5.67 & 4.05 & 2.89 & 1.89 & 2.42 \\
\hline $\begin{array}{l}\text { 12. Little River } \\
\text { 13. Nathaniel }\end{array}$ & 3.03 & 2.12 & 3.75 & 3.38 & 3.15 & 2.30 & 3.07 & 3.47 & 2.06 & 2.14 & 0.44 & 0.62 & 0.64 & 0.82 & 0.73 \\
\hline Mountain & 1.97 & 1.99 & 2.87 & 2.82 & 4.33 & 1.94 & 1.67 & 2.15 & 2.24 & 1.85 & 1.11 & 1.02 & 1.04 & 1.20 & 1.46 \\
\hline 14. Neola & 1.71 & 1.41 & 1.60 & 1.74 & 1.81 & 1.15 & 1.57 & 1.66 & 1.29 & 1.22 & 0.72 & 0.59 & 0.49 & 0.58 & 0.43 \\
\hline 15. Potts Creek & 4.20 & 3.89 & 4.73 & 4.20 & 6.63 & 5.40 & 4.59 & 4.79 & 4.07 & 2.45 & 1.44 & 0.97 & 0.88 & 1.64 & 1.08 \\
\hline 16. R.D. Bailey & 0.60 & 0.40 & 0.47 & 0.46 & 0.47 & 0.44 & 0.51 & 0.49 & 0.53 & 0.70 & 1.34 & 0.60 & 0.77 & 1.30 & 1.90 \\
\hline 17. Sleepy Creek & 5.09 & 4.90 & 6.00 & 6.02 & 5.56 & 3.90 & 4.34 & 4.48 & 4.47 & 4.56 & 3.07 & 2.01 & 2.21 & 3.17 & 3.01 \\
\hline 18. Stonecoal & 7.78 & 5.05 & 7.78 & 6.79 & 6.29 & 3.64 & 6.95 & 5.30 & 4.22 & 3.97 & 2.57 & 2.90 & 3.06 & 4.05 & 3.23 \\
\hline 19. Stoney Run & 3.28 & 2.01 & 3.57 & 2.64 & 3.20 & 2.65 & 2.59 & 2.77 & 2.17 & 1.21 & 0.84 & 0.72 & 0.89 & 1.05 & 0.51 \\
\hline 20. Trout Run & 2.92 & 3.13 & 4.09 & 4.41 & 5.43 & 3.71 & 5.29 & 4.81 & 3.36 & 3.01 & 2.31 & 1.92 & 2.02 & 1.83 & 1.66 \\
\hline
\end{tabular}




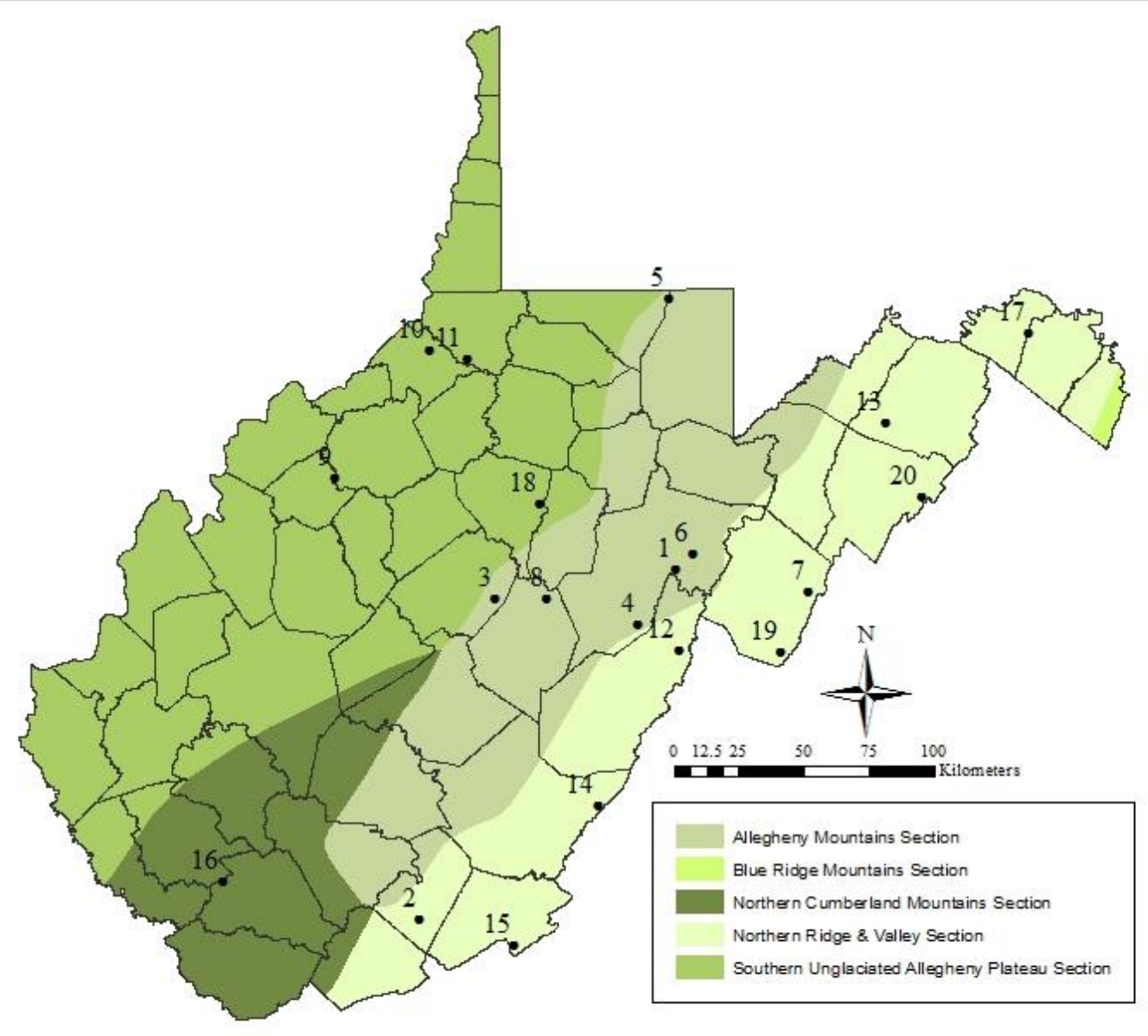

Figure 1. Locations of West Virginia Division of Natural Resources deer-browse exclosure sites, 1984 - 2007.
1. Beaverdam
5. Coopers Rock
9. Hughes River
13. Nathaniel Mt.
17. Sleepy Creek
2. Bluestone
6. Daniels Run
10. The Jug
14. Neola
18. Stonecoal
3. Centrailia
7. Dice Run
11. Lewis Wetzel
15. Potts Creek
19. Stoney Run
4. Cheat Mt.
8. Holly River
12. Little River
16. R.D. Bailey
20. Trout Run 


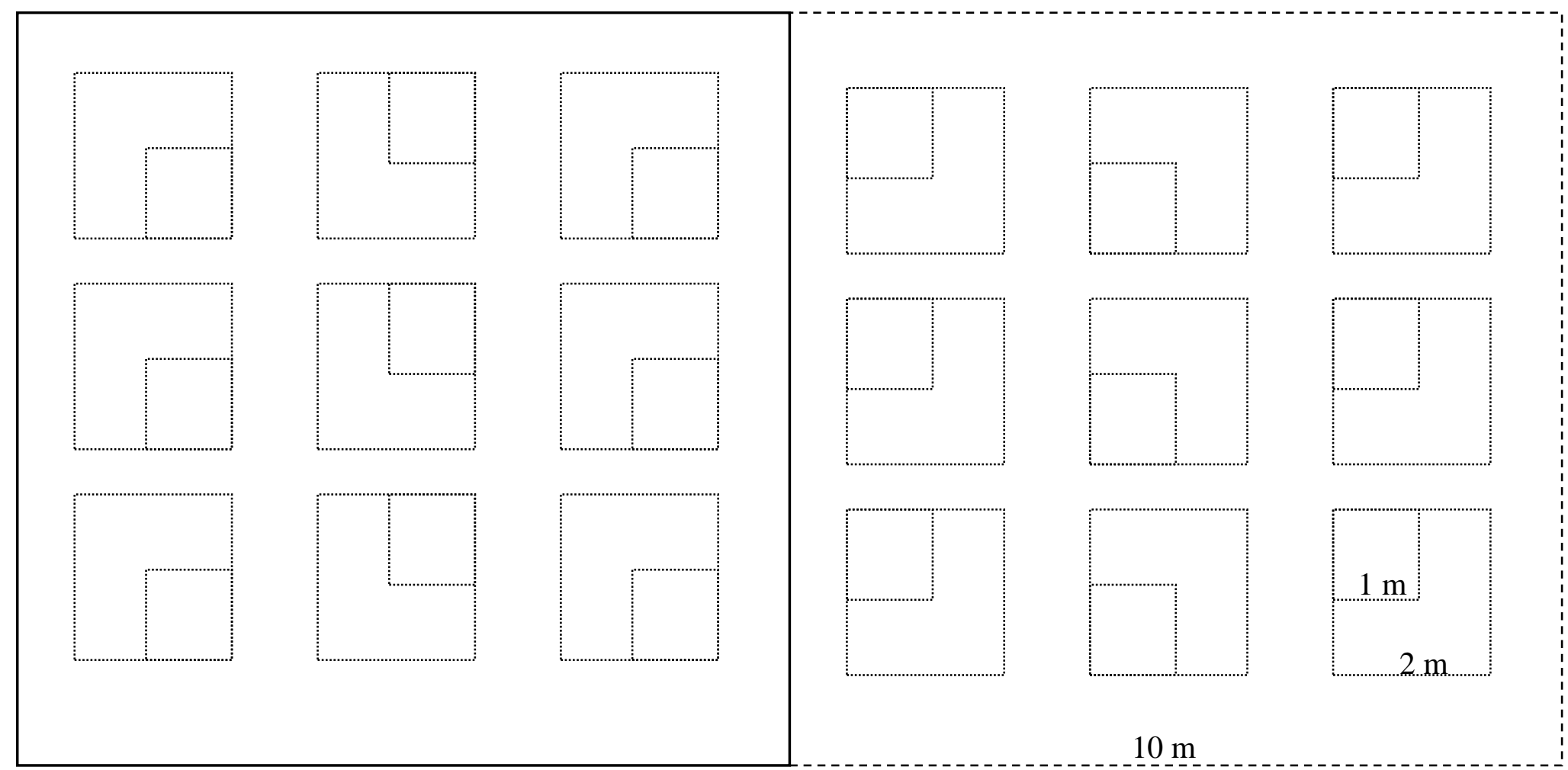

Figure 2. Design of control and treatment plots. Ten meter squares indicate the location of fence and boundary of control plots. Two meter squares indicate the plots measuring understory cover. One meter square indicates the plots measuring ground cover. 


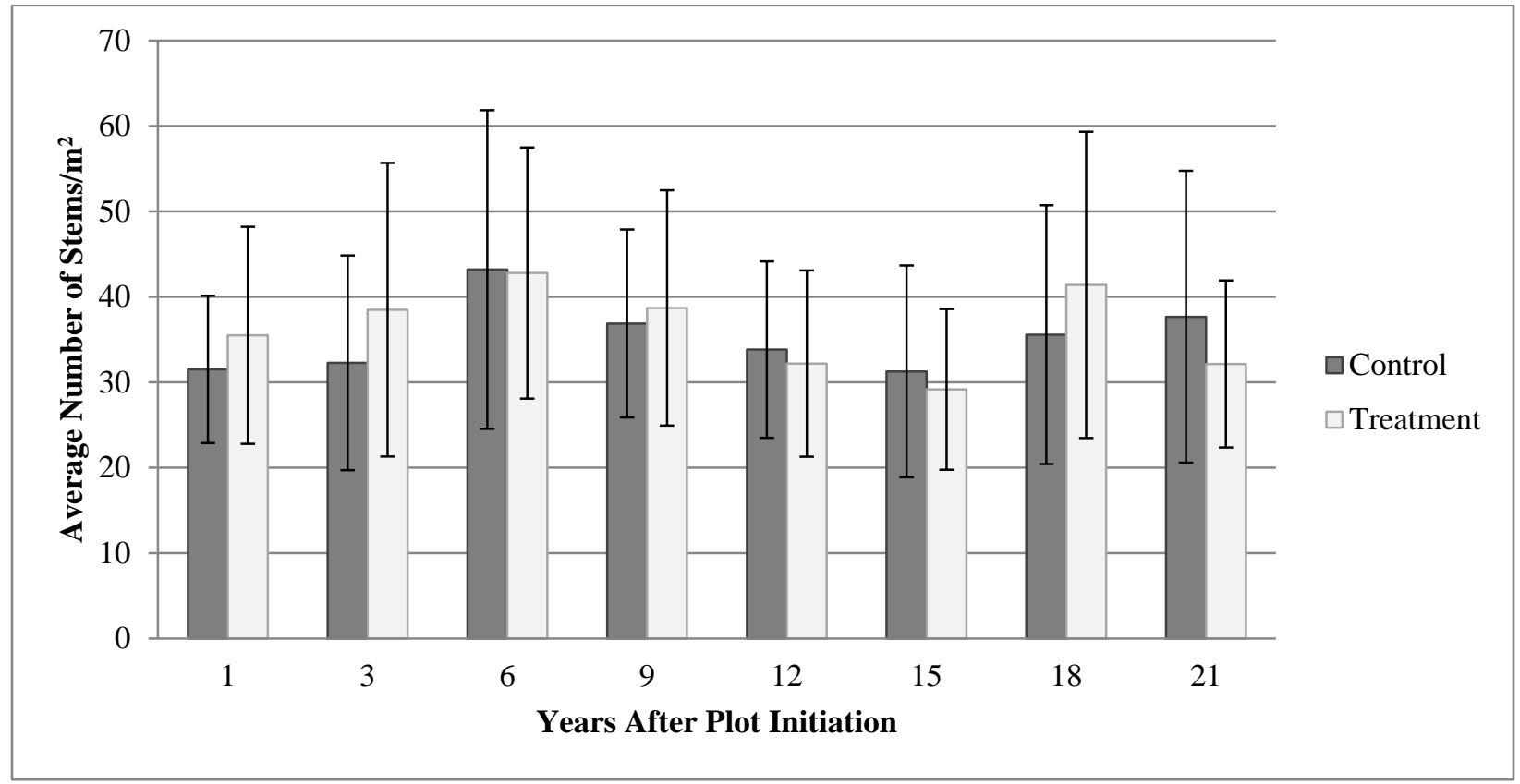

Figure 3. The average stem abundance at ground cover level in West Virginia Division of Natural Resources control and exclosure plots, 1984 - 2007. 


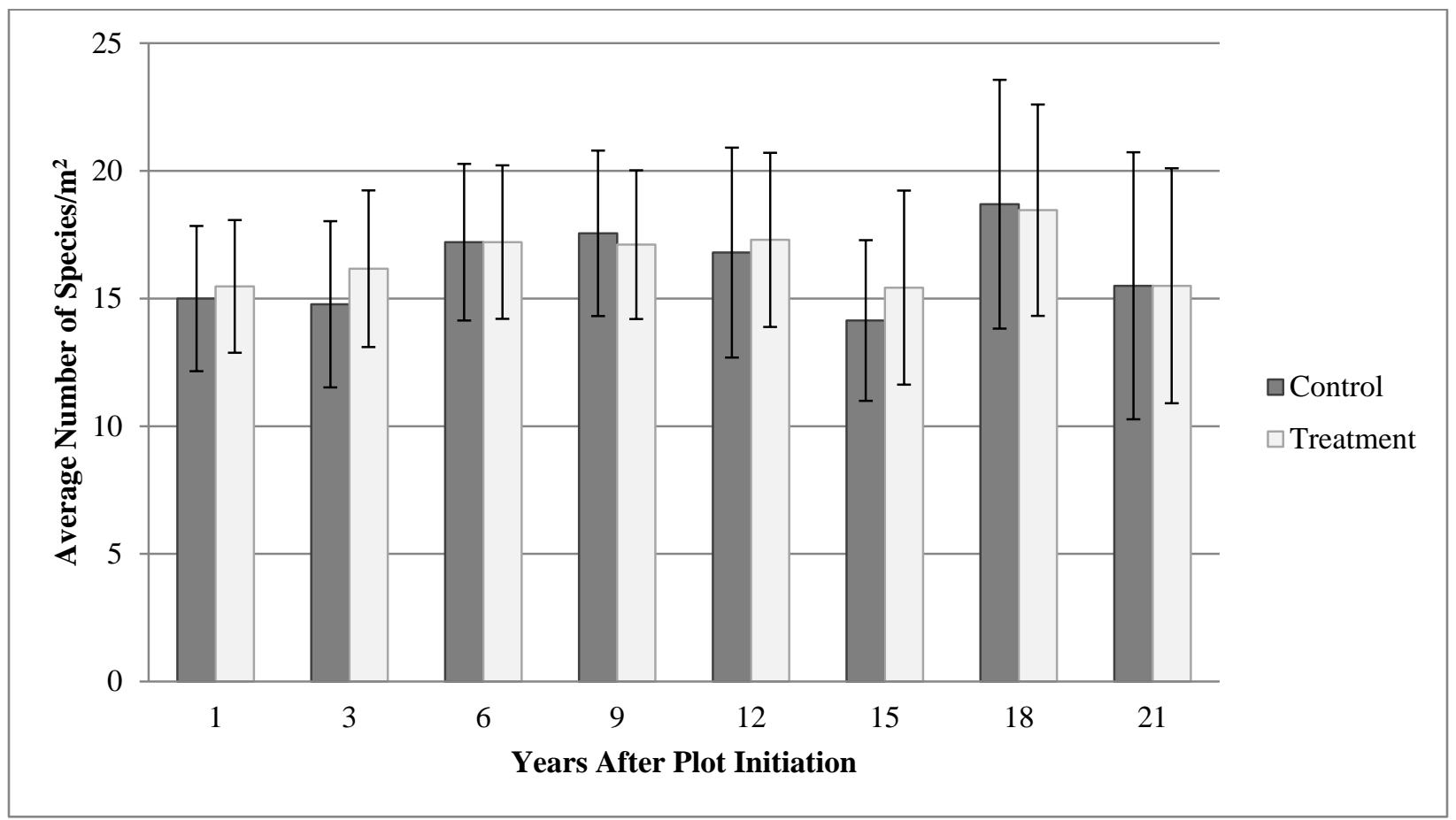

Figure 4. The average species richness at ground cover level in West Virginia Division of Natural Resources control and exclosure plots, 1984 - 2007. 


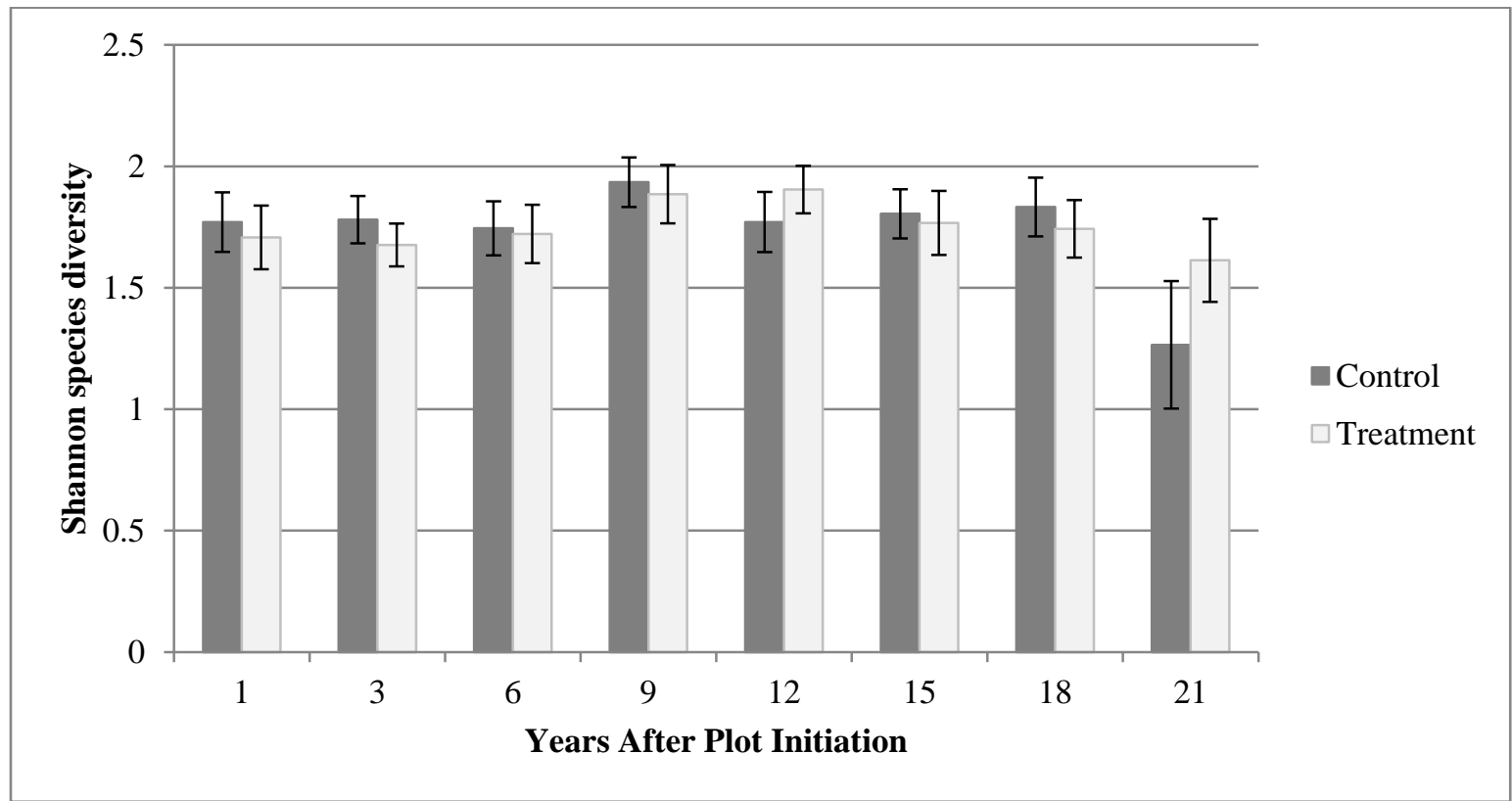

Figure 5. Average Shannon diversity index at the ground cover level in West Virginia Division of Natural Resources control and exclosure plots, $1984-2007$. 


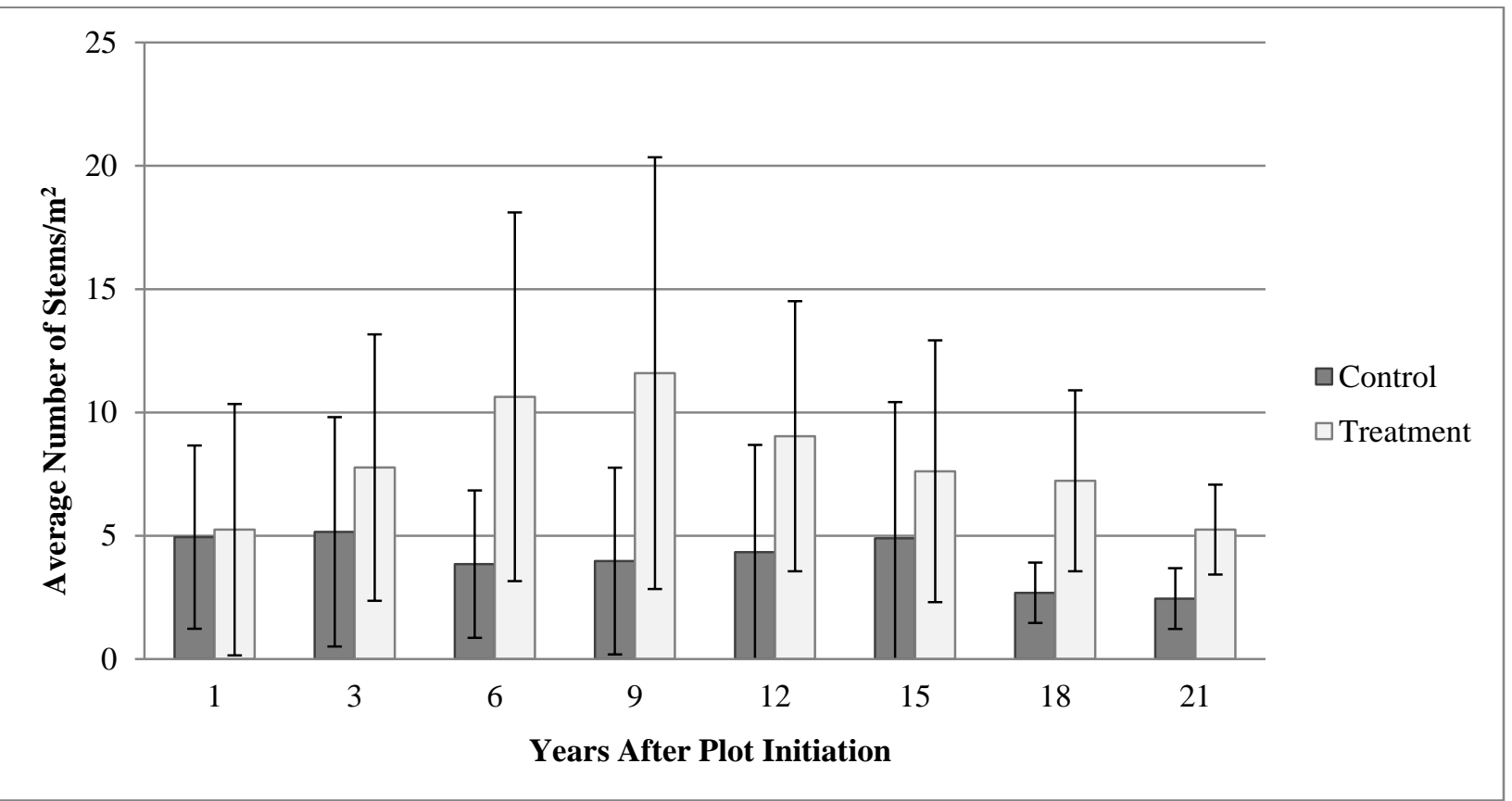

Figure 6. The average stem density at understory level in West Virginia Division of Natural Resources control and exclosure plots, 1984 - 2007. 


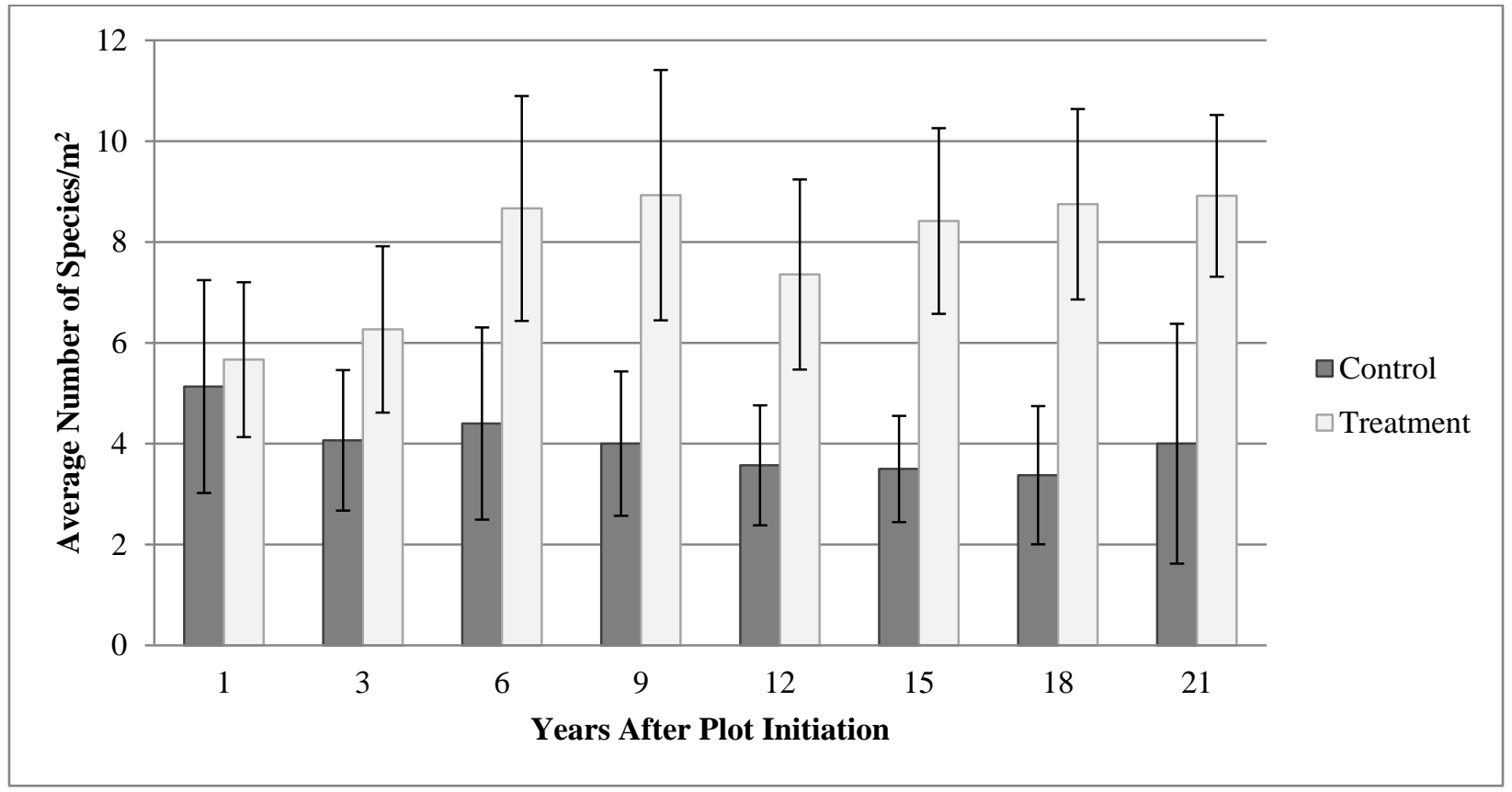

Figure 7. The average species richness at understory level in West Virginia Division of Natural Resources control and exclosure plots, $1984-2007$. 


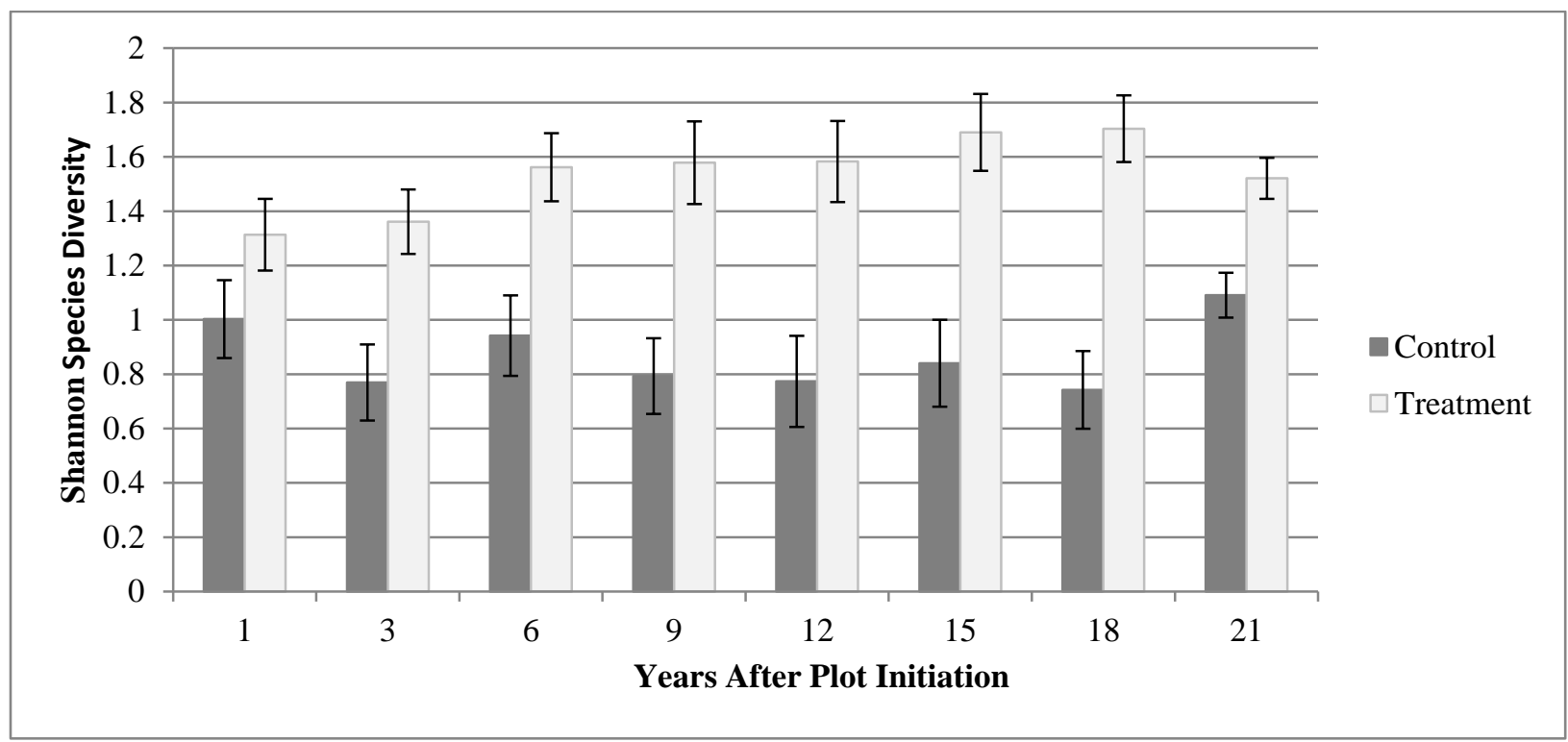

Figure 8. Average Shannon diversity index at the understory level in West Virginia Division of Natural Resources control and exclosure plots, 1984 - 2007. 


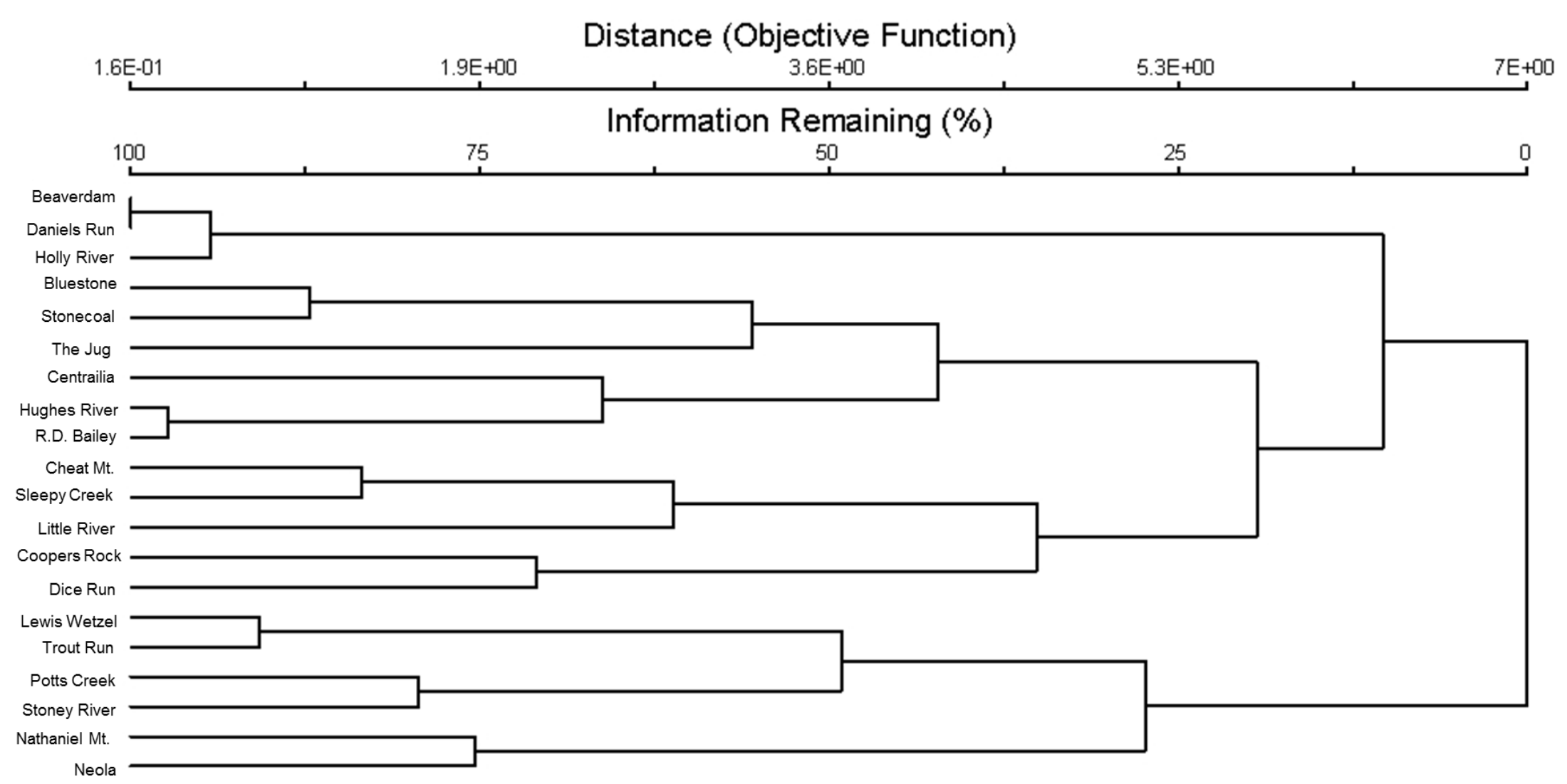

Figure 9. Hierarchical cluster analysis of West Virginia Division of Natural Resources groundcover exclosure plots, $1984-2007$. 


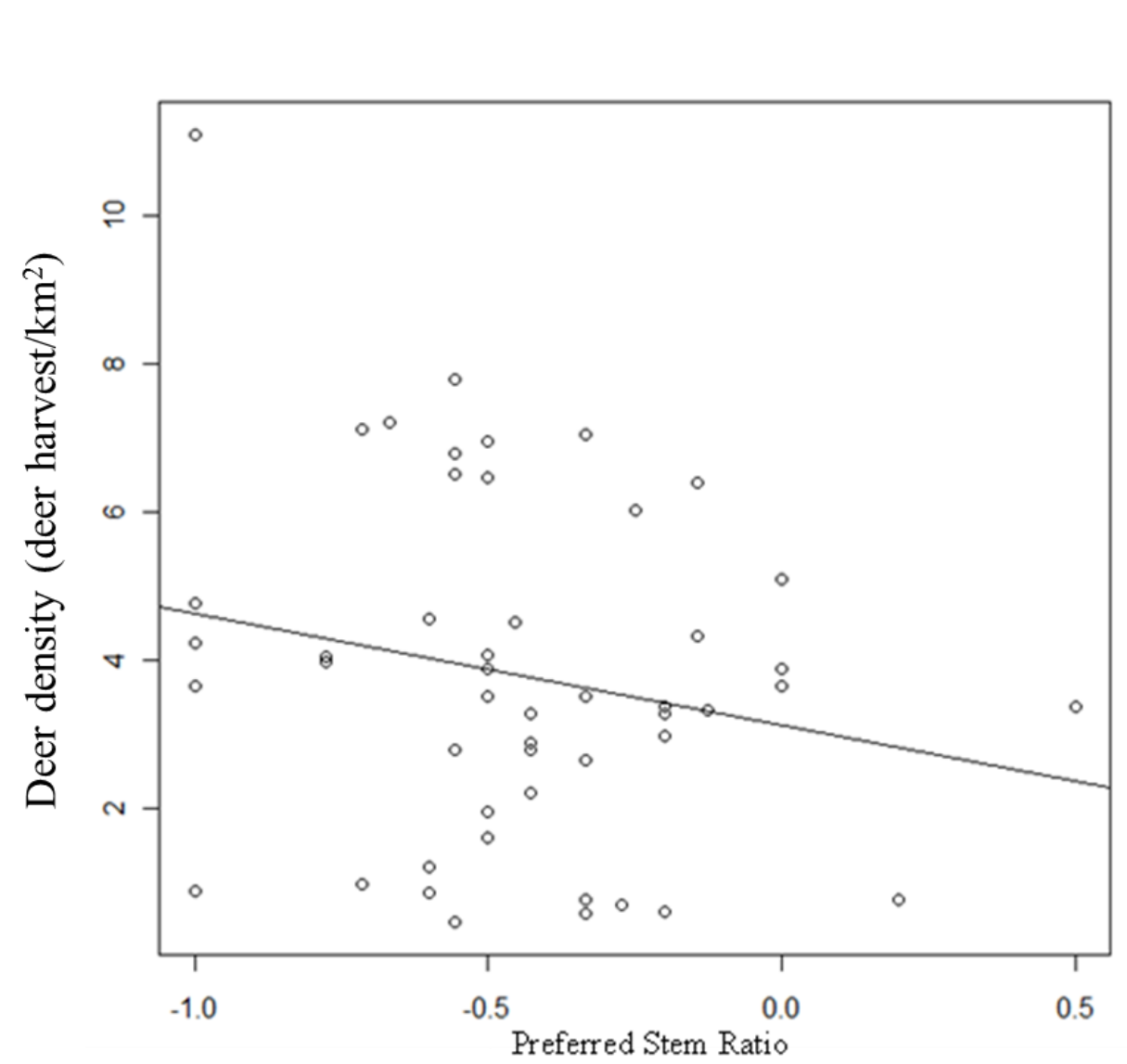

Figure 10. The relation between seedling/sapling ratio of preferred browse species and total white-tailed deer harvest at West Virginia Division of Natural Resource exclosure sites, 1993 2005. 


\title{
CHAPTER V
}

\section{WETLAND SEED DISPERSAL BY WHITE-TAILED DEER IN CANAAN VALLEY, WV}

\author{
Kelley L. Flaherty ${ }^{1}$, James S. Rentch, and James T. Anderson \\ West Virginia University \\ Division of Forestry and Natural Resources \\ P.O. Box 6125 \\ Morgantown, WV 26506-6125 \\ Email: flaherty@calu.edu
}

1 corresponding author

ABSTRACT: Endozoochory, the consumption and dispersal of seeds by animals, plays an important role in the propagation and dispersal of many plant species. White-tailed deer (Odocoileus virginianus Zimm.) have been cited as potential long-distance dispersers of both native and exotic plant species in North America. The potential for dispersal of wetland plants by deer has not been examined. We collected naturally-deposited white-tailed deer fecal pellet piles from wetlands in Canaan Valley, WV in the summer and fall of 2005 and 2006. We coldstratified all pellet piles and germinated seedlings over a layer of sterile potting mix. We determined the percentage of germinated seedlings with a facultative wetland (FACW; plants with $67-99 \%$ frequency of occurrence in wetlands) or obligate wetland (OBL; plants with > 99\% frequency of occurrence in wetlands) plant indicator status in the northeastern United States and compared the frequency of occurrence to those of germinated plants with facultative upland (FACU; plants with $67-99 \%$ frequency of occurrence in non-wetlands) indicator status. We identified 38 unique species germinating from pellet piles over the two year period. Of these 38 species, $38 \%$ had a FACU status, $18 \%$ were FACW, and $21 \%$ were OBL. Additionally, $42 \%$ were graminoid species; forbs and woody species accounted for $29 \%$ each. Seed dispersal by large herbivores is often not considered for wetland plants; however, these data suggest that 
passage by herbivores may be as viable for wetland adapted plants as for upland plants.

Additionally, as these herbivores tend to have larger home ranges than some other wetlandadapted mammals, they could be a valuable means of seed transport between isolated wetland patches and could function in maintaining metapopulations of wetland species. 


\section{INTRODUCTION}

Plant populations differ from animals in that they are sessile and individuals cannot actively disperse from patch to patch. Instead, dispersal is tied directly to reproduction and is often more random in nature than dispersal of animal populations (Hansson 1991). Plants use a variety of vectors as both pollen and seed transports (Drezner et al. 2001). Many plants rely on wind or water to disperse pollen and seeds. That may allow them to colonize patches at great distances but in patchy environments, wind dispersal does not ensure pollen or seeds reach patches with favorable growing conditions (Drezner et al. 2001). Plants that rely on herbivores as seed dispersers may ensure seedling establishment in other suitable patches by using fruit or foliage as an attractant to occupied patches (Janzen 1984; Willson 1993; Witmer 2001; Williams et al. 2008; Iravani et al. 2011). Up to $60 \%$ of the plants in temperate forests may be adapted for endozoochory (Grünewald et al. 2010; Thorsen et al. 2011); however, the type of disperser may affect the distance and time it takes for plant species to disperse via endozoochory (Tanentzap et al. 2012).

The evolution of fruit is believed to have occurred as a means to attract herbivores and frugivores to consume both fruit and seed to be deposited after digestion, ideally in nutrient rich fecal material (Willson and Whelan 1990; Beck and Vander Wall 2010). Additionally, Janzen (1984) hypothesized that in many plants that do not bear fruit, the vegetation acts as an attractant to herbivores who then consume seeds with vegetative matter. However, the colonization of unoccupied patches may still be random as plants cannot attract the herbivores to suitable patches which they do not occupy. Conversely, some herbivores may consume seeds that are not adapted to pass through the digestive tract thus reducing the potential for both increasing the local population or colonization of new patches (Furedi and McGraw 2004). 
Drezner et al. (2001) discussed the method of seed dispersal of riparian plants and argued that obligate wetland plants are more often dispersed by water or wind while upland plants are more often dispersed by animals. This study evaluated few obligate wetland plants $(n=3)$ and many upland plants. Additionally, the traditional method of determining dispersal mechanism is to classify plants based on seed characteristics. However, many seeds do not have characteristic signs for a particular dispersal method, some species may have more than one dispersal method (Drezner et al. 2001) and, though a seed may be physically adapted for one type of dispersal, it is not known whether or not that seed could still germinate if consumed by an herbivore.

\section{The Role of White-tailed Deer in Seed Dispersal}

Much of the research concerning the effects of deer on plant communities have focused on their role as browsers and the potential for overbrowsing of plants (Alverson and Waller 1997; Stromayer and Warren 1997; Royo et al. 2010). However, several studies have looked at the role of white-tailed deer as both seed predators and seed dispersers (Cambell and Gibson 2001; Vellend et al. 2003; Furedi and McGraw 2004; Myers et al. 2004; Bartuszevige and Endress 2008). Due to their large home-range size (e.g. 66 - 235 ha in WV, Campbell et al. 2004) and the potential to retain material in the digestive tract for three or more days (Mautz and Petrides 1971; Moussie et al. 2005), white-tailed deer have the potential to carry seeds great distances (Janzen 1984). Vellend et al. (2003) suggested that this would result in $95 \%$ of germinable seeds being deposited more than $100 \mathrm{~m}$ from the parent plant and $30 \%$ deposited more than $1 \mathrm{~km}$ from the parent plant. This may have a considerable effect on metapopulation initiation, growth, and gene flow of irregularly distributed and rare plant species (Myers et al. 2004). 
Myers et al. (2004) found that 72 species of forest and old-field plants germinated from fecal pellet samples with a mean of 38 germinations per pellet group. The germinated seeds ranged from forbs to tree species and while some were seeds distributed through fruiting mechanisms, most were not. However, Cambell and Gibson (2001) found only 2 species germinated from 22 pellet group samples.

Although deer may play an important part in the dispersal of seed for many plants, they may also play a role in the spread of exotic species (Cambell and Gibson 2001; Bartuszevige and Endress 2008; Williams et al. 2008). Additionally, for some plant species, including American ginseng (Panax cinquefolius) (Furedi and McGraw 2004), white-tailed deer are demonstrated seed predators or consumers, that is, all seeds consumed in the act of herbivory are digested or are non-viable once passed through the digestive system, thus reducing the realized reproductive output of these plants.

Obligate or facultative wetland plants are most likely adapted for dispersal within a small area by wind, water, or animals that frequent various wetland habitats (i.e., waterfowl) to ensure that seeds are deposited in favorable growing conditions. As a result, long-distance colonization rates for wetland plant metapopulations, especially in fragmented wetland habitats, may be low. We believe many wetland plants are not adapted to long distance seed dispersal by large ungulate herbivores such as white-tailed deer and are thus consumed rather than carried by deer. We tested the null hypothesis that there would be no difference in the proportion of wetland and upland plants that are able to germinate after being consumed by white-tailed deer by collecting natural fecal pellet piles from in and around the Canaan Valley, WV, high-elevation wetland complex to determine the species of germinable seeds they contain as well as what percentage come from obligate and facultative wetland plant species. 


\section{Methods}

Study Area

Canaan Valley, located in Tucker County, West Virginia, is the highest elevation valley east of the Rocky Mountains (Fortney 1975). As such, the climate and accordingly, the vegetation, of the valley are more similar to northern boreal forests than to the deciduous forests of surrounding West Virginia. Once home to large stands of red spruce (Picea rubens), intense logging followed by fires drastically changed the soils and vegetation of the valley to their present condition (Fortney 1975). The valley floor averages $975 \mathrm{~m}$ above sea level. This, coupled with surrounding mountains which rise $150-240 \mathrm{~m}$ above the valley, creates a relatively cool, moist climate and a short growing season. The average annual precipitation is $137 \mathrm{~cm}$ and annual snowfall is $305 \mathrm{~cm}$ (Fortney 1993). The average growing season is approximately 90 days (Beverage 1967). Both of these characteristics set this area apart from low elevation wetland and upland areas in the surrounding counties.

Canaan Valley encompasses about $176 \mathrm{~km}^{2}$ (17,600 ha) of land. Approximately $20 \%$ of the land area is made up of various wetland community types and another $23 \%$ is northern hardwood forest (Figure 1). Of all the high-elevation wetlands in West Virginia, Canaan Valley is home to the largest contiguous wetland complex (3,000 ha, Byers et al. 2007). Fortney (1975) described 27 distinct wetland community types ranging from quaking aspen (Populus tremuloides) groves to sphagnum (Sphagnum spp.) and polytrichum (Polytrichum spp.) bogs. Agriculture, rural development, and recreational land make up the remaining portion of the valley (Michael 1992). Of the 583 plant species recorded in Canaan Valley, 229 (39\%) are forbs, $130(22 \%)$ are graminoids, and $89(15 \%)$ are woody species (trees and shrubs)(Fortney 1975). 
Canaan Valley is home to Canaan Valley State Park (2,433 ha) and the Canaan Valley National Wildlife Refuge (6,729 ha) and, at the time of this study, land owned by the Canaan Valley Institute (1,298 ha), a nonprofit organization. Sampling took place on a combination of these three public access properties in the valley.

\section{Field Methods}

We collected fresh white-tailed deer fecal pellet groups bi-monthly from May to December 2005 and 2006 in wetland habitats. In 2005, we collected pellet piles from along three $300 \mathrm{~m}$ randomly placed transects through both herbaceous, shrub, and forested wetlands within the Canaan Valley National Wildlife Refuge and Canaan Valley State Park. In 2006, six additional transects were added for a total of nine transects at sampling locations within the refuge and state park (Figure 1). We collected piles by walking along transects and selecting fresh pellet piles from those within view. We chose piles that were visibly moist and dark in color. All visible pellets were removed from surrounding vegetation and placed in plastic bags. We did not observe any obvious fallen seeds on pellet piles. We attempted to collect pellets without including surrounding debris, including seeds that may have come from the surrounding vegetation rather than through endozoochory. However, we did not search pellets extensively for these seeds.

Individual pellets were broken by rinsing gently through a $0.5 \mathrm{~mm}$ sieve. The resulting seeds and residual matter were stored in petri dishes at $4^{\circ} \mathrm{C}$ for a period of three months to simulate over-wintering (Myers et al. 2004). Following a three month period of cold stratification, the seeds were spread on top of a layer of potting mix in $10 \mathrm{~cm}$ diameter planting pots and kept moist. Piles were then planted in mid-March in individual pots containing sterile growing medium and were subsequently housed in a greenhouse and watered when needed. The 
trays were kept in greenhouse conditions until germination and identification of species germinated was possible. The number of each plant species that germinated from each pellet group was recorded.

\section{Statistical analysis}

We determined the wetland indicator status of all plants germinated from pellet piles. For the purposes of our analysis, we pooled the species that had OBL (plants with $>99 \%$ frequency of occurrence in wetlands) or FACW (plants with 67 - 99\% frequency of occurrence in wetlands; Lichvar et al. 2014) status as these plants are most likely to be adapted for growth and dispersal in wetlands. We used wetland indicator status values for Eastern Mountains and Piedmont region as listed in the U.S. Army Corps of Engineers National Wetland Plant List (Lichvar et al. 2014). We excluded species that were considered facultative (FAC; plants that are equally likely to be found in uplands and wetlands), species with an unknown status, and species that were only identified to the genus level. We also classified each species as graminoid, forb, or woody species (including trees and shrubs). We used a chi-square test to compare the proportion of species germinated each year that were either UPL (plants with $<1 \%$ frequency of occurrence in wetlands) or FACU (plants with $1-33 \%$ frequency of occurrence in wetlands) with those that were either FACW or OBL. We considered differences at the $P<0.05$ level to be significant. We defined the frequency of occurrence as the number of times each species occurred out of the number of total germinated pellet piles. We also compared the frequency of germination events each year that were either UPL or FACU with those that were either FACW or OBL. We repeated these tests for the proportion and frequency of germination of plants that were graminoid, forbs, or woody. 


\section{RESULTS}

We collected 55 pellet piles in 2005 and 160 pellet piles in 2006 . Of those collected in $2005,45 \%$ of the pellet piles planted germinated at least one species resulting in a total of 14 species (Table 1). Of those collected in $2006,38 \%$ of the pellet piles germinated at least one species resulting in a total of 32 species (Table 2). A total of 38 unique species were identified over a period of two years (two additional seedlings were identified to the genus level). In 2005, there was no significant difference between the proportion of species germinated that have a FACW $(n=3)$ or OBL $(n=5)$ wetland indicator status $(57 \%)$ and those that had a FACU $(n=5$, $35 \%)$ status $\left(\chi^{2}=5.29, P>0.07, \mathrm{n}=14\right)($ Table 1$)$. There was also no difference in the frequency of FACW $(\mathrm{n}=6)$ and OBL $(\mathrm{n}=8)(52 \%)$ plants versus FACU plants $(\mathrm{n}=12,44 \%)\left(\chi^{2}=0.154, P\right.$ $=0.695, n=27)$. In 2005 , both graminoids $(n=6)$ and forbs $(n=6)$ made up $43 \%$ of the species that germinated from pellet piles. This was more than the proportion of woody species $(n=2$, $14 \%)$ that germinated; however, the difference was not considered significant $\left(\chi^{2}=2.29, P<\right.$ $0.31, n=14)$. The frequency of both graminoids $(n=12)$ and forbs $(n=12)(44 \%$ for both $)$ was significantly higher than for woody species $\left(11 \%, \chi^{2}=6.00, \mathrm{n}=3, P=0.049, \mathrm{n}=27\right)$. In 2005, the proportion of individual stems that were FACU (53\%) was more than the combined proportion of FACW (13\%) and OBL (32\%) stems counted (Figure 2); however, this difference was not significant $\left(\chi^{2}=0.373, P=0.541, \mathrm{n}=68\right)$. The proportion of individual stems that were forbs (48\%) and graminoids (45\%) were significantly greater than the proportion of woody stems $\left(6 \%, \chi^{2}=23.14, P<0.001, \mathrm{n}=68\right)$, but the proportion of graminoids and forbs did not significantly differ $\left(\chi^{2}=0.06, P=0.80, \mathrm{n}=68\right)$ (Figure 3$)$.

In $2006,31 \%(n=10)$ of species germinated had a FACU status and $3 \%(n=1)$ had UPL status while $16 \%$ had FACW $(n=5)$ and $25 \%$ had OBL $(n=8)$ wetland indicator status. There 
was no significant difference between the proportion with either UPL or FACU and the proportion with either FACW or OBL status $\left(\chi^{2}=0.36, P=0.55, \mathrm{n}=32\right)$. In 2006, there was no significant difference between the frequency of species with either UPL $(1 \%, n=1)$ or FACU $(45 \%, \mathrm{n}=31)$ and those with either FACW $(13 \%, \mathrm{n}=9)$ or OBL $(19 \%, \mathrm{n}=13)$ status $\left(\chi^{2}=2.28\right.$, $P<0.13, \mathrm{n}=69)$. In $2006,44 \%$ of the species germinated were graminoid $(\mathrm{n}=14), 22 \%$ were forbs $(n=7)$, and $34 \%$ were tree or shrub species $(n=11)$. There were no significant differences between the proportion of species that germinated that were classified as graminoids, forbs, or woody species $\left(\chi^{2}=2.31, P=0.31, \mathrm{n}=32\right)$. The frequency of pellet piles germinating graminoid species $(46 \%, \mathrm{n}=32)$ in 2006 was significantly higher than the frequency of woody $(20 \%, \mathrm{n}=14)$ species $\left(\chi^{2}=7.04, P<0.008, \mathrm{n}=69\right)$, but was not higher than the frequency of forbs $\left(33 \%, \chi^{2}=1.43, P>0.22, \mathrm{n}=69\right)$. In 2006 , the proportion of individual stems that were either UPL (2\%) or FACU (57\%) was significantly more than the combined proportion of FACW $(7 \%)$ and OBL $(14 \%)$ stems counted $\left(\chi^{2}=29.12, P<0.0001, \mathrm{n}=169\right)($ Figure 2$)$. The proportion of individual stems that were forbs (39\%) and graminoids (49\%) were significantly greater than the proportion of woody stems $\left(12 \%, \chi^{2}=35.51, P<0.001, \mathrm{n}=169\right)$ but the proportion of graminoids and forbs did not significantly differ $\left(\chi^{2}=1.73, P=0.19, \mathrm{n}=169\right)$ (Figure 3). In 2005, only one annual species (7\%) germinated and, in 2006, only two annual species $(6 \%)$ germinated.

\section{DISCUSSION}

We observed no difference in the frequency of wetland and upland plants germinating in pellet piles collected in 2005. In 2006, however, we observed a significantly higher abundance of upland germinations though there was no difference in the proportion of species attributed to each group. We attribute the inability to detect a difference in 2005 to the smaller sample size. 
While a difference in frequency of 2006 plants seems to agree with the hypothesis that upland plants may be more adapted to dispersal by white-tailed deer, there was no difference in the proportion of wetland and upland species. The difference in frequency could be attributed to the success of several FACU plants (Table 2), such as Oxalis dilleni, which occurred in 11 pellet piles collected that year.

Although we did observe the presence of FACW and OBL wetland species germinating in pellet piles, these observations may underestimate the actual presence of germinable wetland species in pellet piles. All pellet piles were grown in moistened but not saturated soil. Alternate conditions may be required to germinate all wetland species present in a sample. Saturated conditions would be present for at least some of the pellet piles deposited naturally by whitetailed deer. By definition, FACU plants may occur in wetlands between 1 and $33 \%$ of the time. Likewise, FACW plants may occur in uplands between 1 and 33\% of the time (Lichvar et al. 2014). Therefore, the distinction between plants adapted for uplands and those adapted for wetlands is not necessarily clear-cut and may confound the findings of this study. Drezner et al. (2001) discussed the characteristics of seeds that support wind, water, and animal dispersal. However, they noted that many seeds do not have characteristics that fit neatly into one of these categories. Many of the small graminoid wetland seeds (e.g. Juncus effusus and Glyceria canadensis) germinated in this study may fall into that category.

Our study shows that some wetland plants can be successfully dispersed by white-tailed deer. As they have relatively large home ranges compared to other mammal species (Willson 1993), deer have the potential to disperse seeds of wetland species between isolated wetland patches. As dispersers, white-tailed deer could play a role in maintaining or enhancing metapopulations of wetland plants patchily distributed in an upland matrix (Vellend et al. 2003). 
However, white-tailed deer may also confound wetland restoration by successfully dispersing seeds of some exotic species (Vellend 2002; Myers et al. 2004; Bartuszevige and Endress 2008) We found seven exotic species germinated in our pellet piles (Tables 1 and 2).

A high proportion of germinated species were graminoids. In both years, there was no significant difference between proportions of species that were graminoids, forbs, or woody species. We found no difference in the frequency of species in pellet piles in 2005. Again, we believe this was due to the low sample size. In 2006, we found that there was significantly more graminoids than woody species. Endozoochory by large mammals is often associated with the coevolution of fleshy fruits (Willson 1993; Beck and Vander Wall 2010). However, Janzen (1984) suggested that the foliage of forbs and grasses may attract herbivores to disperse small seeds. While fleshy fruit may attract seed dispersers, the mastication process may destroy larger seeds. Small, rounded, hard seeds may support passage through the digestive tract of ungulates better than larger seeds (Moussie et al. 2005; Iravani et al. 2011). Our results support this "foliage as fruit" hypothesis (Janzen 1984) and suggest that graminoids may be better adapted to dispersal by herbivores even though they are not traditionally classified as animal-dispersed seeds.

Successful propagation and dispersal of graminoid species by deer may help to maintain or expand herbaceous openings at both wetland and upland sites. Large areas of Canaan Valley consist of wet meadow habitat. White-tailed deer may help to maintain these meadows, not only by reducing the growth of woody species through browse, but also by dispersing the seeds of graminoid species (Bartuszevige and Endress 2008; Iravani et al. 2011). Many studies have examined the influence of white-tailed deer on upland forest habitat. They are thought to affect the regeneration of forest species through the over-browsing of seedlings (Rooney 2009; 
Griscom et al. 2011; Tanentzap et al. 2012). Over-browsing by deer can have secondary effects by increasing the growth of unpalatable ferns that shade seedlings, which in turn, harbor small mammals that may act as seed predators (de la Cretaz and Kelty 2002; Royo et al. 2010; Griscom et al. 2011). As dispersers of graminoid species, deer also may reduce the capacity for woody species regeneration by increasing the prevalence of grass species on the forest floor. Many studies on the effects of white-tailed deer density on vegetation have been conducted with the use of deer exclosures which effectively reduce the deer density to zero (Rooney 2009; Tanentzap et al. 2012). These studies have been criticized because eliminating native deer from an ecosystem is not a viable or desirable option. These studies may also be criticized because they eliminate both the positive and negative potential for seed germination from pellet piles.

A key question raised by the results of this study are to what degree these data are representative of the species present in the Canaan Valley ecosystem that are germinable when passed though the digestive system of white-tailed deer and what percentage of the total seeds consumed remain intact for each species. Of those species recorded in Canaan Valley, 20\% are obligate wetland species (OBL), 18\% are facultative wetland species (FACW), 15\% are facultative species (FAC), 24\% are facultative upland species (FACU), and only 3\% are upland species (UPL). We believe the abundance and frequency of seeds in pellet piles is likely not a good indicator of the proportions of these plants in the diet of white-tailed deer and should not be used as an indicator of such. Additionally, of those plants eaten, some may not have germinated under the conditions provided. We recorded the presence of species at our study sited that have been reported by others as having germinated from deer pellet piles but did not occur in our samples (e.g. Achillea millefolium and Festuca ovina; Myers et al. 2004; Iravani et al. 2011). A higher sample size may lead to additional species that were not present in our samples as well as 
the opportunity to apply different treatments that could promote the germinations of different species. All studies that we are aware of concerning the germination of plant species from pellet piles have been conducted under highly controlled conditions. It remains to be seen, however, if these results translate to pellet piles that germinate under more natural conditions.

\section{ACKNOWLEDGMENTS}

We thank Valerie Richards for her assistance in maintaining germinating plants and William Grafton for assistance in identifying seedlings. Funding for this project was provided by Canaan Valley Institute, Regional Research Institute, and West Virginia University Davis College of Agriculture, Natural Resources, and Design (McIntire-Stennis). This is scientific article number xxxx of the West Virginia University Agricultural and Forestry Experiment Station.

\section{Literature Cited}

Alverson W.S., and D.M. Waller. 1997. Deer populations and the widespread failure of hemlock regeneration in northern forests. Pp. 280-297 in W.J. McShea, H.B. Underwood, and J.H. Rappole, eds. The science of overabundance: deer ecology and population management. Smithsonian Institution Press. Washington, D.C.

Bartuszevige, A.M., and B.A. Endress. 2008. Do ungulates facilitate native and exotic plant spread? Seed dispersal by cattle, elk and deer in northeastern Oregon. Journal of Arid Environments 72:904-913.

Beck, M.J., and S.B. Vander Wall. 2010. Seed dispersal by scatter-hoarding rodents in arid environments. Journal of Ecology 98:1300-1309.

Beverage, W. 1967. Soil survey, Tucker County, West Virginia. United States Department of Agriculture Soil Conservation Service. Washington, D.C. 
Byers, E.A., J.P. Vanderhorst, and B.P. Streets. 2007. Classification and conservation assessment of high elevation wetland communities in the Allegheny mountains of West Virginia. West Virginia Natural Heritage Program, WVDNR. Elkins, WV.

Cambell, J.E., and D.E. Gibson. 2001. The effect of seeds of exotic species transported via horse dung along trail corridors. Plant Ecology 157:23-35.

Campbell, T.A., B.R. Laseter, W.M. Ford, and K.V. Miller. 2004. Topographic home ranges of white-tailed deer in the central Appalachians. Southeastern Naturalist 3:645-652.

de la Cretaz, A.L., and M.J. Kelty. 2002. Development of tree regeneration in fern-dominated forest understories after reduction of deer browsing. Restoration Ecology 10:416-426.

Drezner, T.D., P.L. Fall, and J.C. Stromberg. 2001. Plant distribution and dispersal mechanisms at Hassayampa River Preserve, Arizona, U.S.A. Global Ecology and Biogeography 10:205-217.

Fortney, R.H. 1975. The Vegetation of Canaan Valley, West Virginia: a taxonomic and ecological study. Dissertation; West Virginia University, Morgantown, WV

Fortney, R.H. 1993. Canaan Valley - An area of special interest within the upland forest region. Pp. 47-65 in S. L. Stephenson, ed. Upland Forests of West Virginia. McClain Printing Co., Parsons, WV.

Furedi, M.A., and J.A. McGraw. 2004. White-tailed deer: dispersers or predators of American ginseng seed? American Midland Naturalist 152:268-276.

Griscom, B., H. Griscom, and S. Deacon. 2011. Species-specific barriers to tree regeneration in high elevation habitats of West Virginia. Restoration Ecology 19:660-670.

Grünewald, C., N. Breitbach, and K. Böhning-Gaese. 2010. Tree visitation and seed dispersal 
of wild cherries by terrestrial mammals along a human land-use gradient. Basic and Applied Ecology 11:532-541.

Hansson, L. 1991. Dispersal and connectivity in metapopulations. Biological Journal of the Linnean Society 42:89-103.

Iravani, M., M. Schütz, P.J. Edwards, A.C. Risch, C. Scheidegger, and H.H. Wagner. 2011. Seed dispersal in red deer (Cervus elaphus L.) dung and its potential importance for vegetation dynamics in subalpine grasslands. Basic and Applied Ecology 12:505-515.

Janzen, D.H. 1984. Dispersal of small seeds by big herbivores: foliage is the fruit. American Naturalist 123:338-353.

Lichvar, R.W., M. Butterwick, N.C. Melvin, and W.N. Kirchner. 2014. The national wetland plant list: 2014 update of wetland plant ratings. Phytoneuron 41:1-42.

Mautz, W.M., and G.A. Petrides. 1971. Food passage rate in the white-tailed deer. Journal of Wildlife Management 35:723-731.

Michael, E.D. 1992. Impact of deer browsing on regeneration of balsam fir in Canaan Valley, West Virginia. Northern Journal of Applied Forestry 9:89-90.

Moussie, A. M., C.E.J. Van der Veen, C.F. Veen, and R. Van Diggelen. 2005. Ecological correlates of seed survival after ingestion by fallow deer. Functional Ecology 19:284290.

Myers, J.A., M. Vellend, S. Gardesca, and P.L. Marks. 2004. Seed dispersal by white-tailed deer; implications for long-distance, migration and invasion of plants in eastern North America. Oecologica 139:35-44.

Rooney, T.P. 2009. High white-tailed deer densities benefit graminoids and contribute to biotic homogenization of forest ground-layer vegetation. Plant Ecology 202:103-111. 
Royo, A.A., S.L. Stout, D.S. deCalesta, and T.G. Pierson. 2010. Restoring forest herb communities through landscape-level deer herd reductions: is recovery limited by legacy effects? Biolical Conservation 143:2425-2434.

Stromayer, K.A.K., and R.J. Warren. 1997. Are over abundant deer herds in the eastern United States creating alternate stable states in forest plant communities? Wildlife Society Bulletin 25:227-234.

Tanentzap, A.J., K.J. Kirby, and E. Goldberg. 2012. Slow responses of ecosystems to reductions in deer (Cervidae) populations and strategies for achieving recovery. Forest Ecology and Management 264:159-166.

Thorsen, M.J., P.J. Seddon, and K.J.M. Dickinson. 2011. Faunal influences on New Zealand seed dispersal characteristics. Evolutionary Ecology 25:1397-1426.

Williams, S.C., J. S. Ward, and U. Ramakrishnan. 2008. Endozoochory by white-tailed deer (Odocoileus virginianus) across a suburban/woodland interface. Forest Ecology and Management 255:940-947.

Willson, M.F. 1993. Mammals as seed-dispersal mutualists in North America. Oikos 67: $159-176$.

Willson, M.F., and C.J. Whelan. 1990. The evolution of fruit color in fleshy-fruited plants. American Naturalist 136:790-809.

Witmer, M.C. 2001. Nutritional interactions and fruit removal: cedar waxwings consumption of Viburnum opulus fruits in spring. Ecology 82:3120-3130.

Vellend, M. 2002. A pest and an invader: white-tailed deer (Odocoileus virginianus Zimm.) as a seed dispersal agent for honeysuckle shrubs (Lonicera L.). Natural Areas Journal 22:230-234. 
Vellend, M., J.A. Myers, S. Gardescu, and P.L. Marks. 2003. Dispersal of Trillium seeds by deer: implications for long-distance migration of forest herbs. Ecology 84:1067-1072. 
Table 1. Species germinated from 55 white-tailed deer pellet piles collected in 2005 from 3 locations in Canaan Valley, West Virginia.

\begin{tabular}{|c|c|c|c|c|c|c|}
\hline Latin Name & Common Name & Form $^{a}$ & Life $^{b}$ & Frequency & Abundance & Indicator Status \\
\hline Carex crinita (L.) & fringed sedge & G & $\mathrm{P}$ & 3 & 10 & OBL \\
\hline Danthonia compressa (Austin) & flattened oatgrass & $\mathrm{G}$ & $\mathrm{P}$ & 2 & 12 & FACU \\
\hline Glyceria canadensis (Michx.) & rattlesnake mannagrass & $\mathrm{G}$ & $\mathrm{P}$ & 1 & 1 & OBL \\
\hline Juncus canadensis (J. Gay ex Laharpe) & Canadian rush & $\mathrm{G}$ & $\mathrm{P}$ & 1 & 2 & OBL \\
\hline Juncus effusus (L.) & common rush & $\mathrm{G}$ & $\mathrm{P}$ & 4 & 5 & FACW \\
\hline Lobelia inflata (L.) & Indian-tobacco & $\mathrm{F}$ & A & 2 & 2 & FACU \\
\hline Lycopus uniflorus (Michx.) & northern bugleweed & $\mathrm{F}$ & $\mathrm{P}$ & 1 & 1 & OBL \\
\hline Mimulus ringens $(\mathrm{L})$. & Allegheny monkey flower & $\mathrm{F}$ & $\mathrm{P}$ & 1 & 9 & OBL \\
\hline Muhlenbergia schreberi (Scribn) & nimblewill & $\mathrm{G}$ & $\mathrm{P}$ & 1 & 1 & FAC \\
\hline Oxalis dillenii (Jacq.) & wood sorrel & $\mathrm{F}$ & $\mathrm{P}$ & 6 & 18 & FACU \\
\hline Plantago rugelii (Decne.) & blackseed plantain & $\mathrm{F}$ & $\mathrm{P}$ & 2 & 1 & FACU \\
\hline Spiraea alba (Du Roi) & meadowsweet & $\mathrm{W}$ & $\mathrm{P}$ & 1 & 1 & FACW \\
\hline Spiraea tomentosa (L.) & steeplebush & $\mathrm{W}$ & $\mathrm{P}$ & 2 & 3 & FACW \\
\hline Veronica officinalis (L.)* & common speedwell & $\mathrm{F}$ & $\mathrm{P}$ & 1 & 2 & FACU \\
\hline
\end{tabular}

a. Forms are designated by $\mathrm{G}=$ graminoid, $\mathrm{F}=\mathrm{forb}$, and $\mathrm{W}=$ woody species.

b. Life forms are designated by $\mathrm{A}=$ annual and $\mathrm{P}=$ perennial.

An [*] indicates plants are exotic to the U.S. 
Table 2. Species germinated from 160 white-tailed deer pellet piles collected in 2006 from 9 locations in Canaan Valley, WV.

\begin{tabular}{|c|c|c|c|c|c|c|}
\hline Latin Name & Common Name & Form $^{a}$ & Life $^{b}$ & Frequency & Abundance & Indicator Status \\
\hline Agrostis perennans (Walter) & upland bentgrass & $\mathrm{G}$ & $\mathrm{P}$ & 2 & 13 & FACU \\
\hline Anthoxanthum odoratum (L.)* & sweet vernal grass & $\mathrm{G}$ & $\mathrm{P}$ & 3 & 4 & FACU \\
\hline Apocynum cannabinum (L.) & Indian hemp & $\mathrm{F}$ & $\mathrm{P}$ & 1 & 2 & FACU \\
\hline Carex crinita $(\mathrm{L})$. & fringed sedge & $\mathrm{G}$ & $\mathrm{P}$ & 3 & 8 & OBL \\
\hline Carex debilis (Michx.) & white-edge sedge & $\mathrm{G}$ & $P$ & 4 & 7 & FAC \\
\hline Carex folliculata (L.) & northern long sedge & $\mathrm{G}$ & $P$ & 2 & 4 & OBL \\
\hline Carex leptalea (Wahlenb.) & bristly-stalked sedge & $\mathrm{G}$ & $\mathrm{P}$ & 1 & 1 & OBL \\
\hline Crataegus spp. & hawthorne & $\mathrm{W}$ & $\mathrm{P}$ & 1 & 1 & FAC \\
\hline Danthonia compressa (Austin) & flattened oatgrass & $\mathrm{G}$ & $\mathrm{P}$ & 4 & 17 & FACU \\
\hline Dichanthelium clandestinum (L.) & deertongue grass & $\mathrm{G}$ & $\mathrm{P}$ & 3 & 12 & FAC \\
\hline Eleagnus umbellata (Thunb)* & autumn olive & $\mathrm{W}$ & $\mathrm{P}$ & 1 & 2 & Kn. \\
\hline Festuca subverticillata (Pers.) & nodding fescue & $\mathrm{G}$ & $\mathrm{P}$ & 1 & 1 & FACU \\
\hline Glyceria canadensis (Michx.) & rattlesnake mannagrass & $\mathrm{G}$ & $\mathrm{P}$ & 1 & 1 & OBL \\
\hline Glyceria striata (Lam.) & fowl mannagrass & $\mathrm{G}$ & $\mathrm{P}$ & 1 & 1 & OBL \\
\hline Holcus lanatus (L.)* & velvet Grass & $\mathrm{G}$ & $\mathrm{P}$ & 2 & 3 & FAC \\
\hline Hypericum densiflorum (Pursh.) & glade St. John's-wort & $\mathrm{W}$ & $\mathrm{P}$ & 1 & 2 & FACW \\
\hline Juncus canadensis (J. Gay ex Laharpe) & Canadian rush & $\mathrm{G}$ & $\mathrm{P}$ & 4 & 7 & OBL \\
\hline Lobelia inflata (L.) & Indian-tobacco & $\mathrm{F}$ & A & 1 & 1 & FACU \\
\hline Oxalis dillenii (Jacq.) & wood sorrel & $\mathrm{F}$ & $\mathrm{P}$ & 11 & 34 & FACU \\
\hline Poa spp. & bluegrass spp. & $\mathrm{G}$ & $\mathrm{P}$ & 1 & 3 & FACW - FACU \\
\hline Persicaria pensylvanicum (L.) & pinkweed & $\mathrm{F}$ & A & 3 & 4 & FACW \\
\hline Prunus serotina (Ehrh.) & black cherry & $\mathrm{W}$ & $\mathrm{P}$ & 1 & 1 & FACU \\
\hline Ranunculus acris (L.) & tall buttercup & $\mathrm{F}$ & $\mathrm{P}$ & 1 & 2 & FAC \\
\hline Rosa multiflora (Thunb.)* & multiflora rose & $\mathrm{W}$ & $\mathrm{P}$ & 2 & 3 & FACU \\
\hline Rumex acetosella (L.)* & sheep sorrel & $\mathrm{F}$ & $\mathrm{P}$ & 1 & 3 & UPL \\
\hline
\end{tabular}

a. Forms are designated by $\mathrm{G}=$ graminoid, $\mathrm{F}=$ forb, and $\mathrm{W}=$ woody species.

b. Life forms are designated by $\mathrm{A}=$ annual, and $\mathrm{P}=$ perennial.

An [*] indicates plants are exotic to the U.S. 
Table 2. Continued

\begin{tabular}{|c|c|c|c|c|c|c|}
\hline Latin Name & Common Name & Form $^{\text {a }}$ & Life $^{b}$ & $\begin{array}{c}\text { Frequenc } \\
\mathrm{y} \\
\end{array}$ & Abundance & Wetland Indicator Status \\
\hline Spiraea alba (Du Roi) & meadowsweet & $\mathrm{W}$ & $\mathrm{P}$ & 2 & 4 & FACW \\
\hline Spiraea tomentosa $(\mathrm{L})$. & steeplebush & $\mathrm{W}$ & $\mathrm{P}$ & 1 & 1 & FACW \\
\hline Trifolium repens $(\mathrm{L} .)^{*}$ & white clover & $\mathrm{F}$ & $\mathrm{P}$ & 5 & 20 & FACU \\
\hline $\begin{array}{l}\text { Vaccinium myrtilloides } \\
\text { (Michx.) }\end{array}$ & velvetleaf blueberry & $\mathrm{W}$ & $\mathrm{P}$ & 2 & 3 & FACW \\
\hline Viburnum nudum (L.) & wild raisin & $\mathrm{W}$ & $\mathrm{P}$ & 1 & 1 & OBL \\
\hline Viburnum recognitum (Fernald) & smooth arrowwood & $\mathrm{W}$ & $\mathrm{P}$ & 1 & 1 & FAC \\
\hline Viola sagittata (Aiton) & arrowleaf violet & $\mathrm{W}$ & $\mathrm{P}$ & 1 & 2 & FAC \\
\hline
\end{tabular}

a. Forms are designated by $\mathrm{G}=$ graminoid, $\mathrm{F}=$ forb, and $\mathrm{W}=$ woody species .

b. Life forms are designated by $\mathrm{A}=$ annual and $\mathrm{P}=$ perennial.

An [*] indicates plants are exotic to the U.S. 


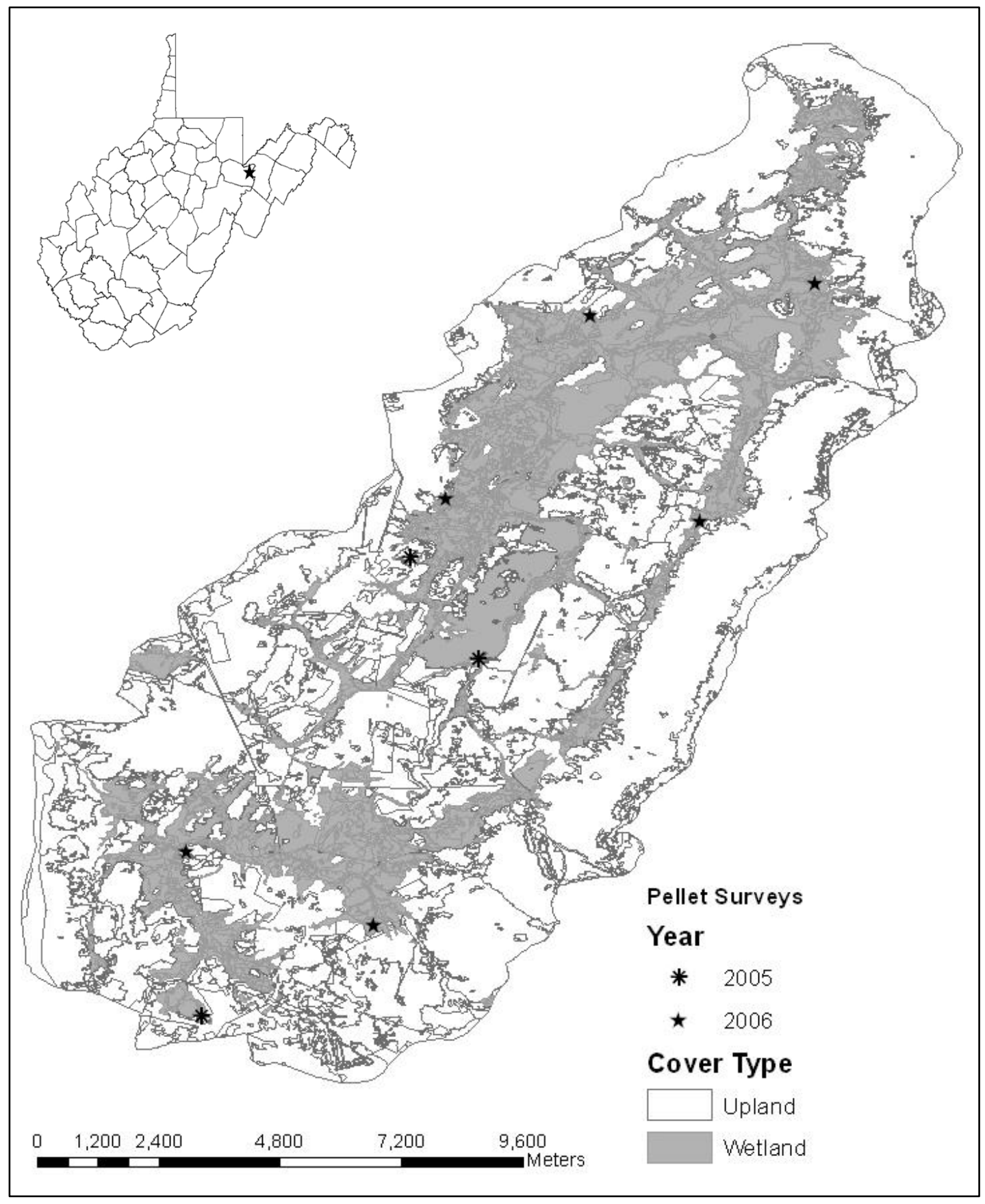

Figure 1. Pellet pile survey locations from 2005-2006 in Canaan Valley, West Virginia. Inset picture shows the location of Canaan Valley in West Virginia. 


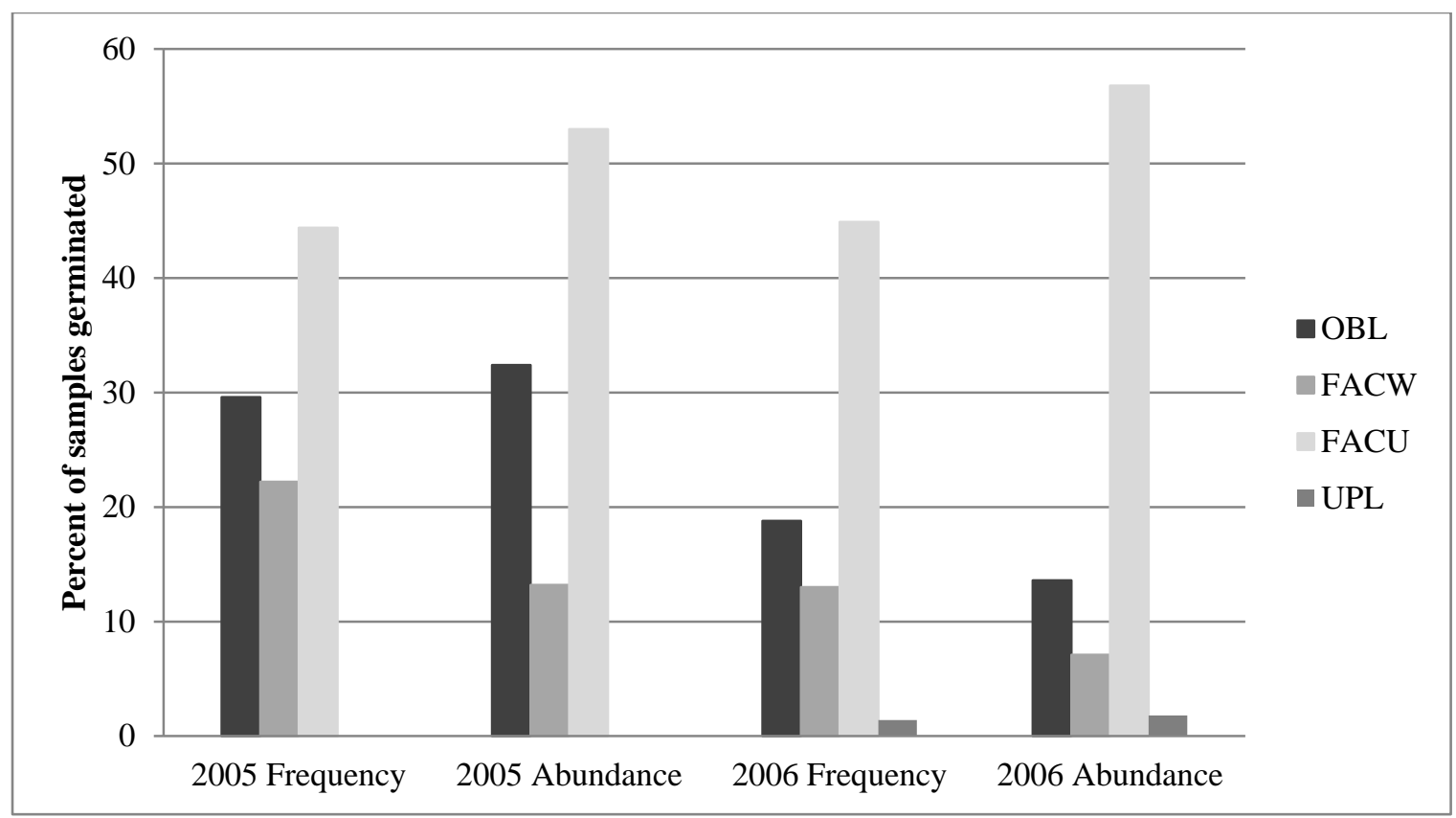

Figure 2. The frequency (number of pellet piles) and abundance (number of individual seedlings) of germinated seedlings from pellet groups collected in 2005-2006 in Canaan Valley, WV, displayed as the proportion from each wetland status group. These groups include facultative wetland (FACW; plants with $67-99 \%$ frequency of occurrence in wetlands), obligate wetland (OBL; plants with $>99 \%$ frequency of occurrence in wetlands), facultative upland (FACU; plants with $67-99 \%$ frequency of occurrence in non-wetlands), and upland (UPL; plants with > $99 \%$ frequency of occurrence in non-wetlands). 


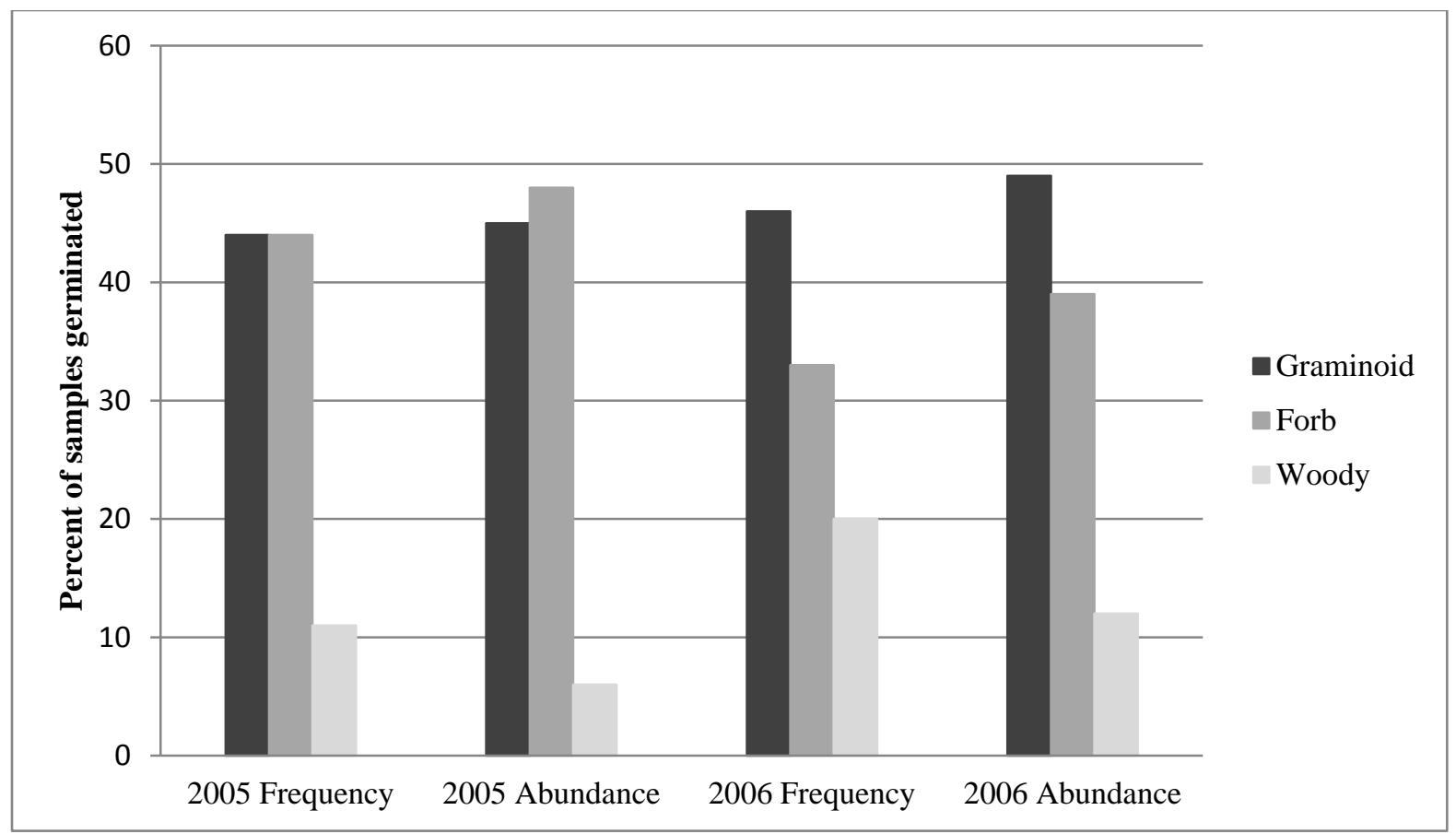

Figure 3. The frequency (number of pellet piles) and abundance (number of individual seedlings) of germinated seedlings from pellet groups collected in 2005-2006 in Canaan Valley, WV, displayed as the proportion from each growth form. 


\section{CHAPTER VI}

20 November 2014

Kelley Flaherty

Alderson Broaddus University

College of Science, Technology, and Math

Box 2096

101 College Hill Dr.

Philippi, WV 26416

Phone: (304) 457-6387

Fax: (304) 457-6239

E-mail: flahertykl@ab.edu

RH: Flaherty et al. · Stakeholders and Deer Management

\section{Comparing Stakeholder Attitudes toward White-tailed Deer Management in Canaan Valley, West Virginia}

KELLEY L. FLAHERTY, ${ }^{1}$ PHILIP J. TURK, ${ }^{2}$ AND JAMES T. ANDERSON ${ }^{1}$

${ }^{1}$ West Virginia University, Division of Forestry and Natural Resources, P.O. Box 6125, Morgantown, WV 26506

${ }^{2}$ Colorado State University, Department of Statistics, Fort Collins, CO 80523-1877

This chapter is written in the style of Human Dimensions of Wildlife 
Canaan Valley, West Virginia provides habitat for many plants considered rare in West Virginia. The local white-tailed deer (Odocoileus virginianus Zimm.) are a popular attraction for visitors as well as resident and nonresident hunters. However, there are concerns over the impact of white-tailed deer herbivory on rare plant communities in the wetlands. The purpose of this study was to evaluate the stakeholder attitudes regarding white-tailed deer management and rare plant conservation. We mailed surveys to property owners in Canaan Valley and Tucker County, WV and provided surveys to visitors at Canaan Valley State Park and National Wildlife Refuge. Incurred crop damage affected attitudes toward deer abundance while residency status affected attitudes toward the presence of deer and rare plant conservation. We found differences between hunters and the nonhunting public attitudes toward white-tailed deer management. Results of this survey may help managers to direct management and education goals toward actual rather than perceived stakeholder attitudes.

Key Words: white-tailed deer, stakeholder, nonresident, visitor, plant conservation. 


\section{Introduction}

Wildlife species are held in public trust; that is, they belong to the people. Many species are managed by state and federal agencies which must take into account the health of the wildlife population, the impact on other plant and animal species, habitat quality, and the wishes of the public for the wildlife population. Public sentiment over the management of white-tailed deer (Odocoileus virginianus) herds in the eastern United States has changed with deer abundance, levels of human-wildlife conflict, increasing rural development, and an increasing interest in nongame wildlife and noncommercial plant species (Holsman \& Peyton, 2003). Public opinions toward white-tailed deer management may vary with the extent of negative experience (Messmer, Cornicelli, Decker, \& Hewitt, 1997; Loker, Decker, \& Schwager, 1999; West \& Parkhurst, 2002), profession (West \& Parkhurst, 2002), and participation in outdoor recreation such as hunting (Brooks, Warren, Nelms, \& Tarrant, 1999; Holsman \& Peyton, 2003). Wildlife is considered a public resource, so its management often involves input from the public sector (McShea \& Rappole, 1997; Shafer-Nolan, 1997). Thus state and local agencies charged with managing deer herds need to balance the attitudes of hunters, antihunters, and nonhunters with public safety and sound biology.

In the 1940s, Leopold, Sowls, and Spencer (1947) found that it was difficult to convince hunters and the general public, who experienced firsthand the shortage of deer as a result of overhunting, that an overabundance of deer could exist at all, much less be a detriment to their habitat. Today, it is still difficult to convince stakeholders, defined here as those who have an interest in the management of white-tailed deer and rare plant conservation, who have experienced the lack of abundance of deer in earlier decades that a problem exists at all (Diefenbach, Palmer, \& Shope, 1997). Since the early 1900s, a greater proportion of the nation's 
general public is disconnected with wildlife and its habitat. Though the urban sprawl phenomenon brought many more people out of the cities and created suburban centers out of formerly rural land, the suburbanites have not embraced the hunting heritage of rural America (Warren, 1997). In the eyes of many, white-tailed deer have become garden pests and road hazards (Warren, 1997). As hunting has decreased as a pastime, more people have embraced animal-welfare or animal-rights perspectives that do not condone the use of hunting as a management tool for deer populations (Rutberg, 1997).

Overabundance of a wildlife population has been defined as fitting into 1 of 4 categories: when an animal threatens human life or livelihood, when animals depress the densities of favored species, when animals are too numerous for their own good, and when their numbers cause ecosystem dysfunction (Caughley 1981). Several studies have shown that threats to human life or livelihood may affect the attitudes of stakeholders toward populations of whitetailed deer. Deer-vehicle collisions (Loker et al., 1999; West \& Parkhurst, 2002), increased rates of lyme disease (West \& Parkhurst, 2002), and damage to crops and home landscaping (Stout, Knuth, \& Curtis, 1997) can lead citizens to view high-density deer populations in a negative light and seek methods of population reduction. Stakeholders were less likely to look negatively on high deer abundance in light of ecosystem dysfunction and depression of nongame wildlife species (Diefenbach et al., 1997; Holsman \& Peyton, 2003).

Canaan Valley, West Virginia (Tucker County) is home to Canaan Valley State Park and the Canaan Valley National Wildlife Refuge. Deer densities in Canaan Valley may be as high as $30 \mathrm{deer} / \mathrm{km}^{2}$ in the southern end of the valley (Appendix 1). Deer hunting is allowed by permit within the National Wildlife Refuge lands and is conducted on private holdings throughout Canaan Valley. However, hunting has been prohibited in sections of the southern end of the 
valley (i.e., Canaan Valley Resort State Park) for at least 30 years prior to this study (Michael, 1992). Recently, the West Virginia legislature has permitted the use of hunting in state parks at the discretion of the West Virginia Division of Natural Resources. Canaan Valley State Park has been considered as a potential location for an organized hunt.

The formation of these public lands has centered on the protection of the unique wetland areas found in Canaan Valley. These provide habitat for over 580 plant species including 80 wetland plants and 34 wetland plant communities that are considered rare or endangered within the state (Fortney, 1975; Michael, 1992; West Virginia Division of Natural Resources, 2012). The wetlands of Canaan Valley support nannyberry (Viburnum lentago), considered rare and imperiled in West Virginia (ranked S2), woodland horsetail (Equisetum sylvaticum), considered rare and critically imperiled (ranked S1) and bog Jacob's-ladder (Polemonium vanbruntiae) (ranked S2) (Rentch \& Anderson, 2008; West Virginia Division of Natural Resources, 2012).

Our objectives were to: a) determine whether the attitudes of residents of Canaan Valley and Tucker County differed from the attitudes of nonresident landowners and visitors with respect to white-tailed deer management and plant conservation; b) determine whether the attitudes of hunters differed from the attitudes of nonhunters with respect to white-tailed deer management and plant conservation, and c) determine how negative experiences with whitetailed deer may influence their attitudes toward management decisions. We hypothesized that the nonresident landowners and visitors to Canaan Valley may have a more urban or suburban background and thus might be less likely to participate in hunting or approve of lethal control methods, and more likely to view white-tailed deer management in an ecosystem context and thus favor the conservation of rare plant species. We hypothesized that hunters were more likely to consider a reduction in deer abundance as an unacceptable "cost" of rare plant conservation 
and were therefore more likely to respond unfavorably toward rare plant conservation. Lastly, we hypothesized that respondents who had experienced negative interactions with deer were more likely to view local deer populations as overabundant and accept measures of deer management.

\section{Study Area}

The Canaan Valley, located in Tucker County, West Virginia, is the largest high-elevation valley east of the Rocky Mountains (Fortney, 1975). It is $21 \mathrm{~km}$ long and ranges in width from $4.8-8.0$ $\mathrm{km}$. The valley encompasses about $176 \mathrm{~km}^{2}$ (17,600 ha) of land. The average valley floor elevation is $980 \mathrm{~m}$ above sea level and the mountains surrounding the valley rise another $300 \mathrm{~m}$ in elevation. The high elevation and topography of Canaan Valley results in a climate more similar to northern boreal forests than to the deciduous forests of surrounding areas in West Virginia. Canaan Valley is home to sub-arctic bogs and stands of conifers such as balsam fir (Abies balsamea) and red spruce (Picea rubens).

About $20 \%$ of the land area is made up of various wetland community types and another $23 \%$ is northern hardwood forest. Of all the high-elevation wetlands in West Virginia, Canaan Valley is home to the largest contiguous wetland areas $(3,000$ ha, Byers, Vanderhorst \& Streets, 2007). Agriculture, rural development, and recreational land make up the remaining land area (Michael, 1992).

\section{Methods}

\section{Selecting Stakeholder Groups}

We chose 4 stakeholder groups that had the potential to influence wild plant conservation and white-tailed deer management in Canaan Valley and the surrounding areas. We surveyed residents of Canaan Valley as well as residents of the surrounding areas in Tucker County, WV, 
who might work or travel through Canaan Valley frequently. Additionally, we sampled nonresidents who owned land in Canaan Valley as well as those who only visit Canaan Valley. We sampled residents and nonresident landowners in 2005 by mail surveys that were sent to addresses selected by systematic random sampling from Tucker County tax records. We mailed the surveys with an included self-addressed, stamped envelope for the return of responses. To assess the attitudes of visitors to Canaan Valley, we supplied survey forms to the visitors' centers at Canaan Valley National Wildlife Refuge and Canaan Valley State Park. Surveys also were distributed to Canaan Valley State Park Ski Lodge and several local businesses; however, no surveys were successfully retrieved from locations outside the state park and national wildlife refuge.

\section{Questionnaire Design}

We created a survey that consisted of 25 questions (Appendix 8). Respondents were asked demographic questions including their age, sex, education level, and residency status. The respondents' views toward rare plant conservation and the status and management of white-tailed deer in Canaan Valley were assessed with 16 opinion questions. Responses to opinion questions were rated on the Likert scale with 6 categories: strongly disagree (-2), disagree $(-1)$, neutral $(0)$, agree $(+1)$, strongly agree $(+2)$, and no opinion. The participants' attitude toward hunting as a management tool as well as their participation in hunting activities was addressed with 3 questions. Two other questions addressed personal experience with a deer-vehicle collision and property damage (e.g., crops).

\section{Statistical Analysis}

We used only the data from respondents that had fully completed surveys. No Opinion responses were pooled with the Neutral responses. The 16 opinion questions were subjected to 
Principal Components Analysis (PCA) to minimize redundancy among the questions and to identify underlying constructs. We standardized and rotated our principal components using the varimax rotation method. We selected three principal components from the correlation matrix based on a scree plot, so that any component left in the analysis explained $>10 \%$ of the total variance in the data set, magnitude of the eigenvalues, and interpretability (Hatcher, 1994). We considered the loadings to be "large" for a question if it was $>0.5$.

We modeled the principal component scores as a function of 4 sociodemographic factors determined from the questionnaire (Residency Status, hunting participation from Question 19, deer-vehicle collisions from Question 7, and deer landscape-crop damage from Question 8) and their two-way interaction using a multi-factor analysis of variance (ANOVA) in program $R(R$ Development Core Team, 2008). We maintained the 0.05 experimentwise $\alpha$ level using a Bonferroni correction; that is, the $\alpha$ level was set to 0.005 for individual tests. Post-hoc multiple comparisons were made using a Bonferroni procedure to compare least squares means between factor levels. Residual diagnostics were run to assess validity of the model assumptions. Additionally, we examined the principal components using a Potential for Conflict Index (PCI)(Vaske, Needham, Newman, Manfredo, \& Petchenik, 2006). The PCI numerically described the amount of disparity between respondents in a particular group by giving more weight to extreme responses and no weight to neutral responses. Thus, the higher the PCI value, the greater the range of responses within a group.

\section{Results}

We received 174 responses from a total of 500 mailed surveys for a response rate of $35 \%$ (Table 1). Additionally, we received 46 visitors' responses. From the 220 total responses, we removed 26 from analysis because of incomplete responses. The three retained principal 
components are summarized in Table 2. Together these components accounted for $60 \%$ of the variation in the data. Interpretation of the loadings on each principal component suggested that each component could be attributed to a distinct construct as measured by several original questions. Principal component 1 (PC1) dealt mainly with attitudes toward seeing deer and overabundance in Canaan Valley and West Virginia (Questions 1-4, and 10, Appendix 8). Component 1 also included an opinion on using professional sharp-shooters to reduce deer numbers (Question 21, Appendix 8). Principal component 2 (PC2) focused on attitudes toward plant conservation and the relation to deer abundance (Questions 6, and 13-15, Appendix 8). Principal component 3 (PC3) focused on management of white-tailed deer (Questions 9, 11, 12, and 17, Appendix 8).

When we modeled the scores for PC1 with respect to the 4 factors (residency status, hunting participation, deer-vehicle collisions and deer landscape/crop damage) we found only the $F$ test for the deer landscape/crop damage was significant $\left(F_{1,163}=12.87, p<0.001\right)$. We found that people who had experienced crop or landscape damage had significantly larger mean principal component 1 scores $(\bar{x}=0.299, \mathrm{SE}=0.118)$ than those who did not $(\bar{x}=-0.359, \mathrm{SE}=$ 0.170). Larger PC1 scores correspond with a lower tolerance of deer. Of the questions that were a part of PC1, the 2 groups tended to differ in opinion the most on the subject of overabundance in Canaan Valley and West Virginia with those that had experienced crop or landscape damage being more likely to describe these populations as being overabundant. There was a substantial amount of conflict among those that had experienced crop or landscape damage with respect to views on professional sharpshooting as a deer population management tool $(\mathrm{PCI}=0.54$; Figure 2). 
Results from modeling PC2 as a function of the 4 sociodemographic factors showed only a significant $F$ test for the residency factor $\left(F_{3,163}=4.91, p<0.003\right)$. Tucker County residents $(\bar{x}=0.578, \mathrm{SE}=0.145)$ had higher $\mathrm{P} 2$ scores on average than nonresident landowners $(\bar{x}=$ $-0.172, \mathrm{SE}=0.153)(\mathrm{t}=-3.55, p<0.001$; Figure 3). Larger PC2 scores indicated lower valuation of plants and plant communities. Tucker County residents also tended to value plants less than Canaan Valley visitors $(\bar{x}=-0.163, \mathrm{SE}=0.269)$; however, this difference $\left(\mathrm{t}_{163}=2.46, p=0.015\right)$ was not considered significant due to the conservative nature of the Bonferroni correction. While for the most part stakeholder groups agreed that they enjoyed seeing wild plants, Tucker County residents appeared less likely to agree that deer could harm plant communities and that plants should be protected from deer (Table 3). PCI scores were higher for Tucker County residents on these topics indicating moderate conflict within that group.

Due to a violation of the assumption of normal errors under ANOVA, the Box-Cox procedure was used to select a normalizing power transformation for the PC3 scores (Box \& Cox 1964). Hunters $(\bar{x}=0.414, \mathrm{SE}=0.037)$ had significantly higher PC3 scores on average than nonhunters $(\bar{x}=-0.308, \mathrm{SE}=0.049)\left(F_{1,163}=14.80, p<0.001\right.$; Figure 4) where least squares means estimates were back-transformed to the original scale and the standard errors in the original scale were approximated via the Delta method. Larger PC3 scores corresponded to a greater support for management actions for white-tailed deer. Of the questions contributing to PC3, nonhunters were more likely than hunters to disagree that deer densities should be managed to increase hunter harvest (Figure 5) and there was moderate conflict within the nonhunting group $(\mathrm{PCI}=0.32)$.

\section{Discussion}

Overall, we found that those respondents who had experienced damage to landscaping or crops 
were less likely to exhibit tolerance of high deer densities and support an increase in the deer herd. Lischka, Riley, and Rudolph (2007) found a positive association between hunting participation and attitudes toward deer abundance and a negative association between farming and deer abundance. People are generally willing to accept deer until they reach some threshold of deer-human conflict (Stout et al., 1997), after which they are more likely to be open to lethal control methods (Messmer et al., 1997).

We did not find a difference between permanent residents, nonresident, and visitor stakeholder opinions regarding white-tailed deer abundance as measured by $\operatorname{PC} 1\left(F_{3,163}=2.17, p\right.$ $<0.093)$. Many of the nonresident landowners and visitors surveyed came from urban or suburban centers such as Baltimore, MD, and Washington, D.C. These respondents may be more acquainted with issues of deer overabundance in suburban parks and refuges (Raik, Siemer, \& Decker, 2005). However, this did not lead them to view the Canaan Valley deer herd as overabundant. The lack of an urban-rural divide might be due to the values of stakeholders who choose to recreate in rural areas. Clendenning, Field, and Kapp (2005) found that many exurbanites seek a return to rural roots and therefore might have values that align more closely with residents.

There were lower percentages of hunters for the visitors and nonresident landowner groups. Holsman and Peyton (2003) found hunters tended to believe that there were fewer deer present in an ecosystem than other groups surveyed. We did not find an association between participation in hunting and attitudes toward deer abundance as measured by $\operatorname{PC} 1\left(F_{1,163}=3.59\right.$, $p<0.060)$ nor did we find sufficient evidence of interaction between hunting participation and residency $\left(F_{3,163}=2.67, p<0.049\right)$. 
Visitors and nonresident landowners were less likely than residents to have been involved in a deer-vehicle collision (Question 7; Table 1). There did not appear to be a desire for fewer deer among those who had recently been involved in a collision. There was no difference with respect to PC1 between those who had been involved in a collision and those who had not $\left(F_{3,163}\right.$ $=0.25, p<0.861)$ nor did we find sufficient evidence of interaction between car collision involvement and residency $\left(F_{9,163}=0.86, p<0.566\right)$. Loker et al. (1999) found that negative experiences with wildlife species did not necessarily result in a feeling of concern over that species.

Views toward professional sharpshooting as a means of reducing deer populations were negative overall (Question 21; Table 1). The mean response of stakeholders that had experienced crop or landscape damage was circumneutral; however, the PCI score for this group was 0.54 indicating strong disagreement within the group (Figure 2). Messmer et al. (1997) found that the general public had a low opinion of sharpshooting compared to other methods of herd reduction. Stout et al. (1999) also found low public support for sharpshooting as a management technique among suburban residents. However, they found that the level of acceptance did not change with increases in deer densities. We also found that many respondents were unsure of the practice of herd reduction by this method and some mentioned that they would be likely to agree contingent upon the use of the deer afterward. Many of those opposed voiced a preference for a controlled public or permit hunt for West Virginia license holders.

Regarding PC2, Tucker County residents were less likely than nonresident landowners and visitors to Canaan Valley to value rare and endangered plants, especially if it meant a need to protect those plants from the local white-tailed deer herd. Clendenning et al. (2005) found that 
there were differences between urbanites and rural residents on some aspects of wildlife management and that seasonal homeowners hold attitudes that support the preservation of the natural amenities around their homes.

Holsman and Peyton (2003) found that stakeholders expressed value for ecosystem management goals in the absence of costs and that deer hunters were unwilling to accept reductions in the deer herd to protect stands of white cedar (Thuja occidentalis). Similarly, others have found that participation in hunting was related to low support for biodiversity and other broad ecological management objectives (Holsman, 2000). We did not find sufficient evidence of an association between hunting participation and valuation of rare plant species as measured by PC2 $\left(F_{1,163}=4.13, p<0.044\right)$ nor did we find sufficient evidence of interaction between hunting participation and residency $\left(F_{3,163}=0.39, p<0.759\right)$. We believe that hunters may not have interpreted questions $6,13,14$, and 15 as support for a reduction in the deer herd and therefore were more likely to value rare plant conservation since no "cost" was involved.

While hunters were more likely than nonhunters to support management actions for white-tailed deer as measured by PC3, the vast majority of respondents from all groups accepted hunting as a tool to manage white-tailed deer populations (Questions 9, 12, and 17; Table 1) with the exception of management for the purpose of increasing hunter harvest (Question 11; Table 1). This suggests that the stereotype of the suburbanite "antihunter" might be unfounded in Canaan Valley and might be the result of a vocal minority (Curtis \& Hauber, 1997; West \& Parkhurst, 2002). Some of the comments received as a part of the survey seemed to reflect this view. Loker et al. (1999) found that suburban residents were generally open to wildlife management, even lethal control options, and believed that managers should use caution in stereotyping the attitudes of suburban residents. The large degree of acceptance seen here might 
be due to the backgrounds of respondents who choose to visit or buy land in Canaan Valley (Clendenning et al., 2005). High deer abundance once made Canaan Valley a popular hunting area within West Virginia. Many visitors and nonresident landowners might actually be coming to the area to hunt and therefore these results might not be applicable to other areas.

We caution the reader that the results given here are exploratory in nature, and are not meant to be construed as confirmatory. The reason is because of the presence of possible sources of selection bias; namely, bias due to undercoverage, nonresponse, and voluntary response sampling. The presence of nonresponse does not ensure that a bias exists. Further follow-up would be necessary to assess the effect of nonresponse bias, if it exists, and to statistically account for it. Nevertheless, our conclusions are at least suggestive and could certainly help Canaan Valley management organizations design more rigorous probability sampling designs that could be analyzed with the same formal approach we have developed here.

It is important to understand public perceptions to successfully execute management plans in the public domain (Swihart \& DeNicola, 1997). Contrary to perceptions, the majority of the visitors and nonresident landowners in Canaan Valley thought that there were too many deer in Canaan Valley State Park and National Wildlife Refuge (Question 4; Table 1). These stakeholder groups also indicated that it was important to conserve rare and endangered plant species even at the expense of white-tailed deer herds (Question 15; Table 1). Management organizations in Canaan Valley including the West Virginia Division of Natural Resources and the United States Fish and Wildlife Service should use the information gathered in this study along with biological data to inform management decisions on the white-tailed deer herd in Canaan Valley. 


\section{Management Implications}

Although many of the views of residents and nonresidents were similar, Tucker County residents were less likely to favor rare plant conservation. Many of the visitors and nonresidents come to Canaan Valley specifically because of its unique characteristics and appear to place more value on these unique plants. Recognition of differences in attitudes between stakeholder groups could be helpful in designing educational programs for users of natural areas (Brooks et al., 1999). In this case, education and emphasis on the importance of rare plant diversity in Canaan Valley may bring more local support for their conservation.

\section{Acknowledgments}

Funding for this work was provided by the Canaan Valley Institute. We thank J. L. Bonner, J. A. Edalgo, J. P. Love and W. E. Veselka IV of West Virginia University for assistance in developing the survey questionnaire. Use of human subjects in this study was approved by West Virginia University's Office of Research Compliance. This is scientific article number XXXX of the West Virginia University Agricultural and Forestry Experiment Station.

\section{References}

Brooks, J. J., Warren, R. J., Nelms, M. G., \& Tarrant, M. A. (1999). Visitor attitudes toward and knowledge of restored bobcats on Cumberland Island National Seashore, Georgia. Wildlife Society Bulletin, 27, 1089-1097.

Box, G. E. P., \& Cox, D. R. (1964). An analysis of transformations. Journal of the Royal Statistical Society, 26, 211-243.

Byers, E. A., Vanderhorst, J. P., \& Streets, B. P. (2007). Classification and conservation assessment of high elevation wetland communities in the allegheny mountains of West Virginia. Elkins, WV: West Virginia Natural Heritage Program, West Virginia 
Division of Natural Resources.

Caughley, G. (1981). Overpopulation. Pages 7-19 in Jewell, P.A., Holt, S., Hart, D., eds. Problems in management of locally abundant wild mammals. New York: Academic Press.

Clendenning, G., Field, D. R., \& Kapp, K. J. (2005). A comparison of seasonal homeowners and permanent residents on their attitudes toward wildlife management on public lands. Human Dimensions of Wildlife, 10, 3-17.

Curtis, P. D., \& Hauber, J. R. (1997). Public involvement in deer management decisions: consensus versus consent. Wildlife Society Bulletin, 25, 399-403.

Diefenbach, D. R., Palmer, W. L., \& Shope, W. K., (1997). Attitudes of Pennsylvania sportsmen towards managing white-tailed deer to protect the ecological integrity of forests. Wildlife Society Bulletin, 25, 244-251.

Fortney, R. H. (1975). The vegetation on Canaan Valley, West Virginia: a taxonomic and ecological study. Dissertation, West Virginia University, Morgantown, WV

Hatcher, L. (1994). A Step-by-Step Approach to Using SAS for Factor Analysis and Structural Equation Modeling. Cary, NC: SAS Institute Inc.

Holsman, R. H. (2000). Goodwill hunting? Examining the role of hunters as ecosystem stewards. Wildlife Society Bulletin, 28, 808-816.

Holsman, R. H., \& Peyton, R. B. (2003). Stakeholder attitudes toward ecosystem management in southern Michigan. Wildlife Society Bulletin, 31, 349-361.

Leopold, A, L., Sowls, K., \& Spencer, D. L. (1947). A survey of overpopulated deer herds in the U.S. Journal of Wildlife Management, 11, 162-177.

Lischka, S. A., Riley, S. J., \& Rudolph, B. A. (2007). Effects of impact perception on 
acceptance capacity for white-tailed deer. Journal of Wildlife Management, 72, 502-509.

Loker, C. A., Decker, D. J., \& Schwager, S. J. (1999). Social acceptability of wildlife management actions in suburban areas: 3 cases from New York. Wildlife Society Bulletin, 27, 152-159.

McShea, W. J., \& Rappole, J. H. (1997). The science and politics of managing deer within a protected area. Wildlife Society Bulletin, 25, 443-446.

Messmer, T. A., Cornicelli, L., Decker, D. J., \& Hewitt, D. G. (1997). Stakeholder acceptance of urban deer management techniques. Wildlife Society Bulletin, 25, 360-366.

Michael, E. D. (1992). Impact of deer browsing on regeneration of balsam fir in Canaan Valley, West Virginia. Northern Journal of Applied Forestry, 9, 89-90.

R Development Core Team. (2008). R: a language and environment for statistical computing. $\mathrm{R}$ foundation for statistical computing. Vienna, Austria.

Raik, D. B., Siemer, W. F., \& Decker, D. J. (2005). Intervention and capacity considerations in community-based deer management: the stakeholders' perspective. Human Dimensions of Wildlife, 10, 259-272.

Rentch, J. S., \& Anderson, J. T. (2008). Stand development of trembling aspen in Canaan Valley, West Virginia. Pages 413-422 in Jacobs, D. F., \& Michler, C. H., eds. 2008. Proceedings, $16^{\text {th }}$ Central Hardwood Forest Conference; West Lafayette, IN. USDA Forest Service Gen. Tech. Rep. NRS-P-24, 413-422.

Rutberg, A. T. (1997). An animal welfare perspective. Pages 37-54 in McShea, W. J., Underwood, H. B., \& Rappole, J. H., eds. The science of overabundance: deer ecology and population management. Washington D.C.: Smithsonian Institution Press.

Shafer-Nolan, A.L. (1997). The science and politics of deer overabundance at Cuyahoga Valley 
National Recreation Area, Ohio. Wildlife Society Bulletin, 25, 457-461.

Stout, R. J., Knuth, B. A., \& Curtis, P. D. (1997). Preferences of suburban landowners for deer management techniques: a step towards better communication. Wildlife Society Bulletin, 25, 348-359.

Swihart, R. K., \& DeNicola, A. J. (1997). Public involvement, science, management, and the overabundance of deer: can we avoid a hostage crisis? Wildlife Society Bulletin, 25, 382387.

Vaske, J. J., Needham, M. D., Newman, P., Manfredo, M.J., \& Petchenik, J. (2006). Potential for conflict index: Hunters' responses to chronic wasting disease. Wildlife Society Bulletin, 34, 44-50.

Warren, R. J. (1997). The challenge of deer overabundance in the $21^{\text {st }}$ century. Wildlife Society Bulletin, 25, 213-214.

West, B. C., \& Parkhurst, J. A. (2002). Interactions between deer damage, deer density, and stakeholder attitudes in Virginia. Wildlife Society Bulletin, 30, 139-147.

West Virginia Division of Natural Resources. 2012. Rare Species List. West Virginia Nongame Wildlife and Natural Heritage Program. Elkins, WV. 
Table 1.

Mean likert scores for 4 stakeholder groups regarding white-tailed deer in Canaan Valley, West Virginia, 2005.

\begin{tabular}{|c|c|c|c|c|c|c|c|c|}
\hline & \multicolumn{2}{|c|}{$\begin{array}{l}\text { Canaan Valley } \\
\text { Residents }\end{array}$} & \multicolumn{2}{|c|}{ Nonresidents } & \multicolumn{2}{|c|}{$\begin{array}{l}\text { Tucker County } \\
\text { Residents }\end{array}$} & \multicolumn{2}{|c|}{ Visitors } \\
\hline & $\bar{x}$ & SE & $\bar{x}$ & SE & $\bar{x}$ & SE & $\bar{x}$ & SE \\
\hline 1 I enjoy seeing white-tailed deer around/near my home. & 1.0 & 0.2 & 1.6 & 0.1 & 1.3 & 0.1 & 1.3 & 0.2 \\
\hline 2 I enjoy seeing white-tailed deer when I visit state or national parks, forests or wildlife refuges. & 1.4 & 0.1 & 1.6 & 0.1 & 1.6 & 0.1 & 1.4 & 0.2 \\
\hline 3 I believe deer are overabundant in the state of West Virginia. & 0.5 & 0.4 & 1.4 & 0.2 & 0.2 & 0.3 & 1.1 & 0.2 \\
\hline $\begin{array}{l}4 \text { I believe deer are overabundant in Canaan Valley National Wildlife Refuge and/or Canaan } \\
\text { Valley Resort State Park. }\end{array}$ & 0.8 & 0.4 & 1.2 & 0.2 & 0.7 & 0.2 & 1.5 & 0.2 \\
\hline 5 I place value on wild plants and trees as sources of food and timber. & 1.5 & 0.2 & 1.5 & 0.1 & 1.6 & 0.1 & 1.5 & 0.1 \\
\hline 6 I enjoy seeing wild plants, flowers, and trees. & 1.5 & 0.1 & 1.5 & 0.1 & 1.4 & 0.1 & 1.7 & 0.1 \\
\hline $7 \mathrm{I}$, or a member of my immediate family, have been involved in a deer/vehicle collision. & 1.4 & 0.2 & 1.0 & 0.1 & 1.8 & 0.1 & 0.8 & 0.1 \\
\hline $\begin{array}{l}\text { I, or a member of my immediate family, have incurred damage to landscaping, crops or other } \\
\text { property (excluding vehicles) from deer. }\end{array}$ & 0.4 & 0.2 & 0.2 & 0.1 & 0.3 & 0.1 & 0.1 & 0.1 \\
\hline 9 I believe it is ethical to manage wild populations of white-tailed deer. & 1.3 & 0.3 & 1.4 & 0.1 & 1.4 & 0.2 & 1.6 & 0.1 \\
\hline 10 I believe white-tailed deer numbers should be increased in West Virginia. & 1.6 & 0.4 & 1.5 & 0.2 & 0.8 & 0.3 & 1.9 & 0.2 \\
\hline 11 I believe white-tailed deer numbers should be managed to increase hunter harvest. & 1.1 & 0.4 & 0.8 & 0.2 & 1.2 & 0.2 & 1.0 & 0.3 \\
\hline 12 I believe white-tailed deer numbers should be managed in balance with their environment. & 1.0 & 0.3 & 1.3 & 0.1 & 1.3 & 0.2 & 1.7 & 0.1 \\
\hline 13 I believe white-tailed deer may have a detrimental effect on some plant communities. & 2.0 & 0.2 & 1.5 & 0.1 & 1.0 & 0.2 & 1.5 & 0.2 \\
\hline 14 I believe rare or endangered plant species should be protected. & 1.6 & 0.2 & 1.6 & 0.1 & 1.1 & 0.2 & 1.7 & 0.1 \\
\hline $\begin{array}{l}15 \text { I believe rare or endangered plant species should be protected from white-tailed deer browsing } \\
\text { if it reduces the abundance of those plants. }\end{array}$ & 1.7 & 0.3 & 1.5 & 0.1 & 0.9 & 0.2 & 1.6 & 0.2 \\
\hline $\begin{array}{l}16 \text { I would not have a problem seeing fenced areas to protect plants when I visit state or national } \\
\text { parks, forests or wildlife refuges. }\end{array}$ & 0.7 & 0.3 & 0.8 & 0.2 & 0.9 & 0.2 & 1.1 & 0.2 \\
\hline 17 I believe hunting is an acceptable tool for managing deer populations. & 1.4 & 0.2 & 1.2 & 0.1 & 1.5 & 0.1 & 1.8 & 0.1 \\
\hline 18 I have participated in legal hunting activities within my lifetime. & 0.2 & 0.2 & 0.0 & 0.1 & 0.6 & 0.1 & 0.2 & 0.1 \\
\hline 19 I have participated in legal hunting activities within the past year. & -0.5 & 0.2 & -0.6 & 0.1 & 0.2 & 0.1 & -0.1 & 0.1 \\
\hline 20 Another member of my household participates in legal hunting activities. & -0.5 & 0.2 & -0.4 & 0.1 & 0.5 & 0.1 & -0.1 & 0.2 \\
\hline 21 I believe professional sharp-shooting is an acceptable tool for managing deer populations. & 1.1 & 0.5 & 0.5 & 0.2 & -0.4 & 0.3 & 1.0 & 0.3 \\
\hline Number of Responses returned & \multicolumn{2}{|c|}{20} & \multicolumn{2}{|c|}{72} & \multicolumn{2}{|c|}{53} & \multicolumn{2}{|c|}{46} \\
\hline
\end{tabular}


Table 2.

Principal components and constructs derived from survey dataset groups regarding white-tailed deer in Canaan Valley, West Virginia, 2005.

\begin{tabular}{ccccc} 
Component & Eigenvalue & Proportion & Cumulative Proportion & Construct \\
\hline PC 1 & 5.4946 & 0.3434 & 0.3434 & Deer abundance/tolerance \\
PC 2 & 2.1058 & 0.1316 & 0.4750 & Rare plant conservation \\
PC 3 & 1.9480 & 0.1218 & 0.5968 & Deer management \\
\hline
\end{tabular}




\section{Table 3.}

Mean and Potential for Conflict Index (PCI) values for four questions contributing to Principal

Component 2 by resident group. Mean values of -2 correspond to strongly disagree and 2 corresponds to strongly agree. Higher PCI values indicate higher potential for conflict among group members.

\begin{tabular}{|c|c|c|c|c|c|c|c|c|}
\hline & \multicolumn{2}{|c|}{ Question $6^{\mathrm{a}}$} & \multicolumn{2}{|c|}{ Question $13^{\mathrm{b}}$} & \multicolumn{2}{|c|}{ Question $14^{\mathrm{c}}$} & \multicolumn{2}{|c|}{ Question $15^{\mathrm{C}}$} \\
\hline & Mean & PCI & Mean & PCI & Mean & PCI & Mean & PCI \\
\hline Canaan Valley Residents & 1.30 & 0.00 & 0.90 & 0.00 & 0.85 & 0.05 & 0.35 & 0.15 \\
\hline Nonresident Landowners & 1.47 & 0.00 & 0.92 & 0.11 & 0.96 & 0.03 & 0.77 & 0.08 \\
\hline Tucker County Residents & 1.22 & 0.02 & 0.26 & 0.33 & 0.24 & 0.30 & 0.02 & 0.33 \\
\hline Visitors & 1.62 & 0.00 & 0.98 & 0.11 & 1.13 & 0.06 & 0.81 & 0.20 \\
\hline
\end{tabular}

${ }^{\mathrm{a}}$ Question 6: I enjoy seeing wild plants, flowers, and trees.

${ }^{\mathrm{b}}$ Question 13: I believe white-tailed deer may have a detrimental effect on some plant communities.

${ }^{c}$ Question 14: I believe rare or endangered plant species should be protected.

${ }^{\mathrm{d}}$ Question 15: I believe rare or endangered plant species should be protected from white-tailed deer browsing if it reduces the abundance of those plants. 
Two Levels of Crop

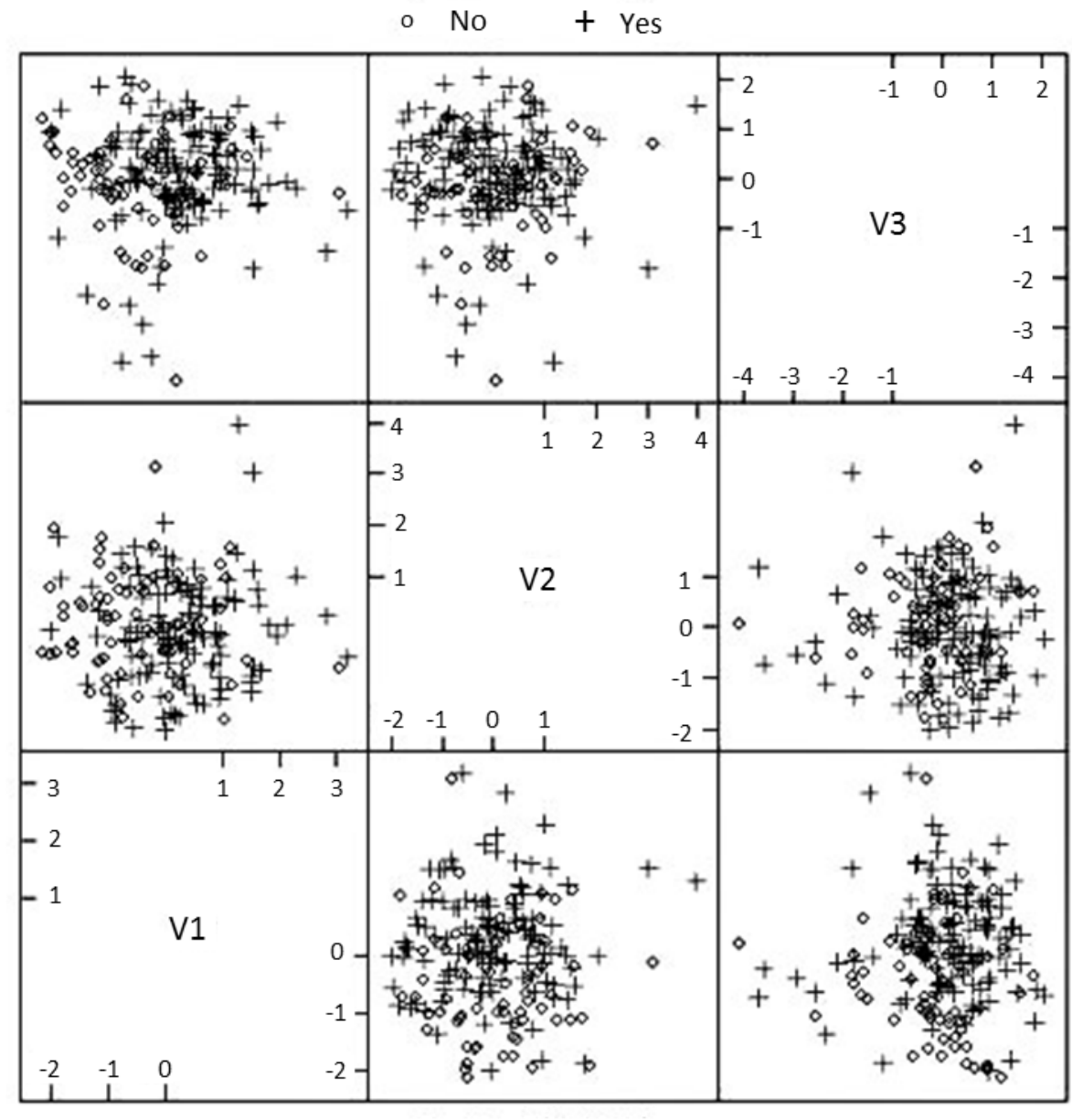

Scatter Plot Matrix

Figure 1. Scatter plot matrix for all three Principal Component Scores for respondents that had (Yes) and had not (No) experienced damage to crops or landscaping attributable to white-tailed deer, 2005. 


\section{Potential for Conflict Index}

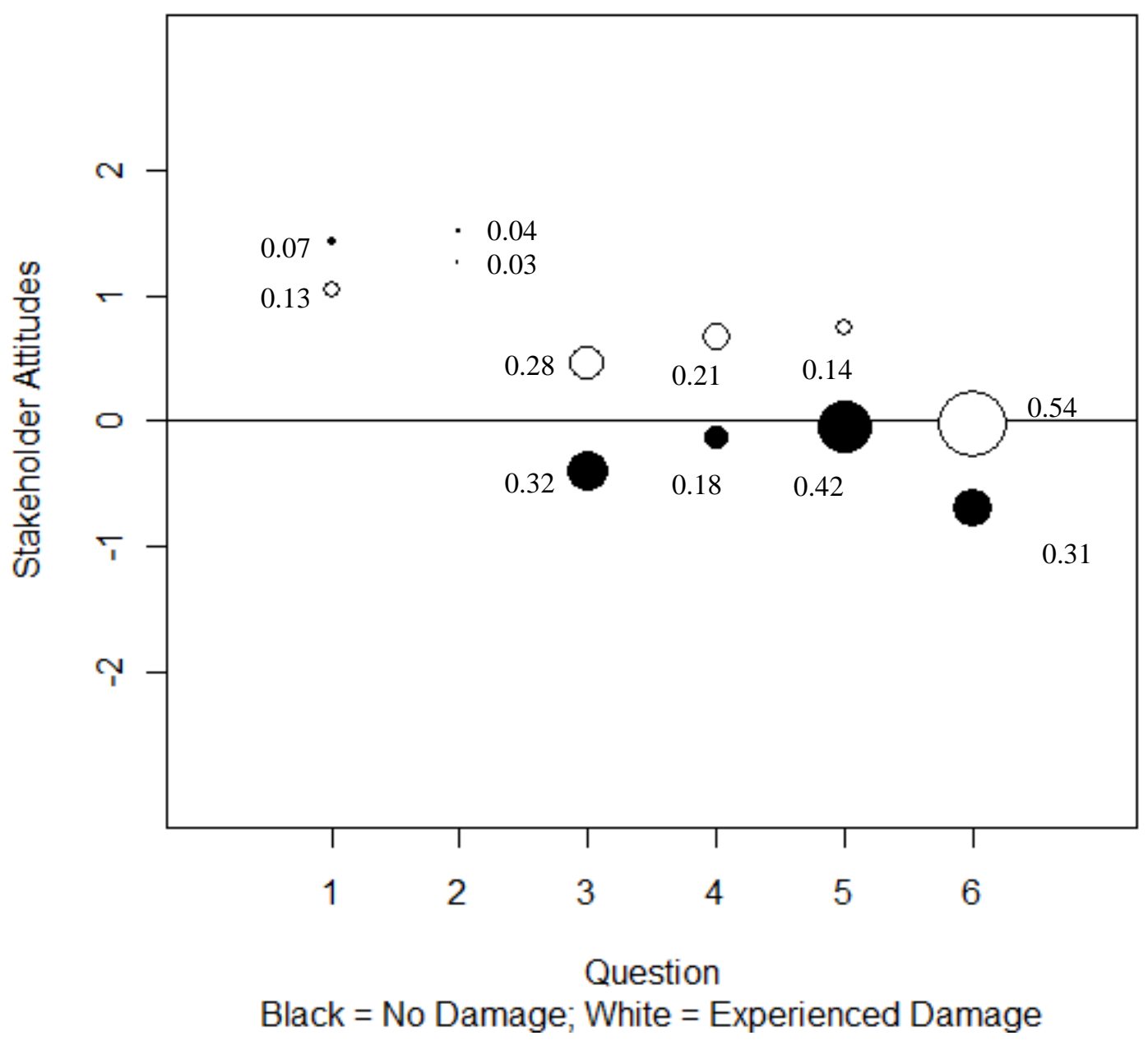

Figure 2. Potential for Conflict Indices (PCI) for the six questions contributing to Principal Component One by respondents that had and had not experienced damage to crops or landscaping. Circles are centered on the mean response for each group where -2.0 corresponds to strongly disagree and 2.0 corresponds to strongly agree. Larger circles indicate higher potential for conflict within group members. PCI values are given next to the corresponding point. The questions are the following;

1. Question 1: I enjoy seeing white-tailed deer around/near my home.

2. Question 2: I enjoy seeing white-tailed deer when I visit state or national parks, forests or wildlife refuges.

3. Question 3: I believe deer are overabundant in the state of West Virginia.

4. Question 4: I believe deer are overabundant in Canaan Valley National Wildlife refuge and/or Canaan Valley Resort State Park.

5. Question 10: I believe white-tailed deer numbers should be increased in West Virginia (reversed scale).

6. Question 21: I believe professional sharpshooting is an acceptable tool for managing deer populations. 


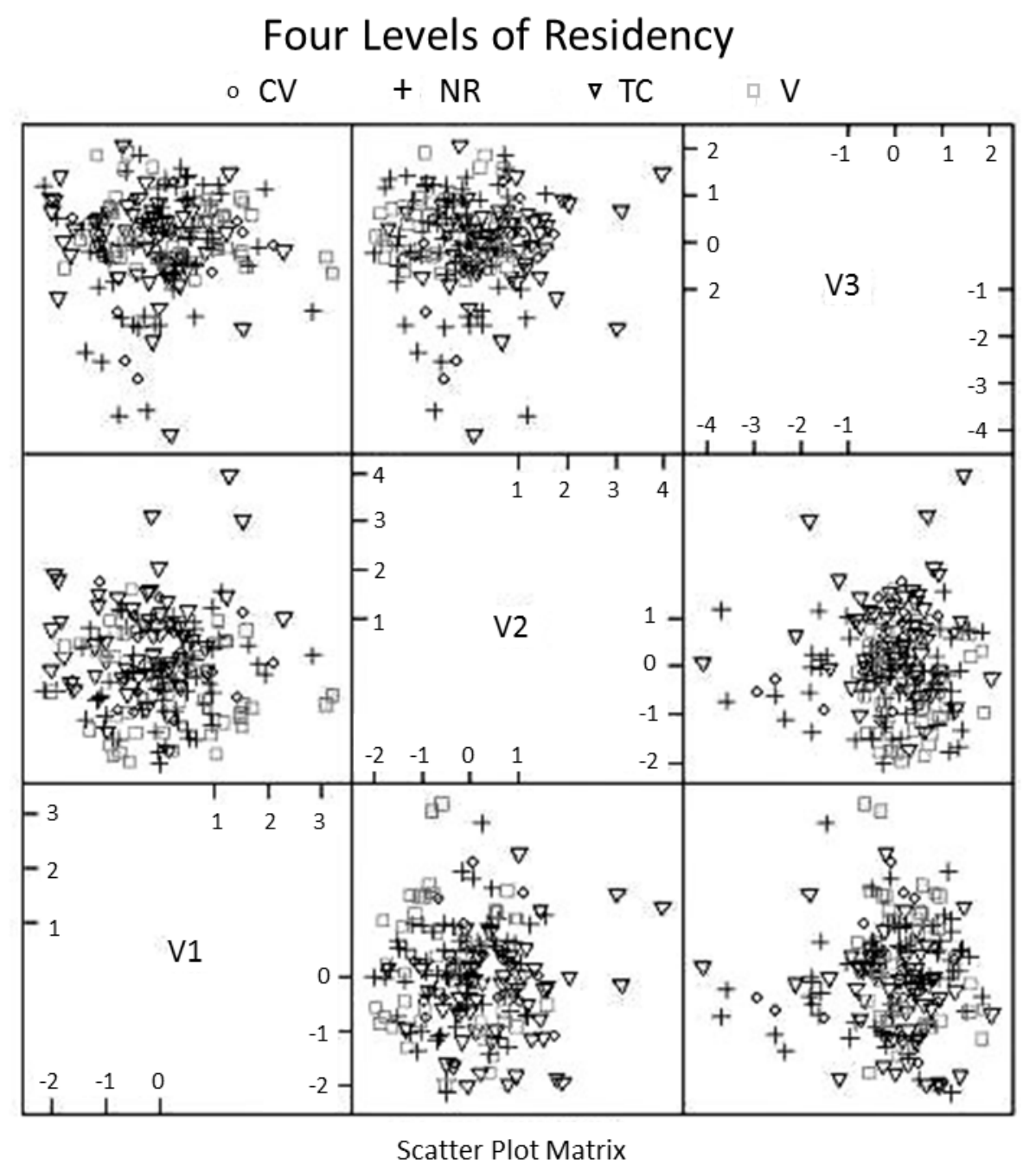

Figure 3. Scatter plot matrix for all three Principal Component Scores for respondents that were Canaan Valley residents (CV), nonresident landowners (NR), Tucker County residents (TC), and visitors to Canaan Valley (V), 2005. 


\section{Two Levels of Hunt}

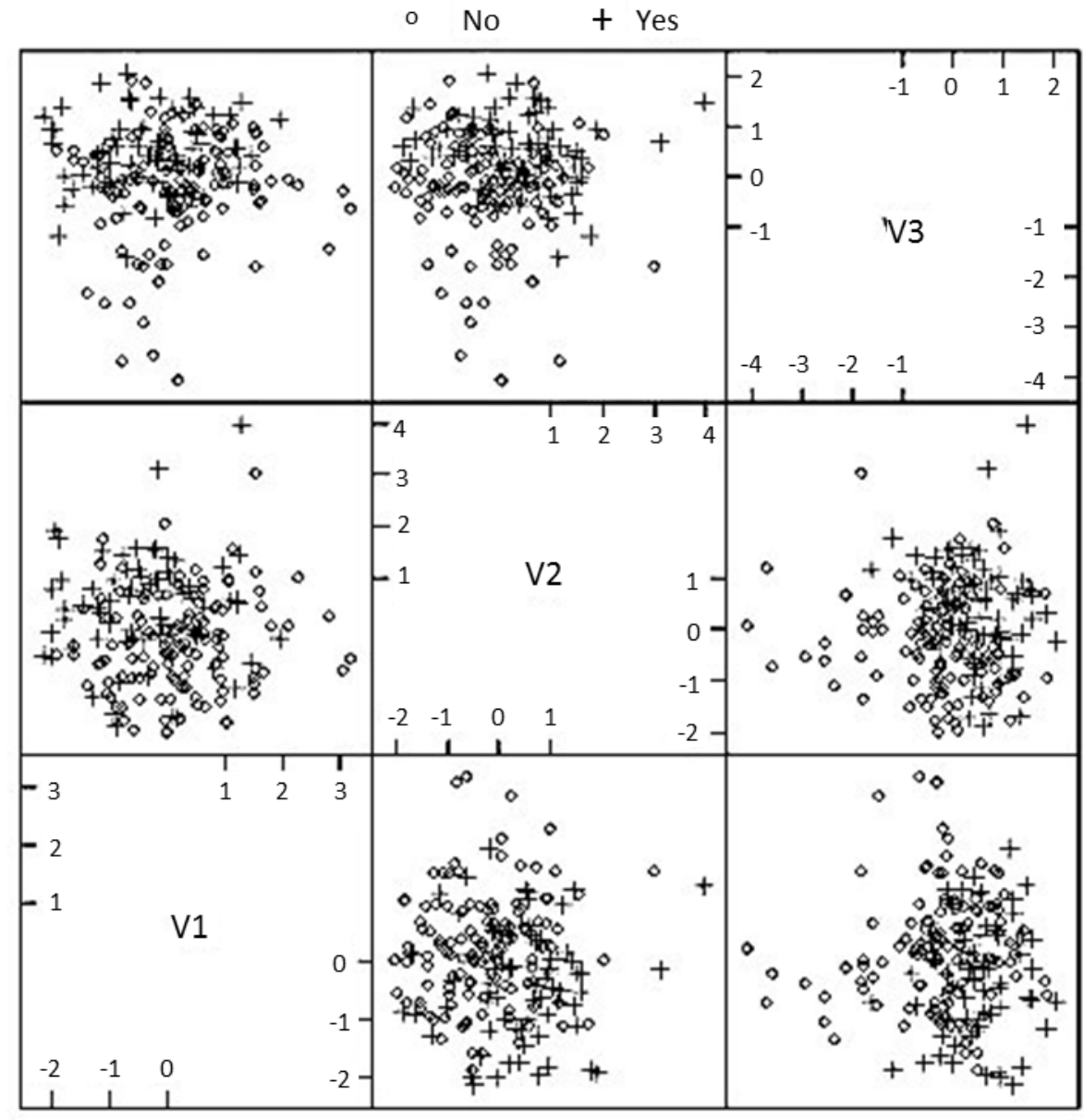

Scatter Plot Matrix

Figure 4. Scatter plot matrix for all three Principal Component Scores for respondents that had (Yes) and had not (No) participated in hunting of any species within the past year, 2005. 


\section{Potential for Conflict Index}

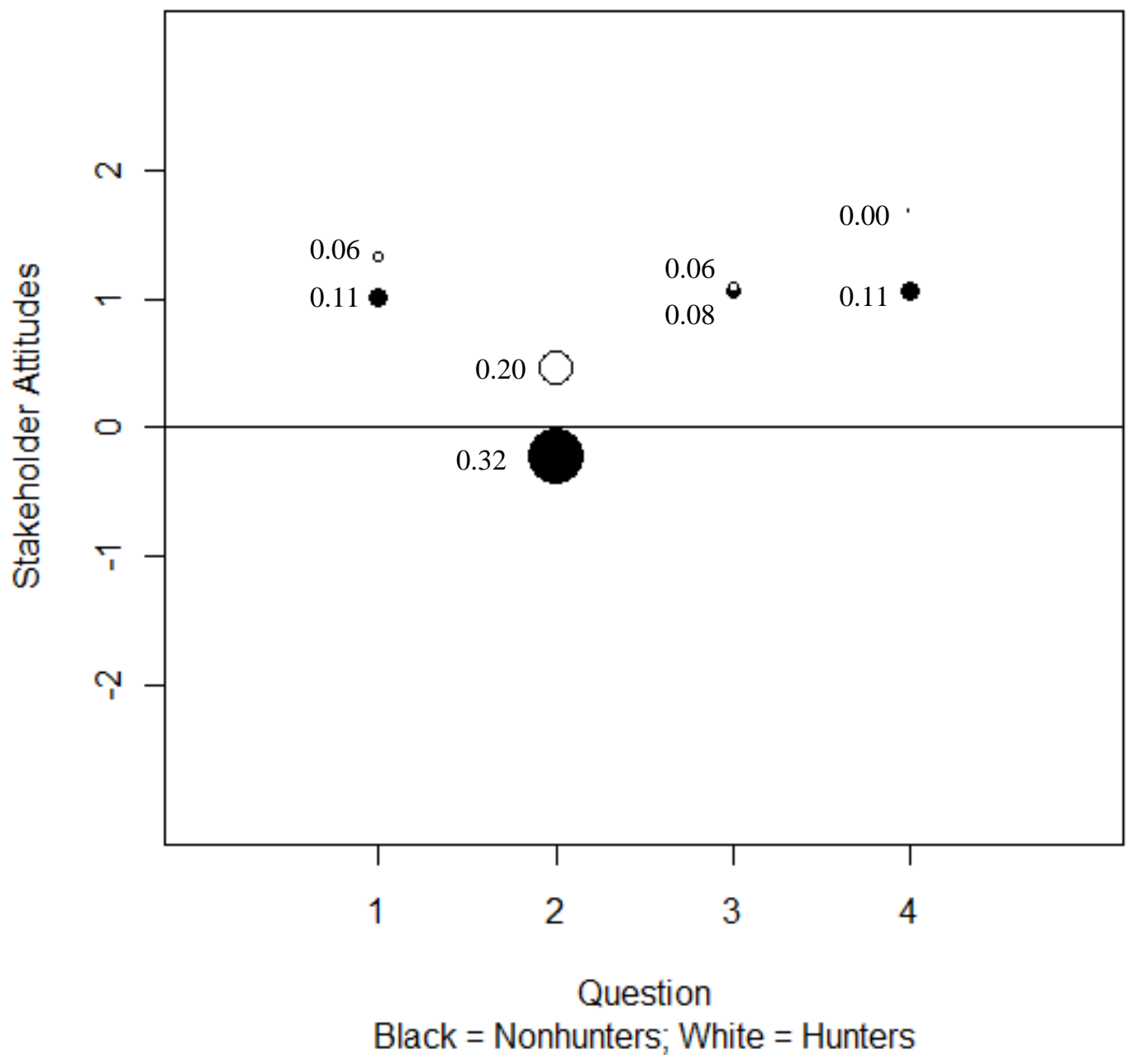

Figure 5. Potential for Conflict Indices (PCI) for the four questions contributing to Principal Component Three by hunters and nonhunters. Circles are centered on the mean response for each group where -2.0 corresponds to strongly disagree and 2.0 corresponds to strongly agree. Larger circles indicate higher potential for conflict among group members. PCI values are given next to the corresponding point. The questions are the following;

1. Question 9: I believe it is ethical to manage populations of white-tailed deer.

2. Question 11: I believe white-tailed deer numbers should be managed to increase hunter harvest.

3. Question 12: I believe white-tailed deer numbers should be managed in balance with their environment.

4. Question 17: I believe hunting is an acceptable tool for managing deer populations 


\title{
CHAPTER VII
}

\section{MANAGEMENT IMPLICATIONS FOR WHITE-TAILED DEER HERBIVORY: COMMUNITY INFLUENCE AND STAKEHOLDER RESPONSE}

\author{
Kelley L. Flaherty \\ Division of Forestry and Natural Resources, West Virginia University, \\ Morgantown, WV 26506, USA
}

Much of the research concerning the effects of deer on plant communities have focused on their role as browsers and the potential for over-browsing of upland plant species (Whitney 1984; Alverson and Waller 1997; Stromayer and Warren 1997). Fewer studies of deer diet have been directed solely toward rare or endangered herbaceous or woody plants (Miller et al. 1992; Urbanek et al. 2012). While research on browse effects on wetland plants is limited, there is evidence that they affect many other herbaceous species through herbivory. Deer have been implicated in the decline of many rare species. The purpose of this study is to evaluate the influences of white-tailed deer browse on plant populations in West Virginia. The study was organized into three general sections: 1) the influence of white-tailed deer browse and seed dispersal on rare wetland plant species and communities in Canaan Valley, West Virginia, 2) the impact of white-tailed deer density on forest understory recruitment in upland forests throughout West Virginia, and 3) public attitudes toward rare plant conservation and white-tailed deer management.

\section{Study Area}

Canaan Valley, in Tucker County, West Virginia, is the largest high-elevation valley east of the Rocky Mountains (Fortney 1975) and is characterized by a relatively cool, moist climate and a short growing season that make the climate and accordingly, the vegetation, of this area more similar to boreal forests of the northeastern United States and Canada than to the deciduous forests of surrounding West Virginia. Canaan Valley is home to the largest contiguous high-elevation wetland area in West Virginia (3,000 ha, Byers et al. 2007) making up about $20 \%$ of the valley floor. Areas 
of Canaan Valley have been set aside as Canaan Valley State Park and Canaan Valley National Wildlife Refuge (NWR).

\section{The Influence of White-tailed Deer Florivory on Polemonium vanbruntiae}

We monitored flowering stems in ten populations of bog Jacob's ladder (Polemonium vanbruntiae) from May 2005 to 2006 to determine the proportion of seeds and stems lost to whitetailed deer florivory. We compared the proportion of stems and seeds lost to browse in sites on the Canaan Valley NWR to sites in Canaan Valley State Park. We used stage-structured matrix modeling to compare the rates of population increase $(\lambda)$ with and without white-tailed deer florivory.

Loss of seeds to white-tailed deer florivory ranged between 0 and $99 \%$ within individual populations and stem loss ranged between 0 and $97 \%$. We found a significant difference in percent stems browsed between the Canaan Valley State Park populations ( $\bar{x}=57 \pm 19 \%)$ and the Canaan Valley NWR populations $\left(\bar{x}=40 \pm 18 \%, \mathrm{~F}_{1,16}=3.27, \mathrm{p}=0.085\right)$. Deer florivory reduced the average growth rate from $1.17(\mathrm{SE}=0.11)$ to1.08 $(\mathrm{SE}=0.13)$. In only one population, $\lambda$ was reduced to less than 1 , indicating a population decline.

Our study suggests that white-tailed deer may consume almost $100 \%$ of the sexually reproductive ramets within $P$. vanbruntiae populations in a given year. As $P$. vanbruntiae can reproduce clonally, high levels of seed loss such as those exhibited here may not have an immediate effect on population persistence. However, a loss of flower and seed production can reduce dispersal into new populations and will reduce genetic variation in a population due to a reduction in sexual reproduction.

- The alteration of deer densities in Canaan Valley to reduce browsing may not immediately benefit $P$. vanbruntiae populations and may be impractical for this sole purpose.

- We believe that short term (May - July) fencing of smaller populations or individuals stems 
would significantly reduce the loss of seed production as flowing ramets were most susceptible immediately prior to and during flowering. The protection of flowering ramets would allow for gene flow through pollination as well the formation of seeds for dispersal.

- Translocation of seeds or individuals from existing populations to suitable, but currently unoccupied patches within Canaan Valley may reduce the chance of localized extirpation through the loss of existing subpopulations.

\section{The Influence of White-tailed Deer Herbivory on Wetland Communities}

We monitored two types of wetland plant communities from those present in Canaan Valley; Solidago spp.-Rubus hispidus. dominated wet meadow communities and regenerating aspen (Populus spp.) dominated communities from 2005-2007. Within each community, we compared the change in species composition in early, late, and continuously fenced treatment plots with control plots using Blocked Multiple Response Permutation Procedures (MRBP) in PC-Ord (McCune and Mefford 1999). We also compared species richness within plots after two years protection from browse. We also examined the changes in woody, forb and graminoid metacommunites as well as the differences between wetland indicator status categories.

There were no significant differences in species richness found between fenced and control plots in either community for any treatment measured in both spring and fall $(\mathrm{p}>0.05)$. In both Solidago spp.-Rubus hispidus. and Populus spp. communities we found that differences in community composition between treatment and control plots depended on both the treatment period and the season of data collection. In both communities, increases in woody species cover were apparent in fenced plots under some, but not all, treatment regimes. Changes in forb cover occurred in both communities but were only apparent when measured in the fall. No differences in graminoid species cover class were detected for fencing period or treatment in either season. There was no 
significant difference in the changes between wetland indicator status categories for either community.

Our study suggests that the elevated deer densities present in the post-logging era impact the herbaceous community by selectively browsing forb species, especially in the spring. Suppression of woody species through selective browsing may play a role in suppressing succession to the historical spruce communities. The timing of herbivory may be a factor in determining the influence of whitetailed deer browse on some species.

- We believe that continuous protection of herbaceous wetland communities on a large scale for the protection of individual threatened and endangered species or the regeneration of historical communities is not feasible in Canaan Valley.

- Small-scale protection of individuals or small populations may increase the survival of woody or forb species.

- However, continuous protection may not be appropriate everywhere in Canaan Valley. Seasonal protection may be more effective on individual plants representing threatened or endangered species where year-long protection may not be appropriate. Protection of forb species should occur in the spring and woody species in the fall and winter.

\section{The Influence of White-tailed Deer Herbivory on Upland Communities}

We analyzed a dataset collected from twenty, paired treatment (fenced) and control sites from upland forests throughout West Virginia between 1984 and 1990. We counted the number of stems for each species in the ground cover and understory vegetation subplots. We compared the number of stems, species richness, and the Shannon diversity values between control plots and treatment every three years following plot establishment. We used MRBP to determine if differences existed in the groundcover and understory communities between fenced and control plots. Finally, we 
evaluated the relation between the seedling-sapling ratio (Sweetapple and Nugent 2004) in control plots and the total deer density at the site from $1993-2007$.

In upland communities, we recorded 197 species present in the ground cover over the study period. After 21 years, we found no significant difference in stem abundance, species richness, or Shannon diversity values in the ground cover. At the ground cover level, we found a significant difference in community composition occurred 21 years after plot initiation $(t=-0.20, \mathrm{p}=0.03)$. We recorded 79 species present in the understory over the study period. We found that treatment had an effect on the stem abundance $\left(F_{1,19}=12.22, \mathrm{p}<0.001\right)$ and Shannon diversity values $\left(F_{1,19}=40.82, \mathrm{p}\right.$ $<0.001)$. There was a significant difference in both species richness and understory community composition 6 years after plot establishment and in most years thereafter $(\mathrm{p}>0.05)$. We found no relation between the seedling-sapling ratio and deer density $\left(R^{2}=0.02, \mathrm{p}=0.17\right)$.

Our results indicate the density of white-tailed deer impacting the control plots at our sites has met or exceeded the capacity of the upland forest to regenerate the current community. The potential still exists to regenerate the current forest state. However, if browse pressure persists as the seed sources decline; the potential for recovery of the current ecosystem will likewise decline (Levine et al. 2012).

- At many locations throughout the state, deer densities must be reduced in order for regeneration of the current complement of overstory species to regenerate.

- Alternately, larger scale ( > $10 \mathrm{~m}$ x $10 \mathrm{~m}$ ) protection of the groundcover and understory communities may allow for localized regeneration of the understory providing for a future seed source.

- Our results suggest that it takes only 6 years of protection to allow species to enter the understory. However, longer protection is necessary to allow those individuals to escape deer browse.

- As differences in groundcover vegetation were found in the $21^{\text {st }}$ year post construction, the 
ability of the community to regenerate on its own may already be diminished. At some sites, a decrease in deer density may not be enough for regeneration. Fencing in conjunction with seeding or transplants may be necessary to restore desirable species.

- At some sites, graminoid and fern cover may also present an obstacle for regeneration.

- We recommend using caution in the application of the seedling-sapling ratio method, or any other vegetation-based deer density index without first testing its applicability to local flora.

\section{White-tailed Deer Seed Dispersal through Endozoochory}

We collected fresh white-tailed deer fecal pellet groups bi-monthly from May to December in wetland habitats within the Canaan Valley National Wildlife Refuge and Canaan Valley State Park. Following a three month period of cold stratification the seeds were spread on top of a layer of potting mix within $10 \mathrm{~cm}$ diameter planting pots and kept moist. We determined the wetland indicator status (Lichvar et al. 2014) and classified each species as graminoid, forb, or woody species. We compared the proportion of species germinated and frequency of occurrence. We repeated these tests for the proportion and frequency of germination of plants that were graminoid, forbs, or woody. We identified 14 species in 2005 and 32 species in 2006 . We did not find a significant different in the proportion of species by wetland indicator status or growth habit. The proportion of stems germinated of both graminoids and forbs were significantly higher than for woody species in both years $(\mathrm{p}<0.05)$ The proportion of upland stems (UPL and FACU) germinating was significantly more than proportion of wetland stems (FACW and OBL) in 2006, but not in 2005.

A difference in frequency of upland species that germinated from fecal samples in 2006 seems to agree with the hypothesis that upland plants may be more adapted to dispersal by whitetailed deer, though this difference in frequency might be attributed to the success of a few FACU plants. We observed the presence of FACW and OBL wetland species germinating in pellet piles; however, these observations may underestimate the actual presence of germinable wetland species in 
pellet piles as we did not provide our samples with wetland conditions for germination. As dispersers, white-tailed deer could play a role in maintaining or enhancing metapopulations of wetland plants patchily distributed in an upland matrix (Vellend et al. 2003).

- White-tailed deer do act as dispersers of exotic plants in Canaan Valley. However, it is unclear if exotic plants are consumed and dispersed disproportionately or if dispersal significantly increases the colonization rate of these species into new areas.

- While dispersal by herbivores is often linked to the production of fleshy fruit, the prevalence of graminoids and small forbs in our sample lends support to the "foliage as fruit" hypothesis (Janzen 1984).

- These results coupled with those of the exclosure studies suggest that white-tailed deer may contribute to increases in graminoid cover through seed dispersal as well as through selective browsing and deer exclusion may serve to change groundcover communities by altering both means.

\section{Stakeholder Views of White-tailed Deer Management and Plant Conservation}

We surveyed stakeholders including residents of Canaan Valley, residents of Tucker County, West Virginia, nonresident landowners and visitors to Canaan Valley using 25 questions designed to assess views toward rare plant conservation and the status and management of white-tailed deer in Canaan Valley. Responses were subjected to Principal Components Analysis (PCA) to identify underlying constructs and we modeled these as a function of socio-demographic factors. Additionally, we examined the principal components using a Potential for Conflict Index (PCI) (Vaske et al. 2006) that numerically described the amount of disparity between respondents in a particular group.

We found that people who had experienced crop or landscape damage tended to have a lower tolerance of deer. Those that had experienced crop or landscape damage were more likely to describe Canaan Valley white-tailed deer populations as being overabundant. Tucker County 
residents tended to value plants and plant communities less than nonresident landowners $(t=-3.55, \mathrm{p}$ $<0.001)$. Although, for the most part, stakeholder groups agreed that they enjoyed seeing wild plants, Tucker County residents appeared less likely to agree that deer could harm plant communities and that plants should be protected from deer. Hunters, in general, showed greater support for management actions for white-tailed deer than nonhunters $\left(F_{1,163}=14.80, \mathrm{p}<0.001\right)$.

Many of the visitors and nonresidents come to Canaan Valley specifically because of its unique characteristics and appear to place more value on these unique plants. Recognition of differences in attitudes between stakeholder groups could be helpful in designing educational programs for users of natural areas (Brooks et al. 1999). In this case, education and emphasis on the importance of rare plant diversity in Canaan Valley may bring more local support for their conservation.

- Local rural residents were less likely to favor rare plant conservation. This suggests the need for building awareness of the unique nature of Canaan Valley vegetation among local residents.

- Many of the Tucker County residents may be less likely to frequent Canaan Valley State Park and National Wildlife Refuge. Thus, educational efforts should not be limited to these two venues to reach the local community.

\section{CONCLUSION}

The plant communities of Canaan Valley today are much different than those that existed in precolonial times. Humans have altered plant communities from a thick overstory dominated by conifers to open herbaceous and shrub-dominated wetlands. It may be unlikely that species such as the $P$. vanbruntiae that rely on mid-successional, wetland habitat were as prevalent at that time as they are today. Therefore, white-tailed deer florivory at current levels is not likely to reduce the Canaan Valley P. vanbruntiae populations below historical levels. However, the loss of colonization potential, when combined with other anthropogenic threats to individual subpopulations persistence, 
may have the potential to lead to extirpation. As $P$. vanbruntiae is rare throughout much of its range, localized extinction of the Canaan Valley population, one of the southernmost populations, may represent a significant loss of diversity in this species. Herbaceous wetland plant communities on the valley floor also represent a significantly different condition than was present in the past. While many of the native species were likely present, they may have been less abundant under thick conifer cover. Thus, increased deer densities in Canaan Valley are not driving native plant densities below historic levels. However, increases in woody plant cover in fenced plots suggest the possibility that high densities of white-tailed deer may prevent the succession of overstory species once prevalent in the valley.

The surrounding upland forests of West Virginia are also likely different from historical communities. Extirpation of dominant species such as the American chestnut (Castanea dentata) as well as harvest practices has changed overstory species composition. At many sites, however, the current compliment of overstory species is not being regenerated and, if current deer densities are maintained, may be replaced with species that are less valuable for both timber and wildlife. The native herbaceous ground cover at our upland sites may represent the historical community. However, at high deer density sites species composition has shifted toward graminoid species potentially further reducing the survival of tree seedlings. White-tailed deer, at high densities, do have the potential to negatively affect both woody and herbaceous forest and wetland communities.

\section{FUTURE RESEARCH NEEDS}

The findings of our study indicate the following needs for future research at both the state and national level:

- Estimation of the natural rate of colonization of new patches for P. vanbruntiae as well as other native threatened and endangered species to determine the actual effect florivory may have on species' dispersal. 
- Examine the role of other landscape factors such as topography and anthropogenic influences in limiting the dispersal of $P$. vanbruntiae.

- Germination of fecal pellet samples under alternate regimes to increase the potential of wetland seed germination.

- Comparison of the actual seed bank potential at WV DNR exclosure sites through ex situ germination studies to determine the relative importance of seed bank, seed rain or seed dispersal in maintaining ground cover diversity.

- Examine the influence of an abundant sapling community on the microclimate and nutrient cycling within WV DNR exclosures and the subsequent influence of those variables on seedling growth.

- Separation of farmers and hunters in determining attitudes toward deer management and plant conservation.

\section{Literature Cited}

Alverson, W.S., and D.M. Waller. 1997. Deer populations and the widespread failure of hemlock regeneration in northern forests. Pages 280-297 in McShea, W.J., H.B. Underwood, and J.H. Rappole. The science of overabundance: deer ecology and population management. Smithsonian Institution Press. Washington D.C., USA.

Brooks, J.J., R.J. Warren, M.G. Nelms, and M.A. Tarrant. 1999. Visitor attitudes toward and knowledge of restored bobcats on Cumberland Island National Seashore, Georgia. Wildlife Society Bulletin 27:1089-1097.

Byers, E.A., J.P. Vanderhorst, and B.P. Streets. 2007. Classification and conservation assessment of high elevation wetland communities in the Allegheny Mountains of West Virginia. West Virginia Natural Heritage Program, WVDNR. Elkins, WV, USA.

Fortney, R.H. 1975. The vegetation of Canaan Valley, West Virginia: a taxonomic and ecological study. Dissertation; West Virginia University, Morgantown, West 


\section{Virginia, USA.}

Janzen, D.H. 1984. Dispersal of small seeds by big herbivores: foliage is the fruit. American Naturalist 123:338-353.

Levine, C.R., R.J. Winchcombe, C.D. Canham, L.M. Christenson, and M.L. Ronsheim. 2012. Deer impacts on seed banks and saplings in eastern New York. Northeastern Naturalist 19:49-66.

Lichvar, R.W., M. Butterwick, N.C. Melvin, and W.N. Kirchner. 2014. The national wetland plant list: 2014 update of wetland plant ratings. Phytoneuron 41:1-42.

McCune, B., and R. Mefford. 1999. PC-Ord. Multivariate analysis of ecological data, version 4. MjM Software Design, Gleneden Bearch, OR, USA.

Miller, S.G., S.P. Bratton, and J. Hadidian. 1992. Impacts of white-tailed deer on endangered and threatened vascular plants. Natural Areas Journal 12:67-74.

Stromayer, K.A.K., and R.J. Warren. 1997. Are over abundant deer herds in the eastern United States creating alternate stable states in forest plant communities? Wildlife Society Bulletin 25:227-234.

Sweetapple, P.J., and G. Nugent. 2004. Seedling ratios: a simple method for assessing ungulate impacts on forest understories. Wildlife Society Bulletin 32:137-147.

Urbanek, R.E., C.K. Nielsen, G.A. Glowacki, and T. Preuss. 2012. Effects of white-tailed deer (Odocoileus virginianus Zimm.) herbivory in restored forest and savanna plant communities American Midland Naturalist 167:240-255.

Vaske, J.J., M.D. Needham, P. Newman, M.J. Manfredo, and J. Petchenik. 2006. Potential for conflict index: hunters' responses to chronic wasting disease. Wildlife Society Bulletin 34:44-50.

Vellend, M., J.A. Myers, S. Gardescu, and P.L. Marks. 2003. Dispersal of Trillium seeds by 
deer: implications for long-distance migration of forest herbs. Ecology 84:1067-1072.

Whitney, G.G. 1984. Fifty years of change in the arboreal vegetation of Heart's Content, an old growth hemlock-white pine-northern hardwood stand. Ecology 65:403-408. 
Appendix 1. Deer density estimates from spotlight sampling conducted in Canaan Valley, WV in 2005 - 2006. Estimates were calculated using the distance sampling program Distance version 6.2 release 1. Strip width refers to the effective strip width of the detection function for each sampling event. The upper and lower confidence limit for deer density was calculated in Distance.

\begin{tabular}{|c|c|c|c|c|c|c|c|c|}
\hline \multicolumn{3}{|c|}{ Sampling Date } & \multirow{2}{*}{$\begin{array}{c}\text { Deer/ha } \\
0.332\end{array}$} & \multirow{2}{*}{$\begin{array}{c}\begin{array}{c}\text { Lower CL } \\
\left(\text { Deer } / \mathrm{km}^{2}\right)\end{array} \\
25.8\end{array}$} & \multirow{2}{*}{$\frac{\text { Deer } / \mathrm{km}^{2}}{33.2}$} & \multirow{2}{*}{$\begin{array}{c}\begin{array}{c}\text { Upper CL } \\
\left(\text { Deer } / \mathrm{km}^{2}\right)\end{array} \\
42.9\end{array}$} & \multirow{2}{*}{$\frac{\text { Deer } / \mathrm{mi}^{2}}{86.0}$} & \multirow{2}{*}{$\begin{array}{c}\text { Strip Width }(\mathrm{m}) \\
43.70\end{array}$} \\
\hline May & 31 & 2005 & & & & & & \\
\hline June & 10 & 2005 & 0.166 & N/A & 16.6 & N/A & 43.0 & N/A \\
\hline July & 12 & 2005 & 0.304 & 21.6 & 30.4 & 42.7 & 78.7 & 82.78 \\
\hline July & 26 & 2005 & 0.321 & 25.1 & 32.1 & 40.5 & 83.1 & 77.19 \\
\hline August & 23 & 2005 & 0.244 & 17.3 & 24.4 & 34.4 & 61.2 & 132.18 \\
\hline December & 15 & 2005 & 0.183 & 12.4 & 18.3 & 26.4 & 47.4 & 85.91 \\
\hline March & 24 & 2006 & 0.257 & 16.7 & 25.7 & 39.3 & 66.6 & 82.17 \\
\hline May & 10 & 2006 & 0.302 & 21.3 & 30.2 & 42.7 & 78.2 & 95.97 \\
\hline May & 24 & 2006 & 0.153 & 11.1 & 15.3 & 21.2 & 39.6 & 151.28 \\
\hline June & 15 & 2006 & 0.285 & 20.6 & 28.5 & 39.4 & 73.8 & 64.00 \\
\hline July & 26 & 2006 & 0.092 & 6.9 & 9.2 & 12.3 & 23.8 & 78.12 \\
\hline December & 19 & 2006 & 0.249 & 16.0 & 24.9 & 38.7 & 64.5 & 85.91 \\
\hline Average & & & 0.241 & & 24.1 & & 62.33 & 93.55 \\
\hline
\end{tabular}


Appendix 2. R Code for the calculation of population growth rates and confidence intervals with the popbio package.

$>$ library(popbio)

$>\mathrm{A}<-$ matrix $(\mathrm{c}(0, .2375,0,0,0,0,0, .041,0,0,0,0, .88, .101, .01,175.4,0, .89, .02, .02,0,0, .03,0,0)$, nrow $=5$ )

$>\mathrm{B}<-$ matrix $(\mathrm{c}(0, .2375,0,0,0,0,0, .056,0,0,0,0, .89, .98, .01,123.9,0, .89, .02, .02,0,0, .03,0,0)$, nrow $=5$ )

$>\mathrm{C}<-$ matrix $(\mathrm{c}(0, .2375,0,0,0,0,0, .048,0,0,0,0, .86, .12, .01,280,0, .85, .02, .02,0,0, .03,0,0)$, nrow $=5)$

$>$ MatrixList <- list $(\mathrm{A}, \mathrm{B}, \mathrm{C})$

$>$ rate $<$ - stoch.growth.rate(MatrixList, prob=NULL, $\operatorname{maxt}=50)$

[1] Calculating stochastic growth at time 1

$>\exp ($ rate $\$ \operatorname{sim})$

[1] 1.120016

$>\exp (\operatorname{rate} \$ \operatorname{sim} . \mathrm{CI})$

[1] 1.0246791 .224224 
Appendix 3. R Code for the calculation of probability of reaching quasi-extinction thresholds with the popbio package.

$>$ library(popbio)

$>\mathrm{A}<-$ matrix $(\mathrm{c}(0, .2375,0,0,0,0,0, .041,0,0,0,0, .88, .101, .01,175.4,0, .89, .02, .02,0,0, .03,0,0)$, nrow $=5$ )

$>\mathrm{B}<-$ matrix $(\mathrm{c}(0, .2375,0,0,0,0,0, .056,0,0,0,0, .89, .98, .01,123.9,0, .89, .02, .02,0,0, .03,0,0)$, nrow $=5$ )

$>\mathrm{C}<-$ matrix $(\mathrm{c}(0, .2375,0,0,0,0,0, .048,0,0,0,0, .86, .12, .01,280,0, .85, .02, .02,0,0, .03,0,0)$, nrow $=5)$

$>$ MatrixList <- list $(\mathrm{A}, \mathrm{B}, \mathrm{C})$

$>\mathrm{n}<-\mathrm{c}(4264,30,16,25,5)$

\#\# exclude seeds, seedlings and dormant individuals using sumweight

$\mathrm{x}<-$ stoch.quasi.ext(MatrixList, $\mathrm{n}, \mathrm{Nx}=8$, nreps $=500$, sumweight $=\mathrm{c}(0,0,1,1,0)$

matplot(x, xlab="Years", ylab="Quasi-extinction probability", 
Appendix 4. Mean and standard deviation of percent cover of species sampled in Solidago spp.-Rubus hispidus communities in Canaan Valley, WV from 2005 - 2007. Blank values indicate the species was not recorded in the treatment group.

\begin{tabular}{|c|c|c|c|c|c|c|c|}
\hline & & \multicolumn{2}{|c|}{ Early } & \multicolumn{2}{|c|}{ Late } & \multicolumn{2}{|c|}{ Continuous } \\
\hline & & $\begin{array}{c}\text { Fenced } \\
\bar{x} \\
\mathrm{SD} \\
\end{array}$ & $\begin{array}{c}\text { Control } \\
\bar{x} \\
\text { SD } \\
\end{array}$ & $\begin{array}{c}\text { Fenced } \\
\bar{x} \\
\text { SD } \\
\end{array}$ & $\begin{array}{c}\text { Control } \\
\bar{x} \\
\text { SD } \\
\end{array}$ & $\begin{array}{c}\text { Fenced } \\
\bar{x} \\
\mathrm{SD} \\
\end{array}$ & $\begin{array}{c}\text { Control } \\
\bar{x} \\
\text { SD } \\
\end{array}$ \\
\hline $\begin{array}{l}\text { Achillea millefolium L. var. occidentalis } \\
\text { DC }\end{array}$ & Spring 2005 & & & & & & $\begin{array}{l}1.750 \\
4.721\end{array}$ \\
\hline Agrostis gigantea Roth & Spring 2005 & & & & & $\begin{array}{l}0.500 \\
1.549\end{array}$ & $\begin{array}{l}1.750 \\
4.721\end{array}$ \\
\hline Amelanchier spp. & Spring 2005 & $\begin{array}{l}0.250 \\
0.796\end{array}$ & & $\begin{array}{l}0.250 \\
0.796\end{array}$ & & & \\
\hline Anthoxanthum odoratum L. & Spring 2005 & $\begin{array}{l}3.500 \\
6.146\end{array}$ & $\begin{array}{l}2.000 \\
4.684\end{array}$ & $\begin{array}{l}0.500 \\
1.549\end{array}$ & $\begin{array}{l}0.500 \\
1.549\end{array}$ & $\begin{array}{l}0.750 \\
4.632\end{array}$ & $\begin{array}{l}0.500 \\
4.684\end{array}$ \\
\hline Apocynum cannabinum $\mathrm{L}$. & Spring 2005 & $\begin{array}{l}0.250 \\
0.796\end{array}$ & $\begin{array}{l}0.250 \\
0.796\end{array}$ & $\begin{array}{l}0.250 \\
0.796\end{array}$ & $\begin{array}{l}0.500 \\
1.549\end{array}$ & & \\
\hline Carex brunnescens (Pers.) Poir. & Spring 2005 & & $\begin{array}{l}0.500 \\
1.549\end{array}$ & $\begin{array}{l}0.250 \\
0.796\end{array}$ & $\begin{array}{l}0.250 \\
0.796\end{array}$ & $\begin{array}{l}0.250 \\
0.796\end{array}$ & $\begin{array}{l}0.250 \\
0.796\end{array}$ \\
\hline Carex bushii Mack. & Spring 2005 & & & & & & \\
\hline Carex debilis Michx. var. rudgei L. Bailey & Spring 2005 & $\begin{array}{c}7.250 \\
12.216\end{array}$ & $\begin{array}{l}5.750 \\
12.792\end{array}$ & $\begin{array}{l}4.750 \\
7.569\end{array}$ & $\begin{array}{c}6.750 \\
12.475\end{array}$ & $\begin{array}{l}1.750 \\
4.721\end{array}$ & $\begin{array}{l}1.750 \\
4.721\end{array}$ \\
\hline Carex folliculata $\mathrm{L}$. & Spring 2005 & & $\begin{array}{l}0.250 \\
0.796\end{array}$ & $\begin{array}{l}0.250 \\
0.796\end{array}$ & & & \\
\hline Carex hirsutella Mack. & Spring 2005 & & & $\begin{array}{l}0.250 \\
0.796\end{array}$ & & & $\begin{array}{l}0.250 \\
0.796\end{array}$ \\
\hline $\begin{array}{l}\text { Carex scoparia Schkuhr ex Willd. var. } \\
\text { scoparia }\end{array}$ & Spring 2005 & & & $\begin{array}{l}0.250 \\
0.796\end{array}$ & & & \\
\hline Carex virescens $\mathrm{L}$. & Spring 2005 & & & $\begin{array}{l}0.250 \\
0.796\end{array}$ & $\begin{array}{l}1.500 \\
4.743\end{array}$ & & \\
\hline
\end{tabular}




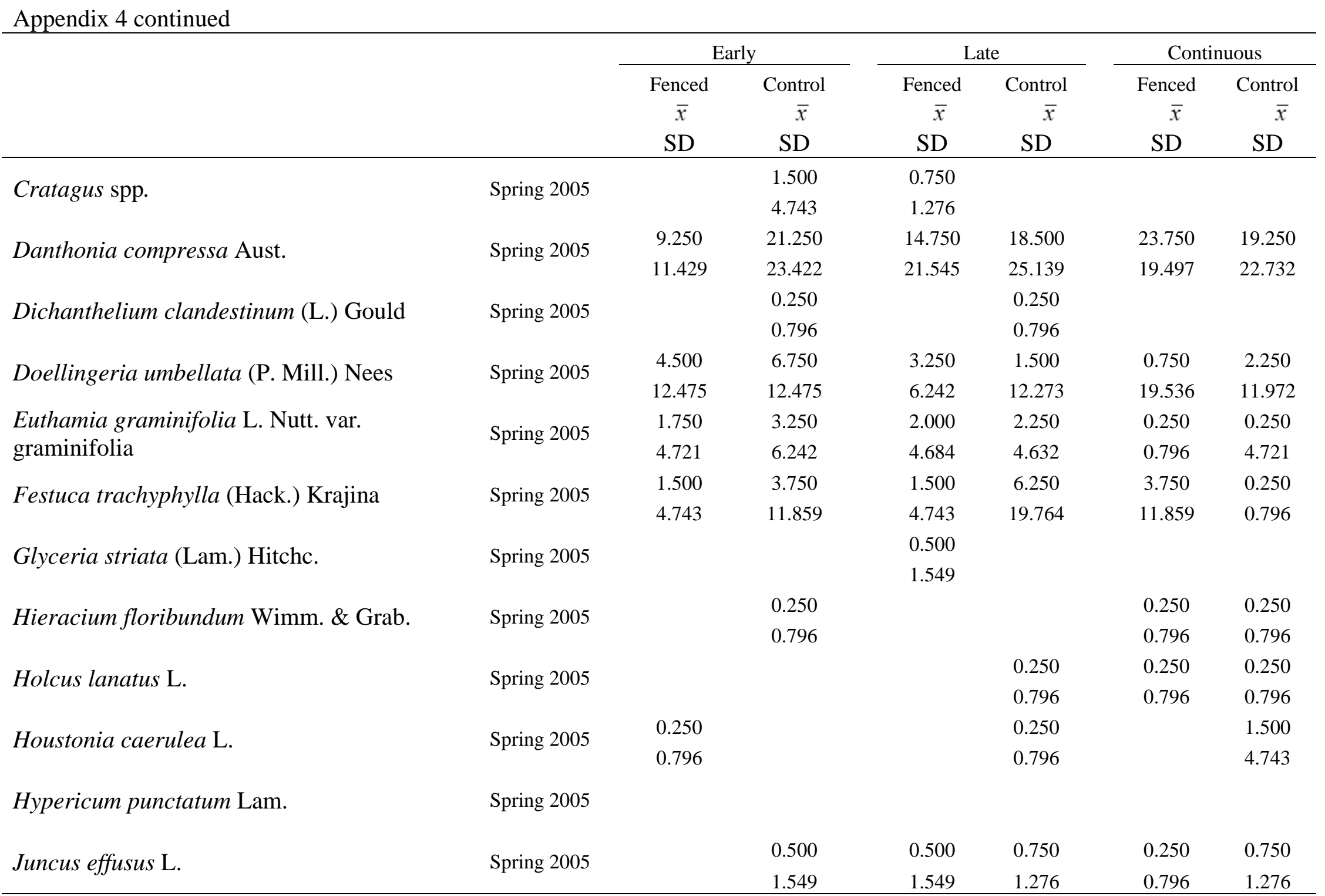




\begin{tabular}{|c|c|c|c|c|c|c|c|}
\hline & & \multicolumn{2}{|c|}{ Early } & \multicolumn{2}{|c|}{ Late } & \multicolumn{2}{|c|}{ Continuous } \\
\hline & & $\begin{array}{l}\text { Fenced } \\
\bar{x} \\
\mathrm{SD} \\
\end{array}$ & $\begin{array}{c}\text { Control } \\
\bar{x} \\
\text { SD } \\
\end{array}$ & $\begin{array}{c}\text { Fenced } \\
\bar{x} \\
\text { SD } \\
\end{array}$ & $\begin{array}{c}\text { Control } \\
\bar{x} \\
\mathrm{SD} \\
\end{array}$ & $\begin{array}{c}\text { Fenced } \\
\bar{x} \\
\text { SD } \\
\end{array}$ & $\begin{array}{c}\text { Control } \\
\bar{x} \\
\text { SD } \\
\end{array}$ \\
\hline Luzula bulbosa (Alph. Wood) & Spring 2005 & & & & & & $\begin{array}{l}0.500 \\
1.549\end{array}$ \\
\hline Lycopodium spp. & Spring 2005 & $\begin{array}{l}0.250 \\
0.796\end{array}$ & & & & $\begin{array}{l}0.500 \\
1.549\end{array}$ & $\begin{array}{l}2.000 \\
4.684\end{array}$ \\
\hline Photinia melanocarpa Michx. & Spring 2005 & & & & $\begin{array}{l}0.250 \\
0.796\end{array}$ & $\begin{array}{l}0.250 \\
0.796\end{array}$ & \\
\hline Poa trivialis L. & Spring 2005 & & & $\begin{array}{l}0.250 \\
0.796\end{array}$ & & & $\begin{array}{l}0.250 \\
0.796\end{array}$ \\
\hline Populus tremuloides Michx. & Spring 2005 & & $\begin{array}{l}0.500 \\
1.549\end{array}$ & $\begin{array}{l}2.000 \\
4.684\end{array}$ & & $\begin{array}{l}1.500 \\
4.743\end{array}$ & $\begin{array}{l}0.250 \\
0.796\end{array}$ \\
\hline Potentilla simplex Michx. & Spring 2005 & $\begin{array}{c}2.500 \\
19.497\end{array}$ & $\begin{array}{l}1.000 \\
4.564\end{array}$ & $\begin{array}{l}1.500 \\
1.300\end{array}$ & $\begin{array}{l}2.750 \\
5.780\end{array}$ & $\begin{array}{c}1.000 \\
11.574\end{array}$ & $\begin{array}{l}2.500 \\
5.917\end{array}$ \\
\hline Prunus serotina Ehrh. & Spring 2005 & & & & & & \\
\hline Pteridium aquilinum (L.) Kuhn & Spring 2005 & $\begin{array}{c}4.750 \\
11.574\end{array}$ & $\begin{array}{c}5.750 \\
12.792\end{array}$ & $\begin{array}{l}1.250 \\
1.318\end{array}$ & $\begin{array}{l}3.500 \\
6.146\end{array}$ & $\begin{array}{l}1.000 \\
1.300\end{array}$ & $\begin{array}{l}3.750 \\
6.387\end{array}$ \\
\hline Ranunculus acris L. var. acris & Spring 2005 & & & & & & $\begin{array}{l}0.250 \\
0.796\end{array}$ \\
\hline Ribes spp. & Spring 2005 & $\begin{array}{l}0.250 \\
0.796\end{array}$ & & & & & \\
\hline Rubus hispidus L. & Spring 2005 & $\begin{array}{l}26.250 \\
19.230\end{array}$ & $\begin{array}{l}32.250 \\
21.776\end{array}$ & $\begin{array}{l}22.000 \\
13.323\end{array}$ & $\begin{array}{l}21.000 \\
11.619\end{array}$ & $\begin{array}{l}21.250 \\
18.257\end{array}$ & $\begin{array}{l}16.500 \\
11.292\end{array}$ \\
\hline Rumex acetosella $L$. & Spring 2005 & & $\begin{array}{l}0.750 \\
1.276\end{array}$ & & & & \\
\hline
\end{tabular}




\begin{tabular}{|c|c|c|c|c|c|c|c|}
\hline & & \multicolumn{2}{|c|}{ Early } & \multicolumn{2}{|c|}{ Late } & \multicolumn{2}{|c|}{ Continuous } \\
\hline & & Fenced & Control & Fenced & Control & Fenced & Control \\
\hline & & $\bar{x}$ & $\bar{x}$ & $\bar{x}$ & $\bar{x}$ & $\bar{x}$ & $\bar{x}$ \\
\hline & & $\mathrm{SD}$ & $\mathrm{SD}$ & SD & SD & $\mathrm{SD}$ & SD \\
\hline \multirow{2}{*}{ Solidago rugosa Mill. } & \multirow{2}{*}{ Spring 2005} & 1.000 & 7.750 & 8.250 & 9.250 & 1.000 & 12.750 \\
\hline & & 15.138 & 7.458 & 15.296 & 11.789 & 2.792 & 2.448 \\
\hline \multirow{2}{*}{ Solidago uliginosa Nutt. } & \multirow{2}{*}{ Spring 2005} & 9.250 & 12.000 & 15.250 & 6.500 & 14.500 & 13.750 \\
\hline & & 7.458 & 6.325 & 13.486 & 11.738 & 9.916 & 14.252 \\
\hline \multirow{2}{*}{ Spiraea alba Du Roi } & \multirow{2}{*}{ Spring 2005} & 2.000 & 0.250 & 0.500 & 3.250 & & \\
\hline & & 4.684 & 4.721 & 11.729 & 6.242 & & \\
\hline \multirow{2}{*}{ Vaccinium angustifolium Ait. } & \multirow{2}{*}{ Spring 2005} & & 0.250 & & & 0.250 & 5.250 \\
\hline & & & 0.796 & & & 0.796 & 12.273 \\
\hline \multirow{2}{*}{ Vaccinium myrtilloides Michx. } & \multirow{2}{*}{ Spring 2005} & 1.500 & 2.000 & 0.500 & 1.500 & 4.500 & 4.750 \\
\hline & & 4.743 & 4.684 & 1.549 & 4.743 & 7.246 & 7.115 \\
\hline \multirow{2}{*}{ Vaccinium pallidum Ait. } & \multirow{2}{*}{ Spring 2005} & & & 1.500 & 0.250 & 3.750 & \\
\hline & & & & 4.743 & 0.796 & 11.859 & \\
\hline \multirow{2}{*}{ Viburnum nudum L. var. cassinoides } & \multirow{2}{*}{ Spring 2005} & & & 0.250 & & & 0.250 \\
\hline & & & & 11.797 & & & 0.796 \\
\hline \multirow{2}{*}{ Viburnum recognitum } & \multirow{2}{*}{ Spring 2005} & & & 1.500 & & & 0.250 \\
\hline & & & & 4.743 & & & 0.796 \\
\hline \multirow{2}{*}{ Acer rubrum $L$. } & \multirow{2}{*}{ Fall 2005} & & & & 0.250 & & \\
\hline & & & & & 0.796 & & \\
\hline \multirow{2}{*}{$\begin{array}{l}\text { Achillea millefolium L. var. occidentalis } \\
\text { DC }\end{array}$} & \multirow{2}{*}{ Fall 2005} & & 1.500 & 0.250 & & & 0.250 \\
\hline & & & 4.743 & 0.796 & & 4.743 & 0.796 \\
\hline \multirow{2}{*}{ Agrostis gigantea Roth } & \multirow{2}{*}{ Fall 2005} & 2.000 & 0.750 & 0.500 & 0.500 & 1.750 & 0.250 \\
\hline & & 4.684 & 1.276 & 1.549 & 1.549 & 6.242 & 11.797 \\
\hline \multirow{2}{*}{ Agrostis perennans (Walt) Tuckerman } & \multirow{2}{*}{ Fall 2005} & & 0.250 & & & & \\
\hline & & & 0.796 & & & & \\
\hline
\end{tabular}




\begin{tabular}{|c|c|c|c|c|c|c|c|}
\hline & & \multicolumn{2}{|c|}{ Early } & \multicolumn{2}{|c|}{ Late } & \multicolumn{2}{|c|}{ Continuous } \\
\hline & & $\begin{array}{c}\text { Fenced } \\
\bar{x} \\
\mathrm{SD} \\
\end{array}$ & $\begin{array}{c}\text { Control } \\
\bar{x} \\
\text { SD } \\
\end{array}$ & $\begin{array}{c}\text { Fenced } \\
\bar{x} \\
\mathrm{SD} \\
\end{array}$ & $\begin{array}{c}\text { Control } \\
\bar{x} \\
\mathrm{SD} \\
\end{array}$ & $\begin{array}{c}\text { Fenced } \\
\bar{x} \\
\mathrm{SD} \\
\end{array}$ & $\begin{array}{c}\text { Control } \\
\bar{x} \\
\mathrm{SD} \\
\end{array}$ \\
\hline \multirow{2}{*}{ Amelanchier spp. } & \multirow{2}{*}{ Fall 2005} & 0.250 & 0.250 & 0.250 & & 0.250 & \\
\hline & & 0.796 & 0.796 & 0.796 & & 0.796 & \\
\hline \multirow{2}{*}{ Anthoxanthum odoratum L. } & \multirow{2}{*}{ Fall 2005} & 0.250 & 0.250 & 0.750 & 1.750 & & \\
\hline & & 4.721 & 0.796 & 1.276 & 4.721 & & \\
\hline \multirow{2}{*}{ Carex blanda Dewey } & \multirow{2}{*}{ Fall 2005} & & & & 0.250 & & \\
\hline & & & & & 0.796 & & \\
\hline \multirow{2}{*}{ Carex debilis Michx. var. rudgei L. Bailey } & \multirow{2}{*}{ Fall 2005} & 0.500 & 0.750 & 0.750 & 0.750 & 0.750 & 2.500 \\
\hline & & 1.549 & 1.276 & 4.632 & 1.276 & 1.276 & 4.564 \\
\hline \multirow{2}{*}{ Carex folliculata $\mathrm{L}$. } & \multirow{2}{*}{ Fall 2005} & 0.250 & & 0.250 & 0.250 & & 0.250 \\
\hline & & 0.796 & & 0.796 & 0.796 & & 0.796 \\
\hline \multirow{2}{*}{ Carex vulpinoidea Michx. } & \multirow{2}{*}{ Fall 2005} & & 0.250 & & & & \\
\hline & & & 0.796 & & & & \\
\hline \multirow{2}{*}{ Danthonia compressa Aust. } & \multirow{2}{*}{ Fall 2005} & 24.500 & 21.000 & 28.000 & 18.750 & 29.250 & 25.250 \\
\hline & & 2.325 & 17.498 & 23.553 & 19.864 & 21.828 & 2.156 \\
\hline \multirow{2}{*}{ Dichanthelium clandestinum (L.) Gould } & \multirow{2}{*}{ Fall 2005} & 1.500 & & & 0.250 & 0.250 & \\
\hline & & 4.743 & & & 0.796 & 0.796 & \\
\hline \multirow{2}{*}{ Doellingeria umbellata (P. Mill.) Nees } & \multirow{2}{*}{ Fall 2005} & 9.000 & 7.250 & 7.500 & 1.500 & 4.750 & 9.500 \\
\hline & & 25.261 & 15.147 & 7.957 & 17.129 & 19.373 & 21.116 \\
\hline \multirow{2}{*}{ Equisitum spp. } & \multirow{2}{*}{ Fall 2005} & & & & 3.750 & & 0.250 \\
\hline & & & & & 11.859 & & 0.796 \\
\hline \multirow{2}{*}{$\begin{array}{l}\text { Euthamia graminifolia L. Nutt. var. } \\
\text { graminifolia }\end{array}$} & \multirow{2}{*}{ Fall 2005} & 1.500 & 7.000 & 4.250 & 2.000 & 1.500 & 1.500 \\
\hline & & 4.743 & 19.536 & 15.581 & 4.684 & 6.325 & 12.273 \\
\hline \multirow{2}{*}{ Festuca trachyphylla (Hack.) Krajina } & \multirow{2}{*}{ Fall 2005} & 6.250 & 1.500 & & & & \\
\hline & & 19.764 & 4.743 & & & & \\
\hline
\end{tabular}




\begin{tabular}{|c|c|c|c|c|c|c|c|}
\hline & & \multicolumn{2}{|c|}{ Early } & \multicolumn{2}{|c|}{ Late } & \multicolumn{2}{|c|}{ Continuous } \\
\hline & & $\begin{array}{c}\text { Fenced } \\
\bar{x} \\
\text { SD } \\
\end{array}$ & $\begin{array}{c}\text { Control } \\
\bar{x} \\
\mathrm{SD} \\
\end{array}$ & $\begin{array}{c}\text { Fenced } \\
\bar{x} \\
\mathrm{SD} \\
\end{array}$ & $\begin{array}{c}\text { Control } \\
\bar{x} \\
\text { SD } \\
\end{array}$ & $\begin{array}{c}\text { Fenced } \\
\bar{x} \\
\text { SD } \\
\end{array}$ & $\begin{array}{c}\text { Control } \\
\bar{x} \\
\text { SD } \\
\end{array}$ \\
\hline Fragaria virginiana Duchesne & Fall 2005 & $\begin{array}{l}0.250 \\
0.796\end{array}$ & & & & & \\
\hline $\begin{array}{l}\text { Hieracium praealtum Vill. ex } \\
\text { Gochnat }\end{array}$ & Fall 2005 & & $\begin{array}{l}0.500 \\
1.549\end{array}$ & & & & $\begin{array}{l}0.250 \\
0.796\end{array}$ \\
\hline Holcus lanatus L. & Fall 2005 & & $\begin{array}{l}0.250 \\
0.796\end{array}$ & $\begin{array}{l}0.250 \\
0.796\end{array}$ & $\begin{array}{l}0.250 \\
0.796\end{array}$ & & $\begin{array}{l}0.250 \\
0.796\end{array}$ \\
\hline Hypericum punctatum Lam. & Fall 2005 & & & & & & $\begin{array}{l}0.250 \\
0.796\end{array}$ \\
\hline Juncus effusus L. & Fall 2005 & $\begin{array}{l}0.250 \\
0.796\end{array}$ & & $\begin{array}{l}0.500 \\
1.549\end{array}$ & $\begin{array}{l}0.250 \\
0.796\end{array}$ & & $\begin{array}{l}0.250 \\
0.796\end{array}$ \\
\hline Luzula bulbosa (Alph. Wood) & Fall 2005 & & & & & $\begin{array}{l}0.250 \\
0.796\end{array}$ & \\
\hline Lycopus virginicus $\mathrm{L}$. & Fall 2005 & & $\begin{array}{l}0.250 \\
0.796\end{array}$ & & & & \\
\hline Lycopodium spp. & Fall 2005 & $\begin{array}{l}0.250 \\
0.796\end{array}$ & $\begin{array}{l}1.500 \\
4.743\end{array}$ & & & $\begin{array}{l}0.250 \\
0.796\end{array}$ & $\begin{array}{l}0.250 \\
0.796\end{array}$ \\
\hline Phleum pratense $\mathrm{L}$. & Fall 2005 & & & & & $\begin{array}{l}0.250 \\
0.796\end{array}$ & \\
\hline Poa pratensis L. ssp. pratensis & Fall 2005 & $\begin{array}{l}0.250 \\
0.796\end{array}$ & $\begin{array}{l}0.250 \\
0.796\end{array}$ & & $\begin{array}{l}0.250 \\
0.796\end{array}$ & $\begin{array}{l}0.250 \\
0.796\end{array}$ & $\begin{array}{l}0.250 \\
0.796\end{array}$ \\
\hline Poa trivialis L. & Fall 2005 & & $\begin{array}{l}0.250 \\
0.796\end{array}$ & & & & \\
\hline Populus tremuloides Michx. & Fall 2005 & $\begin{array}{l}2.000 \\
4.684\end{array}$ & $\begin{array}{l}0.250 \\
0.796\end{array}$ & $\begin{array}{l}1.750 \\
4.721\end{array}$ & & & \\
\hline
\end{tabular}




\begin{tabular}{|c|c|c|c|c|c|c|c|}
\hline & & \multicolumn{2}{|c|}{ Early } & \multicolumn{2}{|c|}{ Late } & \multicolumn{2}{|c|}{ Continuous } \\
\hline & & Fenced & Control & Fenced & Control & Fenced & Control \\
\hline & & $\bar{x}$ & $\bar{x}$ & $\bar{x}$ & $\bar{x}$ & $\bar{x}$ & $\bar{x}$ \\
\hline & & $\mathrm{SD}$ & $\mathrm{SD}$ & $\mathrm{SD}$ & $\mathrm{SD}$ & SD & SD \\
\hline \multirow{2}{*}{ Potentilla canadensis L. } & \multirow{2}{*}{ Fall 2005} & 1.000 & 0.750 & 1.000 & 0.750 & 0.500 & 1.750 \\
\hline & & 1.300 & 1.276 & 4.564 & 4.632 & 4.684 & 6.242 \\
\hline \multirow{2}{*}{ Potentilla simplex Michx. } & \multirow{2}{*}{ Fall 2005} & & 0.500 & & 0.250 & & 0.250 \\
\hline & & & 1.549 & & 0.796 & & 0.796 \\
\hline \multirow{2}{*}{ Pteridium aquilinum (L.) Kuhn } & \multirow{2}{*}{ Fall 2005} & 7.500 & 4.750 & 9.250 & 8.500 & 11.750 & 6.750 \\
\hline & & 12.761 & 7.115 & 15.592 & 12.315 & 17.798 & 12.475 \\
\hline \multirow{2}{*}{ Ranunculus acris L. var. acris } & \multirow{2}{*}{ Fall 2005} & & 0.250 & & & & \\
\hline & & & 0.796 & & & & \\
\hline \multirow{2}{*}{ Rubus hispidus L. } & \multirow{2}{*}{ Fall 2005} & 2.250 & 19.500 & 13.000 & 24.000 & 34.000 & 21.000 \\
\hline & & 27.693 & 25.452 & 2.642 & 27.354 & 2.513 & 23.364 \\
\hline \multirow{2}{*}{ Rumex acetosella L. } & \multirow{2}{*}{ Fall 2005} & 0.500 & 0.250 & & & & \\
\hline & & 1.549 & 0.796 & & & & \\
\hline \multirow{2}{*}{ Scirpus spp. } & \multirow{2}{*}{ Fall 2005} & & & 0.250 & & & \\
\hline & & & & 0.796 & & & \\
\hline \multirow{2}{*}{ Solidago caesia $\mathrm{L}$. } & \multirow{2}{*}{ Fall 2005} & & & 0.250 & & & \\
\hline & & & & 0.796 & & & \\
\hline \multirow{2}{*}{ Solidago rugosa Mill. } & \multirow{2}{*}{ Fall 2005} & 13.500 & 12.750 & 11.250 & 14.000 & 6.000 & 9.750 \\
\hline & & 2.956 & 18.297 & 18.836 & 19.129 & 12.273 & 14.491 \\
\hline \multirow{2}{*}{ Solidago uliginosa Nutt. } & \multirow{2}{*}{ Fall 2005} & 11.750 & 9.000 & 1.000 & 5.250 & 15.750 & 13.000 \\
\hline & & 11.368 & 11.972 & 12.761 & 6.816 & 8.979 & 12.368 \\
\hline \multirow{2}{*}{ Spiraea alba Du Roi } & \multirow{2}{*}{ Fall 2005} & 1.750 & 0.250 & 0.250 & 1.750 & & 0.250 \\
\hline & & 4.721 & 4.721 & 0.796 & 4.721 & & 0.796 \\
\hline \multirow{2}{*}{ Symphyotrichum lateriflorum L. } & \multirow{2}{*}{ Fall 2005} & 0.250 & & & & & \\
\hline & & 0.796 & & & & & \\
\hline
\end{tabular}




\begin{tabular}{|c|c|c|c|c|c|c|c|}
\hline & & \multicolumn{2}{|c|}{ Early } & \multicolumn{2}{|c|}{ Late } & \multicolumn{2}{|c|}{ Continuous } \\
\hline & & $\begin{array}{c}\text { Fenced } \\
\bar{x} \\
\mathrm{SD} \\
\end{array}$ & $\begin{array}{c}\text { Control } \\
\bar{x} \\
\text { SD } \\
\end{array}$ & $\begin{array}{c}\text { Fenced } \\
\bar{x} \\
\mathrm{SD} \\
\end{array}$ & $\begin{array}{c}\text { Control } \\
\bar{x} \\
\text { SD }\end{array}$ & $\begin{array}{c}\text { Fenced } \\
\bar{x} \\
\text { SD }\end{array}$ & $\begin{array}{c}\text { Control } \\
\bar{x} \\
\mathrm{SD}\end{array}$ \\
\hline Taraxacum officinale F.H. Wigg. & Fall 2005 & & $\begin{array}{l}0.250 \\
0.796\end{array}$ & & & & \\
\hline Vaccinium angustifolium Ait. & Fall 2005 & $\begin{array}{l}1.549 \\
0.500\end{array}$ & $\begin{array}{l}1.549 \\
0.500\end{array}$ & $\begin{array}{l}0.796 \\
0.250\end{array}$ & $\begin{array}{l}0.796 \\
0.250\end{array}$ & $\begin{array}{l}1.549 \\
0.500\end{array}$ & $\begin{array}{l}6.242 \\
3.250\end{array}$ \\
\hline Vaccinium myrtilloides Michx. & Fall 2005 & $\begin{array}{l}4.743 \\
1.500\end{array}$ & $\begin{array}{l}0.796 \\
0.250\end{array}$ & $\begin{array}{l}0.796 \\
0.250\end{array}$ & & $\begin{array}{l}4.743 \\
1.500\end{array}$ & $\begin{array}{l}0.796 \\
0.250\end{array}$ \\
\hline Vaccinium pallidum Ait. & Fall 2005 & $\begin{array}{l}1.549 \\
0.500\end{array}$ & & & 4.743 & & $\begin{array}{l}1.276 \\
0.750\end{array}$ \\
\hline Viburnum nudum L. var. cassinoides & Fall 2005 & & & $\begin{array}{l}1.500 \\
4.743\end{array}$ & 1.500 & & \\
\hline Viburnum recognitum & Fall 2005 & & & $\begin{array}{l}1.500 \\
4.743\end{array}$ & $\begin{array}{l}0.250 \\
0.796\end{array}$ & & $\begin{array}{l}0.250 \\
0.796\end{array}$ \\
\hline Violet spp. & Fall 2005 & $\begin{array}{l}0.250 \\
0.796\end{array}$ & & & & & \\
\hline Acer rubrum $L$. & Spring 2006 & & & & $\begin{array}{l}0.250 \\
0.796\end{array}$ & & \\
\hline $\begin{array}{l}\text { Achillea millefolium L. var. occidentalis } \\
\text { DC }\end{array}$ & Spring 2006 & $\begin{array}{l}0.250 \\
0.796\end{array}$ & $\begin{array}{l}0.500 \\
1.549\end{array}$ & $\begin{array}{l}0.250 \\
0.796\end{array}$ & & & $\begin{array}{l}0.250 \\
0.796\end{array}$ \\
\hline Agrostis gigantea Roth & Spring 2006 & $\begin{array}{l}0.250 \\
0.796\end{array}$ & & $\begin{array}{l}0.250 \\
0.796\end{array}$ & & & \\
\hline Anthoxanthum odoratum $\mathrm{L}$. & Spring 2006 & $\begin{array}{l}2.000 \\
4.684\end{array}$ & $\begin{array}{l}1.000 \\
1.300\end{array}$ & $\begin{array}{l}0.750 \\
1.276\end{array}$ & $\begin{array}{l}0.500 \\
1.549\end{array}$ & $\begin{array}{l}0.250 \\
0.796\end{array}$ & $\begin{array}{l}0.750 \\
1.276\end{array}$ \\
\hline Apocynum cannabinum $\mathrm{L}$. & Spring 2006 & & & $\begin{array}{l}0.250 \\
0.796\end{array}$ & $\begin{array}{l}0.250 \\
0.796\end{array}$ & & \\
\hline
\end{tabular}




\begin{tabular}{|c|c|c|c|c|c|c|c|}
\hline & & \multicolumn{2}{|c|}{ Early } & \multicolumn{2}{|c|}{ Late } & \multicolumn{2}{|c|}{ Continuous } \\
\hline & & $\begin{array}{c}\text { Fenced } \\
\bar{x} \\
\text { SD } \\
\end{array}$ & $\begin{array}{c}\text { Control } \\
\bar{x} \\
\mathrm{SD} \\
\end{array}$ & $\begin{array}{c}\text { Fenced } \\
\bar{x} \\
\mathrm{SD} \\
\end{array}$ & $\begin{array}{c}\text { Control } \\
\bar{x} \\
\text { SD } \\
\end{array}$ & $\begin{array}{c}\text { Fenced } \\
\bar{x} \\
\mathrm{SD} \\
\end{array}$ & $\begin{array}{c}\text { Control } \\
\bar{x} \\
\mathrm{SD} \\
\end{array}$ \\
\hline Carex brunnescens (Pers.) Poir. & Spring 2006 & & & & & $\begin{array}{l}0.250 \\
0.796\end{array}$ & \\
\hline Carex bushii Mack. & Spring 2006 & $\begin{array}{l}0.250 \\
0.796\end{array}$ & & & $\begin{array}{l}0.250 \\
0.796\end{array}$ & & \\
\hline Carex debilis Michx. var. rudgei L. Bailey & Spring 2006 & $\begin{array}{l}2.250 \\
6.387\end{array}$ & $\begin{array}{l}2.250 \\
6.387\end{array}$ & $\begin{array}{c}2.000 \\
19.488\end{array}$ & $\begin{array}{l}2.000 \\
6.146\end{array}$ & $\begin{array}{l}1.000 \\
1.300\end{array}$ & $\begin{array}{r}5.250 \\
15.732\end{array}$ \\
\hline Carex folliculata $\mathrm{L}$. & Spring 2006 & & & & & & $\begin{array}{l}0.250 \\
0.796\end{array}$ \\
\hline $\begin{array}{l}\text { Carex scoparia Schkuhr ex Willd. var. } \\
\text { scoparia }\end{array}$ & Spring 2006 & & $\begin{array}{l}0.250 \\
0.796\end{array}$ & $\begin{array}{l}1.500 \\
4.743\end{array}$ & $\begin{array}{l}1.500 \\
4.743\end{array}$ & $\begin{array}{l}1.750 \\
4.721\end{array}$ & $\begin{array}{l}1.500 \\
4.743\end{array}$ \\
\hline Crataegus spp. & Spring 2006 & & & & & $\begin{array}{l}1.500 \\
4.743\end{array}$ & $\begin{array}{l}0.250 \\
0.796\end{array}$ \\
\hline Danthonia compressa Aust. & Spring 2006 & $\begin{array}{l}14.750 \\
16.264\end{array}$ & $\begin{array}{l}22.750 \\
28.426\end{array}$ & $\begin{array}{l}23.250 \\
26.426\end{array}$ & $\begin{array}{c}1.750 \\
16.967\end{array}$ & $\begin{array}{l}15.000 \\
16.457\end{array}$ & $\begin{array}{l}16.000 \\
24.574\end{array}$ \\
\hline Dichanthelium clandestinum (L.) Gould & Spring 2006 & & & & & $\begin{array}{l}0.250 \\
0.796\end{array}$ & \\
\hline Doellingeria umbellata (P. Mill.) Nees & Spring 2006 & $\begin{array}{c}6.000 \\
11.972\end{array}$ & $\begin{array}{l}4.000 \\
5.917\end{array}$ & $\begin{array}{l}5.250 \\
6.816\end{array}$ & $\begin{array}{l}14.750 \\
16.685\end{array}$ & $\begin{array}{r}7.500 \\
12.761\end{array}$ & $\begin{array}{r}7.750 \\
18.492\end{array}$ \\
\hline $\begin{array}{l}\text { Euthamia graminifolia L. Nutt. var. } \\
\text { graminifolia }\end{array}$ & Spring 2006 & $\begin{array}{l}2.250 \\
4.632\end{array}$ & $\begin{array}{l}1.000 \\
1.300\end{array}$ & $\begin{array}{l}0.750 \\
1.276\end{array}$ & $\begin{array}{l}0.500 \\
1.549\end{array}$ & $\begin{array}{l}0.250 \\
0.796\end{array}$ & $\begin{array}{l}0.500 \\
1.549\end{array}$ \\
\hline Hieracium praealtum Vill. ex Gochnat & Spring 2006 & $\begin{array}{l}0.250 \\
0.796\end{array}$ & $\begin{array}{l}0.250 \\
0.796\end{array}$ & & & & $\begin{array}{l}0.250 \\
0.796\end{array}$ \\
\hline Holcus lanatus L. & Spring 2006 & $\begin{array}{l}0.250 \\
0.796\end{array}$ & & $\begin{array}{l}0.250 \\
0.796\end{array}$ & & & \\
\hline
\end{tabular}




\begin{tabular}{|c|c|c|c|c|c|c|c|}
\hline & & \multicolumn{2}{|c|}{ Early } & \multicolumn{2}{|c|}{ Late } & \multicolumn{2}{|c|}{ Continuous } \\
\hline & & $\begin{array}{l}\text { Fenced } \\
\bar{x} \\
\text { SD } \\
\end{array}$ & $\begin{array}{c}\text { Control } \\
\bar{x} \\
\mathrm{SD} \\
\end{array}$ & $\begin{array}{c}\text { Fenced } \\
\bar{x} \\
\text { SD } \\
\end{array}$ & $\begin{array}{c}\text { Control } \\
\bar{x} \\
\text { SD } \\
\end{array}$ & $\begin{array}{c}\text { Fenced } \\
\bar{x} \\
\text { SD } \\
\end{array}$ & $\begin{array}{c}\text { Control } \\
\bar{x} \\
\mathrm{SD} \\
\end{array}$ \\
\hline Hypericum densiflorum Pursh & Spring 2006 & & & & $\begin{array}{l}0.250 \\
0.796\end{array}$ & & \\
\hline Hypericum ellipticum & Spring 2006 & & $\begin{array}{l}0.250 \\
0.796\end{array}$ & & & & \\
\hline Juncus effusus L. & Spring 2006 & & $\begin{array}{l}0.250 \\
0.796\end{array}$ & & & & \\
\hline Poa trivialis $\mathrm{L}$. & Spring 2006 & $\begin{array}{l}0.250 \\
0.796\end{array}$ & & & & & \\
\hline Populus tremuloides Michx. & Spring 2006 & $\begin{array}{l}0.250 \\
0.796\end{array}$ & & $\begin{array}{l}1.500 \\
4.743\end{array}$ & $\begin{array}{l}1.500 \\
4.743\end{array}$ & $\begin{array}{l}0.250 \\
0.796\end{array}$ & $\begin{array}{l}0.250 \\
0.796\end{array}$ \\
\hline Potentilla simplex Michx. & Spring 2006 & $\begin{array}{c}2.000 \\
12.792\end{array}$ & $\begin{array}{c}0.250 \\
11.797\end{array}$ & $\begin{array}{c}0.750 \\
11.655\end{array}$ & $\begin{array}{l}0.750 \\
4.632\end{array}$ & $\begin{array}{l}2.500 \\
4.564\end{array}$ & $\begin{array}{l}1.250 \\
4.480\end{array}$ \\
\hline Prunus serotina Ehrh. & Spring 2006 & & $\begin{array}{l}0.250 \\
0.796\end{array}$ & & & & \\
\hline Pteridium aquilinum (L.) Kuhn & Spring 2006 & $\begin{array}{c}1.500 \\
21.663\end{array}$ & $\begin{array}{c}6.000 \\
11.972\end{array}$ & $\begin{array}{l}12.000 \\
21.370\end{array}$ & $\begin{array}{c}8.250 \\
19.616\end{array}$ & $\begin{array}{c}1.500 \\
11.655\end{array}$ & $\begin{array}{c}9.500 \\
15.447\end{array}$ \\
\hline Rubus hispidus L. & Spring 2006 & $\begin{array}{c}1.500 \\
15.299\end{array}$ & $\begin{array}{l}22.500 \\
22.244\end{array}$ & $\begin{array}{c}26.250 \\
2.917\end{array}$ & $\begin{array}{l}17.500 \\
18.673\end{array}$ & $\begin{array}{l}27.000 \\
21.348\end{array}$ & $\begin{array}{l}23.750 \\
17.874\end{array}$ \\
\hline Rumex acetosella $L$. & Spring 2006 & & $\begin{array}{l}0.250 \\
0.796\end{array}$ & & $\begin{array}{l}0.250 \\
0.796\end{array}$ & & $\begin{array}{l}0.250 \\
0.796\end{array}$ \\
\hline Solidago rugosa Mill. & Spring 2006 & $\begin{array}{l}12.000 \\
22.593\end{array}$ & $\begin{array}{l}5.000 \\
6.972\end{array}$ & $\begin{array}{l}11.750 \\
21.116\end{array}$ & $\begin{array}{l}14.000 \\
17.418\end{array}$ & $\begin{array}{l}8.000 \\
2.448\end{array}$ & $\begin{array}{c}4.000 \\
19.237\end{array}$ \\
\hline Solidago uliginosa Nutt. & Spring 2006 & $\begin{array}{c}1.750 \\
15.323\end{array}$ & $\begin{array}{l}13.500 \\
17.127\end{array}$ & $\begin{array}{c}14.750 \\
2.597\end{array}$ & $\begin{array}{c}6.250 \\
11.929\end{array}$ & $\begin{array}{l}19.000 \\
13.944\end{array}$ & $\begin{array}{l}13.750 \\
14.252\end{array}$ \\
\hline
\end{tabular}




\begin{tabular}{|c|c|c|c|c|c|c|c|}
\hline & & \multicolumn{2}{|c|}{ Early } & \multicolumn{2}{|c|}{ Late } & \multicolumn{2}{|c|}{ Continuous } \\
\hline & & $\begin{array}{c}\text { Fenced } \\
\bar{x} \\
\text { SD } \\
\end{array}$ & $\begin{array}{c}\text { Control } \\
\bar{x} \\
\mathrm{SD} \\
\end{array}$ & $\begin{array}{c}\text { Fenced } \\
\bar{x} \\
\mathrm{SD} \\
\end{array}$ & $\begin{array}{c}\text { Control } \\
\bar{x} \\
\mathrm{SD} \\
\end{array}$ & $\begin{array}{c}\text { Fenced } \\
\bar{x} \\
\mathrm{SD} \\
\end{array}$ & $\begin{array}{c}\text { Control } \\
\bar{x} \\
\mathrm{SD} \\
\end{array}$ \\
\hline \multirow{2}{*}{ Spiraea alba Du Roi } & \multirow{2}{*}{ Spring 2006} & 0.250 & & 0.250 & 3.250 & 1.500 & 1.500 \\
\hline & & 0.796 & 4.743 & 0.796 & 6.242 & 6.325 & 6.325 \\
\hline \multirow{2}{*}{ Vaccinium angustifolium Ait. } & \multirow{2}{*}{ Spring 2006} & 3.750 & 3.750 & & & & \\
\hline & & 11.859 & 11.859 & & & & \\
\hline \multirow{2}{*}{ Vaccinium myrtilloides Michx. } & \multirow{2}{*}{ Spring 2006} & 2.000 & 3.000 & 3.000 & & 3.250 & 3.250 \\
\hline & & 4.684 & 6.325 & 6.325 & & 6.242 & 6.242 \\
\hline Vaccinium pallidum Ait. & Spring 2006 & & & & & & \\
\hline \multirow{2}{*}{ Viburnum nudum L. var. cassinoides } & \multirow{2}{*}{ Spring 2006} & 1.500 & 0.250 & 4.000 & 1.500 & & 0.250 \\
\hline & & 4.743 & 0.796 & 11.797 & 4.743 & & 0.796 \\
\hline \multirow{2}{*}{ Viburnum recognitum } & \multirow{2}{*}{ Spring 2006} & & & 0.250 & & 0.250 & 0.250 \\
\hline & & & & 0.796 & & 0.796 & 0.796 \\
\hline \multirow{2}{*}{ Acer rubrum $\mathrm{L}$. } & \multirow{2}{*}{ Fall 2006} & & & & 0.250 & & \\
\hline & & & & & 0.796 & & \\
\hline \multirow{2}{*}{$\begin{array}{l}\text { Achillea millefolium L. var. occidentalis } \\
\text { DC }\end{array}$} & \multirow{2}{*}{ Fall 2006} & & 1.500 & 0.250 & & & \\
\hline & & & 4.743 & 0.796 & & 4.743 & 4.743 \\
\hline \multirow{2}{*}{ Agrostis gigantea Roth } & \multirow{2}{*}{ Fall 2006} & 1.500 & 1.500 & 0.250 & 1.500 & 0.500 & 0.500 \\
\hline & & 4.743 & 4.743 & 0.796 & 4.743 & 1.549 & 1.549 \\
\hline \multirow{2}{*}{ Amelanchier spp. } & \multirow{2}{*}{ Fall 2006} & 1.500 & 0.250 & 0.250 & & 0.250 & \\
\hline & & 4.743 & 0.796 & 0.796 & & 0.796 & \\
\hline \multirow{2}{*}{ Anthoxanthum odoratum L. } & \multirow{2}{*}{ Fall 2006} & 0.250 & 0.250 & 1.000 & 1.750 & & \\
\hline & & 4.721 & 0.796 & 1.300 & 4.721 & 11.859 & 4.743 \\
\hline \multirow{2}{*}{ Carex blanda Dewey } & \multirow{2}{*}{ Fall 2006} & & & & 0.250 & & \\
\hline & & & & & 0.796 & & \\
\hline
\end{tabular}




\begin{tabular}{|c|c|c|c|c|c|c|c|}
\hline & & \multicolumn{2}{|c|}{ Early } & \multicolumn{2}{|c|}{ Late } & \multicolumn{2}{|c|}{ Continuous } \\
\hline & & Fenced & Control & Fenced & Control & Fenced & Control \\
\hline & & $\bar{x}$ & $\bar{x}$ & $\bar{x}$ & $\bar{x}$ & $\bar{x}$ & $\bar{x}$ \\
\hline & & SD & $\mathrm{SD}$ & SD & $\mathrm{SD}$ & SD & $\mathrm{SD}$ \\
\hline \multirow{2}{*}{ Carex debilis Michx. var. rudgei L. Bailey } & \multirow{2}{*}{ Fall 2006} & 0.500 & 1.750 & 1.750 & 0.750 & 2.000 & 3.750 \\
\hline & & 1.549 & 6.242 & 6.242 & 1.276 & 4.684 & 6.387 \\
\hline \multirow{2}{*}{ Carex folliculata $\mathrm{L}$. } & \multirow{2}{*}{ Fall 2006} & 0.250 & & 0.250 & 0.250 & 0.250 & \\
\hline & & 0.796 & & 0.796 & 0.796 & 0.796 & \\
\hline \multirow{2}{*}{ Carex vulpinoidea Michx. } & \multirow{2}{*}{ Fall 2006} & & 0.250 & & & & \\
\hline & & & 0.796 & & & & \\
\hline \multirow{2}{*}{ Danthonia compressa Aust. } & \multirow{2}{*}{ Fall 2006} & 34.250 & 23.500 & 25.750 & 18.000 & 29.250 & 21.500 \\
\hline & & 17.442 & 18.646 & 23.733 & 14.521 & 18.184 & 17.895 \\
\hline \multirow{2}{*}{ Dichanthelium clandestinum (L.) Gould } & \multirow{2}{*}{ Fall 2006} & & 1.500 & & 0.250 & 0.250 & \\
\hline & & & 4.743 & & 0.796 & 0.796 & \\
\hline \multirow{2}{*}{ Doellingeria umbellata (P. Mill.) Nees } & \multirow{2}{*}{ Fall 2006} & 15.250 & 6.250 & 7.500 & 4.750 & 8.250 & 5.750 \\
\hline & & 13.944 & 11.859 & 7.957 & 12.315 & 15.831 & 15.447 \\
\hline \multirow{2}{*}{ Equisitum spp. } & \multirow{2}{*}{ Fall 2006} & & & & 1.500 & & 0.250 \\
\hline & & & & & 4.743 & & 0.796 \\
\hline \multirow{2}{*}{ Euthamia graminifolia L. Nutt. var. graminifolia } & \multirow{2}{*}{ Fall 2006} & 1.500 & 5.250 & 6.750 & 1.750 & & \\
\hline & & 4.743 & 12.273 & 19.616 & 4.721 & 11.859 & 4.743 \\
\hline \multirow{2}{*}{ Festuca trachyphylla (Hack.) Krajina } & \multirow{2}{*}{ Fall 2006} & 3.750 & 1.500 & 6.250 & & & \\
\hline & & 11.859 & 4.743 & 19.764 & & 1.581 & 1.581 \\
\hline \multirow{2}{*}{ Hieracium praealtum Vill. ex Gochnat } & \multirow{2}{*}{ Fall 2006} & & 0.500 & & & & 0.250 \\
\hline & & & 1.549 & & & & 0.796 \\
\hline \multirow{2}{*}{ Holcus lanatus L. } & \multirow{2}{*}{ Fall 2006} & & & 0.250 & 0.250 & & 0.250 \\
\hline & & & 4.743 & 0.796 & 0.796 & & 0.796 \\
\hline \multirow{2}{*}{ Juncus effusus L. } & \multirow{2}{*}{ Fall 2006} & 0.250 & & 0.750 & 0.250 & & 0.250 \\
\hline & & 0.796 & & 1.276 & 0.796 & & 0.796 \\
\hline
\end{tabular}




\begin{tabular}{|c|c|c|c|c|c|c|c|}
\hline & & \multicolumn{2}{|c|}{ Early } & \multicolumn{2}{|c|}{ Late } & \multicolumn{2}{|c|}{ Continuous } \\
\hline & & $\begin{array}{l}\text { Fenced } \\
\bar{x} \\
\mathrm{SD} \\
\end{array}$ & $\begin{array}{c}\text { Control } \\
\bar{x} \\
\text { SD } \\
\end{array}$ & $\begin{array}{c}\text { Fenced } \\
\bar{x} \\
\text { SD } \\
\end{array}$ & $\begin{array}{c}\text { Control } \\
\bar{x} \\
\text { SD } \\
\end{array}$ & $\begin{array}{c}\text { Fenced } \\
\bar{x} \\
\text { SD } \\
\end{array}$ & $\begin{array}{c}\text { Control } \\
\bar{x} \\
\mathrm{SD} \\
\end{array}$ \\
\hline Luzula bulbosa (Alph. Wood) & Fall 2006 & & & & & $\begin{array}{l}0.250 \\
0.796\end{array}$ & \\
\hline Lycopodium spp. & Fall 2006 & $\begin{array}{l}0.250 \\
0.796\end{array}$ & $\begin{array}{l}1.500 \\
4.743\end{array}$ & & & $\begin{array}{l}0.250 \\
0.796\end{array}$ & $\begin{array}{l}0.250 \\
0.796\end{array}$ \\
\hline Poa pratensis L. ssp. pratensis & Fall 2006 & $\begin{array}{l}0.250 \\
0.796\end{array}$ & $\begin{array}{l}1.500 \\
4.743\end{array}$ & & $\begin{array}{l}0.250 \\
0.796\end{array}$ & $\begin{array}{l}0.250 \\
0.796\end{array}$ & $\begin{array}{l}0.250 \\
0.796\end{array}$ \\
\hline Poa trivialis $\mathrm{L}$. & Fall 2006 & & $\begin{array}{l}0.250 \\
0.796\end{array}$ & & & & \\
\hline Populus tremuloides Michx. & Fall 2006 & $\begin{array}{l}0.250 \\
0.796\end{array}$ & & $\begin{array}{l}1.500 \\
4.743\end{array}$ & & & \\
\hline Potentilla canadensis L. & Fall 2006 & $\begin{array}{l}3.500 \\
6.146\end{array}$ & $\begin{array}{l}0.750 \\
1.276\end{array}$ & $\begin{array}{l}0.500 \\
4.684\end{array}$ & $\begin{array}{l}2.000 \\
6.146\end{array}$ & $\begin{array}{l}0.250 \\
4.721\end{array}$ & $\begin{array}{l}1.500 \\
6.325\end{array}$ \\
\hline Potentilla simplex Michx. & Fall 2006 & $\begin{array}{l}0.250 \\
0.796\end{array}$ & & $\begin{array}{l}0.250 \\
0.796\end{array}$ & $\begin{array}{l}0.500 \\
1.549\end{array}$ & $\begin{array}{l}1.500 \\
4.743\end{array}$ & $\begin{array}{l}1.750 \\
4.721\end{array}$ \\
\hline Pteridium aquilinum (L.) Kuhn & Fall 2006 & $\begin{array}{c}13.500 \\
2.956\end{array}$ & $\begin{array}{l}3.500 \\
6.146\end{array}$ & $\begin{array}{c}7.000 \\
12.350\end{array}$ & $\begin{array}{l}5.000 \\
6.972\end{array}$ & $\begin{array}{c}1.750 \\
15.323\end{array}$ & $\begin{array}{l}4.500 \\
7.246\end{array}$ \\
\hline Ranunculus acris L. var. acris & Fall 2006 & & $\begin{array}{l}0.250 \\
0.796\end{array}$ & & & & \\
\hline Rubus hispidus L. & Fall 2006 & $\begin{array}{c}3.000 \\
22.158\end{array}$ & $\begin{array}{l}24.500 \\
22.927\end{array}$ & $\begin{array}{l}27.750 \\
23.813\end{array}$ & $\begin{array}{l}23.000 \\
24.839\end{array}$ & $\begin{array}{l}36.500 \\
21.596\end{array}$ & $\begin{array}{l}24.250 \\
22.852\end{array}$ \\
\hline Rumex acetosella L. & Fall 2006 & $\begin{array}{l}0.250 \\
0.796\end{array}$ & $\begin{array}{l}0.250 \\
0.796\end{array}$ & & $\begin{array}{l}1.500 \\
4.743\end{array}$ & & $\begin{array}{l}0.250 \\
0.796\end{array}$ \\
\hline Solidago rugosa Mill. & Fall 2006 & $\begin{array}{l}12.000 \\
21.370\end{array}$ & $\begin{array}{c}5.250 \\
15.555\end{array}$ & $\begin{array}{c}11.000 \\
2.597 \\
\end{array}$ & $\begin{array}{c}7.500 \\
11.972\end{array}$ & $\begin{array}{c}8.250 \\
15.831 \\
\end{array}$ & $\begin{array}{c}8.500 \\
14.881\end{array}$ \\
\hline
\end{tabular}




\begin{tabular}{|c|c|c|c|c|c|c|c|}
\hline & & \multicolumn{2}{|c|}{ Early } & \multicolumn{2}{|c|}{ Late } & \multicolumn{2}{|c|}{ Continuous } \\
\hline & & Fenced & Control & Fenced & Control & Fenced & Control \\
\hline & & $\bar{x}$ & $\bar{x}$ & $\bar{x}$ & $\bar{x}$ & $\bar{x}$ & $\bar{x}$ \\
\hline & & $\mathrm{SD}$ & $\mathrm{SD}$ & $\mathrm{SD}$ & SD & $\mathrm{SD}$ & $\mathrm{SD}$ \\
\hline \multirow{2}{*}{ Solidago uliginosa Nutt. } & \multirow{2}{*}{ Fall 2006} & 24.500 & 1.250 & 12.250 & 5.500 & 16.500 & 12.000 \\
\hline & & 21.423 & 11.872 & 14.881 & 6.646 & 12.772 & 11.156 \\
\hline \multirow{2}{*}{ Spiraea alba Du Roi } & \multirow{2}{*}{ Fall 2006} & 1.750 & 0.250 & 3.000 & 0.250 & & 0.500 \\
\hline & & 4.721 & 4.721 & 6.325 & 0.796 & & 1.549 \\
\hline \multirow{2}{*}{ Vaccinium myrtilloides Michx. } & \multirow{2}{*}{ Fall 2006} & 3.000 & 1.750 & 0.250 & 0.250 & 1.750 & 2.000 \\
\hline & & 6.325 & 4.721 & 0.796 & 0.796 & 4.721 & 4.684 \\
\hline \multirow{2}{*}{ Vaccinium pallidum Ait. } & \multirow{2}{*}{ Fall 2006} & 1.500 & 0.250 & 0.250 & & 1.500 & 1.500 \\
\hline & & 4.743 & 0.796 & 0.796 & & 4.743 & 4.743 \\
\hline \multirow{2}{*}{ Viburnum nudum L. var. cassinoides } & \multirow{2}{*}{ Fall 2006} & 0.250 & 0.250 & & & & 0.500 \\
\hline & & 0.796 & 0.796 & & & & 1.549 \\
\hline \multirow{2}{*}{ Viburnum recognitum } & \multirow{2}{*}{ Fall 2006} & & & 1.500 & 0.250 & & 1.500 \\
\hline & & & & 4.743 & 0.796 & & 4.743 \\
\hline \multirow{2}{*}{ Acer rubrum $\mathrm{L}$. } & \multirow{2}{*}{ Spring 2007} & & & & 0.250 & & \\
\hline & & & & & 0.796 & & \\
\hline \multirow{2}{*}{ Achillea millefolium L. var. occidentalis DC } & \multirow{2}{*}{ Spring 2007} & & 0.500 & 0.250 & & & 0.250 \\
\hline & & 4.743 & 1.549 & 0.796 & & & 0.796 \\
\hline \multirow{2}{*}{ Agrostis gigantea Roth } & \multirow{2}{*}{ Spring 2007} & 0.250 & & 0.250 & & & \\
\hline & & 0.796 & & 0.796 & & & \\
\hline \multirow{2}{*}{ Anthoxanthum odoratum L. } & \multirow{2}{*}{ Spring 2007} & 2.000 & 2.250 & 0.500 & 0.500 & 0.250 & 0.500 \\
\hline & & 4.684 & 4.632 & 1.549 & 1.549 & 0.796 & 4.684 \\
\hline \multirow{2}{*}{ Apocynum cannabinum L. } & \multirow{2}{*}{ Spring 2007} & & & 0.250 & & & \\
\hline & & & & 0.796 & & & \\
\hline \multirow{2}{*}{ Carex brunnescens (Pers.) Poir. } & \multirow{2}{*}{ Spring 2007} & & & & & \multirow{2}{*}{\multicolumn{2}{|c|}{$\begin{array}{l}0.250 \\
0.796\end{array}$}} \\
\hline & & & & & & & \\
\hline
\end{tabular}




\begin{tabular}{|c|c|c|c|c|c|c|c|}
\hline & & \multicolumn{2}{|c|}{ Early } & \multicolumn{2}{|c|}{ Late } & \multicolumn{2}{|c|}{ Continuous } \\
\hline & & $\begin{array}{c}\text { Fenced } \\
\bar{x} \\
\mathrm{SD} \\
\end{array}$ & $\begin{array}{c}\text { Control } \\
\bar{x} \\
\text { SD } \\
\end{array}$ & $\begin{array}{c}\text { Fenced } \\
\bar{x} \\
\text { SD } \\
\end{array}$ & $\begin{array}{c}\text { Control } \\
\bar{x} \\
\text { SD } \\
\end{array}$ & $\begin{array}{c}\text { Fenced } \\
\bar{x} \\
\mathrm{SD} \\
\end{array}$ & $\begin{array}{c}\text { Control } \\
\bar{x} \\
\mathrm{SD} \\
\end{array}$ \\
\hline Carex bushii Mack. & Spring 2007 & $\begin{array}{l}0.250 \\
0.796\end{array}$ & & & $\begin{array}{l}0.250 \\
0.796\end{array}$ & & \\
\hline Carex debilis Michx. var. rudgei L. Bailey & Spring 2007 & $\begin{array}{l}1.500 \\
1.300\end{array}$ & $\begin{array}{l}7.500 \\
7.746\end{array}$ & $\begin{array}{c}2.250 \\
12.761\end{array}$ & $\begin{array}{c}4.750 \\
12.315\end{array}$ & $\begin{array}{l}1.250 \\
1.318\end{array}$ & $\begin{array}{l}3.000 \\
7.246\end{array}$ \\
\hline Carex folliculata $\mathrm{L}$. & Spring 2007 & & & & & & $\begin{array}{l}0.250 \\
0.796\end{array}$ \\
\hline $\begin{array}{l}\text { Carex scoparia Schkuhr ex Willd. var. } \\
\text { scoparia }\end{array}$ & Spring 2007 & & $\begin{array}{l}0.250 \\
0.796\end{array}$ & $\begin{array}{l}0.250 \\
0.796\end{array}$ & $\begin{array}{l}1.500 \\
4.743\end{array}$ & $\begin{array}{c}4.000 \\
11.797\end{array}$ & $\begin{array}{l}1.500 \\
4.743\end{array}$ \\
\hline Crataegus spp. & Spring 2007 & & & & & $\begin{array}{l}0.250 \\
0.796\end{array}$ & $\begin{array}{l}0.250 \\
0.796\end{array}$ \\
\hline Danthonia compressa Aust. & Spring 2007 & $\begin{array}{l}17.500 \\
21.487\end{array}$ & $\begin{array}{l}26.500 \\
27.473\end{array}$ & $\begin{array}{l}19.750 \\
27.543\end{array}$ & $\begin{array}{c}5.000 \\
12.148\end{array}$ & $\begin{array}{l}17.000 \\
18.174\end{array}$ & $\begin{array}{l}23.500 \\
24.866\end{array}$ \\
\hline Dichanthelium clandestinum (L.) Gould & Spring 2007 & & & & & $\begin{array}{l}0.250 \\
0.796\end{array}$ & \\
\hline Doellingeria umbellata (P. Mill.) Nees & Spring 2007 & $\begin{array}{c}8.500 \\
12.315\end{array}$ & $\begin{array}{l}2.750 \\
4.480\end{array}$ & $\begin{array}{c}9.500 \\
15.447\end{array}$ & $\begin{array}{l}6.750 \\
7.173\end{array}$ & $\begin{array}{l}12.500 \\
14.672\end{array}$ & $\begin{array}{c}8.000 \\
11.773\end{array}$ \\
\hline $\begin{array}{l}\text { Euthamia graminifolia L. Nutt. var. } \\
\text { graminifolia }\end{array}$ & Spring 2007 & $\begin{array}{l}4.500 \\
7.746\end{array}$ & $\begin{array}{l}1.000 \\
1.300\end{array}$ & $\begin{array}{l}2.000 \\
4.684\end{array}$ & $\begin{array}{l}1.750 \\
4.721\end{array}$ & $\begin{array}{l}1.500 \\
4.743\end{array}$ & $\begin{array}{l}0.500 \\
1.549\end{array}$ \\
\hline Hieracium praealtum Vill. ex Gochnat & Spring 2007 & $\begin{array}{l}0.250 \\
0.796\end{array}$ & & & & & \\
\hline Holcus lanatus L. & Spring 2007 & $\begin{array}{l}0.250 \\
0.796\end{array}$ & & & $\begin{array}{l}0.250 \\
0.796\end{array}$ & & \\
\hline Hypericum densiflorum Pursh & Spring 2007 & & & & $\begin{array}{l}0.250 \\
0.796\end{array}$ & & \\
\hline
\end{tabular}




\begin{tabular}{|c|c|c|c|c|c|c|c|}
\hline & & \multicolumn{2}{|c|}{ Early } & \multicolumn{2}{|c|}{ Late } & \multicolumn{2}{|c|}{ Continuous } \\
\hline & & $\begin{array}{l}\text { Fenced } \\
\bar{x} \\
\text { SD } \\
\end{array}$ & $\begin{array}{c}\text { Control } \\
\bar{x} \\
\text { SD } \\
\end{array}$ & $\begin{array}{c}\text { Fenced } \\
\bar{x} \\
\text { SD } \\
\end{array}$ & $\begin{array}{c}\text { Control } \\
\bar{x} \\
\text { SD } \\
\end{array}$ & $\begin{array}{c}\text { Fenced } \\
\bar{x} \\
\text { SD }\end{array}$ & $\begin{array}{c}\text { Control } \\
\bar{x} \\
\text { SD }\end{array}$ \\
\hline Hypericum ellipticum & Spring 2007 & & $\begin{array}{l}0.250 \\
0.796\end{array}$ & & & & \\
\hline Juncus effusus L. & Spring 2007 & & $\begin{array}{l}0.250 \\
0.796\end{array}$ & & & & \\
\hline Poa trivialis $\mathrm{L}$. & Spring 2007 & $\begin{array}{l}0.250 \\
0.796\end{array}$ & & & & & \\
\hline Populus tremuloides Michx. & Spring 2007 & $\begin{array}{c}3.750 \\
11.859\end{array}$ & & $\begin{array}{l}1.500 \\
4.743\end{array}$ & & $\begin{array}{l}0.250 \\
0.796\end{array}$ & \\
\hline Potentilla simplex Michx. & Spring 2007 & $\begin{array}{c}2.000 \\
12.792\end{array}$ & $\begin{array}{c}0.250 \\
11.797\end{array}$ & $\begin{array}{c}2.000 \\
12.792\end{array}$ & $\begin{array}{l}0.500 \\
4.684\end{array}$ & $\begin{array}{l}4.750 \\
7.569\end{array}$ & $\begin{array}{l}1.500 \\
1.300\end{array}$ \\
\hline Prunus serotina Ehrh. & Spring 2007 & & $\begin{array}{l}0.250 \\
0.796\end{array}$ & & & & \\
\hline Pteridium aquilinum (L.) Kuhn & Spring 2007 & $\begin{array}{l}11.750 \\
21.574\end{array}$ & $\begin{array}{l}3.750 \\
6.387\end{array}$ & $\begin{array}{c}9.500 \\
15.447\end{array}$ & $\begin{array}{c}7.000 \\
19.536\end{array}$ & $\begin{array}{c}13.250 \\
1.699\end{array}$ & $\begin{array}{c}7.250 \\
12.216\end{array}$ \\
\hline Rubus hispidus L. & Spring 2007 & $\begin{array}{l}27.750 \\
26.797\end{array}$ & $\begin{array}{c}2.000 \\
19.497\end{array}$ & $\begin{array}{l}29.750 \\
21.293\end{array}$ & $\begin{array}{l}21.750 \\
22.264\end{array}$ & $\begin{array}{l}32.750 \\
21.183\end{array}$ & $\begin{array}{l}19.000 \\
13.944\end{array}$ \\
\hline Rumex acetosella $\mathrm{L}$. & Spring 2007 & & $\begin{array}{l}0.250 \\
0.796\end{array}$ & & $\begin{array}{l}0.250 \\
0.796\end{array}$ & & $\begin{array}{l}0.250 \\
0.796\end{array}$ \\
\hline Solidago rugosa Mill. & Spring 2007 & $\begin{array}{l}16.750 \\
21.345\end{array}$ & $\begin{array}{l}5.000 \\
6.972\end{array}$ & $\begin{array}{l}11.750 \\
22.478\end{array}$ & $\begin{array}{c}1.500 \\
14.376\end{array}$ & $\begin{array}{l}13.750 \\
18.937\end{array}$ & $\begin{array}{c}4.000 \\
11.929\end{array}$ \\
\hline Solidago uliginosa Nutt. & Spring 2007 & $\begin{array}{l}12.000 \\
15.831\end{array}$ & $\begin{array}{c}9.000 \\
11.972\end{array}$ & $\begin{array}{l}13.250 \\
16.685\end{array}$ & $\begin{array}{c}6.250 \\
11.929\end{array}$ & $\begin{array}{l}25.750 \\
17.981\end{array}$ & $\begin{array}{l}9.250 \\
7.458\end{array}$ \\
\hline Spiraea alba Du Roi & Spring 2007 & $\begin{array}{l}0.250 \\
0.796\end{array}$ & & $\begin{array}{l}1.500 \\
4.743\end{array}$ & $\begin{array}{l}1.750 \\
4.721\end{array}$ & $\begin{array}{c}3.750 \\
11.859\end{array}$ & $\begin{array}{l}1.500 \\
4.743\end{array}$ \\
\hline
\end{tabular}




\begin{tabular}{|c|c|c|c|c|c|c|c|}
\hline & & \multicolumn{2}{|c|}{ Early } & \multicolumn{2}{|c|}{ Late } & \multicolumn{2}{|c|}{ Continuous } \\
\hline & & $\begin{array}{c}\text { Fenced } \\
\bar{x} \\
\mathrm{SD} \\
\end{array}$ & $\begin{array}{c}\text { Control } \\
\bar{x} \\
\mathrm{SD} \\
\end{array}$ & $\begin{array}{c}\text { Fenced } \\
\bar{x} \\
\mathrm{SD} \\
\end{array}$ & $\begin{array}{c}\text { Control } \\
\bar{x} \\
\mathrm{SD} \\
\end{array}$ & $\begin{array}{c}\text { Fenced } \\
\bar{x} \\
\mathrm{SD} \\
\end{array}$ & $\begin{array}{c}\text { Control } \\
\bar{x} \\
\mathrm{SD} \\
\end{array}$ \\
\hline Vaccinium angustifolium Ait. & Spring 2007 & $\begin{array}{c}3.750 \\
11.859\end{array}$ & $\begin{array}{c}3.750 \\
11.859\end{array}$ & & & & \\
\hline Vaccinium myrtilloides Michx. & Spring 2007 & $\begin{array}{l}3.250 \\
6.242\end{array}$ & $\begin{array}{l}1.750 \\
4.721\end{array}$ & $\begin{array}{l}3.000 \\
6.325\end{array}$ & & $\begin{array}{l}4.500 \\
7.246\end{array}$ & $\begin{array}{l}0.750 \\
1.276\end{array}$ \\
\hline Viburnum nudum L. var. cassinoides & Spring 2007 & $\begin{array}{l}1.500 \\
4.743\end{array}$ & $\begin{array}{l}0.250 \\
0.796\end{array}$ & $\begin{array}{c}5.250 \\
12.273\end{array}$ & $\begin{array}{l}0.250 \\
0.796\end{array}$ & & $\begin{array}{l}0.250 \\
0.796\end{array}$ \\
\hline Viburnum recognitum & Spring 2007 & & & $\begin{array}{l}0.250 \\
0.796\end{array}$ & & $\begin{array}{l}1.500 \\
4.743\end{array}$ & 4.743 \\
\hline Acer rubrum $\mathrm{L}$. & Fall 2007 & & & & $\begin{array}{l}0.250 \\
0.796\end{array}$ & & \\
\hline Achillea millefolium L. var. occidentalis DC & Fall 2007 & & $\begin{array}{l}1.500 \\
4.743\end{array}$ & $\begin{array}{l}0.250 \\
0.796\end{array}$ & & 4.743 & $\begin{array}{l}0.250 \\
0.796\end{array}$ \\
\hline Agrostis gigantea Roth & Fall 2007 & $\begin{array}{l}1.500 \\
4.743\end{array}$ & $\begin{array}{l}1.500 \\
4.743\end{array}$ & $\begin{array}{l}0.250 \\
0.796\end{array}$ & $\begin{array}{l}1.500 \\
4.743\end{array}$ & $\begin{array}{l}0.500 \\
1.549\end{array}$ & $\begin{array}{l}1.500 \\
6.325\end{array}$ \\
\hline Amelanchier spp. & Fall 2007 & $\begin{array}{l}1.500 \\
4.743\end{array}$ & $\begin{array}{l}0.250 \\
0.796\end{array}$ & $\begin{array}{l}1.500 \\
4.743\end{array}$ & & $\begin{array}{l}0.250 \\
0.796\end{array}$ & \\
\hline Anthoxanthum odoratum L. & Fall 2007 & $\begin{array}{l}0.500 \\
1.549\end{array}$ & $\begin{array}{l}0.250 \\
0.796\end{array}$ & $\begin{array}{l}1.000 \\
1.300\end{array}$ & $\begin{array}{l}1.750 \\
4.721\end{array}$ & 4.743 & 4.743 \\
\hline Carex blanda Dewey & Fall 2007 & & & $\begin{array}{l}0.250 \\
0.796\end{array}$ & & & \\
\hline Carex debilis Michx. var. rudgei L. Bailey & Fall 2007 & $\begin{array}{l}0.500 \\
1.549\end{array}$ & $\begin{array}{l}2.000 \\
6.146\end{array}$ & $\begin{array}{l}3.000 \\
7.246\end{array}$ & $\begin{array}{l}0.750 \\
1.276\end{array}$ & $\begin{array}{l}2.000 \\
4.684\end{array}$ & $\begin{array}{l}5.000 \\
6.972\end{array}$ \\
\hline Carex folliculata $\mathrm{L}$. & Fall 2007 & $\begin{array}{l}0.250 \\
0.796\end{array}$ & & $\begin{array}{l}0.250 \\
0.796\end{array}$ & $\begin{array}{l}0.250 \\
0.796\end{array}$ & $\begin{array}{l}0.250 \\
0.796\end{array}$ & \\
\hline
\end{tabular}




\begin{tabular}{|c|c|c|c|c|c|c|c|}
\hline & & \multicolumn{2}{|c|}{ Early } & \multicolumn{2}{|c|}{ Late } & \multicolumn{2}{|c|}{ Continuous } \\
\hline & & $\begin{array}{c}\text { Fenced } \\
\bar{x} \\
\text { SD } \\
\end{array}$ & $\begin{array}{c}\text { Control } \\
\bar{x} \\
\mathrm{SD} \\
\end{array}$ & $\begin{array}{c}\text { Fenced } \\
\bar{x} \\
\mathrm{SD} \\
\end{array}$ & $\begin{array}{c}\text { Control } \\
\bar{x} \\
\mathrm{SD} \\
\end{array}$ & $\begin{array}{c}\text { Fenced } \\
\bar{x} \\
\mathrm{SD} \\
\end{array}$ & $\begin{array}{c}\text { Control } \\
\bar{x} \\
\mathrm{SD} \\
\end{array}$ \\
\hline Carex vulpinoidea Michx. & Fall 2007 & & $\begin{array}{l}1.500 \\
4.743\end{array}$ & & & & \\
\hline Danthonia compressa Aust. & Fall 2007 & $\begin{array}{l}27.250 \\
16.299\end{array}$ & $\begin{array}{c}22.250 \\
2.325\end{array}$ & $\begin{array}{c}21.000 \\
2.412\end{array}$ & $\begin{array}{c}16.750 \\
1.869\end{array}$ & $\begin{array}{l}23.750 \\
17.874\end{array}$ & $\begin{array}{l}22.500 \\
19.230\end{array}$ \\
\hline Dichanthelium clandestinum (L.) Gould & Fall 2007 & & $\begin{array}{c}3.750 \\
11.859\end{array}$ & & $\begin{array}{l}0.250 \\
0.796\end{array}$ & $\begin{array}{l}0.250 \\
0.796\end{array}$ & \\
\hline Doellingeria umbellata (P. Mill.) Nees & Fall 2007 & $\begin{array}{l}12.750 \\
15.599\end{array}$ & $\begin{array}{l}4.000 \\
5.917\end{array}$ & $\begin{array}{c}6.000 \\
12.273\end{array}$ & $\begin{array}{l}6.250 \\
7.569\end{array}$ & $\begin{array}{c}1.500 \\
17.129\end{array}$ & $\begin{array}{c}4.750 \\
12.315\end{array}$ \\
\hline Equisitum spp. & Fall 2007 & & & & $\begin{array}{l}1.500 \\
4.743\end{array}$ & & $\begin{array}{l}0.500 \\
1.549\end{array}$ \\
\hline $\begin{array}{l}\text { Euthamia graminifolia L. Nutt. var. } \\
\text { graminifolia }\end{array}$ & Fall 2007 & & $\begin{array}{l}3.000 \\
6.325\end{array}$ & $\begin{array}{c}4.000 \\
12.179\end{array}$ & $\begin{array}{l}1.750 \\
4.721\end{array}$ & $\begin{array}{c}4.000 \\
11.859\end{array}$ & \\
\hline Festuca trachyphylla (Hack.) Krajina & Fall 2007 & $\begin{array}{c}3.750 \\
11.859\end{array}$ & $\begin{array}{l}1.500 \\
4.743\end{array}$ & $\begin{array}{c}3.750 \\
11.859\end{array}$ & & $\begin{array}{c}6.250 \\
19.764\end{array}$ & 1.581 \\
\hline Hieracium praealtum Vill. ex Gochnat & Fall 2007 & & $\begin{array}{l}0.500 \\
1.549\end{array}$ & & & & $\begin{array}{l}0.250 \\
0.796\end{array}$ \\
\hline Holcus lanatus L. & Fall 2007 & & & $\begin{array}{l}4.000 \\
4.743\end{array}$ & $\begin{array}{l}0.250 \\
0.796\end{array}$ & & $\begin{array}{l}0.250 \\
0.796\end{array}$ \\
\hline Juncus effusus L. & Fall 2007 & $\begin{array}{l}0.250 \\
0.796\end{array}$ & & $\begin{array}{l}0.750 \\
1.276\end{array}$ & $\begin{array}{l}0.250 \\
0.796\end{array}$ & & $\begin{array}{l}0.250 \\
0.796\end{array}$ \\
\hline Luzula bulbosa (Alph. Wood) & Fall 2007 & & & & & $\begin{array}{l}0.250 \\
0.796\end{array}$ & \\
\hline Lycopodium spp. & Fall 2007 & $\begin{array}{l}0.250 \\
0.796\end{array}$ & $\begin{array}{l}1.500 \\
4.743\end{array}$ & & & $\begin{array}{l}0.250 \\
0.796\end{array}$ & $\begin{array}{l}0.250 \\
0.796\end{array}$ \\
\hline
\end{tabular}




\begin{tabular}{|c|c|c|c|c|c|c|c|}
\hline & & \multicolumn{2}{|c|}{ Early } & \multicolumn{2}{|c|}{ Late } & \multicolumn{2}{|c|}{ Continuous } \\
\hline & & $\begin{array}{l}\text { Fenced } \\
\bar{x} \\
\mathrm{SD} \\
\end{array}$ & $\begin{array}{c}\text { Control } \\
\bar{x} \\
\text { SD } \\
\end{array}$ & $\begin{array}{c}\text { Fenced } \\
\bar{x} \\
\mathrm{SD} \\
\end{array}$ & $\begin{array}{c}\text { Control } \\
\bar{x} \\
\mathrm{SD} \\
\end{array}$ & $\begin{array}{c}\text { Fenced } \\
\bar{x} \\
\mathrm{SD} \\
\end{array}$ & $\begin{array}{c}\text { Control } \\
\bar{x} \\
\text { SD } \\
\end{array}$ \\
\hline \multirow{2}{*}{ Poa pratensis L. ssp. pratensis } & \multirow{2}{*}{ Fall 2007} & 0.250 & 1.500 & & 0.250 & 0.250 & 0.250 \\
\hline & & 0.796 & 4.743 & & 0.796 & 0.796 & 0.796 \\
\hline \multirow{2}{*}{ Poa trivialis L. } & \multirow{2}{*}{ Fall 2007} & & 0.250 & & & & \\
\hline & & & 0.796 & & & & \\
\hline \multirow{2}{*}{ Populus tremuloides Michx. } & \multirow{2}{*}{ Fall 2007} & & & 1.500 & & & \\
\hline & & 4.743 & & 4.743 & & & \\
\hline \multirow{2}{*}{ Potentilla canadensis L. } & \multirow{2}{*}{ Fall 2007} & 3.250 & 0.750 & 1.000 & 2.250 & 3.000 & 1.750 \\
\hline & & 7.115 & 1.276 & 1.300 & 6.387 & 7.246 & 6.242 \\
\hline \multirow{2}{*}{ Potentilla simplex Michx. } & \multirow{2}{*}{ Fall 2007} & 0.250 & & & 0.250 & & 0.250 \\
\hline & & 0.796 & & & 0.796 & & 0.796 \\
\hline \multirow{2}{*}{ Pteridium aquilinum (L.) Kuhn } & \multirow{2}{*}{ Fall 2007} & 12.250 & 3.500 & 4.750 & 5.000 & 13.000 & 5.500 \\
\hline & & 14.881 & 6.146 & 7.115 & 6.972 & 17.512 & 12.179 \\
\hline \multirow{2}{*}{ Ranunculus acris L. var. acris } & \multirow{2}{*}{ Fall 2007} & & 0.250 & & & & \\
\hline & & & 0.796 & & & & \\
\hline \multirow{2}{*}{ Rubus hispidus L. } & \multirow{2}{*}{ Fall 2007} & 3.000 & 27.250 & 25.250 & 28.000 & 29.250 & 17.000 \\
\hline & & 19.223 & 16.299 & 23.813 & 22.758 & 22.794 & 19.832 \\
\hline \multirow{2}{*}{ Rumex acetosella $\mathrm{L}$. } & \multirow{2}{*}{ Fall 2007} & 0.250 & 0.250 & & 1.500 & & 0.250 \\
\hline & & 0.796 & 0.796 & & 4.743 & & 0.796 \\
\hline \multirow{2}{*}{ Solidago rugosa Mill. } & \multirow{2}{*}{ Fall 2007} & 9.000 & 4.500 & 12.000 & 5.250 & 6.000 & 7.250 \\
\hline & & 17.129 & 5.627 & 16.375 & 7.173 & 12.273 & 12.148 \\
\hline \multirow{2}{*}{ Solidago uliginosa Nutt. } & \multirow{2}{*}{ Fall 2007} & 25.750 & 1.250 & 9.750 & 4.500 & 17.500 & 7.250 \\
\hline & & 19.932 & 11.872 & 11.859 & 5.627 & 14.965 & 6.713 \\
\hline
\end{tabular}




\begin{tabular}{|c|c|c|c|c|c|c|c|}
\hline & & \multicolumn{2}{|c|}{ Early } & \multicolumn{2}{|c|}{ Late } & \multicolumn{2}{|c|}{ Continuous } \\
\hline & & $\begin{array}{c}\text { Fenced } \\
\bar{x} \\
\mathrm{SD} \\
\end{array}$ & $\begin{array}{c}\text { Control } \\
\bar{x} \\
\mathrm{SD} \\
\end{array}$ & $\begin{array}{c}\text { Fenced } \\
\bar{x} \\
\mathrm{SD} \\
\end{array}$ & $\begin{array}{c}\text { Control } \\
\bar{x} \\
\mathrm{SD} \\
\end{array}$ & $\begin{array}{c}\text { Fenced } \\
\bar{x} \\
\mathrm{SD} \\
\end{array}$ & $\begin{array}{c}\text { Control } \\
\bar{x} \\
\text { SD } \\
\end{array}$ \\
\hline \multirow{2}{*}{ Spiraea alba Du Roi } & \multirow{2}{*}{ Fall 2007} & 1.500 & 0.250 & 3.000 & 1.500 & & 0.500 \\
\hline & & 6.325 & 4.721 & 6.325 & 4.743 & & 1.549 \\
\hline \multirow{2}{*}{ Vaccinium myrtilloides Michx. } & \multirow{2}{*}{ Fall 2007} & 3.000 & 1.750 & 0.250 & 0.250 & 1.750 & 0.750 \\
\hline & & 6.325 & 4.721 & 0.796 & 0.796 & 4.721 & 1.276 \\
\hline \multirow{2}{*}{ Vaccinium pallidum Ait. } & \multirow{2}{*}{ Fall 2007} & 1.500 & 0.250 & 0.250 & & 1.500 & 0.250 \\
\hline & & 4.743 & 0.796 & 0.796 & & 4.743 & 0.796 \\
\hline \multirow{2}{*}{ Viburnum nudum L. var. cassinoides } & \multirow{2}{*}{ Fall 2007} & 0.250 & 0.250 & & & 1.500 & 0.250 \\
\hline & & 0.796 & 0.796 & & & 4.743 & 0.796 \\
\hline \multirow{2}{*}{ Viburnum recognitum } & \multirow{2}{*}{ Fall 2007} & & & 1.500 & 0.250 & & 1.500 \\
\hline & & & & 4.743 & 0.796 & & 4.743 \\
\hline
\end{tabular}


Appendix 5. Mean and standard deviation of percent cover for species sampled in Populus spp. communities in Canaan Valley, WV from 2005 - 2007. Blank values indicate the species was not recorded in the treatment group.

\begin{tabular}{|c|c|c|c|c|c|c|c|}
\hline & & \multicolumn{2}{|c|}{ Early } & \multicolumn{2}{|c|}{ Late } & \multicolumn{2}{|c|}{ Continuous } \\
\hline & & $\begin{array}{c}\text { Fenced } \\
\bar{x} \\
\text { SD } \\
\end{array}$ & $\begin{array}{c}\text { Control } \\
\bar{x} \\
\text { SD } \\
\end{array}$ & $\begin{array}{c}\text { Fenced } \\
\bar{x} \\
\text { SD } \\
\end{array}$ & $\begin{array}{c}\text { Control } \\
\bar{x} \\
\text { SD } \\
\end{array}$ & $\begin{array}{c}\text { Fenced } \\
\bar{x} \\
\text { SD } \\
\end{array}$ & $\begin{array}{c}\text { Control } \\
\bar{x} \\
\text { SD } \\
\end{array}$ \\
\hline Acer rubrum $\mathrm{L}$. & Spring 2005 & & $\begin{array}{l}0.250 \\
0.722\end{array}$ & & & & \\
\hline $\begin{array}{l}\text { Achillea millefolium L. var. occidentalis } \\
\text { DC }\end{array}$ & Spring 2005 & $\begin{array}{l}0.250 \\
0.722\end{array}$ & & $\begin{array}{l}0.250 \\
0.722\end{array}$ & & & $\begin{array}{l}0.250 \\
0.722\end{array}$ \\
\hline Agrostis gigantea Roth & Spring 2005 & $\begin{array}{l}0.750 \\
1.137\end{array}$ & $\begin{array}{l}0.750 \\
1.137\end{array}$ & $\begin{array}{l}0.250 \\
0.722\end{array}$ & $\begin{array}{l}1.000 \\
1.239\end{array}$ & $\begin{array}{l}0.250 \\
0.722\end{array}$ & \\
\hline Amelanchier spp. & Spring 2005 & & & $\begin{array}{l}0.250 \\
0.722\end{array}$ & & & \\
\hline Anthoxanthum odoratum L. & Spring 2005 & $\begin{array}{l}13.250 \\
13.676\end{array}$ & $\begin{array}{l}8.500 \\
7.173\end{array}$ & $\begin{array}{l}8.750 \\
6.864\end{array}$ & $\begin{array}{l}12.500 \\
19.433\end{array}$ & $\begin{array}{l}7.000 \\
1.128\end{array}$ & $\begin{array}{l}6.500 \\
5.823\end{array}$ \\
\hline Asclepias incarnata $\mathrm{L}$. & Spring 2005 & & $\begin{array}{l}0.250 \\
0.722\end{array}$ & & & $\begin{array}{l}0.250 \\
0.722\end{array}$ & $\begin{array}{l}0.250 \\
0.722\end{array}$ \\
\hline Brachyelytrum erectum Schreb. & Spring 2005 & & $\begin{array}{l}0.250 \\
0.722\end{array}$ & & & & $\begin{array}{l}1.500 \\
4.331\end{array}$ \\
\hline $\begin{array}{l}\text { Calamagrostis canadensis (Michx.) } \\
\text { Beauv. }\end{array}$ & Spring 2005 & & & $\begin{array}{l}1.500 \\
4.331\end{array}$ & $\begin{array}{c}6.250 \\
18.422\end{array}$ & $\begin{array}{l}4.000 \\
1.784\end{array}$ & $\begin{array}{l}3.000 \\
5.839\end{array}$ \\
\hline Carex brunnescens (Pers.) Poir. & Spring 2005 & $\begin{array}{l}1.500 \\
4.331\end{array}$ & & & & & \\
\hline Carex bushii Mack. & Spring 2005 & $\begin{array}{l}0.250 \\
0.722\end{array}$ & & & $\begin{array}{l}0.250 \\
0.722\end{array}$ & & $\begin{array}{l}0.250 \\
0.722\end{array}$ \\
\hline Carex crinita var. crinita & Spring 2005 & & $\begin{array}{l}1.500 \\
4.331\end{array}$ & $\begin{array}{l}1.500 \\
4.331\end{array}$ & $\begin{array}{l}0.250 \\
0.722\end{array}$ & & \\
\hline $\begin{array}{l}\text { Carex debilis Michx. var. rudgei L. } \\
\text { Bailey }\end{array}$ & Spring 2005 & $\begin{array}{l}2.750 \\
4.191\end{array}$ & $\begin{array}{l}3.000 \\
4.129\end{array}$ & $\begin{array}{l}4.250 \\
6.258\end{array}$ & $\begin{array}{l}1.000 \\
1.239\end{array}$ & $\begin{array}{l}2.250 \\
1.196\end{array}$ & $\begin{array}{l}1.750 \\
4.325\end{array}$ \\
\hline
\end{tabular}




\begin{tabular}{|c|c|c|c|c|c|c|c|}
\hline & & \multicolumn{2}{|c|}{ Early } & \multicolumn{2}{|c|}{ Late } & \multicolumn{2}{|c|}{ Continuous } \\
\hline & & $\begin{array}{c}\text { Fenced } \\
\bar{x} \\
\mathrm{SD} \\
\end{array}$ & $\begin{array}{c}\text { Control } \\
\bar{x} \\
\mathrm{SD}\end{array}$ & $\begin{array}{c}\text { Fenced } \\
\bar{x} \\
\mathrm{SD}\end{array}$ & $\begin{array}{c}\text { Control } \\
\bar{x} \\
\mathrm{SD}\end{array}$ & $\begin{array}{c}\text { Fenced } \\
\bar{x} \\
\text { SD }\end{array}$ & $\begin{array}{c}\text { Control } \\
\bar{x} \\
\text { SD }\end{array}$ \\
\hline Carex folliculata $\mathrm{L}$. & Spring 2005 & & & $\begin{array}{l}0.250 \\
0.722\end{array}$ & $\begin{array}{l}0.500 \\
0.973\end{array}$ & $\begin{array}{l}1.500 \\
0.577\end{array}$ & $\begin{array}{l}0.500 \\
0.973\end{array}$ \\
\hline Carex grascilescens Steud. & Spring 2005 & & & & & & $\begin{array}{l}0.250 \\
0.722\end{array}$ \\
\hline Carex hirsutella Mack. & Spring 2005 & & & $\begin{array}{l}0.250 \\
0.722\end{array}$ & & & \\
\hline $\begin{array}{l}\text { Carex scoparia Schkuhr ex Willd. var. } \\
\text { scoparia }\end{array}$ & Spring 2005 & $\begin{array}{l}3.250 \\
5.786\end{array}$ & $\begin{array}{l}0.750 \\
1.137\end{array}$ & $\begin{array}{l}2.000 \\
4.382\end{array}$ & $\begin{array}{l}3.250 \\
5.786\end{array}$ & & $\begin{array}{l}0.250 \\
0.722\end{array}$ \\
\hline Carex stipata Muhl. & Spring 2005 & & $\begin{array}{l}0.250 \\
0.722\end{array}$ & $\begin{array}{l}1.500 \\
4.331\end{array}$ & & $\begin{array}{l}1.500 \\
0.577\end{array}$ & $\begin{array}{l}0.250 \\
0.722\end{array}$ \\
\hline Carex tribuloides Wahl. & Spring 2005 & & & & $\begin{array}{l}0.250 \\
0.722\end{array}$ & & \\
\hline Carex virescens Muhl. ex Willd. & Spring 2005 & & & $\begin{array}{l}1.750 \\
4.325\end{array}$ & $\begin{array}{l}0.250 \\
0.722\end{array}$ & $\begin{array}{l}4.250 \\
1.737\end{array}$ & \\
\hline Carex vulpinoidea Michx. & Spring 2005 & & & & & $\begin{array}{l}0.250 \\
0.722\end{array}$ & \\
\hline Crataegus spp. & Spring 2005 & & $\begin{array}{l}0.750 \\
1.137\end{array}$ & $\begin{array}{l}0.250 \\
0.722\end{array}$ & $\begin{array}{l}0.250 \\
0.722\end{array}$ & $\begin{array}{l}1.500 \\
0.577\end{array}$ & $\begin{array}{l}0.500 \\
0.973\end{array}$ \\
\hline Danthonia compressa Aust. & Spring 2005 & $\begin{array}{l}0.500 \\
0.973\end{array}$ & $\begin{array}{l}0.250 \\
0.722\end{array}$ & $\begin{array}{l}0.250 \\
0.722\end{array}$ & $\begin{array}{l}4.500 \\
6.785\end{array}$ & $\begin{array}{l}0.250 \\
0.722\end{array}$ & $\begin{array}{c}0.250 \\
11.223\end{array}$ \\
\hline Dichanthelium clandestinum (L.) Gould & Spring 2005 & $\begin{array}{c}7.000 \\
11.498\end{array}$ & $\begin{array}{l}2.500 \\
4.242\end{array}$ & $\begin{array}{c}5.750 \\
11.447\end{array}$ & $\begin{array}{c}15.500 \\
2.817\end{array}$ & $\begin{array}{l}8.250 \\
1.750\end{array}$ & $\begin{array}{l}19.500 \\
21.729\end{array}$ \\
\hline Doellingeria umbellata (P. Mill.) Nees & Spring 2005 & $\begin{array}{l}8.250 \\
7.240\end{array}$ & $\begin{array}{c}8.000 \\
17.623\end{array}$ & $\begin{array}{l}12.000 \\
13.147\end{array}$ & $\begin{array}{l}11.500 \\
17.624\end{array}$ & $\begin{array}{c}9.750 \\
17.627\end{array}$ & $\begin{array}{l}6.500 \\
7.138\end{array}$ \\
\hline
\end{tabular}




\begin{tabular}{|c|c|c|c|c|c|c|c|}
\hline & & \multicolumn{2}{|c|}{ Early } & \multicolumn{2}{|c|}{ Late } & \multicolumn{2}{|c|}{ Continuous } \\
\hline & & Fenced & Control & Fenced & Control & Fenced & Control \\
\hline & & $\bar{x}$ & $\bar{x}$ & $\bar{x}$ & $\bar{x}$ & $\bar{x}$ & $\bar{x}$ \\
\hline & & SD & SD & SD & SD & SD & SD \\
\hline \multirow{2}{*}{ Equisitum spp. } & \multirow{2}{*}{ Spring 2005} & & & 0.250 & 0.250 & & 0.250 \\
\hline & & & & 0.722 & 0.722 & & 0.722 \\
\hline \multirow{2}{*}{ Euthamia graminifolia L. Nutt. } & \multirow{2}{*}{ Spring 2005} & 2.250 & 3.750 & 8.250 & 5.750 & 8.250 & 4.000 \\
\hline & & 4.286 & 5.653 & 7.240 & 6.258 & 1.967 & 6.381 \\
\hline \multirow{2}{*}{ Galium tinctorium (L.) Scop. } & \multirow{2}{*}{ Spring 2005} & & & 0.250 & & & 0.250 \\
\hline & & & & 0.722 & & & 0.722 \\
\hline \multirow{2}{*}{ Glyceria striata (Lam.) Hitchc. } & \multirow{2}{*}{ Spring 2005} & 0.250 & 0.500 & 0.250 & & 1.750 & \\
\hline & & 0.722 & 0.973 & 0.722 & & 0.882 & \\
\hline \multirow{2}{*}{ Hieracium praealtum Vill. ex Gochnat } & \multirow{2}{*}{ Spring 2005} & & 0.250 & 0.250 & & 0.250 & \\
\hline & & & 0.722 & 0.722 & & 0.722 & \\
\hline \multirow{2}{*}{ Holcus lanatus L. } & \multirow{2}{*}{ Spring 2005} & & & 0.250 & 0.250 & & \\
\hline & & & & 0.722 & 0.722 & & \\
\hline \multirow{2}{*}{ Hypericum androsaemum $\mathrm{L}$. } & \multirow{2}{*}{ Spring 2005} & & & 3.750 & 4.000 & 3.000 & \\
\hline & & & & 1.825 & 1.784 & 0.778 & \\
\hline \multirow{2}{*}{ Hypericum densiflorum Pursh } & \multirow{2}{*}{ Spring 2005} & 0.250 & & & & & 0.250 \\
\hline & & 0.722 & & & & & 0.722 \\
\hline \multirow{2}{*}{ Juncus effusus L. } & \multirow{2}{*}{ Spring 2005} & 0.500 & 0.250 & 0.250 & 0.750 & 0.250 & 1.750 \\
\hline & & 0.973 & 0.722 & 0.722 & 1.137 & 0.722 & 4.325 \\
\hline \multirow{2}{*}{ Luzula bulbosa (Alph. Wood) } & \multirow{2}{*}{ Spring 2005} & 0.250 & & 0.250 & & & 0.250 \\
\hline & & 0.722 & & 0.722 & & & 0.722 \\
\hline \multirow{2}{*}{ Lysimachia spp. } & \multirow{2}{*}{ Spring 2005} & & 0.250 & 0.250 & & & \\
\hline & & & 0.722 & 0.722 & & & \\
\hline \multirow{2}{*}{ Mimulus ringens var. ringens } & \multirow{2}{*}{ Spring 2005} & & 0.250 & 0.250 & & & \\
\hline & & & 0.722 & 0.722 & & & \\
\hline
\end{tabular}




\begin{tabular}{|c|c|c|c|c|c|c|c|}
\hline & & \multicolumn{2}{|c|}{ Early } & \multicolumn{2}{|c|}{ Late } & \multicolumn{2}{|c|}{ Continuous } \\
\hline & & $\begin{array}{c}\text { Fenced } \\
\bar{x} \\
\mathrm{SD} \\
\end{array}$ & $\begin{array}{c}\text { Control } \\
\bar{x} \\
\text { SD } \\
\end{array}$ & $\begin{array}{c}\text { Fenced } \\
\bar{x} \\
\mathrm{SD} \\
\end{array}$ & $\begin{array}{c}\text { Control } \\
\bar{x} \\
\text { SD } \\
\end{array}$ & $\begin{array}{c}\text { Fenced } \\
\bar{x} \\
\mathrm{SD} \\
\end{array}$ & $\begin{array}{c}\text { Control } \\
\bar{x} \\
\text { SD } \\
\end{array}$ \\
\hline Packera aurea (L.) A.\&D. Löve & Spring 2005 & $\begin{array}{l}0.250 \\
0.722\end{array}$ & & & & & \\
\hline Poa trivialis L. & Spring 2005 & & $\begin{array}{l}0.250 \\
0.722\end{array}$ & & & $\begin{array}{l}0.250 \\
0.722\end{array}$ & \\
\hline Polygonum sagittatum L. & Spring 2005 & & $\begin{array}{l}0.250 \\
0.722\end{array}$ & & & & \\
\hline Populus tremuloides Michx. & Spring 2005 & $\begin{array}{l}2.500 \\
4.242\end{array}$ & $\begin{array}{c}9.000 \\
17.858\end{array}$ & $\begin{array}{l}1.250 \\
1.287\end{array}$ & $\begin{array}{l}2.000 \\
4.382\end{array}$ & $\begin{array}{l}3.750 \\
1.196\end{array}$ & $\begin{array}{l}4.250 \\
6.258\end{array}$ \\
\hline Potentilla simplex Michx. & Spring 2005 & $\begin{array}{l}5.750 \\
6.258\end{array}$ & $\begin{array}{l}5.500 \\
6.381\end{array}$ & $\begin{array}{l}4.000 \\
5.573\end{array}$ & $\begin{array}{l}1.250 \\
1.287\end{array}$ & $\begin{array}{l}1.250 \\
1.270\end{array}$ & $\begin{array}{l}2.000 \\
4.382\end{array}$ \\
\hline Prunus serotina Ehrh. & Spring 2005 & & $\begin{array}{l}0.250 \\
0.722\end{array}$ & & & $\begin{array}{l}0.250 \\
0.722\end{array}$ & \\
\hline Pteridium aquilinum (L.) Kuhn & Spring 2005 & $\begin{array}{c}5.500 \\
11.223\end{array}$ & $\begin{array}{c}1.750 \\
14.478\end{array}$ & $\begin{array}{l}1.750 \\
4.325\end{array}$ & $\begin{array}{l}3.250 \\
5.786\end{array}$ & $\begin{array}{c}6.250 \\
18.422\end{array}$ & $\begin{array}{l}3.250 \\
5.786\end{array}$ \\
\hline Ranunculus acris L. var. acris & Spring 2005 & $\begin{array}{l}0.750 \\
1.137\end{array}$ & $\begin{array}{l}2.250 \\
4.286\end{array}$ & $\begin{array}{l}2.000 \\
4.382\end{array}$ & $\begin{array}{l}3.000 \\
5.839\end{array}$ & $\begin{array}{l}2.250 \\
1.177\end{array}$ & $\begin{array}{l}2.000 \\
4.382\end{array}$ \\
\hline Rubus hispidus L. & Spring 2005 & $\begin{array}{l}19.500 \\
17.123\end{array}$ & $\begin{array}{l}15.500 \\
12.673\end{array}$ & $\begin{array}{l}24.750 \\
13.694\end{array}$ & $\begin{array}{l}19.000 \\
14.934\end{array}$ & $\begin{array}{l}18.000 \\
13.995\end{array}$ & $\begin{array}{l}24.500 \\
16.667\end{array}$ \\
\hline Scirpus spp. & Spring 2005 & $\begin{array}{l}0.250 \\
0.722\end{array}$ & $\begin{array}{l}0.500 \\
0.973\end{array}$ & $\begin{array}{l}1.500 \\
4.331\end{array}$ & & & \\
\hline Sisyrinchium angustifolium P. Mill. & Spring 2005 & & $\begin{array}{l}0.250 \\
0.722\end{array}$ & $\begin{array}{l}0.250 \\
0.722\end{array}$ & & & \\
\hline
\end{tabular}




\begin{tabular}{|c|c|c|c|c|c|c|c|}
\hline & & \multicolumn{2}{|c|}{ Early } & \multicolumn{2}{|c|}{ Late } & \multicolumn{2}{|c|}{ Continuous } \\
\hline & & Fenced & Control & Fenced & Control & Fenced & Control \\
\hline & & $\bar{x}$ & $\bar{x}$ & $\bar{x}$ & $\bar{x}$ & $\bar{x}$ & $\bar{x}$ \\
\hline & & SD & $\mathrm{SD}$ & SD & SD & SD & SD \\
\hline \multirow{2}{*}{ Solidago rugosa Mill. } & \multirow{2}{*}{ Spring 2005} & 22.500 & 2.250 & 7.000 & 1.000 & 9.750 & 11.250 \\
\hline & & 24.242 & 21.798 & 7.577 & 6.728 & 14.193 & 11.288 \\
\hline \multirow{2}{*}{ Solidago uliginosa Nutt. } & \multirow{2}{*}{ Spring 2005} & 3.000 & 2.750 & 4.250 & 3.250 & 7.500 & 1.750 \\
\hline & & 5.839 & 4.191 & 5.483 & 5.786 & 1.587 & 4.325 \\
\hline \multirow{2}{*}{ Spiraea alba Du Roi } & \multirow{2}{*}{ Spring 2005} & & 1.500 & 2.000 & 1.750 & 1.750 & 4.750 \\
\hline & & & 4.331 & 4.382 & 4.325 & 0.882 & 11.626 \\
\hline \multirow{2}{*}{ Stellaria spp. } & \multirow{2}{*}{ Spring 2005} & & & & 0.250 & & \\
\hline & & & & & 0.722 & & \\
\hline \multirow{2}{*}{ Trifolium repens $\mathrm{L}$. } & \multirow{2}{*}{ Spring 2005} & 0.250 & & & 0.250 & & \\
\hline & & 0.722 & & & 0.722 & & \\
\hline \multirow{2}{*}{ Vaccinium myrtilloides Michx. } & \multirow{2}{*}{ Spring 2005} & & 0.250 & 1.500 & 1.750 & 0.250 & \\
\hline & & & 0.722 & 4.331 & 4.325 & 0.722 & \\
\hline \multirow{2}{*}{ Vaccinium pallidum Ait. } & \multirow{2}{*}{ Spring 2005} & & 1.500 & 1.500 & & & \\
\hline & & & 4.331 & 4.331 & & & \\
\hline \multirow{2}{*}{$\begin{array}{l}\text { Viburnum nudum L. var. cassinoides Torr. \& } \\
\text { Gray }\end{array}$} & \multirow{2}{*}{ Spring 2005} & 0.250 & 1.750 & 0.250 & 0.250 & 1.750 & 0.250 \\
\hline & & 0.722 & 4.325 & 0.722 & 0.722 & 0.882 & 0.722 \\
\hline \multirow{2}{*}{ Viburnum recognitum Fernald } & \multirow{2}{*}{ Spring 2005} & & & & & 0.500 & \\
\hline & & & & & & 0.973 & \\
\hline \multirow{2}{*}{ Achillea millefolium L. var. occidentalis DC } & \multirow{2}{*}{ Fall 2005} & 0.500 & & & & & \\
\hline & & 0.973 & & & & & \\
\hline \multirow{2}{*}{ Ageratina altissima (L.) King \& H. Rob. } & \multirow{2}{*}{ Fall 2005} & 6.250 & 8.750 & 2.500 & 8.750 & 17.000 & 1.000 \\
\hline & & 7.266 & 11.454 & 16.196 & 11.539 & 12.673 & 11.423 \\
\hline \multirow{2}{*}{ Agrostis gigantea Roth } & \multirow{2}{*}{ Fall 2005} & 2.500 & 0.500 & 3.500 & 0.500 & 2.500 & 1.750 \\
\hline & & 0.722 & 0.722 & & 4.325 & & 0.722 \\
\hline
\end{tabular}




\begin{tabular}{|c|c|c|c|c|c|c|c|}
\hline & & \multicolumn{2}{|c|}{ Early } & \multicolumn{2}{|c|}{ Late } & \multicolumn{2}{|c|}{ Continuous } \\
\hline & & Fenced & Control & Fenced & Control & Fenced & Control \\
\hline & & $\bar{x}$ & $\bar{x}$ & $\bar{x}$ & $\bar{x}$ & $\bar{x}$ & $\bar{x}$ \\
\hline & & $\mathrm{SD}$ & $\mathrm{SD}$ & $\mathrm{SD}$ & SD & SD & $\mathrm{SD}$ \\
\hline \multirow{2}{*}{ Agrostis perennans (Walt) Tuckerman } & \multirow{2}{*}{ Fall 2005} & 1.000 & 0.250 & 0.250 & 1.750 & 1.500 & 1.750 \\
\hline & & 1.239 & 0.722 & 0.722 & 4.325 & 1.356 & 4.325 \\
\hline \multirow{2}{*}{ Agrostis hyemalis (Walt.) B.S.P. } & \multirow{2}{*}{ Fall 2005} & & & & 0.250 & & 0.250 \\
\hline & & & & & 0.722 & & 0.722 \\
\hline \multirow{2}{*}{ Amelanchier spp. } & \multirow{2}{*}{ Fall 2005} & & & 0.250 & & & \\
\hline & & & & 0.722 & & & \\
\hline \multirow{2}{*}{ Anthoxanthum odoratum L. } & \multirow{2}{*}{ Fall 2005} & 1.250 & 6.750 & 4.000 & 4.000 & 2.250 & 3.500 \\
\hline & & 11.454 & 7.458 & 5.573 & 5.573 & 17.959 & 5.725 \\
\hline Apocynum cannabinum $\mathrm{L}$. & Fall 2005 & & & & & 0.250 & 0.250 \\
\hline \multirow{2}{*}{ Bromus kalmii Gray } & \multirow{2}{*}{ Fall 2005} & 0.250 & & & 0.250 & & 0.250 \\
\hline & & 0.722 & & & 0.722 & & 0.722 \\
\hline \multirow{2}{*}{$\begin{array}{l}\text { Calamagrostis canadensis (Michx.) } \\
\text { Beauv. }\end{array}$} & \multirow{2}{*}{ Fall 2005} & 0.250 & 6.250 & 1.500 & 6.250 & 6.250 & 6.250 \\
\hline & & 0.722 & 18.422 & 4.331 & 18.422 & 18.422 & 18.422 \\
\hline \multirow{2}{*}{ Carex bushii Mack. } & \multirow{2}{*}{ Fall 2005} & & & & 0.250 & & \\
\hline & & & & & 0.722 & & \\
\hline \multirow{2}{*}{ Carex crinita var. crinita } & \multirow{2}{*}{ Fall 2005} & & & 1.500 & 0.250 & & \\
\hline & & & & 4.331 & 0.722 & & \\
\hline \multirow{2}{*}{ Carex debilis Michx. var. rudgei L. Bailey } & \multirow{2}{*}{ Fall 2005} & 0.500 & 0.250 & 0.500 & 0.250 & & 0.750 \\
\hline & & 0.973 & 0.722 & 0.973 & 0.722 & & 1.137 \\
\hline \multirow{2}{*}{ Carex folliculata $\mathrm{L}$. } & \multirow{2}{*}{ Fall 2005} & & & 0.250 & 0.250 & 1.500 & 0.250 \\
\hline & & & & 0.722 & 0.722 & 4.331 & 0.722 \\
\hline \multirow{2}{*}{ Carex hirsutella Mack. } & \multirow{2}{*}{ Fall 2005} & 0.250 & & & 0.250 & & \\
\hline & & 0.722 & & & 0.722 & & \\
\hline
\end{tabular}




\begin{tabular}{|c|c|c|c|c|c|c|c|}
\hline & & \multicolumn{2}{|c|}{ Early } & \multicolumn{2}{|c|}{ Late } & \multicolumn{2}{|c|}{ Continuous } \\
\hline & & Fenced & Control & Fenced & Control & Fenced & Control \\
\hline & & $\bar{x}$ & $\bar{x}$ & $\bar{x}$ & $\bar{x}$ & $\bar{x}$ & $\bar{x}$ \\
\hline & & SD & SD & SD & SD & SD & SD \\
\hline \multirow{2}{*}{ Carex leptalea Wahl. ssp. leptalea } & \multirow{2}{*}{ Fall 2005} & 0.250 & & 0.250 & & 1.500 & 0.250 \\
\hline & & 0.722 & & 0.722 & & 4.331 & 0.722 \\
\hline \multirow{2}{*}{ Carex lurida Wahl. } & \multirow{2}{*}{ Fall 2005} & & 0.250 & 0.250 & 0.250 & 0.250 & 0.250 \\
\hline & & & 0.722 & 0.722 & 0.722 & 0.722 & 0.722 \\
\hline \multirow{2}{*}{$\begin{array}{l}\text { Carex scoparia Schkuhr ex Willd. var. } \\
\text { scoparia }\end{array}$} & \multirow{2}{*}{ Fall 2005} & 4.000 & 0.500 & 0.250 & 1.750 & 1.750 & \\
\hline & & 1.784 & 0.973 & 0.722 & 4.325 & 4.325 & \\
\hline \multirow{2}{*}{ Carex stipata Muhl. } & \multirow{2}{*}{ Fall 2005} & & 1.500 & & & & \\
\hline & & & 4.331 & & & & \\
\hline \multirow{2}{*}{ Carex swanii Fern. (Mack.) } & \multirow{2}{*}{ Fall 2005} & & & 0.250 & 0.250 & & \\
\hline & & & & 0.722 & 0.722 & & \\
\hline \multirow{2}{*}{ Carex vulpinoidea Michx. } & \multirow{2}{*}{ Fall 2005} & 1.500 & 3.750 & 1.750 & 0.250 & 0.500 & 0.250 \\
\hline & & 4.331 & 1.825 & 4.325 & 0.722 & 0.973 & 0.722 \\
\hline \multirow{2}{*}{ Crataegus spp. } & \multirow{2}{*}{ Fall 2005} & & 0.500 & 0.500 & & & 0.750 \\
\hline & & & 0.973 & 0.973 & & & 1.137 \\
\hline \multirow{2}{*}{ Danthonia compressa Aust. } & \multirow{2}{*}{ Fall 2005} & 6.750 & 1.750 & 12.750 & 8.500 & 3.750 & 9.250 \\
\hline & & 11.586 & 14.478 & 17.746 & 11.432 & 6.495 & 19.896 \\
\hline \multirow{2}{*}{ Dichanthelium clandestinum (L.) Gould } & \multirow{2}{*}{ Fall 2005} & 4.500 & 5.250 & 3.500 & 5.500 & 13.500 & 12.000 \\
\hline & & 1.687 & 6.495 & 5.725 & 11.129 & 24.575 & 13.837 \\
\hline \multirow{2}{*}{ Doellingeria umbellata (P. Mill.) Nees } & \multirow{2}{*}{ Fall 2005} & 8.750 & 16.750 & 12.500 & 12.000 & 17.250 & 5.000 \\
\hline & & 11.454 & 21.491 & 13.790 & 14.122 & 26.317 & 17.937 \\
\hline \multirow{2}{*}{ Equisitum spp. } & \multirow{2}{*}{ Fall 2005} & 0.250 & 1.750 & & & & 0.250 \\
\hline & & 0.722 & 4.325 & & & & 0.722 \\
\hline \multirow{2}{*}{ Euthamia graminifolia L. Nutt. } & \multirow{2}{*}{ Fall 2005} & & & 0.250 & & & \\
\hline & & & & 0.722 & & & \\
\hline
\end{tabular}




\begin{tabular}{|c|c|c|c|c|c|c|c|}
\hline & & \multicolumn{2}{|c|}{ Early } & \multicolumn{2}{|c|}{ Late } & \multicolumn{2}{|c|}{ Continuous } \\
\hline & & $\begin{array}{c}\text { Fenced } \\
\bar{x} \\
\text { SD }\end{array}$ & $\begin{array}{c}\text { Control } \\
\bar{x} \\
\text { SD }\end{array}$ & $\begin{array}{c}\text { Fenced } \\
\bar{x} \\
\text { SD }\end{array}$ & $\begin{array}{c}\text { Control } \\
\bar{x} \\
\text { SD }\end{array}$ & $\begin{array}{c}\text { Fenced } \\
\bar{x} \\
\text { SD }\end{array}$ & $\begin{array}{c}\text { Control } \\
\bar{x} \\
\text { SD }\end{array}$ \\
\hline Glyceria striata (Lam.) Hitchc. & Fall 2005 & & $\begin{array}{l}0.250 \\
0.722\end{array}$ & & & & $\begin{array}{l}0.250 \\
0.722\end{array}$ \\
\hline Hamamelis virginiana $\mathrm{L}$. & Fall 2005 & $\begin{array}{l}0.250 \\
0.722\end{array}$ & $\begin{array}{l}0.250 \\
0.722\end{array}$ & $\begin{array}{l}1.750 \\
4.325\end{array}$ & & $\begin{array}{l}0.250 \\
0.722\end{array}$ & \\
\hline Hieracium aurantiacum $\mathrm{L}$. & Fall 2005 & & $\begin{array}{l}0.250 \\
0.722\end{array}$ & & & & \\
\hline Hieracium floribundum Wimm. \& Grab. & Fall 2005 & $\begin{array}{l}0.250 \\
0.722\end{array}$ & & & & & \\
\hline Hypericum densiflorum Pursh & Fall 2005 & $\begin{array}{l}1.500 \\
4.331\end{array}$ & & $\begin{array}{c}6.250 \\
18.422\end{array}$ & $\begin{array}{l}3.750 \\
1.825\end{array}$ & $\begin{array}{l}1.500 \\
4.331\end{array}$ & \\
\hline Lycopus virginicus $\mathrm{L}$. & Fall 2005 & $\begin{array}{l}0.500 \\
0.973\end{array}$ & $\begin{array}{l}1.500 \\
4.331\end{array}$ & $\begin{array}{l}0.250 \\
0.722\end{array}$ & & $\begin{array}{l}0.250 \\
0.722\end{array}$ & $\begin{array}{l}1.500 \\
4.331\end{array}$ \\
\hline Luzula bulbosa (Alph. Wood) & Fall 2005 & $\begin{array}{l}0.250 \\
0.722\end{array}$ & & & & & \\
\hline Mimulus ringens var. ringens & Fall 2005 & & & & & $\begin{array}{l}0.250 \\
0.722\end{array}$ & $\begin{array}{l}0.250 \\
0.722\end{array}$ \\
\hline Oclemena acuminata (Michx.) Greene & Fall 2005 & & & & $\begin{array}{l}1.500 \\
4.331\end{array}$ & & \\
\hline Panicum spp. & Fall 2005 & & $\begin{array}{l}0.500 \\
0.973\end{array}$ & & $\begin{array}{l}0.250 \\
0.722\end{array}$ & & $\begin{array}{l}0.250 \\
0.722\end{array}$ \\
\hline Polygonum sagittatum L. & Fall 2005 & & & $\begin{array}{l}0.500 \\
0.973\end{array}$ & & & \\
\hline Populus tremuloides Michx. & Fall 2005 & $\begin{array}{l}0.250 \\
0.722\end{array}$ & & & $\begin{array}{l}0.250 \\
0.722\end{array}$ & & \\
\hline
\end{tabular}




\begin{tabular}{|c|c|c|c|c|c|c|c|}
\hline & & \multicolumn{2}{|c|}{ Early } & \multicolumn{2}{|c|}{ Late } & \multicolumn{2}{|c|}{ Continuous } \\
\hline & & Fenced & Control & Fenced & Control & Fenced & Control \\
\hline & & $\bar{x}$ & $\bar{x}$ & $\bar{x}$ & $\bar{x}$ & $\bar{x}$ & $\bar{x}$ \\
\hline & & SD & SD & SD & SD & SD & SD \\
\hline \multirow{2}{*}{ Potentilla canadensis L. } & \multirow{2}{*}{ Fall 2005} & 3.250 & 15.750 & 11.500 & 17.750 & 2.250 & 8.000 \\
\hline & & 27.283 & 15.489 & 14.952 & 2.379 & 15.379 & 13.958 \\
\hline \multirow{2}{*}{ Potentilla simplex Michx. } & \multirow{2}{*}{ Fall 2005} & 5.750 & 3.500 & 0.750 & 0.750 & 2.000 & 2.500 \\
\hline & & 11.153 & 5.725 & 1.137 & 1.137 & 4.382 & 4.242 \\
\hline \multirow{2}{*}{ Prunus serotina Ehrh. } & \multirow{2}{*}{ Fall 2005} & 2.000 & & 0.750 & 0.500 & 0.500 & 0.250 \\
\hline & & 4.382 & & 1.137 & 0.973 & 4.382 & 0.722 \\
\hline \multirow{2}{*}{ Pteridium aquilinum (L.) Kuhn } & \multirow{2}{*}{ Fall 2005} & & & & & 0.250 & \\
\hline & & & & & & 0.722 & \\
\hline \multirow{2}{*}{ Ranunculus acris L. var. acris } & \multirow{2}{*}{ Fall 2005} & 6.750 & 9.250 & 3.500 & 3.750 & 3.750 & \\
\hline & & 11.586 & 14.478 & 5.725 & 5.653 & 1.825 & \\
\hline \multirow{2}{*}{ Ribes spp. } & \multirow{2}{*}{ Fall 2005} & 2.000 & 1.000 & 2.000 & 0.500 & 0.250 & 2.500 \\
\hline & & 4.382 & 1.239 & 4.382 & 0.973 & 0.722 & 4.242 \\
\hline \multirow{2}{*}{ Rubus hispidus L. } & \multirow{2}{*}{ Fall 2005} & 19.250 & 28.250 & 23.000 & 27.500 & 26.750 & 32.500 \\
\hline & & 16.938 & 22.118 & 16.833 & 18.354 & 16.667 & 15.134 \\
\hline \multirow{2}{*}{ Packera aurea (L.) A.\&D. Löve } & \multirow{2}{*}{ Fall 2005} & 0.250 & & & & & 0.250 \\
\hline & & 0.720 & & & & & 0.720 \\
\hline \multirow{2}{*}{ Solidago rugosa Mill. } & \multirow{2}{*}{ Fall 2005} & 6.750 & 18.000 & 15.250 & 16.750 & 12.500 & 14.500 \\
\hline & & 6.265 & 17.854 & 13.533 & 12.673 & 13.790 & 17.336 \\
\hline \multirow{2}{*}{ Solidago uliginosa Nutt. } & \multirow{2}{*}{ Fall 2005} & 8.500 & 5.000 & 6.250 & 4.500 & 9.250 & 3.250 \\
\hline & & 11.626 & 6.646 & 7.266 & 6.785 & 14.556 & 5.786 \\
\hline \multirow{2}{*}{ Spiraea alba Du Roi } & \multirow{2}{*}{ Fall 2005} & 0.250 & 1.750 & 2.250 & 2.000 & 0.500 & 2.750 \\
\hline & & 0.722 & 4.325 & 4.286 & 4.382 & 0.973 & 4.191 \\
\hline \multirow{2}{*}{ Symphyotrichum lateriflorum (L.) } & \multirow{2}{*}{ Fall 2005} & & & & & & 0.250 \\
\hline & & & & & & & 0.722 \\
\hline
\end{tabular}




\begin{tabular}{|c|c|c|c|c|c|c|c|}
\hline & & \multicolumn{2}{|c|}{ Early } & \multicolumn{2}{|c|}{ Late } & \multicolumn{2}{|c|}{ Continuous } \\
\hline & & $\begin{array}{c}\text { Fenced } \\
\bar{x} \\
\text { SD } \\
\end{array}$ & $\begin{array}{c}\text { Control } \\
\bar{x} \\
\text { SD } \\
\end{array}$ & $\begin{array}{c}\text { Fenced } \\
\bar{x} \\
\text { SD } \\
\end{array}$ & $\begin{array}{c}\text { Control } \\
\bar{x} \\
\text { SD } \\
\end{array}$ & $\begin{array}{c}\text { Fenced } \\
\bar{x} \\
\text { SD } \\
\end{array}$ & $\begin{array}{c}\text { Control } \\
\bar{x} \\
\mathrm{SD} \\
\end{array}$ \\
\hline \multirow{2}{*}{ Symphyotrichum puniceum L. Nesom } & \multirow{2}{*}{ Fall 2005} & 1.750 & 0.250 & 0.500 & 0.250 & 1.500 & \\
\hline & & 4.325 & 0.722 & 0.973 & 0.722 & 4.331 & \\
\hline \multirow{2}{*}{ Vaccinium pallidum Ait. } & \multirow{2}{*}{ Fall 2005} & & 0.500 & 0.250 & 0.500 & & \\
\hline & & & 0.973 & 0.722 & 0.973 & & \\
\hline \multirow{2}{*}{ Viburnum nudum L. var. cassinoides } & \multirow{2}{*}{ Fall 2005} & 2.000 & 0.750 & & 0.250 & 1.750 & 0.250 \\
\hline & & 4.382 & 1.137 & & 0.722 & 4.325 & 0.722 \\
\hline \multirow{2}{*}{ Viburnum recognitum Fernald } & \multirow{2}{*}{ Fall 2005} & & & 0.500 & 0.250 & 0.250 & \\
\hline & & & & 0.973 & 0.722 & 0.722 & \\
\hline \multirow{2}{*}{ Achillea millefolium L. var. occidentalis DC } & \multirow{2}{*}{ Spring 2006} & 0.250 & & & 0.250 & 0.250 & 0.250 \\
\hline & & 0.722 & & & 0.722 & 0.722 & 0.722 \\
\hline \multirow{2}{*}{$\begin{array}{l}\text { Ageratina altissima (L.) King \& H. Rob. var. } \\
\text { altissima }\end{array}$} & \multirow{2}{*}{ Spring 2006} & 0.250 & & & & & \\
\hline & & 0.722 & & & & & \\
\hline \multirow{2}{*}{ Agrostis gigantea Roth } & \multirow{2}{*}{ Spring 2006} & 0.250 & 0.500 & 0.500 & 0.500 & 0.250 & 0.750 \\
\hline & & 0.722 & 0.973 & 0.973 & 0.973 & 0.722 & 1.137 \\
\hline \multirow{2}{*}{ Anthoxanthum odoratum L. } & \multirow{2}{*}{ Spring 2006} & 3.750 & 11.000 & 5.750 & 5.750 & 5.750 & 3.250 \\
\hline & & 3.862 & 17.559 & 6.258 & 1.365 & 6.258 & 4.534 \\
\hline \multirow{2}{*}{ Apocynum cannabinum L. } & \multirow{2}{*}{ Spring 2006} & 1.500 & & & 1.500 & & 0.250 \\
\hline & & 4.331 & & & 4.331 & & 0.722 \\
\hline \multirow{2}{*}{ Carex brunnescens (Pers.) Poir. } & \multirow{2}{*}{ Spring 2006} & 0.500 & 0.250 & 0.750 & 0.750 & & 0.500 \\
\hline & & 0.973 & 0.722 & 1.137 & 1.137 & & 0.973 \\
\hline \multirow{2}{*}{ Carex bushii Mack. } & \multirow{2}{*}{ Spring 2006} & 0.750 & 1.000 & 0.250 & 0.250 & 0.750 & 1.000 \\
\hline & & 1.137 & 1.239 & 0.722 & 0.722 & 1.137 & 1.138 \\
\hline \multirow{2}{*}{ Carex crinita var. crinita } & \multirow{2}{*}{ Spring 2006} & & & 0.500 & & & 0.250 \\
\hline & & & & 0.973 & & & 0.722 \\
\hline
\end{tabular}




\begin{tabular}{|c|c|c|c|c|c|c|c|}
\hline & & \multicolumn{2}{|c|}{ Early } & \multicolumn{2}{|c|}{ Late } & \multicolumn{2}{|c|}{ Continuous } \\
\hline & & Fenced & Control & Fenced & Control & Fenced & Control \\
\hline & & $\bar{x}$ & $\bar{x}$ & $\bar{x}$ & $\bar{x}$ & $\bar{x}$ & $\bar{x}$ \\
\hline & & SD & SD & $\mathrm{SD}$ & SD & SD & SD \\
\hline \multirow{2}{*}{ Carex debilis Michx. var. rudgei L. Bailey } & \multirow{2}{*}{ Spring 2006} & 5.250 & 4.750 & 0.750 & 4.000 & 3.000 & 2.000 \\
\hline & & 6.495 & 6.696 & 1.137 & 5.573 & 4.129 & 4.382 \\
\hline \multirow{2}{*}{ Carex folliculata $\mathrm{L}$. } & \multirow{2}{*}{ Spring 2006} & 0.500 & 0.250 & 0.250 & 0.250 & & \\
\hline & & 0.973 & 0.722 & 0.722 & 0.722 & & \\
\hline \multirow{2}{*}{ Carex grascilescens Steud. } & \multirow{2}{*}{ Spring 2006} & & 0.250 & & 0.500 & & 0.250 \\
\hline & & & 0.722 & & 0.973 & & 0.722 \\
\hline \multirow{2}{*}{ Carex scoparia Schkuhr ex Willd. var. scoparia } & \multirow{2}{*}{ Spring 2006} & 0.500 & & 0.500 & 0.500 & 0.500 & 0.500 \\
\hline & & 0.973 & & 0.973 & 0.973 & 0.973 & 0.973 \\
\hline \multirow{2}{*}{ Carex stipata Muhl. } & \multirow{2}{*}{ Spring 2006} & & & & 0.250 & 0.250 & 0.250 \\
\hline & & & & & 0.722 & 0.722 & 0.722 \\
\hline \multirow{2}{*}{ Carex striata Michx. } & \multirow{2}{*}{ Spring 2006} & 0.250 & & & & & \\
\hline & & 0.722 & & & & & \\
\hline \multirow{2}{*}{ Carex vulpinoidea Michx. } & \multirow{2}{*}{ Spring 2006} & 0.250 & 1.750 & 0.250 & & 3.750 & 0.250 \\
\hline & & 0.722 & 18.136 & 0.722 & & 1.825 & 0.722 \\
\hline \multirow{2}{*}{ Crataegus spp. } & \multirow{2}{*}{ Spring 2006} & & 0.500 & 0.750 & 0.250 & & 0.500 \\
\hline & & & 0.973 & 1.137 & 0.722 & & 0.973 \\
\hline \multirow{2}{*}{ Danthonia compressa Aust. } & \multirow{2}{*}{ Spring 2006} & 1.500 & 11.000 & 5.000 & 8.750 & 6.000 & 8.750 \\
\hline & & 2.142 & 18.383 & 1.578 & 11.539 & 11.782 & 11.539 \\
\hline \multirow{2}{*}{ Dichanthelium clandestinum (L.) Gould } & \multirow{2}{*}{ Spring 2006} & 5.250 & 5.500 & 9.750 & 7.250 & 5.000 & 3.750 \\
\hline & & 11.586 & 11.498 & 18.317 & 11.447 & 6.646 & 5.653 \\
\hline \multirow{2}{*}{$\begin{array}{l}\text { Doellingeria umbellata (P. Mill.) Nees var. } \\
\text { umbellata }\end{array}$} & \multirow{2}{*}{ Spring 2006} & 4.500 & 7.000 & 8.250 & 8.750 & 6.500 & 14.000 \\
\hline & & 1.982 & 24.324 & 7.240 & 6.785 & 19.573 & 19.433 \\
\hline \multirow{2}{*}{ Equisitum spp. } & \multirow{2}{*}{ Spring 2006} & & 0.250 & & 0.250 & & 0.250 \\
\hline & & & 0.722 & & 0.722 & & 0.722 \\
\hline
\end{tabular}




\begin{tabular}{|c|c|c|c|c|c|c|c|}
\hline & & \multicolumn{2}{|c|}{ Early } & \multicolumn{2}{|c|}{ Late } & \multicolumn{2}{|c|}{ Continuous } \\
\hline & & $\begin{array}{c}\text { Fenced } \\
\bar{x} \\
\mathrm{SD}\end{array}$ & $\begin{array}{c}\text { Control } \\
\bar{x} \\
\text { SD }\end{array}$ & $\begin{array}{c}\text { Fenced } \\
\bar{x} \\
\mathrm{SD}\end{array}$ & $\begin{array}{c}\text { Control } \\
\bar{x} \\
\text { SD }\end{array}$ & $\begin{array}{c}\text { Fenced } \\
\bar{x} \\
\text { SD }\end{array}$ & $\begin{array}{c}\text { Control } \\
\bar{x} \\
\text { SD }\end{array}$ \\
\hline \multirow{2}{*}{$\begin{array}{l}\text { Euthamia graminifolia L. Nutt. var. } \\
\text { graminifolia }\end{array}$} & \multirow{2}{*}{ Spring 2006} & 3.000 & 1.500 & 4.750 & 4.000 & 2.500 & 2.500 \\
\hline & & 4.129 & 1.356 & 5.272 & 5.573 & 4.242 & 4.242 \\
\hline \multirow{2}{*}{ Fragaria virginiana Duchesne } & \multirow{2}{*}{ Spring 2006} & & 0.250 & 0.250 & & 0.250 & 0.250 \\
\hline & & & 0.722 & 0.722 & & 0.722 & 0.433 \\
\hline \multirow{2}{*}{ Galium tinctorium (L.) Scop. } & \multirow{2}{*}{ Spring 2006} & 0.250 & & & & & \\
\hline & & 0.722 & & & & & \\
\hline \multirow{2}{*}{ Glyceria striata (Lam.) Hitchc. } & \multirow{2}{*}{ Spring 2006} & 0.250 & & 0.250 & & & \\
\hline & & 0.722 & & 0.722 & & & \\
\hline \multirow{2}{*}{ Hieracium aurantiacum $\mathrm{L}$. } & \multirow{2}{*}{ Spring 2006} & & 0.250 & 0.250 & 0.250 & 0.250 & \\
\hline & & & 0.722 & 0.722 & 0.722 & 0.722 & \\
\hline \multirow{2}{*}{ Hieracium praealtum Vill. ex Gochnat } & \multirow{2}{*}{ Spring 2006} & & & & & 0.250 & \\
\hline & & & & & & 0.722 & \\
\hline \multirow{2}{*}{ Holcus lanatus L. } & \multirow{2}{*}{ Spring 2006} & 0.250 & & & & & \\
\hline & & 0.722 & & & & & \\
\hline \multirow{2}{*}{ Houstonia caerulea $\mathrm{L}$. } & \multirow{2}{*}{ Spring 2006} & & 0.250 & & & & \\
\hline & & & 0.722 & & & & \\
\hline \multirow{2}{*}{ Hypericum densiflorum Pursh } & \multirow{2}{*}{ Spring 2006} & 0.250 & 1.500 & 1.500 & & 0.250 & \\
\hline & & 0.722 & 4.331 & 4.331 & & 0.722 & \\
\hline \multirow{2}{*}{ Hypericum ellipticum Hook. } & \multirow{2}{*}{ Spring 2006} & & & & & & 0.250 \\
\hline & & & & & & & 0.722 \\
\hline \multirow{2}{*}{ Juncus effusus L. } & \multirow{2}{*}{ Spring 2006} & 0.250 & 0.250 & 0.500 & 0.250 & 0.250 & 0.500 \\
\hline & & 0.722 & 0.722 & 0.973 & 0.722 & 0.722 & 0.973 \\
\hline \multirow{2}{*}{ Luzula bulbosa (Alph. Wood) } & \multirow{2}{*}{ Spring 2006} & 0.250 & 0.250 & 0.250 & & & 0.250 \\
\hline & & 0.722 & 0.722 & 0.722 & & & 0.722 \\
\hline
\end{tabular}




\begin{tabular}{|c|c|c|c|c|c|c|c|}
\hline & & \multicolumn{2}{|c|}{ Early } & \multicolumn{2}{|c|}{ Late } & \multicolumn{2}{|c|}{ Continuous } \\
\hline & & Fenced & Control & Fenced & Control & Fenced & Control \\
\hline & & $\bar{x}$ & $\bar{x}$ & $\bar{x}$ & $\bar{x}$ & $\bar{x}$ & $\bar{x}$ \\
\hline & & $\mathrm{SD}$ & $\mathrm{SD}$ & SD & $\mathrm{SD}$ & $\mathrm{SD}$ & $\mathrm{SD}$ \\
\hline \multirow{2}{*}{ Lysmachia spp. } & \multirow{2}{*}{ Spring 2006} & 0.500 & 0.250 & 0.250 & 1.750 & 0.500 & 0.250 \\
\hline & & 0.973 & 0.722 & 0.722 & 4.325 & 0.973 & 0.722 \\
\hline \multirow{2}{*}{ Poa trivialis L. } & \multirow{2}{*}{ Spring 2006} & 0.250 & & 0.250 & 0.250 & & 0.250 \\
\hline & & 0.722 & & 0.722 & 0.722 & & 0.722 \\
\hline \multirow{2}{*}{ Polygonum sagittatum L. } & \multirow{2}{*}{ Spring 2006} & & & 0.250 & 0.250 & 0.250 & 0.250 \\
\hline & & & & 0.722 & 0.722 & 0.722 & 0.722 \\
\hline \multirow{2}{*}{ Populus tremuloides Michx. } & \multirow{2}{*}{ Spring 2006} & 5.750 & 12.000 & 11.000 & 8.750 & 11.000 & 24.750 \\
\hline & & 6.437 & 13.817 & 18.498 & 1.744 & 13.248 & 19.365 \\
\hline \multirow{2}{*}{ Potentilla simplex Michx. } & \multirow{2}{*}{ Spring 2006} & 3.000 & 4.000 & 2.000 & 3.250 & 6.500 & 5.750 \\
\hline & & 4.129 & 6.381 & 4.382 & 4.534 & 11.953 & 11.175 \\
\hline \multirow{2}{*}{ Prunus serotina Ehrh. } & \multirow{2}{*}{ Spring 2006} & & & & 0.250 & & \\
\hline & & & & & 0.722 & & \\
\hline \multirow{2}{*}{ Pteridium aquilinum (L.) Kuhn } & \multirow{2}{*}{ Spring 2006} & & 0.500 & 4.000 & 2.000 & 1.500 & 4.750 \\
\hline & & & 0.973 & 1.784 & 4.382 & 4.331 & 6.696 \\
\hline \multirow{2}{*}{ Ranunculus acris L. var. acris } & \multirow{2}{*}{ Spring 2006} & 0.500 & 0.500 & 1.750 & 0.250 & 0.250 & 0.500 \\
\hline & & 0.973 & 0.973 & 4.325 & 0.722 & 0.722 & 0.973 \\
\hline \multirow{2}{*}{ Rubus hispidus L. } & \multirow{2}{*}{ Spring 2006} & 14.500 & 19.000 & 15.000 & 18.750 & 24.750 & 1.000 \\
\hline & & 14.673 & 21.858 & 22.899 & 2.173 & 13.694 & 19.819 \\
\hline \multirow{2}{*}{ Scirpus spp. } & \multirow{2}{*}{ Spring 2006} & 0.250 & & & & & \\
\hline & & 0.722 & & & & & \\
\hline \multirow{2}{*}{ Solidago rugosa Mill. } & \multirow{2}{*}{ Spring 2006} & 3.750 & 7.000 & 16.750 & 7.000 & 5.500 & 14.000 \\
\hline & & 17.832 & 6.853 & 18.813 & 1.862 & 6.853 & 17.216 \\
\hline \multirow{2}{*}{ Solidago uliginosa Nutt. } & \multirow{2}{*}{ Spring 2006} & 1.000 & 2.500 & 6.000 & 1.500 & 9.500 & 2.250 \\
\hline & & 11.596 & 4.242 & 11.782 & 4.331 & 14.453 & 5.653 \\
\hline
\end{tabular}




\begin{tabular}{|c|c|c|c|c|c|c|c|}
\hline & & \multicolumn{2}{|c|}{ Early } & \multicolumn{2}{|c|}{ Late } & \multicolumn{2}{|c|}{ Continuous } \\
\hline & & $\begin{array}{c}\text { Fenced } \\
\bar{x} \\
\text { SD } \\
\end{array}$ & $\begin{array}{c}\text { Control } \\
\bar{x} \\
\text { SD } \\
\end{array}$ & $\begin{array}{c}\text { Fenced } \\
\bar{x} \\
\mathrm{SD} \\
\end{array}$ & $\begin{array}{c}\text { Control } \\
\bar{x} \\
\text { SD } \\
\end{array}$ & $\begin{array}{c}\text { Fenced } \\
\bar{x} \\
\text { SD } \\
\end{array}$ & $\begin{array}{c}\text { Control } \\
\bar{x} \\
\text { SD } \\
\end{array}$ \\
\hline \multirow{2}{*}{ Spiraea alba Du Roi } & \multirow{2}{*}{ Spring 2006} & 5.250 & 0.250 & 5.750 & 1.250 & & 3.500 \\
\hline & & 11.288 & 0.722 & 11.153 & 1.287 & & 5.738 \\
\hline \multirow{2}{*}{ Symphyotrichum praealtum } & \multirow{2}{*}{ Spring 2006} & & & 0.250 & 0.500 & & \\
\hline & & & & 0.722 & 0.973 & & \\
\hline \multirow{2}{*}{ Sisyrinchium angustifolium P. Mill. } & \multirow{2}{*}{ Spring 2006} & & & & & & 0.250 \\
\hline & & & & & & & 0.722 \\
\hline \multirow{2}{*}{ Vaccinium myrtilloides Michx. } & \multirow{2}{*}{ Spring 2006} & 0.250 & 0.500 & & 0.250 & 0.250 & 0.500 \\
\hline & & 0.722 & 0.973 & & 0.722 & 0.722 & 0.973 \\
\hline Vaccinium pallidum Ait. & Spring 2006 & & & & & & \\
\hline \multirow{2}{*}{$\begin{array}{l}\text { Viburnum nudum L. var. cassinoides Torr. \& } \\
\text { Gray }\end{array}$} & \multirow{2}{*}{ Spring 2006} & 0.250 & 0.250 & 0.250 & & 0.500 & 0.750 \\
\hline & & 0.722 & 0.722 & 0.722 & & 0.973 & 1.137 \\
\hline \multirow{2}{*}{ Achillea millefolium L. var. occidentalis DC } & \multirow{2}{*}{ Fall 2006} & 0.500 & & & & & \\
\hline & & 0.973 & & & & & \\
\hline \multirow{2}{*}{$\begin{array}{l}\text { Ageratina altissima (L.) King \& H. Rob. var. } \\
\text { altissima }\end{array}$} & \multirow{2}{*}{ Fall 2006} & 14.250 & 7.500 & 22.750 & 6.500 & 21.500 & 5.500 \\
\hline & & & 0.722 & & & & 0.722 \\
\hline \multirow{2}{*}{ Agrostis gigantea Roth } & \multirow{2}{*}{ Fall 2006} & 1.250 & 0.750 & 1.000 & 2.000 & 1.000 & 1.750 \\
\hline & & 0.722 & 4.331 & & 0.722 & & 4.331 \\
\hline \multirow{2}{*}{ Agrostis perennans (Walt) Tuckerman } & \multirow{2}{*}{ Fall 2006} & 0.500 & & & 0.250 & 0.500 & 1.500 \\
\hline & & 0.973 & & & 0.722 & 4.382 & 4.331 \\
\hline \multirow{2}{*}{ Amelanchier spp. } & \multirow{2}{*}{ Fall 2006} & & & 0.250 & & & \\
\hline & & & & 0.722 & & & \\
\hline \multirow{2}{*}{ Anthoxanthum odoratum L. } & \multirow{2}{*}{ Fall 2006} & 9.750 & 9.250 & 2.750 & 5.250 & 3.500 & 3.750 \\
\hline & & 7.240 & 11.254 & 4.191 & 6.495 & 18.317 & 5.653 \\
\hline
\end{tabular}




\begin{tabular}{|c|c|c|c|c|c|c|c|}
\hline & & \multicolumn{2}{|c|}{ Early } & \multicolumn{2}{|c|}{ Late } & \multicolumn{2}{|c|}{ Continuous } \\
\hline & & $\begin{array}{c}\text { Fenced } \\
\bar{x} \\
\text { SD } \\
\end{array}$ & $\begin{array}{c}\text { Control } \\
\bar{x} \\
\text { SD } \\
\end{array}$ & $\begin{array}{c}\text { Fenced } \\
\bar{x} \\
\text { SD } \\
\end{array}$ & $\begin{array}{c}\text { Control } \\
\bar{x} \\
\text { SD } \\
\end{array}$ & $\begin{array}{c}\text { Fenced } \\
\bar{x} \\
\text { SD } \\
\end{array}$ & $\begin{array}{c}\text { Control } \\
\bar{x} \\
\mathrm{SD} \\
\end{array}$ \\
\hline Apocynum cannabinum $\mathrm{L}$. & Fall 2006 & & & & & $\begin{array}{l}0.250 \\
0.722\end{array}$ & $\begin{array}{l}0.250 \\
0.722\end{array}$ \\
\hline Bromus kalmii Gray & Fall 2006 & $\begin{array}{l}0.250 \\
0.722\end{array}$ & & & $\begin{array}{l}0.250 \\
0.722\end{array}$ & & $\begin{array}{l}0.250 \\
0.722\end{array}$ \\
\hline Calamagrostis canadensis (Michx.) Beauv. & Fall 2006 & $\begin{array}{l}0.250 \\
0.722\end{array}$ & $\begin{array}{l}3.750 \\
1.825\end{array}$ & $\begin{array}{l}1.500 \\
4.331\end{array}$ & $\begin{array}{l}3.750 \\
1.825\end{array}$ & $\begin{array}{l}3.750 \\
1.825\end{array}$ & $\begin{array}{c}6.250 \\
18.422\end{array}$ \\
\hline Carex bushii Mack. & Fall 2006 & & & & $\begin{array}{l}0.250 \\
0.722\end{array}$ & & \\
\hline Carex crinita var. crinita & Fall 2006 & & & $\begin{array}{l}1.500 \\
4.331\end{array}$ & $\begin{array}{l}0.250 \\
0.722\end{array}$ & & \\
\hline Carex debilis Michx. var. rudgei L. Bailey & Fall 2006 & $\begin{array}{l}0.500 \\
0.973\end{array}$ & 4.331 & $\begin{array}{l}0.750 \\
1.137\end{array}$ & $\begin{array}{l}0.250 \\
0.722\end{array}$ & $\begin{array}{l}0.250 \\
0.722\end{array}$ & $\begin{array}{l}0.500 \\
0.973\end{array}$ \\
\hline Carex folliculata $\mathrm{L}$. & Fall 2006 & & & & $\begin{array}{l}0.250 \\
0.722\end{array}$ & $\begin{array}{l}3.000 \\
5.839\end{array}$ & $\begin{array}{l}0.250 \\
0.722\end{array}$ \\
\hline Carex hirsutella Mack. & Fall 2006 & $\begin{array}{l}0.250 \\
0.722\end{array}$ & & & $\begin{array}{l}0.250 \\
0.722\end{array}$ & & \\
\hline Carex leptalea Wahl. ssp. leptalea & Fall 2006 & $\begin{array}{l}0.250 \\
0.722\end{array}$ & & $\begin{array}{l}0.250 \\
0.722\end{array}$ & & $\begin{array}{l}0.250 \\
0.722\end{array}$ & $\begin{array}{l}0.250 \\
0.722\end{array}$ \\
\hline Carex lurida Wahl. & Fall 2006 & & $\begin{array}{l}0.250 \\
0.722\end{array}$ & $\begin{array}{l}0.250 \\
0.722\end{array}$ & $\begin{array}{l}0.250 \\
0.722\end{array}$ & $\begin{array}{l}0.250 \\
0.722\end{array}$ & $\begin{array}{l}0.250 \\
0.722\end{array}$ \\
\hline Carex scoparia Schkuhr ex Willd. var. scoparia & Fall 2006 & $\begin{array}{l}0.250 \\
0.722\end{array}$ & $\begin{array}{l}1.750 \\
4.325\end{array}$ & $\begin{array}{l}0.250 \\
0.722\end{array}$ & $\begin{array}{l}1.750 \\
4.325\end{array}$ & $\begin{array}{l}2.000 \\
4.382\end{array}$ & $\begin{array}{l}0.250 \\
0.722\end{array}$ \\
\hline
\end{tabular}




\begin{tabular}{|c|c|c|c|c|c|c|c|}
\hline & & \multicolumn{2}{|c|}{ Early } & \multicolumn{2}{|c|}{ Late } & \multicolumn{2}{|c|}{ Continuous } \\
\hline & & Fenced & Control & Fenced & Control & Fenced & Control \\
\hline & & $\bar{x}$ & $\bar{x}$ & $\bar{x}$ & $\bar{x}$ & $\bar{x}$ & $\bar{x}$ \\
\hline & & $\mathrm{SD}$ & $\mathrm{SD}$ & $\mathrm{SD}$ & SD & SD & SD \\
\hline \multirow{2}{*}{ Carex stipata Muhl. } & \multirow{2}{*}{ Fall 2006} & & 1.500 & & & & \\
\hline & & & 4.331 & & & & \\
\hline \multirow{2}{*}{ Carex swanii Fern. (Mack.) } & \multirow{2}{*}{ Fall 2006} & & & & 0.500 & & \\
\hline & & & & & 0.973 & & \\
\hline \multirow{2}{*}{ Carex vulpinoidea Michx. } & \multirow{2}{*}{ Fall 2006} & 1.500 & 1.500 & 0.500 & 1.500 & 0.500 & 1.500 \\
\hline & & 4.331 & 4.331 & 0.973 & 4.331 & 0.973 & 4.331 \\
\hline \multirow{2}{*}{ Crataegus spp. } & \multirow{2}{*}{ Fall 2006} & 0.250 & 0.250 & 0.250 & & 0.500 & 0.500 \\
\hline & & 0.722 & 0.722 & 0.722 & & 0.973 & 0.973 \\
\hline \multirow{2}{*}{ Danthonia compressa Aust. } & \multirow{2}{*}{ Fall 2006} & 4.500 & 12.000 & 12.750 & 15.500 & 6.250 & 11.500 \\
\hline & & 6.785 & 14.426 & 13.986 & 21.287 & 14.236 & 2.833 \\
\hline \multirow{2}{*}{ Dichanthelium clandestinum (L.) Gould } & \multirow{2}{*}{ Fall 2006} & 4.250 & 3.500 & 5.750 & 13.250 & 17.500 & 11.500 \\
\hline & & 5.483 & 5.725 & 11.153 & 19.785 & 2.529 & 1.740 \\
\hline \multirow{2}{*}{$\begin{array}{l}\text { Doellingeria umbellata (P. Mill.) Nees var. } \\
\text { umbellata }\end{array}$} & \multirow{2}{*}{ Fall 2006} & 17.250 & 12.750 & 15.500 & 7.750 & 27.250 & 2.750 \\
\hline & & 16.963 & 13.615 & 12.673 & 7.647 & 18.585 & 1.915 \\
\hline \multirow{2}{*}{ Equisitum spp. } & \multirow{2}{*}{ Fall 2006} & 0.250 & 1.750 & 0.250 & 0.250 & & \\
\hline & & 0.722 & 0.722 & 0.722 & 0.722 & & \\
\hline \multirow{2}{*}{ Euthamia graminifolia L. Nutt. var. graminifolia } & \multirow{2}{*}{ Fall 2006} & 17.965 & 15.636 & 0.250 & 0.250 & 17.613 & 9.150 \\
\hline & & 16.450 & 11.382 & 17.383 & 7.138 & 18.933 & 6.381 \\
\hline \multirow{2}{*}{ Glyceria striata (Lam.) Hitchc. } & \multirow{2}{*}{ Fall 2006} & & 0.250 & & 0.250 & & \\
\hline & & & 0.722 & & 0.722 & & \\
\hline \multirow{2}{*}{ Hamamelis virginiana $\mathrm{L}$. } & \multirow{2}{*}{ Fall 2006} & & 0.250 & & & & \\
\hline & & & 0.722 & & & & \\
\hline \multirow{2}{*}{ Hieracium aurantiacum L. } & \multirow{2}{*}{ Fall 2006} & 0.250 & & & & & \\
\hline & & 0.722 & & & & & \\
\hline
\end{tabular}




\begin{tabular}{|c|c|c|c|c|c|c|c|}
\hline & & \multicolumn{2}{|c|}{ Early } & \multicolumn{2}{|c|}{ Late } & \multicolumn{2}{|c|}{ Continuous } \\
\hline & & $\begin{array}{c}\text { Fenced } \\
\bar{x} \\
\mathrm{SD} \\
\end{array}$ & $\begin{array}{c}\text { Control } \\
\bar{x} \\
\mathrm{SD} \\
\end{array}$ & $\begin{array}{c}\text { Fenced } \\
\bar{x} \\
\mathrm{SD} \\
\end{array}$ & $\begin{array}{c}\text { Control } \\
\bar{x} \\
\text { SD } \\
\end{array}$ & $\begin{array}{c}\text { Fenced } \\
\bar{x} \\
\mathrm{SD} \\
\end{array}$ & $\begin{array}{c}\text { Control } \\
\bar{x} \\
\text { SD } \\
\end{array}$ \\
\hline $\begin{array}{l}\text { Hieracium floribundum Wimm. \& } \\
\text { Grab. }\end{array}$ & Fall 2006 & $\begin{array}{l}0.250 \\
0.722\end{array}$ & & & & & \\
\hline Houstonia caerulea L. & Fall 2006 & $\begin{array}{l}0.250 \\
0.722\end{array}$ & & & & & \\
\hline Hypericum densiflorum Pursh & Fall 2006 & $\begin{array}{l}1.500 \\
4.331\end{array}$ & & $\begin{array}{l}3.750 \\
1.825\end{array}$ & $\begin{array}{l}1.500 \\
4.331\end{array}$ & $\begin{array}{l}1.500 \\
4.331\end{array}$ & \\
\hline Lycopus virginicus L. & Fall 2006 & 0.250 & $\begin{array}{l}0.250 \\
0.722\end{array}$ & 0.500 & 1.500 & 1.750 & \\
\hline Luzula bulbosa (Alph. Wood) & Fall 2006 & & $\begin{array}{l}0.250 \\
0.722\end{array}$ & & & & \\
\hline Mimulus ringens var. ringens & Fall 2006 & & & & & & $\begin{array}{l}0.250 \\
0.722\end{array}$ \\
\hline Oclemena acuminata (Michx.) Greene & Fall 2006 & & & & $\begin{array}{l}1.500 \\
4.331\end{array}$ & & \\
\hline Panicum spp. & Fall 2006 & & $\begin{array}{l}0.500 \\
0.973\end{array}$ & & $\begin{array}{l}0.250 \\
0.722\end{array}$ & & $\begin{array}{l}0.250 \\
0.722\end{array}$ \\
\hline Polygonum sagittatum L. & Fall 2006 & $\begin{array}{l}0.250 \\
0.722\end{array}$ & & $\begin{array}{l}0.250 \\
0.722\end{array}$ & 0.250 & & \\
\hline Populus tremuloides Michx. & Fall 2006 & 19.723 & 9.621 & 19.842 & 7.449 & 15.551 & 7.256 \\
\hline Potentilla canadensis L. & Fall 2006 & $\begin{array}{l}45.250 \\
14.135\end{array}$ & $\begin{array}{c}16.250 \\
5.653\end{array}$ & $\begin{array}{c}23.750 \\
5.483\end{array}$ & $\begin{array}{l}9.500 \\
1.287\end{array}$ & $\begin{array}{c}31.750 \\
7.572\end{array}$ & $\begin{array}{l}9.500 \\
5.573\end{array}$ \\
\hline Potentilla simplex Michx. & Fall 2006 & 12.500 & 3.750 & 4.250 & 1.250 & $\begin{array}{l}6.250 \\
0.722\end{array}$ & 4.000 \\
\hline
\end{tabular}




\begin{tabular}{|c|c|c|c|c|c|c|c|}
\hline & & \multicolumn{2}{|c|}{ Early } & \multicolumn{2}{|c|}{ Late } & \multicolumn{2}{|c|}{ Continuous } \\
\hline & & $\begin{array}{c}\text { Fenced } \\
\bar{x} \\
\mathrm{SD} \\
\end{array}$ & $\begin{array}{c}\text { Control } \\
\bar{x} \\
\text { SD } \\
\end{array}$ & $\begin{array}{c}\text { Fenced } \\
\bar{x} \\
\mathrm{SD} \\
\end{array}$ & $\begin{array}{c}\text { Control } \\
\bar{x} \\
\text { SD } \\
\end{array}$ & $\begin{array}{c}\text { Fenced } \\
\bar{x} \\
\mathrm{SD} \\
\end{array}$ & $\begin{array}{c}\text { Control } \\
\bar{x} \\
\text { SD } \\
\end{array}$ \\
\hline Pteridium aquilinum (L.) Kuhn & Fall 2006 & 5.839 & 5.725 & 1.137 & 1.239 & $\begin{array}{l}0.250 \\
1.825\end{array}$ & \\
\hline Ranunculus acris L. var. acris & Fall 2006 & $\begin{array}{l}3.000 \\
4.382\end{array}$ & $\begin{array}{l}2.000 \\
4.382\end{array}$ & $\begin{array}{l}0.750 \\
4.382\end{array}$ & $\begin{array}{l}1.000 \\
0.973\end{array}$ & $\begin{array}{l}3.750 \\
0.722\end{array}$ & 1.287 \\
\hline Ribes spp. & Fall 2006 & 2.000 & 2.000 & 2.000 & 0.500 & 0.250 & 1.250 \\
\hline Rubus hispidus L. & Fall 2006 & 17.969 & 14.360 & 2.772 & 18.694 & 16.148 & 6.495 \\
\hline Rumex acetosella $\mathrm{L}$. & Fall 2006 & 31.750 & 15.500 & 32.500 & 21.750 & 35.750 & 18.750 \\
\hline Solidago caesia $\mathrm{L}$. & Fall 2006 & & $\begin{array}{l}0.250 \\
0.722\end{array}$ & & & & $\begin{array}{l}0.250 \\
0.722\end{array}$ \\
\hline Solidago rugosa Mill. & Fall 2006 & 2.992 & 15.317 & 19.752 & 11.153 & 15.864 & 11.953 \\
\hline Solidago uliginosa Nutt. & Fall 2006 & $\begin{array}{l}17.250 \\
11.733\end{array}$ & $\begin{array}{c}16.750 \\
6.495\end{array}$ & $\begin{array}{l}16.250 \\
11.782\end{array}$ & $\begin{array}{c}18.250 \\
6.696\end{array}$ & $\begin{array}{l}19.750 \\
14.556\end{array}$ & $\begin{array}{l}11.500 \\
11.223\end{array}$ \\
\hline Spiraea alba Du Roi & Fall 2006 & $\begin{array}{l}8.250 \\
0.722\end{array}$ & $\begin{array}{l}3.750 \\
0.722\end{array}$ & $\begin{array}{l}6.000 \\
0.722\end{array}$ & $\begin{array}{l}4.750 \\
0.973\end{array}$ & $\begin{array}{l}5.500 \\
0.722\end{array}$ & $\begin{array}{l}5.500 \\
4.242\end{array}$ \\
\hline Stellaria spp. & Fall 2006 & 0.250 & 0.250 & 0.250 & 0.500 & 0.250 & 2.500 \\
\hline Symphyotrichum lateriflorum (L.) & Fall 2006 & & & & & & $\begin{array}{l}0.250 \\
0.722\end{array}$ \\
\hline $\begin{array}{l}\text { Symphyotrichum puniceum } \mathrm{L} \text {. Nesom var. } \\
\text { puniceum }\end{array}$ & Fall 2006 & $\begin{array}{l}2.000 \\
4.382\end{array}$ & $\begin{array}{l}0.250 \\
0.722\end{array}$ & $\begin{array}{l}1.750 \\
4.325\end{array}$ & $\begin{array}{l}0.250 \\
0.722\end{array}$ & $\begin{array}{l}1.500 \\
4.331\end{array}$ & \\
\hline
\end{tabular}




\begin{tabular}{|c|c|c|c|c|c|c|c|}
\hline & & \multicolumn{2}{|c|}{ Early } & \multicolumn{2}{|c|}{ Late } & \multicolumn{2}{|c|}{ Continuous } \\
\hline & & $\begin{array}{c}\text { Fenced } \\
\bar{x} \\
\text { SD } \\
\end{array}$ & $\begin{array}{c}\text { Control } \\
\bar{x} \\
\text { SD } \\
\end{array}$ & $\begin{array}{c}\text { Fenced } \\
\bar{x} \\
\text { SD } \\
\end{array}$ & $\begin{array}{c}\text { Control } \\
\bar{x} \\
\text { SD } \\
\end{array}$ & $\begin{array}{c}\text { Fenced } \\
\bar{x} \\
\text { SD } \\
\end{array}$ & $\begin{array}{c}\text { Control } \\
\bar{x} \\
\text { SD } \\
\end{array}$ \\
\hline \multirow{2}{*}{ Vaccinium pallidum Ait. } & \multirow{2}{*}{ Fall 2006} & & 0.500 & 0.250 & 0.500 & & \\
\hline & & & 0.973 & 0.722 & 0.973 & & \\
\hline \multirow{2}{*}{$\begin{array}{l}\text { Viburnum nudum L. var. cassinoides Torr. \& } \\
\text { Gray }\end{array}$} & \multirow{2}{*}{ Fall 2006} & 0.500 & 0.750 & & 0.250 & 2.000 & 0.250 \\
\hline & & 0.973 & 1.137 & & 0.722 & 4.382 & 0.722 \\
\hline \multirow{2}{*}{ Achillea millefolium L. var. occidentalis DC } & \multirow{2}{*}{ Spring 2007} & 0.250 & & 0.500 & & 0.250 & \\
\hline & & 0.722 & & 0.973 & & 0.722 & \\
\hline \multirow{2}{*}{$\begin{array}{l}\text { Ageratina altissima (L.) King \& H. Rob. var. } \\
\text { altissima }\end{array}$} & \multirow{2}{*}{ Spring 2007} & & & & & 0.250 & \\
\hline & & & & & & 0.722 & \\
\hline \multirow{2}{*}{ Agrostis gigantea Roth } & \multirow{2}{*}{ Spring 2007} & & 1.000 & 0.500 & 0.500 & & 2.000 \\
\hline & & & 1.239 & 0.973 & 0.973 & & 4.382 \\
\hline \multirow{2}{*}{ Amelanchier spp. } & \multirow{2}{*}{ Spring 2007} & & & & & 0.250 & \\
\hline & & & & & & 0.722 & \\
\hline \multirow{2}{*}{ Anthoxanthum odoratum L. } & \multirow{2}{*}{ Spring 2007} & 3.500 & 5.750 & 9.500 & 7.500 & 3.000 & 6.250 \\
\hline & & 3.965 & 6.696 & 13.851 & 6.528 & 4.129 & 5.979 \\
\hline \multirow{2}{*}{ Apocynum cannabinum $\mathrm{L}$. } & \multirow{2}{*}{ Spring 2007} & 0.250 & & & & 1.500 & 1.500 \\
\hline & & 0.722 & & & & 4.331 & 4.331 \\
\hline \multirow{2}{*}{ Carex brunnescens (Pers.) Poir. } & \multirow{2}{*}{ Spring 2007} & & 0.250 & 1.000 & 0.250 & 1.000 & 0.250 \\
\hline & & & 0.722 & 1.239 & 0.722 & 1.239 & 0.722 \\
\hline \multirow{2}{*}{ Carex bushii Mack. } & \multirow{2}{*}{ Spring 2007} & 1.250 & 0.500 & 0.500 & 3.250 & 0.500 & 0.250 \\
\hline & & 1.287 & 0.973 & 0.973 & 5.786 & 0.973 & 0.722 \\
\hline \multirow{2}{*}{ Carex crinita var. crinita } & \multirow{2}{*}{ Spring 2007} & 1.500 & 0.250 & 0.250 & & 0.250 & 0.750 \\
\hline & & 4.331 & 0.722 & 0.722 & & 0.722 & 1.137 \\
\hline \multirow{2}{*}{ Carex debilis Michx. var. rudgei L. Bailey } & \multirow{2}{*}{ Spring 2007} & 4.000 & 0.500 & 6.750 & 3.500 & 1.250 & 2.250 \\
\hline & & 5.573 & 4.382 & 7.458 & 5.725 & 1.287 & 4.286 \\
\hline
\end{tabular}




\begin{tabular}{|c|c|c|c|c|c|c|c|}
\hline & & \multicolumn{2}{|c|}{ Early } & \multicolumn{2}{|c|}{ Late } & \multicolumn{2}{|c|}{ Continuous } \\
\hline & & Fenced & Control & Fenced & Control & Fenced & Control \\
\hline & & $\bar{x}$ & $\bar{x}$ & $\bar{x}$ & $\bar{x}$ & $\bar{x}$ & $\bar{x}$ \\
\hline & & SD & $\mathrm{SD}$ & $\mathrm{SD}$ & SD & SD & SD \\
\hline \multirow{2}{*}{ Carex folliculata $\mathrm{L}$. } & \multirow{2}{*}{ Spring 2007} & & & 0.250 & 0.750 & 0.250 & \\
\hline & & & & 0.722 & 1.137 & 0.722 & \\
\hline \multirow{2}{*}{ Carex grascilescens Steud. } & \multirow{2}{*}{ Spring 2007} & & & 0.250 & 0.500 & 0.250 & \\
\hline & & & & 0.722 & 0.973 & 0.722 & \\
\hline \multirow{2}{*}{ Carex scoparia Schkuhr ex Willd. var. scoparia } & \multirow{2}{*}{ Spring 2007} & 0.500 & 0.500 & 0.500 & & 0.500 & 2.250 \\
\hline & & 0.973 & 0.973 & 0.973 & & 0.973 & 4.286 \\
\hline \multirow{2}{*}{ Carex stipata Muhl. } & \multirow{2}{*}{ Spring 2007} & 0.250 & & & & 0.250 & 0.250 \\
\hline & & 0.722 & & & & 0.722 & 0.722 \\
\hline \multirow{2}{*}{ Carex striata Michx. } & \multirow{2}{*}{ Spring 2007} & & & & & & 0.250 \\
\hline & & & & & & & 0.722 \\
\hline \multirow{2}{*}{ Carex vulpinoidea Michx. } & \multirow{2}{*}{ Spring 2007} & & 2.000 & 3.750 & 6.750 & & 0.250 \\
\hline & & & 4.382 & 1.825 & 11.586 & & 0.722 \\
\hline \multirow{2}{*}{ Crataegus spp. } & \multirow{2}{*}{ Spring 2007} & 0.250 & 0.500 & 0.250 & & 0.500 & 1.750 \\
\hline & & 0.722 & 0.973 & 0.722 & & 0.973 & 4.325 \\
\hline \multirow{2}{*}{ Danthonia compressa Aust. } & \multirow{2}{*}{ Spring 2007} & 4.000 & 8.750 & 1.750 & 1.500 & 2.000 & 1.500 \\
\hline & & 5.573 & 11.454 & 14.478 & 14.597 & 4.382 & 11.367 \\
\hline \multirow{2}{*}{ Dichanthelium clandestinum (L.) Gould } & \multirow{2}{*}{ Spring 2007} & 3.250 & 3.750 & 7.750 & 9.750 & 8.000 & 11.000 \\
\hline & & 5.786 & 6.495 & 18.168 & 18.317 & 7.412 & 14.355 \\
\hline \multirow{2}{*}{$\begin{array}{l}\text { Doellingeria umbellata (P. Mill.) Nees var. } \\
\text { umbellata }\end{array}$} & \multirow{2}{*}{ Spring 2007} & 14.750 & 7.250 & 7.750 & 3.250 & 14.750 & 4.500 \\
\hline & & 21.822 & 22.347 & 7.647 & 5.272 & 16.457 & 5.384 \\
\hline \multirow{2}{*}{ Euthamia graminifolia L. Nutt. var. graminifolia } & \multirow{2}{*}{ Spring 2007} & 5.000 & 2.750 & 4.000 & 1.750 & 5.250 & 2.750 \\
\hline & & 6.646 & 4.191 & 6.381 & 1.287 & 11.586 & 4.191 \\
\hline \multirow{2}{*}{ Fragaria virginiana Duchesne } & \multirow{2}{*}{ Spring 2007} & 0.250 & & & 0.250 & & \\
\hline & & 0.722 & & & 0.722 & & \\
\hline
\end{tabular}




\begin{tabular}{|c|c|c|c|c|c|c|c|}
\hline & & \multicolumn{2}{|c|}{ Early } & \multicolumn{2}{|c|}{ Late } & \multicolumn{2}{|c|}{ Continuous } \\
\hline & & $\begin{array}{c}\text { Fenced } \\
\bar{x} \\
\text { SD } \\
\end{array}$ & $\begin{array}{c}\text { Control } \\
\bar{x} \\
\mathrm{SD} \\
\end{array}$ & $\begin{array}{c}\text { Fenced } \\
\bar{x} \\
\mathrm{SD} \\
\end{array}$ & $\begin{array}{c}\text { Control } \\
\bar{x} \\
\mathrm{SD} \\
\end{array}$ & $\begin{array}{c}\text { Fenced } \\
\bar{x} \\
\text { SD }\end{array}$ & $\begin{array}{c}\text { Control } \\
\bar{x} \\
\text { SD }\end{array}$ \\
\hline Galium tinctorium (L.) Scop. & Spring 2007 & & & & & $\begin{array}{l}0.250 \\
0.722\end{array}$ & $\begin{array}{l}0.250 \\
0.722\end{array}$ \\
\hline Glyceria striata (Lam.) Hitchc. & Spring 2007 & & & $\begin{array}{l}0.250 \\
0.722\end{array}$ & & & \\
\hline Hieracium aurantiacum $\mathrm{L}$. & Spring 2007 & $\begin{array}{l}0.500 \\
0.973\end{array}$ & & $\begin{array}{l}0.250 \\
0.722\end{array}$ & & & $\begin{array}{l}0.250 \\
0.722\end{array}$ \\
\hline Hieracium praealtum Vill. ex Gochnat & Spring 2007 & & $\begin{array}{l}0.250 \\
0.722\end{array}$ & & & & \\
\hline Holcus lanatus L. & Spring 2007 & & & $\begin{array}{l}0.250 \\
0.722\end{array}$ & & & \\
\hline Houstonia caerulea $\mathrm{L}$. & Spring 2007 & & & & $\begin{array}{l}0.250 \\
0.722\end{array}$ & & \\
\hline Hypericum densiflorum Pursh & Spring 2007 & $\begin{array}{l}0.250 \\
0.722\end{array}$ & $\begin{array}{l}1.500 \\
4.331\end{array}$ & $\begin{array}{l}1.500 \\
4.331\end{array}$ & & $\begin{array}{l}0.250 \\
0.722\end{array}$ & \\
\hline Hypericum ellipticum Hook. & Spring 2007 & $\begin{array}{l}0.250 \\
0.722\end{array}$ & & & & & \\
\hline Juncus effusus L. & Spring 2007 & $\begin{array}{l}0.250 \\
0.722\end{array}$ & $\begin{array}{l}0.250 \\
0.722\end{array}$ & $\begin{array}{l}0.250 \\
0.722\end{array}$ & $\begin{array}{l}0.250 \\
0.722\end{array}$ & $\begin{array}{l}0.500 \\
0.973\end{array}$ & $\begin{array}{l}0.500 \\
0.973\end{array}$ \\
\hline Luzula bulbosa (Alph. Wood) & Spring 2007 & $\begin{array}{l}0.250 \\
0.722 \\
\end{array}$ & & $\begin{array}{l}0.250 \\
0.722 \\
\end{array}$ & & $\begin{array}{l}0.250 \\
0.722 \\
\end{array}$ & $\begin{array}{l}0.250 \\
0.722 \\
\end{array}$ \\
\hline
\end{tabular}




\begin{tabular}{|c|c|c|c|c|c|c|c|}
\hline & & \multicolumn{2}{|c|}{ Early } & \multicolumn{2}{|c|}{ Late } & \multicolumn{2}{|c|}{ Continuous } \\
\hline & & Fenced & Control & Fenced & Control & Fenced & Control \\
\hline & & $\bar{x}$ & $\bar{x}$ & $\bar{x}$ & $\bar{x}$ & $\bar{x}$ & $\bar{x}$ \\
\hline & & $\mathrm{SD}$ & $\mathrm{SD}$ & SD & SD & SD & $\mathrm{SD}$ \\
\hline \multirow{2}{*}{ Lysmachia spp. } & \multirow{2}{*}{ Spring 2007} & 0.250 & 0.250 & & & & 0.500 \\
\hline & & 0.722 & 0.722 & & & & 0.973 \\
\hline \multirow{2}{*}{ Packera aurea (L.) A.\&D. Löve } & \multirow{2}{*}{ Spring 2007} & 0.250 & & & & & \\
\hline & & 0.722 & & & & & \\
\hline \multirow{2}{*}{ Poa trivialis L. } & \multirow{2}{*}{ Spring 2007} & 0.250 & 0.250 & & & & 1.500 \\
\hline & & 0.722 & 0.722 & & & & 4.331 \\
\hline \multirow{2}{*}{ Polygonum sagittatum L. } & \multirow{2}{*}{ Spring 2007} & & 0.500 & & 0.250 & 0.250 & \\
\hline & & & 0.973 & & 0.722 & 0.722 & \\
\hline \multirow{2}{*}{ Populus tremuloides Michx. } & \multirow{2}{*}{ Spring 2007} & 22.750 & 13.750 & 19.000 & 12.000 & 22.250 & 13.750 \\
\hline & & 13.291 & 17.237 & 23.366 & 15.489 & 16.196 & 12.193 \\
\hline \multirow{2}{*}{ Potentilla simplex Michx. } & \multirow{2}{*}{ Spring 2007} & 9.250 & 2.750 & 6.750 & 1.500 & 5.000 & 3.750 \\
\hline & & 11.153 & 4.191 & 7.458 & 1.356 & 7.138 & 5.653 \\
\hline \multirow{2}{*}{ Prunus serotina Ehrh. } & \multirow{2}{*}{ Spring 2007} & & & 0.250 & 0.250 & & \\
\hline & & & & 0.722 & 0.722 & & \\
\hline \multirow{2}{*}{ Pteridium aquilinum (L.) Kuhn } & \multirow{2}{*}{ Spring 2007} & 1.750 & 3.500 & 3.000 & 0.250 & 3.750 & 2.000 \\
\hline & & 4.325 & 5.725 & 5.839 & 0.722 & 1.825 & 4.382 \\
\hline \multirow{2}{*}{ Ranunculus acris L. var. acris } & \multirow{2}{*}{ Spring 2007} & 3.500 & 6.750 & 4.750 & 0.750 & 0.750 & 1.000 \\
\hline & & 5.725 & 11.586 & 6.696 & 1.137 & 1.137 & 1.239 \\
\hline \multirow{2}{*}{ Rubus hispidus L. } & \multirow{2}{*}{ Spring 2007} & 2.500 & 17.750 & 8.750 & 11.750 & 17.250 & 11.500 \\
\hline & & 23.618 & 15.625 & 23.557 & 15.126 & 2.431 & 16.765 \\
\hline \multirow{2}{*}{ Scirpus spp. } & \multirow{2}{*}{ Spring 2007} & & 0.250 & & & & \\
\hline & & & 0.722 & & & & \\
\hline \multirow{2}{*}{ Solidago rugosa Mill. } & \multirow{2}{*}{ Spring 2007} & 15.000 & 14.250 & 5.250 & 6.500 & 17.250 & 7.750 \\
\hline & & 18.478 & 13.615 & 6.495 & 5.823 & 18.969 & 7.647 \\
\hline
\end{tabular}




\begin{tabular}{|c|c|c|c|c|c|c|c|}
\hline & & \multicolumn{2}{|c|}{ Early } & \multicolumn{2}{|c|}{ Late } & \multicolumn{2}{|c|}{ Continuous } \\
\hline & & Fenced & Control & Fenced & Control & Fenced & Control \\
\hline & & $\bar{x}$ & $\bar{x}$ & $\bar{x}$ & $\bar{x}$ & $\bar{x}$ & $\bar{x}$ \\
\hline & & SD & $\mathrm{SD}$ & SD & SD & SD & SD \\
\hline \multirow{2}{*}{ Solidago uliginosa Nutt. } & \multirow{2}{*}{ Spring 2007} & 4.500 & 2.250 & 2.000 & 3.250 & 1.000 & 0.250 \\
\hline & & 7.385 & 4.286 & 5.725 & 5.786 & 1.239 & 0.722 \\
\hline \multirow{2}{*}{ Spiraea alba Du Roi } & \multirow{2}{*}{ Spring 2007} & 1.750 & 0.250 & 5.750 & 1.750 & 0.500 & 3.750 \\
\hline & & 4.325 & 0.722 & 11.153 & 4.325 & 0.973 & 5.653 \\
\hline \multirow{2}{*}{ Symphyotrichum praealtum } & \multirow{2}{*}{ Spring 2007} & & & 0.500 & & 0.250 & \\
\hline & & & & 0.973 & & 0.722 & \\
\hline \multirow{2}{*}{ Trifolium repens $\mathrm{L}$. } & \multirow{2}{*}{ Spring 2007} & 1.500 & & & 0.250 & 0.250 & \\
\hline & & 4.331 & & & 0.722 & 0.722 & \\
\hline \multirow{2}{*}{ Vaccinium myrtilloides Michx. } & \multirow{2}{*}{ Spring 2007} & 0.500 & 0.500 & & 1.750 & & 1.500 \\
\hline & & 0.973 & 0.973 & & 4.325 & & 4.331 \\
\hline \multirow{2}{*}{$\begin{array}{l}\text { Viburnum nudum L. var. cassinoides Torr. \& } \\
\text { Gray }\end{array}$} & \multirow{2}{*}{ Spring 2007} & 0.250 & 0.250 & 0.250 & 0.250 & 0.500 & 0.250 \\
\hline & & 0.722 & 0.722 & 0.722 & 0.722 & 0.973 & 0.722 \\
\hline \multirow{2}{*}{ Viburnum recognitum Fernald } & \multirow{2}{*}{ Spring 2007} & 0.250 & & & & 0.250 & \\
\hline & & 0.722 & & & & 0.722 & \\
\hline \multirow{2}{*}{ Achillea millefolium L. var. occidentalis DC } & \multirow{2}{*}{ Fall 2007} & 0.000 & 0.250 & 0.000 & 0.000 & 0.000 & 0.000 \\
\hline & & 0.000 & 0.722 & 0.000 & 0.000 & 0.000 & 0.000 \\
\hline \multirow{2}{*}{ Ageratina altissima (L.) King \& H. Rob. } & \multirow{2}{*}{ Fall 2007} & 14.250 & 5.250 & 2.750 & 6.500 & 28.500 & 3.750 \\
\hline & & 16.450 & 7.458 & 13.461 & 7.138 & 22.262 & 6.495 \\
\hline \multirow{2}{*}{ Agrostis gigantea Roth } & \multirow{2}{*}{ Fall 2007} & 1.250 & 2.000 & 0.750 & 0.500 & 2.250 & 1.500 \\
\hline & & 0.722 & 4.331 & 0.000 & 0.722 & 0.000 & 4.331 \\
\hline \multirow{2}{*}{ Agrostis perennans (Walt) Tuckerman } & \multirow{2}{*}{ Fall 2007} & 1.000 & 0.500 & 0.000 & 1.500 & 2.750 & 3.000 \\
\hline & & 1.239 & 0.973 & 0.000 & 4.331 & 4.191 & 5.839 \\
\hline \multirow{2}{*}{ Agrostis hyemalis (Walt.) B.S.P. } & \multirow{2}{*}{ Fall 2007} & 0.000 & 0.000 & 0.000 & 0.250 & 0.000 & 0.000 \\
\hline & & 0.000 & 0.000 & 0.000 & 0.722 & 0.000 & 0.000 \\
\hline
\end{tabular}




\begin{tabular}{|c|c|c|c|c|c|c|c|}
\hline & & \multicolumn{2}{|c|}{ Early } & \multicolumn{2}{|c|}{ Late } & \multicolumn{2}{|c|}{ Continuous } \\
\hline & & $\begin{array}{c}\text { Fenced } \\
\bar{x} \\
\mathrm{SD} \\
\end{array}$ & $\begin{array}{c}\text { Control } \\
\bar{x} \\
\text { SD } \\
\end{array}$ & $\begin{array}{c}\text { Fenced } \\
\bar{x} \\
\text { SD } \\
\end{array}$ & $\begin{array}{c}\text { Control } \\
\bar{x} \\
\text { SD } \\
\end{array}$ & $\begin{array}{c}\text { Fenced } \\
\bar{x} \\
\mathrm{SD} \\
\end{array}$ & $\begin{array}{c}\text { Control } \\
\bar{x} \\
\mathrm{SD} \\
\end{array}$ \\
\hline Amelanchier spp. & Fall 2007 & & & $\begin{array}{l}0.250 \\
0.722\end{array}$ & & & \\
\hline Anthoxanthum odoratum L. & Fall 2007 & $\begin{array}{l}9.750 \\
7.240\end{array}$ & $\begin{array}{c}9.250 \\
11.254\end{array}$ & $\begin{array}{l}6.250 \\
1.999\end{array}$ & $\begin{array}{l}5.250 \\
6.495\end{array}$ & $\begin{array}{c}6.000 \\
11.782\end{array}$ & $\begin{array}{l}6.250 \\
7.266\end{array}$ \\
\hline Apocynum cannabinum $\mathrm{L}$. & Fall 2007 & & & & & $\begin{array}{l}0.250 \\
0.722\end{array}$ & $\begin{array}{l}0.250 \\
0.722\end{array}$ \\
\hline $\begin{array}{l}\text { Brachyelytrum erectum (Schreb. ex Spreng.) P. } \\
\text { Beauv. }\end{array}$ & Fall 2007 & & & & & & \\
\hline Bromus kalmii Gray & Fall 2007 & & & & $\begin{array}{l}0.250 \\
0.722\end{array}$ & & $\begin{array}{l}0.250 \\
0.722\end{array}$ \\
\hline Calamagrostis canadensis (Michx.) Beauv. & Fall 2007 & $\begin{array}{l}0.250 \\
0.722\end{array}$ & $\begin{array}{l}1.500 \\
4.331\end{array}$ & $\begin{array}{l}1.500 \\
4.331\end{array}$ & $\begin{array}{l}3.750 \\
1.825\end{array}$ & $\begin{array}{l}3.750 \\
1.825\end{array}$ & $\begin{array}{c}6.250 \\
18.422\end{array}$ \\
\hline Carex bushii Mack. & Fall 2007 & & & & $\begin{array}{l}0.250 \\
0.722\end{array}$ & & \\
\hline Carex crinita var. crinita & Fall 2007 & & & $\begin{array}{l}1.500 \\
4.331\end{array}$ & $\begin{array}{l}0.250 \\
0.722\end{array}$ & & \\
\hline Carex debilis Michx. var. rudgei L. Bailey & Fall 2007 & $\begin{array}{l}0.500 \\
0.973\end{array}$ & $\begin{array}{l}1.500 \\
4.331\end{array}$ & $\begin{array}{l}0.750 \\
1.137\end{array}$ & $\begin{array}{l}0.250 \\
0.722\end{array}$ & $\begin{array}{l}0.500 \\
0.973\end{array}$ & $\begin{array}{l}0.250 \\
0.722\end{array}$ \\
\hline Carex folliculata $\mathrm{L}$. & Fall 2007 & & & & $\begin{array}{l}0.250 \\
0.722\end{array}$ & $\begin{array}{l}0.500 \\
0.973\end{array}$ & $\begin{array}{l}0.250 \\
0.722\end{array}$ \\
\hline Carex hirsutella Mack. & Fall 2007 & $\begin{array}{l}0.250 \\
0.722\end{array}$ & $\begin{array}{l}0.250 \\
0.722\end{array}$ & & $\begin{array}{l}0.250 \\
0.722\end{array}$ & & \\
\hline Carex leptalea Wahl. ssp. leptalea & Fall 2007 & $\begin{array}{l}0.250 \\
0.722\end{array}$ & & $\begin{array}{l}0.250 \\
0.722\end{array}$ & & $\begin{array}{l}0.250 \\
0.722\end{array}$ & $\begin{array}{l}0.250 \\
0.722\end{array}$ \\
\hline
\end{tabular}




\begin{tabular}{|c|c|c|c|c|c|c|c|}
\hline & & \multicolumn{2}{|c|}{ Early } & \multicolumn{2}{|c|}{ Late } & \multicolumn{2}{|c|}{ Continuous } \\
\hline & & Fenced & Control & Fenced & Control & Fenced & Control \\
\hline & & $\bar{x}$ & $\bar{x}$ & $\bar{x}$ & $\bar{x}$ & $\bar{x}$ & $\bar{x}$ \\
\hline & & $\mathrm{SD}$ & $\mathrm{SD}$ & $\mathrm{SD}$ & $\mathrm{SD}$ & SD & SD \\
\hline \multirow{2}{*}{ Carex lurida Wahl. } & \multirow{2}{*}{ Fall 2007} & 0.250 & 0.250 & 0.250 & 0.250 & 0.250 & 0.500 \\
\hline & & 0.722 & 0.722 & 0.722 & 0.722 & 0.722 & 0.973 \\
\hline \multirow{2}{*}{ Carex scoparia Schkuhr ex Willd. var. scoparia } & \multirow{2}{*}{ Fall 2007} & 0.250 & 0.500 & 0.250 & 0.500 & 2.000 & 0.250 \\
\hline & & 0.722 & 0.973 & 0.722 & 0.973 & 4.382 & 0.722 \\
\hline \multirow{2}{*}{ Carex stipata Muhl. } & \multirow{2}{*}{ Fall 2007} & & 1.500 & & & & \\
\hline & & & 4.331 & & & & \\
\hline \multirow{2}{*}{ Carex vulpinoidea Michx. } & \multirow{2}{*}{ Fall 2007} & 0.250 & 0.250 & 0.500 & 3.000 & 0.500 & 1.500 \\
\hline & & 0.722 & 0.722 & 0.973 & 5.839 & 0.973 & 4.331 \\
\hline \multirow{2}{*}{ Crataegus spp. } & \multirow{2}{*}{ Fall 2007} & 0.250 & 0.250 & 1.500 & & 1.750 & 0.500 \\
\hline & & 0.722 & 0.722 & 4.331 & & 4.325 & 0.973 \\
\hline \multirow{2}{*}{ Danthonia compressa Aust. } & \multirow{2}{*}{ Fall 2007} & 6.750 & 11.250 & 8.250 & 12.000 & 5.500 & 5.500 \\
\hline & & 11.586 & 11.586 & 7.240 & 14.426 & 6.381 & 11.223 \\
\hline \multirow{2}{*}{ Dichanthelium clandestinum (L.) Gould } & \multirow{2}{*}{ Fall 2007} & 2.750 & 6.000 & 5.750 & 11.000 & 12.750 & 14.250 \\
\hline & & 4.191 & 7.385 & 11.153 & 18.383 & 13.986 & 17.623 \\
\hline \multirow{2}{*}{$\begin{array}{l}\text { Doellingeria umbellata (P. Mill.) Nees var. } \\
\text { umbellata }\end{array}$} & \multirow{2}{*}{ Fall 2007} & 16.000 & 17.000 & 14.250 & 6.500 & 17.750 & 7.000 \\
\hline & & 16.667 & 12.673 & 14.886 & 7.412 & 14.360 & 6.853 \\
\hline \multirow{2}{*}{ Glyceria striata (Lam.) Hitchc. } & \multirow{2}{*}{ Fall 2007} & & 0.250 & & & & \\
\hline & & & 0.722 & & & & \\
\hline \multirow{2}{*}{ Hieracium aurantiacum $\mathrm{L}$. } & \multirow{2}{*}{ Fall 2007} & & & & & 0.722 & \\
\hline & & & & & & 0.250 & \\
\hline \multirow{2}{*}{ Hypericum densiflorum Pursh } & \multirow{2}{*}{ Fall 2007} & 1.500 & 0.250 & 3.750 & 1.500 & 1.500 & \\
\hline & & 4.331 & 0.722 & 1.825 & 4.331 & 4.331 & \\
\hline
\end{tabular}




\begin{tabular}{|c|c|c|c|c|c|c|c|}
\hline & & \multicolumn{2}{|c|}{ Early } & \multicolumn{2}{|c|}{ Late } & \multicolumn{2}{|c|}{ Continuous } \\
\hline & & Fenced & Control & Fenced & Control & Fenced & Control \\
\hline & & $\bar{x}$ & $\bar{x}$ & $\bar{x}$ & $\bar{x}$ & $\bar{x}$ & $\bar{x}$ \\
\hline & & SD & SD & SD & SD & SD & SD \\
\hline \multirow{2}{*}{ Lycopus virginicus L. } & \multirow{2}{*}{ Fall 2007} & 0.250 & 1.500 & 0.500 & 1.500 & 1.750 & 1.500 \\
\hline & & 0.722 & 4.331 & 0.973 & 4.331 & 4.325 & 4.331 \\
\hline \multirow{2}{*}{ Mimulus ringens var. ringens } & \multirow{2}{*}{ Fall 2007} & & & & & & 0.250 \\
\hline & & & & & & & 0.722 \\
\hline \multirow{2}{*}{ Oclemena acuminata (Michx.) Greene } & \multirow{2}{*}{ Fall 2007} & & & & 1.500 & & \\
\hline & & & & & 4.331 & & \\
\hline \multirow{2}{*}{ Panicum spp. } & \multirow{2}{*}{ Fall 2007} & & 0.500 & & 0.250 & & 0.250 \\
\hline & & & 0.973 & & 0.722 & & 0.722 \\
\hline \multirow{2}{*}{ Polygonum sagittatum L. } & \multirow{2}{*}{ Fall 2007} & & & & 0.250 & & \\
\hline & & 0.722 & & & & & \\
\hline \multirow{2}{*}{ Populus tremuloides Michx. } & \multirow{2}{*}{ Fall 2007} & 0.250 & & & & & \\
\hline & & 2.173 & 9.621 & 21.822 & 6.853 & 18.682 & 6.696 \\
\hline \multirow{2}{*}{ Potentilla canadensis L. } & \multirow{2}{*}{ Fall 2007} & 45.500 & 16.250 & 24.750 & 7.000 & 39.000 & 5.750 \\
\hline & & 11.423 & 5.653 & 5.384 & 1.239 & 11.423 & 4.242 \\
\hline \multirow{2}{*}{ Potentilla simplex Michx. } & \multirow{2}{*}{ Fall 2007} & 11.500 & 3.750 & 3.000 & 1.000 & 1.000 & 2.500 \\
\hline & & & & & & 0.722 & \\
\hline \multirow{2}{*}{ Pteridium aquilinum (L.) Kuhn } & \multirow{2}{*}{ Fall 2007} & & & & & 0.250 & \\
\hline & & & & & & 4.325 & \\
\hline \multirow{2}{*}{ Ranunculus acris L. var. acris } & \multirow{2}{*}{ Fall 2007} & 4.500 & 3.750 & 2.250 & 3.750 & 1.750 & \\
\hline & & 5.786 & 0.973 & 4.286 & 0.973 & 4.382 & \\
\hline
\end{tabular}




\begin{tabular}{|c|c|c|c|c|c|c|c|}
\hline & & \multicolumn{2}{|c|}{ Early } & \multicolumn{2}{|c|}{ Late } & \multicolumn{2}{|c|}{ Continuous } \\
\hline & & Fenced & Control & Fenced & Control & Fenced & Control \\
\hline & & $\bar{x}$ & $\bar{x}$ & $\bar{x}$ & $\bar{x}$ & $\bar{x}$ & $\bar{x}$ \\
\hline & & $\mathrm{SD}$ & $\mathrm{SD}$ & $\mathrm{SD}$ & $\mathrm{SD}$ & SD & SD \\
\hline \multirow{2}{*}{ Rubus hispidus L. } & \multirow{2}{*}{ Fall 2007} & 3.250 & 0.500 & 2.250 & 0.500 & 2.000 & 0.750 \\
\hline & & 17.270 & 12.437 & 23.537 & 11.863 & 18.273 & 9.324 \\
\hline \multirow{2}{*}{ Rumex acetosella L. } & \multirow{2}{*}{ Fall 2007} & 32.000 & 15.750 & 36.000 & 17.000 & 32.000 & 15.000 \\
\hline & & 17.567 & 9.266 & 18.468 & 5.696 & 17.138 & 5.722 \\
\hline \multirow{2}{*}{ Solidago rugosa Mill. } & \multirow{2}{*}{ Fall 2007} & & 0.250 & & & & 0.250 \\
\hline & & 2.992 & 14.886 & 21.289 & 1.470 & 22.734 & 13.533 \\
\hline \multirow{2}{*}{ Solidago uliginosa Nutt. } & \multirow{2}{*}{ Fall 2007} & 17.250 & 16.500 & 2.750 & 13.750 & 22.750 & 1.000 \\
\hline & & 14.597 & 7.266 & 11.447 & 6.696 & 7.138 & 5.725 \\
\hline \multirow{2}{*}{ Spiraea alba Du Roi } & \multirow{2}{*}{ Fall 2007} & 1.500 & 4.750 & 5.750 & 4.750 & 6.500 & 3.500 \\
\hline & & 0.722 & 4.325 & 4.286 & 4.382 & 5.839 & 4.191 \\
\hline Stellaria spp. & Fall 2007 & 0.250 & 1.750 & 2.250 & 2.000 & 3.000 & 2.750 \\
\hline \multirow{2}{*}{ Symphyotrichum lateriflorum (L.) } & \multirow{2}{*}{ Fall 2007} & & & & & & 0.250 \\
\hline & & & & & & & 0.722 \\
\hline \multirow{2}{*}{$\begin{array}{l}\text { Symphyotrichum puniceum L. Nesom var. } \\
\text { puniceum }\end{array}$} & \multirow{2}{*}{ Fall 2007} & 0.750 & 0.250 & 0.500 & 0.250 & 1.500 & \\
\hline & & 1.137 & 0.722 & 0.973 & 0.722 & 4.331 & \\
\hline \multirow{2}{*}{ Vaccinium pallidum Ait. } & \multirow{2}{*}{ Fall 2007} & & 0.500 & 0.250 & 0.500 & & \\
\hline & & & 0.973 & 0.722 & 0.973 & & \\
\hline \multirow{2}{*}{$\begin{array}{l}\text { Viburnum nudum L. var. cassinoides Torr. \& } \\
\text { Gray }\end{array}$} & \multirow{2}{*}{ Fall 2007} & 0.500 & 0.750 & & 0.250 & 3.250 & 0.250 \\
\hline & & 0.973 & 1.137 & & 0.722 & 5.786 & 0.722 \\
\hline \multirow{2}{*}{ Violet spp. } & \multirow{2}{*}{ Fall 2007} & & & 1.750 & 0.250 & 0.250 & \\
\hline & & & & 4.325 & 0.722 & 0.722 & \\
\hline
\end{tabular}


Appendix 6. Mean and standard deviation of stem densities for species observed in the ground cover in West Virginia Division of Natural Resource deer exclosure plots and corresponding control plots, $1984-2007$.

\begin{tabular}{|c|c|c|c|c|c|c|}
\hline & \multicolumn{2}{|c|}{ Year 1} & \multicolumn{2}{|c|}{ Year 3} & \multicolumn{2}{|c|}{ Year 6} \\
\hline & Fenced & Control & Fenced & Control & Fenced & Control \\
\hline & $\bar{x}$ & $\bar{x}$ & $\bar{x}$ & $\bar{x}$ & $\bar{x}$ & $\bar{x}$ \\
\hline & $\mathrm{SD}$ & $\mathrm{SD}$ & SD & $\mathrm{SD}$ & $\mathrm{SD}$ & $\mathrm{SD}$ \\
\hline \multirow{2}{*}{ Agrimonia spp. } & & 0.585 & & 0.433 & & 0.819 \\
\hline & & 0.248 & & 0.173 & & 0.347 \\
\hline \multirow{2}{*}{ Acer pensylvanicum $\mathrm{L}$. } & 0.643 & 0.359 & 0.864 & 0.265 & 0.762 & 0.526 \\
\hline & 0.175 & 0.185 & 0.239 & 0.572 & 0.250 & 0.152 \\
\hline \multirow{2}{*}{ Acer rubrum L. } & 1.456 & 3.316 & 2.556 & 2.754 & 2.958 & 4.544 \\
\hline & 2.276 & 7.952 & 2.796 & 4.815 & 4.640 & 1.813 \\
\hline \multirow{2}{*}{ Acer saccharum Marshall } & 0.292 & 0.153 & 0.679 & 0.185 & 0.153 & 0.199 \\
\hline & 0.195 & 0.397 & 0.182 & 0.547 & 0.232 & 0.596 \\
\hline \multirow{2}{*}{ Acer spicatum Lam. } & & & & & 0.494 & 0.718 \\
\hline & & & & & 0.174 & 0.298 \\
\hline Achillea millefolium L. var. puberula (Rydb.) & 0.468 & & & & & \\
\hline Nobs & 0.198 & & & & & \\
\hline \multirow{2}{*}{ Actaea racemosa $\mathrm{L}$. } & & & 0.374 & 0.123 & & \\
\hline & & & 0.128 & 0.495 & & \\
\hline \multirow{2}{*}{ Aesculus glabra Willd } & & & 0.617 & 0.123 & & \\
\hline & & & 0.255 & 0.495 & & \\
\hline \multirow{2}{*}{ Ageratina altissima (L.) King \& H. Rob. } & 0.129 & 0.494 & 0.222 & 0.825 & 0.333 & 0.544 \\
\hline & 0.448 & 0.150 & 0.578 & 0.176 & 1.379 & 2.261 \\
\hline \multirow{2}{*}{ Adiantum L. } & & 0.585 & & 0.617 & & \\
\hline & & 0.248 & & 0.248 & & \\
\hline \multirow{2}{*}{ Alcalypha virginica spp. L. } & 0.718 & 0.135 & 0.123 & 0.117 & 0.117 & 0.175 \\
\hline & 0.195 & 0.412 & 0.593 & 0.335 & 0.496 & 0.719 \\
\hline \multirow{2}{*}{ Allium tricoccum Aiton } & & 0.117 & & 0.617 & & \\
\hline & & 0.496 & & 0.248 & & \\
\hline
\end{tabular}




\begin{tabular}{|c|c|c|c|c|c|c|}
\hline & \multicolumn{2}{|c|}{ Year 1} & \multicolumn{2}{|c|}{ Year 3} & \multicolumn{2}{|c|}{ Year 6} \\
\hline & Fenced & Control & Fenced & Control & Fenced & Control \\
\hline & $\bar{x}$ & $\bar{x}$ & $\bar{x}$ & $\bar{x}$ & $\bar{x}$ & $\bar{x}$ \\
\hline & $\mathrm{SD}$ & SD & SD & SD & $\mathrm{SD}$ & $\mathrm{SD}$ \\
\hline \multirow{2}{*}{ Ambrosia artemisiifolia $\mathrm{L}$. } & 0.895 & & & & 0.585 & 0.117 \\
\hline & 3.567 & & & & 0.248 & 0.496 \\
\hline \multirow{2}{*}{ Amianthium muscitoxicum (Walter) A. Gray } & 0.123 & 0.526 & 0.386 & 0.386 & 0.164 & 0.526 \\
\hline & 0.521 & 0.223 & 1.273 & 0.124 & 0.695 & 0.223 \\
\hline \multirow{2}{*}{ Amelanchier arborea Michx. } & 0.234 & 0.152 & 0.444 & 0.149 & 0.494 & 0.494 \\
\hline & 0.579 & 0.346 & 1.625 & 0.369 & 0.150 & 0.133 \\
\hline \multirow{2}{*}{ Anemone virginiana $\mathrm{L}$. } & & & & & 0.158 & 0.292 \\
\hline & & & & & 0.464 & 0.125 \\
\hline \multirow{2}{*}{ Antennaria spp. Gaertn. } & 0.257 & 0.494 & 0.988 & 0.556 & 0.333 & 0.292 \\
\hline & 0.618 & 0.174 & 0.472 & 0.223 & 1.179 & 0.871 \\
\hline \multirow{2}{*}{ Aросупит spp. L. } & & & & & & 0.292 \\
\hline & & & & & & 0.125 \\
\hline \multirow{2}{*}{ Aralia nudicaulis $\mathrm{L}$. } & & & & & 0.585 & 0.585 \\
\hline & & & & & 0.248 & 0.248 \\
\hline \multirow{2}{*}{ Arisaema triphyllum $\mathrm{L}$. } & 0.345 & 0.246 & 0.636 & 0.414 & 0.682 & 0.146 \\
\hline & 1.269 & 0.943 & 1.312 & 0.736 & 1.642 & 0.325 \\
\hline \multirow{2}{*}{ Aronia melanocarpa Michx. } & & & & & 0.117 & \\
\hline & & & & & 0.496 & \\
\hline \multirow{2}{*}{ Asarum canadense L. } & 0.494 & 0.181 & 0.315 & 0.327 & 0.117 & 0.247 \\
\hline & 0.174 & 0.743 & 1.359 & 1.794 & 0.350 & 0.772 \\
\hline \multirow{2}{*}{ Asimina triloba (L.) Dunal } & 0.292 & 0.819 & 0.247 & 0.123 & 0.117 & 0.117 \\
\hline & 0.125 & 0.255 & 0.119 & 0.495 & 0.496 & 0.350 \\
\hline \multirow{2}{*}{$\begin{array}{l}\text { Asplenium platyneuron (L.) Britton, Sterns \& } \\
\text { Poggenb. }\end{array}$} & 0.585 & 0.292 & 0.123 & & 0.175 & 0.117 \\
\hline & 0.248 & 0.125 & 0.593 & & 0.744 & 0.496 \\
\hline
\end{tabular}




\begin{tabular}{|c|c|c|c|c|c|c|}
\hline & \multicolumn{2}{|c|}{ Year 1} & \multicolumn{2}{|c|}{ Year 3} & \multicolumn{2}{|c|}{ Year 6} \\
\hline & $\begin{array}{l}\text { Fenced } \\
\bar{x} \\
\text { SD } \\
\end{array}$ & $\begin{array}{c}\text { Control } \\
\bar{x} \\
\text { SD }\end{array}$ & $\begin{array}{c}\text { Fenced } \\
\bar{x} \\
\text { SD } \\
\end{array}$ & $\begin{array}{c}\text { Control } \\
\bar{x} \\
\text { SD } \\
\end{array}$ & $\begin{array}{c}\text { Fenced } \\
\bar{x} \\
\text { SD } \\
\end{array}$ & $\begin{array}{c}\text { Control } \\
\bar{x} \\
\text { SD } \\
\end{array}$ \\
\hline Betula spp. & $\begin{array}{l}0.877 \\
0.230\end{array}$ & $\begin{array}{l}0.936 \\
0.229\end{array}$ & $\begin{array}{l}0.456 \\
1.126\end{array}$ & $\begin{array}{l}0.247 \\
0.762\end{array}$ & $\begin{array}{l}0.287 \\
0.987\end{array}$ & $\begin{array}{l}0.263 \\
0.988\end{array}$ \\
\hline Botrychium virginianum (L.) Sw. & & & & & & $\begin{array}{l}0.585 \\
0.248\end{array}$ \\
\hline Botrychium spp. & & $\begin{array}{l}0.359 \\
0.125\end{array}$ & & $\begin{array}{l}0.433 \\
0.137\end{array}$ & $\begin{array}{l}0.175 \\
0.542\end{array}$ & $\begin{array}{l}0.585 \\
0.248\end{array}$ \\
\hline Bouteloua spp. Lag. & & & $\begin{array}{l}0.111 \\
0.458\end{array}$ & & & $\begin{array}{l}0.585 \\
0.248\end{array}$ \\
\hline Cardamine nuttallii Greene & $\begin{array}{l}0.994 \\
0.422\end{array}$ & $\begin{array}{l}0.292 \\
0.125\end{array}$ & & & & \\
\hline Carex spp. & $\begin{array}{l}0.614 \\
1.545\end{array}$ & $\begin{array}{l}0.538 \\
1.216\end{array}$ & $\begin{array}{l}0.299 \\
0.539\end{array}$ & $\begin{array}{l}1.825 \\
1.946\end{array}$ & $\begin{array}{l}0.696 \\
1.592\end{array}$ & $\begin{array}{l}0.668 \\
1.339\end{array}$ \\
\hline Carya spp. & $\begin{array}{l}0.123 \\
0.228\end{array}$ & $\begin{array}{l}0.129 \\
0.243\end{array}$ & $\begin{array}{l}0.148 \\
0.272\end{array}$ & $\begin{array}{l}0.117 \\
0.286\end{array}$ & $\begin{array}{l}0.158 \\
0.258\end{array}$ & $\begin{array}{l}0.158 \\
0.253\end{array}$ \\
\hline Cassia spp. L. & $\begin{array}{l}0.234 \\
0.992\end{array}$ & $\begin{array}{l}0.135 \\
0.576\end{array}$ & $\begin{array}{l}0.433 \\
0.178\end{array}$ & $\begin{array}{l}0.617 \\
0.248\end{array}$ & $\begin{array}{l}0.585 \\
0.248\end{array}$ & \\
\hline Castanea dentata (Marshall) Borkh. & $\begin{array}{l}0.175 \\
0.744\end{array}$ & & & & & \\
\hline Celastrus scandens L. & & & & & $\begin{array}{l}0.585 \\
0.248\end{array}$ & \\
\hline Centaurea nigra $\mathrm{L}$. & $\begin{array}{l}0.585 \\
0.248\end{array}$ & & & & & \\
\hline Cercis canadensis L. & 0.292 & 0.117 & 0.617 & 0.123 & 0.146 & 0.819 \\
\hline & 0.125 & 0.496 & 0.255 & 0.495 & 0.623 & 0.279 \\
\hline
\end{tabular}




\begin{tabular}{|c|c|c|c|c|c|c|}
\hline & \multicolumn{2}{|c|}{ Year 1} & \multicolumn{2}{|c|}{ Year 3} & \multicolumn{2}{|c|}{ Year 6} \\
\hline & Fenced & Control & Fenced & Control & Fenced & Control \\
\hline & $\bar{x}$ & $\bar{x}$ & $\bar{x}$ & $\bar{x}$ & $\bar{x}$ & $\bar{x}$ \\
\hline & $\mathrm{SD}$ & SD & SD & SD & $\mathrm{SD}$ & $\mathrm{SD}$ \\
\hline \multirow{2}{*}{ Chamaecrista fasciculata (Michx.) Greene } & 0.585 & 0.339 & 0.617 & 0.494 & 0.175 & 0.643 \\
\hline & 0.248 & 0.991 & 0.255 & 0.198 & 0.542 & 0.273 \\
\hline \multirow{2}{*}{ Chamerion angustifolium (L.) Holub } & & 0.585 & & & & \\
\hline & & 0.248 & & & & \\
\hline \multirow{2}{*}{ Chimaphila maculata (L.) Pursh } & 0.585 & 1.175 & 0.617 & & 0.117 & 0.585 \\
\hline & 0.248 & 4.987 & 0.255 & & 0.496 & 0.248 \\
\hline \multicolumn{7}{|l|}{ Chimaphila umbellata (L.) W.P.C. Barton } \\
\hline \multirow{2}{*}{ Chrysanthemum spp. L. } & 0.936 & & 0.617 & 0.123 & 0.359 & 0.585 \\
\hline & 0.397 & & 0.255 & 0.495 & 0.149 & 0.248 \\
\hline \multirow{2}{*}{ Clintonia borealis (Aiton) Raf. } & & 0.117 & 0.617 & & & \\
\hline & & 0.496 & 0.255 & & & \\
\hline \multirow{2}{*}{ Cornus florida $\mathrm{L}$. } & 0.515 & 0.251 & 0.414 & 0.235 & 0.333 & 0.152 \\
\hline & 1.951 & 0.664 & 1.394 & 0.525 & 0.787 & 0.273 \\
\hline \multirow{2}{*}{ Corylus americana Walter } & 0.359 & 0.585 & 0.617 & 0.247 & 0.175 & 0.585 \\
\hline & 0.185 & 0.223 & 0.255 & 0.999 & 0.744 & 0.248 \\
\hline \multirow{2}{*}{ Crataegus spp. } & 0.877 & 0.117 & 0.136 & 0.617 & 0.994 & 0.819 \\
\hline & 0.372 & 0.386 & 0.488 & 0.248 & 0.396 & 0.272 \\
\hline \multirow{2}{*}{ Daucus carota $\mathrm{L}$. } & 0.585 & & & & 0.229 & \\
\hline & 0.248 & & & & 0.968 & \\
\hline \multirow{2}{*}{ Dennstaedtia punctilobula (Michx.) T. Moore } & & & 0.679 & 0.926 & & \\
\hline & & & 0.280 & 0.372 & & \\
\hline \multirow{2}{*}{ Desmodium spp. } & 0.263 & 1.444 & 1.512 & 0.148 & 1.158 & 0.854 \\
\hline & 0.967 & 5.588 & 6.482 & 0.324 & 3.731 & 2.653 \\
\hline
\end{tabular}




\begin{tabular}{|c|c|c|c|c|c|c|}
\hline & \multicolumn{2}{|c|}{ Year 1} & \multicolumn{2}{|c|}{ Year 3} & \multicolumn{2}{|c|}{ Year 6} \\
\hline & Fenced & Control & Fenced & Control & Fenced & Control \\
\hline & $\bar{x}$ & $\bar{x}$ & $\bar{x}$ & $\bar{x}$ & $\bar{x}$ & $\bar{x}$ \\
\hline & $\mathrm{SD}$ & $\mathrm{SD}$ & $\mathrm{SD}$ & $\mathrm{SD}$ & $\mathrm{SD}$ & $\mathrm{SD}$ \\
\hline \multirow{2}{*}{ Dioscorea villosa L. } & 0.585 & 0.718 & 0.130 & 0.386 & 0.819 & 0.468 \\
\hline & 0.137 & 0.163 & 0.257 & 0.638 & 0.234 & 0.121 \\
\hline \multirow{2}{*}{ Dryopteris spp. L. } & 0.936 & 1.696 & 0.649 & 1.265 & 0.251 & \\
\hline & 2.729 & 5.595 & 2.184 & 3.620 & 1.669 & \\
\hline \multicolumn{7}{|l|}{ Elaeagnus umbellata Thunb. } \\
\hline \multirow{2}{*}{ Elymus hystrix L. } & 0.158 & 0.175 & & & & \\
\hline & 0.670 & 0.744 & & & & \\
\hline \multirow{2}{*}{ Epigaea repens L. } & & & 0.185 & & 0.175 & 0.117 \\
\hline & & & 0.764 & & 0.744 & 0.496 \\
\hline \multirow{2}{*}{ Euonymus alatus (Thunb.) Siebold } & 0.585 & 0.117 & & 0.123 & 0.468 & \\
\hline & 0.248 & 0.496 & & 0.495 & 0.198 & \\
\hline \multirow{2}{*}{ Euonymus americanus L. } & & & 0.747 & & & \\
\hline & & & 0.354 & & & \\
\hline \multirow{2}{*}{ Eutrochium purpureum (L.) E.E. Lamont } & & 0.117 & 0.185 & 0.617 & 0.468 & 0.494 \\
\hline & & 0.496 & 0.764 & 0.248 & 0.198 & 0.150 \\
\hline \multirow{2}{*}{ Eutrochium spp. } & & & 0.617 & & & \\
\hline & & & 0.255 & & & \\
\hline \multirow{2}{*}{ Fagus grandifolia Ehrh. } & 0.152 & 0.215 & 0.825 & 0.111 & 0.819 & 0.158 \\
\hline & 0.594 & 0.566 & 0.350 & 0.395 & 0.297 & 0.467 \\
\hline \multirow{2}{*}{ Fraxinus americana $\mathrm{L}}$. & 0.117 & 0.175 & 0.123 & 0.123 & 0.117 & 0.117 \\
\hline & 0.350 & 0.744 & 0.593 & 0.495 & 0.350 & 0.496 \\
\hline \multirow{2}{*}{ Galium spp. } & 0.819 & 0.175 & 0.747 & & 0.117 & 0.718 \\
\hline & 0.347 & 0.744 & 0.280 & & 0.496 & 0.277 \\
\hline
\end{tabular}




\begin{tabular}{|c|c|c|c|c|c|c|}
\hline & \multicolumn{2}{|c|}{ Year 1} & \multicolumn{2}{|c|}{ Year 3} & \multicolumn{2}{|c|}{ Year 6} \\
\hline & Fenced & Control & Fenced & Control & Fenced & Control \\
\hline & $\bar{x}$ & $\bar{x}$ & $\bar{x}$ & $\bar{x}$ & $\bar{x}$ & $\bar{x}$ \\
\hline & $\mathrm{SD}$ & $\mathrm{SD}$ & $\mathrm{SD}$ & $\mathrm{SD}$ & $\mathrm{SD}$ & $\mathrm{SD}$ \\
\hline \multirow{2}{*}{ Geranium spp. L. } & 0.111 & 0.234 & 0.111 & 0.926 & 0.359 & 0.123 \\
\hline & 0.351 & 0.992 & 0.219 & 0.256 & 0.995 & 0.342 \\
\hline \multirow{2}{*}{ Gaultheria procumbens L. } & 2.673 & 2.643 & 2.216 & 1.944 & 4.427 & 1.529 \\
\hline & 1.364 & 6.293 & 6.262 & 7.389 & 13.958 & 4.897 \\
\hline \multirow{2}{*}{ Gaylussacia spp. Kunth } & & & & & & 0.494 \\
\hline & & & & & & 0.174 \\
\hline \multirow{2}{*}{ Gaylussacia ursina (M.A. Curtis) Torr. } & 0.762 & 0.292 & 0.165 & 0.291 & 0.718 & 0.117 \\
\hline & 0.323 & 0.125 & 0.563 & 0.955 & 0.298 & 0.496 \\
\hline \multirow{2}{*}{ Geum spp. L. } & & 0.585 & & & & \\
\hline & & 0.248 & & & & \\
\hline \multirow{2}{*}{ Gillenia trifoliata (L.) Moench } & 0.234 & 0.585 & & 0.123 & & \\
\hline & 0.992 & 0.248 & & 0.495 & & \\
\hline \multirow{2}{*}{ Glycyrrhiza lepidota Pursh } & & & & & 0.585 & \\
\hline & & & & & 0.248 & \\
\hline \multirow{2}{*}{ Gnaphalium obtusifolium L. } & 0.292 & & & & & \\
\hline & 0.125 & & & & & \\
\hline \multirow{2}{*}{ Hamamelis virginiana $\mathrm{L}$. } & 0.234 & 0.117 & & 0.617 & 0.494 & 0.585 \\
\hline & 0.992 & 0.496 & & 0.248 & 0.195 & 0.248 \\
\hline \multirow{2}{*}{ Hedeoma pulegioides $\mathrm{L}$. } & 0.637 & & & & & \\
\hline & 2.744 & & & & & \\
\hline \multirow{2}{*}{$\begin{array}{l}\text { Hepatica nobilis Schreb. var. obtusa (Pursh) } \\
\text { Steyerm. }\end{array}$} & & & & 0.617 & & \\
\hline & & & & 0.248 & & \\
\hline \multirow{2}{*}{ Hieracium fendleri Sch. Bip } & & & & 0.617 & 0.117 & \\
\hline & & & & 0.248 & 0.496 & \\
\hline
\end{tabular}




\begin{tabular}{|c|c|c|c|c|c|c|c|}
\hline & & \multicolumn{2}{|c|}{ Year 1} & \multicolumn{2}{|c|}{ Year 3} & \multicolumn{2}{|c|}{ Year 6} \\
\hline & & Fenced & Control & Fenced & Control & Fenced & Control \\
\hline & & $\bar{x}$ & $\bar{x}$ & $\bar{x}$ & $\bar{x}$ & $\bar{x}$ & $\bar{x}$ \\
\hline & & SD & $\mathrm{SD}$ & SD & SD & SD & $\mathrm{SD}$ \\
\hline \multirow{2}{*}{\multicolumn{2}{|c|}{ Hieracium venosum $\mathrm{L}$. }} & & 0.135 & & & & 0.234 \\
\hline & & & 0.412 & & & & 0.992 \\
\hline \multirow{2}{*}{\multicolumn{2}{|c|}{ Houstonia canadensis Willd. ex Roem. \& Schult. }} & & & & 0.926 & & \\
\hline & & & & & 0.372 & & \\
\hline \multirow{2}{*}{\multicolumn{2}{|c|}{ Hymenocallis spp. Salisb. }} & 0.494 & & & & & \\
\hline & & 0.174 & & & & & \\
\hline \multirow{2}{*}{\multicolumn{2}{|c|}{ Hypericum punctatutm. L. }} & 0.427 & & & & 0.994 & 0.515 \\
\hline & & 1.785 & & & & 0.351 & 2.183 \\
\hline \multirow{2}{*}{ Hypericum prolificum $\mathrm{L}$. } & & 0.246 & & & & & 1.468 \\
\hline & & 1.425 & & & & & 4.441 \\
\hline \multirow{2}{*}{\multicolumn{2}{|c|}{ Juniperus virginiana $\mathrm{L}$}} & & & & & 0.585 & \\
\hline & & & & & & 0.248 & \\
\hline \multirow{2}{*}{\multicolumn{2}{|c|}{ Kalmia latifolia $\mathrm{L}}}$. & 0.247 & 0.368 & 0.396 & 0.778 & 0.222 & 0.215 \\
\hline & & 0.595 & 1.554 & 0.900 & 2.143 & 0.531 & 0.554 \\
\hline \multirow{2}{*}{\multicolumn{2}{|c|}{ Lespedeza spp. Michx. }} & 0.494 & & & & & 0.585 \\
\hline & & 0.174 & & & & & 0.248 \\
\hline \multirow{2}{*}{\multicolumn{2}{|c|}{ Lindera benzoin (L.) Blume }} & 0.292 & 0.679 & 0.386 & & & 0.359 \\
\hline & & 0.125 & 0.174 & 0.869 & & & 0.149 \\
\hline \multirow{2}{*}{ Liriodendron tulipifera $\mathrm{L}$. } & 0.585 & 0.585 & 0.747 & 0.617 & & 0.292 & 0.819 \\
\hline & 0.248 & 0.248 & 0.199 & 0.248 & & 0.195 & 0.129 \\
\hline \multirow{2}{*}{ Lobelia cardinalis L. } & 0.292 & & & & & & \\
\hline & 0.125 & & & & & & \\
\hline \multirow{2}{*}{ Lonicera japonica Thunb. } & 0.345 & 0.117 & 0.165 & 0.148 & & 0.936 & 1.287 \\
\hline & 1.464 & 0.496 & 0.563 & 0.595 & & 0.397 & 5.458 \\
\hline
\end{tabular}




\begin{tabular}{|c|c|c|c|c|c|c|}
\hline & \multicolumn{2}{|c|}{ Year 1} & \multicolumn{2}{|c|}{ Year 3} & \multicolumn{2}{|c|}{ Year 6} \\
\hline & $\begin{array}{c}\text { Fenced } \\
\bar{x} \\
\text { SD } \\
\end{array}$ & $\begin{array}{c}\text { Control } \\
\bar{x} \\
\text { SD } \\
\end{array}$ & $\begin{array}{c}\text { Fenced } \\
\bar{x} \\
\text { SD } \\
\end{array}$ & $\begin{array}{c}\text { Control } \\
\bar{x} \\
\text { SD } \\
\end{array}$ & $\begin{array}{c}\text { Fenced } \\
\bar{x} \\
\text { SD } \\
\end{array}$ & $\begin{array}{c}\text { Control } \\
\bar{x} \\
\text { SD } \\
\end{array}$ \\
\hline Lonicera tatarica $\mathrm{L}$. & & & & & & \\
\hline Lycopodium dendroideum Michx. & & & $\begin{array}{l}0.825 \\
0.339\end{array}$ & & $\begin{array}{l}0.468 \\
0.198\end{array}$ & \\
\hline Lyonia ligustrina (L.) DC. & & & & & $\begin{array}{l}0.877 \\
0.324\end{array}$ & $\begin{array}{l}0.494 \\
0.174\end{array}$ \\
\hline Lysmachia quadrifolia $\mathrm{L}$. & $\begin{array}{l}0.240 \\
0.843\end{array}$ & $\begin{array}{l}0.556 \\
1.656\end{array}$ & $\begin{array}{l}0.148 \\
0.378\end{array}$ & $\begin{array}{l}0.389 \\
1.186\end{array}$ & $\begin{array}{l}0.135 \\
0.350\end{array}$ & $\begin{array}{l}0.298 \\
1.163\end{array}$ \\
\hline Maianthemum canadense Desf. & $\begin{array}{l}0.585 \\
0.248\end{array}$ & $\begin{array}{l}0.359 \\
0.123\end{array}$ & $\begin{array}{l}0.617 \\
0.255\end{array}$ & $\begin{array}{l}0.123 \\
0.446\end{array}$ & $\begin{array}{l}0.170 \\
0.669\end{array}$ & $\begin{array}{l}0.146 \\
0.430\end{array}$ \\
\hline Malus spp. & $\begin{array}{l}0.585 \\
0.248\end{array}$ & & & & & \\
\hline Magnolia acuminata $\mathrm{L}$. & $\begin{array}{l}0.643 \\
0.173\end{array}$ & $\begin{array}{l}0.175 \\
0.452\end{array}$ & & $\begin{array}{l}0.185 \\
0.743\end{array}$ & $\begin{array}{l}0.585 \\
0.248\end{array}$ & \\
\hline Maianthemum racemosum (L.) Link & $\begin{array}{l}0.292 \\
0.871\end{array}$ & & & & $\begin{array}{l}0.585 \\
0.248\end{array}$ & \\
\hline Medeola virginiana $\mathrm{L}$. & $\begin{array}{l}0.175 \\
0.744\end{array}$ & $\begin{array}{l}0.359 \\
0.149\end{array}$ & $\begin{array}{l}0.617 \\
0.255\end{array}$ & $\begin{array}{l}0.386 \\
0.869\end{array}$ & $\begin{array}{l}0.994 \\
0.373\end{array}$ & $\begin{array}{l}0.234 \\
0.771\end{array}$ \\
\hline $\begin{array}{l}\text { Menziesia pilosa (Michx. ex Lam.) } \\
\text { Juss. ex Pers }\end{array}$ & $\begin{array}{l}0.762 \\
0.323\end{array}$ & $\begin{array}{l}0.877 \\
0.324\end{array}$ & $\begin{array}{l}0.117 \\
0.484\end{array}$ & $\begin{array}{l}0.386 \\
0.124\end{array}$ & $\begin{array}{l}0.494 \\
0.150\end{array}$ & \\
\hline Monotropa uniflora $\mathrm{L}$. & & & & & $\begin{array}{l}0.585 \\
0.248\end{array}$ & \\
\hline
\end{tabular}




\begin{tabular}{|c|c|c|c|c|c|c|}
\hline & \multicolumn{2}{|c|}{ Year 1} & \multicolumn{2}{|c|}{ Year 3} & \multicolumn{2}{|c|}{ Year 6} \\
\hline & Fenced & Control & Fenced & Control & Fenced & Control \\
\hline & $\bar{x}$ & $\bar{x}$ & $\bar{x}$ & $\bar{x}$ & $\bar{x}$ & $\bar{x}$ \\
\hline & $\mathrm{SD}$ & $\mathrm{SD}$ & $\mathrm{SD}$ & $\mathrm{SD}$ & SD & $\mathrm{SD}$ \\
\hline \multirow{2}{*}{ Nyssa sylvatica Marshall } & 0.468 & 0.468 & 0.247 & & 0.468 & 0.585 \\
\hline & 0.113 & 0.159 & 0.796 & & 0.113 & 0.248 \\
\hline \multirow{2}{*}{ Oenothera spp. L. } & 0.468 & & & & & \\
\hline & 0.198 & & & & & \\
\hline \multirow{2}{*}{ Onoclea sensibilis L. } & 0.585 & 0.718 & & & & \\
\hline & 0.248 & 0.298 & & & & \\
\hline \multirow{2}{*}{ Ostrya virginiana (Mill.) K. Koch } & 0.585 & 0.153 & 0.433 & 0.179 & 0.877 & 0.240 \\
\hline & 0.163 & 0.396 & 0.918 & 0.642 & 0.256 & 0.559 \\
\hline \multirow{2}{*}{ Oxalis spp. } & 0.740 & 0.164 & 0.123 & 0.123 & 0.374 & 0.287 \\
\hline & 2.973 & 0.558 & 0.349 & 0.495 & 1.234 & 0.765 \\
\hline \multirow{2}{*}{ Oxydendrum arboreum (L.) DC. } & 0.175 & 0.292 & 0.123 & & & \\
\hline & 0.744 & 0.766 & 0.593 & & & \\
\hline \multirow{2}{*}{ Panicum spp. } & 0.754 & 0.117 & 0.272 & 0.444 & 0.953 & 1.234 \\
\hline & 2.594 & 0.325 & 0.562 & 0.783 & 1.926 & 3.242 \\
\hline \multirow{2}{*}{ Packera aurea (L.) Á. Löve \& D. Löve } & 1.422 & 0.359 & & 0.123 & 0.216 & 0.111 \\
\hline & 6.292 & 1.463 & & 0.495 & 0.819 & 0.471 \\
\hline \multirow{2}{*}{ Paronychia spp. L. } & & & & & 0.585 & \\
\hline & & & & & 0.248 & \\
\hline \multirow{2}{*}{ Parthenocissus quinquefolia (L.) Planch. } & 0.164 & 0.175 & 0.185 & 0.198 & 0.215 & 0.216 \\
\hline & 0.545 & 0.569 & 0.539 & 0.573 & 0.663 & 0.574 \\
\hline \multirow{2}{*}{ Phlox spp. L. } & & 0.399 & & & & \\
\hline & & 1.315 & & & & \\
\hline
\end{tabular}




\begin{tabular}{|c|c|c|c|c|c|c|}
\hline & \multicolumn{2}{|c|}{ Year 1} & \multicolumn{2}{|c|}{ Year 3} & \multicolumn{2}{|c|}{ Year 6} \\
\hline & Fenced & Control & Fenced & Control & Fenced & Control \\
\hline & $\bar{x}$ & $\bar{x}$ & $\bar{x}$ & $\bar{x}$ & $\bar{x}$ & $\bar{x}$ \\
\hline & SD & SD & SD & SD & SD & $\mathrm{SD}$ \\
\hline \multirow{2}{*}{ Phytolacca americana $\mathrm{L}$. } & & & & & & 0.359 \\
\hline & & & & & & 0.149 \\
\hline \multirow{2}{*}{ Pilea pumila (L.) A. Gray } & & 0.292 & & & & 0.762 \\
\hline & & 0.125 & & & & 0.323 \\
\hline \multirow{2}{*}{ Pinus strobus L. } & & 0.643 & 0.617 & 0.617 & 0.359 & 0.468 \\
\hline & & 0.166 & 0.255 & 0.248 & 0.149 & 0.175 \\
\hline \multirow{2}{*}{ Pinus virginiana Mill. } & 0.175 & 0.349 & & & 0.585 & \\
\hline & 0.542 & 1.264 & & & 0.248 & \\
\hline \multirow{2}{*}{ Podophyllum peltatum L. } & 0.181 & 0.819 & 0.247 & 0.185 & 0.494 & 0.175 \\
\hline & 0.769 & 0.279 & 0.119 & 0.547 & 0.133 & 0.744 \\
\hline \multirow{2}{*}{ Polygala paucifolia Willd. } & 0.117 & & & & & 0.117 \\
\hline & 0.496 & & & & & 0.496 \\
\hline \multirow{2}{*}{ Polygonum spp. L. } & & 0.585 & 0.374 & 0.185 & & 0.292 \\
\hline & & 0.248 & 0.111 & 0.547 & & 0.125 \\
\hline \multirow{2}{*}{ Polygonum convolvulus L. } & 0.234 & 0.175 & & & 0.117 & 0.359 \\
\hline & 0.682 & 0.744 & & & 0.350 & 0.185 \\
\hline \multirow{2}{*}{ Polygonum hydropiper L. } & & & 0.617 & & 0.585 & 0.468 \\
\hline & & & 0.255 & & 0.248 & 0.198 \\
\hline \multirow{2}{*}{ Polygonatum spp. Mill. } & & & 0.374 & & 0.234 & \\
\hline & & & 0.148 & & 0.771 & \\
\hline \multirow{2}{*}{ Polystichum acrostichoides (Michx.) Schott } & 0.585 & 0.111 & 0.299 & 0.123 & 0.117 & \\
\hline & 0.223 & 0.332 & 0.839 & 0.495 & 0.445 & \\
\hline
\end{tabular}




\begin{tabular}{|c|c|c|c|c|c|c|}
\hline & \multicolumn{2}{|c|}{ Year 1} & \multicolumn{2}{|c|}{ Year 3} & \multicolumn{2}{|c|}{ Year 6} \\
\hline & Fenced & Control & Fenced & Control & Fenced & Control \\
\hline & $\bar{x}$ & $\bar{x}$ & $\bar{x}$ & $\bar{x}$ & $\bar{x}$ & $\bar{x}$ \\
\hline & $\mathrm{SD}$ & $\mathrm{SD}$ & $\mathrm{SD}$ & SD & SD & SD \\
\hline \multirow{2}{*}{ Potentilla spp. } & 1.740 & 0.453 & 0.556 & 0.525 & 1.550 & 0.813 \\
\hline & 5.168 & 1.172 & 1.369 & 1.497 & 3.156 & 1.882 \\
\hline \multirow{2}{*}{ Prenanthes alba $\mathrm{L}$. } & 0.117 & 0.877 & 0.185 & & 0.175 & \\
\hline & 0.350 & 0.372 & 0.556 & & 0.542 & \\
\hline \multirow{2}{*}{ Prunella vulgaris $\mathrm{L}$. } & 0.216 & 0.263 & & & & \\
\hline & 0.918 & 1.116 & & & & \\
\hline \multirow{2}{*}{ Prunus spp. } & 3.368 & 2.374 & 2.864 & 3.123 & 7.368 & 1.762 \\
\hline & 8.767 & 5.743 & 8.176 & 5.666 & 2.590 & 2.636 \\
\hline \multirow{2}{*}{ Prunus pensylvanica $\mathrm{L}$. } & & & 0.185 & & & 0.585 \\
\hline & & & 0.764 & & & 0.248 \\
\hline \multirow{2}{*}{ Pyrularia pubera Michx. } & & & & & 0.359 & \\
\hline & & & & & 0.149 & \\
\hline \multirow{2}{*}{ Pycnanthemum virginianum $\mathrm{L}$. } & 0.152 & & 0.123 & 0.617 & 0.386 & 0.585 \\
\hline & 0.493 & & 0.593 & 0.248 & 1.439 & 0.248 \\
\hline \multirow{2}{*}{ Quercus alba $\mathrm{L}$. } & 0.117 & 0.292 & 0.433 & 0.679 & 0.292 & 0.819 \\
\hline & 0.496 & 0.195 & 0.753 & 0.145 & 0.195 & 0.266 \\
\hline \multirow{2}{*}{ Quercus berberidifolia Liebm. } & & 0.234 & 0.617 & 0.165 & 0.359 & 0.936 \\
\hline & & 0.992 & 0.255 & 0.645 & 0.149 & 0.293 \\
\hline \multirow{2}{*}{ Quercus coccinea Münchh. } & 0.585 & 0.494 & & & & \\
\hline & 0.248 & 0.174 & & & & \\
\hline \multirow{2}{*}{ Quercus prinus L. } & 0.152 & 0.117 & 0.148 & 0.988 & 0.135 & 0.936 \\
\hline & 0.346 & 0.254 & 0.387 & 0.239 & 0.344 & 0.196 \\
\hline
\end{tabular}




\begin{tabular}{|c|c|c|c|c|c|c|}
\hline & \multicolumn{2}{|c|}{ Year 1} & \multicolumn{2}{|c|}{ Year 3} & \multicolumn{2}{|c|}{ Year 6} \\
\hline & Fenced & Control & Fenced & Control & Fenced & Control \\
\hline & $\bar{x}$ & $\bar{x}$ & $\bar{x}$ & $\bar{x}$ & $\bar{x}$ & $\bar{x}$ \\
\hline & $\mathrm{SD}$ & SD & SD & SD & SD & SD \\
\hline \multirow{2}{*}{ Quercus rubra $\mathrm{L}$. } & 0.123 & 0.135 & 0.185 & 0.519 & 0.762 & 0.287 \\
\hline & 0.260 & 0.350 & 0.370 & 1.526 & 0.132 & 0.454 \\
\hline \multirow{2}{*}{ Quercus velutina Lam } & 0.175 & 0.585 & 0.617 & 0.123 & 0.585 & \\
\hline & 0.744 & 0.248 & 0.255 & 0.340 & 0.248 & \\
\hline \multirow{2}{*}{ Rhododendron spp. } & 0.270 & 0.529 & 0.299 & 0.519 & 0.216 & 0.345 \\
\hline & 0.953 & 2.177 & 0.839 & 1.954 & 0.793 & 1.339 \\
\hline \multirow{2}{*}{ Rhus spp. } & 0.117 & 0.175 & 0.123 & & & 0.585 \\
\hline & 0.350 & 0.542 & 0.593 & & & 0.248 \\
\hline \multirow{2}{*}{ Robinia pseudoacacia $\mathrm{L}$} & 0.117 & & & 0.617 & 0.234 & 0.585 \\
\hline & 0.350 & & & 0.248 & 0.771 & 0.248 \\
\hline \multirow{2}{*}{ Rosa multiflora Thunb. } & 0.994 & 0.359 & 0.130 & 0.494 & 0.468 & 0.275 \\
\hline & 0.322 & 0.185 & 0.460 & 0.899 & 0.154 & 0.842 \\
\hline \multirow{2}{*}{ Rubus spp. L.H.Bailey (Dewberry) } & 0.529 & 0.485 & 2.377 & 0.994 & 1.359 & 0.964 \\
\hline & 2.134 & 2.593 & 9.799 & 3.988 & 4.392 & 2.897 \\
\hline \multirow{2}{*}{ Rubus spp. } & 1.386 & 1.298 & 6.543 & 2.975 & 1.947 & 1.193 \\
\hline & 3.924 & 2.692 & 18.438 & 8.421 & 4.434 & 3.138 \\
\hline \multirow{2}{*}{ Rudbeckia hirta L. } & & & & 0.617 & & \\
\hline & & & & 0.248 & & \\
\hline \multirow{2}{*}{ Rumex acetosella $\mathrm{L}$. } & 0.117 & 0.936 & & & & 0.953 \\
\hline & 0.496 & 0.397 & & & & 3.672 \\
\hline \multirow{2}{*}{ Smilax herbacea L. } & 0.585 & & 0.123 & & 0.494 & \\
\hline & 0.248 & & 0.593 & & 0.174 & \\
\hline
\end{tabular}




\begin{tabular}{|c|c|c|c|c|c|c|}
\hline & \multicolumn{2}{|c|}{ Year 1} & \multicolumn{2}{|c|}{ Year 3} & \multicolumn{2}{|c|}{ Year 6} \\
\hline & Fenced & Control & Fenced & Control & Fenced & Control \\
\hline & $\bar{x}$ & $\bar{x}$ & $\bar{x}$ & $\bar{x}$ & $\bar{x}$ & $\bar{x}$ \\
\hline & $\mathrm{SD}$ & SD & SD & SD & SD & SD \\
\hline \multirow{2}{*}{ Sambucus spp. } & 0.585 & & & & & \\
\hline & 0.248 & & & & & \\
\hline \multirow{2}{*}{ Sassafras albidum (Nutt.) Nees } & 0.468 & 0.229 & 0.374 & 0.191 & 0.374 & 0.585 \\
\hline & 1.124 & 0.636 & 0.845 & 0.496 & 1.282 & 1.769 \\
\hline \multirow{2}{*}{ Sanguinaria canadensis $\mathrm{L}$. } & 0.585 & 0.117 & 0.247 & 0.617 & 0.718 & 0.175 \\
\hline & 0.248 & 0.496 & 0.796 & 0.223 & 0.253 & 0.542 \\
\hline \multirow{2}{*}{ Smilax spp. } & 0.386 & 0.444 & 0.481 & 0.315 & 0.588 & 0.399 \\
\hline & 0.629 & 0.529 & 0.584 & 0.594 & 0.598 & 0.414 \\
\hline \multirow{2}{*}{ Solanum americanum Mill. } & 0.153 & 0.363 & & 0.198 & & \\
\hline & 0.421 & 1.512 & & 0.767 & & \\
\hline \multirow{2}{*}{ Solidago spp. } & 0.392 & 0.485 & 0.364 & 0.265 & 0.525 & 0.498 \\
\hline & 1.757 & 1.165 & 0.749 & 0.911 & 1.174 & 1.229 \\
\hline \multirow{2}{*}{ Sedum spp. } & 0.175 & 0.585 & 0.123 & 0.556 & & \\
\hline & 0.744 & 0.248 & 0.593 & 0.223 & & \\
\hline \multirow{2}{*}{ Stellaria media $\mathrm{L}$. } & 0.322 & 0.600 & 0.494 & 0.679 & 0.585 & 0.585 \\
\hline & 1.365 & 2.482 & 0.236 & 0.187 & 0.248 & 0.185 \\
\hline \multirow{2}{*}{ Streptopus lanceolatus (Aiton) Reveal } & 0.234 & & 0.327 & 0.679 & 0.718 & 0.357 \\
\hline & 0.992 & & 1.699 & 0.226 & 0.136 & 1.276 \\
\hline \multirow{2}{*}{ Symphotrichium spp. } & 0.117 & 0.216 & 0.374 & 0.593 & 0.275 & 0.737 \\
\hline & 0.232 & 0.697 & 1.168 & 1.844 & 0.497 & 1.737 \\
\hline \multirow{2}{*}{ Taraxacum officinale F.H. Wigg. } & & & & & 0.585 & \\
\hline & & & & & 0.248 & \\
\hline \multirow{2}{*}{ Thalictrum spp. L. } & 0.359 & 0.585 & & & 0.585 & \\
\hline & 0.149 & 0.248 & & & 0.248 & \\
\hline
\end{tabular}




\begin{tabular}{|c|c|c|c|c|c|c|}
\hline & \multicolumn{2}{|c|}{ Year 1} & \multicolumn{2}{|c|}{ Year 3} & \multicolumn{2}{|c|}{ Year 6} \\
\hline & $\begin{array}{c}\text { Fenced } \\
\bar{x} \\
\text { SD } \\
\end{array}$ & $\begin{array}{c}\text { Control } \\
\bar{x} \\
\text { SD } \\
\end{array}$ & $\begin{array}{c}\text { Fenced } \\
\bar{x} \\
\mathrm{SD} \\
\end{array}$ & $\begin{array}{c}\text { Control } \\
\bar{x} \\
\text { SD } \\
\end{array}$ & $\begin{array}{c}\text { Fenced } \\
\bar{x} \\
\mathrm{SD} \\
\end{array}$ & $\begin{array}{c}\text { Control } \\
\bar{x} \\
\mathrm{SD} \\
\end{array}$ \\
\hline \multirow{2}{*}{ Thelypteris noveboracensis (L.) Nieuwl. } & 4.854 & 1.942 & 2.933 & 1.519 & 4.556 & 3.872 \\
\hline & 11.753 & 4.437 & 6.773 & 2.696 & 8.862 & 11.647 \\
\hline \multirow{2}{*}{ Toxicodendron radicans (L.) Kuntze } & 0.994 & 0.234 & 0.154 & 0.185 & 0.819 & 0.359 \\
\hline & 0.299 & 0.453 & 0.344 & 0.434 & 0.249 & 0.123 \\
\hline \multirow{2}{*}{ Trifolium spp. } & 0.357 & & & & 0.164 & 0.819 \\
\hline & 1.513 & & & & 0.695 & 0.347 \\
\hline \multirow{2}{*}{ Triodanis perfoliata (L.) Nieuwl. } & & 0.117 & 0.617 & 0.374 & & 0.234 \\
\hline & & 0.496 & 0.255 & 0.149 & & 0.992 \\
\hline \multirow{2}{*}{ Tsuga canadensis L. } & & & & 0.617 & & \\
\hline & & & & 0.248 & & \\
\hline \multirow{2}{*}{ Ulmus spp. } & & 0.117 & 0.679 & 0.617 & 0.585 & 0.117 \\
\hline & & 0.496 & 0.280 & 0.248 & 0.248 & 0.496 \\
\hline \multirow{2}{*}{ Trillium spp. } & 0.234 & 0.819 & & 0.617 & & \\
\hline & 0.992 & 0.347 & & 0.248 & & \\
\hline \multirow{2}{*}{ Urtica gracilis Ait. } & 0.153 & 0.146 & 0.123 & 0.617 & & \\
\hline & 0.421 & 0.623 & 0.349 & 0.248 & & \\
\hline \multirow{2}{*}{ Uvularia spp. } & 0.111 & 0.994 & 0.426 & 0.117 & 0.386 & 0.494 \\
\hline & 0.324 & 0.293 & 1.391 & 0.283 & 1.122 & 0.898 \\
\hline \multirow{2}{*}{ Vaccinium spp. } & 2.359 & 2.444 & 3.519 & 2.864 & 1.345 & 1.251 \\
\hline & 3.763 & 4.469 & 7.659 & 7.451 & 2.987 & 31.616 \\
\hline \multirow{2}{*}{ Veronica spp. } & & 0.585 & & 0.617 & 0.359 & \\
\hline & & 0.248 & & 0.248 & 0.149 & \\
\hline \multirow{2}{*}{ Viburnum prunifolium L. } & 0.585 & 0.585 & & & 0.494 & \\
\hline & 0.248 & 0.248 & & & 0.174 & \\
\hline
\end{tabular}




\begin{tabular}{|c|c|c|c|c|c|c|}
\hline & \multicolumn{2}{|c|}{ Year 1} & \multicolumn{2}{|c|}{ Year 3} & \multicolumn{2}{|c|}{ Year 6} \\
\hline & $\begin{array}{l}\text { Fenced } \\
\bar{x} \\
\text { SD }\end{array}$ & $\begin{array}{c}\text { Control } \\
\bar{x} \\
\text { SD }\end{array}$ & $\begin{array}{c}\text { Fenced } \\
\bar{x} \\
\text { SD }\end{array}$ & $\begin{array}{c}\text { Control } \\
\bar{x} \\
\text { SD }\end{array}$ & $\begin{array}{c}\text { Fenced } \\
\bar{x} \\
\text { SD }\end{array}$ & $\begin{array}{c}\text { Control } \\
\bar{x} \\
\text { SD }\end{array}$ \\
\hline \multirow{2}{*}{ Viburnum acerifolium $\mathrm{L}$. } & 0.175 & 0.339 & 0.358 & 0.374 & 0.359 & 0.193 \\
\hline & 0.744 & 1.388 & 1.476 & 0.149 & 0.149 & 0.819 \\
\hline \multirow{2}{*}{ Viburnum lantanoides Michx. } & 0.292 & 0.215 & 0.111 & 0.173 & 0.762 & \\
\hline & 0.125 & 0.893 & 0.458 & 0.694 & 0.323 & \\
\hline \multirow{2}{*}{ Viburnum spp. } & 0.585 & 0.468 & 0.679 & 0.864 & 0.494 & 0.994 \\
\hline & 0.178 & 0.198 & 0.232 & 0.347 & 0.195 & 0.335 \\
\hline \multirow{2}{*}{$\begin{array}{l}\text { Verbesina alternifolia }(\text { L.) Britton } \\
\text { ex Kearney }\end{array}$} & & 0.117 & & & & 0.585 \\
\hline & & 0.496 & & & & 0.248 \\
\hline \multirow{2}{*}{ Viola spp. L. } & 1.725 & 0.825 & 1.259 & 1.562 & 2.684 & 1.912 \\
\hline & 3.554 & 1.495 & 2.577 & 2.445 & 7.344 & 4.642 \\
\hline \multirow{2}{*}{ Vitis spp. } & 0.585 & 0.292 & & & 0.718 & 0.181 \\
\hline & 0.248 & 0.871 & & & 0.298 & 0.537 \\
\hline \multirow{2}{*}{ Zanthoxylum clava-herculis L. } & & & & & & 0.117 \\
\hline & & & & & & 0.496 \\
\hline \multirow{2}{*}{ Vicia caroliniana Walter } & 0.585 & 0.175 & & 0.123 & 0.234 & 0.111 \\
\hline & 0.248 & 0.744 & & 0.495 & 0.771 & 0.446 \\
\hline
\end{tabular}




\begin{tabular}{|c|c|c|c|c|c|c|}
\hline & \multicolumn{2}{|c|}{ Year 9} & \multicolumn{2}{|c|}{ Year 12} & \multicolumn{2}{|c|}{ Year 15} \\
\hline & Fenced & Control & Fenced & Control & Fenced & Control \\
\hline & $\bar{x}$ & $\bar{x}$ & $\bar{x}$ & $\bar{x}$ & $\bar{x}$ & $\bar{x}$ \\
\hline & SD & SD & SD & SD & SD & SD \\
\hline \multirow{2}{*}{ Acer pensylvanicum $\mathrm{L}$. } & 0.988 & 0.556 & 0.111 & 0.156 & 0.119 & 0.214 \\
\hline & 0.219 & 0.145 & 0.253 & 0.412 & 0.347 & 0.612 \\
\hline \multirow{2}{*}{ Acer saccharum Marshall } & 2.747 & 1.374 & 0.617 & 0.339 & 0.595 & 0.239 \\
\hline & 6.660 & 3.244 & 2.386 & 0.752 & 1.826 & 0.458 \\
\hline \multirow{2}{*}{ Acer spicatum Lam. } & & 0.433 & & & & \\
\hline & & 0.178 & & & & \\
\hline \multirow{2}{*}{ Ageratina altissima (L.) King \& H. Rob. } & 0.165 & 0.956 & 0.561 & 1.133 & 1.635 & 0.675 \\
\hline & 0.380 & 2.715 & 1.853 & 2.793 & 2.397 & 2.717 \\
\hline \multirow{2}{*}{ Agrimonia spp. } & & 0.617 & & & & \\
\hline & & 0.255 & & & & \\
\hline \multirow{2}{*}{ Aesculus glabra Willd } & 0.123 & & & & 0.794 & \\
\hline & 0.593 & & & & 0.286 & \\
\hline \multirow{2}{*}{ Actaea racemosa $\mathrm{L}$. } & 0.617 & & & & 0.239 & \\
\hline & 0.255 & & & & 0.620 & \\
\hline \multirow{2}{*}{ Alcalypha virginica spp. L. } & 0.494 & 0.185 & 0.389 & 0.222 & 0.794 & 0.159 \\
\hline & 0.236 & 0.764 & 0.170 & 0.567 & 0.286 & 0.572 \\
\hline \multirow{2}{*}{ Amianthium muscitoxicum (Walter) A. Gray } & 0.191 & 0.747 & 0.128 & 0.944 & 0.175 & \\
\hline & 0.789 & 0.354 & 0.557 & 0.412 & 0.630 & \\
\hline \multirow{2}{*}{ Antennaria spp. Gaertn. } & 0.315 & 0.254 & 0.561 & 0.256 & 0.111 & 0.239 \\
\hline & 1.220 & 1.169 & 2.425 & 0.846 & 0.462 & 0.858 \\
\hline \multirow{2}{*}{ Ambrosia artemisiifolia $\mathrm{L}$. } & & 0.386 & 0.556 & 0.556 & & \\
\hline & & 0.127 & 0.242 & 0.242 & & \\
\hline
\end{tabular}




\begin{tabular}{|c|c|c|c|c|c|c|}
\hline & \multicolumn{2}{|c|}{ Year 9} & \multicolumn{2}{|c|}{ Year 12} & \multicolumn{2}{|c|}{ Year 15} \\
\hline & Fenced & Control & Fenced & Control & Fenced & Control \\
\hline & $\bar{x}$ & $\bar{x}$ & $\bar{x}$ & $\bar{x}$ & $\bar{x}$ & $\bar{x}$ \\
\hline & $\mathrm{SD}$ & $\mathrm{SD}$ & $\mathrm{SD}$ & SD & $\mathrm{SD}$ & $\mathrm{SD}$ \\
\hline \multirow{2}{*}{ Acer rubrum L. } & 2.389 & 5.457 & 1.356 & 3.556 & 1.895 & 3.556 \\
\hline & 3.143 & 1.944 & 1.837 & 8.280 & 2.377 & 4.775 \\
\hline \multirow{2}{*}{ Amelanchier arborea Michx. } & 0.556 & 0.617 & 0.556 & 0.722 & 0.397 & 0.714 \\
\hline & 0.158 & 0.145 & 0.173 & 0.226 & 0.798 & 0.116 \\
\hline \multirow{2}{*}{ Anemone virginiana $\mathrm{L}$. } & & & 0.944 & 0.778 & 0.397 & \\
\hline & & & 0.288 & 0.339 & 0.144 & \\
\hline \multirow{2}{*}{ Apocynum spp. L. } & & 0.185 & 0.556 & & & \\
\hline & & 0.764 & 0.242 & & & \\
\hline \multirow{2}{*}{ Aralia nudicaulis L. } & 0.123 & & 0.167 & & & \\
\hline & 0.593 & & 0.530 & & & \\
\hline \multirow{2}{*}{ Aronia melanocarpa Michx. } & 0.617 & & 0.222 & & 0.794 & \\
\hline & 0.255 & & 0.969 & & 0.286 & \\
\hline \multirow{2}{*}{ Arisaema triphyllum L. } & 0.562 & 0.799 & 0.444 & 0.550 & 0.763 & 0.316 \\
\hline & 1.241 & 1.862 & 1.294 & 1.168 & 1.839 & 0.554 \\
\hline \multirow{2}{*}{ Asarum canadense spp. L. } & 0.864 & 0.278 & 0.167 & 0.144 & 0.952 & \\
\hline & 0.367 & 0.995 & 0.530 & 0.439 & 0.343 & \\
\hline \multirow{2}{*}{ Asimina triloba (L.) Dunal } & 0.617 & 0.123 & 0.222 & 0.500 & 0.794 & 0.159 \\
\hline & 0.255 & 0.349 & 0.969 & 0.174 & 0.286 & 0.572 \\
\hline \multirow{2}{*}{$\begin{array}{l}\text { Asplenium platyneuron (L.) Britton, Sterns \& } \\
\text { Poggenb. }\end{array}$} & 0.185 & 0.123 & 0.111 & 0.556 & & \\
\hline & 0.556 & 0.593 & 0.333 & 0.242 & & \\
\hline \multirow{2}{*}{ Betula spp. } & 0.864 & 0.222 & 0.667 & 0.556 & 0.556 & 0.159 \\
\hline & 0.244 & 0.499 & 0.170 & 0.134 & 0.138 & 0.389 \\
\hline \multirow{2}{*}{ Botrychium virginianum (L.) Sw. } & & 0.926 & 0.556 & 0.444 & & 0.873 \\
\hline & & 0.332 & 0.242 & 0.138 & & 0.285 \\
\hline
\end{tabular}




\begin{tabular}{|c|c|c|c|c|c|c|}
\hline & \multicolumn{2}{|c|}{ Year 9} & \multicolumn{2}{|c|}{ Year 12} & \multicolumn{2}{|c|}{ Year 15} \\
\hline & $\begin{array}{c}\text { Fenced } \\
\bar{x} \\
\text { SD }\end{array}$ & $\begin{array}{c}\text { Control } \\
\bar{x} \\
\text { SD }\end{array}$ & $\begin{array}{c}\text { Fenced } \\
\bar{x} \\
\text { SD }\end{array}$ & $\begin{array}{c}\text { Control } \\
\bar{x} \\
\text { SD }\end{array}$ & $\begin{array}{c}\text { Fenced } \\
\bar{x} \\
\text { SD }\end{array}$ & $\begin{array}{c}\text { Control } \\
\bar{x} \\
\text { SD }\end{array}$ \\
\hline Cardamine nuttallii Greene & & & & & $\begin{array}{l}0.794 \\
0.286\end{array}$ & \\
\hline Carex spp. & $\begin{array}{l}1.165 \\
2.966\end{array}$ & $\begin{array}{l}1.396 \\
2.324\end{array}$ & $\begin{array}{l}0.217 \\
0.442\end{array}$ & $\begin{array}{l}0.317 \\
0.956\end{array}$ & $\begin{array}{l}0.167 \\
0.422\end{array}$ & $\begin{array}{l}0.232 \\
0.374\end{array}$ \\
\hline Carya spp. & $\begin{array}{l}0.864 \\
0.164\end{array}$ & $\begin{array}{l}0.179 \\
0.252\end{array}$ & $\begin{array}{l}0.944 \\
0.244\end{array}$ & $\begin{array}{l}0.100 \\
0.175\end{array}$ & $\begin{array}{l}0.111 \\
0.232\end{array}$ & $\begin{array}{l}0.714 \\
0.132\end{array}$ \\
\hline Cassia spp. L. & & $\begin{array}{l}0.123 \\
0.593\end{array}$ & & & & \\
\hline Celastrus scandens L. & $\begin{array}{l}0.185 \\
0.764\end{array}$ & $\begin{array}{l}0.123 \\
0.593\end{array}$ & $\begin{array}{l}0.444 \\
0.194\end{array}$ & $\begin{array}{l}0.111 \\
0.484\end{array}$ & $\begin{array}{l}0.397 \\
0.144\end{array}$ & \\
\hline Cercis canadensis $\mathrm{L}$. & $\begin{array}{l}0.679 \\
0.280\end{array}$ & $\begin{array}{l}0.679 \\
0.153\end{array}$ & $\begin{array}{l}0.667 \\
0.266\end{array}$ & $\begin{array}{l}0.667 \\
0.163\end{array}$ & $\begin{array}{l}0.952 \\
0.343\end{array}$ & $\begin{array}{l}0.397 \\
0.144\end{array}$ \\
\hline $\begin{array}{l}\text { Chamaecrista fasciculata (Michx.) } \\
\text { Greene }\end{array}$ & $\begin{array}{l}0.185 \\
0.556\end{array}$ & $\begin{array}{l}0.259 \\
0.742\end{array}$ & $\begin{array}{l}0.167 \\
0.530\end{array}$ & $\begin{array}{l}0.156 \\
0.255\end{array}$ & $\begin{array}{l}0.317 \\
0.114\end{array}$ & $\begin{array}{l}0.317 \\
0.884\end{array}$ \\
\hline Chimaphila maculata (L.) Pursh & $\begin{array}{l}0.617 \\
0.255\end{array}$ & & $\begin{array}{l}0.111 \\
0.333\end{array}$ & & $\begin{array}{l}0.794 \\
0.286\end{array}$ & $\begin{array}{l}0.317 \\
0.778\end{array}$ \\
\hline $\begin{array}{l}\text { Chimaphila umbellata (L.) W.P.C. } \\
\text { Barton }\end{array}$ & $\begin{array}{l}0.617 \\
0.255\end{array}$ & $\begin{array}{l}0.617 \\
0.255\end{array}$ & & $\begin{array}{l}0.556 \\
0.242\end{array}$ & & \\
\hline Chrysanthemum spp. L. & & $\begin{array}{l}0.617 \\
0.255\end{array}$ & & & & \\
\hline Cicuta maculata $\mathrm{L}$. & & & & $\begin{array}{l}0.556 \\
0.242\end{array}$ & & \\
\hline
\end{tabular}


Appendix 6 Continued

\begin{tabular}{cccccccc}
\multicolumn{2}{c}{ Year 9 } & & \multicolumn{2}{c}{ Year 12 } & & \multicolumn{2}{c}{ Year 15 } \\
\cline { 1 - 2 } \cline { 7 - 8 } Fenced & Control & & Fenced & Control & & Fenced & Control \\
$\bar{x}$ & $\bar{x}$ & & $\bar{x}$ & $\bar{x}$ & & $\bar{x}$ & $\bar{x}$ \\
$\mathrm{SD}$ & $\mathrm{SD}$ & & $\mathrm{SD}$ & $\mathrm{SD}$ & & $\mathrm{SD}$ & $\mathrm{SD}$ \\
\hline
\end{tabular}

Clintonia borealis (Aiton) Raf.

Cornus florida $\mathrm{L}$.

$\begin{array}{ll}0.154 & 0.173 \\ 0.275 & 0.419 \\ 0.988 & 0.386 \\ 0.335 & 0.127 \\ 0.247 & 0.130 \\ 0.462 & 0.319\end{array}$

0.111

0.484

0.944

0.293

0.194

0.858

0.556

Corylus americana Walter

Crataegus spp.

0.462

0.944

0.377

0.172

0.324

0.167

0.127

0.144

0.726

0.458

$\begin{array}{ll}0.952 & 0.132\end{array}$

Danthonia spicata (L.) Beauv.

0.588

0.363

0.314

0.132

0.372

0.232

\begin{tabular}{llllll}
1.475 & 0.846 & 0.617 & 0.744 & 0.476 & 0.830 \\
3.827 & 2.933 & 1.417 & 2.756 & 0.144 & 0.144 \\
0.433 & 0.386 & 0.944 & 0.222 & 0.143 & 0.556 \\
0.112 & 0.135 & 0.254 & 0.754 & 0.345 & 0.172 \\
0.685 & 1.123 & 0.356 & 0.261 & 1.794 & 1.294 \\
2.281 & 3.419 & 0.834 & 0.761 & 3.429 & 4.247 \\
& & & & & 0.159 \\
0.864 & 0.747 & 0.111 & 0.111 & 0.794 & 0.572 \\
0.356 & 0.222 & 0.484 & 0.484 & 0.286 & \\
0.617 & 0.617 & 0.122 & 0.111 & 0.167 & \\
0.255 & 0.255 & 0.533 & 0.484 & 0.693 & \\
& & 0.111 & 0.278 & & \\
& & 0.484 & 0.122 & & \\
\hline
\end{tabular}

Desmodium spp.

Dioscorea villosa $\mathrm{L}$.

Dryopteris spp. L.

Elaeagnus umbellata Thunb.

Epigaea repens $\mathrm{L}$.

Euonymus alatus (Thunb.) Siebold

Euonymus americanus L.

0.484 


\begin{tabular}{|c|c|c|c|c|c|c|}
\hline & \multicolumn{2}{|c|}{ Year 9} & \multicolumn{2}{|c|}{ Year 12} & \multicolumn{2}{|c|}{ Year 15} \\
\hline & $\begin{array}{c}\text { Fenced } \\
\bar{x} \\
\text { SD } \\
\end{array}$ & $\begin{array}{c}\text { Control } \\
\bar{x} \\
\text { SD } \\
\end{array}$ & $\begin{array}{c}\text { Fenced } \\
\bar{x} \\
\text { SD } \\
\end{array}$ & $\begin{array}{c}\text { Control } \\
\bar{x} \\
\text { SD } \\
\end{array}$ & $\begin{array}{c}\text { Fenced } \\
\bar{x} \\
\text { SD } \\
\end{array}$ & $\begin{array}{c}\text { Control } \\
\bar{x} \\
\mathrm{SD} \\
\end{array}$ \\
\hline \multirow{2}{*}{ Eutrochium purpureum (L.) E.E. Lamont } & 0.433 & 0.185 & 0.222 & & & \\
\hline & 0.153 & 0.764 & 0.969 & & & \\
\hline \multirow{2}{*}{ Fagus grandifolia Ehrh. } & 0.247 & 0.123 & 0.556 & 0.500 & 0.794 & 0.317 \\
\hline & 0.119 & 0.381 & 0.242 & 0.151 & 0.286 & 0.114 \\
\hline \multirow{2}{*}{ Fraxinus americana $\mathrm{L}}$. & 0.123 & 0.123 & 0.278 & 0.389 & 0.317 & \\
\hline & 0.349 & 0.349 & 0.692 & 0.117 & 0.778 & \\
\hline \multirow{2}{*}{ Galium spp. } & 0.654 & 0.352 & 0.256 & 0.494 & 0.127 & 0.111 \\
\hline & 1.526 & 0.714 & 0.393 & 1.131 & 0.275 & 0.320 \\
\hline \multirow{2}{*}{ Gaultheria procumbens L. } & 3.679 & 0.438 & 1.311 & 0.494 & 1.278 & \\
\hline & 11.493 & 1.289 & 3.554 & 1.620 & 3.926 & \\
\hline \multirow{2}{*}{ Gaylussacia spp. Kunth } & 0.926 & & 0.278 & 0.133 & 0.127 & \\
\hline & 0.332 & & 0.122 & 0.581 & 0.458 & \\
\hline \multirow{2}{*}{ Gaylussacia ursina (M.A. Curtis) Torr. } & 0.247 & 0.299 & 0.256 & 0.333 & 0.794 & 0.239 \\
\hline & 0.119 & 0.742 & 0.823 & 0.868 & 0.286 & 0.714 \\
\hline \multirow{2}{*}{ Geranium spp. L. } & 0.278 & 0.352 & 0.417 & 0.667 & 0.278 & \\
\hline & 0.483 & 0.789 & 1.477 & 0.170 & 0.834 & \\
\hline \multirow{2}{*}{ Gillenia trifoliata (L.) Moench } & & & 0.556 & & 0.794 & \\
\hline & & & 0.242 & & 0.286 & \\
\hline \multirow{2}{*}{ Gnaphalium obtusifolium L. } & & 0.123 & & & & \\
\hline & & 0.593 & & & & \\
\hline \multirow{2}{*}{ Hamamelis virginiana $\mathrm{L}$. } & 0.494 & 0.988 & 0.556 & 0.111 & 0.476 & 0.135 \\
\hline & 0.135 & 0.381 & 0.160 & 0.333 & 0.894 & 0.399 \\
\hline
\end{tabular}




\begin{tabular}{|c|c|c|c|c|c|c|}
\hline & \multicolumn{2}{|c|}{ Year 9} & \multicolumn{2}{|c|}{ Year 12} & \multicolumn{2}{|c|}{ Year 15} \\
\hline & $\begin{array}{l}\text { Fenced } \\
\bar{x} \\
\text { SD }\end{array}$ & $\begin{array}{c}\text { Control } \\
\bar{x} \\
\text { SD }\end{array}$ & $\begin{array}{c}\text { Fenced } \\
\bar{x} \\
\mathrm{SD}\end{array}$ & $\begin{array}{c}\text { Control } \\
\bar{x} \\
\text { SD }\end{array}$ & $\begin{array}{c}\text { Fenced } \\
\bar{x} \\
\mathrm{SD}\end{array}$ & $\begin{array}{c}\text { Control } \\
\bar{x} \\
\text { SD }\end{array}$ \\
\hline Hieracium fendleri Sch. Bip & & & 0.556 & $\begin{array}{l}0.389 \\
0149\end{array}$ & & 0.794 \\
\hline Hieracium venosum $\mathrm{L}$. & & $\begin{array}{l}0.117 \\
0.344\end{array}$ & & $\begin{array}{l}0.833 \\
0.255\end{array}$ & & \\
\hline Houstonia canadensis Willd. ex Roem. \& Schult. & $\begin{array}{l}0.123 \\
0.593\end{array}$ & & $\begin{array}{l}0.278 \\
0.122\end{array}$ & $\begin{array}{l}0.111 \\
0.484\end{array}$ & & \\
\hline Hypericum prolificum $\mathrm{L}$. & $\begin{array}{l}0.123 \\
0.593\end{array}$ & $\begin{array}{l}0.179 \\
0.739\end{array}$ & & & & \\
\hline Hypericum punctatutm. L. & $\begin{array}{l}0.154 \\
0.636\end{array}$ & $\begin{array}{l}0.327 \\
1.349\end{array}$ & $\begin{array}{l}0.722 \\
0.315\end{array}$ & $\begin{array}{l}0.311 \\
1.356\end{array}$ & & $\begin{array}{l}0.397 \\
0.144\end{array}$ \\
\hline Isotria vertucillata Willd. & $\begin{array}{l}0.154 \\
0.636\end{array}$ & & & & $\begin{array}{l}0.294 \\
1.588\end{array}$ & \\
\hline Juniperus virginiana $\mathrm{L}$ & $\begin{array}{l}0.617 \\
0.255\end{array}$ & & $\begin{array}{l}0.556 \\
0.242\end{array}$ & $\begin{array}{l}0.556 \\
0.242\end{array}$ & $\begin{array}{l}0.794 \\
0.286\end{array}$ & \\
\hline Kalmia latifolia $\mathrm{L}$. & $\begin{array}{l}0.173 \\
0.430\end{array}$ & $\begin{array}{l}0.165 \\
0.466\end{array}$ & $\begin{array}{l}0.256 \\
0.587\end{array}$ & $\begin{array}{l}0.722 \\
0.293\end{array}$ & $\begin{array}{l}0.159 \\
0.293\end{array}$ & $\begin{array}{l}0.316 \\
0.749\end{array}$ \\
\hline Lindera benzoin (L.) Blume & $\begin{array}{l}0.617 \\
0.167\end{array}$ & $\begin{array}{l}0.556 \\
0.140\end{array}$ & $\begin{array}{l}0.944 \\
0.288\end{array}$ & $\begin{array}{l}0.194 \\
0.586\end{array}$ & & $\begin{array}{l}0.239 \\
0.858\end{array}$ \\
\hline Liriodendron tulipifera $\mathrm{L}$. & $\begin{array}{l}0.617 \\
0.255\end{array}$ & $\begin{array}{l}0.747 \\
0.192\end{array}$ & $\begin{array}{l}0.444 \\
0.147\end{array}$ & $\begin{array}{l}0.944 \\
0.273\end{array}$ & $\begin{array}{l}0.239 \\
0.620\end{array}$ & $\begin{array}{l}0.397 \\
0.679\end{array}$ \\
\hline Lobelia cardinalis $\mathrm{L}$. & $\begin{array}{l}0.617 \\
0.255\end{array}$ & $\begin{array}{l}0.247 \\
0.119\end{array}$ & & & & \\
\hline Lespedeza spp. Michx. & $\begin{array}{l}0.247 \\
0.119\end{array}$ & $\begin{array}{l}0.216 \\
0.898\end{array}$ & $\begin{array}{l}0.100 \\
0.436\end{array}$ & $\begin{array}{l}0.556 \\
0.242\end{array}$ & & \\
\hline
\end{tabular}




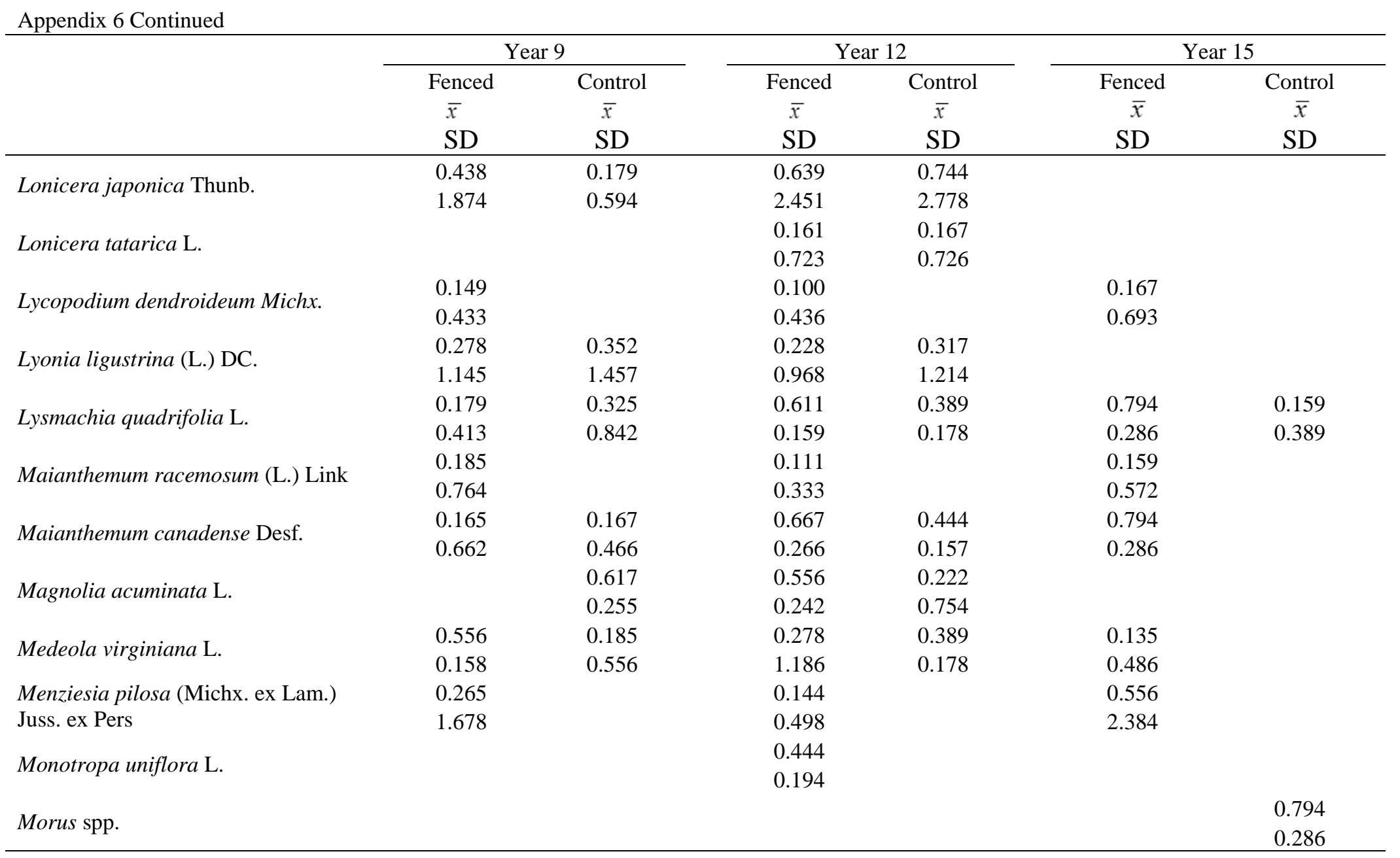




\begin{tabular}{|c|c|c|c|c|c|c|}
\hline & \multicolumn{2}{|c|}{ Year 9} & \multicolumn{2}{|c|}{ Year 12} & \multicolumn{2}{|c|}{ Year 15} \\
\hline & $\begin{array}{c}\text { Fenced } \\
\bar{x} \\
\text { SD } \\
\end{array}$ & $\begin{array}{c}\text { Control } \\
\bar{x} \\
\mathrm{SD} \\
\end{array}$ & $\begin{array}{c}\text { Fenced } \\
\bar{x} \\
\mathrm{SD} \\
\end{array}$ & $\begin{array}{c}\text { Control } \\
\bar{x} \\
\mathrm{SD} \\
\end{array}$ & $\begin{array}{c}\text { Fenced } \\
\bar{x} \\
\mathrm{SD} \\
\end{array}$ & $\begin{array}{c}\text { Control } \\
\bar{x} \\
\mathrm{SD} \\
\end{array}$ \\
\hline Nyssa sylvatica Marshall & $\begin{array}{l}0.185 \\
0.415\end{array}$ & $\begin{array}{l}0.247 \\
0.593\end{array}$ & $\begin{array}{l}0.389 \\
0.178\end{array}$ & $\begin{array}{l}0.556 \\
0.242\end{array}$ & $\begin{array}{l}0.794 \\
0.978\end{array}$ & $\begin{array}{l}0.159 \\
0.389\end{array}$ \\
\hline Osmorhiza spp. & $\begin{array}{l}0.123 \\
0.593\end{array}$ & & & $\begin{array}{l}0.556 \\
0.242\end{array}$ & & \\
\hline Ostrya virginiana (Mill.) K. Koch & $\begin{array}{l}0.259 \\
0.679\end{array}$ & $\begin{array}{l}0.386 \\
0.578\end{array}$ & $\begin{array}{l}0.500 \\
1.383\end{array}$ & $\begin{array}{l}0.650 \\
1.548\end{array}$ & $\begin{array}{l}0.825 \\
1.892\end{array}$ & $\begin{array}{l}1.627 \\
4.165\end{array}$ \\
\hline Oxalis spp. & $\begin{array}{l}0.130 \\
0.384\end{array}$ & $\begin{array}{l}0.142 \\
0.414\end{array}$ & $\begin{array}{l}0.122 \\
0.459\end{array}$ & $\begin{array}{l}0.156 \\
0.234\end{array}$ & $\begin{array}{l}0.239 \\
0.858\end{array}$ & \\
\hline Oxydendrum arboreum (L.) DC. & & & $\begin{array}{l}0.556 \\
0.242\end{array}$ & & $\begin{array}{l}0.794 \\
0.286\end{array}$ & \\
\hline Packera aurea (L.) Á. Löve \& D. Löve & $\begin{array}{l}0.185 \\
0.764\end{array}$ & $\begin{array}{l}0.386 \\
0.127\end{array}$ & $\begin{array}{l}0.256 \\
1.887\end{array}$ & $\begin{array}{l}0.311 \\
1.356\end{array}$ & & \\
\hline Packera spp. & & $\begin{array}{l}0.123 \\
0.593\end{array}$ & & & & \\
\hline Panicum spp. & $\begin{array}{l}0.352 \\
0.776\end{array}$ & $\begin{array}{l}0.396 \\
0.533\end{array}$ & $\begin{array}{l}0.450 \\
1.164\end{array}$ & $\begin{array}{l}0.789 \\
1.558\end{array}$ & $\begin{array}{l}0.429 \\
1.224\end{array}$ & $\begin{array}{l}1.183 \\
1.755\end{array}$ \\
\hline Paronychia spp. L. & & & & & & \\
\hline Parthenocissus quinquefolia (L.) Planch. & $\begin{array}{l}0.426 \\
1.154\end{array}$ & $\begin{array}{l}0.142 \\
0.414\end{array}$ & $\begin{array}{l}0.889 \\
2.323\end{array}$ & $\begin{array}{l}0.194 \\
0.546\end{array}$ & $\begin{array}{l}0.675 \\
1.361\end{array}$ & $\begin{array}{l}0.397 \\
0.914\end{array}$ \\
\hline Phytolacca americana $\mathrm{L}$. & & & & $\begin{array}{l}0.333 \\
0.145\end{array}$ & & $\begin{array}{l}0.794 \\
0.286\end{array}$ \\
\hline Pilea pumila (L.) A. Gray & & & & $\begin{array}{l}0.333 \\
0.145\end{array}$ & & \\
\hline
\end{tabular}




\begin{tabular}{|c|c|c|c|c|c|c|}
\hline & \multicolumn{2}{|c|}{ Year 9} & \multicolumn{2}{|c|}{ Year 12} & \multicolumn{2}{|c|}{ Year 15} \\
\hline & $\begin{array}{c}\text { Fenced } \\
\bar{x} \\
\text { SD } \\
\end{array}$ & $\begin{array}{c}\text { Control } \\
\bar{x} \\
\text { SD }\end{array}$ & $\begin{array}{c}\text { Fenced } \\
\bar{x} \\
\text { SD } \\
\end{array}$ & $\begin{array}{c}\text { Control } \\
\bar{x} \\
\text { SD } \\
\end{array}$ & $\begin{array}{c}\text { Fenced } \\
\bar{x} \\
\text { SD } \\
\end{array}$ & $\begin{array}{c}\text { Control } \\
\bar{x} \\
\text { SD } \\
\end{array}$ \\
\hline \multirow{2}{*}{ Pinus strobus L. } & 0.386 & 0.130 & 0.222 & 0.611 & 0.317 & 0.119 \\
\hline & 0.135 & 0.434 & 0.969 & 0.243 & 0.884 & 0.372 \\
\hline Pinus taeda L. & & & & & & $\begin{array}{l}0.159 \\
0.572\end{array}$ \\
\hline Pinus virginiana Mill. & & & & $\begin{array}{l}0.111 \\
0.484\end{array}$ & & $\begin{array}{l}0.794 \\
0.286\end{array}$ \\
\hline \multirow{2}{*}{ Podophyllum peltatum L. } & 0.617 & 0.247 & 0.117 & 0.556 & 0.143 & \\
\hline & 0.167 & 0.119 & 0.329 & 0.242 & 0.457 & \\
\hline \multirow{2}{*}{ Polygonatum spp. Mill. } & 0.494 & & 0.222 & & 0.714 & \\
\hline & 0.178 & & 0.969 & & 0.258 & \\
\hline \multirow{2}{*}{ Polygonum spp. L. } & 0.185 & 0.123 & 0.222 & & & \\
\hline & 0.764 & 0.593 & 0.969 & & & \\
\hline \multirow{2}{*}{ Polygonum convolvulus L. } & 0.386 & & & & 0.794 & \\
\hline & 0.127 & & & & 0.286 & \\
\hline \multirow{2}{*}{ Polygonum hydropiper L. } & & & & 0.111 & & \\
\hline & & & & 0.484 & & \\
\hline \multirow{2}{*}{ Polygonum persicaria L. } & & & 0.556 & 0.944 & & \\
\hline & & & 0.242 & 0.412 & & \\
\hline \multirow{2}{*}{ Polystichum acrostichoides (Michx.) Schott } & 0.247 & & 0.217 & 0.217 & 0.556 & 1.952 \\
\hline & 0.796 & & 0.919 & 0.765 & 0.144 & 3.949 \\
\hline \multirow{2}{*}{ Potentilla spp. } & 0.796 & 0.433 & 0.683 & 0.433 & 0.158 & 0.794 \\
\hline & 1.335 & 1.389 & 1.368 & 1.182 & 0.324 & 0.286 \\
\hline \multirow{2}{*}{ Prenanthes alba L. } & 0.617 & & 0.278 & 0.333 & 0.635 & 0.556 \\
\hline & 0.255 & & 0.692 & 1.000 & 0.215 & 0.124 \\
\hline \multirow{2}{*}{ Prunus spp. } & 3.956 & 3.457 & 2.433 & 1.150 & 1.786 & 4.556 \\
\hline & 1.967 & 11.874 & 9.237 & 2.266 & 4.718 & 11.876 \\
\hline
\end{tabular}




\begin{tabular}{|c|c|c|c|c|c|c|}
\hline & \multicolumn{2}{|c|}{ Year 9} & \multicolumn{2}{|c|}{ Year 12} & \multicolumn{2}{|c|}{ Year 15} \\
\hline & $\begin{array}{l}\text { Fenced } \\
\bar{x} \\
\text { SD }\end{array}$ & $\begin{array}{c}\text { Control } \\
\bar{x} \\
\text { SD }\end{array}$ & $\begin{array}{c}\text { Fenced } \\
\bar{x} \\
\text { SD } \\
\end{array}$ & $\begin{array}{c}\text { Control } \\
\bar{x} \\
\text { SD }\end{array}$ & $\begin{array}{c}\text { Fenced } \\
\bar{x} \\
\text { SD } \\
\end{array}$ & $\begin{array}{c}\text { Control } \\
\bar{x} \\
\text { SD }\end{array}$ \\
\hline \multirow{2}{*}{ Pycnanthemum virginianum $\mathrm{L}$. } & 0.247 & 0.247 & 0.111 & 0.111 & 0.159 & \\
\hline & 0.796 & 0.119 & 0.484 & 0.333 & 0.572 & \\
\hline \multirow{2}{*}{ Pyrola americana Sweet } & & 0.994 & 0.556 & & 0.794 & \\
\hline & & 4.977 & 0.242 & & 0.286 & \\
\hline \multirow{2}{*}{ Pyrularia pubera Michx. } & 0.185 & & 0.611 & 0.410 & 0.119 & 0.794 \\
\hline & 0.764 & & 0.266 & 1.690 & 0.429 & 0.286 \\
\hline \multirow{2}{*}{ Quercus alba L. } & 0.617 & 0.825 & 0.278 & 0.722 & 0.635 & 0.143 \\
\hline & 0.229 & 0.177 & 0.712 & 2.797 & 0.177 & 0.321 \\
\hline \multirow{2}{*}{ Quercus berberidifolia Liebm. } & 0.386 & 0.142 & 0.200 & 0.222 & 0.366 & 0.500 \\
\hline & 0.127 & 0.585 & 0.847 & 0.969 & 1.316 & 1.828 \\
\hline \multirow{2}{*}{ Quercus coccinea Münchh. } & & & & & & 0.794 \\
\hline & & & & & & 0.286 \\
\hline \multirow{2}{*}{ Quercus prinus L. } & 0.136 & 0.136 & 0.444 & 0.222 & 0.159 & 0.794 \\
\hline & 0.377 & 0.322 & 0.177 & 0.649 & 0.572 & 0.199 \\
\hline \multirow{2}{*}{ Quercus rubra L. } & 0.111 & 0.299 & 0.122 & 0.261 & 0.214 & 0.132 \\
\hline & 0.264 & 0.355 & 0.276 & 0.472 & 0.467 & 0.247 \\
\hline \multirow{2}{*}{ Quercus velutina Lam } & & & & & 0.159 & 0.635 \\
\hline & & & & & 0.389 & 0.150 \\
\hline \multirow{2}{*}{ Ranunculus spp. } & & & & 0.389 & 0.794 & 0.532 \\
\hline & & & & 1.695 & 0.286 & 1.769 \\
\hline \multirow{2}{*}{ Rhododendron spp. } & 0.123 & 0.222 & 0.222 & 0.778 & 0.476 & 0.476 \\
\hline & 0.349 & 0.864 & 0.969 & 0.339 & 0.172 & 0.172 \\
\hline
\end{tabular}




\begin{tabular}{|c|c|c|c|c|c|c|}
\hline & \multicolumn{2}{|c|}{ Year 9} & \multicolumn{2}{|c|}{ Year 12} & \multicolumn{2}{|c|}{ Year 15} \\
\hline & Fenced & Control & Fenced & Control & Fenced & Control \\
\hline & $\bar{x}$ & $\bar{x}$ & $\bar{x}$ & $\bar{x}$ & $\bar{x}$ & $\bar{x}$ \\
\hline & $\mathrm{SD}$ & $\mathrm{SD}$ & $\mathrm{SD}$ & $\mathrm{SD}$ & $\mathrm{SD}$ & $\mathrm{SD}$ \\
\hline \multirow{2}{*}{ Robinia pseudoacacia $\mathrm{L}$} & & 0.494 & 0.556 & 0.333 & 0.239 & 0.794 \\
\hline & & 0.236 & 0.242 & 0.122 & 0.858 & 0.286 \\
\hline \multirow{2}{*}{ Rosa multiflora Thunb. } & 0.179 & 0.191 & 0.178 & 0.150 & 0.556 & 0.952 \\
\hline & 0.435 & 0.455 & 0.629 & 0.365 & 0.144 & 0.237 \\
\hline \multirow{2}{*}{ Rubus spp. L.H.Bailey (Dewberry) } & 1.185 & & 1.250 & 0.839 & 1.540 & \\
\hline & 4.887 & & 5.449 & 3.657 & 5.551 & \\
\hline \multirow{2}{*}{ Rubus spp. } & 1.912 & 1.833 & 1.122 & 0.256 & 2.468 & 1.889 \\
\hline & 4.882 & 4.659 & 1.948 & 0.359 & 5.670 & 5.171 \\
\hline \multirow{2}{*}{ Ruellia spp. L. } & & & & 0.222 & & \\
\hline & & & & 0.969 & & \\
\hline \multirow{2}{*}{ Rumex acetosella $\mathrm{L}$. } & & 0.623 & & 0.183 & & 0.754 \\
\hline & & 2.156 & & 0.726 & & 2.496 \\
\hline \multirow{2}{*}{ Sanguinaria canadensis L. } & 0.386 & 0.747 & 0.333 & & & \\
\hline & 0.127 & 0.354 & 0.160 & & & \\
\hline \multirow{2}{*}{ Sassafras albidum (Nutt.) Nees } & 0.747 & 0.414 & 0.122 & 0.400 & 0.143 & 0.263 \\
\hline & 0.354 & 1.496 & 0.296 & 1.126 & 0.318 & 0.744 \\
\hline \multirow{2}{*}{ Scutellaria lateriflora L. } & & & & 0.778 & & \\
\hline & & & & 0.339 & & \\
\hline \multirow{2}{*}{ Sedum spp. } & & & 0.667 & 0.222 & 0.111 & 0.132 \\
\hline & & & 0.296 & 0.969 & 0.462 & 0.372 \\
\hline \multirow{2}{*}{ Smilax spp. } & 0.291 & 0.396 & 0.544 & 0.556 & 0.926 & 0.944 \\
\hline & 0.350 & 0.527 & 0.594 & 0.718 & 1.387 & 0.982 \\
\hline \multirow{2}{*}{ Smilax herbacea L. } & 0.864 & & & & & \\
\hline & 0.367 & & & & & \\
\hline
\end{tabular}




\begin{tabular}{|c|c|c|c|c|c|c|}
\hline & \multicolumn{2}{|c|}{ Year 9} & \multicolumn{2}{|c|}{ Year 12} & \multicolumn{2}{|c|}{ Year 15} \\
\hline & $\begin{array}{c}\text { Fenced } \\
\bar{x} \\
\text { SD } \\
\end{array}$ & $\begin{array}{c}\text { Control } \\
\bar{x} \\
\text { SD } \\
\end{array}$ & $\begin{array}{c}\text { Fenced } \\
\bar{x} \\
\text { SD } \\
\end{array}$ & $\begin{array}{c}\text { Control } \\
\bar{x} \\
\text { SD } \\
\end{array}$ & $\begin{array}{c}\text { Fenced } \\
\bar{x} \\
\mathrm{SD} \\
\end{array}$ & $\begin{array}{c}\text { Control } \\
\bar{x} \\
\text { SD } \\
\end{array}$ \\
\hline Solanum americanum Mill. & & $\begin{array}{l}0.123 \\
0.593\end{array}$ & & $\begin{array}{l}0.167 \\
0.726\end{array}$ & & \\
\hline Solidago spp. & $\begin{array}{l}0.358 \\
0.824\end{array}$ & $\begin{array}{l}0.148 \\
0.399\end{array}$ & $\begin{array}{l}0.278 \\
0.846\end{array}$ & $\begin{array}{l}0.200 \\
0.528\end{array}$ & $\begin{array}{l}0.873 \\
0.193\end{array}$ & \\
\hline Streptopus lanceolatus (Aiton) Reveal & $\begin{array}{l}0.386 \\
0.812\end{array}$ & $\begin{array}{l}0.617 \\
0.255\end{array}$ & & $\begin{array}{l}0.389 \\
0.146\end{array}$ & $\begin{array}{l}0.952 \\
0.287\end{array}$ & $\begin{array}{l}0.317 \\
0.654\end{array}$ \\
\hline Stellaria media $\mathrm{L}$. & & $\begin{array}{l}0.617 \\
0.255\end{array}$ & $\begin{array}{l}0.556 \\
0.242\end{array}$ & $\begin{array}{l}0.278 \\
0.919\end{array}$ & & $\begin{array}{l}0.635 \\
0.229\end{array}$ \\
\hline Symphotrichium spp. & $\begin{array}{l}0.340 \\
1.915\end{array}$ & $\begin{array}{l}0.296 \\
1.657\end{array}$ & $\begin{array}{l}0.367 \\
1.472\end{array}$ & $\begin{array}{l}0.278 \\
0.923\end{array}$ & $\begin{array}{l}0.325 \\
0.846\end{array}$ & $\begin{array}{l}0.317 \\
0.654\end{array}$ \\
\hline Thalictrum spp. L. & & & & $\begin{array}{l}0.278 \\
0.986\end{array}$ & & \\
\hline Thelypteris noveboracensis (L.) Nieuwl. & $\begin{array}{c}4.912 \\
14.662\end{array}$ & $\begin{array}{l}1.963 \\
3.572\end{array}$ & $\begin{array}{l}1.333 \\
2.533\end{array}$ & $\begin{array}{l}2.811 \\
8.956\end{array}$ & $\begin{array}{c}4.619 \\
11.187\end{array}$ & $\begin{array}{c}4.714 \\
12.385\end{array}$ \\
\hline Toxicodendron radicans (L.) Kuntze & $\begin{array}{l}0.198 \\
0.358\end{array}$ & $\begin{array}{l}0.617 \\
0.140\end{array}$ & $\begin{array}{l}0.328 \\
0.526\end{array}$ & $\begin{array}{l}0.167 \\
0.397\end{array}$ & $\begin{array}{l}0.397 \\
0.830\end{array}$ & $\begin{array}{l}0.143 \\
0.312\end{array}$ \\
\hline Triodanis perfoliata (L.) Nieuwl. & $\begin{array}{l}0.123 \\
0.593\end{array}$ & $\begin{array}{l}0.185 \\
0.764\end{array}$ & & & & \\
\hline Ulmus spp. & & $\begin{array}{l}0.617 \\
0.255\end{array}$ & $\begin{array}{l}0.333 \\
0.122\end{array}$ & $\begin{array}{l}0.222 \\
0.567\end{array}$ & & \\
\hline Uvularia spp. & $\begin{array}{l}0.791 \\
1.688 \\
\end{array}$ & $\begin{array}{l}0.386 \\
0.812 \\
\end{array}$ & $\begin{array}{l}0.567 \\
1.334 \\
\end{array}$ & $\begin{array}{l}0.389 \\
0.882 \\
\end{array}$ & $\begin{array}{l}0.675 \\
1.689 \\
\end{array}$ & $\begin{array}{l}0.317 \\
0.778 \\
\end{array}$ \\
\hline
\end{tabular}




\begin{tabular}{|c|c|c|c|c|c|c|}
\hline & \multicolumn{2}{|c|}{ Year 9} & \multicolumn{2}{|c|}{ Year 12} & \multicolumn{2}{|c|}{ Year 15} \\
\hline & Fenced & Control & Fenced & Control & Fenced & Control \\
\hline & $\bar{x}$ & $\bar{x}$ & $\bar{x}$ & $\bar{x}$ & $\bar{x}$ & $\bar{x}$ \\
\hline & SD & $\mathrm{SD}$ & SD & SD & SD & SD \\
\hline \multirow{2}{*}{ Vaccinium spp. } & 1.825 & 2.825 & 2.144 & 2.350 & 0.841 & 2.357 \\
\hline & 3.575 & 4.266 & 4.139 & 5.189 & 1.693 & 7.220 \\
\hline \multirow{2}{*}{ Verbesina alternifolia (L.) Britton ex Kearney } & & 0.185 & & 0.222 & & \\
\hline & & 0.764 & & 0.667 & & \\
\hline \multirow{2}{*}{ Veronica spp. } & 0.191 & 0.247 & & & & \\
\hline & 0.762 & 0.119 & & & & \\
\hline \multirow{2}{*}{ Viola spp. L. } & 2.562 & 1.840 & 1.250 & 5.478 & 0.366 & 1.587 \\
\hline & 6.556 & 3.129 & 3.693 & 17.170 & 0.449 & 3.326 \\
\hline \multirow{2}{*}{ Viburnum spp. } & 0.374 & 0.679 & 0.556 & 0.100 & 0.794 & 0.159 \\
\hline & 0.148 & 0.280 & 0.173 & 0.386 & 0.286 & 0.572 \\
\hline \multirow{2}{*}{ Viburnum acerifolium $\mathrm{L}$. } & 0.556 & 0.140 & & 0.389 & 0.952 & 0.556 \\
\hline & 0.230 & 0.560 & & 0.170 & 0.343 & 0.238 \\
\hline \multirow{2}{*}{ Viburnum lantanoides Michx. } & 0.386 & & 0.500 & & & \\
\hline & 0.127 & & 0.218 & & & \\
\hline \multirow{2}{*}{ Viburnum prunifolium $\mathrm{L}$. } & 0.617 & 0.185 & 0.128 & 0.444 & & \\
\hline & 0.255 & 0.764 & 0.557 & 0.194 & & \\
\hline \multirow{2}{*}{ Vicia caroliniana Walter } & & 0.926 & & 0.500 & & \\
\hline & & 0.382 & & 0.174 & & \\
\hline \multirow{2}{*}{ Vitis spp. } & 0.386 & 0.179 & 0.444 & 0.833 & 0.794 & 0.714 \\
\hline & 0.127 & 0.594 & 0.147 & 0.215 & 0.286 & 0.229 \\
\hline
\end{tabular}




\begin{tabular}{|c|c|c|c|c|}
\hline & \multicolumn{2}{|c|}{ Year 18} & \multicolumn{2}{|c|}{ Year 21} \\
\hline & Fenced & Control & Fenced & Control \\
\hline & $\bar{x}$ & $\bar{x}$ & $\bar{x}$ & $\bar{x}$ \\
\hline & SD & $\mathrm{SD}$ & $\mathrm{SD}$ & $\mathrm{SD}$ \\
\hline \multirow{2}{*}{ Acer pensylvanicum $\mathrm{L}$. } & 0.119 & 0.214 & 0.256 & 0.179 \\
\hline & 0.347 & 0.612 & 0.888 & 0.454 \\
\hline \multirow{2}{*}{ Acer rubrum $\mathrm{L}$. } & 1.895 & 3.556 & 2.154 & 2.838 \\
\hline & 2.377 & 4.775 & 3.152 & 4.584 \\
\hline \multirow{2}{*}{ Acer saccharum Marshall } & 0.595 & 0.239 & 1.942 & 0.197 \\
\hline & 1.826 & 0.458 & 2.914 & 0.412 \\
\hline \multirow{2}{*}{ Ageratina altissima (L.) King \& H. Rob. } & 1.635 & 0.675 & 0.299 & 0.342 \\
\hline & 2.397 & 2.717 & 0.944 & 0.576 \\
\hline \multirow{2}{*}{ Agrimonia spp. } & & & & 0.598 \\
\hline & & & & 0.273 \\
\hline \multirow{2}{*}{ Aesculus glabra Willd } & 0.794 & & 0.855 & \\
\hline & 0.286 & & 0.297 & \\
\hline \multirow{2}{*}{ Actaea racemosa $\mathrm{L}$. } & 0.239 & & & \\
\hline & 0.620 & & & \\
\hline \multirow{2}{*}{ Alcalypha virginica spp. L. } & 0.794 & 0.159 & 0.855 & 0.179 \\
\hline & 0.286 & 0.572 & 0.297 & 0.489 \\
\hline \multirow{2}{*}{ Amelanchier arborea Michx. } & 0.397 & 0.714 & 0.239 & 0.154 \\
\hline & 0.798 & 0.116 & 0.331 & 0.188 \\
\hline \multirow{2}{*}{ Amianthium muscitoxicum (Walter) A. Gray } & 0.175 & & & \\
\hline & 0.630 & & & \\
\hline \multirow{2}{*}{ Anemone virginiana $\mathrm{L}$. } & 0.397 & & 0.179 & 0.179 \\
\hline & 0.144 & & 0.489 & 0.592 \\
\hline \multirow{2}{*}{ Antennaria spp. Gaertn. } & 0.111 & 0.239 & 0.983 & 0.256 \\
\hline & 0.462 & 0.858 & 3.279 & 0.888 \\
\hline
\end{tabular}




\begin{tabular}{|c|c|c|c|c|}
\hline & \multicolumn{2}{|c|}{ Year 18} & \multicolumn{2}{|c|}{ Year 21} \\
\hline & $\begin{array}{c}\text { Fenced } \\
\bar{x} \\
\text { SD }\end{array}$ & $\begin{array}{l}\text { Control } \\
\bar{x} \\
\text { SD }\end{array}$ & $\begin{array}{c}\text { Fenced } \\
\bar{x} \\
\text { SD }\end{array}$ & $\begin{array}{l}\text { Control } \\
\bar{x} \\
\text { SD }\end{array}$ \\
\hline Apocynum spp. L. & & & $\begin{array}{l}0.342 \\
0.118\end{array}$ & \\
\hline Aronia melanocarpa Michx. & $\begin{array}{l}0.794 \\
0.286\end{array}$ & & & \\
\hline Arisaema triphyllum L. & $\begin{array}{l}0.763 \\
1.839\end{array}$ & $\begin{array}{l}0.316 \\
0.554\end{array}$ & $\begin{array}{l}0.256 \\
0.640\end{array}$ & $\begin{array}{l}0.179 \\
0.391\end{array}$ \\
\hline Asarum canadense spp. L. & $\begin{array}{l}0.952 \\
0.343\end{array}$ & & & \\
\hline Asimina triloba (L.) Dunal & $\begin{array}{l}0.794 \\
0.286\end{array}$ & $\begin{array}{l}0.159 \\
0.572\end{array}$ & $\begin{array}{l}0.855 \\
0.297\end{array}$ & \\
\hline $\begin{array}{l}\text { Asplenium platyneuron (L.) Britton, Sterns \& } \\
\text { Poggenb. }\end{array}$ & & & $\begin{array}{l}0.342 \\
0.118\end{array}$ & $\begin{array}{l}0.256 \\
0.888\end{array}$ \\
\hline Betula spp. & $\begin{array}{l}0.556 \\
0.138\end{array}$ & $\begin{array}{l}0.159 \\
0.389\end{array}$ & & $\begin{array}{l}0.126 \\
0.355\end{array}$ \\
\hline Botrychium virginianum (L.) Sw. & & $\begin{array}{l}0.873 \\
0.285\end{array}$ & $\begin{array}{l}0.111 \\
0.355\end{array}$ & $\begin{array}{l}0.179 \\
0.569\end{array}$ \\
\hline Cardamine nuttallii Greene & $\begin{array}{l}0.794 \\
0.286\end{array}$ & & & \\
\hline Carex spp. & $\begin{array}{l}0.167 \\
0.422\end{array}$ & $\begin{array}{l}0.232 \\
0.374\end{array}$ & $\begin{array}{l}0.462 \\
1.258\end{array}$ & $\begin{array}{l}0.538 \\
0.855\end{array}$ \\
\hline Carya spp. & $\begin{array}{l}0.111 \\
0.232\end{array}$ & $\begin{array}{l}0.714 \\
0.132\end{array}$ & $\begin{array}{l}0.942 \\
0.235\end{array}$ & $\begin{array}{l}0.111 \\
0.174\end{array}$ \\
\hline Celastrus scandens L. & $\begin{array}{l}0.397 \\
0.144\end{array}$ & & & \\
\hline
\end{tabular}




\begin{tabular}{|c|c|c|c|c|}
\hline & \multicolumn{2}{|c|}{ Year 18} & \multicolumn{2}{|c|}{ Year 21} \\
\hline & $\begin{array}{l}\text { Fenced } \\
\bar{x} \\
\text { SD }\end{array}$ & $\begin{array}{c}\text { Control } \\
\bar{x} \\
\mathrm{SD} \\
\end{array}$ & $\begin{array}{c}\text { Fenced } \\
\bar{x} \\
\text { SD } \\
\end{array}$ & $\begin{array}{c}\text { Control } \\
\bar{x} \\
\text { SD }\end{array}$ \\
\hline Cercis canadensis $\mathrm{L}$. & $\begin{array}{l}0.952 \\
0.343\end{array}$ & $\begin{array}{l}0.397 \\
0.144\end{array}$ & $\begin{array}{l}0.111 \\
0.355\end{array}$ & $\begin{array}{l}0.427 \\
0.126\end{array}$ \\
\hline Chamerion angustifolium (L.) Holub & & & & $\begin{array}{l}0.393 \\
1.362\end{array}$ \\
\hline Chamaecrista fasciculata (Michx.) & 0.317 & 0.317 & 0.145 & 0.265 \\
\hline Greene & 0.114 & 0.884 & 0.533 & 0.886 \\
\hline & 0.794 & 0.317 & 0.769 & 0.513 \\
\hline Chımaphıla maculata (L.) Pursh & 0.286 & 0.778 & 0.192 & 0.128 \\
\hline Chimaphila umbellata (L.) W.P.C. & & & & 0.855 \\
\hline Barton & & & & 0.297 \\
\hline Cicuta maculata $\mathrm{L}$. & & & & $\begin{array}{l}0.855 \\
0.297\end{array}$ \\
\hline Claytonia spp. L. & & & $\begin{array}{l}0.855 \\
0.297\end{array}$ & \\
\hline Cornus florida $\mathrm{L}$. & $\begin{array}{l}0.239 \\
0.858\end{array}$ & $\begin{array}{l}0.556 \\
0.172\end{array}$ & $\begin{array}{l}0.239 \\
0.526\end{array}$ & $\begin{array}{l}0.154 \\
0.336\end{array}$ \\
\hline Corylus americana Walter & $\begin{array}{l}0.127 \\
0.458\end{array}$ & & & \\
\hline Crataegus spp. & $\begin{array}{l}0.952 \\
0.314\end{array}$ & $\begin{array}{l}0.132 \\
0.372\end{array}$ & & \\
\hline Danthonia spicata (L.) Beauv. & & $\begin{array}{l}0.232 \\
0.830\end{array}$ & & \\
\hline
\end{tabular}




\begin{tabular}{|c|c|c|c|c|}
\hline \multirow{4}{*}{ Appendix 6 Continued } & \multicolumn{2}{|c|}{ Year 18} & \multicolumn{2}{|c|}{ Year 21} \\
\hline & Fenced & Control & Fenced & Control \\
\hline & $\bar{x}$ & $\bar{x}$ & $\bar{x}$ & $\bar{x}$ \\
\hline & $\mathrm{SD}$ & SD & SD & $\mathrm{SD}$ \\
\hline \multirow{2}{*}{ Desmodium spp. } & 0.476 & 0.476 & 0.419 & 0.889 \\
\hline & 0.144 & 0.144 & 0.959 & 2.926 \\
\hline \multirow{2}{*}{ Dioscorea villosa $\mathrm{L}$. } & 0.143 & 0.556 & 0.855 & 0.513 \\
\hline & 0.345 & 0.172 & 0.185 & 0.149 \\
\hline \multirow{2}{*}{ Dryopteris spp. L. } & 1.794 & 1.294 & 0.239 & 0.564 \\
\hline & 3.429 & 4.247 & 0.829 & 1.334 \\
\hline \multirow{2}{*}{ Elaeagnus umbellata Thunb. } & & 0.159 & 0.342 & \\
\hline & & 0.572 & 0.118 & \\
\hline \multirow{2}{*}{ Epigaea repens $\mathrm{L}$. } & 0.794 & & 0.111 & 0.126 \\
\hline & 0.286 & & 0.355 & 0.298 \\
\hline \multirow{2}{*}{ Euonymus alatus (Thunb.) Siebold } & 0.167 & & & 0.855 \\
\hline & 0.693 & & & 0.297 \\
\hline \multirow{2}{*}{ Eutrochium purpureum (L.) E.E. Lamont } & & & & 0.855 \\
\hline & & & & 0.297 \\
\hline \multirow{2}{*}{ Fagus grandifolia Ehrh. } & 0.794 & 0.317 & 0.179 & 0.256 \\
\hline & 0.286 & 0.114 & 0.592 & 0.640 \\
\hline \multirow{2}{*}{ Fraxinus americana $\mathrm{L}$. } & 0.317 & & 0.855 & 0.179 \\
\hline & 0.778 & & 0.297 & 0.489 \\
\hline \multirow{2}{*}{ Galium spp. } & 0.127 & 0.111 & 0.325 & 0.769 \\
\hline & 0.275 & 0.320 & 1.934 & 0.236 \\
\hline \multirow{2}{*}{ Gaultheria procumbens $\mathrm{L}$. } & 1.278 & & 3.325 & 0.543 \\
\hline & 3.926 & & 7.681 & 1.385 \\
\hline \multirow{2}{*}{ Gaylussacia spp. Kunth } & 0.127 & & & \\
\hline & 0.458 & & & \\
\hline \multirow{2}{*}{ Gaylussacia ursina (M.A. Curtis) Torr. } & 0.794 & 0.239 & 0.120 & 0.834 \\
\hline & 0.286 & 0.714 & 0.294 & 1.493 \\
\hline
\end{tabular}




\begin{tabular}{|c|c|c|c|c|}
\hline & \multicolumn{2}{|c|}{ Year 18} & \multicolumn{2}{|c|}{ Year 21} \\
\hline & $\begin{array}{c}\text { Fenced } \\
\bar{x} \\
\text { SD }\end{array}$ & $\begin{array}{c}\text { Control } \\
\bar{x} \\
\text { SD }\end{array}$ & $\begin{array}{c}\text { Fenced } \\
\bar{x} \\
\text { SD }\end{array}$ & $\begin{array}{c}\text { Control } \\
\bar{x} \\
\text { SD } \\
\end{array}$ \\
\hline Geum spp. L. & & & $\begin{array}{l}0.427 \\
0.148\end{array}$ & $\begin{array}{l}0.479 \\
1.628\end{array}$ \\
\hline Geranium spp. L. & $\begin{array}{l}0.278 \\
0.834\end{array}$ & & $\begin{array}{l}0.179 \\
0.592\end{array}$ & $\begin{array}{l}0.942 \\
0.296\end{array}$ \\
\hline Gillenia trifoliata (L.) Moench & $\begin{array}{l}0.794 \\
0.286\end{array}$ & & & \\
\hline Hamamelis virginiana $\mathrm{L}$. & $\begin{array}{l}0.476 \\
0.894\end{array}$ & $\begin{array}{l}0.135 \\
0.399\end{array}$ & $\begin{array}{l}0.342 \\
0.913\end{array}$ & $\begin{array}{l}0.179 \\
0.489\end{array}$ \\
\hline Hieracium fendleri Sch. Bip & & $\begin{array}{l}0.794 \\
0.286\end{array}$ & & $\begin{array}{l}0.684 \\
0.269\end{array}$ \\
\hline Hieracium venosum $\mathrm{L}$. & & & & $\begin{array}{l}0.111 \\
0.385\end{array}$ \\
\hline Hypericum punctatutm. L. & & $\begin{array}{l}0.397 \\
0.144\end{array}$ & & \\
\hline Isotria vertucillata Willd. & $\begin{array}{l}0.294 \\
1.588\end{array}$ & & $\begin{array}{l}0.145 \\
0.347\end{array}$ & $\begin{array}{l}0.427 \\
0.126\end{array}$ \\
\hline Juniperus virginiana $\mathrm{L}$ & $\begin{array}{l}0.794 \\
0.286\end{array}$ & & & \\
\hline Kalmia latifolia $\mathrm{L}$. & $\begin{array}{l}0.159 \\
0.293 \\
\end{array}$ & $\begin{array}{l}0.316 \\
0.749\end{array}$ & $\begin{array}{l}0.251 \\
0.422 \\
\end{array}$ & $\begin{array}{l}0.197 \\
0.650 \\
\end{array}$ \\
\hline
\end{tabular}




\begin{tabular}{|c|c|c|c|c|}
\hline \multirow{2}{*}{$\begin{array}{lll}1 \times 0 \\
\end{array}$} & \multicolumn{2}{|c|}{ Year 18} & \multicolumn{2}{|c|}{ Year 21} \\
\hline & $\begin{array}{l}\text { Fenced } \\
\bar{x} \\
\text { SD }\end{array}$ & $\begin{array}{c}\text { Control } \\
\bar{x} \\
\text { SD }\end{array}$ & $\begin{array}{c}\text { Fenced } \\
\bar{x} \\
\text { SD }\end{array}$ & $\begin{array}{c}\text { Control } \\
\bar{x} \\
\text { SD } \\
\end{array}$ \\
\hline \multirow{2}{*}{ Lindera benzoin (L.) Blume } & & 0.239 & 0.179 & 0.427 \\
\hline & & 0.858 & 0.592 & 0.148 \\
\hline \multirow{2}{*}{ Liriodendron tulipifera $\mathrm{L}$. } & 0.239 & 0.397 & 0.513 & 0.162 \\
\hline & 0.620 & 0.679 & 0.133 & 0.319 \\
\hline \multirow{2}{*}{ Lonicera japonica Thunb. } & & & 0.418 & 0.251 \\
\hline & & & 1.298 & 0.716 \\
\hline \multirow{2}{*}{ Lonicera tatarica L.) } & & & 0.256 & \\
\hline & & & 0.888 & \\
\hline \multirow{2}{*}{ Lycopodium dendroideum Michx. } & 0.167 & & 0.238 & \\
\hline & 0.693 & & 0.799 & \\
\hline \multirow{2}{*}{ Lyonia ligustrina (L.) DC. } & & & 0.179 & \\
\hline & & & 0.592 & \\
\hline \multirow{2}{*}{ Lysmachia quadrifolia $\mathrm{L}$. } & 0.794 & 0.159 & 0.513 & 0.179 \\
\hline & 0.286 & 0.389 & 0.133 & 0.489 \\
\hline \multirow{2}{*}{ Maianthemum racemosum (L.) Link } & 0.159 & & & \\
\hline & 0.572 & & & \\
\hline \multirow{2}{*}{ Maianthemum canadense Desf. } & 0.794 & & 0.128 & 0.342 \\
\hline & 0.286 & & 0.337 & 0.913 \\
\hline \multirow{2}{*}{ Magnolia acuminata $\mathrm{L}$. } & & & 0.855 & 0.855 \\
\hline & & & 0.297 & 0.297 \\
\hline \multirow{2}{*}{ Magnolia tripetala } & & & & 0.855 \\
\hline & & & & 0.297 \\
\hline
\end{tabular}




\begin{tabular}{|c|c|c|c|c|}
\hline & \multicolumn{2}{|c|}{ Year 18} & \multicolumn{2}{|c|}{ Year 21} \\
\hline & Fenced & Control & Fenced & Control \\
\hline & $\bar{x}$ & $\bar{x}$ & $\bar{x}$ & $\bar{x}$ \\
\hline & $\mathrm{SD}$ & SD & SD & $\mathrm{SD}$ \\
\hline \multirow{2}{*}{ Medeola virginiana $\mathrm{L}$. } & 0.135 & & 0.126 & \\
\hline & 0.486 & & 0.355 & \\
\hline \multirow{2}{*}{ Menziesia pilosa (Michx. ex Lam.) Juss. ex Pers } & 0.556 & & 0.359 & \\
\hline & 2.384 & & 1.244 & \\
\hline \multirow{2}{*}{ Morus spp. } & & 0.794 & & \\
\hline & & 0.286 & & \\
\hline \multirow{2}{*}{ Nyssa sylvatica Marshall } & 0.794 & 0.159 & 0.513 & 0.256 \\
\hline & 0.978 & 0.389 & 0.133 & 0.468 \\
\hline \multirow{2}{*}{ Ostrya virginiana (Mill.) K. Koch } & 0.825 & 1.627 & 0.419 & 0.413 \\
\hline & 1.892 & 4.165 & 1.145 & 0.819 \\
\hline \multirow{2}{*}{ Oxalis spp. } & 0.239 & & 0.256 & 0.342 \\
\hline & 0.858 & & 0.640 & 0.673 \\
\hline \multirow{2}{*}{ Oxydendrum arboreum (L.) DC. } & 0.794 & & 0.179 & \\
\hline & 0.286 & & 0.592 & \\
\hline \multirow{2}{*}{ Packera aurea (L.) Á. Löve \& D. Löve } & & & 0.111 & 0.265 \\
\hline & & & 0.385 & 0.918 \\
\hline \multirow{2}{*}{ Panicum spp. } & 0.429 & 1.183 & 0.179 & 0.863 \\
\hline & 1.224 & 1.755 & 0.441 & 1.291 \\
\hline \multicolumn{5}{|l|}{ Paronychia spp. L. } \\
\hline \multirow{2}{*}{ Parthenocissus quinquefolia (L.) Planch. } & 0.675 & 0.397 & 0.966 & 0.598 \\
\hline & 1.361 & 0.914 & 2.270 & 0.123 \\
\hline \multirow{2}{*}{ Phytolacca americana L. } & & 0.794 & & \\
\hline & & 0.286 & & \\
\hline \multirow[t]{2}{*}{ Pinus strobus L. } & 0.317 & 0.119 & 0.598 & 0.564 \\
\hline & 0.884 & 0.372 & 1.737 & 1.346 \\
\hline
\end{tabular}




\begin{tabular}{|c|c|c|c|c|}
\hline \multirow{4}{*}{ Appendix 6 Continued } & \multicolumn{2}{|c|}{ Year 18} & \multicolumn{2}{|c|}{ Year 21} \\
\hline & Fenced & Control & Fenced & Control \\
\hline & $\bar{x}$ & $\bar{x}$ & $\bar{x}$ & $\bar{x}$ \\
\hline & SD & SD & SD & SD \\
\hline \multirow{2}{*}{ Pinus taeda $\mathrm{L}$. } & & 0.159 & & \\
\hline & & 0.572 & & \\
\hline \multirow{2}{*}{ Pinus virginiana Mill. } & & 0.794 & & \\
\hline & & 0.286 & & \\
\hline \multirow{2}{*}{ Podophyllum peltatum $\mathrm{L}$. } & 0.143 & & 0.162 & 0.342 \\
\hline & 0.457 & & 0.531 & 0.118 \\
\hline \multirow{2}{*}{ Polygonatum spp. Mill. } & 0.714 & & & \\
\hline & 0.258 & & & \\
\hline \multirow{2}{*}{ Polygonum convolvulus L. } & 0.794 & & 0.684 & 0.179 \\
\hline & 0.286 & & 0.237 & 0.592 \\
\hline \multirow{2}{*}{ Polygonum hydropiper L. } & & & 0.855 & 0.342 \\
\hline & & & 0.297 & 0.118 \\
\hline \multirow{2}{*}{ Polystichum acrostichoides (Michx.) Schott } & 0.556 & 1.952 & 0.598 & 0.238 \\
\hline & 0.144 & 3.949 & 0.273 & 0.738 \\
\hline \multirow{2}{*}{ Potentilla spp. } & 0.158 & 0.794 & 0.889 & 1.427 \\
\hline & 0.324 & 0.286 & 1.933 & 3.930 \\
\hline \multirow{2}{*}{ Prenanthes alba $\mathrm{L}$. } & 0.635 & 0.556 & 0.342 & 0.256 \\
\hline & 0.215 & 0.124 & 0.818 & 0.888 \\
\hline \multirow{2}{*}{ Prunus spp. } & 1.786 & 4.556 & 2.598 & 0.786 \\
\hline & 4.718 & 11.876 & 5.593 & 1.441 \\
\hline \multirow{2}{*}{ Pycnanthemum virginianum $\mathrm{L}$. } & 0.159 & & 0.342 & \\
\hline & 0.572 & & 0.118 & \\
\hline \multirow{2}{*}{ Pyrola americana Sweet } & 0.794 & & & 0.179 \\
\hline & 0.286 & & & 0.592 \\
\hline
\end{tabular}




\begin{tabular}{|c|c|c|c|c|}
\hline \multirow{4}{*}{ Appendix 6 Continued } & \multicolumn{2}{|c|}{ Year 18} & \multicolumn{2}{|c|}{ Year 21} \\
\hline & Fenced & Control & Fenced & Control \\
\hline & $\bar{x}$ & $\bar{x}$ & $\bar{x}$ & $\bar{x}$ \\
\hline & $\mathrm{SD}$ & $\mathrm{SD}$ & $\mathrm{SD}$ & $\mathrm{SD}$ \\
\hline \multirow{2}{*}{ Pyrularia pubera Michx. } & 0.119 & 0.794 & 0.145 & 0.179 \\
\hline & 0.429 & 0.286 & 0.533 & 0.592 \\
\hline \multirow{2}{*}{ Quercus alba L. } & 0.635 & 0.143 & 0.256 & 0.251 \\
\hline & 0.177 & 0.321 & 0.485 & 0.414 \\
\hline \multirow{2}{*}{ Quercus berberidifolia Liebm. } & 0.366 & 0.500 & 0.855 & 0.855 \\
\hline & 1.316 & 1.828 & 0.297 & 0.297 \\
\hline \multirow{2}{*}{ Quercus coccinea Münchh. } & & 0.794 & & 0.855 \\
\hline & & 0.286 & & 0.297 \\
\hline \multirow{2}{*}{ Quercus prinus L. } & 0.159 & 0.794 & 0.128 & 0.126 \\
\hline & 0.572 & 0.199 & 0.337 & 0.245 \\
\hline \multirow{2}{*}{ Quercus rubra L. } & 0.214 & 0.132 & 0.239 & 0.154 \\
\hline & 0.467 & 0.247 & 0.414 & 0.233 \\
\hline \multirow{2}{*}{ Quercus velutina Lam } & 0.159 & 0.635 & 0.179 & 0.598 \\
\hline & 0.389 & 0.150 & 0.489 & 0.142 \\
\hline \multirow{2}{*}{ Ranunculus spp. } & 0.794 & 0.532 & & \\
\hline & 0.286 & 1.769 & & \\
\hline \multirow{2}{*}{ Rhododendron spp. } & 0.476 & 0.476 & 0.427 & 0.513 \\
\hline & 0.172 & 0.172 & 1.354 & 1.413 \\
\hline \multirow{2}{*}{ Robinia pseudoacacia $\mathrm{L}$} & 0.239 & 0.794 & & 0.855 \\
\hline & 0.858 & 0.286 & & 0.297 \\
\hline \multirow{2}{*}{ Rosa multiflora Thunb. } & 0.556 & 0.952 & 0.487 & 0.197 \\
\hline & 0.144 & 0.237 & 1.264 & 0.438 \\
\hline \multirow{2}{*}{ Rubus spp. L.H.Bailey (Dewberry) } & 1.540 & & & \\
\hline & 5.551 & & & \\
\hline \multirow{2}{*}{ Rubus spp. } & 2.468 & 1.889 & 0.960 & 0.942 \\
\hline & 5.670 & 5.171 & 1.345 & 3.343 \\
\hline
\end{tabular}




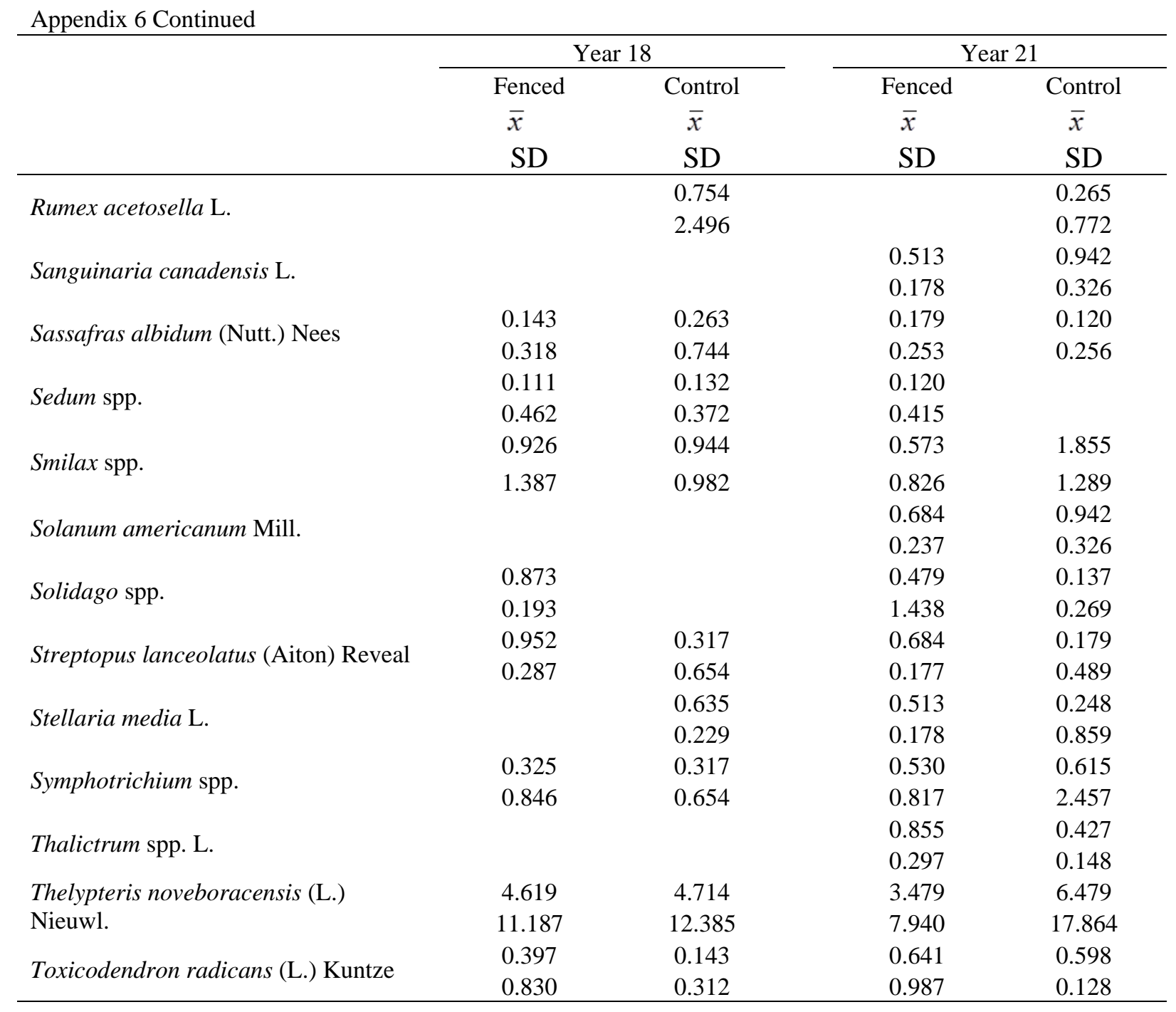




\begin{tabular}{|c|c|c|c|c|}
\hline \multirow{4}{*}{ ix 6 Cont } & \multicolumn{2}{|c|}{ Year 18} & \multicolumn{2}{|c|}{ Year 21} \\
\hline & Fenced & Control & Fenced & Control \\
\hline & $\bar{x}$ & $\bar{x}$ & $\bar{x}$ & $\bar{x}$ \\
\hline & SD & SD & SD & SD \\
\hline \multirow{2}{*}{ Uvularia spp. } & 0.675 & 0.317 & 0.385 & 0.855 \\
\hline & 1.689 & 0.778 & 1.237 & 0.297 \\
\hline \multirow{2}{*}{ Vaccinium spp. } & 0.841 & 2.357 & 3.735 & 2.794 \\
\hline & 1.693 & 7.220 & 8.454 & 4.393 \\
\hline \multirow{2}{*}{ Verbesina alternifolia (L.) Britton ex Kearney } & & & & 0.855 \\
\hline & & & & 0.297 \\
\hline \multirow{2}{*}{ Veronica spp. } & & & 0.855 & \\
\hline & & & 0.297 & \\
\hline \multirow{2}{*}{ Viola spp. L. } & 0.366 & 1.587 & 0.615 & 2.769 \\
\hline & 0.449 & 3.326 & 1.438 & 7.863 \\
\hline \multirow{2}{*}{ Viburnum spp. } & 0.794 & 0.159 & 0.154 & 0.120 \\
\hline & 0.286 & 0.572 & 0.363 & 0.415 \\
\hline \multirow{2}{*}{ Viburnum acerifolium $\mathrm{L}$. } & 0.952 & 0.556 & & \\
\hline & 0.343 & 0.238 & & \\
\hline \multirow{2}{*}{ Viburnum lantanoides Michx. } & & & 0.128 & \\
\hline & & & 0.444 & \\
\hline \multirow{2}{*}{ Viburnum prunifolium $\mathrm{L}$. } & & & 0.256 & \\
\hline & & & 0.888 & \\
\hline \multirow{2}{*}{ Vicia caroliniana Walter } & & & & 0.137 \\
\hline & & & & 0.474 \\
\hline \multirow{2}{*}{ Vitis spp. } & 0.794 & 0.714 & 0.942 & 0.128 \\
\hline & 0.286 & 0.229 & 0.217 & 0.265 \\
\hline
\end{tabular}


Appendix 7. Mean and standard deviation of stem densities for species observed in the understory of West Virginia Division of Natural Resource deer exclosure plots and corresponding control plots, $1984-2007$.

\begin{tabular}{|c|c|c|c|c|c|c|}
\hline & \multicolumn{2}{|c|}{ Year 1} & \multicolumn{2}{|c|}{ Year 3} & \multicolumn{2}{|c|}{ Year 6} \\
\hline & Fenced & Control & Fenced & Control & Fenced & Control \\
\hline & $\bar{x}$ & $\bar{x}$ & $\bar{x}$ & $\bar{x}$ & & \\
\hline & SD & SD & $\mathrm{SD}$ & SD & $\mathrm{SD}$ & $\mathrm{SD}$ \\
\hline \multirow{2}{*}{ Acer pensylvanicum $\mathrm{L}$. } & 0.155 & 0.189 & 0.725 & 0.885 & 0.178 & 0.440 \\
\hline & 0.297 & 0.592 & 0.236 & 0.239 & 0.417 & 0.182 \\
\hline \multirow{2}{*}{ Acer saccharum Marshall } & 0.440 & 0.665 & 0.330 & 0.165 & 0.775 & 0.220 \\
\hline & 0.880 & 0.174 & 0.859 & 0.719 & 0.199 & 0.660 \\
\hline \multirow{2}{*}{ Acer spicatum Lam. } & & & 0.165 & & & \\
\hline & & & 0.719 & & & \\
\hline \multirow{2}{*}{ Actaea racemosa $\mathrm{L}$. } & & & 1.255 & & & \\
\hline & & & 5.255 & & & \\
\hline \multirow{2}{*}{ Aesculus glabra Willd } & & & & 0.555 & & 0.550 \\
\hline & & & & 0.218 & & 0.240 \\
\hline \multirow{2}{*}{ Amelanchier arborea Michx. } & 0.275 & 0.945 & 0.885 & 0.110 & 0.275 & 0.110 \\
\hline & 0.590 & 0.363 & 0.288 & 0.479 & 0.590 & 0.330 \\
\hline \multirow{2}{*}{ Aronia melanocarpa Michx. } & & & & & 0.335 & \\
\hline & & & & & 0.146 & \\
\hline \multirow{2}{*}{ Betula spp. } & 0.665 & 0.110 & 0.155 & 0.615 & 0.440 & 0.165 \\
\hline & 0.134 & 0.330 & 0.245 & 0.168 & 0.946 & 0.393 \\
\hline \multirow{2}{*}{ Carya spp. } & 0.665 & & 0.110 & 0.110 & 0.220 & 0.220 \\
\hline & 0.177 & & 0.330 & 0.479 & 0.747 & 0.959 \\
\hline \multirow{2}{*}{$\begin{array}{l}\text { Castanea dentata (Marshall) } \\
\text { Borkh. }\end{array}$} & 0.165 & 0.347 & & 0.110 & 0.110 & 0.110 \\
\hline & 0.719 & 0.113 & & 0.479 & 0.330 & 0.479 \\
\hline \multirow{2}{*}{ Celastrus scandens L. } & & & & & 0.390 & \\
\hline & & & & & 0.170 & \\
\hline \multirow{2}{*}{ Cercis canadensis L } & 0.445 & 0.500 & 0.445 & 0.665 & 0.775 & 0.720 \\
\hline & 0.151 & 0.174 & 0.129 & 0.226 & 0.267 & 0.268 \\
\hline
\end{tabular}




\begin{tabular}{|c|c|c|c|c|c|c|}
\hline & \multicolumn{2}{|c|}{ Year 1} & \multicolumn{2}{|c|}{ Year 3} & \multicolumn{2}{|c|}{ Year 6} \\
\hline & Fenced & Control & Fenced & Control & Fenced & Control \\
\hline & $\bar{x}$ & $\bar{x}$ & $\bar{x}$ & $\bar{x}$ & $\bar{x}$ & $\bar{x}$ \\
\hline & SD & SD & SD & $\mathrm{SD}$ & $\mathrm{SD}$ & SD \\
\hline \multirow{2}{*}{ Cornus florida L. } & 0.178 & 0.227 & 0.150 & 0.775 & 0.289 & 0.144 \\
\hline & 0.346 & 0.568 & 0.159 & 0.161 & 0.649 & 0.296 \\
\hline \multirow{2}{*}{ Corylus americana Walter } & 0.720 & 0.195 & 0.189 & 0.161 & 0.300 & 0.117 \\
\hline & 0.193 & 0.775 & 0.571 & 0.718 & 1.283 & 0.578 \\
\hline \multirow{2}{*}{ Crataegus spp. } & 0.165 & 0.550 & 0.155 & & 0.720 & 0.110 \\
\hline & 0.525 & 0.240 & 0.435 & & 0.244 & 0.330 \\
\hline \multirow{2}{*}{ Euonymus bungeanus Maxim. } & & & & & 0.110 & \\
\hline & & & & & 0.479 & \\
\hline \multirow{2}{*}{ Fagus grandifolia Ehrh. } & 0.166 & 0.139 & 0.940 & 0.495 & 0.194 & 0.178 \\
\hline & 0.462 & 0.339 & 0.272 & 0.123 & 0.648 & 0.523 \\
\hline \multirow{2}{*}{ Fraxinus americana L. } & 0.220 & 0.445 & 0.220 & 0.390 & 0.330 & 0.165 \\
\hline & 0.569 & 0.147 & 0.569 & 0.147 & 0.743 & 0.719 \\
\hline \multirow{2}{*}{ Gaylussacia spp. Kunth } & & & 0.335 & 0.165 & 0.100 & 0.256 \\
\hline & & & 0.146 & 0.719 & 0.436 & 0.860 \\
\hline \multirow{2}{*}{ Gaylussacia ursina Torr } & 0.467 & 0.300 & 0.534 & 0.217 & 0.665 & 0.725 \\
\hline & 1.763 & 1.258 & 1.770 & 0.539 & 0.290 & 0.218 \\
\hline \multirow{2}{*}{ Hamamelis virginiana L. } & 0.445 & 0.110 & 0.725 & & 0.500 & 0.550 \\
\hline & 0.151 & 0.479 & 0.224 & & 0.139 & 0.240 \\
\hline \multirow{2}{*}{ Kalmia latifolia $\mathrm{L}}$. & 0.317 & 0.328 & 0.233 & 0.183 & 0.272 & 0.239 \\
\hline & 0.744 & 0.939 & 0.524 & 0.529 & 0.628 & 0.734 \\
\hline \multirow{2}{*}{ Liriodendron tulipifera $\mathrm{L}$. } & 0.835 & 0.550 & 0.165 & & 0.165 & 0.550 \\
\hline & 0.340 & 0.240 & 0.525 & & 0.525 & 0.240 \\
\hline \multirow{2}{*}{ Lindera benzoin (L.) Blume } & 0.117 & 0.500 & 0.211 & 0.500 & 0.200 & 0.111 \\
\hline & 0.460 & 0.218 & 0.870 & 0.194 & 0.872 & 0.317 \\
\hline \multirow{2}{*}{ Lonicera japonica Thunb } & 0.161 & 0.161 & 0.500 & & 0.667 & 0.200 \\
\hline & 0.718 & 0.718 & 2.179 & & 2.953 & 0.872 \\
\hline
\end{tabular}




\begin{tabular}{|c|c|c|c|c|c|c|}
\hline & \multicolumn{2}{|c|}{ Year 1} & \multicolumn{2}{|c|}{ Year 3} & \multicolumn{2}{|c|}{ Year 6} \\
\hline & $\begin{array}{l}\text { Fenced } \\
\bar{x} \\
\text { SD } \\
\end{array}$ & $\begin{array}{c}\text { Control } \\
\bar{x} \\
\mathrm{SD} \\
\end{array}$ & $\begin{array}{c}\text { Fenced } \\
\bar{x} \\
\text { SD } \\
\end{array}$ & $\begin{array}{c}\text { Control } \\
\bar{x} \\
\text { SD } \\
\end{array}$ & $\begin{array}{c}\text { Fenced } \\
\bar{x} \\
\mathrm{SD} \\
\end{array}$ & $\begin{array}{c}\text { Control } \\
\bar{x} \\
\mathrm{SD} \\
\end{array}$ \\
\hline Lyonia ligustrina (L.) DC. & & & & & $\begin{array}{l}0.250 \\
1.897\end{array}$ & \\
\hline Magnolia acuminata $\mathrm{L}$. & $\begin{array}{l}0.110 \\
0.330\end{array}$ & $\begin{array}{l}0.200 \\
0.823\end{array}$ & & & $\begin{array}{l}0.220 \\
0.569\end{array}$ & \\
\hline Malus spp. & $\begin{array}{l}0.550 \\
0.240\end{array}$ & & $\begin{array}{l}0.165 \\
0.719\end{array}$ & & & $\begin{array}{l}0.550 \\
0.240\end{array}$ \\
\hline $\begin{array}{l}\text { Menziesia pilosa (Michx. ex Lam.) Juss. } \\
\text { ex Pers }\end{array}$ & & $\begin{array}{l}0.110 \\
0.479\end{array}$ & & & & \\
\hline Morus spp. & & & $\begin{array}{l}0.550 \\
0.240\end{array}$ & & $\begin{array}{l}0.550 \\
0.240\end{array}$ & \\
\hline Nyssa sylvatica Marshall & $\begin{array}{l}0.330 \\
0.859\end{array}$ & $\begin{array}{l}0.110 \\
0.479\end{array}$ & $\begin{array}{l}0.275 \\
0.768\end{array}$ & $\begin{array}{l}0.110 \\
0.330\end{array}$ & $\begin{array}{l}0.825 \\
0.134\end{array}$ & $\begin{array}{l}0.550 \\
0.240\end{array}$ \\
\hline Ostrya virginiana (Mill.) K. Koch & $\begin{array}{l}0.330 \\
0.990\end{array}$ & $\begin{array}{l}0.385 \\
0.871\end{array}$ & $\begin{array}{l}0.385 \\
0.159\end{array}$ & $\begin{array}{l}0.720 \\
0.290\end{array}$ & $\begin{array}{l}0.133 \\
0.285\end{array}$ & $\begin{array}{l}0.335 \\
0.123\end{array}$ \\
\hline Oxydendrum arboreum (L.) DC. & $\begin{array}{l}0.500 \\
0.148\end{array}$ & $\begin{array}{l}0.550 \\
0.240\end{array}$ & $\begin{array}{l}0.110 \\
0.479\end{array}$ & $\begin{array}{l}0.550 \\
0.240\end{array}$ & $\begin{array}{l}0.110 \\
0.330\end{array}$ & \\
\hline Pinus strobus L. & $\begin{array}{l}0.335 \\
0.146\end{array}$ & $\begin{array}{l}0.665 \\
0.290\end{array}$ & $\begin{array}{l}0.220 \\
0.959\end{array}$ & $\begin{array}{l}0.256 \\
0.859\end{array}$ & $\begin{array}{l}0.940 \\
0.318\end{array}$ & $\begin{array}{l}0.133 \\
0.531\end{array}$ \\
\hline Pinus taeda $\mathrm{L}$. & & & $\begin{array}{l}0.110 \\
0.479\end{array}$ & & & \\
\hline Pinus virginiana Mill. & $\begin{array}{l}0.390 \\
0.170\end{array}$ & & $\begin{array}{l}0.165 \\
0.719\end{array}$ & & $\begin{array}{l}0.550 \\
0.240\end{array}$ & $\begin{array}{l}0.550 \\
0.240\end{array}$ \\
\hline Prunus spp. & $\begin{array}{l}1.500 \\
4.514\end{array}$ & $\begin{array}{l}1.820 \\
4.616\end{array}$ & $\begin{array}{l}0.275 \\
0.976\end{array}$ & $\begin{array}{l}1.517 \\
6.586\end{array}$ & $\begin{array}{l}0.455 \\
1.448\end{array}$ & $\begin{array}{l}0.372 \\
1.622\end{array}$ \\
\hline
\end{tabular}




\begin{tabular}{|c|c|c|c|c|c|c|}
\hline & \multicolumn{2}{|c|}{ Year 1} & \multicolumn{2}{|c|}{ Year 3} & \multicolumn{2}{|c|}{ Year 6} \\
\hline & Fenced & Control & Fenced & Control & Fenced & Control \\
\hline & $\bar{x}$ & $\bar{x}$ & $\bar{x}$ & $\bar{x}$ & $\bar{x}$ & $\bar{x}$ \\
\hline & SD & SD & SD & SD & SD & SD \\
\hline \multirow{2}{*}{ Prunus pensylvanica $\mathrm{L}$. } & & & 0.172 & & 0.945 & \\
\hline & & & 0.750 & & 0.412 & \\
\hline \multirow{2}{*}{ Pyrularia pubera Michx. } & & & 0.280 & & 0.780 & \\
\hline & & & 0.122 & & 0.340 & \\
\hline \multirow{2}{*}{ Quercus alba L. } & 0.228 & 0.220 & 0.500 & 0.335 & 0.220 & 0.275 \\
\hline & 0.917 & 0.747 & 0.125 & 0.146 & 0.569 & 0.976 \\
\hline \multirow{2}{*}{ Quercus berberidifolia Liebm. } & 0.695 & 0.495 & 0.428 & 0.461 & 0.355 & 0.184 \\
\hline & 3.273 & 2.155 & 1.866 & 1.984 & 1.366 & 0.775 \\
\hline \multicolumn{7}{|l|}{ Quercus coccinea Münchh. } \\
\hline \multirow{2}{*}{ Quercus prinus L. } & & 0.550 & 0.550 & & 0.220 & 0.110 \\
\hline & & 0.240 & 0.240 & & 0.747 & 0.330 \\
\hline \multirow{2}{*}{ Quercus rubra L. } & 0.165 & 0.500 & 0.440 & 0.280 & 0.550 & 0.445 \\
\hline & 0.525 & 0.194 & 0.182 & 0.122 & 0.953 & 0.125 \\
\hline \multirow{2}{*}{ Quercus velutina Lam. } & 0.550 & & 0.165 & & 0.330 & \\
\hline & 0.240 & & 0.525 & & 0.786 & \\
\hline \multirow{2}{*}{ Rhododendron spp. } & 0.165 & & 0.275 & & 0.670 & \\
\hline & 0.719 & & 0.976 & & 0.185 & \\
\hline \multirow{2}{*}{ Robinia pseudoacacia L. } & 0.550 & 0.550 & 0.550 & & 0.220 & 0.550 \\
\hline & 0.240 & 0.240 & 0.240 & & 0.747 & 0.240 \\
\hline \multirow{2}{*}{ Rosa multiflora Thunb. } & 0.550 & & 0.110 & & 0.610 & 0.110 \\
\hline & 0.240 & & 0.330 & & 0.197 & 0.330 \\
\hline
\end{tabular}




\begin{tabular}{|c|c|c|c|c|c|c|}
\hline & \multicolumn{2}{|c|}{ Year 1} & \multicolumn{2}{|c|}{ Year 3} & \multicolumn{2}{|c|}{ Year 6} \\
\hline & Fenced & Control & Fenced & Control & Fenced & Control \\
\hline & $\bar{x}$ & $\bar{x}$ & $\bar{x}$ & $\bar{x}$ & $\bar{x}$ & $\bar{x}$ \\
\hline & $\mathrm{SD}$ & $\mathrm{SD}$ & SD & SD & $\mathrm{SD}$ & SD \\
\hline \multirow{2}{*}{ Rubus spp. } & 0.495 & 0.220 & 0.945 & 0.111 & 2.588 & 0.967 \\
\hline & 0.885 & 0.660 & 3.598 & 0.484 & 8.228 & 4.163 \\
\hline \multirow{2}{*}{ Sambucus spp. } & & & 0.550 & & & \\
\hline & & & 0.240 & & & \\
\hline \multirow{2}{*}{ Sassafras albidum (Nutt.) Nees } & 0.610 & 0.720 & 0.665 & 0.445 & 0.172 & 0.610 \\
\hline & 0.242 & 0.265 & 0.266 & 0.174 & 0.551 & 0.218 \\
\hline \multirow{2}{*}{ Smilax spp. } & 0.184 & 0.660 & 0.215 & 0.660 & 0.339 & 0.184 \\
\hline & 0.591 & 0.127 & 0.417 & 0.127 & 0.757 & 0.418 \\
\hline \multirow{2}{*}{ Symphoricarpos orbiculatus Moench } & & & & & 0.550 & \\
\hline & & & & & 0.240 & \\
\hline \multirow{2}{*}{ Ulmus spp. } & & & & & 0.220 & \\
\hline & & & & & 0.747 & \\
\hline \multirow{2}{*}{ Vaccinium spp. } & 0.489 & 0.339 & 0.139 & 0.110 & 0.400 & 0.228 \\
\hline & 1.769 & 1.151 & 0.659 & 0.479 & 1.744 & 0.994 \\
\hline \multirow{2}{*}{ Viburnum acerifolium L. } & 0.220 & 0.720 & & 0.220 & 0.550 & 0.110 \\
\hline & 0.959 & 0.314 & & 0.959 & 0.240 & 0.479 \\
\hline \multirow{2}{*}{ Viburnum lantanoides Michx. } & 0.445 & 0.178 & 0.280 & 0.110 & 0.780 & \\
\hline & 0.194 & 0.776 & 0.122 & 0.479 & 0.340 & \\
\hline \multirow{2}{*}{ Viburnum prunifolium L. } & 0.445 & 0.335 & & & 0.610 & 0.335 \\
\hline & 0.194 & 0.146 & & & 0.266 & 0.146 \\
\hline \multirow{2}{*}{ Vitis spp. } & 0.110 & 0.385 & 0.220 & 0.550 & 0.385 & 0.165 \\
\hline & 0.330 & 0.159 & 0.747 & 0.240 & 0.164 & 0.525 \\
\hline
\end{tabular}




\begin{tabular}{|c|c|c|c|c|c|c|}
\hline & \multicolumn{2}{|c|}{ Year 9} & \multicolumn{2}{|c|}{ Year 12} & \multicolumn{2}{|c|}{ Year 15} \\
\hline & Fenced & Control & Fenced & Control & Fenced & Control \\
\hline & $\bar{x}$ & $\bar{x}$ & $\bar{x}$ & $\bar{x}$ & $\bar{x}$ & $\bar{x}$ \\
\hline & SD & $\mathrm{SD}$ & SD & SD & $\mathrm{SD}$ & $\mathrm{SD}$ \\
\hline \multirow{2}{*}{ Acer pensylvanicum L. } & 0.115 & 0.330 & 0.148 & 0.220 & 0.660 & 0.813 \\
\hline & 0.297 & 0.786 & 0.422 & 0.440 & 0.126 & 0.248 \\
\hline \multirow{2}{*}{ Acer rubrum $\mathrm{L}$. } & 0.339 & 0.139 & 0.467 & 0.185 & 0.319 & 0.118 \\
\hline & 0.400 & 0.265 & 0.453 & 0.344 & 0.383 & 0.299 \\
\hline \multirow{2}{*}{ Acer saccharum Marshall } & 0.139 & 0.110 & 0.893 & 0.733 & 0.333 & 0.733 \\
\hline & 0.413 & 0.330 & 0.289 & 0.274 & 0.350 & 0.274 \\
\hline \multirow{2}{*}{ Acer spicatum Lam. } & & 0.550 & & & & \\
\hline & & 0.240 & & & & \\
\hline \multirow{2}{*}{ Actaea racemosa $\mathrm{L}$. } & & & & & 0.733 & \\
\hline & & & & & 0.274 & \\
\hline \multirow{2}{*}{ Aesculus glabra Willd } & & 0.550 & & & & \\
\hline & & 0.240 & & & & \\
\hline \multirow{2}{*}{ Albizia julibrissin Durazz. } & 0.550 & & & & & \\
\hline & 0.240 & & & & & \\
\hline \multirow{2}{*}{ Amelanchier arborea Michx. } & 0.885 & 0.110 & 0.593 & & 0.133 & 0.147 \\
\hline & 0.156 & 0.479 & 0.195 & & 0.197 & 0.549 \\
\hline \multirow{2}{*}{ Aronia melanocarpa Michx. } & 0.390 & & & & 0.733 & \\
\hline & 0.170 & & & & 0.274 & \\
\hline \multirow{2}{*}{ Asimina triloba (L.) Dunal } & 0.100 & 0.284 & & 0.178 & 0.178 & 0.267 \\
\hline & 0.436 & 0.914 & & 0.666 & 0.666 & 0.998 \\
\hline \multirow{2}{*}{ Betula spp. } & 0.660 & 0.550 & 0.887 & 0.733 & 0.813 & 0.147 \\
\hline & 0.146 & 0.240 & 0.182 & 0.274 & 0.174 & 0.374 \\
\hline
\end{tabular}




\begin{tabular}{|c|c|c|c|c|c|c|}
\hline & \multicolumn{2}{|c|}{ Year 9} & \multicolumn{2}{|c|}{ Year 12} & \multicolumn{2}{|c|}{ Year 15} \\
\hline & Fenced & Control & Fenced & Control & Fenced & Control \\
\hline & $\bar{x}$ & $\bar{x}$ & $\bar{x}$ & $\bar{x}$ & $\bar{x}$ & $\bar{x}$ \\
\hline & SD & SD & SD & SD & $\mathrm{SD}$ & SD \\
\hline \multirow{2}{*}{ Carya spp. } & 0.885 & 0.220 & 0.125 & 0.513 & 0.880 & 0.367 \\
\hline & 0.265 & 0.747 & 0.326 & 0.113 & 0.151 & 0.111 \\
\hline \multirow{2}{*}{ Castanea dentata (Marshall) Borkh. } & 0.110 & 0.550 & 0.733 & & 0.733 & \\
\hline & 0.330 & 0.240 & 0.274 & & 0.274 & \\
\hline \multirow{2}{*}{ Celastrus scandens L. } & 0.165 & & & & 0.373 & \\
\hline & 0.719 & & & & 0.140 & \\
\hline \multirow{2}{*}{ Cercis canadensis L } & 0.500 & 0.390 & 0.164 & 0.373 & & 0.147 \\
\hline & 0.139 & 0.129 & 0.423 & 0.140 & & 0.549 \\
\hline \multirow{2}{*}{ Cornus florida $\mathrm{L}$. } & 0.189 & 0.650 & 0.133 & 0.367 & 0.133 & 0.147 \\
\hline & 0.385 & 0.951 & 0.216 & 0.111 & 0.212 & 0.374 \\
\hline \multirow{2}{*}{ Corylus americana Walter } & 0.500 & 0.335 & & & 0.830 & 0.733 \\
\hline & 2.311 & 0.146 & & & 2.931 & 0.274 \\
\hline \multirow{2}{*}{ Crataegus spp. } & 0.610 & 0.550 & 0.520 & & 0.593 & 0.147 \\
\hline & 0.174 & 0.240 & 0.167 & & 0.195 & 0.549 \\
\hline \multirow{2}{*}{ Euonymus bungeanus Maxim. } & & 0.550 & 0.733 & & 0.147 & \\
\hline & & 0.240 & 0.274 & & 0.549 & \\
\hline \multirow{2}{*}{ Fagus grandifolia Ehrh. } & 0.178 & 0.239 & 0.214 & 0.333 & 0.178 & 0.333 \\
\hline & 0.559 & 0.736 & 0.494 & 0.763 & 0.422 & 0.777 \\
\hline \multirow{2}{*}{ Fraxinus americana $\mathrm{L}$. } & 0.610 & 0.110 & 0.147 & 0.733 & 0.740 & 0.733 \\
\hline & 0.130 & 0.479 & 0.549 & 0.274 & 0.156 & 0.274 \\
\hline \multirow{2}{*}{ Gaylussacia spp. Kunth } & 0.280 & & & 0.667 & & 0.220 \\
\hline & 0.122 & & & 0.249 & & 0.823 \\
\hline
\end{tabular}




\begin{tabular}{|c|c|c|c|c|c|c|}
\hline & \multicolumn{2}{|c|}{ Year 9} & \multicolumn{2}{|c|}{ Year 12} & \multicolumn{2}{|c|}{ Year 15} \\
\hline & Fenced & Control & Fenced & Control & Fenced & Control \\
\hline & $\bar{x}$ & $\bar{x}$ & $\bar{x}$ & $\bar{x}$ & $\bar{x}$ & $\bar{x}$ \\
\hline & SD & SD & $\mathrm{SD}$ & SD & $\mathrm{SD}$ & SD \\
\hline \multirow{2}{*}{ Gaylussacia ursina Torr } & 0.156 & 0.284 & 0.293 & 0.520 & 0.237 & 0.437 \\
\hline & 0.629 & 0.941 & 0.198 & 0.146 & 0.625 & 1.292 \\
\hline \multirow{2}{*}{ Hamamelis virginiana L. } & 0.220 & 0.110 & 0.513 & & 0.667 & 0.147 \\
\hline & 0.959 & 0.479 & 0.120 & & 0.198 & 0.549 \\
\hline \multirow{2}{*}{ Kalmia latifolia $\mathrm{L}}$. & 0.316 & 0.161 & 0.252 & 0.185 & 0.473 & 0.385 \\
\hline & 0.717 & 0.486 & 0.650 & 0.693 & 1.135 & 1.229 \\
\hline \multirow{2}{*}{ Lindera benzoin (L.) Blume } & 0.183 & 0.835 & 0.293 & 0.520 & 0.259 & 0.133 \\
\hline & 0.749 & 0.225 & 0.748 & 0.167 & 0.941 & 0.358 \\
\hline \multirow{2}{*}{ Liriodendron tulipifera $\mathrm{L}$. } & 0.275 & & 0.293 & & 0.147 & \\
\hline & 0.685 & & 0.849 & & 0.549 & \\
\hline \multirow{2}{*}{ Lonicera japonica Thunb } & 0.378 & 0.289 & & & 0.578 & 0.293 \\
\hline & 1.648 & 1.260 & & & 2.163 & 0.198 \\
\hline \multirow{2}{*}{ Lonicera tatarica $\mathrm{L}$} & 0.165 & 0.165 & 0.813 & 0.520 & & \\
\hline & 0.719 & 0.719 & 0.343 & 0.195 & & \\
\hline \multirow{2}{*}{ Lyonia ligustrina (L.) DC. } & 0.156 & 0.110 & 0.520 & 0.593 & 0.667 & \\
\hline & 0.678 & 0.479 & 0.146 & 0.223 & 0.249 & \\
\hline \multirow{2}{*}{ Magnolia acuminata $\mathrm{L}$. } & 0.220 & 0.550 & 0.293 & 0.733 & 0.367 & 0.733 \\
\hline & 0.440 & 0.240 & 0.486 & 0.274 & 0.656 & 0.274 \\
\hline \multirow{2}{*}{ Morus spp. } & 0.110 & & 0.733 & & 0.733 & \\
\hline & 0.479 & & 0.274 & & 0.274 & \\
\hline \multirow{2}{*}{ Nyssa sylvatica Marshall } & 0.830 & & 0.367 & & 0.133 & \\
\hline & 0.168 & & 0.111 & & 0.245 & \\
\hline \multirow{2}{*}{$\begin{array}{l}\text { Ostrya virginiana (Mill.) K. } \\
\text { Koch }\end{array}$} & 0.385 & 0.220 & 0.440 & 0.147 & 0.156 & 0.887 \\
\hline & 0.159 & 0.747 & 0.112 & 0.549 & 0.417 & 0.195 \\
\hline
\end{tabular}




\begin{tabular}{|c|c|c|c|c|c|c|}
\hline & \multicolumn{2}{|c|}{ Year 9} & \multicolumn{2}{|c|}{ Year 12} & \multicolumn{2}{|c|}{ Year 15} \\
\hline & $\begin{array}{l}\text { Fenced } \\
\bar{x} \\
\mathrm{SD} \\
\end{array}$ & $\begin{array}{c}\text { Control } \\
\bar{x} \\
\text { SD }\end{array}$ & $\begin{array}{c}\text { Fenced } \\
\bar{x} \\
\mathrm{SD} \\
\end{array}$ & $\begin{array}{c}\text { Control } \\
\bar{x} \\
\text { SD } \\
\end{array}$ & $\begin{array}{c}\text { Fenced } \\
\bar{x} \\
\text { SD } \\
\end{array}$ & $\begin{array}{c}\text { Control } \\
\bar{x} \\
\mathrm{SD} \\
\end{array}$ \\
\hline \multirow{2}{*}{ Oxydendrum arboreum (L.) DC. } & 0.335 & & 0.440 & & 0.593 & 0.147 \\
\hline & 0.146 & & 0.112 & & 0.157 & 0.549 \\
\hline \multirow{2}{*}{ Parthenocissus quinquefolia (L.) Planch. } & & & & & 0.147 & \\
\hline & & & & & 0.549 & \\
\hline \multirow{2}{*}{ Picea rubens Sarg. } & & 0.550 & 0.733 & & 0.733 & \\
\hline & & 0.240 & 0.274 & & 0.274 & \\
\hline \multirow{2}{*}{ Pinus strobus L. } & 0.128 & 0.139 & 0.133 & 0.170 & 0.148 & 0.193 \\
\hline & 0.356 & 0.581 & 0.349 & 0.673 & 0.324 & 0.729 \\
\hline \multirow{2}{*}{ Pinus virginiana Mill. } & & 0.550 & & 0.733 & 0.147 & 0.220 \\
\hline & & 0.240 & & 0.274 & 0.549 & 0.596 \\
\hline \multirow{2}{*}{ Prunus spp. } & 0.355 & 0.184 & 0.520 & 0.733 & 0.126 & 0.293 \\
\hline & 1.142 & 0.775 & 0.167 & 0.274 & 0.274 & 0.638 \\
\hline \multirow{2}{*}{ Pyrularia pubera Michx. } & 0.155 & & 0.185 & 0.733 & 0.193 & \\
\hline & 0.460 & & 0.693 & 0.274 & 0.729 & \\
\hline \multirow{2}{*}{ Quercus alba L. } & 0.440 & 0.275 & 0.513 & 0.367 & 0.293 & 0.513 \\
\hline & 0.946 & 0.768 & 0.973 & 0.111 & 0.638 & 0.132 \\
\hline \multirow{2}{*}{ Quercus berberidifolia Liebm. } & 0.289 & 0.835 & 0.373 & & 0.422 & 0.111 \\
\hline & 1.260 & 0.364 & 0.140 & & 1.579 & 0.417 \\
\hline \multirow{2}{*}{ Quercus prinus L. } & 0.280 & 0.110 & 0.367 & 0.147 & 0.733 & \\
\hline & 0.122 & 0.479 & 0.111 & 0.549 & 0.274 & \\
\hline \multirow{2}{*}{ Quercus rubra L. } & 0.940 & 0.280 & 0.155 & 0.293 & 0.440 & \\
\hline & 0.256 & 0.122 & 0.390 & 0.198 & 0.967 & \\
\hline \multirow{2}{*}{ Quercus velutina Lam. } & & & 0.147 & & 0.147 & 0.447 \\
\hline & & & 0.374 & & 0.374 & 0.167 \\
\hline
\end{tabular}




\begin{tabular}{|c|c|c|c|c|c|c|}
\hline & \multicolumn{2}{|c|}{ Year 9} & \multicolumn{2}{|c|}{ Year 12} & \multicolumn{2}{|c|}{ Year 15} \\
\hline & Fenced & Control & Fenced & Control & Fenced & Control \\
\hline & $\bar{x}$ & $\bar{x}$ & $\bar{x}$ & $\bar{x}$ & $\bar{x}$ & $\bar{x}$ \\
\hline & SD & SD & $\mathrm{SD}$ & $\mathrm{SD}$ & $\mathrm{SD}$ & SD \\
\hline \multirow{2}{*}{ Robinia pseudoacacia L. } & & & 0.733 & & & \\
\hline & & & 0.274 & & & \\
\hline \multirow{2}{*}{ Rhododendron spp. } & 0.220 & 0.220 & 0.447 & & 0.593 & \\
\hline & 0.959 & 0.959 & 0.144 & & 0.172 & \\
\hline \multirow{2}{*}{ Rhus spp. } & 0.275 & & 0.447 & & & \\
\hline & 0.843 & & 0.144 & & & \\
\hline \multirow{2}{*}{ Rosa multiflora Thunb. } & 0.440 & 0.110 & 0.197 & 0.667 & 0.147 & \\
\hline & 0.182 & 0.330 & 0.429 & 0.249 & 0.549 & \\
\hline \multirow{2}{*}{ Rubus spp. } & 4.350 & 1.272 & 3.943 & 1.933 & 1.185 & 2.740 \\
\hline & 11.944 & 5.494 & 7.291 & 7.234 & 3.896 & 7.762 \\
\hline \multirow{2}{*}{ Sambucus spp. } & & & & & 0.733 & \\
\hline & & & & & 0.274 & \\
\hline \multirow{2}{*}{ Sassafras albidum (Nutt.) Nees } & 0.150 & 0.550 & 0.813 & & 0.148 & \\
\hline & 0.185 & 0.240 & 0.160 & & 0.324 & \\
\hline \multirow{2}{*}{ Smilax spp. } & 0.389 & 0.183 & 0.489 & 0.200 & 0.933 & 0.147 \\
\hline & 0.769 & 0.468 & 1.119 & 0.417 & 1.413 & 0.312 \\
\hline \multirow{2}{*}{$\begin{array}{l}\text { Toxicodendron radicans }(\mathrm{L} .) \\
\text { Kuntze }\end{array}$} & 0.550 & & & & & \\
\hline & 0.240 & & & & & \\
\hline \multirow{2}{*}{ Ulmus spp. } & 0.550 & & & & 0.293 & \\
\hline & 0.240 & & & & 0.198 & \\
\hline \multirow{2}{*}{ Vaccinium spp. } & 0.200 & 0.228 & 0.126 & 0.667 & 0.170 & 0.133 \\
\hline & 0.626 & 0.691 & 0.471 & 0.222 & 0.395 & 0.386 \\
\hline \multirow{2}{*}{ Viburnum spp. } & 0.110 & & 0.593 & & 0.813 & \\
\hline & 0.479 & & 0.195 & & 0.252 & \\
\hline
\end{tabular}




\begin{tabular}{|c|c|c|c|c|c|c|}
\hline & \multicolumn{2}{|c|}{ Year 9} & \multicolumn{2}{|c|}{ Year 12} & \multicolumn{2}{|c|}{ Year 15} \\
\hline & Fenced & Control & Fenced & Control & Fenced & Control \\
\hline & $\bar{x}$ & $\bar{x}$ & $\bar{x}$ & $\bar{x}$ & $\bar{x}$ & $\bar{x}$ \\
\hline & SD & SD & SD & SD & $\mathrm{SD}$ & SD \\
\hline \multirow{2}{*}{ Viburnum acerifolium $\mathrm{L}$. } & 0.165 & & 0.293 & & 0.147 & \\
\hline & 0.719 & & 0.198 & & 0.549 & \\
\hline \multirow{2}{*}{ Viburnum lantanoides Michx. } & 0.390 & & 0.667 & & 0.447 & \\
\hline & 0.170 & & 0.249 & & 0.167 & \\
\hline \multirow{2}{*}{ Viburnum prunifolium L. } & 0.100 & 0.555 & & & 0.178 & 0.667 \\
\hline & 0.436 & 0.242 & & & 0.666 & 0.249 \\
\hline \multirow{2}{*}{ Vitis spp. } & 0.165 & 0.110 & 0.733 & 0.733 & 0.367 & 0.147 \\
\hline & 0.393 & 0.330 & 0.274 & 0.274 & 0.868 & 0.374 \\
\hline
\end{tabular}




\begin{tabular}{|c|c|c|c|c|}
\hline & \multicolumn{2}{|c|}{ Year 18} & \multicolumn{2}{|c|}{ Year 21} \\
\hline & $\begin{array}{c}\text { Fenced } \\
\bar{x} \\
\text { SD } \\
\end{array}$ & $\begin{array}{c}\text { Control } \\
\bar{x} \\
\mathrm{SD} \\
\end{array}$ & $\begin{array}{c}\text { Fenced } \\
\bar{x} \\
\mathrm{SD} \\
\end{array}$ & $\begin{array}{c}\text { Control } \\
\bar{x} \\
\text { SD } \\
\end{array}$ \\
\hline \multirow{2}{*}{ Acer pensylvanicum $\mathrm{L}$. } & 0.115 & 0.700 & 0.950 & 0.786 \\
\hline & 0.267 & 0.272 & 0.285 & 0.283 \\
\hline \multirow{2}{*}{ Acer rubrum $\mathrm{L}$. } & 0.489 & 0.153 & 0.459 & 0.950 \\
\hline & 0.618 & 0.221 & 0.687 & 0.187 \\
\hline \multirow{2}{*}{ Acer saccharum Marshall } & 0.233 & 0.116 & 0.246 & 0.236 \\
\hline & 0.496 & 0.338 & 0.450 & 0.614 \\
\hline \multirow{2}{*}{ Actaea racemosa $\mathrm{L}$. } & 0.579 & & & \\
\hline & 0.246 & & & \\
\hline \multirow{2}{*}{ Amelanchier arborea Michx. } & 0.456 & 0.116 & 0.117 & \\
\hline & 1.556 & 0.491 & 0.231 & \\
\hline \multirow{2}{*}{ Aronia melanocarpa Michx. } & 0.116 & & & \\
\hline & 0.491 & & & \\
\hline \multirow{2}{*}{ Asimina triloba (L.) Dunal } & 0.234 & 0.437 & 0.157 & 0.197 \\
\hline & 0.966 & 1.236 & 0.567 & 0.688 \\
\hline \multirow{2}{*}{ Berberis spp. } & & & 0.236 & \\
\hline & & & 0.850 & \\
\hline \multirow{2}{*}{ Betula spp. } & 0.637 & & 0.393 & \\
\hline & 0.125 & & 0.892 & \\
\hline \multirow{2}{*}{ Carya spp. } & 0.123 & 0.700 & 0.157 & 0.793 \\
\hline & 0.257 & 0.158 & 0.271 & 0.155 \\
\hline \multirow{2}{*}{$\begin{array}{l}\text { Castanea dentata (Marshall) } \\
\text { Borkh. }\end{array}$} & 0.116 & & 0.557 & \\
\hline & 0.338 & & 0.173 & \\
\hline \multirow{2}{*}{ Celastrus scandens L. } & 0.116 & & & \\
\hline & 0.491 & & & \\
\hline
\end{tabular}




\begin{tabular}{|c|c|c|c|c|}
\hline & \multicolumn{2}{|c|}{ Year 18} & \multicolumn{2}{|c|}{ Year 21} \\
\hline & Fenced & Control & Fenced & Control \\
\hline & $\bar{x}$ & $\bar{x}$ & $\bar{x}$ & $\bar{x}$ \\
\hline & SD & SD & SD & SD \\
\hline \multirow{2}{*}{ Cercis canadensis L. } & 0.140 & 0.579 & 0.166 & 0.636 \\
\hline & 0.500 & 0.246 & 0.516 & 0.229 \\
\hline \multirow{2}{*}{ Cornus florida $\mathrm{L}$. } & 0.874 & 0.579 & 0.714 & \\
\hline & 0.163 & 0.246 & 0.162 & \\
\hline \multirow{2}{*}{ Corylus americana Walter } & 0.678 & & 0.314 & \\
\hline & 2.649 & & 0.113 & \\
\hline \multirow{2}{*}{ Crataegus spp. } & 0.647 & & 0.557 & \\
\hline & 0.190 & & 0.289 & \\
\hline \multirow{2}{*}{ Euonymus bungeanus Maxim. } & & 0.116 & & 0.786 \\
\hline & & 0.491 & & 0.283 \\
\hline \multirow{2}{*}{ Fagus grandifolia Ehrh. } & 0.140 & 0.198 & 0.127 & 0.254 \\
\hline & 0.400 & 0.499 & 0.235 & 0.517 \\
\hline \multirow{2}{*}{ Fraxinus americana $\mathrm{L}$. } & 0.522 & 0.116 & 0.393 & 0.786 \\
\hline & 0.192 & 0.491 & 0.671 & 0.283 \\
\hline \multirow{2}{*}{ Gaylussacia spp. Kunth } & 0.758 & & & \\
\hline & 0.322 & & & \\
\hline \multirow{2}{*}{ Gaylussacia ursina Torr } & 0.128 & 0.234 & 0.167 & 0.182 \\
\hline & 0.374 & 0.480 & 0.470 & 0.414 \\
\hline \multirow{2}{*}{ Hamamelis virginiana L. } & 0.584 & 0.174 & 0.793 & \\
\hline & 0.225 & 0.737 & 0.257 & \\
\hline \multirow{2}{*}{ Juniperus virginiana $\mathrm{L}$. } & & 0.579 & & \\
\hline & & 0.246 & & \\
\hline \multirow{2}{*}{ Kalmia latifolia $\mathrm{L}}$. & 0.497 & 0.316 & 0.126 & 0.393 \\
\hline & 1.377 & 1.216 & 0.340 & 1.115 \\
\hline
\end{tabular}




\begin{tabular}{|c|c|c|c|c|}
\hline & \multicolumn{2}{|c|}{ Year 18} & \multicolumn{2}{|c|}{ Year 21} \\
\hline & Fenced & Control & Fenced & Control \\
\hline & $\bar{x}$ & $\bar{x}$ & $\bar{x}$ & $\bar{x}$ \\
\hline & $\mathrm{SD}$ & SD & $\mathrm{SD}$ & $\mathrm{SD}$ \\
\hline \multirow{2}{*}{ Lindera benzoin (L.) Blume } & 0.228 & 0.169 & 0.393 & 0.129 \\
\hline & 0.818 & 0.525 & 0.984 & 0.379 \\
\hline \multirow{2}{*}{ Liriodendron tulipifera $\mathrm{L}$. } & 0.116 & & 0.236 & 0.786 \\
\hline & 0.491 & & 0.850 & 0.283 \\
\hline \multirow{2}{*}{ Lonicera japonica Thunb. } & 0.889 & 0.584 & 0.314 & 0.786 \\
\hline & 3.720 & 0.248 & 0.113 & 0.283 \\
\hline \multirow{2}{*}{ Lonicera tatarica $\mathrm{L}$} & 0.295 & 0.353 & 0.479 & 0.636 \\
\hline & 0.125 & 0.150 & 0.173 & 0.229 \\
\hline \multirow{2}{*}{ Lyonia ligustrina (L.) DC. } & 0.463 & & 0.314 & \\
\hline & 0.135 & & 0.875 & \\
\hline \multirow{2}{*}{ Magnolia acuminata $\mathrm{L}$. } & 0.174 & & 0.236 & \\
\hline & 0.412 & & 0.451 & \\
\hline \multirow{2}{*}{ Morus spp. } & 0.579 & & 0.786 & \\
\hline & 0.246 & & 0.283 & \\
\hline \multirow{2}{*}{ Nyssa sylvatica Marshall } & 0.584 & & 0.236 & \\
\hline & 0.155 & & 0.614 & \\
\hline \multirow{2}{*}{$\begin{array}{l}\text { Ostrya virginiana (Mill.) K. } \\
\text { Koch }\end{array}$} & 0.222 & 0.174 & 0.175 & 0.157 \\
\hline & 0.495 & 0.537 & 0.423 & 0.385 \\
\hline \multirow{2}{*}{$\begin{array}{l}\text { Oxydendrum arboreum (L.) } \\
\text { DC. }\end{array}$} & 0.174 & 0.116 & 0.236 & 0.157 \\
\hline & 0.737 & 0.491 & 0.850 & 0.567 \\
\hline \multirow{2}{*}{ Picea rubens Sarg. } & 0.579 & & & \\
\hline & 0.246 & & & \\
\hline \multirow{2}{*}{ Pinus strobus L. } & 0.116 & 0.164 & 0.117 & 0.254 \\
\hline & 0.380 & 0.669 & 0.343 & 0.855 \\
\hline
\end{tabular}




\begin{tabular}{|c|c|c|c|c|}
\hline & \multicolumn{2}{|c|}{ Year 18} & \multicolumn{2}{|c|}{ Year 21} \\
\hline & Fenced & Control & Fenced & Control \\
\hline & $\bar{x}$ & $\bar{x}$ & $\bar{x}$ & $\bar{x}$ \\
\hline & SD & SD & SD & SD \\
\hline \multirow{2}{*}{ Pinus virginiana Mill. } & 0.174 & 0.174 & 0.786 & \\
\hline & 0.737 & 0.537 & 0.283 & \\
\hline \multirow{2}{*}{ Prunus spp. } & 0.134 & 0.116 & 0.118 & 0.786 \\
\hline & 0.262 & 0.338 & 0.163 & 0.283 \\
\hline \multirow{2}{*}{ Pyrularia pubera Michx. } & 0.158 & & 0.214 & 0.786 \\
\hline & 0.670 & & 0.773 & 0.283 \\
\hline \multirow{2}{*}{ Quercus alba L. } & 0.522 & 0.642 & 0.550 & 0.714 \\
\hline & 0.192 & 0.219 & 0.123 & 0.229 \\
\hline \multirow{2}{*}{ Quercus berberidifolia Liebm. } & 0.252 & 0.174 & 0.714 & \\
\hline & 0.861 & 0.737 & 0.258 & \\
\hline \multirow{2}{*}{ Quercus prinus L. } & 0.415 & 0.289 & 0.714 & 0.479 \\
\hline & 0.153 & 0.999 & 0.229 & 0.173 \\
\hline \multirow{2}{*}{ Quercus rubra L. } & 0.140 & & 0.190 & \\
\hline & 0.446 & & 0.568 & \\
\hline \multirow{2}{*}{ Quercus velutina Lam. } & 0.453 & 0.758 & 0.471 & 0.129 \\
\hline & 0.889 & 0.297 & 0.994 & 0.342 \\
\hline \multirow{2}{*}{ Rhododendron spp. } & 0.758 & & 0.117 & \\
\hline & 0.274 & & 0.295 & \\
\hline \multirow{2}{*}{ Rhus spp. } & 0.116 & & & \\
\hline & 0.491 & & & \\
\hline \multirow{2}{*}{ Robinia pseudoacacia L. } & 0.174 & & 0.786 & 0.236 \\
\hline & 0.537 & & 0.283 & 0.850 \\
\hline \multirow{2}{*}{ Rosa multiflora Thunb. } & 0.187 & 0.300 & 0.294 & 0.950 \\
\hline & 0.549 & 0.127 & 0.765 & 0.285 \\
\hline
\end{tabular}




\begin{tabular}{|c|c|c|c|c|}
\hline & \multicolumn{2}{|c|}{ Year 18} & \multicolumn{2}{|c|}{ Year 21} \\
\hline & Fenced & Control & Fenced & Control \\
\hline & $\bar{x}$ & $\bar{x}$ & $\bar{x}$ & $\bar{x}$ \\
\hline & SD & SD & SD & SD \\
\hline \multirow{2}{*}{ Rubus spp. } & 0.917 & 0.444 & 0.460 & 0.314 \\
\hline & 2.361 & 1.885 & 1.460 & 0.113 \\
\hline \multirow{2}{*}{ Sambucus spp. } & 0.579 & & & \\
\hline & 0.246 & & & \\
\hline \multirow{2}{*}{ Sassafras albidum (Nutt.) Nees } & 0.816 & 0.174 & 0.557 & 0.157 \\
\hline & 0.232 & 0.737 & 0.158 & 0.567 \\
\hline \multirow{2}{*}{ Smilax spp. } & 0.795 & 0.158 & 0.864 & 0.166 \\
\hline & 1.537 & 0.367 & 1.562 & 0.338 \\
\hline \multirow{2}{*}{ Ulmus spp. } & 0.295 & & & \\
\hline & 0.125 & & & \\
\hline \multirow{2}{*}{ Vaccinium spp. } & 0.932 & 0.758 & 0.714 & 0.157 \\
\hline & 0.284 & 0.248 & 0.245 & 0.385 \\
\hline \multirow{2}{*}{ Viburnum spp. } & 0.995 & & 0.159 & \\
\hline & 0.352 & & 0.488 & \\
\hline \multirow{2}{*}{ Viburnum acerifolium $\mathrm{L}$. } & 0.116 & & 0.236 & \\
\hline & 0.491 & & 0.850 & \\
\hline \multirow{2}{*}{ Viburnum lantanoides Michx. } & 0.295 & & 0.479 & \\
\hline & 0.125 & & 0.173 & \\
\hline \multirow{2}{*}{ Viburnum prunifolium $\mathrm{L}$. } & 0.128 & 0.353 & 0.157 & \\
\hline & 0.495 & 0.150 & 0.385 & \\
\hline \multirow{2}{*}{ Vitis spp. } & 0.463 & 0.579 & 0.236 & 0.786 \\
\hline & 0.897 & 0.246 & 0.451 & 0.283 \\
\hline
\end{tabular}


Appendix 8. Survey Instrument administered by mail to stakeholder groups in Canaan Valley and Tucker County, WV. Survey instrument was provided to visitors at Canaan Valley State Park and National Wildlife Refuge.

\section{Canaan Valley White-tailed Deer Survey}

Date

This survey was developed in cooperation with West Virginia University, Canaan Valley National Wildlife Refuge and Canaan Valley Resort State Park to gather public opinion regarding the local deer herd and the importance of rare plant species found in Canaan Valley. Please take a few moments to answer the following 25 questions. Your answers will remain completely confidential. If you have already filled out this survey in another location, please indicate so below and return the uncompleted form in the provided envelope

I have previously completed this survey

\section{Please fill in all boxes that apply to you}

Residential Status: I am a:

$\square$ Visitor to Canaan Valley

$\square$ Resident of Canaan Valley (\# years )

$\square$ Resident of Tucker County (\# years

$\square$ Own or rent $2^{\text {nd }}$ home in Canaan Valley

Age: My age (years) is:

$\square$ 18-25 $\square$ 26-45 $\square$ 46-60 $\square$ More than 60

Education Level: What is the highest level of education you have completed?

$\begin{array}{lll}\square \text { Below High School } & \square \text { High school } & \square \text { Some Undergraduate college } \\ \square \text { Undergraduate college } & \square \text { Graduate College }\end{array}$

Gender:
$\square$ Male
$\square$ Female

Please circle the response that most closely fits your opinion.

1. I enjoy seeing white-tailed deer around/near my home.

Strongly Agree Agree Neutral Disagree Strongly Disagree No Opinion

2. I enjoy seeing white-tailed deer when I visit state or national parks, forests or wildlife refuges.

Strongly Agree Agree Neutral Disagree Strongly Disagree No Opinion

3. I believe deer are overabundant in the state of West Virginia.

Strongly Agree Agree Neutral Disagree Strongly Disagree No Opinion

4. I believe deer are overabundant in Canaan Valley National Wildlife Refuge and/or Canaan Valley Resort State Park.

Strongly Agree Agree Neutral Disagree Strongly Disagree No Opinion

5. I place value on wild plants and trees as sources of food and timber. 
Strongly Agree $\quad$ Agree Neutral Disagree $\quad$ Strongly Disagree No Opinion

6. I enjoy seeing wild plants, flowers, and trees.

Strongly Agree Agree Neutral Disagree $\quad$ Strongly Disagree No Opinion

7. I, or a member of my immediate family, have been involved in a deer/vehicle collision.

Never In the past yearIn the past 5 years $\quad$ More than 5 years ago

8. I, or a member of my immediate family, have incurred damage to landscaping, crops or other property (excluding vehicles) from deer.

Yes $\quad$ No

9. I believe it is ethical to manage wild populations of white-tailed deer.

Strongly Agree Agree Neutral Disagree Strongly Disagree No Opinion

10. I believe white-tailed deer numbers should be increased in West Virginia.

Strongly Agree Agree Neutral Disagree Strongly Disagree No Opinion

11. I believe white-tailed deer numbers should be managed to increase hunter harvest.

Strongly Agree Agree Neutral Disagree Strongly Disagree No Opinion

12. I believe white-tailed deer numbers should be managed in balance with their environment.

Strongly Agree Agree Neutral Disagree $\quad$ Strongly Disagree No Opinion

13. I believe white-tailed deer may have a detrimental effect on some plant communities.

Strongly Agree Agree Neutral Disagree $\quad$ Strongly Disagree No Opinion

14. I believe rare or endangered plant species should be protected.

Strongly Agree Agree Neutral Disagree $\quad$ Strongly Disagree No Opinion

15. I believe rare or endangered plant species should be protected from white-tailed deer browsing if it reduces the abundance of those plants.

Strongly Agree $\quad$ Agree Neutral Disagree $\quad$ Strongly Disagree No Opinion

16. I would not have a problem seeing fenced areas to protect plants when I visit state or national parks, forests or wildlife refuges.

Strongly Agree $\quad$ Agree Neutral Disagree $\quad$ Strongly Disagree No Opinion

17. I believe hunting is an acceptable tool for managing deer populations.

Strongly Agree Agree Neutral Disagree $\quad$ Strongly Disagree No Opinion

18. I have participated in legal hunting activities within my lifetime. 
19. I have participated in legal hunting activities within the past year.

Yes No

20. Another member of my household participates in legal hunting activities.

Yes No

21. I believe professional sharp-shooting is an acceptable tool for managing deer populations. (This statement refers to people who are hired to kill a large number of deer in order to reduce herd numbers).

Strongly Agree Agree Neutral Disagree Strongly Disagree No Opinion

Optional- Please provide your zip code only so that we may determine where our respondents are from. (This answer is completely optional)

Additional Comments

Thank you for taking the time to participate in this survey. Your cooperation is greatly appreciated. 